\title{
Die offiziellen almohadischen Briefe - ein vernachlässigtes Fragment im Mosaik der politischen und literarischen Geschichte des Maghreb im Mittelalter
}

\author{
Dissertation \\ zur Erlangung des philosophischen Doktorgrades \\ an der Philosophischen Fakultät der Georg-August-Universität Göttingen \\ vorgelegt von \\ Andreas Herdt \\ aus Kustanaj, Kasachstan \\ Göttingen 2009
}


1. Gutachter: $\quad$ Prof. Dr. Tilman Nagel

2. Gutachter: $\quad$ Prof. Dr. Sebastian Günther

3. Gutachter: $\quad$ Prof. Dr. Tobias Brandenberger

Tag der mündlichen Prüfung: 21.10.2009 


\section{EIDESSTATTLICHE VERSICHERUNG}

Hiermit versichere ich an Eides statt, dass ich die eingereichte Dissertation „Die offiziellen almohadischen Briefe - ein vernachlässigtes Fragment im Mosaik der politischen und literarischen Geschichte des Maghreb im Mittelalter" selbständig und ohne unerlaubte Hilfe verfasst habe. Anderer als der von mir angegebenen Hilfsmittel und Schriften habe ich mich nicht bedient. Alle wörtlich oder sinngemäß den Schriften anderer Autorinnen oder Autoren entnommenen Stellen habe ich kenntlich gemacht. Die Abhandlung ist noch nicht veröffentlicht worden und noch nicht Gegenstand eines Promotionsverfahrens gewesen.

Göttingen, den 17. Juni 2009 


\author{
Meiner lieben Familie \\ in aufrichtiger tiefer Dankbarkeit
}



Inhaltsverzeichnis

$\begin{array}{lll}\text { I. Einleitung } & \text { S. } 5\end{array}$

$\begin{array}{ll}\text { II. Verwendete Quellen } & \text { S. } 10\end{array}$

$\begin{array}{lll}\text { 1. Zusammenfassung des Briefes Nr. } 8 & \text { S. } 14\end{array}$

$\begin{array}{ll}\text { 1.1. Übersetzung des Briefes Nr. } 8 & \text { S. } 14\end{array}$

$\begin{array}{ll}\text { 1.2. Einleitung zum historischen Kommentar } & \text { S. } 19\end{array}$

1.3. „Man hat euch ferner darüber berichtet, dass Abū-Zakarīyā' Yahyyā Ibn-al-'Azīz-bi-'llāh

Ibn-al-Manșūr Ibn-an-Nāṣir und seine gesamten Brüder [...]

keinen anderen Ausweg sahen als ihren angestammten Wohnsitz zu verlassen und ihre trauten Orte und Weiten aufzugeben [... $]^{\text {“ }} \quad$ S. 22

1.4. „Die Belagerten einigten sich also darauf, eine Abordnung zu entsenden $[\ldots]^{\text {“ }}$

1.5. „Was aber den erwähnten Abū-Zakarīyā' samt seinen Anverwandten [...] anbetrifft, so trat er mit ihnen in bester Verfassung und mit vornehmstem Geleit die Reise nach dieser Gegend [...] an.“

1.6. „Was diese befestigte Stadt anbelangt, so ist sie der höchste Gipfel [...]“ S. 25

$\begin{array}{lll}\text { 1.7. Zusammenfassung } & \text { S. } 28\end{array}$

$\begin{array}{ll}\text { 2. Zusammenfassung des Briefes Nr. } 9 & \text { S. } 30\end{array}$

$\begin{array}{ll}\text { 2.1. Übersetzung des Briefes Nr. } 9 & \text { S. } 31\end{array}$

2.2. „All dies fand seinen Abschluss darin, dass diese große (almohadische) Sache die genannten östlichen Gebiete unter ihre Botmäßigkeit brachte, in ihnen die Worte (wörtl. die Sprache) des Glaubens laut und weithin erschallen ließ $[\ldots]^{\text {“ }}$

2.3. „Als Gott gewollt hat, dass wir an ihnen das Urteil der Qual vollstrecken und auf dem Weg zu ihnen die dürren Landstriche dieser Wüste durchziehen $[\ldots]^{\text {“ }}$

2.4. „Was die arabischen Beduinen dieser Gebiete betrifft, die in ihnen ein parasitenhaftes Dasein führen $[\ldots]^{\text {“ }}$ S. 46

2.5. „Doch es war Gottes Wille, dass diese Elenden zu denjenigen gehören sollten, welche das Verderben in seinen Abgrund hinabschleuderte [...]“ 
2.6. „Das Töten dieser Feinde und ihre Verfolgung dauerten vom Anbruch dieses gesegneten Tages bis zu dessen Ende an.“

2.7. „Dabei vermischten sie sich mit ihren Viehherden, dem Vieh gleich, das sich mit dem Vieh vermischt [...]“

2.8. Zusammenfassung des historischen Kommentars

3. Zusammenfassung des Briefes Nr. 26

S. 55

3.1. Übersetzung des Briefes Nr. 26

S. 56

3.2. Historischer Kontext

S. 63

3.3. „Ihr [...] habt bereits erfahren, was in dieser gesegneten Gegend an erhabenen Ereignissen und ruhmreichen Siegen ermöglicht wurde $[\ldots]^{\text {“ }}$

3.4. „Man machte ihnen kund, dass das, was man sich von ihnen (leidenschaftlich) wünscht, der Feldzug gegen die Christen in al-Andalus [...] ist.““

3.5. „All dies riefen wir den Versammelten mit solchen Worten in Erinnerung, die ihre Herzen erreichten $[\ldots]^{\text {]“ }}$

3.6. „Einer derjenigen, die bei dieser glückhaften Versammlung und bei dem neuen Guten zugegen waren, [...] war Šaih Abū-Sirḥān Mas`ūd Ibn-Sultān Ibn-Zimām.“

3.7. Zusammenfassung des historischen Kommentars

4. Zusammenfassung des Briefes Nr. 29

4.1. Übersetzung des Briefes Nr. 29

4.2. Einleitung zum historischen Kommentar

4.3. „Ihr habt bereits erfahren [...] wie sich [...] dieser Elende von Mallorca [...] befand [...]“

4.4. „In diesem geschilderten Zustand verharrte er, bis er die Klinge seines (eigenen) Todes ausgrub $[\ldots]^{\text {“ }}$

4.5. „Als dies geschah, nahm dieser Frevler Fühlung mit dem in Biğāya befindlichen Abschaum auf $[\ldots]^{\text {“ }}$

4.6. „Nach diesem begehrte er weitere Städte unter seine Botmäßigkeit zu zwingen, und seine verderbte Seele verleitete ihn dazu, sich auch der näheren Umgebung 
von Biğāya zu bemächtigen $[\ldots]^{\star \star}$

S. 120

4.7. „So ging er um Algier, Miliana, Ašìr und Qal'at herum und kehrte dann nach Biğāya zurück.“

4.8. „Nachdem uns [...] über das Unwesen dieses Frevlers berichtet wurde $[\ldots]^{“}$

4.9. „Die (übrigen) Untertanen [...] folgten diesem (geschilderten) rechten Handeln: Sie setzten gefangen und schlugen in Eisen all diejenigen der Elenden, derer sie habhaft werden konnten.“

4.10. Zusammenfassung des historischen Kommentars

S. 130

5. Zusammenfassung des Briefes Nr. 30

S. 131

5.1. Übersetzung des Briefes Nr. 30

5.2. „Ferner, ihr [...] habt bereits erfahren, dass diese

Elenden, nämlich die asiatischen Söldner, und ihre Brüder in der Verirrung, diese Mallorquiner, in die Randbezirke dieser Gegenden Ifrīqīyas einfielen.“

5.3. „Dank Gottes wundersamem Eingreifen gelangten wir nach Ifrīqīya just in dem Moment, als ihre Saat zur Reife gelangte.“

5.4. „Und nachdem sie Gott [...] darum angerufen haben, ihnen bei der Vernichtung und Austilgung dieser elenden Feinde beizustehen, brachen sie von Tunis $[\ldots]$ auf.“

5.5. „Als die blitzschnellen almohadischen Kämpfer sich auf sie stürzten [...] da erschauerten sie so, wie Wölfe beim Anblick der Löwen erschauern [...].“

5.6. „Dank dem glückhaften Eingreifen Gottes zugunsten der Almohaden [...] ist von den Almohaden auch nicht einer (in der Schlacht) gefallen [...]“ ${ }^{\text {“ }}$ S. 156

5.7. „Diese alte Stadt Gabès ist das Herz (wörtl. der Geist und $\begin{array}{ll}\text { der Sinn) Ifrīqīyas.“ } & \text { S. } 160\end{array}$

5.8. Zusammenfassung des historischen Kommentars $\quad$ S. 164

$\begin{array}{ll}\text { 6. Zusammenfassung des Briefes Nr. } 31 & \text { S. } 166\end{array}$

6.1. Übersetzung des Briefes Nr. $31 \quad$ S. 166

6.2. „Die Städte der Region Nafzāwa sowie Tawzar, Taqyūs, al-Ḥamma und Nafṭa ergaben sich den Almohaden [...]“ 
6.3. „Am Tage, an welchem die Almohaden ihr Lager vor Gafsa aufschlugen, trafen bei ihnen die Gesandten Qarāqūšs mit einem Brief von ihm ein $[\ldots]^{“ /}$

S. 176

6.4. „Diesem gesegneten Feldzug [...] lag (ausschließlich) das Bestreben zugrunde, die Übeltäter zu bezwingen $[\ldots]^{\text {‘ }}$

6.5. Zusammenfassung des historischen Kommentars

7. Zusammenfassung des Briefes Nr. 32

S. 185

7.1. Übersetzung des Briefes Nr. 32

S. 186

7.2. Zusammenfassung der überlieferten Quellenzeugnisse

S. 199

7.3. „Da entbrannten in diesen Feinden lodernd und lichterloh die Flammen des Entsetzens und der Furcht.“

7.4. „Diese Zusicherung der körperlichen Unversehrtheit wurde der Gesamtheit der asiatischen Söldner und ihrer Anhänger sowie allen Bewohnern und der Allgemeinheit Gafsas gewährt [...]“

7.5. Zusammenfassung des historischen Kommentars

$\begin{array}{ll}\text { 8. Abschließende Betrachtungen } & \text { S. } 208\end{array}$

$\begin{array}{ll}\text { 8.1. Thematische Gliederung } & \text { S. } 208\end{array}$

$\begin{array}{ll}\text { 8.2. Der Aufbau der almohadischen Briefe } & \text { S. } 210\end{array}$

$\begin{array}{ll}\text { 8.3. Die Verbreitungsweise } & \text { S. } 217\end{array}$

$\begin{array}{ll}\text { 8.4. Endergebnis und Ausblick } & \text { S. } 221\end{array}$

Anhang 1: Inhaltsverzeichnis und Zusammenfassung $\begin{array}{ll}\text { der siebenunddreißig almohadischen Briefe } & \text { S. } 233\end{array}$

$\begin{array}{ll}\text { Anhang 2: Belegsammlung des metaphorischen Sprachgebrauchs } & \text { S. } 268\end{array}$

$\begin{array}{ll}\text { Literaturverzeichnis } & \text { S. } 325\end{array}$ 
I. Einleitung

Die Geschichte des Maghreb und al-Andalus ${ }^{\prime 1}$ im 12. und 13. Jahrhundert, die von dem almohadischen Reich bestimmt und nachhaltig geprägt worden ist, konnte lange Zeit nur anhand einiger weniger Quellen erforscht werden, von denen die meisten erst aus der Zeit nach dem Sturz der almohadischen Dynastie im Jahr 1269 stammen. Solche Quellen wie ,al-Anīs al-muțib bi-raụ̣ al-qirṭās fī ahbār mulūk al-Mağrib wa-ta'rīh madinat Fa's s'2 von Ibn-Abī-Zar` (gest. 1326), das anonyme Werk aus dem ausgehenden 14. Jahrhundert „Kitāb al-ḥulal al-maušīya fĩ dikr al-ahbbār al-marrākušīya“, „Kitāb al'ibar“ von Ibn-Haldūn (1332-1406), „Ta'rīh ad-daulatain al-muwaḥhidīya wa-'1-ḥafșīya““ von az-Zarkašī aus dem 15. Jahrhundert behandeln zwar auch die almohadische Epoche, vermitteln jedoch ein höchst summarisches Bild sowohl dieser Dynastie als auch der während ihres Bestandes stattgehabten Ereignisse. Außerdem enthalten sie häufig ungenaue oder widersprüchliche Angaben, die das ohnehin nicht immer klare historische Bild der almohadischen Bewegung eher verdunkeln als aufhellen.

Diese ungünstige Forschungslage änderte sich erst im 19. Jahrhundert nachhaltig, als eine Reihe von zeitgenössischen almohadischen und anderen Quellen entdeckt wurden, die wichtige Einblicke in die Eigentümlichkeiten des almohadischen gesellschaftlichen Gefüges erlaubten sowie eine weitergehende Erhellung der Ereignisgeschichte dieser Zeit ermöglichten. Dazu zählen „Kitāb al-mu`ğib fî-talhīṣ ahbār al-Mağrib“ von 'Abdal-Wāḥid al-Marrakušī (1185-1250), der zweite Band des „al-Mann bi-'1-imāma“ von Ibn-Ṣāḥib-aṣ-Ṣalāt, der die amohadische Dynastie behandelnde Teil des Werks ,alBayān al-mugrib fi 'hutiṣār ahbār mulūk al-Andalus wa-'l-Mag̉rib“ von Ibn-'Idārī alMarrākušī (gest. Anfang des 14. Jh.), drei handschriftliche Fragmente, die der französische Orientalist E. Lévi-Provençal im Jahr 1928 unter dem Titel „Kitāb ahbār al-mahdī Ibn-Tūmart wa-'btidā' daulat al-muwaḥhidīn“ herausgegeben hat, der

\footnotetext{
${ }^{1}$ Mit der Bezeichnung al-Andalus meinte man den Teil der Iberischen Halbinsel, der von Muslimen beherrscht wurde. Nach dem Abschluss der arabischen Eroberung im frühen 8. Jahrhundert erstreckte sich dieser Name beinahe auf die gesamte Iberische Halbinsel. Mit dem Fortschreiten der Reconquista jedoch, d. h. der Rückeroberung durch die christlichen Königreiche des Nordens, betrug die territoriale Ausdehnung von al-Andalus in der Mitte des 12. Jahrhunderts bereits weniger als die Hälfte des Gesamtgebietes der Iberischen Halbinsel.

${ }^{2}$ Im Verlaufe der Arbeit wird auf die Übersetzung der Titel von angeführten arabischen Werken verzichtet. Denn die mittelalterlichen arabischen Titel wirken, da sie in der Gedanken- und Vorstellungswelt jener fernen Zeit fest verankert sind, häufig - für unser heutiges Empfinden zumindest blumig und unverständlich. So lautet der Name eines bekannten historisch-literarischen Werks von alMaqarrī (gest. 1631) „Nafḥ aṭ-ṭib min gusụn al-Andalus ar-rațīb wa-dikr wazīrihā Lisān-ad-Dīn Ibn-alHațīb“, wörtl.: Entströmen des Dufts von dem frischen Zweig von al-Andalus und die Erwähnung des dortigen Wezirs Lisān-ad-Dīn Ibn-al-Hạțīb, und er lässt den heutigen Leser über dessen Inhalt eigentlich im Dunkeln.
} 
dreizehnte Band des „Naẓm al-ğumān“ von Ibn-Qaț̣ān und die siebenunddreißig offiziellen almohadischen Briefe, die im Mittelpunkt der vorliegenden Untersuchung stehen.

Die Briefe unserer Sammlung, „Mağmū̄ rasā’il muwaḥhidīya min inšā’ kuttāb ad-daula al-mu'miniya“63 wurden in den jeweiligen Regierungszeiten der ersten vier almohadischen Kalifen abgefasst und von E. Lévi-Provençal im Jahre 1941 veröffentlicht. Den überwiegenden Teil dieser Schreiben hat der Wissenschaftler einem handschriftlichen Band entnommen, den der französische Orientalist Georges S. Colin in Marroco erworben und ihm später zur Verfügung gestellt hatte. Den almohadischen Brief Nr. 10, der im erwähnten Band ursprünglich nicht enthalten war, hat E. LéviProvençal aus der Enzyklopädie „Șubḥ al-a šā fī șinācat al-inšăa“ al-Qalqašandīs (13551418) übernommen und der Sammlung „Mağmū' rasā’il muwaḥhidīya“ beigefügt. ${ }^{4}$ Im Vorwort zu seiner Sammlung betont Lévi-Provençal, dass diese almohadischen Briefe einen hohen historischen und literarischen Wert besitzen. Der historische Wert dieser Briefe rühre davon her, „dass sie ein direktes, genaues und geordnetes Zeugnis der wichtigsten Ereignisse sind, die während der Herrschaft der almohadischen Dynastie stattgefunden haben und politische Maßnamen, gesellschaftliche Reformen, Feldzüge und Siege umfassen. Ihr literarischer Wert erklärt sich daraus, dass diese Briefe jedem, der die Entwicklung der Literatur im Maghreb erforscht, die mannigfaltigen Proben der offiziellen Schreibkunst im Zeitalter der Almohaden vor Augen führen. “5 Trotz dieses sehr positiven, ja enthusiastischen Urteils Lévi-Provençals wurde den Briefen bisher keine wissenschaftliche Untersuchung, die der Frage nach ihrem historischen oder literarischen Wert nachginge, gewidmet. In den einschlägigen Arbeiten wurden sie rasch zu einer willkommenen weiteren Quelle, und die Frage nach dem ihnen zukommenden Stellenwert innerhalb anderer überlieferter schriftlicher Zeugnisse, ja

\footnotetext{
${ }^{3}$ Im Verlaufe der Arbeit wird dafür die Abkürzung ,Mağmū‘ rasā’il muwaḥhidīya“ gebraucht.

${ }^{4}$ Mağmūc rasāìil muwaḥhidīya, S. [2]. In diesem Zusammenhang muss darauf hingewiesen werden, dass „Mağmū rasā'il muwaḥhidìya“ inzwischen nicht die einzige Sammlung von den offiziellen almohadischen Schreiben ist. Im Jahre 1995 veröffentlichte der marokkanische Forscher Ahmad 'Azzāwī eine weitere Sammlung unter dem Titel „Rasā'il muwaḥhidīya : mağmū'a ğadīda“, in welcher er - mit Ausnahme der bereits von Lévi-Provençal siebenunddreißig veröffentlichten Briefe - alle almohadischen Schreiben, die er sowohl in den überlieferten gedruckten arabischen Quellen als auch in den ihm zur Verfügung stehenden Handschriften finden konnte, zusammengetragen hat. Diese neue Sammlung stellt eine fundierte und gewissenhafte Edition dieser neuen almohadischen Texte dar und der jedem almohadischen Brief vorangestellte kurze historische Kommentar erleichtert wesentlich die Lektüre dieser Zeugnisse. Die Veröffentlichung dieser Sammlung bildet außerdem eine willkommene erhebliche Erweiterung des Korpus der offiziellen almohadischen Schriftstücke und bietet somit eine solide Grundlage für deren weitere Erforschung unter mannigfaltigen Gesichtspunkten.

${ }^{5}$ Mağmū' rasā'il muwaḥhịidìya, S. [2].
} 
nach ihrem Wert für die Erforschung der Geschichte des Maghreb im Mittelalter überhaupt blieb bisher unbeantwortet.

Aus diesem Grunde werden in der vorliegenden Arbeit zum ersten Mal ausgewählte almohadische Briefe selbst in den Mittelpunkt der Analyse gerückt, um vor dem Hintergrund überlieferter arabischer Quellentexte ihren historischen Gehalt zu ermitteln. Ausgewertet werden die Briefe Nr. 8, 9, 26, 29, 30, 31 und 32, die von den militärischen Unternehmungen der Almohaden im Zentralen Maghreb sowie in Ifrīqīya (d.h. annähernd dem Gebiet des heutigen Tunesiens) berichten. Dieser Auswahl lag die Überlegung zu Grunde, dass man den Inhalt dieser literarisierten Feldzugberichte anhand anderer Quellen eher überprüfen kann, als zum Beispiel Aussagen anderer Schriftstücke der Sammlung, deren Inhalt in den auf uns gekommenen Quellendarstellungen keinen bzw. einen äußerst geringfügigen Niederschlag gefunden hat ${ }^{6}$.

Das eben formulierte Ziel, die betreffenden Briefe in den Mittelpunkt der Betrachtung zu rücken und somit zur Sprache zu bringen, impliziert darüber hinaus, dass sie als Ganzes in den Blick genommen werden und dass ein möglichst breites Spektrum ihrer Aussagen - auch eventuelle propagandistisch motivierte Verzerrungen und Übertreibungen - analysiert wird. Denn nicht selten kann man in der europäischsprachigen Forschungsliteratur beobachten, dass man den almohadischen Briefen nur solche Aussagen entnimmt, die die bereits auf anderen Wegen gewonnenen ereignisgeschichtlichen Erkenntnisse stützen, ergänzen oder korrigieren. Indem man jedoch den Blick auf das ohnehin Bekannte und nicht selten ausschließlich für die Ereignisgeschichte Verwertbare richtet, erschließt man sich nur einen verhältnismäßig geringfügigen Aspekt der almohadischen Briefe und läuft Gefahr, ihren immensen Wert für die Forschung zu verkennen. Nur indem man einerseits über die im engeren Sinne ereignisgeschichtlich relevanten Aussagen der Briefe hinaus auch solche ihrer Ausführungen ernst nimmt, die aus heutiger Sicht als geringfügig, unwirklich oder schlicht phantastisch erscheinen, und sie nicht von vornherein als belangloses rhetorisches Beiwerk abtut, und indem man andererseits diese Schrifstücke in ihrem historischen Kontext als in sich stimmige, auf eine bestimmte Wirkung bei ihren Rezipienten hin angelegte Zeugnisse betrachtet, kann man ihren Stellenwert innerhalb des offiziellen almohadischen Schrifttums verstehen und der Antwort auf die Frage

\footnotetext{
${ }^{6}$ Vorausgreifend sei hier gesagt, dass im Verlaufe der Arbeit die Überlieferungsbasis für einige dieser Schreiben sich kleiner als zuerst angenommen erwiesen hat, doch ist sie allemal größer als diejenige für andersartige Verlautbarungen aus „Mağmū' rasā’il muwaḥhịidìya“.
} 
nach ihrem eigentlichen Zweck näher kommen. Die umfassende, auf das tiefschürfende Verständnis dieser einzigartigen Schriftstücke abzielende Betrachtung bedeutet, dass diese gleichermaßen als literarische, historische und religionsgeschichtliche Zeugnisse angesehen werden müssen. Die zahlreichen überwiegend koranisch geprägten Bezeichnungen für die Feinde der Almohaden, häufig eingeflochtene koranische Zitate und Ausdrücke, eingestreute klassische arabische idiomatische Wendungen, Versfragmente aus der vorislamischen arabischen Dichtung, die im westarabischen literarischen Schrifttum gebräuchlichen Allegorien sowie Bezugnahmen auf die almohadische Doktrin müssen als solche erkannt und in ihrem Zusammentreffen auf der einen Seite sowie in ihrer Wirkung auf die Rezipienten auf der anderen analysiert werden. Dieser Untersuchungsansatz, der auf das über die wörtliche Übersetzung hinausreichende Verständnis hinzielt, erfordert weitest gehende Vertrautheit mit den einschlägigen literarischen und religiösen arabischsprachigen vom 7. bis 12 . Jahrhundert verfassten Schriften mit überregionaler Ausstrahlung sowie mit überragender regionaler Wirkung ${ }^{7}$. Daher kann für die im Folgenden gegebenen Übersetzungen nicht der Anspruch erhoben werden, sämtliche darin vorkommenden religiösen und literarischen Bezugnahmen, Koranzitate sowie idiomatischen Ausdrücke seien als solche erkannt worden. Aber diejenigen darunter, die eben doch erkannt und verstanden werden konnten, machen deutlich, wie groß der Umfang der noch zu leistenden Arbeit ist und wie substanzreich der Beitrag der almohadischen Briefe für die Erforschung der mittelalterlichen Sprach- und Literaturgeschichte des Maghreb sein könnte. Einen ersten Schritt in diese Richtung soll die vorliegende Untersuchung bilden. Der vorliegenden Arbeit werden zwei Anhänge beigefügt: im Anhang Nr. 1 werden alle Briefe der Sammlung „Mağmū ${ }^{c}$ rasā’il muwaḥhidīya“ in deutscher Sprache zusammengefasst. Hierbei wird ganz bewusst darauf verzichtet, die Schreiben vorwegnehmend einer historisch kritischen Betrachtung zu unterziehen. Ihr Inhalt wird nach Möglichkeit ganz so wiedergegeben, wie ihn die Zuhörerschaft beim Verlesen dieser Stücke verstanden haben dürfte. Nicht ihren historischen Gehalt, sondern ihre wesentlichen Aussagen versucht die Wiedergabe zu treffen.

Den Inhalt des zweiten Anhangs bilden erste vorläufige Ergebnisse meiner Beschäftigung mit dem almohadischen und mit dem mittelalterlichen metaphorischen Sprachgebrauch des Maghreb allgemein. Die Notwendigkeit, diesen spezifischen Sprachgebrauch zu erhellen, ergab sich aus dem Bestreben, die analysierten Briefe

\footnotetext{
${ }^{7}$ Siehe ein besonders interessantes Beispiel hierfür bei der Übersetzung des Briefes Nr. 30, Kap. 5.1., in
} 
möglichst umfassend $\mathrm{zu}$ verstehen und getreu $\mathrm{zu}$ übersetzen. Hierbei wurde immer wieder festgestellt, dass bei vielen Aussagen des arabischen Textes die wörtliche Übersetzung ins Deutsche den gemeinten Sinn häufig nicht nur nicht traf, sondern vielmehr zu dessen Verzerrung zu führen drohte. Der Versuch, die im arabischen Original intendierte Bedeutung auf eigene Spracherfahrung gestützt zu erfühlen und wiederzugeben, erbrachte oft unbefriedigend mehrdeutige Interpretationsmöglichkeiten, die desto mehrdeutiger wurden, je mehr muttersprachliche Spracherfahrungen anderer mitberücksichtigt wurden. Daher wurde parallel zur Übersetzung die systematische Erschließung des metaphorischen Sprachgebrauchs nicht nur der almohadischen Briefe, sondern auch nasridischer und almoravidischer offizieller Schreiben sowie anderer literarischer Texte westarabischer Prägung in Angriff genommen. Hierbei hat sich schrittweise ein ganz neues umfangreiches und höchst interessantes Forschungsfeld aufgetan. Die Menge des mittels allegorischen Sprachgebrauchs zum Ausdruck Gebrachten hat sich bei näherem Hinsehen als so umfangreich erwiesen, dass die Erschließung dieses außerordentlich viel versprechenden Bereichs nur ansatzweise durchgeführt werden konnte. Es wurde ferner deutlich, dass der ermittelte Sinn mancher Allegorien je nach Autor und Abfassungsepoche verschiedene Bedeutungsnuancen annehmen konnte. Aus diesem Grunde sind die in diesem Anhang erschlossenen Bedeutungen allgemein und können ihrerseits sicherlich noch weiter differenziert werden. Zum anderen wurde augenscheinlich, dass einige der in Maghreb üblichen Allegorien sich in den zeitlich früheren und als klassisch geltenden literarischen Erzeugnissen orientalischer Provenienz belegt waren. Der zweifelsohne dynamische und vielfältige Prozess solcher literarischen Entlehnungen und Übrnahmen konnte nur anhand einiger Beispiele aus den Makamen von al-Harīrī (gest. 1122) angerissen werden, und er gewährt einen wichtigen Einblick in das bemerkenswerte literarische und sprachliche Phänomen des Maghreb im Mittelalter: die weitreichende formale Ausrichtung des literarischen Schrifttums des Maghreb an demjenigen des Orients im Hinblick auf die Sprache, den Stil und den allegorischen Sprachgebrauch ${ }^{8}$, die sich einerseits in der fortschreitenden eigenständigen Weiterentwicklung und Differenzierung des Übernommenen fortsetzt und andererseits in einem auffälligen Kontrast zur im Maghreb gesprochenen Sprache steht, die von den Zeitgenossen des

\footnotetext{
Fußnote Nr. 401.

${ }^{8}$ Der bekannte buidische Wesir und Literat as-Sāhib Ibn-'Abbād (gest. 995) soll, nachdem er das umfangreiche literarische Werk des andalusischen Autors Ibn-'Abd-Rabbihī (860 - 940) ,al-'Tqd al-farīd“" gelesen hatte, enttäuscht ausgerufen haben: „Das ist doch unsere eigene Handelsware, die zu uns zurückgekehrt ist!“” (The encyclopaedia of Islam, Bd. 3, S. 677).
} 
Orients häufig als sehr weit von der Hochsprache entfernt und daher als unverständlich empfunden wurde 9 .

Es ist meine Hoffnung, die auf diese Weise entstandene Belegsammlung, deren kleiner Auszug hier in lateinischer Transkription vorliegt, weiter ausbauen und sie zu einem späteren Zeitpunkt - in Originalschrift und um arabischen Kommentar erweitert - dem Urteil des interessierten arabischkundigen Publikums vorlegen zu können.

\section{Verwendete Quellen}

1) „Kitāb al-mư ğib fĩ talhīṣ ahbār al-Mag̉rib“ (Kurztitel: al-Mưğib) von 'Abd-al-Wāḥid al-Marrakušī (1185-1250). Dieser Autor verließ aus unbekannten Gründen im Jahr 1217 al-Andalus, begab sich nach dem islamischen Osten und schrieb im Jahr 1224 vermutlich in Ägypten ${ }^{10}$ sein Werk nieder. Wie der Autor im Vorwort zu seinem Buch bemerkt, hat er sich bei der Darstellung der Geschichte des Maghreb auf keine Chroniken oder Geschichtsbücher stützen können. Insbesondere bezüglich der Geschichte der Almohaden habe er kein einziges Geschichtswerk zu Rate ziehen können. Des Weiteren sei das, was er über die Almohaden in Erinnerung behalten habe, höchst ungeordnet und vereinzelt ${ }^{11}$. Doch wenn auch die Zeitangaben dieses Autors deshalb oft unkorrekt sind, enthält sein Werk wertvolle Angaben über die Geschehnisse im almohadischen Reich und gewährt wichtige Einblicke aus erster Hand in das Leben am almohadischen Hof in Marrakech.

2) „al-Bayān al-mugirib fī ahbbār al-Andalus wa-'l-Mag̉rib: qism al-muwaḥhịīn““ (Kurztitel: al-Bayān al-mugirib) von Ibn- Idāāī al-Marrākušī. Die präzisen Lebensdaten dieses Autors sind unbekannt, man kann jedoch mit ziemlicher Genauigkeit sagen, dass er auch im Jahr 1312 an seinem genannten Werk arbeitete. Der dritte Teil seines Werkes, in dem dieser Autor nach eigener Aussage unter anderem auch die Geschichte des almohadischen Reiches darzustellen gedachte, ist bis heute in insgesamt vier Handschriftenfassungen unvollständig überliefert. Die am besten erhaltene von ihnen beinhaltet die von 1168 bis 1267 reichenden Ereignisse. Der Autor stützte sich unter anderem auf die almohadischen Quellen, die heute entweder nur teilweise überliefert oder gänzlich verschollen sind. Aus diesem Grunde ist der überlieferte Text Ibn-'Idārīs „der reichhaltigste, interessanteste, wichtigste und glaubwürdigste, um aus der

\footnotetext{
${ }^{9}$ Vgl. F. Corriente „Hașā’iṣ kalām ahl al-Andalus : natran wa-naẓman“, S. 47, in: Revista del Instituto Egipcio de Estudios Islámicos, Jg. 23.1985/86.

${ }^{10}$ The history of the Almohades, S. VIII f.
} 
arabischen Sicht die Geschichte des Maghreb im 12. und 13. Jahrhundert zu studieren." ${ }^{12}$

3) „al-Mann bi-'l-imāma“ von Ibn-Ṣāḥib-aṣ-Ṣalāt. Vom Werk dieses almohadischen Historiographen ist nur der zweite Band überliefert, in welchem die Begebenheiten im almohadischen Reich und am almohadischen Hofe vom Jahr 1160 bis 1173 dokumentiert sind. Bei aller Ausführlichkeit der darin enthaltenen Berichte und Informationen muss man allerdings berücksichtigen, dass Ibn-Ṣāḥib-aṣ-Ṣalāt ein offizieller almohadischer Geschichtsschreiber war und am almohadischen Hofe ein Amt bekleidete, so dass seine Angaben die von der offiziellen Seite gewünschte und propagierte Sichtweise darstellen.

4) Aus der Feder von Ibn-Qaț̣ān, einem Autor aus dem 13. Jahrhundert, stammt das Werk „Naẓm al-ğumān“. Von diesem ursprünglich mehrbändigen Werk ist lediglich der 13. Band überliefert, welcher aufschlussreiche Informationen aus erster Hand über die Organisation des almohadischen Reiches enthält.

5) Bei „Kitāb al-istibṣār fị 'ağā'ib al-amṣāa" handelt es sich um ein anonymes geographisches Werk aus dem ausgehenden 12. Jahrhundert, dessen Autor eindeutig proalmohadischer Gesinnung war. Obgleich es in erster Linie ein geographisches Werk ist, finden sich darin zahlreiche historisch und ereignisgeschichtlich relevante Angaben sowie auch einige kurze Auszüge aus den offiziellen almohadischen Briefen.

6) Der Verfasser einer weiteren Schrift, at-Tiğān̄i, bildet unter den arabischen Reisenden des Maghreb im Mittelalter eine interessante Ausnahme. Denn während andere Reisebeschreibungen häufig entweder aus der Feder muslimischer Wallfahrer stammen, die auf ihrem Weg zu den heiligen Stätten des Islam die durchquerten Städte und Ortschaften beschreiben, oder von Männern verfasst sind, die fast ausschließlich um des Wissenserwerbs in der islamischen Theologie und in den verwandten Disziplinen willen (arab.: riḥla fi talab al-ilm) die auf diesem Gebiet bekannten Koriphäen häufig im islamischen Osten aufsuchten, bereiste at-Tiğānī im Zeitraum zwischen 1306 und 1309 - zum Glück für die heutige Geschichtsforschung - nur das Gebiet des heutigen Tunesiens. Neben geographischer Beschreibung der von ihm besuchten Orte geht er oft auch auf ihre Geschichte ein. Seine Reisebeschreibung enthält unter anderem wertvolle Zitate und Passagen anderer Autoren, die selbst Zeugen der Ereignisse in dieser Region waren und deren Schriften heute als verschollen gelten.

\footnotetext{
${ }^{11}$ al-Mu' ğib, S. 4.

12 al-Bayān al-mugrib fi ijtisar ajbār mulūk al-andalus wa al-magrib, Los almohades, Tomo I, Prólogo, S. XI.
} 
Besonders aufschlussreich und genau sind die Angaben dieses Autors über die Aktivitäten der Banū-Ḡānīya, des asiatischen Söldners Qarāqūš und der arabischen Stämme in Ifrīqìya.

7) „Kitāb a'azzu mā yuṭlab“ oder wie der französischie Titel dieses Werks lautet „Le livre de Mohammed Ibn Toumert, Mahdi des Almohades“ (Kurztitel: Le livre de Mohammed Ibn Toumert), stellt eine Sammlung der grundlegenden Gedanken und Lehren des almohadischen Mahdi dar, die sein Nachfolger 'Abd-al-Mu'min aufschreiben ließ. Diese Sammlung, die im Jahr 1903 vom ungarischen Orientalisten Ignatz Goldziher kommentiert und herausgegeben wurde, ist für das Verständnis der offiziellen almohadischen Sicht auf die verschiedenen Begebenheiten, wie sie z. B. in den almohadischen Briefen zum Ausdruck kommt, sehr aufschlussreich.

Die im Folgenden aufgezählten Quellen lassen sich sehr treffend durch das Urteil Huici Mirandas beschreiben: „All diese Quellen, die so konzis sind und vor geraumer Zeit veröffentlicht wurden, enthalten viele Fehler oder stellen die Tatsachen mit verdächtiger Parteilichkeit dar." ${ }^{13}$

8) „Kitāb al-ibar“ von Ibn-Hुaldūn (1332-1406). Das Werk dieses berühmten Autors enthält zahlreiche Angaben über die almohadische Dynastie, die jedoch an verschiedenen Stellen seines Werkes vorkommen und sich nicht selten widersprechen, wie es noch an einigen Beispielen in dieser Arbeit $\mathrm{zu}$ sehen sein wird ${ }^{14}$. Aus diesem Grunde sind die Angaben dieses Autors mit Vorsicht zu behandeln. Wie auch Ibn-'Id̄ārī bediente sich Ibn-Hुaldūn historischer Werke, die heute als unauffindbar gelten, was seine Angaben somit für unsere Zwecke wertvoll macht.

9) Die Weltchronik des arabischen Historiographen Ibn-al-Ațīr (gest. 1234), ,al-Kāmil fi 't-ta'rīh “ (Kurztitel: al-Kāmil), enthält interessante und ausführliche Berichte über die bekanntesten Unternehmungen der Almohaden, ist jedoch in vielerlei Hinsicht unvollständig. Trotzdem lassen sich diesem Werk andere, nicht unbedingt proalmohadische Darstellungen entnehmen, die das gesamte Geschichtsbild der damaligen Zeit etwas differenzierter als die almohadischen und proalmohadischen Quellen zeichnen.

\footnotetext{
${ }^{13}$ Historia política del imperio almohade, Bd. 1, S. 11. Dieser Orientalist zählt auch „al-Mu`ğib“ dazu.

${ }^{14}$ Vgl. Kap. 3.6. der vorliegenden Arbeit. Der Grund hierfür liegt manchmal darin, dass Ibn-Haldūn seine Informationen aus den Quellen anderer Autoren geschöpft und sie dabei in ihrer ursprünglichen Fassung belassen hat. Dies verleiht seinem Werk an vielen Stellen eine gewisse Heterogenität. Zum anderen lässt die Edition seines Werkes noch sehr viel zu wünschen übrig, und so kommt es durchaus vor, dass Unachtsamkeiten des Herausgebers z. B. bei der Setzung von diakritischen Punkten zu erheblichen Sinnveränderungen führen.
} 
10) „al-Ḥulal al-maušīya fī dikr al-ahbār al-marrākušīya“ (Kurztitel: al-Ḥulal almaušìya), ein anonymes Werk aus dem Jahr 1384, enthält unter anderem auch eine summarische Beschreibung der Entstehung der almohadischen Bewegung, der Regierungszeit der almohadischen Herrscher sowie der hervorstechendsten Ereignisse jener Zeit.

11) Im ,al-Anīs al-muțiib bi-rauḍ al-qirțās fī ahbār mulūk al-Mag̉rib wa ta’rīh madinat Fas“ (Kurztitel: Rauḍ al-qirtās) von Ibn-Abī-Zar` (gest. 1326) findet sich ebenfalls eine summarische Darstellung der Geschichte der Almohaden. Von allen anderen Quellen ist dieses Werk dasjenige, dessen Angaben für am wenigsten glaubwürdig gehalten werden ${ }^{15}$.

12) „Ta'rīh̆ ad-daulatain al-muwaḥhidīya wa-'l-ḥafșīya““ (Kurztitel: Ta’rīh ad-daulatain) von az-Zarkašī stammt aus dem 15. Jahrhundert und ist der hafṣidischen Dynastie gewidmet. Da diese aus der almohadischen Dynastie hervorgegangen ist, wird die Geschichte des almohadischen Reiches in groben Zügen vorangestellt.

\footnotetext{
${ }^{15}$ Historia política del imperio almohade, Bd. 1, S. 11.
} 
1. Zusammenfassung des Briefes Nr. 8

Dieser Brief, datiert vom 10. November des Jahres 1152 und abgefasst in Biğãya im Namen des Befehlshabers der Gläubigen, richtet sich an die Țālibs und die Gesamtheit der Almohaden von Tilimsen und ist, wie aus seinen Hinweisen hervorgeht, einer der Briefe, die im Rahmen des von den Almohaden im Jahre 1152 unternommenen Feldzuges zur Unterwerfung des Zentralen Maghreb geschrieben wurden. Anfangs erfolgt eine kurze Schilderung der Flucht des ḥammādidischen Herrschers AbūZakariyā' Yạ̣yā Ibn-al-'Azīz-bi-'llāh Ibn-al-Manșūr Ibn-an-Nāṣir samt seinen Familienangehörigen aus Biğāya nach Constantine. Daran schließt sich die Beschreibung der Entsendung einiger almohadischer Einheiten nach der Bezwingung der Stadt Qal'at Banī-Hammād zur Eroberung Constantines. Nach der Aufnahme der Belagerung dieser Stadt beschließen deren Bewohner, eine Delegation an den almohadischen Herrscher $\mathrm{zu}$ entsenden, die sich ihm unterwerfen und ihn um die Gewährung der Sicherheitsgarantie bei der Kapitulation bitten soll. Dieser Bitte wird entsprochen und Constantine wird von den Almohaden friedlich in Besitz genommen. Der Brief schließt mit der Beschreibung der außerordentlichen Bedeutung der eingenommenen Stadt für die gesamte Region.

\section{1. Übersetzung des Briefes Nr. 8}

Vom Befehlshaber der Gläubigen - Gott möge ihm Seinen Beistand gewähren und Seine Unterstützung bescheiden - an die Taālibs ${ }^{16}$ von Tilimsen sowie an alle Almohaden dort - Gott möge ihren edlen Rang durch ihre Furcht gegenüber Ihm

\footnotetext{
${ }^{16}$ Den Bezeichnungen der almohadischen Funktionsträger sind - soweit meine Kenntnis reicht - zwei Untersuchungen gewidmet: In seiner sehr genauen und tiefschürfenden Studie ,,al-Muwahhịidun fi 'l-Ġarb al-Islāmī" untersucht 'Izz-ad-Dīn 'Umar Mūsā die verschiedenen Funktionsbezeichnungen und ihre jeweiligen Aufgabenbereiche im almohadischen Reich anhand des überlieferten Quellenmaterials; ferner widmet sich der französische Forscher Emile Fricaud in seinem Aufsatz „Les Talaba dans la société almohade : (le temps d'Averroès)“ vor allem der Funktionsbezeichnung „Țālibs“ und hellt die in den Quellen nachweisbare Unterscheidung in die „Tālibs der ständigen Präsenz beim almohadischen Kalifen“ und in die übrigen „Ṭālibs der Almohaden“ sowie ihre jeweiligen Zuständigkeitbereiche auf. Mit der im Text oben verwendeten Bezeichnung „Ṭālibs“ - arab.: at-țālib und im Pl. at-țalaba - sind hier und im weiteren Verlaufe der Arbeit „Tālibs der Almohaden“ gemeint, also almohadische Funktionsträger, die im Gegensatz zu den „Ṭālibs der ständigen Präsenz beim almohadischen Kalifen“ in allen Städten des almohadischen Reiches im Umfeld der jeweiligen almohadischen Statthalter und Funktionsträger anzutreffen waren. Das Aufgabengebiet dieser Țālibs ist in den Quellen nicht klar benannt. Die von Emile Fricaud gegebene Zusammenstellung der überlieferten Quellenzeugnisse über deren Aktivitäten (S. 369 ff.) ergibt, dass das Aufgabenspektrum dieser Tālibs die Teilnahme an militärischen Unternehmungen allgemein - auch die selbständige Leitung von militärischen Operationen kleineren und größeren Umfangs (siehe hierzu die Übersetzung und die Zusammenfassung des Briefes Nr. 29, die Zusammenfassung des Briefes Nr. 16) - , die Weiterverbreitung von offiziellen almohadischen Verlautbarungen, die Unterweisung der Untertanen in der almohadischen Lehre sowie die Aufrechterhaltung der öffentlichen (almohadischen) Ordnung - siehe hierzu die Zusammenfassung des Briefes Nr. 23, in dem den Ṭālibs exekutive Befugnisse eingeräumt werden - umfasste.
} 
währen lassen. Frieden, Gnade Gottes - lobgepriesen sei Er - und Seine Segen mögen euch zuteil werden ${ }^{17}$.

Dieses unser Schreiben an euch - Gott möge Seine Hulderweisungen euch zu Wachstum und Zunahme gereichen lassen, Er möge Seine Gaben und Geschenke euch zur Sieghaftigkeit und zum Wohl weiter anschwellen lassen, und Er möge in euren Gegenden und in eurem Erhofften die Glückhaftigkeit ausbreiten - ergeht an euch aus der Stadt Biğāya - Gott möge sie vor allem Übel bewahren - und verkündet Zustände, die sich in der bestmöglichen Weise zum Wohl gefügt haben, (ferner) Siege, die in ununterbrochener Abfolge sowohl in den fernen als auch in den nahen Landstrichen der Erde erfochten wurden, (des Weiteren) Siegesmeldungen, welche darüber erhaben sind, als dass sie auf gewöhnliche und althergebrachte Weise überbracht und vernommen ${ }^{18}$ werden könnten, sowie klare Wunderzeichen ${ }^{19}$, deren Augenscheinlichkeit und Offensichtlichkeit jeden Beweis und seine Existenz überflüssig gemacht haben und $\left[\right.$ unklar $^{20}$ ]. Wir bitten Gott - gepriesen sei Er - , wo doch die Gewaltigkeit dessen, was wir schauen und sehen, das Innere und das Äußere der Menschen in Bewunderung hat ersterben lassen und (aufgrund seiner Helligkeit) sowohl das Auge des Einsichtsvermögens als auch die Augen geblendet hat, darum, dass Er uns Seinen Beistand zuteil werden lässt, der (uns bei den Ihm gebührenden Danksagungen) hilft und uns dabei Kräfte verleiht, dass Er uns ferner ein solches Handeln eingibt, das durch den Dank für Seine bewundernswürdigen Gunstbezeigungen recht ist, und dass Er uns die Kraft gibt, die nicht dabei erlahmt noch schwindet, das Ihm Gebührende zu vollziehen.

Man hat euch - Gott möge eure Freude währen lassen und eure Danksagungen vermehrfachen - bereits über das Eingreifen Gottes - lobgepriesen sei Er - zugunsten der Almohaden bei der Eroberung dieser Gegenden in Kenntnis gesetzt, welche (d. h. die Gegenden) den Almohaden Gott durch Seine Macht und Kraft zu bezwingen half, deren Finsternis Er vor den Lichtern dieser glückhaften (almohadischen) Sache weichen ließ und deren flache Senken und Bodenerhebungen Er die Füße Seiner Streiter und

\footnotetext{
${ }^{17}$ Im Verlaufe der Arbeit wird der üblicherweise auf diese formalisierte Einleitung folgende Teil, der streng genommen noch zur Einleitung gehört und von der eigentlichen Inhaltsmitteilung durch ,,ammā ba'd“" abgegrenzt wid, übergangen und es wird auf ihn gesondert im Kapitel 8.2. eingegangen.

${ }^{18}$ Im Original (Mağmūc rasā'il muwaḥhidīya, S. 23) steht an dieser Stelle „,bašā’ir yunazzahu bašruhā wa-

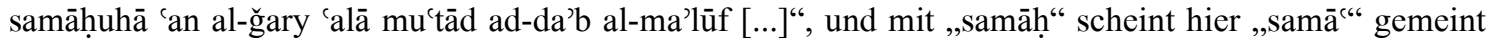
zu sein.

${ }^{19}$ Die Wendung ,āyāt baiyināt“ kommt an mehreren Stellen im Koran vor (z.B. Sure 34, Vers 43; Sure 45, Vers 25; Sure 56, Vers 9 usw.) und bezeichnet dort die geoffenbarten Verse.
} 
Helfer betreten ließ. Man hat euch des Weiteren darüber in Kenntnis gesetzt, wie die wahren Zustände in diesen Gegenden waren und wie sich die Wanderung von ihrem Muhașṣab zu ihrem 'Arğ vollzog ${ }^{21}$. Man hat euch ferner darüber berichtet, dass AbūZakarīyā' Yahyā Ibn-al-'Azīz-bi-'llāh Ibn-al-Manṣūr Ibn-an-Nāṣir und seine gesamten Brüder, Anverwandten und Onkel, als zu ihnen der Verteidiger, der seine Schützlinge nicht enttäuscht, kam und als der Anführer, der den Sieg über jede Festung ertrotzt, sich $\mathrm{zu}$ ihnen auf unebenen und ebenen Wegen begab, keinen anderen Ausweg sahen als ihren angestammten Wohnsitz zu verlassen und ihre trauten Orte und Weiten aufzugeben, und dies, weil es der vollkommene Ratschluss Gottes zugunsten dieser gesegneten (almohadischen) Sache war und weil Gott darin das enthalten ließ, was den Almohaden (später) das Wohl einbringen sollte. Der Ort, an welchen sie sich begaben, und von dessen Unbezwingbarkeit und Uneinnehmbarkeit sie überzeugt waren sowie auf dessen Festigkeit und Schutz sie vertraut hatten, war die Stadt Constantine - Gott möge dieser Stadt Prosperität bescheiden. Denn diese Stadt befand sich in einer solchen Höhe, wo sie durch Menschenkraft nicht erlangt (d. h. bezwungen) werden konnte und von wo aus sie dank ihrer Unnahbarkeit voller Hochmut auf alle Lebewesen feindselig hinabschaute. Zum Zeitpunkt des Aufenthaltes der genannten Gruppe in Constantine und ihrer Zugehörigkeit zu denjenigen, denen diese Stadt Herberge und Zufluchtsort war, befanden sich die Truppenteile der Almohaden in der Nähe von Qal'a ${ }^{22}$ - Gott möge dieser Stadt vor allem Übel bewahren - , nachdem sie durch Gottes Beistand Qal'a bezwungen und den Lohn dafür in der erhofften Weise empfangen hatten. Man entsandte von diesen genannten Truppenteilen dank Gottes Hilfe solche Almohaden (nach Constantine), von deren Entsendung man Gutes erhoffte, und man ermunterte sie zum Dienst an dieser großen (almohadischen) Sache und an deren Zielen ${ }^{23}$. Als diese genannten Almohaden - Gott möge ihnen den Erfolg verleihen - in die Nähe von Constantine - Gott möge diese Stadt vor allem Übel bewahren - gelangten, wurde ihnen der Sieg beschieden, welchen man euch bereits dargelegt und kundgemacht sowie das

\footnotetext{
${ }^{20}$ Hier folgt im arabischen Original (Mağmū ${ }^{c}$ rasā’il muwahhidīya, S. 23) folgende Passage „wa-in ta'uddū ni`mata Allāh lā tuḥṣūhā fỉ 'l-mustaulīya muḥsāa al-'āda wa-ma'dūdahū“, die mir unverständlich ist.

${ }^{21}$ Im arabischen Original (Mağmū` rasā’il muwaḥhidīya, S. 24) heißt es ,wa-qad taqaddama i'lāmukum [...] kaifa kānat șūrat al-ḥāl fĩ darağihā wa-taṣarruf al-intiqāl min muhașṣabihā ilā 'arğihā“،. Muhașṣab ist eine fakultative Pilgerstation in der Nähe von Minā (Kitāb al-istibșār fī ‘ağā'ib al-amșār, S. 32, Fußnote 5 und Kitāb mu'ğam al-buldān, Bd. 4, S. 426) und 'Arğ ist ein Passweg zwischen Mekka und Medina, der von Pilgern passiert wird (Kitāb mu'ğam al-buldān, Bd. 3, S. 637).

${ }^{22}$ Mit Qal'at ist die Stadt Qal'at Banī Hammād im Südosten Algeriens gemeint.

${ }^{23}$ Das im arabischen Original (Mağmù̄ rasā'il muwaḥhidīya, S. 24) an dieser Stelle gebrauchte ,iirāḍ“ im Satz ,wa-ḥuḍ̣a 'alā hidmat had̄ā al-amr al-‘azīm wa-i'rāḍihī“ müsste höchstwahrscheinlich zu ,aggrāḍihī“ korrigiert werden
} 
wundersame und bewundernswerte Wirken der Geschicke Gottes dabei (wörtl. bei dessen Gewährung) auseinandergesetzt hat. Auf diese Weise habt ihr erfahren, wie die Scharen der Missleitung und ihre Anhängerschaft dank diesem Sieg in die Flucht geschlagen wurden. Was die Almohaden - Gott möge ihnen den Erfolg verleihen anbetrifft, so schlugen sie danach ihr Lager vor dieser Stadt und vor ihren Gipfeln ${ }^{24}$ auf. Sie (d. h. Constantine) erlitt durch diese Almohaden einiges ${ }^{25}$ und nicht ließ man den Vogel Katha darin den Schlaf kosten (wörtl. beißen) ${ }^{26}$.

Der Zelte der Almohaden umschlossen Constantine eng von allen Seiten her und die fortdauernde Belagerung war (für die Belagerten) zermürbend, und im Verlaufe dessen manifestierte sich die Wahrheit deutlich, und der Beistand (Gottes) trug zum Sieg der mächtigen (almohadischen) Gemeinschaft bei. Dies dauerte an, bis Gott das Einsichtsvermögen der im obigen erwähnten Gruppe auf das rechte Handeln richtete (wörtl. auf die Gebetsrichtung des rechten Handelns lenkte) und sie erkennen ließ, dass das Heil an der Seite dieser (almohadischen) Schar ist und dass man das Leben (nur) am Weilort der Almohaden, welcher der feste Sitz der Glückseligkeit und deren Heimstatt ist, findet. Die Belagerten einigten sich also darauf, eine Abordnung zu entsenden, welche sich aus den beiden Brüdern von Abū-Zakarīyā’, ferner den Šaihs des Stammes Ṣanhāğa sowie denjenigen Constantines zusammensetzte. Diese Abordnung sollte schutzsuchend die alleinig feste Handhabe ${ }^{27}$ umklammern, die Ergebenheit der (almohadischen) Sache gegenüber bekunden, welcher niemand zu trotzen imstande ist, und das an der Zusicherung der körperlichen und materiellen Unversehrtheit und an dem Schenken des Lebens zu erflehen, was dem aufrichtig Buße Tuenden und Flehenden das dauernde und bleibende Wohl beschert. Diese Gesandten trafen in dieser

\footnotetext{
${ }^{24}$ Eine von den Almohaden belagerte Stadt kann mit einem Berg verglichen werden, dessen Gipfel erklommen zu haben der Bezwingung dieser Stadt gleichkommt. Siehe zu dieser Vorstellung die Einträge im Kapitel „Festungskonzepte“ im Anhang 2.

${ }^{25}$ Im arabischen Text an dieser Stelle (Mağmū' rasā’il muwaḥhidīya, S. 24) ,wa-ḥalla al-muwaḥhidūn [...]

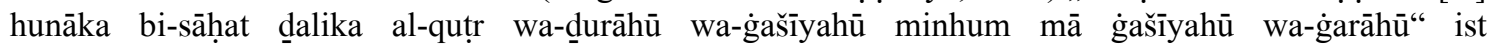
höchstwahrscheinlich nicht ,garāhū“", sondern ,'arāhü“" gemeint.

${ }^{26}$ Möglicherweise eine Anspielung auf die arabische Redewendung „Lau turika al-qatā lailan la-nāma“, d. h. hätte man den Katha-Vogel nachts schlafen lassen und ihn nicht aufgescheucht, hätte er weiter geschlafen. Diese Redewendung soll im folgenden Zusammenhang geprägt worden sein: Eines Nachts schlichen sich die Angreifer an das Haus ihres Opfers heran und scheuchten dabei einen Katha-Vogel auf. Die Frau desjenigen, dem der Überfall gelten sollte, weckte ihren Mann auf und wies ihn auf die nahende Gefahr hin; als ihr Mann mürrisch erwiderte: „Das sind doch nur Katha-Vögel“, sagte sie den eingangs angeführten Satz (Nihāyat al-arab fī funūn al-adab, Bd. 3, S. 49). Demnach dürfte die Anspielung auf diese Redewendung die Bedeutung haben, die von den Almohaden durchgeführten Überfälle auf die Belagerten waren so häufig und folgten in derartiger Dichte aufeinander, dass der Katha-Vogel, unablässig aufgescheucht, nicht zum Schlafen kam. Bei al-Mufaḍ̣al Ibn-Salama (Kitāb al-fāhuir, S. 117) findet sich hingegen ein gänzlich abweichender Bericht über den Zusammenhang, in dem diese Wendung geprägt worden sein soll, die jedoch letztlich auf eine sehr ähnliche Bedeutung hinausläuft.
} 
behüteten Residenzstadt (d. h. Biğāya) ein, und dabei eilte ihre Hoffnung vor ihnen her und ihr Streben (nach der Zusammenkunft mit den Almohaden) kündete von ihrem Anliegen. Sie überbrachten die ihnen aufgetragene Botschaft und brachten ihren und der Einwohner von Constantine Wunsch nach einem glimpflichen Ausgang zum Ausdruck. Und Gott erwies ihnen allen Seine Huld, indem ihrem Wunsch entsprochen wurde und alles für sie ein glückliches Ende nahm. Die Mitglieder dieser Abordnung traten daraufhin frohlockend (wörtl. mit frohlockenden Stirnlinien) die Rückreise zu ihrem Absender an und ihre Rückkehr war dabei in die Gewänder des körperlichen Wohlbefindens und des Wohlergehens [gehüllt ?] ${ }^{28}$. Sie kehrten nach Constantine zurück und fanden, dass die Bewohnerschaft sich voller Ungeduld in Erwartung freudiger Botschaften befand und dieser Gesandten während ihrer Abwesenheit lobend gedachte, und die Letzteren teilten den Bewohnern die Wohltat mit, welche ihnen durch das gewaltige Wirken Gottes zuteil geworden war. Ihre Gesamtheit sah, dass Gott gepriesen sei Er - durch Seine Hulderweisung das, was sie erbeten hatten, weit übertroffen hat und die zu ihrem Leben unabdingbaren Mittel dort hat entströmen lassen, wo sie es nicht vermutet hatten. Sie sahen ferner, dass Gott ihnen an Seiner Güte und Gnade mehr hat angedeihen lassen, als sie sich erhofft hatten, und dies zu einer Zeit, als sie keinen Zufluchtsort hatten außer demjenigen, den sie hatten verlassen und aufgeben müssen. Als all dies ihnen klar wurde und sie es als Wahrheit erkannten und als ihnen die übliche Vorgehensweise dieser gesegneten (almohadischen) Sache und der ihr unveräußerlich innewohnende Großmut zuteil wurden, öffneten sie die Tore der genannten Stadt. Ihre Gesamtheit ging zu den Almohaden hinaus, voller Freude über diese Güte und umfassende Barmherzigkeit Gottes ihnen gegenüber und im Schatten dieser alles umgebenden und vollkommenen (almohadischen) Botschaft Schutz suchend. Danach betraten einige Sachwalter der Almohaden und ihre Kämpfer - Gott möge ihnen den Erfolg verleihen - Constantine, welchen man sich in dieser Stadt niederzulassen und dort zu wohnen angeordnet hatte. Was aber den erwähnten AbūZakarīyā’ samt seinen Anverwandten - Gott möge ihnen den Erfolg verleihen -

\footnotetext{
${ }^{27} \mathrm{Zu}$,al-'Urwa al-wutqā"“ siehe z. B. Sure 2, Vers 256 des Korans, wo es „der einzig rechte Glaube“ bedeutet.

${ }^{28}$ Der Satz im arabischen Original (Mağmū` rasā’il muwaḥhidīya, S. 25) lautet „wa-tatahammal bi-ḥulal al-'āfiya wa-'n-ni`ma aṣ-șāfiya karratuhum“, wobei „tataḥammal“" an dieser Stelle m. E. nicht zu passen scheint. Was die erwähnten Gewänder (arab.: al-hulal) anbetrifft, so kann im mittelalterlichen arabischsprachigen Schrifttum ein emotionaler Zustand durch das Bild, man sei in das Kleid o.ä. einer bestimmten seelischen Verfassung „eingehüllt", wiedergegeben werden. Siehe hierzu die zahlreichen Belege im Kapitel „Kleider und Gewänder“ im Anhang 2.
} 
anbetrifft, so trat er mit ihnen in bester Verfassung und mit vornehmstem Geleit die Reise nach dieser Gegend - Gott möge sie vor allem Übel bewahren - an.

Gott hat Seinen Gunsterweis durch diese vollkommene Bezwingung (Constantines) und durch Sein umfassendes Eingreifen (zugunsten der Almohaden) in einer solchen Weise vollendet, dass er (d. h. der Gunsterweis) alle Hoffnungen der Hoffenden und alle Bitten der Bittenden erfüllte. Was diese befestigte Stadt anbelangt, so ist sie der höchste Gipfel, sie ist die Vorzügliche, die Vortreffliche sowie der Kopf des Körpers, dessen Glieder zum vollendeten Ganzen zusammengefügt sind (wörtl. dessen Glieder lückenlos aufeinander folgen). Durch Constantine werden die Schweißnähte und die Grundpfeiler dieser weitläufigen Gegend zusammengehalten und dank eben dieser Stadt findet man dort das räuberische Treiben derjenigen, die auf ein solches Treiben erpicht sind, nicht. Und durch keine andere Stadt als Constantine ist es möglich, die territoriale Einheit dieser Gegend zu gewährleisten und über sie die absolute Herrschaft auszuüben. Constantine bildet den abschließenden Teil des Buches dieser genannten Region, und gerade der abschließende Teil macht ein Buch wertvoll. Gott bitten wir um Seinen langfristigen Beistand dabei, Ihm für die augenscheinlichen Gnadenbezeigungen in gebührender Weise danken zu können. Wir bitten Ihn ferner darum, uns die Macht zu verleihen, die aufs engste mit Seiner Hilfe verknüpft ist, sowie darum, uns die Kraft zu bescheiden, die denjenigen, die sich für sie dankbar bezeigen, ein um das andere Mal zuteil wird, durch Seine Gnade. Der Friede, die Gnade Gottes und Seine Segen mögen euch zuteil werden.

Abgefasst am 10. November 1152.

\subsection{Einleitung zum historischen Kommentar}

Es sei eingangs auf eine Gemeinsamkeit hingewiesen, die allen überlieferten Quellenberichten zu den Ereignissen der nachfolgend auszuwertenden Passagen des Briefes eigen ist: Sie sind sehr spärlich und knapp und aus eben diesem Grunde wird es bei der historischen Analyse in nur bedingtem Maße möglich sein, Abschnitte des Briefes im Hinblick auf ihren historischen Gehalt zu untersuchen.

In der Sammlung „Mağmū' rasā’il muwaḥhidīya“ sind insgesamt drei Briefe überliefert, nämlich die Briefe Nr. 7, 8 und 9, die im Rahmen der almohadischen Unternehmung zur Zerschlagung des hammādidischen Reiches ${ }^{29}$ im Zenralen Maghreb verfasst wurden. Es

\footnotetext{
${ }^{29}$ Das Reich der Hammādiden (arab.: Banū-Hammād), die mit den Zīrīden verwandt waren, bestand von 1014 bis 1152. Zunächst als Statthalter ihrer zīrīdischen Vettern herrschten die Hammādiden über den Zentralen Maghreb und machten sich 1014 selbständig. Die Haupstädte dieses Reiches waren
} 
ist sicherlich davon auszugehen, dass auf Anordnung 'Abd-al-Mu'mins, der diesen Feldzug persönlich leitete, eine größere Zahl von offiziellen Briefen abgefasst wurde als nur die drei überlieferten. Darauf lässt z. B. der Satz „Man hat euch [...] bereits über das Eingreifen Gottes [...] zugunsten der Almohaden bei der Eroberung dieser Gegenden in Kenntnis gesetzt $[\ldots]^{630}$ im Brief Nr. 8 schließen, denn in der Sammlung „Mağmū' rasā’il muwaḥhidīya“" sind keine weiteren Schreiben mit der Schilderung der Eroberung dieser einzelnen Gebiete des Zentralen Maghreb enthalten. Im Brief Nr. 8 findet sich auch ein anderer Hinweis auf einen weiteren - theoretisch also fünften almohadischen Brief, der nach dem Sieg der almohadischen Truppenteile vor Constantine geschrieben wurde, was eindeuig aus dem Satz „Als diese genannten Almohaden [...] in die Nähe von Constantine [...] gelangten, wurde ihnen der Sieg beschieden, welchen man euch bereits dargelegt und kundgemacht [...] hat ${ }^{\star 331}$ hervorgeht. Die Annahme liegt nahe, dass nach dem für die Almohaden erfolgreichen Abschluss jeder wichtigen Etappe ihrer Unternehmung Siegesmeldungen verfasst und verschickt wurden. Beim almohadischen Eroberungszug in den Zentralen Maghreb ist also höchstwahrscheinlich von mindestens fünf Schreiben auszugehen. Interessant ist in diesem Zusammenhang der Hinweis von Ibn-Iḍārī al-Marrākušī, 'Abd-al-Mu'min habe Abū-Ğa'far Ibn-'Ațiyaa ${ }^{32}$ ein in sprachlicher Hinsicht vortreffliches Schreiben an die Gesamtheit der Bewohner von Maghreb und al-Andalus mit der Schilderung der Einnahme Biğāyas abfassen lassen, bei dessen sprachlicher Ausgestaltung dieser almohadische Sekretär ein unnachahmlich hohes Niveau erreicht habe. Dieses Schreiben sei danach an die gesamten Gebiete des almohadischen Reiches geschickt worden $^{33}$. Es kann nicht ausgeschlossen werden, dass damit der hier zu analysierende

nacheinander die Städte Ašīr, Qal'at Banī-Hammād und ab 1068 Biğāya. (Singer, Hans-Rudolf: Der Maghreb und die Pyrenäenhalbinsel bis zu Ausgang des Mittelalters, S. 286-289)

${ }^{30}$ Mağmū' rasāìil muwaḥhidīya, S. 23.

${ }^{31}$ Mağmū' rasā̄il muwaḥhịidìya, S. 24.

32 Abū-Ğa'far Ibn-'Atịya war die wohl schillerndste und zugleich traurigste Gestalt unter den almohadischen Sekretären. Er hat im almoravidischen Reich bis zu dessen Zerschlagung durch die Almohaden im Jahr 1147 das Amt des Sekretärs (arab.: al-kätib) bekleidet. Danach erlangte er die Gunst 'Abd-al-Mu'mins mittels eines Schreibens, das er nach dem Sieg der Almohaden über einen Aufständischen namens al-Māsī und dessen Anhängerschaft verfasste und das den Kalifen durch seine sprachliche Schönheit so tief beeindruckt haben soll, dass er ihn zu seinem Sekretär und Minister berief. Später fiel er jedoch in Ungnade und wurde zusammen mit seinem Bruder Abū-'Aqīl im Jahr 1158 umgebracht (I'tāb al-kuttāb, S. 225 f., Kitāb ar-rauḍ al-mi'tāa, S. 522, Mağmū'a ğadīda, Bd. 1, S. 18-19).

33 al-Bayān al-muġrib, S. 47. Diese Angabe ist in zweifacher Hinsicht interessant. Denn sie zeigt, dass ein Teil der almohadischen Schreiben entgegen unserem zeitgenössischen Verständnis an die Allgemeinheit gerichtet wurde. Zum anderen muss man angesichts der Angabe, die Briefe seien an alle Gebiete des Reiches geschickt worden, zwangsläufig davon ausgehen, dass die - zumindest an die Allgemeinheit gerichteten - almohadischen Briefe nach Eingang bei ihren Adressaten und nach ihrer Bekanntgabe kopiert wurden, um dann an weitere almohadische Gebiete geschickt und dort bekannt gegeben $\mathrm{zu}$ werden. 
Brief gemeint ist oder aber auch dass damit auf ein weiteres - in diesem Falle also sechstes - almohadisches offizielles Schreiben Bezug genommen wird ${ }^{34}$.

Zum Zeitpunkt der Durchführung dieser Unternehmung befand sich der letzte ziridische Herrscher al-Hasan Ibn-'Alī ${ }^{35}$ unter einer Art Hausarrest in Algier. Denn im Jahre 1148 nahmen die Truppen Rogers II., des Herrschers von Sizilien und Süditalien, al-Mahdīya, die Residenzstadt dieses genannten Herrschers, ein. Er floh samt seiner Familie und seinem Hof. Der Schilderung von at-Tiğānī nach ${ }^{36}$, soll er nach seiner Flucht aus alMahdīya nach Ägypten auszuwandern vorgehabt haben, woran ihn jedoch die Flotte des normannischen Königs konsequent gehindert habe. Danach habe er sich zu 'Abd-alMu'min zu begeben gedacht haben. Er habe seinen Onkel Yạ̣yā Ibn-al-'Azīz in Biğāya diesbezüglich in Kenntnis gesetzt und um die Erlaubnis gebeten, sein Vorhaben zu verwirklichen. Nach anfangs wohlwollender Haltung ließ jedoch der Letztere al-Hasan Ibn-'Alī, der sich bereits in der Nähe Biğāyas befand, auf mehr oder minder unsanfte Weise nach Algier geleiten und ihn dort, wie oben erwähnt, samt seinen gesamten Familienangehörigen unter Hausarrest stellen ${ }^{37}$.

Was den ḥammādidischen Herrscher Yahyā Ibn-al-'Azīz zum Zeitpunkt des almohadischen Vorrückens anbetrifft, so befand sich dieser in Biğāya, der Hauptstadt des hammādidischen Reiches. Er scheint keine absolute Kontrolle über die Gebiete seines Reiches ausgeübt zu haben und soll eine große Vorliebe für Frauen und Jagd gehabt haben, auch dann, als ihm die Herrschaft über sein Reich zugunsten șanhāğitischer Stämme zusehends entglitt ${ }^{38}$.

\footnotetext{
34 Diese Annahme stützt die einleitende Bemerkung im arabischen Original (Mağmūc rasā’il muwaḥhidīya, S. 22) zum hier zu analysierenden Brief Nr. 8, dass dessen Verfasser Abū-'Aqīl 'Ațiya Ibn'Ațiya, der Bruder des uns bekannten Abū-Ğa'far Ibn-'Ațìya, ist.

${ }^{35}$ Die Zïriden waren eine berberische Sippe, die den Fatimiden in Ifrīqīya wertvolle Dienste leisteten. Bei ihrer Übersiedlung nach Ägypten ernannten die Fatimiden Buluggīn Ibn-Zīrī (971-984) zu ihrem Statthalter über Ifrīqiya. Von ihrer Haupstadt aus in Kairuan herrschten die Zïriden über dieses Gebiet und entledigten sich der fatimidischen Oberherrschaft endgültig 1051. Die Reaktion Kairos bestand darin, die arabischen Beduinenstämme der Stammesverbände Banū-Riyāḥ und Banū-Sulaim zum Einfall in Ifrīqīya zu bewegen. Im Gefolge des damit ausgelösten Zusammenbruchs des Zīriden-Reiches wurde die Hauptstadt nach al-Mahdīya verlegt, von wo aus die Zïriden vergeblich das normannische Ausgreifen nach Ifrīqīya zu verhindern suchten. Der letzte Herrscher dieser Dynastie al-Hasan Ibn-'Alī verlor alMahdiya 1148 und floh westwärts. (Siehe hierzu Singer, Hans-Rudolf: Ziriden, in: Lexikon des Mittelalters, Bd. 9, S. 626 f.)

${ }^{36}$ Riḥlat at-Tiğānī, S. 341 f. Eine detaillierte Darstellung dieser Ereignisse anhand überlieferter arabischer Quellen findet sich auch in „La Berbérie Orientale“ (Bd. 1, S. 362-363).

${ }^{37}$ Bei Ibn-Haldūn (Kitāb al-ibar, Bd. 6, S. 332) findet sich eine abweichende Schilderung sowohl der Abfolge dieser Ereignisse als auch der Umstände der Unterbringung von al-Hasan Ibn- 'Alī in Algier.

${ }^{38}$ Kitāb al-'ibar, Bd. 6, S. 362f. Ein ähnlich unvorteilhaftes Bild dieses Herrschers malen auch at-Tiğānī (Riḥlat at-Tiğānī, S. 344) und Ibn-al-Ațīr (al-Kāmil, Bd. 9, S. 31).
} 
1.3. „Man hat euch ferner darüber berichtet, dass Abū-Zakarīyā' Yahyā Ibn-al-'Azīz bi-'llāh Ibn-al-Manșūr Ibn-an-Nāṣir und seine gesamten Brüder [...] keinen anderen Ausweg sahen als ihren angestammten Wohnsitz zu verlassen und ihre trauten Orte und Weiten aufzugeben $[\ldots]^{\text {“ }}$

Das eigentliche Ziel der almohadischen Unternehmung im Jahre 1152, die zur Unterwerfung des hammādidischen Reiches im Zentralen Maghreb geführt hat ${ }^{39}$, war dank rigoroser Massnahmen zu deren Geheimhaltung ${ }^{40}$ auch nach dem Aufbruch der almohadischen Armee unbekannt gewesen. In Eilmärschen erreichte 'Abd-al-Mu'min Tilimsen, von wo aus er am nächsten Tag seinen forcierten Marsch nach Algier fortsetzte und auf dem Wege dorthin die Stadt Miliana unterwarf. Nach der Einnahme Algiers zog 'Abd-al-Mu’min nun in Begleitung al-Ḥasan Ibn-'Alīs nach Biğāya. Allem Anschein nach wurde die ḥammādidische Hauptstadt den almohadischen Truppen von ḥammādidischem Wesir namens Maymūn Ibn-Ḥamdūn „übergeben“, Yaḥyā Ibn-al'Azīz konnte dabei fliehen. In den arabischen Quellen sind zwei im Detail zwar abweichende, in groben Zügen letztlich aber doch miteinander übereinstimmende Fassungen bezüglich des genauen Ablaufs dieser Flucht überliefert. Einer Version zufolge habe sich Yahyā Ibn-al-'Azīz ursprünglich auf dem Seeweg nach Bagdad begeben wollen. Als er jedoch samt seinen Familienangehörigen in der Stadt 'Annāba angelangt war, richtete der Statthalter dieser Stadt, sein Bruder al-Hạarit, scharfe Vorwürfe an ihn wegen der aus seiner Sicht mutlosen Preisgabe der hammādidischen Besitzungen, und darauf hin habe sich Yahyā nach Constantine begeben, dessen Statthalter, sein weiterer Bruder namens al-Ḥasan Ibn-al-'Azīz, zu seinen Gunsten auf die Herrschaft über diese Stadt verzichtet habe ${ }^{41}$. Einer anderen Version zufolge sei Yaḥyā Ibn-al-'Azīz aus Biğāya direkt nach Constantine geflohen ${ }^{42}$. Fast allen Quellen ${ }^{43}$ ist dabei gemeinsam, dass sie von der Flucht des letzten hammādidischen Herrschers sprechen, während die entsprechende Passage im almohadischen Brief euphemistisch mit „Verlassen“ und „Aufgabe“ auf diese Tatsache Bezug nimmt. Es fällt ferner auf,

\footnotetext{
${ }^{39}$ Eine ausführliche Darstellung von einzelnen Etappen dieser Unternehmung findet sich in „La Berberie Orientale “ (Bd. 1, S. 365-374) und in „Historia política del imperio almohade“ (Bd. 1, S. 161-167).

${ }^{40}$ Siehe hierzu den Bericht in „Kitāb ahbār al-mahdī Ibn-Tūmart“ (S. 113).

${ }^{41}$ „Rihlat at-Tiğānī“ (S. 344) und „Kitāb al-'ibar” (Bd. 6, S. 364). In ,al-Mu ğib“ (S. 206) und ,al-Anīs al-mutrib“ (S. 251) werden nur kurz die einzelnen Etappen dieser Route erwähnt.

42 „al-Kāmil” (Bd. 9, S. 31) ,al-Ḥulal al-maušìya“ (S. 149) und „Kitāb ahbār al-mahdī Ibn-Tūmart“ (S. 114).

${ }^{43}$ Eine Ausnahme bilden ,,al-Kāmil“ (Bd. 9, S. 31) sowie „Kitāb al-'ibar““ (Bd. 6, S. 364). Ibn al-'Idārī spricht in diesem Zusammenhang sogar davon, dass Yahyā, nachdem sein Statthalter über Algier auf der Flucht vor Almohaden $\mathrm{zu}$ ihm gelangte und ihn über das Vorrücken der almohadischen Armee in Kenntnis setzte, ein Schiff besorgt habe, anschließend an Bord gegangen sei und ,es von Panik ergriffen für seine einzige Rettung hielt"، (al-Bayān al-mugirib, S. 46).
} 
dass die Angaben des Briefes über den letzten ḥammādidischen Herrscher sehr knapp sind. Man könnte annehmen, die Rezipienten des Briefes hätten bereits ein ausreichendes $\mathrm{Ma}$ an Kenntnis der historischen und politischen Gegebenheiten des Zentralen Maghreb besessen, so dass einige allgemeine Stichworte ihnen bereits genügt haben können. Dies würde einen hohen Grad an Informiertheit voraussetzen. Wenn jedoch diese Kenntnis nicht bzw. nur rudimentär vorhanden war, dann trugen die im Brief enthaltenen Informationen über Yạ̣yā Ibn-al-'Azīz sicherlich nicht nur nicht zu einer klareren Vorstellung über die politischen Verhältnisse des genannten Gebiets beim Vorrücken der almohadischen Armee bei, sondern waren letztlich sogar irreführend.

1.4. „Die Belagerten einigten sich also darauf, eine Abordnung zu entsenden [...].“

Was diese Aussage des Briefes anbelangt, so kann sie anhand überlieferter arabischer Quellen nicht überprüft werden. Denn sie alle reichen bei der Beschreibung des Feldzuges zur Unterwerfung des Zentralen Maghreb nicht über den kurzen Hinweis hinaus, Yaḥyā Ibn-al-'Azīz sei bei seiner Flucht aus Biğāya, über deren einzelne Stationen diese Quellen teilweise widersprüchliche Informationen enthalten, in Constantine angelangt und habe sich später den Almohaden ergeben, nachdem ihm und seinen Familienangehörigen körperliche und materielle Unversehrtheit zugesichert worden wäre ${ }^{44}$. Aus diesem Grund können die Angaben des Briefes über den detaillierten Verlauf dieser Ereignisse durchaus als einzigartig gelten, die allerdings nicht nachprüfbar sind. Es liegt trotzdem nahe, ihnen in wesentlichen Zügen Glauben zu schenken. In „Mağmū' rasā’il muwaḥhịīìa“ ist ein weiterer almohadischer Brief an die Bewohner Constantines überliefert, auf dessen Inhalt näher einzugehen hier geboten erscheint, da er die Entscheidung der Einwohner Constantines, die Belagerung ihrer Stadt in der geschilderten Weise gütlich beenden zu wollen, verständlich macht.

Dieser almohadische Brief Nr. 7, datiert vom 27. August des Jahres 1152 und abgefasst in der Stadt Biğāya im Namen des Befehlshabers der Gläubigen, richtet sich an die Šaihs, Notabeln und die gesamte Bewohnerschaft Constantines. In folgender Weise lässt sich sein Inhalt wiedergeben: Nach der Eroberung der östlichen Gebiete ${ }^{45}$ beschließen die Almohaden, die genannten Adressaten zum Gehorsam gegenüber Gott und Seinem

44 „Rihlat at-Tiğānī“ (S. 344), „Kitāb al-cibar” (Bd. 6, S. 364 und S. 490), ,al-Mự̆ib“ (S. 206) und ,alAnīs al-muțib“ (S. 253), „al-Kāmil” (Bd. 9, S. 31), „al-Ḥulal al-maušīya“ (S. 149) und ,al-Bayān almugrib“ (S. 46). In ,,al-Mu’nis” (S. 115) findet sich die sicherlich nicht zutreffende Angabe, Yahyyā Ibnal-'Azīz sei in Biğāya belagert worden und habe sich dort ergeben.

${ }^{45}$ Mit den „östlichen Gebieten“ meint man in den almohadischen Briefen und Quellen annähernd das Gebiet des Zentralen Maghreb, das vom als „Ifrīqīya“ bezeichneten Gebiet unterschieden wird. Siehe zu dieser geographischen Einteilung „Mağmū' rasā’il muwaḥḥidīya“, S. 18 und 33 f. 
Gesandten aufzufordern, d. h. sich den Almohaden zu unterwerfen. Diese Mahnung wird von Aufrufen religiösen Charakters sowie Warnungen davor, sie zu missachten, begleitet. Dabei wird diesen Warnungen durch die Schilderung verhängnisvoller Folgen der Verschmähung derartiger Aufforderungen am Beispiel lokaler Herrscher Nachdruck verliehen. Darauf folgt der Hinweis auf das Beispiel des Šaih Abū-Muhammad Maimūn Ibn-'Alī Ibn-Hamdūn ${ }^{46}$ und seines Bruders Abū-'Abdallāh Muhammad Ibn-'Alī IbnHamdūn, die sich samt ihren Verwandten bereits zum Almohadentum ${ }^{47}$ bekannt hätten, und auf die ihnen daraus erwachsenden Vorteile. Der Brief schließt mit dem Hinweis auf die Abschaffung der nicht-koranischen Steuern und Abgaben in den von den Almohaden in Besitz genommenen Gebieten sowie auf die getreue Anwendung der schariatischen Normen dort.

Hierbei muss man bedenken, dass - wie wir dem entsprechenden Bericht Ibn-al-Atîrs entnehmen können - die Bewohner von Biğāya kraft der durch die Mitglieder der Familie Ibn-Hamdūn vereinbarten Sicherheitsgarantien vor der Übergabe dieser Stadt an die Almohaden keinen Plünderungen durch die Eroberer ausgesetzt wurden ${ }^{48}$, wohingegen Qal'at Banī-Hammād, nachdem es Widestand geleistet hatte, von den Almohaden gewaltsam eingenommen, anschließend zerstört wurde und viele Tote zu beklagen hatte ${ }^{49}$. Vor diesem Hintergrund muss das Angebot 'Abd-al-Mu'mins seine Anziehungskraft auf die Bewohner von Constantine ausgeübt haben, zumal die almohadische Armee vor den Toren der Stadt - schenkt man den Ausführungen des Briefes Glauben - durch ihre unausgesetzten Operationen eine veritable Drohkulisse gebildet hat. Wenn man darüber hinaus berücksichtigt, dass, wie oben gezeigt, die wohlgemerkt sehr knappen - Angaben in den überlieferten Quellen Yahyā Ibn-al-'Azīz übereinstimmend als einen eher unfähigen und trägen Herrscher schildern, so wird die Entscheidung, durch eine Abordnung günstige Bedingungen für die Übergabe Constantines auszuhandeln, nachvollziehbar. Interessanterweise wird diese Entscheidung, eine Abordnung an 'Abd-al-Mu'min $\mathrm{zu}$ entsenden und so einen

\footnotetext{
${ }^{46}$ Bei dieser Person handelt es sich um den ehemaligen Minister von Yahyā Ibn-al-'Azīz, der aufgrund vohergegangener schriftlicher Absprachen und geheimer Vereinbarungen mit 'Abd-al-Mu'min der heranrückenden almohadischen Armee die Tore Biğāyas geöffnet haben soll (al-Bayān al-muġrib, S. 46 und al-Hulal al-maušìya, S. 149).

${ }^{47}$ 'Izz-ad-Dīn 'Umar Mūsā zeigt auf, dass der Begriff „tauhịi“, d. h. „das Almohadentum“ bzw. „das Bekenntnis zum Almohadentum", nach der Einnahme Marrakechs 1147 einen wichtigen Bedeutungswandel erfahren hat, nämlich von seinem ursprünglich religiösen hin zum politischen Gehalt: am Anfang habe er das Bekenntnis zur Lehre des Muhammad Ibn-Tümart gemeint, später habe er den Sinn gehabt, sich der almohadischen Herrschaft zu unterwerfen (al-Muwaḥhidūn fi 'l-G̈arb al-Islāmī, S. 104).

48 al-Kāmil, Bd. 9, S. 31.

${ }^{49}$ Kitāb al-'ibar, Bd. 6, S. 364 und S. 491.
} 
friedlichen Ausgang der Umzingelung der Stadt herbeizuführen, zu welcher der oben wiedergegebene almohadische Brief, die Verwüstung von Qal'at Banī-Hammād, die drohende Einnahme Constantines und die Untauglichkeit von Yahya Ibn-al-Aziz in einer nicht mehr in Erfahrung zu bringenden Weise beigetragen oder sie vielleicht gar bedingt haben, im Brief mit „Dies (d. h. die Belagerung) dauerte an, bis Gott das Einsichtsvermögen der im Obigen erwähnten Gruppe auf das rechte Handeln richtete $[\ldots]^{6{ }^{650}}$ umschrieben bzw. übergangen.

Geht man der Frage nach, wie lange die Belagerung Constantines dauerte, so stellt man fest, dass hierzu so gut wie keine näheren Zeitangaben überliefert sind. Es gibt lediglich zwei Anhaltspunkte, nämlich das Datum der Abfassung des Briefes Nr. 7 und des Briefes Nr. 8, welche jeweils am 27. August 1152 bzw. am 10. November des gleichen Jahres ergangen sind. Man kann also eine Belagerungszeit von mindestens drei Monaten annehmen. Durch den Aufbau des Briefes und aufgrund des weitest gehenden Fehlens von Zeitangaben müssen die Rezipienten jedoch den - irrigen - Eindruck gehabt haben, die Inbesitznahme Constantines, ja die gesamte Unternehmung in den Zentralen Maghreb habe sich binnen kürzester Zeit rasch vollzogen.

1.5. „Was aber den erwähnten Abū-Zakarīyā' samt seinen Anverwandten [...] anbetrifft, so trat er mit ihnen in bester Verfassung und vornehmest geleitet die Reise nach dieser Gegend [...] an.“

Yahyā Ibn-al-'Azīz und seine Familienangehörigen begaben sich zunächst nach Biğāya zu 'Abd-al-Mu'min, der sie mit Ehren empfangen und gütig behandelt hat ${ }^{51}$, und zogen wenig später mit ihm nach Marrakech ${ }^{52}$. Die Quellen schildern das Leben dieses Herrschers auch im Exil als ein Leben in Wohlstand und Muße $\mathrm{e}^{53}$. So soll er sich z. B. insbesondere der Löwenjagd mit Metallnetzen gewidmet haben und die auf diese Weise erjagten Tiere dann 'Abd-al-Mu'min geschenkt haben, der ihn dafür reichlich entlohnt habe ${ }^{54}$. Einige Jahre später wurde Yahyā in einem der Paläste in Salé untergebracht und starb dort im Jahr 557 H. / 1161-1162 n. Chr. ${ }^{55}$

\section{6. „Was diese befestigte Stadt anbelangt, so ist sie der höchste Gipfel [...]“}

\footnotetext{
${ }^{50}$ Mağmū' rasā’il muwaḥịidìa, S. $24 \mathrm{f}$.

${ }^{51}$ Riḥlat at-Tiğānī, S. 344.

52 al-Kāmil, Bd. 9, S. 31, al-Mư̌̆ib, S. 207, al-Anīs al-muțrib, S. 253, al-Bayān al-muğrib, Riḥlat atTiğānī, S. 344, S. 46, al-Ḥulal al-maušīya, S. 149, Kitāb al-cibar, Bd. 6, S. 364.

${ }^{53}$ al-Mu'ğib, S. 207, Riḥlat at-Tiğānī, S. 344, al-Ḥulal al-maušīya, S. 149, al-Bayān al-muğrib, S. 46.

54 al-Hulal al-maušìya, S. 149, al-Bayān al-muğrib, S. 46.

${ }^{55}$ Kitāb al-cibar, Bd. 6, S. 364.
} 
Die almohadischen Briefe bilden ein einzigartiges schriftliches Zeugnis, um die im mittelalterlichen literarischen arabischen Schrifttum gängigen Metaphern und Allegorien kennen zu lernen. Diese Metaphern sind - soweit meine Kenntnis reicht bisher nicht Gegenstand einer wissenschaftlichen Untersuchung geworden, sodass die auf die Ermittlung des historischen Gehalts und somit auf das präzise Verständnis jedes einzelnen Sinnabschnittes zielende Lektüre der almohadischen Zeugnisse als auch anderer ähnlicher Zeugnisse aus der Zeit vor und nach der almohadischen Periode sich als problematisch erweist. Denn viele Aussagen der almohadischen Briefe sind in genannte Metaphern und Allegorien gefasst, deren gemeinter Sinn jedoch bisher nicht systematisch erforscht wurde. Auf diese Weise steht der Forscher sehr oft vor arabischen Sätzen, die er zwar wörtlich meistens übersetzen kann, deren eigentliche Aussage ihm dennoch häufig verborgen bleibt und die er nur anhand eigener subjektiver Deutung wiedergeben kann. Hinzu kommt das weit verbreitete Mittel in den schriftlichen arabischen Zeugnissen des Mittelalters, eine Aussage in mehrere unterschiedliche Metaphern und Allegorien zu kleiden und sie aneinander zu reihen, so dass die Unkenntnis dieser Umschreibungen das Verständnis der betreffenden Textpassagen erheblich erschwert.

Auf den eingangs angeführten Satz übertragen bedeutet dies, dass dieser genau genommen aus zwei Aussagen besteht, einer wörtlichen und einer übertragenen, und somit ein repräsentatives Beispiel für die mittelalterliche Metaphorik bildet. Laut der ersten Aussage ist die Stadt Constantine ein Gipfel und dies bietet heute ein sehr breites Spektrum an Interpretationsmöglichkeiten. Und obwohl Constantine wirklich auf einem Berg liegt, weist das angeführte Zitat weit über diese bloße geographische Gegebenheit hinaus und enthält weitere, dem zeitgenössischen Rezipienten wohl bekannte Aussagen. Denn im Schrifttum der genannten Gattung waren unterschiedliche Festungskonzepte üblich ${ }^{56}$ : So war beispielsweise die Vorstellung weit verbreitet, eine zu bezwingende Stadt sei eine schöne Frau, welcher sich zu bemächtigen - z.B. durch Heirat oder auch Überwältigung - sie einzunehmen hieße. Eng damit zusammenhängend und weit verbreitet war auch der Vergleich einer befestigten Stadt mit einem störrigen Reittier, welches $\mathrm{zu}$ besteigen bzw. zu zähmen ebenfalls der Einnahme dieser Stadt gleichbedeutend wäre. Darüber hinaus waren noch weitere Vergleiche bzw. Metaphern im Umlauf, welchen andere Vorstellungen zu Grunde lagen, so z. B. der Vergleich einer Feste mit einem hohen Berg, den zu besteigen deren Inbesitznahme bedeutete. Für die 
angeführten Beispiele gilt, dass deren jeweilige metaphorische Verfasstheit sich ganz allgemein auf die Austattung der geschilderten Objekte mit anderen Eigenschaften bzw. Attributen bestimmend auswirkte. So wird beispielsweise erst vor dem Hintergrund der Möglichkeit des Vergleichs einer Stadt mit einer schönen Frau die gemeinte Bedeutung des Zitats von Lisān-ad-Dīn Ibn-al-Hुaṭīb verständlich: ,illā annahā (aiy al-madīna almaḍūra) lā tadfac 'an qurțihā wa-siwārihā bi-aswārihā wa-lā tamna' naz' ṣidārihā biğidārihā" ${ }^{\text {‘57 }}$, wörtl „,die geschilderte Stadt ist weder imstande, ihren Schmuck aus Edelsteinen $^{58}$ und ihr Armband (vor Angreifern) durch ihre Stadtmauer zu schützen, noch kann sie Gewalttäter mittels ihrer (niedrigen) Mauer daran hindern, den Brustlatz ihr vom Leibe zu reißen“, d. h. die Wehrhaftigkeit der geschilderten Stadt ist gering, sodass es ein Leichtes ist, sie zu erobern.

In einer sehr ähnlichen Weise verhält es sich beim sehr beliebten Vergleich einer befestigten Stadt mit einem hohen Berg. Dies hatte ebenfalls zur Folge, dass einige dem „Berg“ eigene Teile, wie z. B. Bergpfad, Bergfuss, Berghang oder eben am häufigsten Berggipfel, auf die zu schildernde Stadt übertragen wurden und dann im neuen Zusammenhang eine durch den Bezug auf dieses Objekt spezifische Bedeutung annahmen. In diesem Falle musste der Rezipient ausgehend von den ihm vertrauten Metaphern und Allegorien die abstrakten Umschreibungen auf die konkreten und in der Wirklichkeit benennbaren Entsprechungen erst beziehen. Auf der anderen Seite und unabhängig von der Frage, welcher konkreten Entsprechung bzw. welchen Entsprechungen die betreffende Metapher bzw. Allegorie zuzuordnen war, hatten diese abstrakten Umschreibungen die ihnen eigenen Konnotationen. Um nur ein relevantes Beispiel zu nennen, wurden mit dem Vergleich einer Stadt mit einem hohen Berg entweder deren Uneinnehmbarkeit und Wehrhaftigkeit oder nicht selten auch deren Unbotmäßigkeit konnotiert. Für die Analyse des Satzes „Was diese befestigte Stadt anbelangt, so ist sie der höchste Gipfel [... $]^{659}$ im Sinne der in dieser Arbeit gestellten Aufgabe gilt also festzuhalten, dass hier ein literarisches Stilmittel vorliegt, mit welchem nicht so sehr die geographische Lage Constantines oder die wirkliche Höhe seiner Bauten zum Ausdruck gebracht werden soll, sondern vielmehr die Tatsache, dass die Stadt uneinnehmbar ist, obgleich die beiden Aussagen, sowohl die wörtliche als

\footnotetext{
56 Siehe hierzu auch die im Kapitel „Festungskonzepte“ des Anhanges Nr. 2 zusammengetragenen Textbelege.

${ }^{57}$ Mušāhadāt Lisān ad-Dīn Ibn-al-Hatịib fĩ bilād al-Mağrib wa-'l-Andalus, S. 95.

${ }^{58}$ Dozy erklärt ,al-qurț“ u. a. mit „,petite lame ronde, ornée de pierres précieuses, que les dames portent sur le front ou sur la poitrine“" (Supplément aux dictionnaires arabes, Bd. 2, S. 338).

${ }^{59}$ Mağmū' rasā̄il muwaḥhidìya, S. 26.
} 
auch die übertragene, sich nicht ausschließen, sondern vielmehr sich ergänzen. Der superlativische Gebrauch des zu „Gipfel“ gehörenden Adjektivs lässt den Sinn der gesamten Wendung auf „,die absolute Uneinnehmbarkeit Constantines“ hinauslaufen.

Den sich an den angeführten Satz anschließenden Ausführungen des Briefes lassen sich insgesamt zwei wichtige Merkmale Constantines entnehmen: Erstens ist diese Stadt absolut uneinnehmbar und zweitens besitzt sie eine äußerst wichtige strategische Bedeutung. Bei al-Bakrī findet sich eine kurze Beschreibung Constantines. Demnach war es eine große und bevölkerungsreiche Stadt, deren Wehrhaftigkeit und Uneinnehmbarkeit diejenigen aller anderen bekannten Städte übertraf. Sie war umgeben von drei großen befahrbaren Flüssen, die sich alle in den äußerst tiefen Umfassungsgraben ergossen. Über diesen spannte sich eine Brücke, die aus drei übereinander liegenden Gewölbebrücken bestand und auf der man zum Stadttor gelangte $^{60}$. Auf die in diesem Bericht erwähnte einzigartige Uneinnehmbarkeit Constantines weisen auch explizit die jeweiligen Berichte von al-Idrīs $\overline{1}^{61}$, dem anonymen „Kitāb al-istibṣār fī 'ağā'ib al-amșār، ${ }^{62}$ und al-Ḥimyarî ${ }^{63}$ hin, so dass die betreffende Angabe des Briefes diesbezüglich als zutreffend betrachtet werden kann. Doch es gibt einen entscheidenden Unterschied zwischen den Schilderungen von wehrhaften Festen in den geographischen Schriften und in den offiziellen almohadischen Schriftstücken: Den Letzteren nämlich dient die Betonung der Wehrhaftigkeit von Städten auf der einen und ihre Inbesitznahme durch die Almohaden auf der anderen Seite zur Hervorhebung des Beistandes Gottes gegenüber den Bekennern des Almohadentums und somit letztlich zur Legitimierung der almohadischen Herrschaft. Vorausgreifend kann man sagen, dass sämtliche in „Mağmū rasā’il muwaḥhidīya“ enthaltenen Schilderungen von Städten, die von den Almohaden belagert und besiegt werden, als absolut unübertreffbar im Hinblick auf ihre Uneinnehmbarkeit geschildert werden ${ }^{64}$. Was die strategische Bedeutung Constantines anbetrifft, so lassen sich diesbezüglich den herangezogenen geographischen Werken keine Hinweise darauf entnehmen, die dies bestätigten, widerlegten oder relativierten.

\subsection{Zusammenfassung}

\footnotetext{
${ }^{60}$ Kitāb al-mugrib fĩ dikr bilād Ifrīqīya wa-'1-Mağrib, S. 63.

${ }^{61}$ Kitāb nuzhat al-muštāq fi 'hytirāq al-āfāq, S. 266.

${ }^{62}$ Kitāb al-istibsār fī 'ağāìb al-amṣār, S. 165-166.

${ }^{63}$ Kitāb ar-rauḍ al-mictāar, S. 480 f.

${ }^{64}$ Siehe die Zusammenstellung der entsprechenden Passagen im Kapitel 5.7. dieser Arbeit.
} 
Im Mittelpunkt des Briefes Nr. 8 steht die almohadische Unternehmung gegen Constantine im Jahr 1152 sowie die Schilderung von Ereignissen, die zur Einnahme dieser Stadt geführt haben. Anhand vorhandener arabischer Quellen konnte ermittelt werden, dass die Angaben des Briefes in groben Zügen mit den überlieferten historiographischen Angaben übereinstimmen. Im Falle der Entsendung der Abordnung aus Constantine nach Biğāya konnte die Information des Briefes allerdings nicht näher überprüft werden. Ferner konnte festgestellt werden, dass einige seiner Aussagen (z. B. über die Einnahme Biğāyas oder die Flucht des letzten hammādidischen Herrschers nach Constantine) in mehrdeutige euphemistische Ausdrücke gefasst sind und daher ohne Blick auf die überlieferten historiographischen Berichte irreführend oder zumindest missverständlich wären.

Darüber hinaus weist der Brief einige formale Merkmale auf, die Schlüsse auf die bei den Rezipienten erzielte Wirkung bei der öffentlichen Verlesung des Briefes erlauben. So besteht ein wesentliches Merkmal des Briefes darin, dass sowohl die Unternehmung in den Zentralen Maghreb als auch ihre einzelnen Etappen im Gegensatz zu anderen historiographischen Berichten ${ }^{65}$ als von göttlichem Ratschluss sowie von göttlichem Beistand und seinem direkten Eingreifen zugunsten der Almohaden begleitet dargestellt werden. Es sind ferner eingeflochtene koranische Wendungen (s. Fußnoten Nr. 19 und 27) zu nennen, die auf der sprachlichen Ebene das göttliche Moment allen Tuns der almohadischen Herrscher der zeitgenössischen Zuhörerschaft suggerieren sollten. Des Weiteren konnte eine literarische Entlehnung in Form einer - später klassisch gewordenen - arabischen Redewendung sowie einige im mittelalterlichen literarischen Schrifttum gängige Metaphern und Allegorien (s. Fußnoten Nr. 24, 26 und 28) festgestellt werden. In einem Fall konnte der implizite Hinweis auf die geographischen Gegebenheiten der Arabischen Halbinsel aufgezeigt werden (s. Fußnote Nr. 21). Des Weiteren fiel auf, dass die im Brief dargestellten Ereignisse in einem zeitlosen Raum angesiedelt sind. Denn es sind darin mit Ausnahme des Datums der Abfassung des Schreibens keine sonstigen Zeitangaben enthalten, die auf die Dauer der geschilderten Abläufe schließen ließen, so dass dem Rezipienten der - irrige - Eindruck vermittelt worden sein dürfte, diese hätten sich in einer lückenlosen zeitlichen Abfolge zügig

\footnotetext{
${ }^{65}$ Eine Ausnahme bilden hierbei ,al-Bayān al-muğrib“, dessen Autor in seiner Schilderung den Berichten almohadischer Geschichtsschreiber folgt, und ,al-Hulal al-maušĩya“, dessen Verfasser seinerseits sich weitgehend bei den analysierten Passagen auf ,,al-Bayān al-mugrrib“ stützt.
} 
vollzogen, wobei sie sich in Wirklichkeit über einen Zeitraum von mehreren Monaten erstreckt hatten ${ }^{66}$.

\section{Zusammenfassung des Briefes Nr. 9}

Dieser Brief, datiert vom 26. Juni des Jahres 1153 und abgefasst im Namen des Befehlshabers der Gläubigen in Tilimsen, ist an Šaih Abū-Muhammad Wasnār, an seine Gefährten von den Ṭālibs sowie an die Šaihss, Notabeln und die gesamte Bewohnerschaft von Marrakech adressiert. Laut diesem Brief ist er eines der Schreiben, die im Rahmen der militärischen Unternehmung der Almohaden in den Zentralen Maghreb abgefasst wurden. Er schildert eine Schlacht zwischen den Almohaden und den arabischen Beduinen sowie auch die damit im Zusammenhang stehenden Ereignisse. Folgender Ablauf dieser Geschehnisse geht aus dem Brief hervor: Bei der Unterwerfung des Zentralen Maghreb werden die arabischen Stämme in die Wüste abgedrängt und die almohadischen Truppenverbände lagern nach ihrem Sieg über die Städte Qal'at Banī-Hammād und Constantine kampfbereit in naher Entfernung von ihnen. Die erwähnten Stämme schicken dem almohadischen Herrscher, der zu diesem Zeitpunkt mit dem Gros der almohadischen Armee auf dem Weg nach dem Äußersten Maghreb inzwischen in Mattīğa angekommen ist, einerseits Loyalitätsbekundungen und mobilisieren gleichzeitig andererseits alle arabischen Stämme, die sowohl in Ifrīqīya (d.h. annähernd im Gebiet des heutigen Tunesiens) als auch in den bis nach Alexandria reichenden Gebieten siedeln. Als die genannten almohadischen Verbände sich in Marsch nach Maghreb ${ }^{67}$ setzen, werden sie von den zusammengescharten arabischen Stämmen verfolgt, so dass die Almohaden, in der Umgebung von Sétif angelangt, sich dem Kampf gegen ihre Verfolger zu stellen beschließen und dies dem almohadischen Herrscher mitteilen. Dieser schickt Verstärkung, welche noch vor der Schlacht die verfolgten Truppenverbände der Almohaden erreicht. Bei dem bald darauf folgenden Zusammenstoß erleiden die arabischen Stämme eine vernichtende Niederlage und

\footnotetext{
${ }^{66}$ Der Gerechtigkeit halber muss man sagen, dass der Eindruck der scheinbar raschen Abfolge von Ereignissen, die sich in Wirklichkeit über längere Zeiträume hingezogen haben, auch von den herangezogenen historiographischen arabischen Werken häufig vermittelt wird. Doch im Unterschied zu den Darstellungen in den almohadischen Briefen behandeln diese Werke Ereignisse in einem größeren zeitlichen Zusammenhang, wie z.B. die Dokumentierung der politischen Geschichte einer Dynastie bzw. mehrerer Dynastien oder eines geographischen Raumes wie bei „al-Mann bi-'l-imāma“, ,al-Bayān almug̉rib“, ,al-Anīs al-muṭrib“, „Kitāb al-'ibar“, ,al-Kāmil“" usw., was eine gewisse Prägnanz und selektive Vorgehensweise bei den geschilderten Begebenheiten erfordert. Die almohadischen Briefe hingegen berichten in detaillierter Weise über einzelne zeitlich begegrenzte historische Vorgänge, wobei die ausführliche Schilderung dessen, wie sich die Etappen dieser Vorgänge im Einzelnen vollzogen haben, auf mehrere Schreiben verteilt sein kann.

${ }^{67}$ Siehe Ausführungen hierzu im Kapitel 2.3.
} 
ergreifen die Flucht. An die Beschreibung dieser Ereignisse schließen sich die Ausführungen über die Verfolgung der versprengten Stämme und die Gewaltigkeit der den Almohaden dabei zufallenden Beute an. Nach der Ankündigung der baldigen Ankunft der almohadischen Truppenverbände in Tilimsen schließt der Brief mit dem Aufruf, Gott für diesen Sieg der Almohaden zu danken und die bekannt gegebenen Mitteilungen nah und fern zu verbreiten.

\section{1. Übersetzung des Briefes Nr. 9}

Vom Befehlshaber der Gläubigen - Gott möge ihm Seinen Beistand und Seine Hilfe zuteil werden lassen - an den Šaih Abū-Muhammad Wasnār, an die Gemeinschaft seiner Gefährten von den Țālibs und Šaihs ${ }^{68}$, an die Notabeln und die gesamten Bewohner der Stadt Marrakech - Gott möge ihnen allen edlen Rang durch ihre Ehrfurcht vor Ihm verleihen und ihnen dabei beistehen, Ihm für Seine Gunsterweisungen zu danken. Friede, Gottes Gnade und Seine Segen mögen euch zuteil werden ${ }^{69}$.

Dieses unser Schreiben ergeht an euch - Gott möge es euch zuteil werden lassen, die Ihm dankenden Diener der ersten Reihe zu sein, Er möge euch die Zeugnisse Seines Eingreifens erfahren lassen, durch welche ihr des euch Genehmen und Ersehnten teilhaftig werdet, Er möge euch vermittels (Seiner) Fortsetzung eurer Sieghaftigkeit und (Seiner fortwährenden) Gewährung der Obsiege und Triumphe euch gegenüber die Mächtigkeit nicht benehmen, welche auf ihrem gefügig gemachten Höcker trägt ${ }^{70}$, in ihre schattenspendend gemachten Wolken hüllt ${ }^{71}$ und nach ihrer vollkommen gemachten Vollständigkeit strebt - aus der Residenzstadt Tilimsen - Gott möge diese Stadt behüten. Es ergeht an euch, nachdem der von Gott den Almohaden gewährte Sieg sich als so erhaben erwiesen hat, dass er in Worte nicht zu fassen ist, nachdem er all das übertroffen hat, was hätte erhofft werden können, sowie all das, was man hätte ersehnen

\footnotetext{
${ }^{68}$ Im einleitenden Teil der im Folgenden $\mathrm{zu}$ behandelnden almohadischen Briefe werden mit der Bezeichnung „Šaihs"“ allgemein Funktionsträger gemeint, die innerhalb der almohadischen Herrschaftsstruktur ranghohe Positionen einnahmen. Siehe dazu „Les Ṭalaba dans la société almohade : (le temps d'Averroès)“" (S. 347).

${ }^{69}$ Der darauf folgende einleitende Teil wurde bei der Übersetzung übergangen, s. Kapitel 8.2.

${ }^{70}$ Gemeint ist mit dem Bild, die Mächtigkeit sei (für die Almohaden) gefügig gemacht worden, dass die Almohaden allein sie besitzen, mit anderen Worten, dass die absolute Sieghaftigkeit und Unbesiegbarkeit den Almohaden eigen sind.

${ }^{71}$ Im arabischen Text (Mağmūc rasā’il muwaḥhidīya, S. 27) steht an dieser Stelle „Allāh [...] lā a'damakum bi-waṣl al-istîlā' wa-idāmat al-iẓhār wa-'l-i'lā' 'izzatan [...] šāmilatan bi-ġamāmihā almuḍallal“". Man kann in den almohadischen Briefen eine Tendenz zu Vertauschung der beiden Laute ,ẓā̄‘ und „ḍād“ miteinander feststellen. Die angefühte Passage scheint diese Tendenz zu bestätigen.
} 
oder heischen können. Wollte ${ }^{72}$ man diesen Sieg nacherzählen, so würden sich das Stegreif-Reden und das Improvisieren als unzulänglich erweisen. Angesichts der Gewaltigkeit dieses erwähnten Sieges stehen die Mittel der ausdrucksstarken Darstellung und der getreuen Wiedergabe unvermögend da. Weder eine partielle noch eine allgemeine Beschreibung, weder eine detaillierte noch eine summarische Schilderung sind imstande, ihm gerecht zu werden. Bemühte man sich darum, das wirkliche und wahre Ausmaß dieses Sieges wiederzugeben, so würde man feststellen, dass ein solcher Sieg über alle Beschreibung erhaben ist.

Es ist bereits vorher an euch - Gott möge euch den Erfolg verleihen und euch Seinen Beistand dabei erweisen, Ihm für Seine Gaben zu danken - ein kurzer und allgemeiner Bericht ergangen. Dieses folgende Schreiben, dessentwegen Tage angebrochen und Nächte eingebrochen sind, enthält nun einiges von dem, was sich wirklich zugetragen hat (wörtl. was die Übereinkunft und Übereinstimmung unumstößlich gemacht haben), sowie auch frohe Mitteilungen, bei deren ersten Worten bereits alle Wünsche und Sehnsüchte in Erfüllung gegangen sein werden. Das glückhafte Eingreifen Gottes bei der Eroberung dieser östlichen Gebiete ${ }^{73}$ erfolgte in der euch vorher bekannt gegebenen Weise. Diese Eroberung gestaltete sich nämlich in vollkommener Weise (wörtl. in lückenloser und wohlgeordneter Abfolge). In deren Verlaufe wurden die Störrigen gezähmt, die in großer Entfernung Befindlichen herangerückt, und den Seelen wurde durch die Behebung des Hinderlichen und des Störenden Erleichterung verschafft. Dabei erklomm diese große (almohadische) Sache nach und nach die Stufen $^{74}$ dieser östlichen Gebiete und bemächtigte sich ihrer äußersten Grenzen und Scheiden. Ferner förderte diese almohadische Sache durch ihre im Diesseits weit, weit reichenden Segen, dank welchen die Bestimmungen und Normen des geoffenbarten (islamischen) Gesetzes fortbestehen, das Hervorsprießen der ersten Keime des gewaltigen Wachstums und bewirkte dessen Fortsetzung. All dies fand seinen Abschluss darin, dass diese große (almohadische) Sache die genannten östlichen Gebiete unter ihre Botmäßigkeit brachte, in ihnen die Worte (wörtl. die Sprache) des Glaubens laut und weithin erschallen ließ und dort das Schwerverständliche der Koranauslegung zu den klaren Versen bis in alle Ewigkeit gemacht hat. Was die arabischen Beduinen dieser Gebiete betrifft, die in ihnen

\footnotetext{
${ }^{72} \mathrm{Da}$ die folgende Passage wörtlich übersetzt unverständlich ist, wird sie sinngemäß wiedergegeben.

${ }^{73}$ Mit den östlichen Gebieten ist in den almohadischen Briefen annähernd das Gebiet des Zentralen Maghreb gemeint.

${ }^{74}$ Oben im Kap. 1.6. wurde bereits kurz darauf hingewiesen, dass in den almohadischen Briefen die Vorstellung nicht selten ist, die zu erobernde Stadt, Gegend usw. sei ein Berggipfel, den man ersteigt, d. h. unterwirft. Siehe hierzu ferner die Einträge im Kapitel „Festungskonzepte“ im Anhang 2.
} 
ein parasitenhaftes Dasein führen (wörtl. die an ihren beiden vorderen und hinteren Zitzen saugen ${ }^{75}$ ) und diese Landstriche der Zerstörung und Entvölkerung preisgeben, so wurden sie durch den (almohadischen) Sieg in die angrenzende Wüste geschleudert, das Entsetzen ließ sie in ihre kahlen Örter fliehen, und das Ungestüme des Angriffs der Anhänger des Mahdi lehrte sie einiges von dessen (d. h. des Angriffs) Helden und reißenden Tieren ${ }^{76}$. So fanden sich diese Beduinen zwischen dem langsamen Vorrücken der Verwirrtheit und des Hochmuts einerseits und dem Zurückweichen des Vortäuschens und Vorspiegelns andererseits wieder. Dabei heuchelten sie Reue vor und verharrten meistens auf den Stufen des Zweifelns und Argwohns ${ }^{77}$. Die almohadischen Kriegsscharen, welche (dem Gros der almohadischen Armee) zur Bezwingung von Qal'aat Banī-Hammād und Constantine - Gott möge diese beiden Städte beschützen vorausgeeilt waren, waren im Begriff, in diesen vor ihnen liegenden Gegenden die Flammen (des Krieges) zu entfachen, sie trachteten danach, sie (d. h. die Beduinen) inmitten ihrer Stätten ${ }^{78}$ und in den Burgen ${ }^{79}$ ihrer Meuterei zu überfallen, baten um die Erlaubnis, diesen ihren Wunsch verwirklichen zu dürfen, und schauten auf die Gebilde des Unwahren und der Verwirrung dieser Irrenden. Was diese Letzteren - Gott möge sie bestrafen - anbetrifft, so schickten sie ununterbrochen Briefe, um (die Almohaden) zu täuschen, sich vor den Folgen des Bruchs mit ihnen fürchtend und bald gefügig, bald aufbegehrend voller Unschlüssigkeit zwischen Annäherung und Abkehr schwankend.

\footnotetext{
${ }^{75}$ Siehe hierzu die Belege im Kapitel „Nutznießung anhand des Bildes von Euterzitzen“ im Anhang 2.

${ }^{76}$ Das an dieser Stelle im arabischen Text 28) gebrauchte Wort setzt sich aus folgenden Radikalen zusammen: Ḍād, Rā’, Alif, Hamza. Die Vokalisierungsmöglichkeit „dirā’‘, Plural von „dirw“, also „Jagdhunde“ erscheint hier nahe liegend. In den almohadischen Briefen ist es aber höchst unüblich, dass die Almohaden mit Tieren verglichen werden, abgesehen von einigen wenigen Vergleichen mit Löwen bei Schlachtschilderungen (z.B. im Brief Nr. 37, S. 257, Z. 8 oder im Brief Nr. 30, S. 188, Z. 6) Dazu sei angemerkt, dass nach Wahrmund (Bd. 2, S. 91), al-Munğid fi 'l-luğa wa-'l-a'lām (S. 450) und al-Ǧauharī (Bd. 2, S. 1750) „dirā’“ nur „Jagdhunde“ bedeutet. Eine Ausnahme bildet Ibn-Manzūr, der folgenden Ausspruch Mohammeds anführt „inna Qaisan dirā’ al-'arab“ und daran folgende Erklärung anschließt: „, dirā" ist Plural von „dirw“, womit von den wilden Tieren solche bezeichnet werden, die an die Jagd gewöhnt und auf ihre Beute begierig sind; dieser Ausspruch bedeutet, dass die Angehörigen des Stammes Qais tapfer sind, wobei sie mit wilden Tieren hinsichtlich ihrer Tapferkeit verglichen werden“ (Bd. 4, S. 124).

${ }^{77}$ Im mittelalterlichen arabischsprachigen Schrifttum ist die Vorstellung nicht unüblich, seelische und emotionale Zustände bzw. Empfindungen seien geographisch verfasst, d. h. man empfinde etwas, indem man sich am geographischen Ort der entsprechenden Empfindung aufhalte. Siehe hierzu die Einträge im Kapitel „Seiten und die geographische Verfasstheit von seelischen und emotionalen Zuständen“ im Anhang 2.

${ }^{78} \mathrm{Im}$ arabischen Original steht an dieser Stelle (Mağmū' rasā’il muwahhidīya, S. 28) ,wa-'asākir almuwaḥhidīn [...] harīṣūn 'alā gazwihim fī 'uqr mawāqifihim". Interessanterweise kommen ,uqur" sowie das von „ġazw“ abgeleitete Verb „g்uzìya“ in einem Ausspruch von 'Alī Ibn-Abī-Ṭālib vor: „Mā guzīya qaum fī 'uqr dārihim illā dallū“" (Ma 'ttafaqa lafẓuhū wa-'htalafa ma'nāhū, S. 253), d. h. „Jede Gemeinschaft, die inmitten ihrer Wohnstätten überfallen wird, ist der Verächtlichkeit anheim gefallen“"

${ }^{79}$ Siehe zur Vorstellung, der Islam als auch andere religiöse Auffassungen seien errichtete Bauten, die Textbelege im Kaptel „Bauten“ sowie auch im Kapitel „Seiten und die geographische Verfasstheit von seelischen und emotionalen Zuständen" im Anhang 2.
} 
Diese ihre Unstetigkeit war deutlich zu sehen, und dieses ihr Misstrauen, wo doch das Offenkundige sichtbar geworden war, war abstoßend und verwerflich. Doch die Sicherheit gebot es den vorausgeeilten Almohaden, gegen die genannten Beduinen trotz deren Torheit nicht vorzugehen, sondern die Letzteren auch weiterhin aus ihrem Schlummer aufzurütteln zu suchen, auf dass sie endlich erwachten. Währenddessen trafen die Briefe und die Gesandten dieser Beduinen ein um das andere Mal bei uns ein. Und bekanntlich wohnen dieser mächtigen (almohadischen) Sache Nachsicht, Huld und Milde im Umgang mit den Unwissenden sowie die wohlwollende gütige Haltung den Eigensinnigen (wörtl. Fernen) und Widerspenstigen gegenüber inne. All dies ließ man diesen Beduinen angedeihen, auf dass die Buße ihnen Wohl einbringt, ihnen die vortrefflichste Gnade zuteil wird und sowohl die Worte als auch der Sinn der Botschaft des Almohadentums sie erreichen. Denn man will den Erdbewohnern nichts abverlangen, außer dass sie in aufrichtiger Weise Buße vollziehen, den wahren Glauben verinnerlichen und sich dem geoffenbarten Gesetz unterordnen.

Doch es war Gottes Wille, dass diese Elenden zu denjenigen gehören sollten, welche das Verderben in seinen Abgrund hinabschleuderte, welche die Bestrafung mittels ihres Zerwerfens und Zerfleischens sich zerstreuen ließ und welche $\mathrm{zu}$ einem weithin sichtbaren abschreckenden Beispiel wurden ${ }^{80}$. Denn während all dessen, wovon wir euch berichtet haben, nämlich während man ihr Vertrauen zu gewinnen bemüht war, sich ihren Barfüßigen und ihren Verbündeten ${ }^{81}$ gegenüber duldsam zeigte und die Almohaden, obwohl sie es vermocht hätten, davon abstanden, diese Elenden auszumerzen und auszurotten, in eben dieser Zeit also verschickten sie Briefe an diejenigen der im von Ifrīqīya bis fast nach Alexandria reichenden Gebiet siedelnden arabischen Beduinen, die von Unwissenheit geschlagen und durch Irrtum geblendet waren. An diese schrieben sie Hilfe und Beistand heischend, erbaten Verstärkung und Unterstützung von ihnen und riefen sie dazu auf, ihnen gegen die Almohaden tatkräftig beizustehen.

Als Gott gewollt hat, dass wir an ihnen das Urteil der Qual vollstrecken ${ }^{82}$ und auf dem Weg zu ihnen die dürren Landstriche dieser Wüste durchziehen, und dies beim

\footnotetext{
${ }^{80}$ Der nachfolgenden Übersetzung entspricht im arabischen Text (Mağmū` rasā’il muwaḥhidīya, S. 29) „wa-tanșibuhū al-'ibra 'alā manzūhat sabīlihā wa-țarīqihā“. Vielleicht ist hier „mandūḥat“ statt „manzūḥat“" gemeint, zumal das letztere in „Lisān al-'arab“ nicht belegt ist.

${ }^{81}$ An dieser Stelle (Mağmū` rasā’il muwaḥhidīya, S. 29) wird im arabischen Text das Wort „aḥlāf“" gebraucht. Möglicherweise handelt es sich hier ursprünglich um das Wort „ağlāf“, d. h. „die Verrohten“, das m. E. in den Zusammenhang der Passage besser passen würde.

${ }^{82}$ Der Satzanfang im arab. Original an dieser Stelle (Mağmūc rasā’il muwaḥhidīya, S. 29) ,fa-hīna šā’a Allāh an nuhiqq 'alaihim kalimat al-'ad̄āb“'lehnt sich an ,a-fa-man ḥaqqa 'alaihī kalimat al-'ad̄āb a-fa-anta
} 
Entschluss, die Rück- und Heimreise (nach Maghreb) anzutreten, trieben die Umherschweifenden ihre eigenen $\mathrm{Füß}^{83}$ her, ihre Überstürzung stürzte sie ins Verderben, und das (ihnen bevorstehende) Unheil ließ sie herbeieilen, ohne dass es ihnen einen Aufschub in Bezug auf die ihnen vorherbestimmte Todesstunde gewährte. Denn es begab sich, dass all diejenigen, die wir von den arabischen Beduinen jener fernen Orte genannt haben, nämlich die Stämme des Stammesverbandes Hilāl Ibn-'Āmir von den Beduinen des Jemens und die auf Kriege und Raubüberfälle erpichten Massen, in ihrer Gesamtheit eintrafen, danach strebend, ihre missgeleiteten Brüder in die Irre zu führen und sie dazu anzustacheln, und den Hilferufen mit äußerster Entschlossenheit und größter Tatkraft in aufeinander folgenden Scharen folgend. All diese kamen an, bis die Hilfe Heischenden mit den diesem Ruf Folgenden zusammentrafen und der Teufel die Augen zusammenkneifend ${ }^{84}$ und schnaufend sich auf ihre Brüste setzte ${ }^{85}$. Er ließ sie in ihren verstockten (wörtl. finsteren) Herzen vermeinen, dass es ihr Heer sei, welchem der Sieg beschieden sein würde, er ließ sie wähnen, sie flößten allen ein in seiner Wirkung nicht nachlassendes Entsetzen ein, und er ließ sie ihre bösen Werke gut dünken, wobei doch Gott derjenige ist, der ihre Werke aufschreibt und tilgt. Ihre Mengen trafen nach und nach in der Gegend von Constantine ein, ihre Scharen nahmen an ihrer Hartherzigkeit $\mathrm{zu}$ und wurden immer dichter, und ihre eintreffenden Verstärkungen, welche jene wasserreichen Tränken und Quellen überschwemmten, bestärkten sich gegenseitig in ihrem irrtümlichen Urteil. Dies dauerte an, bis die Zahl ihrer Reiter und Fußsoldaten so gewaltig wurde, dass sie sich nicht beziffern ließ, und sie die Gesamtheit (wörtl. das Unebene und das Flache) der Anhöhen und der Niederungen dieses Landstrichs bevölkert haben. Doch diese Anhöhen und Niederungen konnten sie nicht tragen, sie vermochten nicht, für sie ein fester Grund zu

tunqid min an-nār" (Sure 39, Vers 19) oder „,qālū balā wa-lakin haqqat kalimat al-'adāa 'alā al-kāfirīn" (Sure 39, Vers 71) an.

${ }^{83}$ Der arabische Satz an dieser Stelle (Mağmū' rasā'il muwaḥhidīya, S. 30), ,atat bi-'1-hāàimīn arğuluhum“ wurde wörtlich übersetzt, und er weist sowohl im Hinblick auf seinen Wortlaut als auch insbesondere auf seinen gemeinten Sinn große Ähnlichkeit mit der arabischen Redewendung auf: ,atatka bi-ḥā’in riğlāhū““ (Kitāb ğamharat al-amtāl, Bd. 1, S. 119), d. h. ,es ist in deine Gewalt derjenige auf seinen eigenen Füßen gelangt, dessen Todesstunde geschlagen hat". Die Vermutung liegt daher nahe, dass hier nicht „hāa'imīn“, sondern ,hā’inīn“ gemeint ist, zumal in ,al-Bayān al-muğrib“ (S. 199) an einer sinngemäß sehr ähnlichen Stelle, in der die angeführte Redewendung abgewandelt vorkommt, auch „hāàn“ gebraucht wird.

${ }^{84}$ Dies scheint die Bedeutung des Verbs ,yutabbin“ an dieser Stelle (Mağmū̄ rasā’il muwaḥhidìya, S. 30) zu sein.

${ }^{85}$ Möglicherweise liegt hier eine Anspielung auf die koranische Vorstellung vor, das Schicksal eines Menschen sei ein Vogel an seinem Hals (Sure 17, Vers 13). Vgl. auch Fil'štinskij, Arabskaja literatura v srednie veka, Bd. 1, S. 125. 
sein und nicht [unklar ${ }^{86}$. Die dort zum damaligen Zeitpunkt befindlichen Almohaden gingen daran, der an sie ergangenen Anordnung, nach Westen ${ }^{87}$ aufzubrechen und dorthin zu ziehen und dabei alle Streitigkeiten und Gefechte mit diesen zum Verderben Verurteilten zu meiden, Folge zu leisten. Doch dieser offenkundige Zustand mehrte nur noch ihre (d. h. der arabischen Beduinen) Verblendung und hatte zur Folge, dass sie in ihrem Aufbegehren unentwegt weiter verharrten ${ }^{88}$. Die göttlichen Geschicke überließen es diesen Elenden, sich selbst am Halfter des Ausgeliefertseins zu zerren, und bargen für sie einiges an künftigen Heimsuchungen (wörtl. verbargen unsichtbar und nicht wahrnehmbar in der Brust der Zeit einige Heimsuchungen). Und jedes Mal, wenn die genannten Almohaden in Richtung ihres Zielortes (d. h. nach Westen) eine Etappe zurücklegten, zogen diese Irrenden ihnen nach. Diese Elenden handelten dabei gemäß ihrer tadelnswerten Einbildung und ihrer (irrigen) Vorstellung. Sie wähnten, diese ihre örtliche Nähe zu den erwähnten Almohaden und ihr Vermögen, in dieser falschen Weise zu handeln, seien eines der Zeugnisse ihrer Macht und eine der Früchte ihres Urteilsvermögens und ihrer Überlegung. In Wādī al-Aqwās nahe Sétif - Gott möge diese Stadt prosperieren lassen - sahen die Almohaden, dass die erwähnten Elenden sie einem Schatten gleich verfolgten ${ }^{89}$ und von ihnen weder beim Aufbrechen noch beim Absteigen wichen. Die Almohaden erkannten ferner, dass die gegebenen Umstände es erforderlich machten, diese Elenden zu bekriegen und sie abzuschütteln, sowie es geboten, sich dem Kampf für den Obsieg des Islam gegen die arabischen Stämme zu stellen und diese niederzukämpfen. Die Almohaden fanden kein anderes Heilmittel, welches das unheilbare Übel dieser Elenden hätte heilen und in der geschilderten Situation die Erlösung von diesen Beduinen hätte bescheren können, als, nachdem man sich auf Ihn verlassen und sich Seiner Allmacht anvertraut hatte, den Kampf gegen sie zu führen. Mittels eines Schreibens gaben sie uns ihren Entschluss bekannt und setzten

\footnotetext{
${ }^{86}$ An dieser Stelle (Mağmū` rasā’il muwahhidīya, S. 30) lautet der arabische Satz „lā wasi`at (aiy anğād tilka al-arḍ wa-ag̣wāruhā) an takūn lahum (aiy li-'l-'arab) qarāran wa-lā an yakūn lahā ahlan“, dessen letzter Teil unverständlich ist.

${ }^{87}$ Im arabischen Text (Mağmū' rasā'il muwahhidīya, S. 30) steht an dieser Stelle „wa-'l-muwahhidūn alkā'inūn id dāka hunāk muqbilūn 'alā mā umirū bihī min irtihālihim ilā al-'arab wa-'ntiqālihim“. Doch m. E. liegt hier ein Druckfehler vor und mit ,al-'arab“ ist eigentlich ,al-Ġarb“ gemeint, denn nur so lassen sich diese und weitere Ausführungen des Briefes zu einer logischen und nachvollziehbaren Abfolge der Ereignisse zusammenfügen.

${ }^{88}$ An dieser Stelle wird im arabischen Text (Mağmū' rasā’il muwaḥhidīya, S. 30) das Wort „'ufūk“ in der Bedeutung „Verharren in einem missbilligenswerten Handeln“ gebraucht, das allerdinges weder in dieser Lautgestalt noch in dieser Bedeutung belegt ist.

${ }^{89}$ Mit dem arabischen Satz an dieser Stelle (Mağmū' rasā'il muwaḥhidīya, S. 31) „ra'aū anna al-ašqīyā' al-maḍūrīn yulāzimūnahum mulāzamat az-zill"“ wird sehr wahrscheinlich auf die arabische Redewenung „alzam li-'l-mar’ min zillihī“ (Kitāb ğamharat al-amtāl, Bd. 2, S. 218), d. h. „etwas bzw. jemand haftet einer Person dichter als deren eigener Schatten an“, Bezug genommen.
} 
uns die Lage, in welcher sie sich dort befanden, auseinander. Ferner berichteten sie, dass sie zum Zeitpunkt der Abfassung des genannten Schreibens die zum Angriff notwendigen Maßnahmen trafen und mit Hilfe Gottes - gepriesen sei Er - sich anschickten, ihren Feinden auf dem Schlachtfeld entgegenzutreten.

Dank dem (von Gott) gewährten Beistand und dank unserem Beschluss, der auf dem Wege der Klarheit und Deutlichkeit zum Rechten gelangt, erfolgte die Entsendung der gesegneten Scharen und rechtgeleiteten Gruppen des almohadischen Heeres - Gott möge ihnen beistehen - nach der benannten Gegend, um den dort befindlichen Almohaden bei ihrer (beabsichtigten) Unternehmung beizustehen und ihren Segen zu mehren. Was uns anbetrifft, so rasteten wir in der Region Mattīğa - Gott möge diese Region prosperieren lassen - auf unserem Wege nach Maghreb, uns gemäß dem Verkündigten und dem Vorherbestimmten (wohl) befindend. Die zu ihren Brüdern entsandte almohadische Verstärkung zog nach all ihren Kräften rasch dahin und hoffte, bei diesem (bevorstehenden) Wohl ihrer Anteile teilhaftig zu werden. Sie stieß zu ihren almohadischen Brüdern - Gott möge ihnen allen beistehen - in der ersehnten und erhofften Weise und erschien Sieg und Triumph ankündigend an ihrer Seite. So fand die Vereinigung dieser beiden almohadischen Scharen durch Gottes Gnade noch vor dem Zusammenstoß mit den Feinden statt. Die Almohaden - Gott möge ihnen beistehen fanden die Herden dieser Elenden äußerst weithin ausgebreitet auf jenen Gipfeln ${ }^{90}$ vor. Die Almohaden hielten eine in ihrer Ganzheit löbliche Versammlung ab, gingen daran, die Sache Gottes zu beobachten und zu befolgen, und es wurden ihnen - Gott möge ihnen beistehen - mehrere ermahnende und befeuernde Predigten gehalten ${ }^{91}$. Die Entschlossenheit der Almohaden, dem Wort Gottes zum Obsieg zu verhelfen, wurde in einer nicht zu steigernden Weise glühend, ihre Reue war lobenswert und man erhoffte die Belohnung beim Schlagen der festgesetzten Todesstunde und beim Kommen der vorherbestimmten Todeszeit. Und nachdem sie Gott um Hilfe angerufen und sich auf Seinen einzig wirksamen Beistand verlassen hatten, stürmten sie gegen ihre Feinde beim Sonnenaufgang an, und der Mahlstein des Krieges fing an, sich zu drehen (wörtl.

\footnotetext{
90 An dieser Stelle (Mağmū` rasā'il muwaḥhidīya, S. 31 f.) lautet der arabische Satz ,fa-alfaū [...] āğālahum 'alā gāayat al-istišrā' wa-nihāyat al-istirsāl 'alā tilka al-adrā’‘، Hierbei bildet ,adrā'‘، den Plural von ,adS. 207) wird ,adrā̄“ in der Bedeutung „die Gipfel“" gebraucht, sodass es hier als nahe liegend erscheint, „adrā̄“ auch mit „Gipfeln“ zu übersetzen, zumal damit in den almohadischen Briefen häufig die Auflehnung gegen die almohadische Herrschaft konnotiert wird.

91 'Izz-ad-Dīn 'Umar Mūsā trägt in seiner Studie einige aufschlussreiche Quellenbelege diesbezüglich zusammen. Diesen nach war es üblich, dass vor der Schlacht nacheinander der Befehlshaber der Armee und der Oberste Prediger (arab.: hațīb al-hiläfa) sich an die Armeeangehörigen in oben angedeutetem
} 
wurde errichtet). Dabei befanden sich die Almohaden in der Mitte dieses Mahlsteins, und es wurde ihnen der Beistand Gottes und Sein nahes zum Sieg führendes Eingreifen $^{92}$ zugunsten Seiner siegreichen Partei zuteil.

Als die Feinde Gottes dieses Vorstürmen der mit eisernem Kampfeswillen erfüllten Almohaden sowie die Zeichen ihrer absoluten Verwurzelung im Glauben sahen, wollten sie zum Handeln übergehen, doch war ihnen dies nicht beschieden. Diese Feinde wähnten, ihr energisches Vorgehen gegen die Almohaden stehe den ihnen Gleichen an, nämlich dem gemeinen Pöbel, und den ihnen Ähnlichen, nämlich dem niederträchtigen Pack. Doch dieses Illusorische ihrer Einbildung sollte ihnen die Schrecknisse jenes Bewährungsortes nicht ersparen. Der Beistand Gottes, der die Streiter für Sein Wort umgab, schweißte die Almohaden in vollkommener Weise zusammen und verlieh ihnen die Charaktereigenschaften der edlen Gottesfürchtigen ${ }^{93}$. Die Ungläubigen ritten heidnische Attacken gegen sie, welche ihnen jedoch nichts anderes als grausame Bestrafung einbrachten und bei welchen sie im unerbittlichen Kampf rasch niedergestreckt wurden (wörtl. das heftige Gefecht sie verschlang). Diese in ihrer Gewaltigkeit größten Schrecknisse wurden ihren gesamten Helden und Vornehmen sowie all denjenigen ihrer Anführer zuteil, die auf ihr Heldentum und ihre Beherztheit pochten. Da gerieten diese Ungläubigen in heftige Bedrängnis ${ }^{94}$, und ihre vernichtende Niederlage ließ sie die Flucht nach jenen Ställen und Lagerplätzen der Kamele ergreifen. Dabei vermischten sie sich mit ihren Viehherden, dem Vieh gleich, das sich mit dem Vieh vermischt, und ihre in der Mitte Befindlichen mussten erschöpft und wider ihren Willen zu den an ihrem Rande Verbliebenen zurückweichen. Sie wurden Gott allein besitzt Stärke und Macht - weithin verstreut, nachdem sie versammelt

Sinne sowohl auf Arabisch als auch auf Berberisch wandten (al-Muwaḥhidūn fí 'l-Ġarb al-Islāmī, S. 250 f.).

${ }^{92}$ Die arabische Entsprechung ,fathuhū al-qarīb“ kommt mit unwesentlichen Abweichungen im Koran (Sure 61, Vers 13; Sure 48, Vers 18 und daselbst, Vers 27) vor.

${ }^{93}$ Mit dem an dieser Stelle (Mağmū' rasā'il muwaḥhidīya, S. 32) gebrauchten ,al-barara al-kirām“ werden in anderen almohadischen Briefen (S. 35, 82, 96, 150 und 200) die Gefährten Mohammeds bezeichnet. Mit dem Gebrauch des Adjektivs ,ğāhilī“ im nächsten Satz wird auf diese Weise bewusst die Assoziation mit den Kämpfen in der Frühzeit der islamischen Geschichte geweckt, was u. a. die Aufwertung der Almohaden bei gleichzeitiger Abwertung der beduinischen Stämme zur Folge hat und diese Schlacht fast ausschließlich in eine religiöse Dimension rückt. Interessanterweise heißt es in einem Bericht von IbnȘāhịib-aș-Ṣalāt (al-Mann bi-'l-imāma, S. 196) u.a. über ein Geplänkel zwischen den Almohaden und IbnMardanīš, die almohadischen Kämpfer hätten so zäh und ungestüm wie in der Zeit der Gottesfürchtigen (arab.: zamān al-abrār) gekämft, was Ibn-'Idārī al-Marrākušī, der sich auf diesen Bericht weitest gehend stützt, mit den Worten zusammenfasst, die Almohaden hätten derart zäh und ungestüm gekämpft, wie nicht einmal in der Anfangszeit des Islam gekämpft worden sei (al-Bayān al-muġrib, S. 88).

${ }^{94}$ Der arabische Satz an dieser Stelle des Textes (Mağmū' rasā'il muwahhidīya, S. 32) „,fa-'Itaqat 'alaihim ḥalaqatā al-bițān“ ist eine geringfügig abgewandelte arabische Redewendung ,iltaqā ḥalaqatā al-bițān“ (Kitāb ğamharat al-amtāl, Bd. 1, S. 188), d.h.: die beiden Ringe des Bauchriemens (des Reittieres) haben 
gewesen waren, und sie lösten sich voneinander, nachdem sie ein zusammengefügtes Ganzes gebildet hatten. Die Todesgeschicke fingen an, sie aufzupicken, um sie dann zu Boden zu strecken und auf die Erde hinabzuschnellen, und ihnen vor Augen zu führen, dass das Verfehlen des rechten Weges die Verfehlenden ins Unglück stürzt und sie in Widerwärtiges verwickelt ${ }^{95}$.

Das Töten der Feinde und ihre Verfolgung dauerten vom Anbruch dieses gesegneten Tages bis zu dessen Ende an. Dabei bewegten sich die Almohaden ihren eigenen Berichten zufolge inmitten frei und nach Belieben weidender Kamele, inmitten auf ihrem Gestell ruhender Frauensänften sowie Kühe und Schafe, die man aufgrund ihrer gewaltigen Zahl nicht zu überblicken vermochte und welche die Augen der Schauenden aufgrund ihrer unendlichen und unbegrenzten Menge nicht fassen konnten. Sie bewegten sich inmitten des eben Genannten sowie anderer Beutegüter und Beutestücke, die mit nichts zu vergleichen noch gleichzusetzen waren, und sahen dabei Lebewesen hinter Lebewesen und Dinge unmittelbar aufeinander folgen, und dies vierzig oder fünfzig Meilen ${ }^{96}$ weit. Bei alledem wurden die Feinde Gottes niedergemacht, in die Flucht geschlagen, rasch dahingerafft, von den scharfen Schwertern zerschnitten und auf die alles durchstechenden ${ }^{97}$ und biegsamen Lanzen aufgereiht. Über sie (d. h. über die Gegner der Almohaden) waren üble Heimsuchungen hereingebrochen, welchen sowohl ihre Herrschenden als auch ihre Beherrschten haben sich fügen müssen. Das Unglück umzingelte Hilāl Ibn-`'̄Amir, ließ den Halbmond schwinden und entvölkerte das Bevölkerte $^{98}$. Nur die Nacht bewahrte die Genicke der fliehenden Übeltäter vor den Schwertklingen der Almohaden, denn sie hüllte diese Fliehenden in ihr Dunkel ein und verbarg sie so (schützend) samt ihren letzten Lebensfunken.

Danach teilte man die Heere der Almohaden - Gott möge sie zahlreich machen - in der Frühe des nächsten Morgens in Gruppen auf. Jede von diesen Gruppen schlug eine jeweils andere Richtung ein und lag der Verfolgung ihres Ziels und dem geschwinden

\footnotetext{
sich berührt, womit die äüßerst missliche bzw. gefährliche Lage des betreffenden Objektes zum Ausdruck gebracht wird.

${ }_{95}$ Im mittelterlichen Schrifttum ist die Vorstellung nicht selten, Todesgeschicke sowie Unheile seien nicht näher definierte - Lebewesen, die den Tieren eigene Körperteile wie Arme, Klauen oder Reißzähne hätten. Siehe hierzu die im Kapitel „Körperhaftigkeit bzw. Konkretheit des Abstrakten“ des Anhanges 2 zusammengetragenen Textbelege.

${ }^{96}$ Eine Meile war zwei Kilometer lang (W. Hinz: Islamische Maße und Gewichte, S. 63).

${ }^{97}$ Im arabischen Text (Mağmū' rasā’il muwahhidīya, S. 33) steht „wa-'ntizāam bi-kull nāqid ladn“ und mit „,nāqid“" ist m. E. „nāfiḍ“" gemeint.

${ }_{98}$ In diesem Satz liegt ein Wortspiel vor, denn „al-hilāl“ bedeutet „Halbmond“ und „,āmir““ „,besiedelt, bevölkert; bewirtschaftetet (Land)“.
} 
Dahinziehen $^{99}$ ob. Manche dieser genannten almohadischen Gruppen entfernten sich im Eifer dieser Verfolgungsjagd vier - einige mehr, andere weniger - Tagesreisen vom Rest der Almohaden. Dabei führten sie Überfälle durch, machten Beute und durchzogen die Gesamtheit dieser weitausgestreckten Wüstenstriche unermüdlich und ohne Zögern, bis sie die ersten Bezirke Ifrīqīyas und ihre Grenzgebiete erreichten. Dort angelangt sahen sie keine Spur vom Rest dieser Abtrünnigen und fanden niemanden, der über diese Feinde etwas hätte erzählen oder berichten können. Danach kehrten diese Almohaden dank der Gnade Gottes und Seiner Barmherzigkeit zurück und brachten eine solche Menge an Beutegütern, die zu den bereits erwähnten hinzukamen, und an Beutestücken, vor deren Gewaltigkeit das Zählen und das Beziffern jedes Zählenden zusammenschrumpfen, mit sich, dass diese Menge sich nicht in Zahlen fassen lässt und dass man angesichts ihrer Immensität sich noch mehr schier nicht vorzustellen vermag. Nachdem die Almohaden - Gott möge ihnen beistehen - in ihr Hauptlager zurückgekehrt waren und nachdem sie ihr Erstrebtes erlangt hatten, fingen sie an, die gefangengenommenen Weiber dieser Ungläubigen, deren Beute sowie deren Waffen und Pferde, die das Gefecht ihnen zufallen ließ, zusammenzubringen. Dies alles konnte allerdings aufgrund seiner unermesslichen Menge nicht in seiner Gesamtheit zusammengebracht werden und war über jede Beschreibung durch ,viel“ und „zahlreich“ erhaben. Dann setzten sich diese erwähnten Almohaden mit alledem, was sie mit sich zu führen vermochten, in Bewegung und schlugen den Weg zu diesen Gegenden - Gott möge sie beschützen - ein, und dies, nachdem sie sich außerstande gesehen hatten, die mitgeführte Beute in irgendeiner Weise zu beziffern, und ohne dass sie den Umfang der gesamten Beute hatten angeben können. Sie - Gott möge sie behüten - rücken jetzt mit all diesen erbeuteten Gütern heran auf die vollkommenste Weise, welche man sich nur erhoffen kann und welche der edle Rang (dieser Almohaden) erfordert.

Wir haben euch - Gott möge euch Macht verleihen - dies mitgeteilt, auf dass euer Anteil an diesem Sieg groß wird, über welchen man, soweit sich die Horizonte erstrecken, spricht und dessen Verkündigung und Verlautbarung in den Gegenden ${ }^{100}$ und Landstrichen erschallt ist. Diese Mitteilung haben wir euch ferner zukommen

\footnotetext{
${ }^{99}$ Im arabischen Satz (Mağmūc rasā’il muwaḥhidīya, S. 33) steht „,i`dād sairihī‘, doch ist hier damit wohl ,ịg $\underline{\text { did }}$ sairihī“ gemeint.

${ }^{100}$ Im arabischen Text (Mağmū` rasā'il muwaḥhidīya, S. 34) wird an dieser Stelle „abṣār“ gebraucht, doch vermutlich ist damit ,anẓār" gemeint.
} 
lassen, damit ihr Gott mit eurer ganzen $\mathrm{Kraft}^{101}$ für diesen Sieg dankt und (dabei) eure Entschlossenheit, diesen Sieg ruchbar und bekannt zu machen, zu Hilfe nehmt. Gelobt sei Gott, der uns und euch mit Seinen Segen überschüttet hat, der aufgrund der Wahrheit dieser wahrhaftigen (almohadischen) Sache sich verpflichtet hat, $\mathrm{zu}$ ihr Seine beglaubigenden Wunderzeichen geschehen $\mathrm{zu}$ lassen ${ }^{102}$, und der die Belohnung im Jenseits den Streitern für Seine wohlgefügte und einzig wahrhafte Anbetung (d. h. Islam) und Seinen Statthaltern hat vorbehalten sein lassen. Friede, Gottes Gnade und Seine Segen mögen euch zuteil werden!

Abgefasst am 26. Juni des Jahres 1153.

2.2. „All dies fand seinen Abschluss darin, dass diese große (almohadische) Sache die genannten östlichen Gebiete unter ihre Botmäßigkeit brachte, in ihnen die Worte (wörtl. die Sprache) des Glaubens laut und weithin erschallen ließ [...]“

Es ist ein wesentliches Merkmal der almohadischen Ideologie, dass sie die einzig gültige Wahrhaftigkeit des Almohadentums postuliert und somit die universale Herrschaft der almohadischen Botschaft beansprucht. Dieser absolute Wahrheitsanspruch spiegelt sich in den almohadischen Schriften u. a. darin wider, dass sogar die muslimischen Widersacher der Almohaden oft als „Ungläubige“ bezeichnet werden und dass auch mit anderen verächtlichen Bezeichnungen, von welchen der Großteil aus dem Koran entlehnt ist, nicht gegeizt wird. Der offiziellen almohadischen Logik nach war nur ein Almohade ein wahrer Gläubiger und allein das Almohadentum der wahre Glaube ${ }^{103}$. Bei der Lektüre von almohadischen Quellen kann diese Perspektive nicht selten den Eindruck entstehen lassen, die Almohaden hätten ihre Kämpfe oft mit Nicht-Muslimen ausgefochten. Auch von Muslimen bewohnte Gebiete wie der Zentrale Maghreb, der sich zum Zeitpunkt der Abfassung des zu analysierenden Briefes Nr. 9 bereits seit Jahrhunderten unter islamischer Herrschaft befand, sowie andere islamisierte, den Almohaden jedoch nicht botmäßige Landstriche wurden in den offiziellen almohadischen Verlautbarungen als nicht islamisch, ja als von Ungläubigen beherrscht beschrieben. Vor diesem Hintergrund wird durch das eingangs angeführte Zitat gleich zweifach ausgesagt, dass die almohadische Herrschaft in den unterworfenen Gebieten errichtet wurde. Darin ist davon die Rede, dass in den unterworfenen Gebieten

\footnotetext{
${ }^{101}$ Im arabischen Satz an dieser Stelle (Mağmū` rasā'il muwaḥhidīya, S. 34) ,wa-li-taškurū Allāh 'alaihī šukran yastanfị gàayat istiṭācatikum“ ist mit ,yastanfidِ“ sicherlich ,yastanfid“" gemeint.

${ }^{102}$ Dies ist m. E. der gemeinte Sinn von „wa-nașaba 'alā ḥaqīqat hadāa al-amr al-ḥaqq illan min adillat āyātihī" an dieser Stelle (Mağmū' rasā’il muwaḥhidīya, S. 34).

${ }^{103}$ Vgl. ,,al-Muwaḥhidūn fi 'l-Ġarb al-Islāmī"“ (S. 82).
} 
die Worte des Glaubens laut und weithin erschallt seien. Der Ausdruck „Worte des Glaubens“ impliziert, dass in den Moscheen die „wahre“, d. h. die almohadische Botschaft, nun verkündet worden sei. Wollte man den genauen Verkündigungsort in der Moschee ermitteln, welchen der Rezipient des Briefes damit assoziiert haben dürfte, so käme höchstwahrscheinlich die Moscheekanzel in Frage. Denn die Kanzel wird in den offiziellen almohadischen Schreiben als Verkündungsort der „wahren“ religiösen Botschaft aufgefasst. So findet sich - um nur ein besonders eloquentes Beispiel anzuführen - im Brief Nr. 36, der nach der Eroberung der bis dahin von den BanūGānīya beherrschten Insel Mallorca durch die Almohaden im Jahr 1203 abgefasst wurde, folgender Satz: „Wa-uqīmat al-ḩuṭba 'alā minbar kāna ašcata ag̉bara țumma ‘āda bi-'1-qaul aṣ-șādiq wa-'1-i'tiqād al-ḥaqq azhara anḍara“'104, d. h. „Dann wurde die Predigt gehalten auf der Kanzel, welche, nachdem sie zerzaust ${ }^{105}$ und staubfarben gewesen war, nun durch die wahrhaftigen Worte und die wahre Überzeugung wieder hellglänzend und hellleuchtend geworden ist".

2.3. „Als Gott gewollt hat, dass wir an ihnen das Urteil der Qual vollstrecken und auf dem Weg zu ihnen die dürren Landstriche dieser Wüste durchziehen [...]“

Bei der Übersetzung des Briefes wurde auf die Passage „,wa-'1-muwaḥhidūn al-kā'inūn iḍ dāka hunāk muqbilūn 'alā mā umirū bihī min irtiḥālihim ilā al-'arab wa'ntiqālihim““106, d. h. „Die dort zum damaligen Zeitpunkt befindlichen Almohaden gingen daran, der an sie ergangenen Anordnung, zu den arabischen Stämmen hin aufzubrechen und zu ihnen zu ziehen [...], Folge zu leisten“, hingewiesen. Sowohl Lévi-Provençal $^{107}$ als auch Amrosio Huici Miranda ${ }^{108}$ folgen der Variante „al-'arab“. Huici-Miranda versteht diese Ausführungen des Briefes dahingehend, dass die im Zentralen Maghreb nach der Rückkehr des Gros der almohadischen Armee in den

\footnotetext{
${ }_{104}^{104}$ Mağmū' rasā'il muwaḥhidīya, S. 246.

105 Der Gebrauch des Adjektivs ,zerzaust“ in Verbindung mit einer Moscheekanzel ist insofern interessant, als damit auf die in den literarischen Schriften verbreitete Vorstellung angespielt wird, die Kanzel habe eine Stirnlocke (arab.: ad- $\underline{d} u$ 'āba). In eben diesen Zusammenhang ist auch der Satz einzuordnen, der in einem Bericht Ibn-Șāhib-aș-Ṣalāts über die Ankunft einer Siegesmeldung in Sevilla und über deren Verlesung vorkommt: ,wa-quri'at ar-risāla wa-'l-abyāt wa-wāṣila wa-tulīyat wa-urtuqīyat bihā dawā'īb al-manābir wa-usmi‘a bihā al-ḥāẹir wa-'l-bādī' (al-Mann bi-'l-imāma, S. 74), d. h. „das eingegangene Schreiben und die ihm beigefügten Verse wurden laut verlesen und man hat damit die Stirnlocken der Kanzeln bestiegen - d. h. man hat dieses Schreiben und die Verse von den Kanzeln herab verkündet - und diese Siegesmitteilungen sowohl die Stadt- als auch die Landbewohner vernehmen lassen"

${ }^{106}$ Mağmū̌ rasā’il muwaḥhidīya, S. 30.

107 „Un recueil de lettres officielles almohades: une étude diplomatique et historique (S. 1-80) bei der Zusammenfassung des Briefes Nr. 9.

${ }^{108}$ Historia política del imperio almohade, Bd. 1, S. 165-166.
} 
Maghreb verbliebenen Truppen die Anordnung erhalten, den arabischen Stämmen entgegenzuziehen, doch angesichts der zahlenmäßigen Überlegenheit der Letzteren den inzwischen in Mattīğa angelangten 'Abd al-Mu'min davon benachrichtigen, der ihnen Verstärkung schickt ${ }^{109}$. Folgte man Huici-Miranda, müsste man annehmen, dass das almohadische Kontingent anfangs den Beduinen entgegenzieht, dann jedoch angesichts ihrer Mengen umkehrt, um in die entgegengesetzte Richtung, nämlich nach Westen, zu fliehen. Obwohl der an dieser Stelle detaillierte Bericht des Briefes keinerlei Hinweise auf solche jähe Richtungsänderung enthält, wäre diese Deutung der Ereignisse trotzdem denkbar, denn manchmal können auch sehr detaillierte Ausführungen der almohadischen Schreiben - intendierte - verzerrende Darstellungen enthalten ${ }^{110}$, sodass Sachverhalte, die als dem offiziell gepflegten Bild der Almohaden abträglich empfunden wurden, durchaus verzerrt bzw. verschwiegen werden konnten. Doch bei der betreffenden Passage des Briefes scheint es sich um einen Fehler zu handeln, und „al-Ġarb“ ist wohl anstelle von ,al-'arab“ gemeint: Die Ausführungen des Briefes an der in Frage kommenden Stelle sprechen davon, dass die Almohaden die Anordnung erhalten, nach ihrem Zielort - der Lesart des arabischen Originals nach zu den arabischen Beduinen also - zu ziehen und dabei alle Streitigkeiten und Gefechte mit den arabischen Beduinen zu meiden; ferner berichtet der Brief davon, dass jedes Mal, wenn die Almohaden in Richtung ihres Zielortes eine Etappe zurücklegten, die arabischen Stämme ihnen nachgezogen seien und sie einem Schatten gleich bis Wādī al-Aqwās verfolgt hätten. Es wäre also eher unwahrscheinlich, dass die almohadischen Einheiten $\mathrm{zu}$ den arabischen Stämmen aufbrechen und gleichzeitig jegliche Zusammenstöße mit ihnen vermeiden sollten. Nicht minder unverständlich bliebe auch, wie dieses almohadische Kontingent bei seinem $\mathrm{Zug}$ zu den Beduinenstämmen hin von diesen Letzteren gleichzeitig verfolgt, ja gejagt werden sollte. Andererseits werden im eingangs angeführten Satz zwei arabische Wörter ,irtiḥāl“ und ,intiqāl““ gebraucht. Interessanterweise findet sich ,intiqāl“ im Brief Nr. 26 wieder, der u. a. über den Aufbruch der arabischen Stämme Ifrīqīyas nach al-Andalus zwecks Teilnahme an den militärischen Unternehmungen der Almohaden dort berichtet. Darin kommt „intiqāl““ in der Bedeutung „Umsiedlung (in den Westen)“ vor. In ähnlicher Weise verhält es sich

\footnotetext{
${ }^{109}$ Historia política del imperio almohade, Bd. 1, S. 165-166.

${ }^{110}$ So - um nur zwei besonders auffällige Beispiele anzuführen - heißt es im almohadischen Brief über die berühmte Schlacht zwischen den almohadischen und christlichen Truppen bei Las Navas de Tolosa, die gesamten almohadischen Kämpfer hätten nach ihrer Niederlage unversehrt das Schlachtfeld verlassen (Mağmū'a ğadīda, Bd. 1, S. 270), und im Brief Nr. 30 wird bei der scheinbar lückenlosen Darstellung einer der Etappen der almohadischen Unternehmung nach Ifrīqīya die Niederlage der almohadischen Truppen in der Nähe von Gafsa einfach übergangen (Mağmū` rasā’il muwaḥhịìiya, S. 186-187).
} 
„raḥill“, das im eben genannten Brief synonym zu ,intiqāl“" gebraucht wird und wie auch „,irtihāal“ eine Ableitung von der arabischen Wurzel „RḤL“ bildet. Es ist anzunehmen, dass auch in den betreffenden Passagen des Briefes Nr. 9 sowohl mit „intiqāl“ als auch mit „,irtihāal“ das Zurücklegen von größeren Strecken gemeint ist. Der Darstellung des Briefes jedoch nach, hat sich das später verfolgte almohadische Kontingent in naher Entfernung von den arabischen Stämmen befunden, was aus dem Satz „Die almohadischen Kriegsscharen, welche (dem Gros der almohadischen Armee) zur Bezwingung von Qal'at Banī-Hammād und Constantine [...] vorausgeeilt waren [...] schauten auf die Gebilde des Unwahren und der Verwirrung dieser Irrenden“"111 hervorgeht. Aus diesen Gründen halte ich es für sehr wahrscheinlich, dass es sich bei „al-'arab“ im arabischen Original um einen Druckfehler handelt und dass ,al-Ġarb“ stattdessen gemeint ist ${ }^{112}$. Demnach müssen die bei Constantine lagernden almohadischen Truppenteile den Befehl erhalten haben, nicht $\mathrm{zu}$ den arabischen Stämmen, „al-`arab“, sondern nach Maghreb, ,al-Ġarb“, aufzubrechen. Diese Korrektur ist insofern wichtig, als sie die Schilderungen des Briefes zu einer logischen Abfolge der stattgefundenen Ereignisse zusammenzufügen und somit ein besseres Verständnis eines ereignisgeschichtlichen Teilaspekts des Schreibens Nr. 9 erlaubt.

Vor diesem Hintergrund mag der letzte Teil des eingangs angeführten Zitats, die Almohaden hätten auf ihrem Weg zu den arabischen Beduinen dürre Landstriche der Wüste durchzogen, befremdlich anmuten. Denn - stimmten die oben angestellten Überlegungen - das almohadische Kontingent zog ja nach dem Äußersten Maghreb und entfernte sich somit von den arabischen Stämmen, welche dessen Verfolgung aufgenommen haben. Es stellt sich daher die Frage, wie dieser offenkundige Widerspruch, der sich einerseits zwischen der Aussage des Briefes und dem wahrscheinlich anzunehmenden Verlauf der Ereignisse andererseits ergibt, gelöst werden könnte? Wir wollen deshalb das Augenmerk kurz auf ähnliche Aussagen in anderen almohadischen Briefen richten und sie in die Betrachtung einbeziehen. Dabei stellen wir fest, dass die offiziellen almohadischen Schreiben Schilderungen enthalten, wie die Almohaden auf dem Weg zu ihren Widersachern lang ausgestreckte und wasserlose Wüsteneien hätten durchziehen müssen. Häufig wird damit implizit zum

\footnotetext{
${ }^{111}$ Mağmū' rasā’il muwaḥhịīìa, S. 28.

112 Die geographische Bezeichnung „al-Ġarb“ kommt in den überlieferten zeitgenössischen almohadischen Quellen vor und kann verschiedene Bedeutungen haben. So z. B. bezeichnet ,al-Ġarb“ in „al-Mann bi-'1-imāma“ (S. 94 und 181) den westlichen Teil von al-Andalus und in „Kitāb aḩbār al-mahdī Ibn-Tūmart" (S. 20, 101, 127, 179 und 183 der Übersetzung) das Gebiet im Norden des heutigen Marokkos. In einem in „Mağmū'a ğadīda“ (Bd. 1, S. 122) überlieferten almohadischen Brief wird „alGarb“ jedoch auch auf die Gesamtheit der Gebiete des heutigen Marokkos bezogen.
} 
Ausdruck gebracht, dass die Almohaden dabei allein dank dem wundersamen göttlichen Beistand letztlich erfolgreich und unversehrt an ihrem Ziel angelangt seien. Folgende Beispiele seien als Belege hierfür angeführt:

Bei der Schilderung der almohadischen Unternehmung gegen die sich in Gafsa verschanzten Aufständischen im Brief Nr. $20^{113}$, bei der das entsandte almohadische Kontingent den Weg dorthin über Kairuan einschlägt, heißt es: „wa-ahadẹ̄ 'alā turuq ba'uda al-'ahd bi-sulūkihā wa-'štabahat 'alā 'amarat hadihīi al-aṣqā' manāhiğuhā wasubuluhā wa-alfaū bihā min al-marāfiq al-wāsi'a wa-'l-miyāh al-ma'īna mā lam

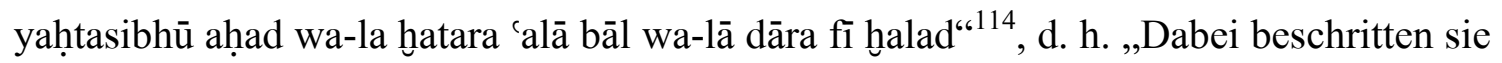
(d. h. die Almohaden) Wege, die schon seit langer Zeit nicht mehr beschritten wurden und deren Durchgänge und Pfade bei den Bewohnern dieser Gegenden in Vergessenheit geraten waren. Auf diesen Wegen fanden sie reichlich Nahrung und frei dahinfließendes Wasser, was niemand erwartet noch gedacht und womit keiner gerechnet hatte“.

Im Brief Nr. 30, der im Rahmen der almohadischen Unternehmung zwecks Befriedung Ifrīqīyas im Jahre 1187 verfasst wurde, finden sich Sätze, die den Weg der almohadischen Kontingente zu ihren Feinden beschreiben. Auch diesmal bildet Kairuan eine der Etappen auf dem Marsch der Almohaden nach Gafsa: „Wa-'qtafā almuwaḥhidūn [...] ātārahum ilā maqrabat minhā (aiy Qafṣa) wa-ahadeū 'alā tarīq lam yahțur bi-bāl al-ašqīyā' as-sulūk 'alaihā wa-lā iḥtalağa $\left[\operatorname{sic}^{115}\right]$ fì ṣudūrihim ihtidā' ilaihāa ${ }^{\text {(116 }}$, d. h. „Die Almohaden ihrerseits [...] folgten diesen ihren Feinden nach und kamen in die Nähe Gafsas. Sie zogen dorthin auf einem solchen Wege, von welchem diese Elenden niemals gedacht hätten, dass man ihn hätte einschlagen können, und welchen beschreiten zu können ihnen nimmer in den Sinn gekommen wäre“.

Der Brief Nr. 31, der den Bericht über die Fortsetzung der almohadischen Unternehmung von 1187 nach Ifrīqīya enthält, beschreibt in folgender Weise den Marsch der almohadischen Armee von Gabès nach Ğarīd: ,[...] nahaḍa al-muwaḥhidūn [...] min Qābis [...] āḩid̄in 'alā șaḥrāihā wa-qāṣidīn ilā al-bilād al-ğarīdīya min warā’ihā 'alā țuruq lā 'ahda lahā bi-'l-'asākir wa-lā 'alama fîhā li-cāmir wa-lā manfaḍa amāmahā li-wārid wa-lā șādir‘،117, d. h. ,[...] es brachen die Almohaden [...] von Gabès [...] auf

\footnotetext{
${ }^{113}$ Lévi-Provençal hat diesen Brief in die Zeit der almohadischen Unterwerfung Ifrīqīyas, welche der erste almohadische Kalif 'Abd-al-Mu'min (1147-1163) im Jahre 1160 abgeschlossen hat, datiert. Eine andere Abschrift dieses Briefes ist jedoch vom 1180 datiert (Mağmū'a ğadīda, Bd. 1, S. 161) und wurde somit in der Regierungszeit von Yūsuf Ibn-'Abd-al-Mu'min (1163-1184) verfasst.

${ }^{114}$ Mağmū̌ rasāìil muwaḥhidīya, S. 103.

${ }^{115}$ Das arabische Verb ,ihtalağa“" ist hier sicherlich gemeint.

${ }^{116}$ Mağmū' rasā'il muwaḥhidīya, S. $186 \mathrm{f}$.

${ }^{117}$ Mağmūc rasā'il muwaḥḥidīya, S. 195.
} 
und drangen in die nahe dieser Stadt gelegene Wüste ein, um so nach Ğarīd zu gelangen. Dabei zogen sie auf Wegen, die kein Heer jemals zuvor beschritten hatte, die noch nie ein Bewohner genutzt hatte und die sich in der Unendlichkeit verlieren“.

Vor dem Hintergrund dieser angeführten Passagen sowie auch der Tatsache, dass sich auch in einigen anderen almohadischen Briefen Hinweise auf die Unpassierbarkeit von Wegen finden ${ }^{118}$, welche die Almohaden zu ihren Feinden hätten zurücklegen müssen und letztlich mit göttlichem Beistand auch erfolgreich zurückgelegt hätten, erscheint die Vermutung naheliegend, dass es sich beim im Brief erwähnten Durchziehen von dürren Landstrichen der Wüste eher um einen den Zuhörern geläufigen Topos zu handeln scheint.

2.4. „Was die arabischen Beduinen dieser Gebiete betrifft, die in ihnen ein parasitenhaftes Dasein führen $[\ldots]^{\text {“ }}$

Als die Fatimiden im Jahre 972 Ifrīqīya endgültig verließen und nach Ägypten umzogen, wurde der Sanhāğa-Fürst Buluggīn Ibn-Zīrī zum fatimidischen Vizekönig über Ifrīqīya ernannt. Doch schon nach dem Tod dieses ziridischen Herrschers versuchte sein Sohn und Nachfolger al-Manșūr (984-996), die nominelle fatimidische Herrschaft abzuschütteln. Daraufhin wurde aus Kairo ein Agitator (dācīi) in das Gebiet des berberischen Stammes Kutāma geschickt, der die Angehörigen dieses Stammes zu einem Aufstand gegen al-Manșūr bewegen konnte, der jedoch niedergeschlagen wurde. Im Jahre 1047 stellte sich der ziridische Herrscher al-Mu'izz Ibn-Bādis formell unter die Herrschaft des abbasidischen Kalifen und kündigte somit den Gehorsam gegenüber den fatimidischen Kalifen endgültig auf. Die Anerkennung des abbasidischen Kalifen hatte einen symbolischen Charakter und beschränkte sich darauf, dass der Letztere nun in der Freitagspredigt erwähnt wurde. Dieses Mal bestand jedoch die Reaktion Kairos darin, die arabischen Stammesverbände Banū-Hilāl und Banū-Sulaim zum Marsch nach Ifrīqīya zu bewegen.

Das ursprüngliche Siedlungsgebiet dieser Stammesverbände lag im Gebiet Nağd auf der Arabischen Halbinsel, und einige ihrer Unterstämme kamen bereits im neunten Jahrhundert nach Ägypten. Im elften Jahrhundert siedelten diese Stämme in Oberägypten, wohin sie der fatimidische Kalif 'Azīz Ibn-al-Mu'izz nach seinem Sieg über die Qarmaten ${ }^{119}$ im Jahr 978, deren Verbündete diese Stämme waren, umsiedelte

\footnotetext{
${ }^{118}$ Mağmū'a ğadīda, Bd. 1, S. 146 f., 253 und 266.

119 Qarmaten waren Anhänger einer aus dem Ismaelitentum hervor gegangenen islamischen Bewegung. Im 9. und 10. Jahrhundert lieferten sie sich erbitterete Kämpfe mit Abbasiden und Fatimiden.
} 
und ihnen verbot, den Nil zu überqueren. Als al-Mucizz Ibn-Bādis auf die oben erwähnte Art die absolute Loslösung vom fatimidischen Kalifen al-Mustanșir herbeiführte, wurde diesen Stämmen auf den Rat des fatimidischen Wesirs al-Yāzūri hin der Weg nach Ifrīqīya freigegeben. Sie bekamen auch von al-Mustanșir im Voraus die nominelle Belehnung mit den Provinzen Ifrīqīyas. Der Stammesverband Banū-Hilāl, der zahlreiche Stämme umfasste, setzte sich als erster in Bewegung. Es waren die Stämme dieses Verbandes, die in Ifrīqīya einfielen. Banū-Sulaim folgten einige Zeit später, ließen sich jedoch im heutigen Cyrenaika und Tripolitanien nieder und erreichten erst am Anfang des dreizehnten Jahrhunderts Ifrīqīya. Der damalige ziridische Herrscher, die drohende Gefahr verkennend, maß den Nachrichten über das Herannahen der Beduinenstämme keinerlei Bedeutung bei und versuchte sogar anfangs, die ankommenden Hilāl-Stämme für sich zu gewinnen und sie zu seiner Garde zu machen. Doch diese versuchte Einbindung der Beduinen in den eigenen Dienst scheiterte kläglich. Die einzelnen Stämme, die keine Zentralgewalt über sich akzeptierten und oft untereinander verfeindet waren, zeigten keine Bereitschaft, sich irgendeiner politischen Ordnung zu unterwerfen und ließen sich viel eher von Gier nach Beute leiten. Die lokale Macht der Ziriden vermochte den einfallenden Stämmen keinen ernsthaften Widerstand entgegenzusetzen, und die aus den berberischen Zanata- und Sanhāğastämmen bestehende Allianz wurde in der Schlacht bei Haidarān im Jahr 1052 in der Nähe von Gabès von den arabischen Beduinen vernichtend geschlagen. Nach dieser Niederlage floh al-Mu'izz nach Kairuan, und ganz Ifrīqīya war nun der Gewalt der Eindringlinge ausgeliefert. Es setzte die Flucht der autochtonen Bevölkerung aus den Dörfern in die Städte ein. Im Gefolge von diesem Zusammenbruch der ziridischen Zentralgewalt erklärten sich einige ehemalige Gouverneure der Ziriden für unabhängig, z.B. in Gafsa, Sfax oder Sūsa, und sicherten sich ihre Unabhängigkeit mittels Zahlungen an die in ihrer Umgebung nun siedelnden und waltenden arabischen Beduinenstämme. Andere Städte wurden zum Eigentum einzelner Hilāl-Stämme. Der Herrschaftsbereich der Ziriden, die ihre Hauptstadt al-Qairawān im Jahre 1057 verließen und sich in der gut befestigten al-Mahdiya verschanzten, war nun auf einen schmalen, von Sousse bis Sfax reichenden Küstenstreifen zusammengeschrumpft. Was die Banū-Hammād anbetrifft, so erlitten sie ein ähnliches Schicksal. Obwohl sie anfangs einige arabische Stämme für ihre politischen Ziele gewinnen und so ihre Herrschaft weitgehend behaupten konnten, verkamen sie letztlich zu bloßen Marionetten in den Händen ihrer mächtigen 
beduinischen Alliierten ${ }^{120}$. Im Jahre 1090 gaben sie ihre Hauptstadt Qal'at BanīḤammād auf und zogen nach Biğāya um, das bis zur almohadischen Eroberung ihre Hauptstadt bleiben sollte. Dort fristeten sie, den Ziriden in Mahdiya gleich, ein in politischer Hinsicht unbedeutendes Dasein.

Die durch den Einfall der arabischen Nomaden ausgelösten allgemeinen Unsicherheit und Verfall des urbanen Lebens fügten dem wirtschaftlichen und kulturellen Leben dieser Region einen nachhaltigen Schaden $\mathrm{zu}^{121}$. Das allgemeine Chaos und Anarchie, in welche der Einfall dieser Stämme Ifrīqīya stürzte, hatten unter anderem einen Exodus der Stadtbevölkerung aus dem Landesinneren zu den Küstenstädten, wie Tūnis, Susa, Sfax, Monastir, aber auch nach Qal'at Banī-Hammād, zur Folge ${ }^{122}$. Dieses Ereignis leitete aber auch einen wichtigen sprachlichen Wandel ein - die tiefgreifende und umfassende Arabisierung Ifrīqīyas.

2.5. „Doch es war Gottes Wille, dass diese Elenden zu denjenigen gehören sollten, welche das Verderben in seinen Abgrund hinabschleuderte [...]“

Wie im Falle des Briefes Nr. 8, finden sich in nur wenigen überlieferten arabischen Quellen Berichte über die im Mittelpunkt des Briefes Nr. 9 stehenden Ereignisse. Es sind vor allem Ibn-al-Ațīr und Ibn-Ḩaldūn, die diese Geschehnisse etwas näher beleuchten. Daher wird sich die historische Analyse der ausgewählten Passagen vornehmlich auf die von diesen beiden Autoren überlieferten Berichte stützen.

Mit dem angeführten Zitat werden im Brief die eigentlichen Beweggründe der arabischen Beduinenstämme elegant übergangen und es bleibt im Dunkeln, warum diese Stämme die für sie von den Almohaden ausgehende Gefahr als derart ernst einschätzten, dass sie sich veranlasst sahen, viele andere arabische Stämme zum Kampf gegen diese zu mobilisieren. Im Brief findet man keine Antwort darauf. Einige seiner Ausführungen, welche viele pejorative und koranisch geprägte Bezeichnungen der arabischen Beduinen enthalten, sollen den Eindruck erwecken, die Beduinen handelten in der geschilderten Art und Weise aus ihrer bloßen ihnen gleichsam innewohnenden Heimtücke heraus. Ibn-al-Atīr hingegen gibt in seinem Bericht einen plausibleren Grund für diesen frühen Versuch der arabischen Beduinenstämme, die militärischen Erfolge der Almohaden im Zentralen Maghreb rückgängig zu machen: „Im Monat Șafar (d. h. vom 11. März bis 9 April) dieses Jahres (d. h. 548 H. / 1153 n. Chr.) kam es zur

\footnotetext{
${ }^{120}$ Abun-Nasr, Jamil M., A history of the Maghrib, S. 70.

${ }^{121}$ Abun-Nasr, Jamil M., A history of the Maghrib, S. 70.

122 Singer, Hans-Rudolf, Der Maghreb und die Pyrenäeninsel bis zum Ausgang des Mittelalters, S. 287.
} 
Schlacht zwischen den Truppen 'Abd-al-Mu'mins und den arabischen Beduinen bei der Stadt Sétif. Aus folgendem Grund kam es dazu: Als 'Abd-al-Mu'min die Gebiete der Banū-Hammād unter seine Botmäßigkeit brachte, haben sich die in den Gebieten, die sich von Tripolis bis hin zu den Randbezirken des Maghreb ${ }^{123}$ erstrecken, siedelnden arabischen Stämme, nämlich Banū-Hilāl, al-Abtağ ${ }^{124}$, 'Adīy, Riyāḥ, Za'ab ${ }^{125}$ und etliche andere, versammelt und gesagt: ,Wenn wir 'Abd-al-Mu'min in unserer Nähe dulden, wird er uns aus dem Maghreb vertreiben, und deswegen müssen wir dieser Gefahr steuern und ihn aus diesen Gebieten verdrängen, bevor sich seine Herrschaft dort gefestigt hat. “ “126 Daraus geht hervor, dass die arabischen Stämme, die nicht nur im gesamten Gebiet von Ifrīqīya ihre uneingeschränkte Herrschaft ausübten, sondern auch große Teile insbesondere des Zentralen Maghreb kontrollierten, in der almohadischen Präsenz vor allem die Gefährdung ihrer Besitzungen in den genannten Gebieten sahen. Dies dürfte also eines der Hauptmotive für ihren Versuch gebildet haben, die Almohaden zu verdrängen. Ferner muss darauf hingewiesen werden, dass die arabischen Stämme seit ihrem Einfall in Ifrīqīya keine starke Zentralmacht gekannt haben, und höchstens nominell den ziridischen oder hammādidischen Herrschern unterstanden. Deswegen muss das Vorhaben der Almohaden, die unterworfenen Gebiete einer starken und effizienten Zentralgewalt zu unterstellen sowie die arabischen Stämme in die almohadische Politik einzubinden und für die almohadischen Ziele einzusetzen, im krassen Widerspruch zur bisherigen gewohnten Lebensweise dieser Stämme gestanden haben. Ibn-Haldūn berichtet ebenfalls an zwei Stellen seines Werkes über diese Begebenheiten, gibt jedoch keine Beweggründe an, sodass der angeführte Bericht von Ibn-al-Atîr den einzigen Anhaltspunkt bei der Klärung der Frage nach dem eigentlichen Motiv der Beduinen zu bilden scheint.

In dem eingangs angeführten Zitat wird im Brief auch ein anderer Umstand übergangen, der für das Verständnis des Vorgehens der Almohaden nicht unwesentlich ist. IbnHaldūn erhellt einige Zusammenhänge der almohadischen Unterwerfung des Zentralen Magheb folgendermaßen: „Als die Almohaden sämtliche Gebiete im Maghreb ${ }^{127}$ unter ihre Botmäßigkeit im Jahr 541 H. / 1146 n. Chr. gebracht hatten und der Anführer der Almohaden 'Abd-al-Mu'min mit seinem Heer nach Ifrīqīya ${ }^{128}$ zog, trafen bei ihm in

\footnotetext{
${ }^{123}$ Damit sind hier Gebiete gemeint, die sich vom heutigen Tunesien ostwärts erstrecken.

${ }^{124}$ Ein Druckfehler, damit ist der Stamm al-Atbağ gemeint.

${ }^{125}$ Ein weiterer Druckfehler, damit ist der Stamm Zugiga gemeint.

${ }^{126}$ al-Kāmil, Bd. 9, S. 41.

${ }^{127}$ Damit ist hier annähernd das Gebiet des heutigen Marokkos gemeint.

${ }^{128}$ Gemeint ist hier der almohadische Feldzug zur Unterwerfung des Zentralen Maghreb im Jahr 1152.
} 
Algier zwei Oberhäupter der arabischen Stämme in damaliger Zeit ein, nämlich Abu-'1Ğalīl Ibn-Šākir vom Stamm al-Ațbağ und Ḥabbās Ibn-Mušaifir von den Ğušam. 'Abdal-Mu'min empfing sie gütig, ernannte sie zu den Anführern über ihre jeweiligen Stämme und setzte danach seinen Marsch nach Biğāya fort, welches er im Jahr 559 H. / 1163 n. Chr. ${ }^{129}$ in Besitz nahm. Danach jedoch kündigten die arabischen Hilāl-Stämme 'Abd-al-Mu'min den Gehorsam auf [!] und scharten sich zur Wiederherstellung der Herrschaft der Banū-Ḥammād zusammen.“" ${ }^{130}$ Aus diesem Bericht geht hervor, dass einige arabische Stämme sich bereits in einer frühen Phase des almohadischen Feldzuges in den Zentralen Maghreb den Almohaden unterworfen haben. Und erst vor dem Hintergrund dieser Information hellt sich der auf den ersten Blick befremdende und nicht ganz eindeutige Satz des Briefes „Doch die Sicherheit gebot es den erwähnten Almohaden, gegen die genannten Beduinen trotz deren Torheit nicht vorzugehen

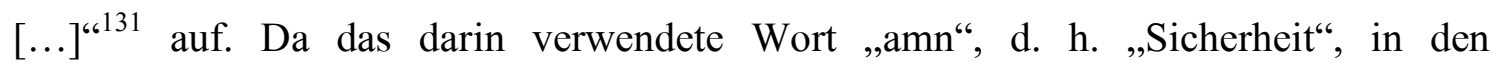
almohadischen Quellen synonym zu ,amān“, d. h. „die körperliche und materielle Unversehrtheit“ bzw. „die Zusicherung der körperlichen und materiellen Unversehrtheit", gebraucht werden kann ${ }^{132}$, wird mit diesem Satz höchstwahrscheinlich darauf Bezug genommen, dass einigen arabischen Stämmen bei der geschilderten Kontaktaufnahme zu den Almohaden in Algier von den Letzteren die körperliche und materielle Unversehrtheit zugesichert wurde. Dies wiederum könnte eine mögliche Erklärung dafür sein, warum das Gros der almohadischen Armee gegen die eigentlichen Herrscher im ḥammādidischen Königreich, nämlich gegen die arabischen Stämme, nicht vorgegangen war. Was den Verlauf und den Ausgang der Schlacht betrifft, so decken sich die jeweiligen Berichte von Ibn-al-Ațīr ${ }^{133}$ und Ibn-Haldūn ${ }^{134}$ allgemein mit der Darstellung des Briefes.

Abschließend sei noch darauf hingewiesen, dass der Darstellung des Briefes nach alles darin geschilderte Geschehen im göttlichen Willen seine Ursache hat und von diesem bestimmt wird. So sei es das glückhafte Eingreifen Gottes gewesen, dank welchem die Almohaden den Zentralen Maghreb erobert hätten, es sei Gottes Wille gewesen, dass das Verderben die arabischen Beduinen in seinen Abgrund hinabgeschleudert habe, Gott habe gewollt, dass die Almohaden das Urteil der Qual an den Beduinen

\footnotetext{
${ }^{129}$ Bei diesem Datum handelt es sich zweifellos um einen Fehler, und das Jahr 1152 ist gemeint.

${ }^{130}$ Kitāb al-'ibar, Bd. 6, S. 43-44.

${ }^{131}$ Mağmū' rasā'il muwaḥidīya, S. 29.

${ }^{132}$ Mağmūc rasā'il muwaḥhịidìa, S. 189, al-Bayān al-muğrib, S. 178.

133 al-Kāmil, Bd. 9, S. 41.

${ }^{134}$ Kitāb al-'ibar, Bd. 6, S. 44 und 491.
} 
vollstrecken, dank göttlichem Beistand sei die rechtzeitige Entsendung der Verstärkung zum verfolgten almohadischen Kontingent erfolgt und mittels der göttlichen Unterstützung hätten die Almohaden über ihre Feinde den Sieg davongetragen. Diese Deutung der Ereignisse spiegeln die beiden anderen zitierten Quellen selbstverständlich nicht wider.

2.6. „Das Töten dieser Feinde und ihre Verfolgung dauerten vom Anbruch dieses gesegneten Tages bis zu dessen Ende an.“

Der Schilderung des Briefes nach hat die Schlacht zwischen den almohadischen Truppen und den arabischen Stämmen einen Tag lang gedauert. Dieser Aussage widersprechen zwei Berichte Ibn-Haldūns, in welchen der Autor die Dauer der bei Sétif stattgefundenen Schlacht mit drei Tagen angibt ${ }^{135}$. Dieser Widerspruch zwischen der Darstellung des Briefes und der Überlieferung des genannten Autors lässt sich mangels anderer Berichte diesbezüglich nicht lösen. Das folgende allgemeine Merkmal der almohadischen Briefe jedoch könnte einen möglichen Erklärungsansatz hierfür liefern: Bereits bei der Zusammenfassung des Briefes Nr. 8 wurde festgestellt, dass sich die almohadischen Schreiben durch ihre „Zeitlosigkeit“ auszeichnen können, welche sich im weitestgehenden Fehlen von Zeitangaben äußert, sodass die Dauer der in ihnen geschilderten Ereignisse nicht nur sich kaum näher bestimmen lässt, sondern auch als nur eine kurze Spanne während dargestellt wird.

Eine Ausnahme bildet hierbei das Datum der Abfassung von einigen almohadischen Schreiben. Doch hierbei handelt es sich um eine Angabe, die höchstens Rückschlüsse auf allgemeine zeitliche Verhältnisse des Inhalts des jeweiligen Briefes und dies durch einen Vergleich mit in anderen Quellen überlieferten Daten erlaubt und somit keinen Aufschluss über die Dauer des bekannt gegebenen Inhalts im Einzelnen gibt. Die obige Feststellung trifft auch für den Brief Nr. $9 \mathrm{zu}$, denn abgesehen vom eingangs angeführten Satz, enthält er keine weiteren Zeitangaben. Man muss hierbei bedenken, dass der Brief Nr. 8 vom 10. November 1152 und der Brief Nr. 9 vom 26. Juni 1153 datiert ist. Mit anderen Worten, die im Brief Nr. 9 geschilderten Ereignisse haben sich über einen Zeitraum von knapp acht Monaten erstreckt. Somit fällt das offenkundige Missverhältnis auf, das zwischen den raffenden Schilderungen des Briefes, die durch das Fehlen von zeitlrelevanten Angaben sowie durch einige formale Merkmale suggerieren, die darin dargestellten Ereignisse seien rasch und nahtlos ineinander

\footnotetext{
${ }^{135}$ Kitāb al-cibar, Bd. 6, S. 44 und 491.
} 
übergehend vonstatten gegangen, und der tatsächlichen Dauer der stattgehabten Abläufe besteht.

2.7. „Dabei vermischten sie sich mit ihren Viehherden, dem Vieh gleich, das sich mit dem Vieh vermischt $[\ldots]^{\text {“ }}$

Es gibt in den almohadischen Briefen viele Bezeichnungen für „Feinde“. Man kann diese in folgende drei Gruppen unterteilen: Erstens, koranisch geprägte Bezeichnungen, zweitens, die meistens aus der Tierwelt entlehnten nicht koranischen Bezeichnungen, die aufgrund ihrer Erwähnung in den als klassisch geltenden literarischen arabischen Werken einen hohen Bekanntheitsgrad besaßen, und drittens, allgemeine pejorative Bezeichnungen mit nicht näher definierbarem Ursprung. Die übergroße Mehrheit der Bezeichnungen für Feinde im Brief Br. 9 sowie in den noch zu analysierenden Schreiben ist koranisch geprägt ${ }^{136}$ :

„Ğuhhāl““ (S. 29), d. h. „die Unwissenden“, ist im Koran zwar nicht belegt, wohl aber dessen Synonym ,ğāhilīn“ in Sure 6, Vers 35; Sure 7, Vers 199; Sure 11, Vers 46 usw. „al-ašqīyā’“ (S. 29), „al-ašqīyā̄”“ (S. 31), d. h. „,die Elenden“, ist im Koran nicht belegt, wohl aber dessen Singularform ,šaqī“ in Sure 11, Vers 105.

„al-hāsirīn“ (S. 30), d. h. „die zum Verderben Verurteilten“, ist im Koran in Sure 2, Vers 64; Sure 3, Vers 85; Sure 3, Vers 149 usw. belegt.

„aḍ-ḍāllūn“ (S. 30), d. h. „die Irrenden“, ist im Koran in Sure 3, Vers 90; Sure 15, Vers 56; Sure 56, Vers 51 usw. belegt.

„kāfirīn“ (S. 32), d. h. „die Ungläubigen“, kommt im Koran in Sure 2, Vers 19; Sure 2, Vers 24; Sure 2, Vers 34 usw. vor.

„wa-alfaū āğālahum 'alā gāâat min al-istišrā' wa-nihāyat min al-istirsāl 'alā tilka al-

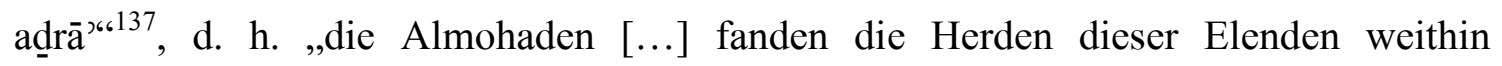
verbreitet und äußerst ausgebreitet auf jenen Gipfeln vor“, „fa-'ḩtalaṭū bi-mawāšǐhim ihtilāt al-an‘ām bi-'1-an`ām““138 , d. h. „Dabei vermischten sie sich mit ihren Viehherden, dem Vieh gleich, das sich mit dem Vieh vermischt“. „Das Vieh“ kommt an mehreren Stellen im Koran vor, und in zwei Fällen, nämlich in Sure 7, Vers 179 und Sure 25, Vers 44, wird ausgesagt, das mit „das Vieh“ bezeichnete Objekt sei in der absoluten Missleitung befangen. Ein ebenso wenig vorteilhaftes Bild einzelner unter dem Oberbegriff „Vieh“ zusammengefasster Tiere ergeben auch folgende klassische

\footnotetext{
${ }^{136}$ Die im Folgenden in Klammern beigefügten Seitenangaben verweisen auf die Seiten des arabischen Originals „Mağmū̄ rasā’il muwaḥhidìya“.

${ }^{137}$ Mağmū' rasā̄il muwaḥhidìya, S. 31 ff.
} 
arabische Redewendungen: „Aḥmaq min ar-rahl“"139, d. h. „blöder als ein Lamm“, „aḥmaq min an-na`ğa 'alā al-ḥaự“"140, d. h. „,blöder als ein Schaf am Wassertrog“,

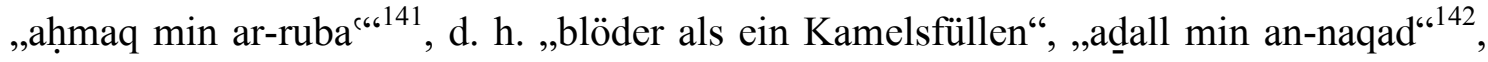
d. h. „unterwürfiger als kurzfüßige Schafe“, ,,adall min al-ḥuwār“"143, d. h. ,verächtlicher als ein Kamelsfüllen“, „,aqwad min muhr“, d. h. „fügsamer als ein Fohlen“, und „așwal min al-ğamal“"144, d. h. „,beißwütiger als ein Kamel“. Darüber hinaus kann die Aussage, jemand verhalte sich feige bzw. kleinmütig, mittels des Bildes, jemand habe sich zu einem Schaf oder einer Eselin gewandelt, getroffen werden ${ }^{145}$.

„wa-tahaiyalū al-iqdām 'alā tabt al-aqdām min madārik amtālihim min aṭ-ṭgàām waaškālihim min aubāšs al-li’ām“‘146, d. h. „Diese Feinde wähnten, ihr energisches Vorgehen gegen die Almohaden stehe den ihnen Gleichen an, nämlich dem gemeinen Pöbel, und den ihnen Ähnlichen, nämlich dem niederträchtigen Pack““.

„a'dā' Allāh“ (S. 33), d. h. „die Feinde Gottes“, ist im Koran in Sure 41, Vers 19 und Sure 41, Vers 28 belegt.

„al-mufsidīn“ (S. 33), d. h. "die Übeltäter”, ist im Koran in Sure 2, Vers 60; Sure 3, Vers 63; Sure 5, Vers 64 usw. belegt.

„al-māriqīn“ (S. 34), d. h. „die Abtrünnigen“, kommt in einem Ausspruch von Mohammed sowie von 'Alī Ibn-Abī-Ṭālib vor ${ }^{147}$.

Im Satz des Briefes „Die Almohaden fanden kein anderes Heilmittel, welches das unheilbare Übel dieser Elenden hätte heilen und in dieser geschilderten Situation die Erlösung von diesen Beduinen hätte bescheren können usw. “148 wird die metaphorische Ausdrucksweise sichtbar, die den mittelalterlichen literarischen Schriften eigen ist. Dabei hatte der Begriff „Krankheit“ ein ganzes Bündel von Bedeutungen. Damit konnten u. a. - oft politische - Zustände und Verhältnisse, die als unerwünscht, missbilligenswert oder schmerzlich empfunden wurden, umschrieben werden. So

\footnotetext{
${ }^{138}$ Mağmū' rasā'il muwaḥhidīya, S. 32.

${ }^{139}$ Kitāb ğamharat al-amtāl, Bd. 1, S. 392.

${ }^{140}$ Kitāb ğamharat al-amtāl, Bd. 1, S. 392.

${ }^{141}$ Kitāb ğamharat al-amtāā, Bd. 1, S. 392.

${ }^{142}$ Kitāb ğamharat al-amtāl, Bd. 1, S. 469.

${ }^{143}$ Kitāb ğamharat al-amtāl, Bd. 1, S. 469.

${ }^{144}$ Kitāb ğamharat al-amtāal, Bd. 1, S. 587.

${ }^{145}$ Beispielsweise durch „,ista'tana al-himār“, d. h. „ein Esel ist zu einer Eselin geworden“ (al-Munğid fi 'l-lug̉a wa-'l-a lām, S. 982) und „,man șāra na ğatan akalahū aḍ-di’b“, d. h. „,wer zu einem Schaf wird, den frisst der Wolf auf" (al-Munğid fi 'l-lugga wa-'l-a'lām, S. 1010). Feigheit als eine Eigenschaft der Schafe geht auch aus der bis heute verbreiteten Wendung ,istan`ağa fulān“, d. h. ,jemand hat sich zu einem Schaf gewandelt", hervor.

${ }^{146}$ Mağmū' rasā'il muwaḥhidīya, S. 32.

${ }^{147}$ Lisān al-'arab, Bd. 6, S. 45.

${ }^{148}$ Mağmū' rasā'il muwaḥhidìya, S. 31.
} 
wurden beispielsweise die als gestört und zerrütet empfundenen politischen Verhältnisse eines Königreiches oder auch eines von dessen Gebieten als „von Krankheit befallen“ bezeichnet werden. Ferner konnte „Krankheit“ auf die Lage eines beschriebenen Objekts bezogen werden und hatte dann die gemeinte Bedeutung „Not“ bzw. „Bedrängnis“, in welcher es sich befand. Und schließlich konnte durch das Bild, eine Gegend, eine Stadt sei von einer Krankheit befallen, ausgedrückt werden, dass das geschilderte Objekt unbotmäßig geworden ist und der Macht des jeweiligen Herrschers entglitten ist bzw. entrissen wurde. Diese letzte Bedeutung des metaphorischen Gebrauchs von allerlei Krankheiten, Gebrechen und Übeln kommt in den almohadischen Schreiben sehr häufig vor. Der zitierte Satz muss daher den Rezipienten des Briefes ein vielfältiges Bedeutungsbündel geboten haben, wobei m. E. sehr wahrscheinlich die Bedeutung „Auflehnung gegen die almohadische Herrschaft“ diejenige davon gewesen sein dürfte, welche dieser Rezipient damit am ehesten assoziiert hat. Die Gleichsetzung der arabischen Beduinen mit einer Krankheit hatte darüber hinaus ein wichtiges psychologisches Moment: Dadurch erfolgt die Ausstattung der almohadischen Feinde mit einem Merkmal, das sie einerseits entmenschlicht und andererseits jedes auf ihre Ausmerzung gerichtetes Vorgehen nicht nur als gerechtfertigt, sondern vielmehr als notwendig erscheinen lässt. Auf diese Weise entfällt auch jegliche Notwendigkeit, nicht nur das Handeln des Feindes, sondern auch das almohadische Vorgehen gegen ihn für den Rezipienten näher begründen zu müssen.

\subsection{Zusammenfassung des historischen Kommentars}

Im Mittelpunkt des Briefes Nr. 9 stehen die Ereignisse, die nach dem Abschluss der almohadischen Unterwerfung des Zentralen Maghreb stattgefunden haben. Den Schwerpunkt der Schilderung bildet die Schlacht zwischen den almohadischen Truppen und den arabischen Stämmen bei Sétif. Aufgrund der Tatsache, dass die wenigen Berichte diesbezüglich in den überlieferten historiographischen Werken sehr allgemein sind, lassen sich dem Brief Nr. 9 neue, den ereignisgeschichtlichen Aspekt näher beleuchtende Informationen entnehmen (s. Kapitel 2.3.), welche allerdings ihrerseits noch einer weiteren Klärung bedürften. Die Darstellung des Briefes stimmt mit dem aus den herangezogenen Berichten gewonnenen Bild in allgemeinen Grundzügen überein, doch erst vor dem Hintergrund dieser historiographischen Überlieferungen (s. Kapitel 2.5.) können einige von dessen Passagen in ihrem geschichtlichen Kontext gesehen und verstanden werden. 
Der Brief Nr. 9 weist darüber hinaus einige formale Merkmale auf, welche ihn von den historischen Quellentexten wesentlich unterscheiden: Es ist vor allem das religiöse Element, das diesen Brief auf inhaltlicher und sprachlicher Ebene durchwebt. Dieses gelangt dergestalt zum Ausdruck, dass allen geschilderten Vorgängen der Wille Gottes zu Grunde gelegt wird, dem gemäß sie sich vollzogen hätten (s. Kapitel 2.5.), dass koranische Zitate (s. Fußnoten Nr. 82 und 92) und koranische Bezeichnungen für die Feinde der Almohaden (s. Kapitel 2.7.) verwendet werden und dass auf jeweils einen Ausspruch von Mohammed und von 'Alī Ibn-Abī-Ṭālib implizit Bezug genommen wird (s. jeweils die Fußnoten Nr. 76 und 78). Des Weiteren wurde auf einige wörtliche und modifizierte Zitate von klassischen arabischen Redewendungen (s. Fußnoten Nr. 83, 89 und 94) hingewiesen, die neben einigen aus dem literarischen Schrifttum entlehnten Waffenbezeichnungen und Metaphern (s. jeweils die Fußnoten Nr. 97 und 74) sowie Allegorien (s. Fußnoten Nr. 75, 77, 79, 90 und 95 sowie Kapitel 2.7.) das neben dem religiösen etwas weniger ausgeprägte literarische Element bilden. Ferner fällt auf, dass die Darstellungsweise des Briefes den Rezipienten den irreführenden Eindruck einer quasi übergangslos raschen Abfolge der Geschehnisse vermitteln sollte.

\section{Zusammenfassung des Briefes Nr. 26}

Dieser Brief, datiert vom 4. März des Jahres 1181 und abgefasst im Namen des Befehlshabers der Gläubigen in Tunis, richtet sich an die Ṭālibs, Almohaden, Notabeln und die gesamte Bewohnerschaft von Cordoba und teilt den Adressaten den Aufbruch arabischer Beduinenstämme Ifrīqīyas nach al-Andalus zwecks Teilnahme an den militärischen Unternehmungen der Almohaden dort mit. Dies wird in folgender Weise geschildert: Während der Entsendung der Almohaden zu den Küstenregionen Ifrīqīyas, die nach dem erfolgreichen Abschluss eines Feldzuges dorthin erfolgt, werden die Šaihs und die angesehenen Männer der Stämme des Stammesverbandes Banū-Riyāḥ versammelt. Es werden mit ihnen Aufklärungsgespräche religiösen Charakters geführt und man ruft sie dazu auf, die Christen in al-Andalus zu bekriegen und dazu dorthin umzusiedeln. Begeistert willigen die Versammelten in diesen Aufruf ein, und alle betreffenden Stämme dieser Region brechen bald unter Aufsicht der almohadischen Funktionäre, der Ṭālibs und Ḥāfiẓs, nach al-Andalus auf. Einer derjenigen, die dem Aufruf freudig zustimmen, ist Šaih̆ Abū-Sirḥān Mas'ūd Ibn-Sulțān Ibn-Zimām, der samt all seinen Familienangehörigen als einer der ersten die Auswanderung westwärts antritt. Nach dem Abzug dieser Stämme ist niemand mehr von den arabischen Beduinen in 
Ifrīqīya geblieben. Des Weiteren wird ein vorher erfolgter ähnlicher Aufruf an die Sulaim-Stämme erwähnt, die in den um Tripolis und östlich und südlich davon befindlichen Gegenden siedeln. Von diesen erwartet man nun, dass sie wie die RiyāḥStämme nach al-Andalus ziehen. Der Brief schließt mit der Aufforderung, diese Mitteilungen $\mathrm{zu}$ verkünden und sie bei den Zusammenkünften der Almohaden zu verbreiten.

\section{1. Übersetzung des Briefes Nr. 26.}

Vom Befehlshaber der Gläubigen, dem Sohn des Befehlshabers der Gläubigen - Gott möge ihm Seinen Beistand gewähren und ihm Seine Unterstützung zuteil werden lassen - an die Tāalibs, Almohaden, Šaihss, Notabeln der Stadt Cordoba und all ihre Bewohner Gott möge ihren erhabenen Rang durch ihre Frömmigkeit vor Ihm fortdauern lassen und über ihnen die Ankunft Seiner frohen Botschaft erstrahlen lassen. Gottes Frieden, Gnade und Seine Segen mögen euch zuteil werden ${ }^{149}$.

Ihr - Gott möge euch Erfolg erlangen lassen - habt bereits erfahren, was in dieser gesegneten Gegend an erhabenen Ereignissen und gewaltigen Siegen ermöglicht wurde, die alle über die Reichweite der Verstandeskraft hinausgingen, das Maß der Vorstellungskraft überstiegen und der beste Beweis (wörtl. der tugendhafteste Zeuge) dafür waren, dass diese almohadische Botschaft von Gott gewollt ist. Diese Botschaft, welche die Ordnung des Islam ist, die Gesamtheit des Guten für die Geschöpfe wahrt und in den Ebenen (wörtl. Stufen) ihrer Erhabenheit so hoch wie Tage und Nächte reicht, bis sie die Gemeinschaft der Gläubigen durch Gottes Gnade - gelobt sei Er zum Paradies geleiten wird. Wir haben euch - Gott möge euch den Erfolg zuteil werden lassen - auch in Kenntnis gesetzt über die Entsendung der Almohaden - Gott möge ihnen Macht und Stärke verleihen - zu diesen Küstenregionen nach jenem gesegneten Feldzug, durch welchen Gott die Leuchte des Islam und des Glaubens ${ }^{150}$ erhöht und die Zwietrachtstifter, Heuchler und Rebellen erniedrigt hatte. Dieser Entsendung lag einerseits der inbrünstige Eifer zugrunde, der Mühsal abzuhelfen, die die Bekenner der Einzigkeit Gottes im Gehorsam dem Barmherzigen ${ }^{151}$ gegenüber zu ertragen hatten, und sie (d. h. diese Entsendung) erfolgte andererseits, um den Schwertern eine Erholung zu gönnen ${ }^{152}$, damit ihre Klingen (wörtl. Stellen an den Schwertklingen, auf welche die

\footnotetext{
${ }^{149}$ Der darauf folgende einleitende Teil wurde bei der Übersetzung übergangen, s. Kapitel 8.2.

${ }^{150}$ Damit ist die almohadische Bewegung gemeint.

${ }^{151}$ Der Barmherzige ist einer der Namen Gottes im Islam.

152 Das an dieser Stelle (Mağmū $\bar{c}^{\varsigma}$ rasā'il muwaḥhidīya, S. 152) gebrauchte arabische Wort lautet „,ĭgāman“ und ist ein Verbalsubstantiv von Verb ,ağamma“, welches seinerseits zurückgeführt werden
} 
Schwerter beim Versetzen der Hiebe fallen) von den Köpfen der Meuterer und der Aufrührer klar werden. Im Verlaufe dieser Entsendung wurden die Šaihs der arabischen Stämme, ihre Notabeln, bedeutendste Anführer und (ehrenhafte) Männer (wörtl. Anführer und Männer, auf die man hinweist ${ }^{153}$ ), sowie auch ihre wichtigen Persönlichkeiten von allen Stämmen des Verbandes Riyāḥ - Gott möge sie alle den Erfolg erlangen lassen - versammelt. Nachdem dies geschehen war, erinnerte man sie an die rechtmäßigen Anteile dieser ruhmvollen Bewegung (am Weltgeschehen) und an ihre reichlichen und großen Gaben. Man rief ihnen ebenso in Erinnerung die edlen Taten, die ehemals ihre arabischen Vorfahren am Anfang des Islam begangen hatten, und das Versprechen Gottes dieser siegreichen Gemeinschaft gegenüber, dass die Araber ihr Eigentum sein würden, so wie es auch der Auserkorene - das trefflichste Gebet und der vorzüglichste Friedensgruß seien ihm - verkündet hatte. Man ermunterte die Versammelten, ihren Vorfahren gleich beim Beistand dem Islam gegenüber edle Heldentaten zu vollbringen. Man machte ihnen kund, dass das, was man sich von ihnen (leidenschaftlich) wünschte, der Feldzug gegen die Christen ${ }^{154}$ in al-Andalus - Gott möge seine Gesamtheit den Almohaden zugänglich machen - ist. Denn als sich das Unwesen der Christen auf dieser Insel hinzog, ließ Gott ihnen gegenüber lange Zeit Nachsicht und Milde walten. Diese (Christen) aber wurden noch dreister gegen Ihn. Und so wurden die Versammelten dazu aufgerufen, zu diesem erwähnten Feldzug allesamt hinzueilen (wörtl. zu fliehen), jenen gleich, die sich von ihrer Heimat getrennt und die Anhänglichkeit gegenüber ihrem Heim und Wohnort (wörtl. das Kostbare ihres Heimes und Wohnortes) von sich geschleudert haben. Und obwohl dieses Land (d. h. Ifrīqīya) d e r Bodenstaub war, der ihre Haut zuerst berührt hatte, und obwohl sie ihre Jugend in ihm verbracht hatten, so vereinigte doch der Grenzdienst zwecks Erlangung des Wohlgefallens Gottes, zu dem sie sich begeben sollten, das Gute in ihrer Glaubenspraxis und in ihren weltlichen Angelegenheiten in sich sowie auch den Ruhm,

\footnotetext{
kann auf einerseits die Wurzel „ğamma“ mit dem Verbalsubstantiv ,ğumūm“, d. h. „,in Fülle vorhanden sein (Wasser)“, die dann im vierten Stamm „das Wasser sich sammeln lassen“ bedeutet, und andererseits auf die Wurzel „ğamma“ mit zwei Verbalsubstantiven „ğamm“ und „ğamām“, d. h. ,zur Erholung ohne Arbeit gelassen werden (Pferd)“, die im vierten Stamm „Erholung gönnen, geben“ heißt. Daraus ergeben sich zwei unterschiedliche Übersetzungsmöglichkeiten des Satzes. Die erste wäre: ...um an einem Orte die Schwerter sich sammeln zu lassen, auf dass ihre Klingen klar werden von den Köpfen der Ungehorsamen und Widerspenstigen. Die zweite würde lauten: ...um den Schwertern die Erholung zu gönnen, auf dass die Klingen klar werden von den Köpfen der Ungehorsamen und Widerspenstigen, d.h damit die Klingen sich von ihren Köpfen trennen und sichtbar werden.

${ }^{153}$ Eigentlich wird die Wendung ,,al-mušār ilaihim“ mit „,die oben Genannten, Erwähnten“ übersetzt. Da jedoch in diesem Brief „die Anführer und (ehrenhafte) Männer“ vorher nicht erwähnt werden, wird hier ,al-mušār ilaihim“ wörtlich übersetzt.

${ }^{154}$ Im arabischen Text wird die Bezeichnung ,,ar-Rūm“ gebraucht. Damit meinte man früher eigentlich die Byzantiner. Hier sind damit jedoch die christlichen Königreiche der Iberischen Halbinsel gemeint.
} 
der sich für sie dadurch ergeben würde, dass sie in den Reihen des erhabenen Wortes Gottes sein würden. Es wurde ihnen erklärt, dass wenn sie sich diesem glückhaften Feldzug und diesem lobenswerten Ziel mit lauteren Absichten und mit erneuter Entschlossenheit zuwänden, in ihrer Gesamtheit und ohne Ausnahme hineilten, all jene von ihren Angehörigen, Kindern, von ihrem Vieh und Schafen mit sich ziehen ließen, denen ihre Gedanken gelten (wörtl. an denen ihre Gedanken hängen), diese hinter sich an dem Ort in al-Andalus - Gott möge es in seiner Gesamtheit den Almohaden zugänglich machen - sich niederlassen machten, der ihnen zugewiesen sein würde, danach dem Feind standhaft widerstünden und sich gänzlich der Sache Gottes verschrieben (wörtl. sich dem Hin- und Hergehen auf dem Pfade Gottes widmeten), dann würden ihre Gedanken allein dem Angriff auf die Feinde gelten, ihr Gefecht gegen die Gegner würde heftiger, ihr Bedrängen der Polytheisten ungestümer, ihr Eilen zu jedem Hilferuf, den sie vernehmen, schneller und ihr Anstürmen wider jeden Ort, der mit den Ungläubigen kollaboriert (wörtl. zugunsten der Ungläubigen wacht), fester sein. All dies riefen wir den Versammelten in Erinnerung mit solchen Worten, die ihre Herzen erreichten, zu ihren Seelen gelangten und in ihrem Inneren wirkten (wörtl. sich Unruhe stiftend bewegten). Dann regte sich ihr Zorn zugunsten dessen, wozu man sie aufrief, ihre Kampfbegierde, der Glaubenspraxis Gottes Beistand zu leisten, entbrannte, und ihre Gedanken und Vorsätze ließen sie zu diesem glückhaften Ziel hineilen. Das, was ihnen bei dieser Versammlung vorgebracht wurde, nahmen sie alle auf mit solchem Entgegeneilen, solcher Freude und solchem Versprechen, sich darin anzustrengen (wörtl. die Ärmel hochzukrempeln), auf, dass man hoffen kann, dass Gott - gepriesen sei Er - unsere und ihre Hoffnung in Erfüllung gehen lassen wird, dem Islam beizustehen, Seinem Wort zum Obsieg zu verhelfen, Seine Feinde zu bekriegen, diejenigen zu packen, die sich Gott und Seinem Gesandten durch ihre Abkehr von Seiner Sache widersetzen und dem (wahren) Glauben mit ihrem Polytheismus und ihrem Unglauben zu trotzten suchen. Was die Versammelten betrifft, so waren trotz vieler verschiedener Stämme von Riyāh, zahlreicher Unterstämme dieses Stammesverbandes und trotz der Verzweigtheit seiner Sippen und Familien bei dieser Versammlung all seine Notabeln, seine Verständigen und Ältesten zugegen. Jeder (von ihnen) erzeigte so viel am schönen und edlen Hineilen (zu dem ihnen unterbreiteten Anliegen der Almohaden) und hat sich so sehr beeindrucken lassen zugunsten dieses löblichen Wunsches, der sich $\mathrm{zu}$ euren Gunsten auswirken und euch reichliche Belohnung einbringen wird, dass all dies das Auge erfreute, die Brust mit Behagen und 
das Herz mit froher Nachricht erfüllte. In Eintracht miteinander einigten sie sich darauf, sich in Bewegung $\mathrm{zu}$ setzen in dieser gesegneten Form, bei welcher sie die Verfügungsgewalt über ihren Aufbruch den Almohaden übertrugen, sich dieser großen Bewegung überließen und in diesen löblichen Wunsch einwilligten. Sie einigten sich auch darauf, dass dieser ihr Grenzdienst auf dem Pfade Gottes all das, was sie einst an Auflehnung und Irrtümern verübt, als auch die Spuren ihres unheilbringenden Treibens und ihres Trotzes, die sie ehemals vorgezogen und begangen hatten, ersetzen sollte. Und so setzten sie sich mit Gottes Hilfe in Bewegung. Einige der Wege, die sie dabei beschritten, befanden sich in den Wüsten, andere verliefen der Küste entlang. Dabei schlug jeder Stamm von ihnen solche Wege ein, die sich zum Ort seines Umsiedlungszuges (nach al-Andalus) am nächsten befanden, am bequemsten für diesen Stamm, seine Angehörigen und sein Hab und Gut ${ }^{155}$ waren, sowie auch ihm das höchste Maß (wörtl. am dichtesten waren) an Leichtigkeit und Bewegungsfreiheit auf seinem Marsch boten. Wir gelangten zur Einsicht, dass dies für sie passender und bequemer war, denn anderenfalls hätten sie sich bei ihrem Zug drängen müssen und hätten ihrer gewaltigen Menschenmengen wegen, die alles bedeckten, selbst in dieser sich weit erstreckenden Gegend sich nicht frei fortbewegen können. Sie ließen einige der Ṭālibs und Hāfiẓs ${ }^{156}$ - Gott möge ihnen einen erhabenen Rang gewähren - ihre Begleiter sein, damit diese Aufsicht über die richtige Glaubenspraxis der Stämme führten (wörtl. damit sie ihr Krummes gerade machten) und über die Zahl der Auswandernden wachten. Gott machte dabei ihr Ziel erhaben und ließ Gottesfurcht ihr Reisevorrat sein. Und so legten sie rasch Strecken in den weitläufigen Ebenen zurück, weite Wüsten füllten sich mit ihren Scharen, und sie begannen diesen ihren Umsiedlungszug in einer solchen Weise, die mit den Rechtsschulen im Einklang stand und mit dem Zeremoniell der Pilgerfahrt vereinbar war. Ihre Scharen - Gott möge euch den Erfolg erlangen lassen und euch allen durch Furcht vor Ihm den erhabenen Rang verleihen - sind wahrlich unüberschaubar (wörtl. lassen sich nicht umfassen), übersteigen die mehrfach addierten

\footnotetext{
${ }^{155}$ Im arabischen Text wird an dieser Stelle das Wort „al-māl“, Habe bzw. Besitz, gebraucht. Es werden im Arabischen zwei Arten des Besitzes unterschieden, nämlich „der sprechende Besitz“, mit dem Sklaven und Vieh bezeichnet werden, und „der stumme Besitz“, also Immobilien, Geld usw. Hier meint der Text beide Arten des Besitzes.

${ }^{156}$ Mit der Bezeichnung „Hāfizs“ wurden häufig hochrangige almohadische Funktionäre sowohl in der Verwaltung als auch im Heerwesen bezeichnet (Les Talaba dans la société almohade : (le temps d'Averroès), S. 347 f., al-Muwaḥhịūn fi 'l-Ġarb al-Islāmī, S. 99). Diese Funktionäre sind hier jedoch nicht gemeint. Wie es scheint, hat es zwei Klassen der „Hāfizs“ gegeben: diejenigen, deren Zuständigkeitsbereiche eben umrissen wurden, und andere - niederen Ranges - mit einem nicht näher definierten Aufgabengebiet. Die überlieferte Bezeichnung dieser „Hāfizs““ als „Schüler der Ṭālibs“ (arab.: sigār at-țalaba) - (al-Muwaḥhidūn fi 'l-Ġarb al-Islāmī, S. 100) - sowie die obige Passage des Briefes legen nahe, dass sie Aufgaben wahrgenommen haben, die denen ihrer Meister ähnlich waren.
} 
gewaltigen Mengen und füllen Niederungen und Anhöhen aus. Und ihre in eure Gegenden gelangenden Scharen werden so zahlreich sein, dass der Blick, diese Scharen $\mathrm{zu}$ fassen nicht imstande, matt zu Boden sinken wird, und dass zur Errechnung und Schätzung dieser Scharen der Geist und die Gedanken nicht fähig sein werden, mit Gottes Kraft. Er ist derjenige, der um Hilfe angerufen wird.

Einer derjenigen, die bei dieser glückhaften Versammlung und bei dem neuen Guten zugegen waren, dieser von göttlicher Unterstützung und von Seiner rechten Lenkung behüteten Erwähnung beiwohnten, war Šaih ${ }^{157}$ Abū-Sirḥān Mas'ūd Ibn-Sulțān IbnZimām - Gott möge ihm den erhabenen Rang verleihen. Bei diesen edlen Ansprachen, gesegneten Gesprächen, bei denen man das oben Erwähnte den Versammelten in Erinnerung rief, und bei diesen erhabenen Versammlungen, die alle zu der Gesamtheit der Werke des Glaubens und des Gehorsams gegenüber dem Barmherzigen ${ }^{158}$ zählten, bei alledem äußerte er solche schönen Worte und bezeigte solche schönen Taten, die alle von seiner aufrichtigen Entschlossenheit in allen Lebenslagen zeugten, dass man für seine reuevolle Rückkehr (zu Gott) dankte und seine Selbstaufopferung (für die Sache Gottes) für wahr erachtete. Danach, dem Aufbruch anderer Šaihs der arabischen Stämme folgend, brachen alle auf: er, seine Familienangehörigen, seine Kinder und die Gesamtheit derjenigen seiner Gemeinschaft, seines Stammes und seiner Verwandten, die ihm treu waren und ihr Leben mit dem seinen unauflösbar verbunden sahen (wörtl. die mit seinem Strick verknüpft waren), sowie auch jene, die ihm ergeben waren (wörtl. bei seinem Stehenbleiben stehenblieben und bei seinem Zurückbleiben zurückblieben). Deswegen zog er wie ein durch (Gottes Beistand) Erfolg Erlangender und Glücklicher, Gesegneter und (von Gott) Geleiteter im ersten Zug voran, dem Glückhaften entgegeneilend und sich zum Gehorsam beeilend. Dabei ließen sich seine Augen und seine Einsicht vom Eifer leiten, und der Heilige Krieg für die Sache Gottes durchdrang (wörtl. nahm ganz ein) seine Gedanken. Jeder von diesen arabischen Beduinen hatte ehemals Tadelnswertes (wörtl. hat die Meinung über sich schlecht gemacht) begangen durch Verbrechen und Sünden, die er sich zuschulden kommen ließ und dadurch, dass er sich dem Rufer Gottes feindlich entgegenstellte, als er ihn im Besitz der Einsicht (in das Verborgene) und des Wissens zum Leben rief. Nun bekundete jeder von diesen Beduinen seinen Gehorsam (den Almohaden gegenüber), überließ (den Almohaden) die Verfügungsgewalt über seine Umsiedlung und hoffte, dass sein (Lebens-) Werk den

\footnotetext{
${ }^{157}$ Die Bezeichnung „Šaih““ an dieser Stelle hat die Bedeutung „Oberhaupt eines Beduinenstammes“ und ist nicht mit seinem Homonym, zu dem Näheres in der Fußnote Nr. 68 angegeben wurde, zu verwechseln.

${ }^{158}$ Einer der Namen Gottes im Islam.
} 
Abschluss im Grenzdienst auf dieser Insel findet. Dies taten sie, sich für die Sache Gottes aufopfernd, sich im Gehorsam ihrem Herrn gegenüber anstrengend und damit Gott Gehorsam und Treue schwörend, auf dass Er das von ihnen früher Verübte ausradiere und sich diesem beginnenden Guten zuwende. Sie (alle) freuten sich über diesen Treueschwur, den sie gegenüber Dem getan haben, der den Lohn der Gläubigen nicht verliert. Und so sehen Gott, Gläubige und diejenigen, welche Gott zu Kalifen über die Gläubigen auserwählt hat, ihre Werke.

Nach diesem (durch Gottes Beistand) erfolgreichen Feldzug und nach dieser lauteren Absicht blieb von den arabischen Stämmen keiner in diesen Gebieten, dessen Aufruf, in die westlichen Gebiete zu kommen, und dessen Ankunft dorthin man noch hätte erstreben und ersehnen können. Sie alle zogen von diesen Siedlungsorten ab und überließen sie ihren Bewohnern. Dieser Abzug geschah bis auf einige Sulaim-Stämme, die in den um Tripolis befindlichen Gegenden siedeln sowie auch in den Gebieten in seinem Hinterland, die sich östlich und in die Wüste hinein erstreckend bis Barqa und Alexandria reichen. Es war vor der hier geschilderten Entsendung der Almohaden eine zahlenmäßig beträchtliche Gruppe der Šaihs und Notabeln dieser Stämme bei uns eingetroffen. Ihnen allen hatte man all das in Erinnerung gerufen, was man ihren Brüdern, den Riyāh-Stämmen, in Erinnerung rief. Sie gaben diesbezüglich ihre Versprechen, die sie mit Schwüren bekräftigten. Nachdem sie zu ihren jeweiligen Stämmen zurückgekehrt waren, wandte man sich in mündlicher und schriftlicher Form an sie, man verkündete ihnen die frohe Botschaft und ermahnte sie. Wenn nun diese Ermahnungen sie hellhörig gemacht haben und wenn das von ihnen erfahrene Maß an wohlgesinnter Behandlung und Verkündung der frohen Botschaft, an Drohung und an Warnung sich als genügend dafür erweisen sollte, dass sie das, was sie Gott gelobten, einhalten, so wird man sie anderen gegenüber lobend erwähnen, sie mit ihrer frohen Botschaft direkt ansprechen, und sie werden das Tor beschreiten, welches ihre Brüder beschritten haben, mittels ihrer Schwüre des machtvollen Schutzes Gottes teilhaftig werden, die Berichtigung ihrer Überzeugungen und ihrer Glaubenspraxis erfahren und durch den Heiligen Krieg für die Sache Gottes in ihrem Glauben wachsen. Anderenfalls ist hinter ihnen ein Häscher her, der sein Ziel niemals verfehlt, und ein Packender von den Heerscharen Gottes, der zu Grunde richtet. Und vielleicht wird Gott sie den Weg der Frommen beschreiten lassen und sie rechtleiten, sie vor ihrem Verderben bewahren und an einem Ort vereinigen, der ihre Herzen von Feindseligkeiten und Gewalttaten, die sie ehemals verübt hatten, läutert, mit Gottes Kraft. 
Und auch wenn bei dieser glückhaften und gesegneten Expedition - Gott möge euch den Erfolg erlangen lassen - nichts anderes (mehr) geschehen wäre, als nur das, was an den Begebenheiten mit den arabischen Stämmen erfolgt ist, an ihrem (durch die Almohaden herbeigeführten) Ablassen von diesen Gebieten und (ihrem) Aufbruch zum Heiligen Krieg, zu dem sie geeilt sind, und an der Einwilligung, die sie alle bezeugten mit Seelen, die sich dem Gehorsam zuwandten, mit Gesichtern, die durch die frohe Nachricht ihrer Buße jauchzten, mit Herzen, die dem Guten entgegenflatterten, und mit Absichten, die sich darüber einig waren, dem Aufruf Gottes Genüge zu leisten, so wäre das für sich allein ein großer Beweis dafür, dass der Verstand zum Begreifen dieser ruhmreichen Bewegung sich nicht emporschwingen kann, die Vorstellungskraft zu ihr nicht hinaufzureichen vermag und dass sie sich des Beistandes Gottes erfreut durch das Licht, durch welches das Herz eines jeden erstrahlt, dem Er durch Seinen Beistand zu Seinem Wohlgefallen und zu Seinem Erfolg verholfen hat. Dieser große Beweis wurde bei den arabischen Beduinen erbracht, die sich niemals von einem Anführer hatten leiten lassen und sich von ihren Bezwingern nur mühsam beherrschen ließen (wörtl. in der Hand ihres Bezwingers nicht weich waren), indem sie ihren Anwandlungen folgten, sich von ihrem Hochmut leiten ließen, gegenüber ihrem Schöpfer hochmütig waren und all das verschmähten, was sie als für ihre Würde herabmindernd wähnten. Die Vergegenwärtigung ${ }^{159}$ des Propheten - das vollkommene Gebet und der Friedensgruß seien ihm - ließ jetzt ihre Herzen zugunsten dieser erhabenen Bewegung so sehr erweichen, dass sie sich ihr unterordneten und ergaben (wörtl. die Schlüssel des Sichüberlassens und des Sichergebens zu ihr warfen), und (diese Vergegenwärtigung) bewirkte, dass ihre Widerspenstigkeit gegenüber dieser erhabenen Bewegung schwand und ihre Köpfe (wörtl. Nacken) sich vor ihr (demütig) neigten. Nun leisteten sie der wahren Glaubenspraxis Gottes Beistand, bis sie wiederhergestellt (wörtl. an ihrem Ursprung fest stand) war, warfen auf das Unwahre und den Unglauben diejenigen, die der Wahrheit entbehrten, und ließen sich von der Sache Gottes, Seinem Gesandten und Seinem Buch leiten. Danach warfen sie diejenigen, die das Wahre für unwahr erklärten, auf die (richtige) Auslegung (Seines Buches), bis sie dem Unwahren (auf diese Weise) solche Schäden zufügten, dass es sich verzog. Sie bedrängten auch hart diejenigen, die

\footnotetext{
${ }^{159}$ Mit dem Satz an dieser Stelle (Mağmū` rasā’il muwaḥhidīya, S. 157) „fa-alāna qulūbahum al-ān lihad̄ā al-amr al-`aẓìm [...] min al-inhā’ li-rasūlihī [...]“, der wörtl. „Und es hat ihre Herzen erweichen lassen [...] einiges des Gelangenlassens zu Seinem Propheten [...]“ heißt, kann auch gemeint sein, dass die angeblich auf al-Ḥasan, den ältesten Sohn von 'Alī Ibn-Abī-Ṭālib, zurückgehende Abstammung Muhammad Ibn-Tümarts und 'Abd-al-Mu'mins (siehe hierzu Kap. 3.5.) den arabischen Beduinen in Erinnerung gerufen wurde.
} 
ehemals Unrecht begingen. Wir unsererseits hoffen, dass Gott ihre Herzen mit dem Licht dieser erhabenen Sache erstrahlen lässt, auf dass sie ihr jetzt Beistand leisten, so wie sie es einst taten, und damit sie ihren erhabenen Rang vollkommen machen. Und demjenigen, der sein Versprechen gegenüber Gott erfüllt, werden wir großen Lohn darreichen.

Diese frohe Nachricht haben wir zu euch - Gott möge euch den Erfolg erlangen lassen und euch durch die Furcht Ihm gegenüber auszeichnen - schleunigst gelangen lassen, damit ihr wisst, dass unsere Gedanken immer euch gelten, dass uns an den Begebenheiten in diesen Gebieten (in Ifrīqìya) nichts von euren Gegenden ablenkt, und dass ihr so viel an (unserer) Fürsorge erfahrt, dass dies eure Wünsche in Erfüllung gehen lässt. Also verkündet diese frohe Nachricht - Gott möge euch den Erfolg erlangen lassen - in euren Landstrichen, macht sie zum Gegenstand eurer (innigsten) Gedanken und eurer Gespräche und macht die Danksagungen an Gott für das, womit Er euch durch diese Nachricht beschenkt hat, zum Anlass für eure Versammlungen und Zusammenkünfte. Und Gott wird euch dann das an Seiner Gnade und Güte erfahren lassen, was sich auf eure Gesamtheit erstreckt und euren Aufenthaltsort erhaben macht. Es gibt keinen Gott außer Ihm. Er ist unsere Genüge und wunderbarer Sachwalter. Der Frieden, Gottes Gnade und Seine Segen mögen euch zuteil werden.

Abgefasst am 4. März 1181.

\subsection{Historischer Kontext}

Der normannische König von Sizilien Roger II. (1102-1154) zeigte seit seinem Herrschaftsantritt im Jahre 1112 ein reges Interesse an Nordafrika bzw. an dessen Küstenstädten. Einerseits ging es ihm um die Sicherung des einträglichen Mittelmeerhandels, den die nordafrikanischen Piraten von ihren Stützpunkten an der Küste Ifrīqīyas aus erheblich störten, und andererseits um die Kontrolle des aus Sudan kommenden Goldes, mit welchem die Nordafrikaner die aus Sizilien importierten Nahrungsprodukte (z.B. Hartweizen, Pökelfleisch, Käse), Holz und Pech für den Schiffbau bezahlten. Nach langwierigen Militäraktionen, deren Folge u. a. die Flucht des ziridischen Herrschers aus al-Mahdiya war $^{160}$, gelang es Roger II. schließlich, bis 1148 die Küstenstädte Ifrīqīyas von Tripolis bis Ra’s aṭ-Ṭīb unter seine Botmäßigkeit zu zwingen. Die eroberten Städte erhielten eine gewisse Autonomie: abgesehen von der Verpflichtung, die Kopfsteuer (arab.: al-ğizya) und die Grundsteuer (arab.: al-harāg) an 
die normannische Obrigkeit zu enrichten, durfte die muslimische Bevölkerung auch weiterhin ihre Religion ausüben, ihr wurde weitgehende Selbstverwaltung eingeräumt und sie behielt die islamische Rechtsprechung. Im Jahr 1154 starb Roger II., und seine Nachfolge trat sein Sohn Guillaume I. an. Kurze Zeit nach seinem Herrschaftsantritt kam es zu Aufständen in den eroberten Küstenstädten Ifrīqīyas. Diese wurden wahrscheinlich durch wachsende Spannungen zwischen den christlich-normannischen Gouverneuren bzw. Garnisonen und der moslemischen Bevölkerung ausgelöst, die sich einerseits daraus ergaben, dass die Haltung dieser Garnisonen gegenüber Muslimen immer härter wurde, und andererseits aus den Versuchen - zumindest in einem dokumentierten Fall ${ }^{161}$ - , auf die religiösen Belange der Muslime Einfluss zu nehmen. Die erste Stadt, in der 1156 die christlichen Garnison und Bevölkerung massakriert wurden, und welche damit zum Fanal für die Rebellion gegen die christlichnormannische Präsenz in Ifrīqīya wurde, war Sfax. Einige Zeit später kam es zu einem Aufstand in der Stadt Zawīla, deren Bewohner, unterstützt von arabischen Beduinen und einigen Bewohnern von Sfax, al-Mahdiya belagerten. Guillaume I. schickte Verstärkung, und bei einem Ausfall der Belagerten wurden die Aufständischen in die Flucht geschlagen. Die Bewohner von Zawīla, von ihren Verbündeten, arabischen Beduinen und den Helfern aus Sfax, im Stich gelassen, wurden vor den Toren ihrer Stadt von den christlichen Truppen niedergemetzelt. Wenig später bemächtigten sich diese Truppen auch der Stadt selbst, wo sie ein Blutbad anrichteten. Eine kleine Gruppe der Bewohner von Zawīla soll dieses Massaker überlebt haben und zu 'Abd-al-Mu'min nach Marrakech geflohen sein ${ }^{162}$. Weitere Aufstände folgten in Gabès, angeführt von Muhammad Ibn-Rušaid, und in Tripolis 1159, angeführt von Abū-Yahyā Ibn-Matrūḥ. Was Tūnis betrifft, so scheint der Herrscher über diese Stadt, 'Abdallāh Ibn-Hurasān, seine Unabhängigkeit bereits gegenüber Roger II. behauptet haben zu können ${ }^{163}$. Am Vorabend der almohadischen Unterwerfung Ifrīqīyas im Jahre 1159/60 befanden sich unter der normannischen Herrschaft lediglich die Städte al-Mahdiya, Zawīla und Sousse.

\footnotetext{
${ }^{160} \mathrm{Zu}$ einzelnen Etappen des normannischen Ausgreifens nach Ifrīqìya siehe „La Berberie orientale sous les Zirides“ (Bd. 1, S. 334 ff.)

161 at-Tiğānī berichtet darüber, dass die christliche Garnison von Tripolis aus Furcht davor, die Bewohnerschaft dieser Stadt könnte mit den Almohaden Fühlung aufnehmen, die Schmähung der Almohaden in den Moscheen dieser Stadt angeordnet habe. Diese Einmischung habe dann zur Rebellion der Bewohnerschaft gegen die in der Stadt befindlichen Christen geführt (Riḥlat at-Tiğānī, S. 242).

162 al-Kāmil, Bd. 9, S. 48.

${ }^{163}$ La Berbérie Orientale, Tome 1, S. 378.
} 
Wie erinnerlich führte der almohadische Feldzug in den Zentralen Maghreb im Jahr 1152 zur Zerschlagung des ḥammādidischen Königreiches und betraf das Gebiet von Ifrīqīya vorerst nicht. Im Jahre 1159/60 erfolgte dann eine weitere militärische Unternehmung der Almohaden, deren Ziel diesmal Ifrīqīya bildete. Die erste Stadt, die von den Almohaden belagert wurde, war Tūnis. Nach der Einnahme von Tūnis brach das almohadische Heer in Richtung al-Mahdiya auf, welche nach mehrmonatiger Belagerung im Januar 1160 kapitulierte. Die lokalen Herrscher der Städte Sfax, Sousse und Tripolis trafen bei 'Abd-al-Mu'min ein und unterwarfen sich ihm freiwillig. Andere Städte Ifrīqīyas scheinen von anderen almohadischen Truppenkontingenten, die der Sohn des genannten Befehlshabers der Gläubigen 'Abdallāh anführte, noch während der Belagerung al-Mahdiyas bezwungen worden zu sein ${ }^{164}$.

In folgender Weise berichtet Ibn-al-Atīr über den Versuch 'Abd-al-Mu'mins, die arabischen Stämme dieser Landstriche für den Dschihad in Maghreb und al-Andalus zu gewinnen: „Als 'Abd-al-Mu'min al-Mahdiya erobert hatte und nach Maghreb zurückzukehren gedachte, versammelte er die Anführer der arabischen Beduinenstämme von den Banū-Riyāḥ, die in Ifrīqīya siedelten, und sagte zu ihnen: ,Es obliegt uns wieder, dem Islam Beistand zu leisten, denn das Unwesen der Polytheisten (gemeint sind hier die christlichen Königreiche) in al-Andalus hat bedrohliche Maße angenommen, und sie haben sich zahlreicher Städte dort bemächtigt, die sich einst unter der Herrschaft der Muslime befunden hatten. Niemand vermag sie so zu bekämpfen, wie ihr sie bekämpft. Durch euch wurden die Länder bei der Ausbreitung des Islam erobert und durch euch sollen die Feinde in al-Andalus jetzt abgewehrt werden. Wir wollen von euch zehntausend tapfere und mutige Reiter, die um der Sache Gottes willen die Ungläubigen bekriegen. ' Die Versammelten antworteten: „Hören und Gehorchen!‘ Diese Antwort ließ er (d. h. 'Abd-al-Mu'min) durch ihren Schwur bei Gott - gepriesen sei Er - bekräftigen, den sie auf den Koran leisteten." ${ }^{165}$ Weiter berichtet Ibn-al-Atīr, dass ausser dem Stammesoberhaupt namens Yūsuf Ibn-Mālik samt seinem Stamm alle anderen arabischen Stämme hinsichtlich der Absichten 'Abd-al-Mu'mins misstrauisch geworden waren. Sie hätten ihn deswegen auf dem Rückweg nach Maghreb nachts verlassen und seien zu ihren jeweiligen Stämmen zurück geflohen. 'Abd-al-Mu'min habe seinen Weg nach Maghreb fortgesetzt und sich in einem Tal nahe Constantine in den Hinterhalt gelegt. Als die geflohenen Beduinen in der Gewißheit, 'Abd-al-Mu'min sei samt der almohadischen Armee nach Maghreb weitergezogen, nach einiger Zeit zu

${ }^{164}$ La Berbérie Orientale, Tome 1, S. 399. 
ihren Siedlungsorten zurückgekehrt seien, hätten sie die almohadischen Eliteeinheiten bei nahe Kairuan gelegenem Ğabal al-Qarn überrumpelt und aufgerieben. Einer der Anführer der arabischen Stämme, die dem Gemetzel bei Ğabal al-Qarn mit knapper Not entronnen seien, sei Mas`ūd Ibn-Zimām al-Ballāt gewesen ${ }^{166}$.

Doch auch nach der almohadischen Unterwerfung und der grausamen Bestrafung ${ }^{167}$ einiger arabischer Stämme blieb Ifrīqīya aufgrund ihrer geographischen Entfernung vom Zentrum der almohadischen Macht und der sich daraus ergebenden Unfähigkeit der almohadischen Herrscher, auf immer wieder aufflackernde antialmohadische Aufstände schnell zu reagieren, ein Gebiet, das sich schwierig kontrollieren ließ. Aus den wiederholten almohadischen Feldzügen nach Ifrīqīya kann man schließen, dass die in dieser Region stationierten almohadischen Kontingente nicht zahlreich genug waren, um die Rebellion in Gafsa im Jahre 1180 niederzuschlagen oder den Überfall der auf Mallorca verbliebenen Almoraviden auf Biğāya im Jahre 1184 abzuwehren. Die arabischen Stämme Ifrīqīyas, die sich keiner Autorität zu unterwerfen bereit waren, stellten einen Faktor dar, der dieses Gebiet erheblich schwächte. Sie schlugen sich buchstäblich auf die Seite jedes Aufständischen, der sich gegen die bestehende Autorität auflehnte und ihnen die Möglichkeit bot, an Plünderungszügen teilzunehmen. 'Abd-alMu'min und seine Nachfolger versuchten, diesen Faktor in den Äußersten Maghreb zu verlegen, wo sie diese arabischen Stämme besser kontrollieren und sie bei den almohadischen Unternehmungen in al-Andalus wirksamer einsetzen zu können hofften.

3.3. „Ihr [...] habt bereits erfahren, was in dieser gesegneten Gegend an erhabenen Ereignissen und ruhmreichen Siegen ermöglicht wurde $[\ldots]^{\text {“ }}$

Mit diesen Ereignissen ist die Expedition der Almohaden nach Ifrīqīya gemeint, die im Jahre 1180/81 durchgeführt wurde. Diese Unternehmung, die zur Niederwerfung der

165 al-Kāmil, Bd. 9, S. 65.

166 al-Kāmil, Bd. 9, S. 65. Huici-Miranda (Historia política del imperio almohade, Bd. 1, S. 195) hält den angeführten Bericht Ibn-al-Atīrs für eine Legende, und tatsächlich finden sich seltsamerweise in ,,alMann bi-'1-imāma”, ,,al-Bayān al-muġrib”, ,,al-Mu'ğib“, „,Riḥlat at-Tiğānī“, ,al-Anīs al-muțib“, ,,al-Hulal al-maušīya“ und „al-Mu’nis fī-ahbār Ifrīqīya wa-Tūnis“ keinerlei Angaben über diese Begebenheit. Dennoch muss der Bericht Ibn-al-Atīrs einen wahren Kern enthalten, denn der almohadische Brief Nr. 21 (Mağmū` rasā’il muwaḥhidīya, S. 113-121) berichtet schwülstig und von vielen Andeutungen durchwebt über die Ausmerzung des Stammesverbandes Banū-Riyāh sowie die Auswanderung des Stammes BanūMuhammad samt seinem Oberhaupt Abū-Yaq'ūb Yūsuf Ibn-Mālik nach dem Äußersten Maghreb, und wird erst vor dem Hintergrund des Berichtes von Ibn-al-Atīr verständlich. Ibn-Haldūn zufolge, habe 'Abd-al-Mu'min nach der Unterwerfung Ifrīqīyas auf dem Weg nach Maghreb davon erfahren, dass die arabischen Stämme ihm den Gehorsam aufgesagt hätten, daraufhin habe er ein almohadisches Kontingent entsandt, welches diese arabischen Beduinen in der Nähe von Kairuan vernichtend geschlagen habe (Kitāb al-ibar, Bd. 6, S. 494).

${ }^{167}$ Nach dieser verlustreichen Schlacht wurden die Leichen der gefallenen Beduinen zu einem riesigen Berg aufgetürmt, der noch lange Zeit danach weithin sichtbar war (al-Kāmil, Bd. 9, S. 65). 
Rebellion in der Stadt Gafsa erfolgte, leitete einer der Söhne und der spätere Nachfolger 'Abd-al-Mu'mins, Abū-Ya'qūb Yūsuf (1163-1184). 'Abd-al-Wāḥid al-Marrākušī berichtet wie folgt über diesen Aufstand: „Am Anfang des Jahres (5)75 H. (1180) verließ Abū-Yacqūb Marrakech und zog nach Ifrīqīya gegen die Stadt Gafsa. Denn es begehrte in ihr ein Mann namens 'Alī Ibn-ar-Rand ${ }^{168}$ (gegen die Almohaden) auf, welcher sich den Ehrentitel an-Nāṣir li-Dīn an-Nabī (d. h. derjenige, welcher der Glaubenspraxis Mohammeds zum Obsieg verhilft) zugelegt hatte. Abū-Ya'qūb und die Almohaden belagerten und besiegten ihn. So bereiteten sie diesem Aufstand ein Ende und schlugen ihn nieder." ${ }^{\text {(169 }}$ Aus diesem Bericht geht nicht klar hervor, warum es zu diesem Aufstand kam, und die ganze Unternehmung nach Ifrīqīya wird bei diesem Autor mit dieser kurzen Bemerkung zusammengefasst. Eine aufschlussreichere Darstellung der Gründe dieser Erhebung findet man indes bei Ibn-Hualdūn. Ihm zufolge ernannte 'Abd-al-Mu'min nach der Unterwerfung Ifrīqīyas im Jahr 1160 einen almohadischen Gouverneur über Gafsa. Aus nicht weiter erklärten Gründen habe ihn jedoch dieser almohadische Kalif bereits nach drei Tagen abgesetzt und einen anderen Almohaden mit diesem Amt betraut, den er später ebenfalls der Statthalterschaft über Gafsa zugunsten eines gewissen 'Umrān Ibn-Mūsa aṣ-Ṣanhāḡī entkleidet habe. Der Letztere habe seine Untertanen jedoch so schlecht behandelt, dass sie jemanden nach Biğāya zu 'Alī Ibn-al-'Azīz Ibn-al-Mu'tazz, einem Nachkommen der ehemaligen Herrscherdynastie in Gafsa, geschickt und zusammen mit ihm gegen den almohadischen Statthalter rebelliert hätten. Als dieser umgebracht worden sei, habe man den erwähnten 'Alī zum Herrscher über Gafsa ernannt, der seine Besitzungen gut verwaltet und die Untertanen beschützt habe. Daraufhin habe Yūsuf Ibn-'Abd-al-Mu'min im Jahre 563 H. (1168 n. Chr. ${ }^{170}$ ) seinen Bruder Abū-Zakarīya einen Feldzug gegen diesen Herrscher durchführen lassen, in dessen Verlaufe 'Alī besiegt und samt seinen Familienangehörigen nach Marrakech gebracht worden sei. Dort sei die Dynastie der Banu-'r-Rand erloschen ${ }^{171}$.

Es findet sich bei Ibn-Hुaldūn an einer anderen Stelle seines Werkes ein weiterer Bericht über diese Ereignisse in Gafsa, der einige ehebliche Abweichungen zum eben

\footnotetext{
${ }^{168}$ Nach Darstellung in Kitāb al-ibar, Bd. 6, S. 338 f., soll beim Einfall der arabischen Beduinenstämme im 11. Jh. in Ifrīqīya ein gewisser 'Abdallāh Ibn-Muhammad Ibn-ar-Rand ziridischer Statthalter von Gafsa gewesen sein, der sich später für unabhängig erklärt habe. Er und seine Nachkommen sollen Gafsa bis zur almohadischen Unterwerfung Ifrīqīyas im Jahr 1160 regiert haben. Der letzte Herrscher der Dynastie Banu-'r-Rand ist demnach nach dessen Absetzung nach Biğāya gebracht worden, wo er verstorben ist.

${ }^{169}$ al-Mu ğ ğib, S. 252.

${ }^{170}$ Es handelt sich bei diesem Datum im Bericht um einen zu korregierenden Fehler.
} 
angeführten Abschnitt aufweist: „Und wie wir bereits bei der Behandlung der Banu-'rRand erwähnt haben (d. h. im eben zitierten Bericht), griff im Jahre (5)75 H. (1179 n. Chr.) 'Alī Ibn-al-Mu'izz [sic], genannt at-Ṭawīl, ein Nachkomme der Banu-'r-Rand, welche einst die Herrscher von Gafsa waren, zu den Waffen. Als der (almohadische) Kalif (d. h. Yūsuf Ibn-'Abd-al-Mu'min) Kenntnis davon bekam, brach er von Marrakech auf und schlug den Weg zu ihm ein.“" ${ }^{172} \mathrm{Da}$ andere Quellen bestätigen, dass der Herrscher von Gafsa nach der Expedition von 1180 nach Marrakech gebracht wurde und dass sein Beiname at-Ṭawīl war ${ }^{173}$, kann man mit großer Wahrscheinlichkeit annehmen, dass Ibn-Hुaldūn in seinen beiden Berichten den selben Aufständischen meint. Es ist allerdings seltsam, dass sich dieser Historiograph in solch offensichtlicher Weise beim Namen desjenigen, der diesen Aufstand niederschlug, beim Namen des Aufständischen sowie bei der Datierung der almohadischen Unternehmung widerspricht. Die antialmohadische Erhebung in Gafsa, die darauf folgende Ernennung 'Alī Ibn-ar-Rands von der Bewohnerschaft dieser Stadt zu ihrem Herrscher, das Jahr 1180 als Datum der almohadischen Unternehmung gegen Gafsa unter der Leitung Yūsuf Ibn-'Abd-al-Mu'mins und die Umsiedlung 'Alīs in den Maghreb werden ebenfalls in „Kitāb al-istibṣār fī 'ağā'ib al-amṣār“ erwähnt ${ }^{174}$.

In „Mağmū'a ğadīda“ sind zwei almohadische Briefe, nämlich Nr. 30 und Nr. 31, überliefert, welche sowohl von der Revolte in Gafsa als auch von deren Niederschlagung handeln ${ }^{175}$. Obgleich weite Passagen dieser beiden Schreiben sehr allgemein und pathetisch sind, schildern sie jedoch - tendenziell - ausführlich den Ablauf der Bezwingung Gafsas. Folgender Hergang der Ereignisse lässt sich ihnen entnehmen: Die Bewohner von Gafsa, geblendet von der Festigkeit und Uneinnehmbarkeit ihrer Stadt, ziehen die Missleitung dem wahren Glauben vor (d. h. werden den Almohaden unbotmäßig), was das militärische Durchgreifen der Almohaden nach sich zieht. Die almohadische Armee gelangt zuerst nach Kairuan, und es wird an die Rebellen der Aufruf übermittelt, von ihrem Treiben Abstand zu nehmen, welchen sie jedoch missachten. Nach der Umzingelung der Stadt werden die Kriegsmaschinen zusammen gebaut, mit welchen die Almohaden die Stadt unter Beschuss nehmen. Beim nachfolgenden Gefecht zerstören diese teilweise die vor den

\footnotetext{
${ }^{171}$ Kitāb al-ibar, Bd. 6, S. 339 f.

${ }^{172}$ Kitāb al-cibar, Bd. 6, S. 502.

${ }^{173}$ Tā'rīh ad-daulatain, S. 14, al-Bayān al-muġrib, S. 141. Eine Ausnahme bildet dabei der Bericht in alAnīs al-muțib (S. 278), demzufolge Abū-Ya'qūb Yūsuf diesen Aufständischen getötet habe.

${ }^{174}$ Kitāb al-istibșār fī 'ağā'ib al-amșār, S. 151.

${ }^{175}$ Mağmū'a ğadīda, Bd. 1, S. 144-161.
} 
Mauern Gafsas befindliche niedrigere Mauer (arab.: as-sitāra), und diese Kampfhandlungen werden von den Nivellierungsarbeiten am Stadtgraben begleitet, die den almohadischen Kämpfern den Zugang zur Stadtmauer verschaffen. Zur Erstürmung der Stadt kommt es allerdings nicht mehr, da die Bewohner weiteren Widerstand aufgeben und mittels einer Abordnung darum bitten, sie $\mathrm{zu}$ verschonen. Der almohadische Kalif entspricht dieser Bitte. Beide Briefe schließen mit der Beschreibung der außerordentlichen Uneinnehmbarkeit Gafsas und ihrer vielfältigen Vorzüge.

Bei Ibn-al-Atīir findet sich auch eine detaillierte und aufschlussreiche Beschreibung dieser Einnahme Gafsas. Demnach hat 'Alī Ibn-al-Mu'izz Ibn-al-Mu'tazz, den dieser Autor irrtümlicherweise für den almohadischen Statthalter von Gafsa hält, gesehen, dass die „Türken“ einige Gebiete Ifrīqīyas in ihre Gewalt gebracht und großen Zulauf seitens der arabischen Beduinenstämme hatten. Dies habe ihn dazu verleitet, nach alleiniger Herrschaft zu streben. Zusammen mit den Bewohnern Gafsas habe er die in dieser Stadt befindlichen Almohaden im Jahr 1177 umgebracht. Der almohadische Statthalter von Biğāya habe Yūsuf Ibn-'Abd-al-Mu'min daraufhin über die ins Wanken geratene Ordnung in Ifrīqīya, darüber, dass sich viele arabische Beduinen Qarāqūš anschlössen, sowie über die Rebellion in Gafsa in Kenntnis gesetzt. Dieser sei dann mit dem almohadischen Heer im Jahr 1180 zu Befriedung Ifrīqīyas aufgebrochen. Nach dreimonatiger Belagerung Gafsas habe sich 'Alī Ibn-al-Mu'izz Ibn-al-Mu'tazz ergeben und sei nach Maghreb umgesiedelt worden ${ }^{176}$. Was die Bezeichnung „Türken“ betrifft, so sei hier beiläufig nur soviel gesagt, dass Ibn-al-Atīr damit asiatische Söldner meint, die im letzten Drittel des zwölften Jahrhunderts aus Ägypten in das Gebiet des heutigen Libyens gelangten, sich dort einiger seiner Teile bemächtigten, und später in Ifrīqīya einfielen. Es wird noch in den nächsten Kapiteln zu ermitteln sein, wann genau diese genannte Gruppe in der politischen Geschichte Ifrīqīyas in Erscheinung getreten ist.

3.4. „Man machte ihnen kund, dass das, was man sich von ihnen (leidenschaftlich) wünscht, der Feldzug gegen die Christen in al-Andalus [...] ist.“

Der Kampf gegen die Ungläubigen, der Dschihad, bildete einen der Grundpfeiler der almohadischen Propaganda. Am Anfang der almohadischen Bewegung war dieser Krieg nicht nur gegen die Ungläubigen, sondern auch insbesondere gegen die Almoraviden Pflicht der Almohaden ${ }^{177}$. Nach dem Sieg über die Almoraviden meinte man mit Dschihad speziell den bewaffneten Kampf gegen die christlichen Königreiche in al-

${ }^{176}$ al-Kāmil, Bd. 9, S. 151-152. 
Andalus. Wie man aus den zeitgenössischen Quellen jener Zeit ersehen kann, büsste der Begriff ,ğihād“ nichts an seiner anfänglichen Aktualität ein. Dies zeigt in sehr anschaulicher Weise ein Bericht 'Abd-al-Wāhid al-Marrākušīs, in welchem die Vorbereitungen der Almohaden für einen Feldzug zur Wiedereroberung der Stadt Santarem beschrieben werden, bei dem der almohadische Kalif Yūsuf Ibn-'Abd-alMu'min den Tod finden sollte: „Als der Befehlshaber der Gläubigen die (almohadische) Armee für den Feldzug gegen die Christen gerüstet hatte, gab er den Religionsgelehrten die Anordnung, Prophetenaussprüche zum Thema „Dschihad“ zu sammeln, welche anschließend den Almohaden diktiert und von den ihnen memoriert werden sollten. Und so entstand diese ihre Gewohnheit, die bis zum heutigen Tage fortbesteht ${ }^{178}$. [...] Er persönlich (d. h. Abū-Yáqūb Yūsuf) diktierte diese Aussprüche den Menschen. Jeder der Almohaden und der Saiyids ${ }^{179}$ kam mit seiner eigenen Tafel, auf welcher er das Diktierte aufschrieb. “180 Obwohl die almohadische Herrschaft bis zum Jahr 1172 auf die Gesamtheit der Gebiete von al-Andalus ausgedehnt werden konnte, war die Gefahr, welche von den christlichen Königreichen der Iberischen Halbinsel ausging, immer gegenwärtig. Die christlichen Herrscher von Leon, Kastilien, Portugal und Aragon führten unabhängig voneinander militärische Unternehmungen ins muslimische Gebiet durch und machten so die ständige Präsenz von größeren almohadischen Kontingenten zum Schutze dieser Gebiete unerlässlich. Um dieser Gefahr entgegenzuwirken, unternahmen die almohadischen Herrscher ihrerseits Kriegszüge ins christliche Gebiet. Die militärischen Erfolge der Almohaden, die dabei erzielt wurden, waren allerdings von beschränkter Dauer. Denn die territoriale Nähe ermöglichte es den christlichen Herrschern, erneute Einfälle in das almohadische Gebiet zu unternehmen und dadurch die almohadischen Erfolge schon nach kurzer Zeit wieder rückgängig zu machen. Das Muster der almohadischen Siege auf der einen Seite, die eine immense logistische und finanzielle Herausforderung bedeuteten, und ihrer begrenzten Wirkung auf der anderen, lässt sich auch in Ifrīqīya verfolgen, wobei es dort, bedingt durch eine weitaus größere Entfernung vom almohadischen Machtzentrum, gefährlichere und für diese Region letztlich unheilvollere Züge hatte. So hatten die im Jahr 1184 gegen 'Alī Ibn-Ġānīya und im Jahr 1187 gegen 'Alī Ibn-Ġānīya und Qarāqūš unternommenen almohadischen

\footnotetext{
${ }^{177}$ Vgl. die Ausführungen diesbezüglich in „Kitāb ahbār al-mahdī Ibn-Tūmart“ (S. 9).

178 'Abd al-Wāhị al-Marrākušĩ schrieb sein Werk im Jahr 1224 nieder.

${ }^{179}$ Mit der Bezeichnung „Saiyid“ meinte man die männlichen Nachkommen von 'Abd-al-Mu'min, die als Statthalter über die Städte des almohadischen Reiches eingesetzt wurden (Les Talaba dans la société almohade : (le temps d'Averroès, S. 346).

${ }^{180} \mathrm{al}-\mathrm{Mu}$ '̆ğib, S. $254 \mathrm{f}$.
} 
Expeditionen zwar zu entscheidenden Siegen auf dem Schlachtfeld geführt, jedoch konnten diese beiden Anführer ihre Aktivitäten fast unmittelbar nach dem Abzug der almohadischen Truppen wieder aufnehmen, was die bei diesen almohadischen Unternehmungen erzielten Erfolge rasch wieder zunichte machte. Bezüglich der Zahlen von christlichen oder almohadischen Armeen bei den militärischen Auseinandersetzungen in al-Andalus lässt feststellen, dass sie von den zeitgenössischen Geschichtsschreibern beider Lager meistens tendenziös übertrieben sind. Huici Miranda könnte jedoch damit Recht haben, dass ,nur die numerische Überlegenheit und die Aufrollung des christlichen Heeres von hinten es den Almoraviden und den Almohaden ermöglicht haben, ihre sterilen und spektakulären Siege davon zu tragen." ${ }^{181}$ In den Zusammenhang dieser almohadischen Bemühungen um al-Andalus ${ }^{182}$ ist auch die an die arabischen Stämme Ifrīqīyas gerichtete Aufforderung, in den Maghreb umzusiedeln, einzuordnen. Dieser Einladung lagen zu Grunde einerseits „das Streben der almohadischen Befehlshaber der Gläubigen, ihren Besitz in al-Andalus zu sichern“ ${ }^{\text {183, }}$ und andererseits die Vorstellung, sie dort besser kontrollieren zu können und gleichzeitig Ifrīqīya von dem potentiellen Unruheferment zu befreien. Ibn-al-Atīr zufolge hat 'Abd-al-Mu'min schon nach der Unterwerfung Ifrīqīyas die arabischen Stämme aufgefordert, mit ihm zehntausend Reiter zum Beistand des Islam und zur Bekämpfung der Ungläubigen nach dem Äußersten Maghreb mitziehen zu lassen. Nach anfänglicher Einwilligung in diesen Aufruf hätten jedoch die meisten dieser Stämme nachts den almohadishen Zug verlassen und seien dafür in der Schlacht bei Ğabal alQarn bestraft worden ${ }^{184}$. Selbst wenn der bei diesem Autor überlieferte Wortlaut dieser

\footnotetext{
${ }^{181}$ Las grandes batallas de Reconquista durante las invasiones africanas (Almoravides, Almohades y Benimerines), S. 11.

${ }^{182}$ Welchen Stellenwert al-Andalus für die almohadischen Herrscher hatte und welch großes Interesse sie diesem Landstrich beimaßen, bringt am besten die Rede des dritten almohadischen Herrschers al-Manșūr zum Ausdruck, welche er unmittelbar vor seinem Tod hielt und welche verschiedene Empfehlungen an die Almohaden enthält. So habe al-Manșūr u. a. die Almohaden ermahnt, sich um die Waisen und um die Waise zu kümmern. Auf die Frage, wer damit gemeint sei, habe er geantwortet: „Die Waise ist alAndalus und die Waisen sind dessen Bewohner, [die dort ansässigen] Muslime. Hütet euch davor, das zu vernachlässigen, was für al-Andalus förderlich ist, nämlich seine Mauern instand zu halten, seine Grenzstädte zu beschützen, seine Kämpfer durch Kriegsübungen zu ertüchtigen und die Zahl seiner muslimischen Bewohner zu mehren. Wisset - Gott möge euch Mächtigkeit verleihen - , dass uns keine andere Sorge mehr beschäftigt als die Sorge um al-Andalus, und al-Andalus vertrauen wir jetzt Gott und eurer Obhut an.“ (al-Bayān al-muġrib, S. 231 f.) In dieser Rede al-Manșūrs sind neben allgemeinen Empfehlungen religiösen Charakters auch solche enthalten, die bestimmten Personen gelten bzw. Personenegruppen wie etwa den „ğuzz“, Țālibs oder den arabischen Beduinen. Dabei wird außer alAndalus kein anderer Landstrich erwähnt, dem die Almohaden hätten noch ihre Aufmerksamkeit widmen sollen. Interessanterweise wird in ,,al-Ḥulal al-maušīya“ (S. 160) die obige Rede al-Manșūrs auf den alAndalus betreffenden Teil gekürzt, der von einigen unwesentlichen Abweichungen abgesehen mit der angeführten Passage aus ,,al-Bayān al-muġrib“ übereinstimmt.

${ }^{183}$ Aportación de los árabes nómadas a la organización del ejército almohade, S. 396.

${ }^{184}$ Siehe hierzu das Kapitel 3.2.
} 
Aufforderung 'Abd-al-Mu'mins anders gewesen sein mag, so kann man daraus ersehen, dass die angestrebte Auswanderung arabischer Stämme in den Maghreb damit begründet und rechtfertigt wurde, den Dschihad gegen die Ungläubigen zu führen und dadurch ihrem „Unwesen“ Einhalt zu gebieten. Die sanfte und nachsichtige Behandlung der arabischen Stämme Ifrīqīyas, die Förderung ihrer Umsiedlung in den Maghreb und ihre Eingliederung in das almohadische Heer wurden auch von den Nachfolgern 'Abdal-Mu'mins fortgesetzt. Am besten gibt diese Politik der almohadischen Herrscher gegenüber den arabischen Stämmen Ifrīqīyas die Empfehlung des dritten almohadischen Kalifen Abū-Yūsuf Ya'qūb al-Manșūr (1184 - 1199) wieder, die er kurz vor seinem Tod den Almohaden gegeben haben soll: „Was die arabischen Beduinen betrifft, so seid umgänglich mit ihnen und geht mit ihnen sanft um. Behandelt sie gütig, und wenn jemand von ihnen zu euch kommt, so beschenkt ihn reichlich und behandelt ihn mit äußerster Güte. Beteiligt sie an euren militärischen Unternehmungen und lasset sie nicht in Muße weilen noch ruhen. “ ${ }^{185}$ Der letzte Satz ist dabei informativ und ermahnend zugleich, denn er bestätigt den bereits in der Aufforderung 'Abd-al-Mu'mins formulierten eigentlichen Zweck des erwünschten Aufenthaltes der arabischen Stämme im Äußersten Maghreb und warnt davor, sie untätig sein zu lassen.

Obwohl konkrete Zahlen über die in Maghreb eintreffenden arabischen Beduinenstämme fehlen, kann man sich trotzdem eine ungefähre Vorstellung vom zahlenmäßigen Anteil arabischer Beduinen am almohadischen Heer verschaffen. Bei einem Vergleich zwischen dem Anteil der Angehörigen dieser Stämme an den almohadischen Truppen bei einer Expedition gegen Ibn-Mardanīš im Jahr 1165 und einer Erwähnung der Zahlenstärke der almohadischen Armee bei einem anderen, späteren Anlass kommt Aguilar Sebastian zum Schluss, dass der prozentuelle Anteil der arabischen Stämme an der almohadischen Armee binnen weniger als fünfzehn Jahren von zwanzig auf fünfzig Prozent gestiegen $w^{186}$. Neben arabischen Beduinen waren es auch die asiatischen Söldner, die nach der Expedition al-Manșūrs nach Ifrīqīya im Jahr $1187 \mathrm{im}$ verstärkten Maße in das almohadische Heer eingegliedert wurden. Diese beiden Gruppen genossen bei den almohadischen Kalifen ein hohes Ansehen und wurden entsprechend gefördert und belohnt. So wurden dem Bericht 'Abd-al-Wāhịid alMarrākušīs zufolge die asiatischen Söldner gegenüber den Almohaden dadurch in offensichtlicher Weise bevorzugt, dass sie ihren Sold jeden Monat mit strikter

\footnotetext{
${ }^{185}$ al-Bayān al-muğrib, S. 232.

${ }^{186}$ Aguilar Sebastián, Victoria, Aportacion de los árabes a la organización militar del ejército almohade, S. 401.
} 
Regelmäßigkeit empfingen, während den Almohaden der Sold nur alle vier Monate ausgezahlt wurde ${ }^{187}$. Dabei lässt die Betonung der strikten Regelmäßigkeit in diesem Bericht erkennen, dass die Auszahlung des Soldes bei den nicht-asiatischen Angehörigen des Almohadenheeres nicht immer zum festgelegten Zeitpunkt erfolgte, was auf - vorsichtig ausgedrückt - eine gewisse Unausgeglichenheit des almohadischen Haushaltes in dieser Zeit schließen lässt ${ }^{188}$. Über die Höhe des Soldes, den die arabischen Beduinen bekamen, findet man genaue Angaben bei Ibn-Ṣāḥib-aṣ-Ṣalāt. In seinem Bericht über die Verteilung der „,baraka““189 an das almohadische Heer vor dem bevorstehenden Feldzug nach al-Andalus heißt es: „Dann ließ er (d. h. Yūsuf Ibn-`Abdal-Mu'min) die Almohaden herantreten. Und jedem Reiter mit kompletter Ausrüstung wurden zehn Dinar und einem jedem ohne komplette Ausrüstung acht Dinar ausgezahlt. Jeder Fußsoldat mit kompletter Ausrüstung bekam fünf Dinar, und ein jeder mit einer nicht kompletten Ausrüstung bekam drei Dinar. Danach ordnete er die Auszahlung des Soldes an die arabischen Beduinen an. Jeder Reiter von ihnen, der eine komplette Ausrüstung besaß, empfing fünfundzwanzig Dinar, ohne komplette Ausrüstung fünfzehn Dinar, und jeder Fußsoldat sieben Dinar. Der Sold jeden Šaihs eines arabischen Stammes betrug fünfzig Dinar und die des Stammesoberhaupts zweihundert Dinar. “190 In diesem Bericht, demzufolge übrigens die Šaihs der arabischen Beduinen zusammen mit Yūsuf Ibn-'Abd al-Mu'min und anderen hohen almohadischen Würdenträgern saßen, sieht man den offensichtlichen Vorzug, der bei der Verteilung der „baraka“ den arabischen Stämmen gegenüber den übrigen Almohaden gewährt wurde. Es springt auch in die Augen, dass das Verhältnis der „Solddiskrepanz“ zwischen den Almohaden und den Angehörigen der arabischen Stämme am größten bei den Reitern mit kompletter Ausrüstung war. Bei den Reitern mit nicht kompletter Ausrüstung wird sie geringer und bei den Fußsoldaten geringfügig. Das lässt darauf schließen, dass mit der Höhe dieses Soldes gezielt die arabischen Reiter gefördert werden sollten. Interessant ist in diesem Bericht auch, dass bei den arabischen Fußsoldaten kein

\footnotetext{
${ }^{187}$ al-Mu'̌̌̆ib, S. 289.

188 Ein wichtiger Hinweis darauf, dass die hier angesprochenen finanziellen Probleme des Almohadenreichs auch in der Regierungszeit Muhammad an-Nāṣirs fortbestanden, lässt sich dem Bericht al-Himyarīs entnehmen, in dem er als einen der Gründe für die Niederlage der Almohaden bei las Navas de Tolosa die ausgebliebene Soldauszahlung an die Angehörigen der almohadischen Armee nennt (arRauḍ al-mi'ṭār, S. 416). 'Abd-al-Wāḥid al-Marrākušī hält dies gar für den Hauptgrund der Niederlage (al$\mathrm{Mu}$ '⿳̆口̆ib, S. 322).

${ }^{189}$ Mit „baraka“ meinte man in dieser Zeit in Maghreb den Sold der Almohaden, der am Anfang eines jeden Monats ausgezahlt wurde, aber auch bei verschiedenen Anlässen verteilt werden konnte (al-Mann bi-'l-imāma, S. 42 der Einleitung). Daraus geht hervor, dass die Almohaden eigentlich genauso wie die asiatischen Söldner ihren Sold jeden Monat erhalten sollten, doch nur alle vier Monate faktisch erhielten. 190 al-Mann bi-'l-imāma, S. 348.
} 
Unterschied zwischen solchen mit kompletter und nicht kompletter Ausrüstung gemacht wurde. Das in diesem Bericht kleinste Verhältnis der „Solddiskrepanz“ zwischen beduinischen und almohadischen Fußsoldaten kann auch darauf hinweisen, dass beduinische Fußsoldaten ganz im Gegenteil zu ihren Reitern nicht gefördert werden sollten.

3.5. „All dies riefen wir den Versammelten mit solchen Worten in Erinnerung, die ihre Herzen erreichten $[\ldots]^{\text {“ }}$

Der Brief erwähnt Treffen, in deren Verlauf seitens der Almohaden die Einladung an die arabischen Stämme Ifrīqīyas erfolgte, den Dschihad in al-Andalus zu führen. Der Wortlaut der dabei geführten Gespräche und die Argumente, die man bei diesen Versammlungen vorbrachte, werden nur in ganz allgemeinen Zügen angedeutet. Im Folgenden soll versucht werden, ihren Inhalt anhand existierender Hinweise im Brief und einiger Angaben aus anderen Quellen genauer zu umreißen. Hierfür bietet sich ein Bericht Ibn-Ṣāḥib-aṣ-Ṣalāts darüber an, dass Yūsuf Ibn-'Abd-al-Mu'min im Jahre 1170, also zehn Jahre vor dem Datum, an dem der hier zu analysierende Brief verfasst wurde, einen Feldzug nach al-Andalus vorbereitete und $\mathrm{zu}$ diesem Zweck die arabischen Stämme Ifrīqīyas einlud ${ }^{191}$. Diese Einladung erfolgte in Form eines Gedichts, das sich bei diesem Autor in voller Länge findet. Es beginnt folgendermaßen ${ }^{192}$ :

„Lasset die Streitrosse sich den westlichen Gebieten zuwenden (und dorthin ziehen),

Zum Feldzug gegen zahlreiche Feinde und zur Erlangung des Begehrenswerten.

Und lasset sich erhitzen die (feurigen) Pferdefüllen, welche anstürmen gegen die Feinde,

Denn es haben sich zum Krieg bereit gemacht glatthaarige Pferde mit langgestreckten Körpern.

Nicht wird man des Erstrebten habhaft außer mittels des Einsatzes von Lanzen, Und nicht wird der Ruhm erlangt außer durch Vorstürmen der Kriegsscharen.

Das Erhoffte erlangt nur, wer angesichts der Schrecknisse nicht zurückweicht, Und nicht dabei erlahmt, unermüdlich den Schwierigkeiten zu trotzen, Und wer das Getümmel des entbrannten Gefechts für die wohlschmeckendste Wasserquelle hält,

\footnotetext{
191 Wohlgemerkt wurden laut Ibn-Haldūn häufig die Aufrufe der almohadischen Herrscher an die arabischen Beduinenstämme Ifrīqìyas, sich zur Teilnahme an den militärischen Unternehmungen in Maghreb einzufinden, in Gedichte gefasst (Kitāb al- ibar, Bd. 6, S. 44).

192 Bei der nachfolgenden Übersetzung wird auf die Beibehaltung des Reims bewusst zugunsten der wörtlichen Wiedergabe verzichtet.
} 
Selbst wenn das Blau nicht die Farbe der massigen Wasserwogen dieser Quelle ist ${ }^{193}$, Und wer alles außer was er sich durch sein Schwert aneignet verabscheut, Und stolz alle übrigen Erwerbsmöglichkeiten verschmäht.، ‘194

Aus dem ersten und dritten Vers wird ersichtlich, dass der Aufruf sich insbesondere an die Reiter richtet, was die Überlegungen stützt, die im Zusammenhang mit der Höhe des Soldes an die Reiter der arabischen Beduinen und der Almohaden oben geäußert wurden.

Dem Gedicht nach erlangt das Begehrenswerte also nur derjenige, der es sich durch sein Schwert aneignet und allen anderen Möglichkeiten, in dessen Besitz zu gelangen, nur diese eine vorzieht. Dieser Grundsatz lässt sich nicht immer in der Politik der almohadischen Herrscher gegen ihre Gegner verfolgen. Es sei hier z. B. an almohadische Versuche erinnert, sich der Insel Mallorca auf friedlichem Wege zu bemächtigen, wobei erst das Misslingen dieses Versuchs zur militärischen Besetzung der Insel geführt hat, oder an Friedensverträge mit christlichen Reichen der Iberischen Halbinsel sowie an Handelsbeziehungen mit christlichen Reichen ${ }^{195}$. Es handelt sich jedoch hierbei keineswegs um eine allgemein gültige Forderung an alle Bekenner des Almohadentums, denn dann hätten ja selbst die almohadischen Herrscher ihr nicht Genüge leisten können ${ }^{196}$. Es geht vielmehr darum, gezielt einige Eigenschaften der arabischen Beduinen anzusprechen, $\mathrm{zu}$ loben und sie in den Interessen der almohadischen Machthaber förderliche Bahnen zu lenken. Die Behauptung des Gedichts, das Erstrebenswerte sei grundsätzlich nur durch Kampf und ausschließlich gewaltsam zu erlangen, ist hier als ein Mittel zu verstehen, die arabischen Beduinen in einer solchen Weise anzusprechen, die den an sie gerichteten Aufruf die größtmögliche Wirkung entfalten lässt. Es wurden z. B. bestimmte beduinische Eigenschaften sowie Lebensweise thematisiert, welche trotz ihres offensichtlich mit der Zentralherrschaft unvereinbaren Charakters mit den Bedürfnissen der almohadischen Machtausübung doch in Einklang gebracht werden sollten. Dies geschah beispielsweise dadurch, dass die erwähnten Eigenschaften und die Lebensweise im Gedicht in ihrer existierenden

\footnotetext{
${ }^{193}$ Der arabische Vers lautet an dieser Stelle „wa-in a'raḍat zurqā ǧimām al-mašārib“, dessen gemeinten Sinn ich in der Übersetzung richtig getroffen zu haben hoffe.

194 al-Mann bi-'l-imāma, S. 325 und al-Bayān al-muġrib, S. 114, Verse 1-9.

${ }^{195}$ Vgl. Mağmū'a ğadīda, Bd. 1, S. 173 ff. sowie daselbst, Bd. 2, S. 240 f., 260 f.

196 „La période almoravide se caractériserait par une intransigeance qu'on voit apparaître aussi dans les exhortations, évoquées plus haut, à résister contre les chrétiens [...], alors que, si l'on considère les lettres avec les souverains étrangers, les Almohades semblent avoir développé une véritable diplomatie [...]“" (Los almohades : problemas y perspectivas, S. 496).
} 
Form bestätigt und somit implizit akzeptiert wurden. Es werden aber auch Beweggründe der Beduinen angesprochen, die ihnen in den almohadischen Briefen unter anderen Vorzeichen wüste Beschimpfungen einbrachten ${ }^{197}$. Folgende Beispiele mögen das Gesagte verdeutlichen. Das Wort „das Begehrenswerte“ (arab.: ar-raǵāib) im Gedicht ist mehrdeutig. Damit kann im Grunde jedes Objekt, auf das menschliches Wünschen und Trachten gerichtet ist, gemeint sein, wobei es erst durch den jeweiligen Kontext seine konkrete, gemeinte Bedeutung gewinnt. Worin dieses Begehrenswerte besteht, wird im Gedicht nicht präzisiert. Aus diesem Grunde darf man hier die Intention des Abfassers dieser Verse vermuten, wohlüberlegt und absichtsvoll die Deutung dieses vagen Begehrenswerten den Adressaten des Gedichts anheimgestellt zu haben. Ein Bericht Ibn-Haldūns über den bereits im Kapitel 2.4. kurz umrissenen Einfall der arabischen Beduinenstämme in Ifrīqīya weist auf eine der vielen Möglichkeiten hin, was genau die arabischen Beduinen mit dem „Begehrenswerten“ z. B. assoziiert hatten. Wie erinnerlich hat man nach der folgenreichen Gehorsamsaufkündigung von Mucizz IbnBādis gegenüber den fatimidischen Kalifen in Kairo den arabischen Stämmen der BanūHilāl erlaubt, den Nil zu überqueren, und ihnen den Maghreb „übereignet“. Hierzu führt Ibn-Hुaldūn aus: „Da entbrannten die Begehrlichkeiten der arabischen Beduinenstämme (arab.: fa-tami`at al-'arab), sie überquerten den Nil und zogen nach Barqa ${ }^{198}$. Dort stiegen sie $a b$, eroberten die Städte dieses Gebiets und plünderten sie aus (arab.: istabāhūhā). Dann schrieben sie an ihre auf der östlichen Seite des Nils zurückgebliebenen Brüder Briefe, in welchen sie die Begehrlichkeiten ihrer Brüder im Hinblick auf dieses Land weckten (arab.: yuraggỉibūnahum fi '1-bilāđ).“" ${ }^{199}$ In diesem sehr aufschlussreichen Bericht wird das arabische Verb „ragiba“, von dem das Wort für „das Begehrenswerte“ hergeleitet wird, durch die Beschreibung der Plünderungszüge der arabischen Stämme in Barqa als „,begehren, Städte zu erobern und auszuplündern“ definiert. Es ist anzunehmen, dass auch mehr als ein Jahrhundert nach diesen Briefen die arabischen Beduinen Ifrīqīyas kein wesentlich abweichendes Verständnis vom „Begehrenswerten“ hatten. Eben diese Bedeutung wird auch durch den Kontext des Gedichts nahegelegt, in dem es ausschließlich um den bewaffneten Kampf gegen die almohadischen Feinde auf der einen und um die Kriegsbeute auf der anderen Seite geht.

\footnotetext{
${ }^{197}$ Vgl. Kapitel 5 unten.

198 Das heißt östliches Libyen. Mit Barqa meinten arabische Autoren sowohl die antike Stadt, die heute den Namen al-Marğ trägt, als auch die zu ihr gehörende Gegend, die eine in das Mittelmeer hineinragende Halbinsel bildet und heute Cyrenaika heißt.

${ }^{199}$ Kitāb al-'ibar, Bd. 6, S. 31.
} 
Diese nicht eindeutige Festlegung auf eine Bedeutung eines mehrdeutigen Wortes trifft auch für weitere Ausdrücke des Gedichts zu, wie „das Erstrebenswerte“ oder „Hoffnungen“, die ebenfalls ein breites Spektrum an Deutungsmöglichkeiten erlauben. In diesem Zusammenhang ist darauf hinzuweisen, dass es häufig die Aussicht auf Kriegsbeute war, welche die in Ifrīqīya siedelnden arabischen Stämme sich Qarāqūš oder 'Alī Ibn-Ġānīya anschließen lie $\beta^{200}$. Die Anziehungskraft der Beute auf die arabischen Beduinen Ifrīqīyas dürfte den almohadischen Kalifen nicht unbekannt gewesen sein. Deswegen darf man vermuten, dass durch bewusste Offenlassung des gemeinten Sinns des „Begehrenswerten“ den Adressaten des Gedichts implizit die Kriegsbeute in Aussicht gestellt wurde. Es handelt sich in diesem Fall somit darum, die für die almohadische Herrschaft eigentlich höchst abträglichen Beweggründe arabischer Stämme zum Wirken zu bringen und diese Triebfedern durch Einbettung in den Kontext des Kampfes gegen die Feinde des Islam in al-Andalus den Adressaten zu Ruhm und Spolien und der almohadischen Obrigkeit zum Nutzen gereichen zu lassen. Dieses Muster, dass gewisse beduinische Eigenschaften und Vorstellungen durch den von den Amohaden gewünschten Kontext ein anderes Vorzeichen und somit eine andere, positive Wertung erfahren, lässt sich auch am Thema des Kampfes verfolgen, das aufs engste mit dem Motiv der Kriegsbeute verbunden ist. Der Kampf wird im Gedicht als das einzige Mittel zur Erlangung des Erstrebenswerten beschrieben. Dadurch wird auch hier eine jeder Zentralgewalt schädliche und an sich unheilvolle Lebenseinstellung als löblich hingestellt, ausschließlich durch Schwert sich etwas anzueignen und andere, d. h. friedliche Erwerbsmöglichkeiten, zu verabscheuen. Doch gerade wegen einer solchen Vorstellung vom ruhmreichen Broterwerb werden die arabischen Beduinen z. B. im Brief Nr. 20 als „Gesindel“ gebrandmarkt, mit welchem der Herrscher von Gafsa „Überfälle verübte und Karawanen ausraubte“201. Dabei handelten diese Beduinen genau nach dem im Gedicht als nachahmungswürdig geschilderten Grundsatz.

Im Verlaufe des Gedichts erfolgen auch weitere Aufrufe, nach Maghreb hinzueilen. Davon verdienen zwei besondere Aufmerksamkeit, denn sie werden jeweils mit unterschiedlichen Argumenten begründet. Im obigen Fall kam ein solcher Aufruf in

\footnotetext{
${ }^{200}$ Dies geht u. a. aus dem Bericht at-Tiğānīs über die Plünderungszüge Qarāqūšs hervor. Dieser Söldner habe nach der Unterwerfung der Region Ğabal Nafūsa die sich ihm angeschlossenen arabischen Stämme mit reicher Kriegsbeute zufrieden gestellt und habe sich später den Hass der Bevölkerung in den von ihm eroberten Städten dadurch eingehandelt, dass er diese Bevölkerung mit erdrückenden Abgaben belegen musste, um weitere, bei ihm ankommende arabische Stämme zufrieden stellen zu können. Vgl. auch „Les Benou Ghânya“" (S. 49).

${ }^{201}$ Mağmū' rasā̄il muwaḥhidīya, S. 101.
} 
Verbindung mit der impliziten Inaussichtstellung der Spolien. Jetzt soll ein Aufruf zitiert werden, bei dem das Thema des Dschihad aufgegriffen wird:

„Erhebet euch zum Obsieg des Islam, wie sich jemand im Zustand der Gefühlswallung erhebt,

und kehret zum Wahren zurück, wie ein demutsvoller Bittender zurückkehrt!‘202

Das Wort „Gefühlswallung“ ist hierbei sehr wichtig, denn es zeigt, dass die erwartete Antwort der arabischen Beduinen auf den erfolgten Aufruf aufgrund spontaner Emotionen, man könnte auch sagen: im Affekt erfolgen sollte. Auch im Brief wird darüber berichtet, dass man den versammelten Stämmen die Einladung zum Dschihad mit solchen Worten in Erinnerung brachte, dass ihr Zorn sich zugunsten dessen geregt habe, wozu man sie aufrief. Obwohl diese Zeilen im Brief die Reaktion der Beduinen am Schluss der Versammlung beschreiben und somit das Ergebnis der mit den Almohaden geführten Gespräche bilden, kann man dieser Beschreibung doch entnehmen, dass sowohl im Brief als auch im Gedicht die Aufrufe zum Dschihad auf emotional bedingte Antworten und affektartige Reaktionen abzielen. Nach einigen Zeilen erfolgt ein weiterer Aufruf, bei dem die Notwendigkeit des Dschihad mit zwei weiteren Argumenten untermauert wird:

„Ihr habt dem Islam am Anfang zum Obsieg verholfen, und ihm zum Obsieg (jetzt) zu verhelfen obliegt euch, und seine Wiederherstellung ist ein Ernst, welcher Pflicht ist.

Leistet das, was eure Vorfahren geleistet hatten,

Und verabsäumet nicht, diese ruhmreichen Heldentaten wieder zu vollbringen.

Gott hat den Propheten, dessen Familienangehörige und Seinen Mahdi, der ohne jeglichen Makel war, euch entstammen lassen.

Dadurch, dass sein Nachfolger aus euch ist und seine Vorväter von euch abstammen, ist euch der Vorzug, mit ihm verwandt zu sein, zuteil geworden,

Und die Gemeinschaft des Mahdi ist aus euch und wahrlich sie neigt sich aufgrund engster Bande, die zwischen den einzelnen Abstammungen bestehen, euch sehnsuchtsvoll zu. “203

Der Beistand dem Islam gegenüber und die Heldentaten der Vorfahren der arabischen Beduinen, wovon in den zuerst angeführten Versen die Rede ist, finden sich in etwas abgeänderter Form zum einen im in Kapitel 3.2. zitierten Aufruf 'Abd-al-Mu'mins an

${ }^{202}$ al-Mann bi-'l-imāma, S. 326, Vers 14. In ,al-Bayān al-muğrib“ (S. 115) fehlt dieser Vers. 
die arabischen Stämme Ifrīqīyas im Jahr 1160, mit ihm zwecks Abwehr christlicher Feinde in al-Andalus ein Kontingent ziehen $\mathrm{zu}$ lassen $^{204}$, und zum anderen im Brief selbst „Man ermunterte die Versammelten, ihren Vorfahren gleich beim Beistand dieser

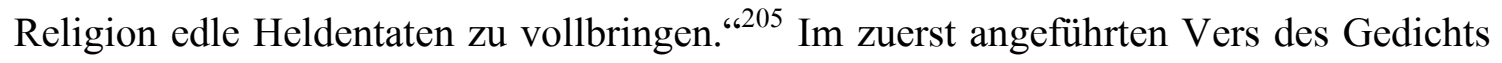
wird der Beistand der arabischen Beduinenstämme dem Islam gegenüber in der Frühzeit der islamischen Geschichte, womit die Verdienste dieser Gruppen bei der raschen Ausbreitung der neuen Religion im 7. Jahrhundert gemeint sein dürften, mit dem Beistand, den die betreffenden arabischen Stämme nun im ausgehenden 12. Jahrhundert leisten sollen, für gleichwertig erklärt. Wenn diese Aussage wirklich die Intention der zitierten Passage gebildet hat, so werden damit geschichtliche Ereignisse mit den wirklichkeitsfernen Wunschvorstellungen der almohadischen Machthaber - wohl absichtsvoll - gleichgesetzt. Denn bei den genannten frühen Eroberungszügen der Muslime ging es darum, das zunächst auf die Arabische Halbinsel begrenzte Gebiet des neuen islamischen Gemeinwesens um ein Vielfaches nördlich, westlich und östlich zu erweitern. Im Falle von al-Andalus konnte es sich aber im zur Rüste gehenden 12. Jahrhundert um keine vergleichbare Entwicklung handeln. Mit dem Aufruf zum erneuten Beistand dem Islam gegenüber ist sowohl im Brief als auch im Gedicht eher gemeint, das im ständigen Schrumpfen begriffene Gebiet von al-Andalus nicht noch weiter schrumpfen $\mathrm{zu}$ lassen. Diese intendierte Verknüpfung von überlieferten Tatsachen mit - wie es sich später herausstellen sollte - illusorischen Zukunftsvisionen muss zum Zeitpunkt der Bekanntgabe dieses Gedichts eine nicht zu unterschätzende Botschaft an die Adressaten enthalten haben, nämlich das Versprechen der unbezifferbar riesigen Menge an Beutegütern.

In diesem Abschnitt beruft man sich ferner auf die gemeinsame genealogische Abstammung zwischen den Almohaden und den arabischen Stämmen. Dies mag erstaunen, denn Muhammad Ibn-Tūmart wurde in einem Berberdorf geboren ${ }^{206}$ und die Stämme, die sich als erste zum Almohadentum bekannten, waren berberische Stämme des Anti-Atlasgebirges. Die Behauptung, die arabischen Beduinenstämme Ifrīqīyas und die Almohaden hätten aufgrund enger genealogischer Bande gemeinsame Vorfahren

\footnotetext{
203 al-Mann bi-'l-imāma, S. 326, Verse 19-24.

204 „Als 'Abd-al-Mu'min al-Mahdiya erobert hatte und nach Maghreb zurückzukehren gedachte, versammelte er die Anführer der Araber von den Banū-Hilāl, die in Ifrīqīya waren, und sagte zu ihnen: ,Es obliegt uns wieder, dem Islam Beistand zu leisten [...] Durch euch wurden die Länder bei der Ausbreitung des Islam erobert und durch euch soll der Feind jetzt abgewehrt werden." " (al-Kāmil, Bd. 9, S. 65).

${ }^{205}$ Mağmūc rasā’il muwaḥhidīya, S. 152.
} 
und seien somit miteinander verwandt gewesen, könnte zum einen auf die im Mittelalter im Umlauf befindlichen Legenden über die Abstammung der Berber zurückgehen ${ }^{207}$. Ferner finden sich in „Kitāb ahbār al-Mahdī“ u. a. einige Auszüge aus „Kitāb al-ansāb fī márifat al-aṣhāb“, die gleich zwei Genealogien des Mahdi enthalten ${ }^{208}$. Der ersten Genealogie zufolge, welche der Autor dieses Buches für die richtige hält, sei Muḥammad Ibn-Tūmart ein Abkömmling der Idrisiden, wobei auch einige berberische Namen in seiner auf al-Ḥasan Ibn-'Alī Ibn-Abī Ṭālib zurückgeführten Abstammung vorkommen. Nach der zweiten Version stammt er ebenfalls von al-Ḥasan ab, wobei in diesem Fall all seine Vorfahren Araber sind. Das Gemeinsame dieser beiden Genealogien besteht darin, dass die Abstammung Muḥammad Ibn-Tūmarts über alHasan auf 'Alī Ibn-Abī-Ṭālib zurückgeführt und der Mahdi somit in unmittelbare genealogische Nähe des Propheten gerückt wird. Nicht alle almohadischen Autoren, geschweige denn spätere arabische Historioghraphen, hielten diese Abstammung des Mahdi für überzeugend ${ }^{209}$. Huici Miranda hielt ihn gar für einen „hundertprozentigen Berber، ${ }^{، 210}$. Was die Herkunft 'Abd-al-Mu'mins betrifft, so ist er einem anderen Abschnitt des genannten Buches zufolge ebenfalls ein Abkömmling des al-Hasan Ibn'Alī Ibn-Abī Ṭālibs ${ }^{211}$. Laut Angaben 'Abd-al-Wāḥid al-Marrākuš̄is, der sich hier bemerkenswerterweise nur auf Informationen Dritter beruft, ohne seine Meinung dazu zu äußern, ging 'Abd-al-Mu'mins und seines Stammes Abstammung auf Qais-'Ailān zurück, auf den Ahnherrn also, auf den die Banū-Hilāl ihre Abstammung zurückführten. Aus diesen zitierten Versionen ergibt sich eine von der offiziellen almohadischen Seite propagierte gemeinsame Abstammung zwischen dem Mahdi und 'Abd-al-Mu'min einerseits und zwischen den Beduinenstämmen Ifrīqīyas und 'Abd-al-Mu'min andererseits, worauf höchstwahrscheinlich im Gedicht mit „engen Banden“ Bezug

\footnotetext{
${ }^{206} \mathrm{Zu}$ seinem genauen Geburtsort gibt es zwei unterschiedliche Überlieferungen jeweils von Ibn-alQatțān und 'Abd-al-Wāhịid al-Marrākušī (Historia política del imperio almohade, Bd. 1, S. 23).

207 Es waren die Historiographen und Geographen des arabisch-islamischen Ostens, die im 9. und 10. Jahrhundert grundlegende Angaben zum Mythos des Ursprungs der Berber lieferten. Dem einen Abstammungsmythos zufolge, der am häufigsten zitiert wurde, waren die Berber Angehörige des arabischen Stammes Muḍar und dereinst in Palästina seßhaft, die nach dem Tod ihres Königs Goliath nach Maghreb ausgewandert seien. Dem zweiten Mythos zufolge waren sie die Nachkommen Hams, Sohns des Noah. Dem dritten nach waren viele berberische Stämme himjaritischer Abstammung. (Shatzmiller, Maya, Le mythe d'origine berbère (aspects historiographiques et sociaux), S. 147).

${ }^{208}$ Kitāb ahbār al-mahdī, S. 21.

209 'Abd al-Wāhid al-Marrākušī beschränkt sich dabei auf eine kurze Bemerkung: „Dieser Muhammad Ibn-Tūmart hat eine auf al-Ḥasan Ibn-al-Ḥasan Ibn-'Alī Ibn-Abī-Ṭālib zurückgehende Abstammung, die er aufgezeichnet hatte“" (al-Mu'ğib, S. 178). Die dabei erkennbare Zurückhaltung des Autors legt nahe, dass er persönlich diese Abstammung für nicht überzeugend genug hielt, sich ihr vorbehaltlos anzuschließen.

${ }^{210}$ Historia política del imperio almohade, Bd. 1, S. 26.

${ }^{211}$ Kitāb ahbār al-mahdī, S. 21.
} 
genommen wird. Den genealogischen Ausführungen in „Kitāb al-ansāb fī márifat alaṣhāb" geht ein anderes Kapitel voraus, in welchem sein Autor zahlreiche Zitate und Beispiele aus dem Koran anführt, welche veranschaulichen sollen, dass nicht Blutsbande, sondern allein fromme Werke eines jeden Muslims am Tage des Jüngsten Gerichts ausschlaggebend sein würden. Wie es in der Einleitung zu diesem Kapitel heißt, bringe sein Verfasser diese Beispiele aus dem Koran, ,auf dass niemand sich auf seine Abkunft verlässt, denn nicht sie ermöglicht den Eintritt ins Paradies, sondern [...] die Gottesfurcht, fromme Werke und die Gnade Gottes ${ }^{\text {‘212 }}$. Daraus wird ersichtlich, dass die almohadischen Herrscher offiziell der Abstammung zwar keine entscheidende Bedeutung beimaßen, in der Praxis jedoch für ihre Zwecke sich auch auf das „genealogische“ Argument durchaus beriefen. Deswegen kommt es $\mathrm{zu}$ diesem widersprüchlich anmutenden Moment, das aus der Nebeneinanderstellung von Berichten über die jeweiligen Abstammungen von dem Mahdi und 'Abd-al-Mu'min einerseits und dem Abschnitt über die absolute Wirkungslosigkeit aller Blutsbande am Tage des Jüngsten Gerichts andererseits resultiert. Die Lösung dieses Widerspruchs ist wohl in dem Wissen der almohadischen Herrscher darum zu suchen, dass das alleinige Bewusstsein, mit jemandem gemeinsame Vorfahren zu haben, des Betreffenden - in diesem Fall der arabischen Beduinenstämme - Handeln und Denken nachhaltig beeinflussen konnte.

At-Tiğānī verdanken wir die Überlieferung eines Gedichts, das Yahyā Ibn-Ġānīya, einer der erbittersten und mächtigsten Gegner der Almohaden in Ifrīqīya, an die Angehörigen der Banū-Sulaim verfasst haben soll und in welchem auch er ,den Beduinen des Stammesverbandes Sulaim die gemeinsamen genealogischen Bande zwischen ihm und ihnen in Erinnerung ruft und sie (d. h. Angehörige dieses Stammesverbandes) für ihre Gefolgschaft gegenüber Qarāqūš tadelt.، ${ }^{\text {213 }}$ Worauf dieser Anspruch auf gemeinsame Blutsbande beruht, kann hier nicht näher behandelt werden, es sei lediglich darauf hingewiesen, dass Yahyyā Ibn-Ġānīya keiner arabischen, sondern berberischer Abstammung war $^{214}$. In den Zusammenhang der Berufung auf die einende ethnische Herkunft ist ferner die Beschreibung der Schlacht bei Haidarān im Jahre 1052, die sich bei Ibn-Haldūn findet, einzuordnen. $\mathrm{Zu}$ dieser Schlacht sei es kurze Zeit nach dem Einfall der Banū-Hilāl in Ifrīqīya gekommen. Dabei hätten die Scharen dieser arabischen Beduinenstämme den Truppen der Bewohner Ifrīqīyas gegenübergestanden;

\footnotetext{
${ }^{212}$ Kitāb ahbār al-mahdī, S. 18.

${ }^{213}$ Rihllat at-Tiğānī, S. 115.

${ }^{214}$ Alfred Bel, Les Benou Ghânya, S. 2.
} 
unter den Letzteren hätten sich die „Nachkommen der ersten arabischen Eroberer“ (arab.: baqāyā 'arab al-fath) befunden. Im Laufe der Schlacht seien sie wegen der weit in die Vergangenheit zurückreichenden gemeinsamen Abstammung mit den arabischen Beduinenstämmen (arab.: al-'așabiya al-qadìma ${ }^{215}$ ) zu den Eindringlingen übergelaufen, und dies habe letztlich den Ausgang der Schlacht entschieden ${ }^{216}$. Selbst wenn man bedenkt, dass zwischen der Ankunft der Araber der Eroberungszeit und derjenigen der arabischen Stämme dreieinhalb Jahrhunderte lagen und dass Ibn-Haldūn in diesem Bericht die Macht des Bewusstseins der einen gemeinsamen Abkunft überschätzt haben $\operatorname{mag}^{217}$, so zeigt dieses Beispiel, welch große Wirkung Ibn-Haldūn dem Bewusstsein einer solchen Bindung beimaß. Wenn man berücksichtigt, dass Ibn-Haldūn einige Zeit bei den arabischen Stämmen Ifrīqīyas verbrachte und ein Kenner dieser beduinischen Welt und ihres eigentümlichen Wertsystems war, so muss man dieser Aussage wenigstens eine gewisse Plausibilität einräumen. Aus den oben angeführten Ausführungen geht hervor, dass sowohl die Almohaden als auch Yạ̣yā Ibn-Ġānīya dem Bewusstsein der gemeinsamen genealogischen Abstammung eine kaum mindere Wirkungskraft als Ibn-Hुaldūn beimaßen und es für ihre Ziele geschickt einzusetzen wussten.

3.6. „Einer derjenigen, die bei dieser glückhaften Versammlung und bei dem neuen Guten zugegen waren, [...] war Šaih Abū-Sirhān Mas'ūd Ibn-Sultān Ibn-Zimām.“

Die Erwähnung dieses Šaihs findet sich wie erinnerlich im Bericht Ibn-al-Ațīrs über die Schlacht bei Ğabal al-Qarn ${ }^{218}$. Damals hätten er und andere arabische Šaihs den nach Maghreb zurückkehrenden 'Abd-al-Mu'min verlassen und seien mit ihren jeweiligen Stämmen in die Wüste geflüchtet. Als diese Stämme wenig später bei Ğabal al-Qarn von den almohadischen Truppen überrumpelt worden seien und es zur Schlacht gekommen sei, habe Mas'ūd Ibn-Zimām al-Ballāṭ ${ }^{219}$ mit seinen Familienangehörigen

\footnotetext{
${ }^{215}$ Die heute gegebenen Übersetzungen für den arab. Begriff ,al-'așabìya“ sind häufig unkonkret und keine von ihnen ergäbe in der wiedergegebenen Passage Ibn-Hुaldūns Sinn. Für dessen obige Übersetzung waren jeweils die arab. Ableitungen ,al-'așaba“, d.h. „Verwandte“ (Munğid fí 'l-lug̉a wa-'l-a'lām, S. 805), „qarābat al-'așab“, d.h. „die auf den Vater zurückgehenden Blutsbande“ (Arabsko-russkij slovar', Bd. 2, S. 518), und „al-cāșib“, d.h. „ein Verwandter väterlicherseits“ (daselbst), richtungsweisend.

${ }^{216}$ Kitāb al-cibar, Bd. 6, S. 32.

217 „Mais il semble bien que le génial auteur des „Prolégomènes“ ait tenté de justifier là l'une de ses théories sociologiques les plus chères: la solidarité entre clans prétendant descendre d'un même ancêtre éponyme.“ (La Berbérie Orientale, Bd. 1, S. 217).

${ }^{218}$ Siehe hierzu Kapitel 3.2.

${ }^{219}$ Obwohl dieser Name bei Ibn-al-Atīr in etwas anderer Form überliefert ist als bei Ibn-Haldūn (Kitāb al'ibar, Bd. 6, S. 70), die mit der des Briefes gänzlich übereinstimmt, oder bei at-Tiğān̄ī, der von Mas'ūd Ibn-Rimān spricht (Riḥlat at-Tiğānī, S. 113), handelt es sich trotz all dieser Namensvarianten zweifelsohne um eine und dieselbe historische Person.
} 
andere Šaihs der arabischen Stämme im Stich gelassen und sei vom Schlachtfeld geflohen. Dieser Bericht Ibn-al-Atīrs schliesst mit der Bemerkung: „Sicherheit und Ruhe kehrten in Ifrīqīya ein mit den Statthaltern, die 'Abd-al-Mu'min einsetzte, und von den Anführern der arabischen Stämme blieb niemand in diesem Gebiet 'Abd-al-Mu'min ungehorsam, außer Mas'ūd al-Ballāṭ Ibn-Zimām [sic], der sich mit seinen Gefolgsleuten in den Randbezirken Ifrīqīyas aufhielt. “220 Was das weitere Schicksal Mas`ūd IbnSultāns in den nachfolgenden ca. zwanzig Jahren anbetrifft, so sind darüber keine Berichte überliefert und es ist anzunehmen, dass er sich bis zum Jahr 1181, in dem unser Brief abgefasst wurde, der almohadischen Herrschaft entzog. Vielleicht kann der Hinweis des Briefes, Šaih Mas'ūd sei reuevoll zu Gott zurückgekehrt, als ein Indiz für diese Annahme gewertet werden.

In allen almohadischen Briefen der Sammlung „Mağmū` rasā’il muwaḥhidīya“ wird der Name dieses Šaihs nur in den Briefen Nr. 26 und Nr. 36 erwähnt. Abgesehen davon kommt er in den sonstigen überlieferten almohadischen Quellen nicht vor. Dem Brief Nr. 26 zufolge wohnte dieser Šaih zusammen mit anderen Vertretern der beduinischen Stämme den Aufklärungsgesprächen bei und konnte für die Auswanderung nach Maghreb gewonnen werden. Ferner habe sowohl Šaih Mas'ūd als auch die überwiegende Mehrheit der arabischen Stämme kurz nach dem Abschluss der Niederschlagung der Revolte von Gafsa, also um das Jahr 1181, Ifrīqīya endgültig verlassen.

Was den Lebenslauf von Šaih Abū-Sirhān Mas‘ūd Ibn-Sultān Ibn-Zimām nach dem Jahr 1181 anbetrifft, so sind im Reisebericht at-Tiğānīs im Zusammenhang mit der Beschreibung der Aktivitäten der von Qarāqūš angeführten asiatischen Söldner einige Angaben darüber enthalten. Da das Datum der genauen Ankunft dieser Gruppe sowohl zur Erhellung der Ereignisgeschichte Ifrīqīyas im 12. Jahrhundert als auch zum Verständnis der Ausführungen des almohadischen Briefes über den Šaih Abū-Sirḥān Mas'ūd Ibn-Sultān Ibn-Zimām wesentlich beitragen kann, soll im Folgenden versucht werden, es anhand überlieferten Quellenmaterials zu ermitteln.

Im Jahr 1168 unterwarf Asad-ad-Dīn Širkūh mit seinem Neffen Ṣalāh-ad-Dīn Yūsuf Ibn-Aiyūb im Auftrag ihres syrischen Oberherren Nūr-ad-Dīn das seit 969 fatimidische Ägypten. Zwei Monate nach dieser Eroberung starb Asad-ad-Dīn, und Ṣalāh-ad-Dīn wurde somit zum alleinigen Gouverneur über das unterworfene Gebiet. Daraufhin kündigte er seinem früheren Oberherrn die Gefolgschaft auf und wurde damit zum

\footnotetext{
${ }^{220}$ al-Kāmil, Bd. 9, S. 65.
} 
unabhängigen Herrscher über Ägypten ${ }^{221}$. At-Tiğānī berichtet, dass Ṣalāh-ad-Dīn aus Angst vor einem möglichen Angriff seitens Nūr-ad-Dīns eine Ausweichmöglichkeit in einen anderen Landstrich im Jahr 568 H. (1172/73 n. Chr.) habe schaffen wollen. Dabei habe er zwischen Jemen und Maghreb geschwankt. Sein Bruder Turanšāh Ibn-Aiyūb habe ihm vorgeschlagen, Jemen für ihn zu erobern und im Falle, dass Ṣalāḥ-ad-Dīn Ägypten verlassen sollte, an ihn abzutreten. Seitens eines anderen Verwandten von Ṣalāḥ-ad-Dīn namens Taqīy-ad-Dīn sei ein ähnlicher Vorschlag hinsichtlich des Maghreb unterbreitet worden, doch habe der Letztere dann aus Furcht vor enormen und lebensgefährlichen Schwierigkeiten dieses Unterfangens davon Abstand genommen. Einer der Offiziere Taqīy-ad-Dīns armenischer Herkunft namens Qarāqūšs, habe sich jedoch entschlossen, dieses Unternehmen alleine in Angriff $\mathrm{zu}$ nehmen, und sei zusammen mit anderen asiatischen Söldnern nach Maghreb geflohen ${ }^{222}$. Auch ein gewißer Ibrāhīm Ibn-Qarātikīn sei in Begleitung einer weiteren Gruppe dieser Söldner westwärts geflohen und habe sich Qarāqūš angeschlossen. Später hätten sich jedoch die beiden Anführer voneinander getrennt, und von da an habe jeder versucht, sein eigenes „Königreich“ zu schaffen. Qarāqūš habe auf seinem Zug westwärts einige libysche Städte unterworfen und sei schließlich nach Fazzān gelangt, wo er der Herrschaft der lokalen Dynastie der Banu-'1-Hatțāb ein Ende bereitet habe ${ }^{223}$. Etwas später führt der Autor aus: „Und in dieser Weise handelte er (d. h. Qarāqūš) weiter, Städte bezwingend und in ihnen die Freitagspredigt im Namen derjenigen halten lassend, die erwähnt wurden (d. h. Șalāh-ad-Dīn und Taqīy-ad-Dīn), bis er nach Tripolis gelangte. Dort schlossen sich ihm Angehörige des Stammes Dabbāb an und zusammen mit ihnen zog er gegen Ğabal Nafūsa. Er (d. h. Qarāqūš) unterwarf dieses Gebirge und eignete sich die immensen Besitztümer der dortigen Bewohner an, mit welchen er die arabischen Beduinen zufrieden stellte. Und es begab sich, dass Mas'ūd Ibn-Rimān, der Anführer des Stammes Banū-Riyah, in dieser Zeit den Gehorsam gegenüber den Nachkommen von 'Abd-al-Mu'min aufgesagt hatte und ihnen entflohen war. Nach seiner Ankunft in dieser Gegend trat er bald auf der Seite der Stammes Zugab, bald auf der Seite des Stammes Dabbāb auf. Als er von der Ankunft Qarāqūšs mit seinen Bogenschützen von den asiatischen Söldnern hörte, war er darüber erfreut und stieß samt all jenen, die von den Tapferen des Stammes Riyāh sich um ihn geschart hatten, zu ihm. Mit ihnen umzingelte Qarāqūš Tripolis und traf auf Städte, die weder mit einem Aufrührer noch

\footnotetext{
${ }^{221}$ Les Benou Ghânya, S. 58.

${ }^{222}$ A. Bel gibt als Datum für diese Flucht das Jahr 1172/73 an (Les Benou Ghânya, S. 60).
} 
mit einem Aufständischen gerechnet hatten, so dass sie, ohne Garnisonen, Kriegsgeräte und Nahrungsmittelvorräte, wehrlos waren. Aus diesem Grunde konnte Qarāqūš all jene Städte unterwerfen. Als dies geschah, wurde seine Macht so groß, dass sich selbst die Bewohner von Tūnis und von anderen Städten vor seinen Übergriffen fürchteten. Es strömten $\mathrm{zu}$ ihm von allerorts arabische Beduinen, was ihn dazu zwang, seinen Untertanen eine unerträgliche Abgabenlast aufzubürden. Deswegen fassten die Menschen Hass gegen ihn, nachdem ihm anfangs die Zuneigung aller gegolten hatte. Wir haben in diesem Werk dank Gottes - gepriesen sei er - Beistand nach Möglichkeit von seinen Gräueltaten, von seinen kriegerischen Auseinandersetzungen mit den Söhnen 'Abd-al-Mu'mins sowie davon berichtet, dass er ca. vierzig Jahre lang bis zu seinem gewaltsamen Tod durch den Mallorquiner bald zu ihnen auswanderte (d. h. sich zum Almohadentum bekannte), bald ihnen entfloh (d. h. ihnen die Gefolgschaft aufkündigte).“224

Mit Mas'ūd Ibn-Rimān ist in diesem Bericht zweifellos der uns aus dem almohadischen Brief bekannte Šaih Abū-Sirhāan Mas'ūd Ibn-Sultān Ibn-Zimām gemeint. Dies wirft die Frage auf, warum er nach seiner geschilderten Auswanderung nach Maghreb wieder in Ifrīqīya anzutreffen bzw. wann er dorthin zurückgekehrt ist. Nachfolgende Überlegungen sollen zur Klärung dieser Frage beitragen.

Beim Feldzug 'Abd-al-Mu'mins zur Eroberung Ifrīqīyas im Jahr 1159/60 war unter den Delegationen der Städte, die sich freiwillig der almohadischen Herrschaft unterwarfen, auch Abū-Yahyā Ibn-Matrūḥ, den die Bevölkerung von Tripolis nach der Vertreibung der normannischen Garnison im Jahr 1158 zu ihrem Herrscher erwählt hatte. Als die Notabeln dieser Stadt bei den vor al-Mahdiya lagernden Almohaden ankamen, „empfing sie 'Abd-al-Mu'min wohlwollend und bestätigte Abū-Yahyā Ibn-Maṭūḥ in seinem Amt als [nunmehrigen almohadischen] Statthalter von Tripolis. ${ }^{\text {‘225 }}$ Weiter führt at-Tiğānī aus, dass Abū-Yahyā Ibn-Matrūḥ über die Bewohnerschaft von Tripolis in vorbildlicher Weise bis ins greise Alter hinein geherrscht und dann in der Regierungszeit von Abū-Ya'qūb Yūsuf Ibn-'Abd-al-Mu’min (1163-1184) von Gebrechlichkeit gelähmt um die Erlaubnis gebeten habe, die Pilgerfahrt zu den heiligen islamischen Stätten antreten zu dürfen, die ihm erteilt worden $\operatorname{sei}^{226}$. Tripolis gehörte

\footnotetext{
${ }^{223}$ Rihlat at-Tiğānī, S. 111 ff. Ibn-Ḩaldūn (Kitāb al-cibar, Bd. 6, S. 394 f.) zitiert diesen Bericht at-Tiğānīs fast wörtlich.

${ }^{224}$ Rihlat at-Tiğānī, S. 113. An einer anderen Stelle (Riḥlat at-Tiğānī, S. 110) gibt dieser Autor das Jahr 609 H. (1212/13 n. Chr.) als Datum für Qarāqūšs gewaltsamen Tod in der Stadt Waddān an.

${ }^{225}$ Riḥlat at-Tiğānī, S. 242-243, La Berbérie Orientale, Tome 1, S. 395.

${ }^{226}$ Riḥlat at-Tiğānī, S. 243. Daselbst findet sich auch die Angabe aus einem anderen Werk, aus welchem at-Tiğānī zitiert, dass Abū-Yaḥyā Ibn-Maṭūḥ im Jahre 586 H., d. h. ca. 1190, in Alexandria angelangt sei.
} 
demnach ab dem Jahr 1160 zum almohadischen Herrschaftsbereich, und der Versuch, dies zu ändern, hätte früher oder später militärisches Durchgreifen der Almohaden dagegen zur Folge gehabt. Nach gegenwärtiger Quellenlage aber wurden weder bei der Niederwerfung des Aufstandes in Gafsa im Jahre 1180 noch während des darauf folgenden Aufenthaltes der almohadischen Armee mindestens bis März $1181^{227}$ in Ifrīqiya almohadische Truppen nach Tripolis entsandt. Sowohl almohadische als auch spätere Berichte sprechen bei der Schilderung der Expedition von 1180 nur von einem Aufstand in Gafsa, dessen Niederschlagung diese Unternehmung zum Ziel gehabt habe, und erwähnen dabei weder Tripolis noch Qarāqūš. Ibn-al-Atīr bildet hierbei insofern eine Ausnahme, als ihm zufolge Qarāqūš sich bereits seit dem Jahr 1172 in Ifrīqīya aufgehalten und Tripolis im genannten Jahr zusammen mit Šaih Mas`ūd Ibn-Zimām eingenommen habe ${ }^{228}$, doch erwähnt auch dieser Autor bei der almohadischen Expedition zur Befriedung Gafsas im Jahr 1180 keine Entsendung von almohadischen Einheiten nach Tripolis ${ }^{229}$. Aḥmad 'Azzāwī, der Herausgeber von „Mağmū'a ğadīda“, folgt in seiner Einleitung zu den Briefen 30 und 31, welche die Niederschlagung der eben erwähnten Revolte in Gafsa zum Gegenstand ihrer Schilderung haben, dem obigen Bericht Ibn-al-Atīrs und versteht die im abschließenden Teil des Briefes Nr. 30 befindliche Bemerkung, dass von Gafsa aus die arabischen Stämme des Umlandes sowie die Gebiete, die sich von Gafsa bis Tripolis erstrecken, kontrollieren ließen (arab.: fa-inna hadֵihī al-balda [...] muțilla ‘alā ‘arab had̄ihī al-ǧihāt wa-mā yattaṣil bihā ilā Tarābulus bi-'1-qahr aš-šadī ${ }^{230}$ ) dahingehend, dass damit implizit die Hoffnung der Almohaden, Tripolis Qarāqūš bald wieder entreißen zu können, gemeint sei ${ }^{231}$. Doch angesichts der Tatsache, dass den überlieferten Quellen trotz ausführlicher Darstellung der Ereignisse im in Frage kommenden Zeitraum keine Berichte über eine almohadische Unternehmung zur Befreiung von Tripolis sowie keine expliziten Hinweise darauf, dass diese Stadt einer ernsthaften Bedrohung ausgesetzt gewesen sei, sich entnehmen lassen, darf m. E. geschlussfolgert werden, dass Tripolis seit 1160 ununterbrochen bis mindestens März 1181 nicht nur der almohadischen Herrschaft unterstand, sondern auch keiner Gefahr ausgesetzt war, den Almohaden entrungen zu werden.

\footnotetext{
Zwischen diesen beiden Zeitangaben liegen also mindestens sechs Jahre, was die Frage nach ihrer Genauigkeit aufwirft.

${ }^{227}$ Vom 4. März 1181 ist der almohadische Brief Nr. 26 datiert.

228 al-Kāmil, Bd. 9, S. 119.

${ }^{229}$ al-Kāmil, Bd. 9, S. 152.

${ }^{230}$ Mağmū'a ğadīda, Bd. 1, S. 149.

${ }^{231}$ Mağmū'a ğadìda, Bd. 1, S. 149, Fußnote Nr. 28.
} 
Auch einige Jahre später scheint Tripolis immer noch „almohadisch“ gewesen zu sein. Dies geht aus folgenden Ereignissen hervor. Im November des Jahres $1184^{232}$ landeten in Biğāya almoravidische Kontingente der Insel Mallorca unter dem Kommando von 'Alī Ibn-Ġānīya und bemächtigen sich nach der Einnahme dieser Stadt auch einiger Städte des Zentralen Maghreb. Die almohadischen Flotte und Heer, die zur Wiedereroberung dieser Städte entsandt wurden, konnten sie wieder unter die almohadische Botmäßigkeit bringen und die Angreifer vertreiben. Es kam jedoch nicht zur entscheidenden Schlacht mit dem Gros der Mallorquiner unter der Führung 'Alī IbnGānīyas, da er samt seinen Anhängern angesichts der anrückenden Almohaden in den Süden entwich. Die almohadische Armee kehrte, nachdem sie die Eindringlinge erfolglos zu stellen versucht hatte, nach Marrakech zurück. Im almohadischen Brief Nr. $29^{233}$, in dem die einzelnen Etappen dieser Expedition ausführlich geschildert werden, sowie im nicht minder ausführlichen ,al-Bayān al-muġrib“ wird nicht über eine almohadische Entsendung nach Tripolis, die im Falle fremder Besetzung dieser Stadt eigentlich hätte erfolgen müssen ${ }^{234}$, berichtet. Ein weiteres Indiz dafür, dass Qarāqūšs bis November 1184 noch nicht in Ifrīqīya eingefallen war, liefert ferner Ibn-'Idārī. Diesem Autor zufolge ist der zum Zeitpunkt des genannten almoravidischen Überfalls auf Biğāya dort befindliche Statthalter von Ifrīqīya, Abū-Mūsā, in Gefangenschaft der Angreifer geraten. Er habe dort in Begleitung seiner Gefährten auf dem Weg nach Marrakech gerastet und habe schon seit Jahren keine antialmohadische Revolte niederzuschlagen gehabt $^{235}$. Andere überlieferte Quellen enthalten ebenfalls keine Hinweise auf Bemühungen der Almohaden, das laut Ibn-al-Atīir ${ }^{236}$ in 1172 von Qarāqūš in Besitz genommene Tripolis zurückzuerobern. Die Annahme scheint berechtigt, dass Tripolis bis zur Rückkehr der almohadischen Truppen nach Maghreb im Sommer des Jahres $1185^{237}$ sich weiterhin in der Gewalt des dort amtierenden almohadischen Statthalters befand.

Nach seiner Flucht nach dem Ğabal Aurās durchzog 'Alī Ibn-Ġānīya plündernd diese Region und bezwang, in Ğarīd angekommen, im Jahr 1186 die befestigte Stadt Tawzar. Von dort aus begab er sich nach Gafsa, die sich ihm widerstandslos ergab, und später

\footnotetext{
${ }^{232}$ Historia política del imperio almohade, Bd. 1, S. 323.

${ }^{233}$ Mağmū' rasā’il muwaḥhidīya, S. 168-180.

${ }^{234}$ Zumindest für die almohadische Flotte wäre es ein Leichtes gewesen, Tripolis zu erreichen.

235 al-Bayān al-muġrib, S. 176.

${ }^{236}$ al-Kāmil, Bd. 9, S. 119.

${ }^{237}$ Biğāya dürfte von den Almohaden im Juni 1185 zurückerobert worden sein (Historia política del imperio almohade, Bd. 1, S. 327).
} 
nach Tripolis, wo er in Qarāqūš einen Verbündeten gegen die Almohaden fand ${ }^{238}$. Diese antialmohadische Allianz, der sich auch viele arabische Beduinenstämme Ifrīqīyas und Reste der almoravidischen Stämme Lamtūna und Masūfa bald anschlossen, konnte sich anschließend mit Ausnahme von Tūnis und al-Mahdiya des gesamten Gebiets von Ifrīqīya bemächtigen ${ }^{239}$, was eine neue militärische Unternehmung der Almohaden zur Folge hatte, welche diesmal Ya'qūb al-Manșūr im Jahr 1187 persönlich leitete. Erst im Zusammenhang mit dieser Unternehmung fällt der Name „Qarāqūšs“ in „Mağmū‘ rasā’il muwaḥhidīya“ zum ersten Mal, nämlich in einem vom 23. Oktober des Jahres 1187 datierten Brief Nr. 30, der über eine der ersten Etappen dieser almohadischen Expedition nach Ifrīqīya berichtet ${ }^{240}$. Auch in ,al-Bayān al-muğrib“, dessen Autor bei der Schilderung dieser Ereignisse weitgehend der ausführlichen Chronik ,,al-Mann bi-'1imāma“ folgt, wird der Name „Qarāqūšs“ erst im Zusammenhang mit der genannten Unternehmung erwähnt ${ }^{241}$. Vor diesem Hintergrund darf angenommen werden, dass Qarāqūš zu einem letztlich nicht genauer bestimmbaren Zeitpunkt in einem Zeitraum, der vom Abschluss der almohadischen Rückeroberung Biğāyas im Sommer 1185 bis zur Ankunft 'Alī Ibn-Ġānīyas nach Tripolis im Jahr 1186 reicht, diese Stadt in Besitz genommen hat. Wenn dies nun stimmt, so ist die Frage unumgänglich, wie sich Šaih Mas'ūd Ibn-Sulțān zwischen 1185 und 1186 in Ifriqiya, nämlich laut at-Tiğānī ${ }^{242}$ bei der Belagerung Tripolis' an der Seite von Qarāqūš, aufgehalten haben soll, wenn er doch laut dem almohadischen Brief Nr. 20 um das Jahr 1181 nach dem Äußersten Maghreb ausgewandert war. Folgende Möglichkeiten bieten sich zur Lösung des aufgezeigten Widerspruchs an: Entweder ist Šaih Mas'ūd nicht ausgewandert, sondern hat seine Auswanderung nur vorgetäuscht, um auf diese Weise den Abzug der almohadischen Armee abzuwarten; oder aber die geschilderte Umsiedlung hat wirklich stattgefunden, er ist aber später wieder nach Ifrīqīya zurückgekehrt. Der Bericht Ibn-al-Ațīrs über die Belagerung Gafsas im Jahr 1180 schließt damit, dass Abū-Ya'qūb Yūsuf Mas'ūd nach Maghreb ziehen ließ, nachdem dieser seine feindselige Haltung den Almohaden gegenüber aufgegeben und sich Abū-Ya'qūb Yūsuf unterworfen hatte ${ }^{243}$. Dies sowie die

\footnotetext{
${ }^{238}$ Historia política del imperio almohade, Bd. 1, S. 330, Les Benou Ghânya, S. 57-58. Bei Ibn-Haldūn (Kitāb al-'ibar, Bd. 6, S. 508) findet sich eine im Hinblick auf die zeitliche Abfolge etwas abweichende Version dieser Eroberungen.

${ }^{239}$ al-Kāmil, Bd. 9, S. 171, Historia política del imperio almohade, Bd. 1, S. 330-331.

${ }^{240}$ Mağmū' rasā’il muwaḥhidīya, S. 189.

241 al-Bayān al-mugrrib, S. 189.

${ }^{242}$ Riḥlat at-Tiğānī, S. 113.

243 al-Kāmil, Bd. 9, S. 152.
} 
pathetische Beschreibung der Auswanderung von Šaih Mas`ūd im Brief sprechen dafür, dass er Ifrīqīya um das Jahr 1181 wirklich verlassen hat ${ }^{244}$.

Es findet sich bei Ibn-Haldūn folgender Bericht, der eine Lösung für die gestellte Frage bieten könnte: „Ihr (d. h. des Stammes Riyāḥ) Anführer in der Zeit der almohadischen Herrschaft war Mas'ūd Ibn-Sulțān Ibn-Zimām Ibn-Radīnī Ibn-Dāwūd, dessen Beiname Bult war, und dies wegen seiner Stärke und seiner Hartnäckigkeit. Und als al-Manșūr ${ }^{245}$ den Stamm Riyāḥ nach Maghreb brachte, blieb 'Asākir, ein Bruder Mas'ūds, wegen der Beweise des Gehorsams und der Loyalität (gegenüber den Almohaden) mit den Gruppen dieses Stammes (in Ifrīqīya) zurück. Er (d. h. Ya'qūb al-Manșūr) hieß Mas`ūd und seine Gemeinschaft in der Gegend namens Hibț siedeln, [...] in welcher sie sich niederließen. Mas'ūd Ibn-Zimām entfloh von dort im Jahre 590 H. (1194) mit einer Gruppe seiner Gemeinschaft und gelangte nach Ifrīqīya. Die Söhne seines Bruders 'Asākir stießen zu ihm, und zusammen kamen sie in die Gegend von Tripolis. Dort stiegen sie bei den Stämmen Zugiab und Diyāb ab und schlossen sich bald diesem, bald jenem Stamm an (wörtl. wälzten sich zwischen diesem und jenem Stamm). Danach trachtete Mas'ūd Ibn-Zimām danach, in den Dienst Qarāqūšs zu treten, und war zusammen mit seiner Gemeinschaft mit ihm (d. h. Qarāqūš) bei der Einnahme von Tripolis, wie wir es noch im Abschnitt über Qarāqūš beschreiben werden.“246 Was diesen von Ibn-Haldūn vorausgreifend genannten Abschnitt über Qarāqūš betrifft, so liegt ihm nach eigenem Bekunden des Autors - freilich mit wenigen unwesentlichen Abweichungen - der oben bereits angeführte Bericht at-Tiğānīs über die Ankunft Qarāqūšs in Ifrīqīya zu Grunde ${ }^{247}$. Damit kann als erwiesen gelten, dass der eben zitierte Bericht Ibn-Haldūns einen offensichtlichen Anachronismus enthält, denn er fußt auf den Ausführungen at-Tiğānīs über die erste Belagerung und Einnahme Tripolis' durch Qarāqūš zusammen mit Šaih Mas'ūd Ibn-Sulțān Ibn-Zimām nach der Flucht des Letzteren aus dem Äußersten Maghreb und dies kann unmöglich zum ersten Mal nach 1194 stattgefunden haben, da wir Qarāqūšs in Tripolis laut Ibn-Haldūn ${ }^{248}$ bereits vor und laut den almohadischen Briefen ${ }^{249}$ und dem Bericht in ,al-Bayān al-mugrrib“‘250 bei der almohadischen Unternehmung von 1187 in Tripolis antreffen, ganz abgesehen von der m. E. schlicht unzutreffenden - Angabe Ibn-al-Ațīs, Qarāqūš sei bereits im Jahr 1172

\footnotetext{
${ }^{244}$ Auch der weniger zuverlässige Ibn-Abī-Zar' bestätigt dies (al-Anīs al-mutrib, S. 279).

${ }^{245}$ Gemeint ist hier der dritte almohadische Kalif Abū-Yūsuf Ya'qūb al-Manșūr (1184-1199).

${ }^{246}$ Kitāb al-'ibar, Bd. 6, S. 70.

${ }^{247}$ Kitāb al-'ibar, Bd. 6, S. 394 f. und Riḥlat at-Tiğānī, S. 113.

${ }^{248}$ Kitāb al-'ibar, Bd. 6, S. 395.

${ }^{249}$ Mağmū' rasā̄il muwaḥhidìya, S. 189.

${ }^{250}$ al-Bayān al-mugirib, S. 189.
} 
Herr über Tripolis geworden ${ }^{251}$. Qarāqūš hat zwar dem Bericht at-Tiğānīs zufolge ein zweites Mal Tripolis nach 1190 erobert, nach dem es ,seine Autorität anerkannt hatte, ihm später jedoch unbotmäßig geworden war'‘252, doch geschah dies ganz gewiß nicht im Anschluss an seine Ankunft in Ifrīqīya aus Ägypten. Ibn-Haldūn legt zwar seinen Angaben den Bericht at-Tiğānīs zu Grunde, bringt dabei jedoch entweder selbst oder ein späterer Kopist die Zeitangaben durcheinander. Hinzu kommt, dass Ibn-Haldūn mit dem obigen Hinweis auf die angeblich von Ya'qūb al-Manșūr veranlasste Deportation einiger arabischer Stämme nach dem Äußersten Maghreb unter den arabischen Historiographen fast allein $\mathrm{zu}$ stehen scheint $^{253}$ und sich in den überlieferten zeitgenössischen almohadischen Quellen keine Belege dafür finden lassen ${ }^{254}$. Nichtsdestoweniger gibt dieser Autor die Antwort auf die aufgeworfene Frage, wieso Mas'ūd Ibn-Sultān nach seiner Umsiedlung in den Maghreb nach einiger Zeit wieder in Ifrīqīya anzutreffen war. Die Flucht dieses Šaihs aus dem Maghreb wird in dem oben zitierten Bericht at-Tiğānīs mit dem mehrdeutigen „Und es begab sich, dass Mas'ūd IbnRimān, der Anführer des Stammes Banū-Riyaḥ, in dieser Zeit den Gehorsam gegenüber den Nachkommen 'Abd-al-Mu'mins aufgesagt hatte und ihnen entflohen war" angedeutet und gewinnt erst vor dem Hintergrund des Berichts Ibn-Haldūns den gemeinten Sinn. Auf diese Weise findet sich neben dem Bericht Ibn-al-Atīrs auch von Ibn-Haldūn und indirekt auch von at-Tiğānī die Aussage des Briefes bestätigt, dass Šaih Mas'ūd nach 1181 Ifrīqīya verlassen hatte. Dem gegenwärtig vorhandenen Quellenmaterial nach zu urteilen dürfte er aber - wenn die obigen Überlegungen stimmen - irgendwann zwischen den Jahren 1181 und 1186 wieder nach Ifrīqīya zurückgekehrt sein. Diese Flucht stellt die Glaubwürdigkeit seines im Brief geschilderten „Entgegeneilens zur almohadischen Sache“ in Frage oder relativiert sie zumindest erheblich. Ferner stehen in unübersehbarem Widerspruch zur Version eines freiwilligen Aufbruchs im Brief die jeweiligen Angaben von Ibn-al-Atīr und IbnHaldūn, Šaih Mas`ūd sei nach Maghreb gebracht worden ${ }^{255}$.

\footnotetext{
${ }^{251}$ al-Kāmil, Bd. 9, S. 119.

${ }^{252}$ Riḥlat at-Tiğānī, S. 104.

${ }^{253}$ Einzig Ibn-Abī-Zar ${ }^{\complement}$ berichtet noch darüber (al-Anīs al-mutrib, S. 287 und S. 302 f.).

254 Weder „Kitāb al-istibșār fî 'ağā'ib al-amșār” noch „al-Bayān al-muğrib“, dessen Autor die almohadische Expedition zur Befriedung Ifrīqīyas unter der Leitung Ya'qūb al-Manșūrs sehr ausführlich dokumentiert, lassen sich Hinweise darauf entnehmen. Mehr noch, der almohadische Brief Nr. 33 berichtet über den Abschluss dieser almohadischen Unternehmung sowie über die dabei erzielten Ergebnisse. Dabei wird u. a. ausgeführt, dass die asiatischen Söldner in großer Zahl nach dem Ä̈̈ßersten Maghreb auswandern (Mağmū' rasā’il muwaḥhidīya, S. 214) und dass die dem Stammesverband Banū Sulaim gehörenden arabischen Stämme 'Auf und aš-Šarīd - Banū Riyạ̣ werden im Brief nicht erwähnt sich wieder der almohadischen Herrschaft fügen und in Ifrīqìya bleiben (daselbst, S. 216).

${ }^{255}$ al-Kāmil, Bd. 9, S. 152, Kitāb al-'ibar, Bd. 6, S. 70.
} 
Über das Leben des „Anführers der Riyāhiden“ nach seiner Flucht aus dem Maghreb lässt sich nur so viel sagen, dass er sich höchstwahrscheinlich auch weiterhin almohadischer Herrschaft nicht zu fügen bereit war und dem alten, vom „Ungehorsam“ geprägten Lebenswandel anhing. Auf ein zwiespältiges Verhältnis dieser Person zu den Almohaden weist jedenfalls eine fast beiläufige Bemerkung im almohadischen Brief Nr. 37 hin, der im Jahr 1204 während des almohadischen Feldzuges gegen Yahyā IbnGānīya nach Ifrīqīya verfasst wurde. Darin findet sich die Erwähnung, dass nach dem Sieg der Almohaden über die Banū-Ġānīya und ihre Verbündeten bei Rās Tāğrā „AbūSirhạan Mas'ūd Ibn-Sulțān Ibn-Zimām (bei den Almohaden) antraf, sich schleppend, gebunden mit den Fesseln seiner Gebrechlichkeit, und für diejenigen, welche von seinen Kindern, Verwandten und von seinem Hause hinter ihm blieben, die Gnade dieser ruhmvollen Bewegung und ihre Obhut erbat. ‘256 Ibn-Haldūn zufolge, der als einziger von allen arabischen Historiographen über das Schicksal Mas'ūds nach dessen Entweichen aus Maghreb Näheres berichtet, habe dieser nach seiner Ankunft in Ifrīqīya bis zu seinem Tod gegen die Almohaden gekämpft. Sein Sohn Muhammad habe nach ihm diesen Kampf weitergeführt ${ }^{257}$. Dies relativiert die eben angeführte erneute Unterwerfung Mas'ūds, welche auch diesmal nicht endgültig gewesen zu sein scheint.

\subsection{Zusammenfassung des historischen Kommentars}

Aufgrund der Tatsache, dass der Brief Nr. 26 lediglich eine abschließende Teiletappe der almohadischen Unternehmung zur Befriedung Gafsas im Jahr 1180 zum Gegenstand der Schilderung hat, die in den überlieferten historischen Quellen höchstens am Rande eine Erwähnung gefunden hat, ist es schwierig, den Inhalt des Briefes im Hinblick auf seinen historischen Gehalt zu überprüfen. Dies wird zusätzlich auch dadurch erschwert, dass ein Schwerpunkt der Beschreibung auf der Wirkung liegt, welche die Gespräche der entsandten Almohaden auf die Beduinen gehabt hätten. Einen weiteren nicht nachprüfbaren Schwerpunkt bildet ferner die ausführliche Beschreibung der Auswanderung der arabischen Stämme aus Ifrīqīya, wobei bezüglich der Menge der umgesiedelten Stämme feststeht, dass sie im Brief maßlos übertrieben ist. Die einzige namentlich genannte Person ist Šaih Abū-Sirḥān Mas'ūd Ibn-Sulțān Ibn-Zimām, dessen Erwähnung auf eine besondere Bedeutung schließen lässt, die man ihm beimaß. Die Ausführungen des Briefes über die Auswanderung dieser Person nach Maghreb sind insofern wichtig, als sie die nicht eindeutigen und widersprüchlichen Informationen

\footnotetext{
${ }^{256}$ Mağmū' rasā'il muwaḥhidīya, S. 259.
} 
über Šaih Abū-Sirhān Mas'ūd aus anderen Quellen zu gewichten erlauben und zur Aufhellung einiger ereignisgeschichtlicher Aspekte der Geschichte Nordafrikas im 12. Jahrhundert beitragen. Die spätere Flucht dieser Person nach Ifrīqīya sowie ihre lebenslange feindselige Haltung gegenüber den Almohaden steht jedoch in einem unlösbaren Widerspruch zu den Schilderungen des Briefes über die vollzogene „Besserung“ Šaih Mas`ūds.

\section{Zusammenfassung des Briefes Nr. 29}

Dieser Brief, datiert vom 6. Juli des Jahres 1185 und abgefasst im Namen des Befehlshabers der Gläubigen in Marrakech, ist an die Ṭālibs, Almohaden, Šaihss, Notabeln und die gesamte Bewohnerschaft Sevillas adressiert. Seinen Inhalt bildet der Bericht über die erfolgreiche Unternehmung der Almohaden gegen den Herrscher von Mallorca, der zusammen mit seinen Anhängern einige Städte des Zentralen Maghreb in seine Gewalt gebracht hatte. In folgender Weise werden diese Ereignisse geschildert: Die Adressaten wissen bereits über die vom Herrscher von Mallorca vorgetäuschte Bereitschaft, den Almohaden zu gehorchen und $\mathrm{zu}$ dienen, wobei dieser doch in Wirklichkeit immer auf Feindschaft sann. So nimmt er Fühlung mit dem Pöbel von Biğāya auf und bemächtigt sich mit dessen Hilfe dieser Stadt. Als er in Biğāya Fuß fasst, strömen $\mathrm{zu}$ ihm von überall her allerlei Frevler und Meuterer. Dieser Machtzuwachs weckt seine Begehrlichkeiten auch in Bezug auf andere Gebiete, und dieser Herrscher bringt auch Algier, Miliana, Ašìr und Qal'at Banī-Ḥammād in seine Gewalt, wonach er nach Biğāya zurückkehrt. Die Bevölkerung der unterworfenen Gebiete setzt der erwähnte Gewaltherrscher der Entehrung aus, er enteignet sie nach seinem Belieben und erlegt ihr erdrückende Abgaben auf. Auch von seinen Anhängern muss die Bevölkerung allerlei Erniedrigungen und Übergriffe erleiden. Angesichts dieser Erfolge wähnt er nun, das gesamte Gebiet beherrschen zu können, und begibt sich nach Constantine, das er vergeblich zu bezwingen sucht. Als die Almohaden von alledem Kenntnis erlangen, rüsten sie sich zum Feldzug. Einige Tāalibs werden mit der Aufgabe betraut, die Flotte eiligst klarzumachen. Anderen Ṭālibs wird die Befehlsgewalt über das ausrückende almohadische Heer übertragen, und man gibt ihnen neben Empfehlungen religiösen Charakters die Anweisung, den Bewohnern der unterworfenen Gebiete körperliche und materielle Unversehrtheit zuzusichern sowie den militärischen Aktionen die Aufforderung vorauszuschicken, sich den Almohaden zu

\footnotetext{
${ }^{257}$ Kitāb al-'ibar, Bd. 6, S. 70.
} 
unterwerfen. Was den Herrscher von Mallorca anbelangt, so durchstreift er einer Heimsuchung gleich derweil die Gegenden. Dabei erweist es sich für die Almohaden als glückhaft, dass er sein Lager bei Constantine aufschlagen lässt, das er unablässig, jedoch erfolglos belagert und somit von der rechtzeitigen Flucht nach Mallorca später abgelenkt wird. Indes erreicht das almohadische Heer Miliana, dessen Bewohner reuig um Vergebung bitten und sich entschuldigen, sich in der Gewalt der Angreifer befunden zu haben. Die Angreifer fliehen in alle Richtungen, werden jedoch von den in der Umgebung siedelnden Stämmen teils umgebracht teils gefangen genommen und den Almohaden übergeben. Den Țālibs der almohadischen Flotte, die gemäß einer vorher getroffenen Abmachung sich mit der almohadischen Armee in Algier hätten treffen sollen, gelingt es mit der Unterstützung der Einwohner, mit eigenen Kräften diese Stadt in Besitz zu nehmen. Dabei werden der Cousin des Herrschers von Mallorca sowie einige seiner Gefährten gefasst. Von den Šaihss der Stadt erfahren diese Almohaden, dass die in Biğāya gefangen gehaltenen Almohaden von den Angreifern nach Mallorca gebracht werden sollen, und deswegen setzt die almohadische Flotte eiligst ihren Weg nach Biğāya fort. In der Nähe dieser Stadt angelangt hält Šaih Abū-Muhammad 'Abdallāh Ibn-Abī-Ishạāq eine Ansprache an die Bevölkerung und gewinnt sie für die Almohaden. Ein heftiges Gefecht entbrennt danach vor den Mauern der Stadt zwischen den Almohaden und den mallorquinischen Angreifern, welche schließlich in die Flucht geschlagen werden können. Die Almohaden betreten daraufhin die Stadt, finden ihre gefangen gesetzten Brüder unversehrt vor und bemächtigen sich der Schiffe des mallorquinischen Herrschers. Sie benachrichtigen von diesem Sieg die Ṭālibs der inzwischen bei Mattīğa angelangten almohadischen Armee, die ihrerseits diese Benachrichtigung um den Bericht über ihre militärischen Erfolge erweitern und an den almohadischen Herrscher weiterschicken. Was den Herrscher von Mallorca bei Constantine anbetrifft, so ist er, von all seinen Verwandten und Helfern im Stich gelassen, dem Tode geweiht.

Der Brief schließt mit der Aufforderung, Gott für die Siege der Almohaden gebührend $\mathrm{zu}$ danken, diese Mitteilungen überall $\mathrm{zu}$ verbreiten und die vom vorliegenden Brief angefertigten Kopien an die Gebiete in der Umgebung zu verschicken.

\section{1. Übersetzung des Briefes Nr. 29}

Vom Befehlshaber der Gläubigen, dem Sohn des Befehlshabers der Gläubigen, dem Enkel des Befehlshabers der Gläubigen - Gott möge ihnen Seinen Bestand zuteil 
werden lassen und ihnen Seine Unterstützung gewähren - an die Tāalibs, Almohaden, Šaihs, Notabeln und die Gesamtheit der Bewohner Sevillas - Gott möge ihnen allen Seine Barmherzigkeit und Milde angedeihen lassen. Friede, Gottes Gnade und Seine Segen mögen euch zuteil werden ${ }^{258}$.

Dieses unser Schreiben an euch - Gott möge euch erfreuliche und angenehme Nachrichten vernehmen lassen und euch durch Seine Gnade und durch Seine Macht alle sichtbaren Gnadenerweisungen und allumfassende Unversehrtheit angedeihen lassen, und Er möge euch durch das Gerechte und Gütige dieser großen (almohadischen) Sache am rechten Pfeiler und im schützenden Schatten Zuflucht nehmen lassen - ergeht an euch aus der Residenzstadt Marrakech - Gott möge sie vor allem Übel bewahren. Wir preisen Gott - lobgepriesen sei Er - für Seine Gnadenbezeigungen, welche aufzuzählen unmöglich ist, und für Seine (glückhaften) Geschicke, die sich weder umschreiben noch beziffern $^{259}$ lassen, und welche zu benennen Worte nicht imstande sind, selbst wenn man mit ihnen das Äußerste (am Ausdrucksvermögen) erreichte und selbst wenn man darum höchste Anstrengungen aufwendete. Wir bitten Ihn - gelobt sei Er - um Seinen Beistand dabei, Ihm für diese Seine Gnadenbezeigungen und (glückhaften) Geschicke gebührend danken zu können, uns dabei Seiner (rechten) Leitung und Unterstützung erfreuend [unklar ${ }^{260}$ ]. Mit diesem Schreiben empfehlen wir euch an, Furcht vor Gott lobgepriesen sei Er - zu haben, Seinen Willen zu befolgen, Ihn um Beistand anzurufen und euch auf Ihn allein zu verlassen.

Ihr habt bereits erfahren - Gott möge euch den Erfolg bescheren und euch rechtleiten, Er möge euch den Weg zu eurem Wohl beschreiten und einschlagen lassen und Er möge euch dabei, am des Gehorsams festesten Band ${ }^{261}$ Zuflucht zu nehmen, Seinen Beistand und Seine Unterstützung gewähren - wie sich der Ungläubige, der Treulose, der Verfluchte, der (letztlich) dem Verderben anheim fallende Verräter, der Überrest des irrenden Abschaums und das Überbleibsel des dahinschwindenden Unglaubens, dieser Elende von Mallorca - Gottes Fluch sei über ihm - befand, dass er sich nämlich auf seine Insel verkroch, die Aufrichtigkeit seines Aus- und Inwendigen im Hinblick auf

\footnotetext{
${ }^{258}$ Der darauf folgende einleitende Teil wurde bei der Übersetzung übergangen, s. Kapitel 8.2.

${ }^{259}$ An dieser Stelle (Mağmūc rasā'il muwaḥhidīya, S. 170) lautet das arabische Original ,,[...] wa-qisamihī allatī lā yuhịt bihā ar-rasm wa-'l-ğadd“. Wahrscheinlich müsste statt „ğadd“ „hadd“ gelesen werden.

${ }^{260} \mathrm{Im}$ arabischen Satz an dieser Stelle (Mağmū' rasā'il muwaḥhidīya, S. 170) ,wa-nas'aluhū subhānahū taufĩqan ilā qiyām bi-šukrihā (aiy bi-šukr ni'amihī wa-qisamihī) [...] wa-'aunan 'alā taufĩqihī al-wāğib min ḥaqqihā yumtarā bihī al-mazīd min faụlihī wa-yustanğaz al-wa'd“ ist die Passage ab „wa-'aunan“ bis „,haqqihā" unverständlich.

${ }_{261}^{26}$ Im arabischen Original (Mağmū' rasā’il muwaḥhidīya, S. 170) steht ,wa-a ānakum (Allāh) 'alā al-

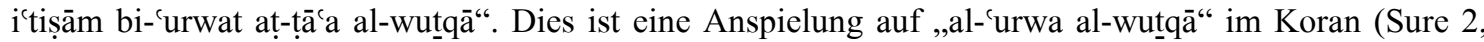
Vers 256 und Sure 31, Vers 22).
} 
den Gehorsam (den Almohaden gegenüber) vorgab, die Absicht gefasst zu haben vorspiegelte, sich in die Scharen der Almohaden einzureihen und in ihren Dienst zu treten, sowie vortäuschte, das Einsichtsvermögen wiedererlangt zu haben. Dabei sann er auf Feindschaft Gott und Seinem Gesandten gegenüber, hielt sich vom Pfade der Wahrheit und vom rechten Weg fern und gedachte inwendig, die breite offenkundige Bahn zu verlassen und von ihr abzuweichen [unklar ${ }^{262}$ ]. Er passte ferner die Gelegenheit $\mathrm{ab}$, eine Revolte oder eine Meuterei anzuzetteln, und wartete heimlich auf die (für die Almohaden) widerwärtigen Schicksalsfügungen ${ }^{263}$, die sich (letztlich) für ihn selbst bei seiner Befeindung der Almohaden und seiner Auflehnung gegen sie als schadhaft erweisen sollten. In diesem geschilderten Zustand verharrte er, bis er die Klinge seines (eigenen) Todes ausgrub, mit seinem eigenen Huf sein Verderben aufscharrte ${ }^{264}$ und sich selbst in das hinabstürtzte, wo ihn seine bösen Ränke umgaben ${ }^{265}$ von links, rechts, vorn und hinten. Er verschmähte die Gunstbezeigungen Gottes, und Gott ließ ihn daraufhin das Gewand des Hungers und der Angst spüren ${ }^{266}$. Er (d. h. der erwähnte Herrscher) trachtete, nach der Fügungsgewalt Gottes zu langen, und wurde dabei zu einem (schmählich) Davongejagten ${ }^{267}$. Das ist die übliche vornehme Verfahrensweise Gottes mit denjenigen, die Seiner Sache (d. h. dem Almohadentum) trotzen, die Er auserkoren hat, um die einzig wahre Anbetung wieder obwalten zu lassen, und die Er

${ }^{262}$ Der vom Herausgeber vokalisierte Satz im arabischen Original an dieser Stelle (Mağmū' rasā'il muwaḥhidīya, S. 170) lautet „mubra' li-'l-ğusur fi 'l-irtiğā' “ und wirkt auf den ersten Blick unverständlich. Folgende zwei Überlegungen könnten dazu beitragen, dessen Sinn zu verstehen: statt „ğusur“ müsste man m. E. ,ğasr“ lesen, das als Verbalsubstantiv vom Verb „ğasara“ - siehe „Supplément aux dictionnaires arabes“ (Bd. 1, S. 194) - belegt ist; wenn hier mit „irtigāà “ " das Brüllen (einer Kamelin) gemeint ist, so ergäbe dies eine aufschlussreiche Analogie zum Verb „na`aqa“, d. h. „krähen (Rabe); blöken (Schaf)“, das in der Wendung „na'aqa bi-'l-fitna“, d. h. den Almohaden den Gehorsam aufkündigen, gegen sie rebellieren“ z.B. in „al-Mann“ (S. 231) vorkommt. Auf diese Weise könnte das obige Zitat sinngemäß mit „er, d. h. der Herrscher von Mallorca, war völlig von dem Vorhaben beherrscht, die Rebellion gegen die Almohaden anzuzetteln“ übersetzt werden.

${ }^{263}$ Das hier gebrauchte ,dā'irat as-sū' kommt im Koran in Sure 48, Vers 6 und in Sure 9, Vers 98 vor. In Parets Übersetzung ,schlimme Schicksalswendungen“.

${ }^{264}$ Die arabische Entsprechung an dieser Stelle lautet (Mağmū` rasā’il muwahhidīya, S. 170), ,ilā an istatāra šafrat hatfihī wa-baḥata 'an hulkihī bi-ẓilfihī“, wobei der letzte Teil dieses Zitats wörtlich eigentlich „bis er [...] nach seinem Verderben mit seinem eigenen Huf scharrte“. Damit wird Bezug genommen auf die arabische Redewendung (Kitāb ğamharat al-amtāl, Bd. 1, S. 363) ,hatfahā tabhat da’n bi-azlāfihā“،, d. h. „ihr Verderben scharren die Schafe mit ihren eigenen (gespaltenen) Hufen auf“' Das Interessante dabei ist, dass sich darüber hinaus sowohl „šafra“ als auch ,atāāa“, das sich wie auch „,istatāra“ von der arabischen Wurzel „TWR“ ableitet, im Kommentar zur angeführten Redewendung finden.

${ }^{265}$ Anspielung auf Sure 35, Vers 43.

${ }^{266}$ Zitat aus dem Koran (Sure 16, Vers 112), nur dass das Subjekt am Anfang des Satzes und später das Objekt sich im Koran auf ,sie“, d. h. eine Stadt beziehen. Siehe ferner die Textbelege im Kapitel „Kleider und Gewänder" im Anhang 2.

${ }^{267}$ Der arabische Satz an dieser Stelle (Mağmūc rasā’il muwahhịidīya, S. 171) lautet ,wa-rāma as-sumūw ilā manāl ḥukm Allāh bi-raddihī hāài’an wa-șarfihī". Der letzte Teil dieses Satzes könnte sich eventuell auf das koranische „qulnā lahum kūnū qiradatan hāsi'īn“, d. h. werdet zu davongejagten Affen, (Sure 2, Vers 65 und Sure 7, Vers 166) beziehen. 
auserwählt hat, um das von Ihm geoffenbarte Gesetz zu verbreiten und zu festigen, und welcher Er an Seinem unterstützenden Beistand und Seiner zum Obsieg verhelfenden Hilfe das Reichliche und das Offenkundige beschert hat. Und so ist jeder, der in Erscheinung tritt, um das Almohadentum von sich $\mathrm{zu}$ weisen und sich von ihm abzukehren, umringt von seiner rechten und von seiner linken Seite von den zu Grunde richtenden Fährnissen. Dies ist das vollkommene Wirken Gottes - lobgepriesen sei Er , durch welches Er die vollkommenen Erzeigungen Seiner Huld zugunsten des Almohadentums hat unaufhörlich geschehen und sie in der gewohnten vortrefflichen Weise fortwähren lassen sowie das Mehrfache ihres Wachstums und ihrer Zunahme in jeder Unternehmung und bei jeder in Angriff genommenen Aufgabe hat augenscheinlich werden lassen. Gelobt sei Gott für die Erweisungen Seiner Gnade, die kein Fassungsvermögen je zu fassen (wörtl. zu zählen noch aufzuzählen) vermag.

Als sich diesem Frevler eine günstige Gelegenheit bot, ergriff er - wie er wähnte $\operatorname{sie}^{268}$, und als er den günstigen Augenblick für den Angriff gekommen sah, machte er sich mit seinem nichtigen Urteilsvermögen daran, diesen Augenblick zu nutzen, und erhoffte sich von seinen wesenlosen Wünschen und seinen nicht eintreffenden Hoffnungen, dass sie sich bewahrheiten und in Erfüllung gehen würden. Doch Gott ließ diese seine Hoffnungen sich als wesenlos erweisen, Er hat dessen kurze Schatten zusammenschrumpfen lassen ${ }^{269}$ und ließ das Los dessen verwerflichen Trachtens das Verschwinden dessen [kreisender ${ }^{270}$ ] Sache und ihr Verglühen sein. Als dies geschah (d. h. als sich diese erwähnte günstige Gelegenheit ergab), nahm dieser Frevler Fühlung mit dem in Biğāya befindlichen Abschaum auf, dessen Gläubigkeit gering, dessen Glaube und feste Überzeugung schwach waren und dessen Herzen der Satan, der unzertrennliche Geselle, schön dünkte. Er (d. h. dieser Abschaum) ermöglichte diesem Frevler, die Herrschaft über Biğāya an sich zu reißen (wörtl. ermöglichte ihm, den Rücken Biğāyas zu besteigen, und half ihm dabei, den Gipfel dieser Stadt zu erklimmen ${ }^{271}$ ) und half ihm, sie zu unterwerfen und zu bezwingen. Und als er in Biğāya Fuß gefasst hatte, seine Anhänger, diese Missetäter und Hurer, in ihr ausgeschwärmt waren und der Morgen und der Tag seiner wesenlosen Hoffnung, Biğāya in seine

\footnotetext{
${ }^{268}$ Im arabischen Text (Mağmū' rasā'il muwaḥhidīya, S. 171) steht „lammā 'annat li-'l-fāsiq al-furṣa iğtanama bi-za'mihī intihāzahā“, was wörtlich übersetzt lautet „,nutzte er ihre Ergreifung““.

${ }_{269}$ Hier eine Umschreibung für ,,jemands Macht, Einfluss schwinden lassen“.

${ }^{270}$ Die arabische Entsprechung an dieser Stelle (Mağmūc rasā’il muwaḥhidīya, S. 171) lautet ,talāšī amrihī ad-dā'ir".

${ }^{271}$ Der arabische Satz hierfür lautet (Mağmū' rasā’il muwaḥhidīya, S. 171) „fa-yassarū lahū tamahhud ṣahwatihā wa-a'ānūhū 'alā tašattum dirwatihā". Höchstwahrscheinlich ist mit „tašattum“ „tasannum“ gemeint. Siehe ferner die Einträge im Kapitel „Festungskonzepte“ im Anhang 2.
} 
Gewalt zu bringen, glanzerfüllt angebrochen waren, da rotteten sich die Räuber und Wegelagerer (wörtl. Wölfe und Hunde der Überfälle) um ihn zusammen, da stieß das Pack der Meuterei und ihr Gesindel zu ihm und es scharten sich um ihn die Meuten der ihm in seiner Unwissenheit Ähnlichen und der ihm in seiner Missleitung Helfenden zusammen. All dieser Haufen ließ diesen seinen Überfall an Gefährlichkeit zunehmen und Besorgnis erregende Ausmaße annehmen. Nach alledem begehrte er, weitere Städte unter seine Botmäßigkeit zu zwingen, und seine verderbte Seele verleitete ihn dazu, sich auch der näheren Umgebung von Biğāya zu bemächtigen und die nahen Landstriche und Gegenden in seine Gewalt zu bringen. Zum Gegenstand der Begehrlichkeiten und Hoffnungen dieses Ungläubigen wurde danach, noch mehr zu besitzen. Die Schonfrist jedoch, die Gott ihm dabei gewährte, verblendete ihn, und seine Unwissenheit und Missleitung setzten sein schwaches Einsichtsvermögen außer Kraft. So ging er um Algier, Miliana, Aš̄ir und Qal'at ${ }^{272}$ herum $^{273}$ und kehrte dann nach Biğāya zurück. Dieser zum Verderben Verurteilte und Ungläubige kam zurück, nachdem er diese (genannten) Gegenden durchzogen hatte. Bei seinem Durchziehen demütigte er die dortige Bevölkerung, gab die Bewohnerschaft der Entehrung preis, so wie etwa jemand der Entehrung preisgibt, der Gebote und Verbote missachtet, und zermalmte diese Gegenden, einem Mühlstein gleich, der mit seiner ledernen, das hinabrieselnde Mehl auffangenden Unterlage sich drehend zermalmt ${ }^{274}$, ohne jegliche Rücksicht auf die unter ihnen (d. h. unter der Bevölkerung) bestehenden Schutzverpflichtungen und verwandtschaftlichen Bindungen ${ }^{275}$. Bei diesem erwähnten Durchziehen eignete er sich gewaltsam den Besitz der Bewohner an und zweckentfremdete ihn. Der Bevölkerung bürdete er dabei eine unerträgliche und unzumutbare Last an (willkürlichen) Steuern und Abgaben auf, ließ an ihr seine tyrannischen Urteile vollstrecken, und seine Anhänger machten sie zur Zielscheibe ihrer tätlichen Angriffe und Gewalttätigkeiten. Er zwang der Bevölkerung seine Willkür auf, und sie wurde ohne Unterlass von (seinen) Demütigungen heimgesucht. Bei alledem folgte dieser Frevler in dieser seinen Verblendung seiner eigenen Laune und ließ sich durch die ihm gewährte Zeit, in der

\footnotetext{
${ }^{272}$ Mit Qal'at ist die Stadt Qal'at Banī-Hammād im Südosten Algeriens gemeint.

273 Dies ist die wörtliche Übersetzung des arabischen Satzes an dieser Stelle (Mağmūc rasā’il muwaḥhidīya, S. 172) „wa-tațauwafa 'alā al-Ğazā’ir [...]“. Aus den weiteren Schilderungen des Briefes geht eindeutig hervor, dass hier die Inbesitznahme Algiers und der im Folgenden genannten Städte gemeint ist.

${ }^{274}$ Zitat aus dem bekannten Gedicht von Zuhair Ibn-Abī-Sulmā (ca. 530-627). Siehe dazu „Šarh alqașā’id as-sab` at-ṭiwāl al-ğāhilīyāt‘‘ (S. 268).

${ }_{275^{\circ}}$ Die Wendung des arabischen Textes (Mağmū` rasā’il muwahhịidīya, S. 172) „wa-'arakahā [...] dūna murāqabat dimmatin fīhim wa-lā illin“ ist eine Anspielung auf Sure 9, Vers 10 des Korans, wo es heißt „kaifa wa-in yazhhurū 'alaikum lā yarqubū fîkum illan wa-lā dimmatan [...]“.
} 
geschilderten Weise handeln zu können, täuschen, dabei Gottes - gelobt sei Er (geoffenbarte) Wort vergessend „und es wird erfahren der Ungläubige, wer letztlich des Paradieses teilhaftig wird.“276

Und als aufgrund dessen, was ihm in Biğãya und in den westlich davon gelegenen Gebieten gelungen war, es ihn nach noch mehr gelüstete, und als ihn seine verderbliche Begehrlichkeit und seine Habgier übermannten und als ihn seine sich nicht bewahrheitenden Mutmaßungen glauben ließen, er würde auch Biğãyas weitere befestigte Orte bezwingen und sowohl dessen Städte als auch Landgebiete unter seine Botmäßigkeit zwingen können, da brach er nach Constantine auf - Gott möge sie beschützen - , darauf hoffend, die Bewohnerschaft dieser Stadt überlisten zu können, wähnend, seine Kriegslisten ${ }^{277}$ würden sich dabei wirksam erweisen, sich dieser Stadt $\mathrm{zu}$ bemächtigen, und äußerste Anstrengungen aufbietend und seine List und Trug anwendend, um sie in seine nichtige Gewalt $\mathrm{zu}$ bekommen. Doch er fand das Einsichtsvermögen ihrer Bewohner intakt, ihre (religiösen) Überzeugungen in der Gottesfurcht gegründet und ihre Herzen in vollkommener Weise durchdrungen von allen Anfechtungen standhaltendem Gehorsam und unbedingter Treue vor. So misslang mit Gottes Hilfe dieses sein Trachten, sein Entschluss erwies sich als nichtig und seinen gedemütigten Anhängern waren seine Schimpf und Schmach bei der Belagerung dieser Stadt augenscheinlich geworden. Dieser Frevler unterwarf Constantine einer fortdauernden Belagerung und mühte sich vergebens ab, sie in heimtückischer Weise einzunehmen (wörtl. begehrte Regen von seinen vergeblichen Bemühungen um ihre heimtückische Einnahme, die allerdings nur wasserlose Wolken waren). Bei all diesem ließen ihn ihre Bewohner - Gott möge ihnen beistehen - den Tod kosten, flößten ihm an Geringschätzung und Demütigung den Kelch des augenblicklich eintretenden Todes ${ }^{278}$ ein und töteten von seiner geringen Rotte und versprengten Bande zahlreiche Scharen, je einzeln und je zwei. Doch dieser Frevler setzte die Belagerung Constantines unentwegt fort, das verlustreiche Geschäft dabei hinnehmend, in die Gewänder der Verächtlichkeit und Nichtigkeit gehüllt, in die Kleider der Schmach und des Schimpfes

\footnotetext{
${ }^{276}$ Auch hier (Mağmū' rasā’il muwahhidīya, S. 172) liegt ein leicht abgewandeltes Koranzitat vor, denn dort heißt es „wa-saya lam al-kuffār li-man 'uqbā ad-dār““ (Sure 13, Vers 42), d. h. „und die Ungläubigen werden erfahren, wer (letztlich) des Paradieses teilhaftig wird“".

${ }^{277}$ Das an dieser Stelle (Mağmū‘ rasā'il muwahḥidīya, S. 172) gebrauchte Wort „hīyal“ konnte früher neben der genannten noch die Bedeutung „Gerätschaften z. B. zum Brescheschlagen“ haben.

${ }^{278}$ An dieser Stelle (Mağmū' rasā'il muwaḥhidīya, S. 173) steht im arabischen Text „ka'san ru’āman“ und damit ist sicherlich ,ka'san zu'āman“ gemeint.
} 
gekleidet $^{279}$ und das ertragend, was ihm an der Zermürbung (wörtl. am Schartigmachen der Klinge) seines dem Verderben geweihten Mobs und seiner unbelehrbaren Anhänger zuteil wurde.

Nachdem uns - Gott möge euch den Erfolg verleihen und euch Seinen Willen befolgen lassen - über das Unwesen dieses Frevlers berichtet wurde und nachdem bei uns über seine hinterhältige und heimtückische Einnahme Biğāyas kein Zweifel mehr bestand, richteten wir unser Augenmerk darauf, wie wir der Not der Muslime abhelfen könnten, in deren Mitte die Tyrannei dieses Frevlers um sich gegriffen hatte, und welche (d. h. Muslime) seit langer Zeit bereits seine Gewalt- und Zwangsmaßnahmen haben ertragen müssen. Dieser Aufgabe nahmen wir uns mit gebührendem Fleiß an, indem wir die (almohadischen) Truppen in Bereitschaft versetzten und die für die Rückeroberung dieser Gebiete erforderlichen Maßnahmen ergriffen. Dabei hatten wir die unumstößliche Gewissheit, dass Gott - lobgepriesen sei Er - all jenen auflauert ${ }^{280}$, die Ihm trotzen und von Seinem Weg abweichen, und dass Seine göttliche Hilfe und Seine göttlichen Beistandsleistungen sowohl Ausrüstung als auch Mengen (der Krieger) überflüssig machen und den Kriegsscharen und Truppen ebenbürtig sind. Nichtsdestominder trafen wir die genannten Vorbereitungen mit gebührender Entschlossenheit und unserer Gewohnheit gemäß handelnd. Dabei hatten wir die Zuversicht, dass Er uns Seinen Beistand und Unterstützung erfahren lassen wird, erbaten (von Gott) die Erfüllung Seiner immer eintreffenden Verheißungen, setzten all unser Vertrauen in Ihn - Preis sei Ihm - bei allen sowohl leicht als auch schwer zu bewältigenden Aufgaben und baten Ihn - lobgepriesen sei Er - inbrünstig um die zum Erfolg und zu rechtem Handeln verhelfenden Erzeigungen Seiner Huld. Wir betrauten einige der Ṭālibs - Gott möge ihnen beistehen - mit der Aufgabe, bezüglich der Kriegsschiffe die nötigen Maßnahmen zu ergreifen, sie klarzumachen und all das zur Verfügung zu stellen, was diese Schiffe an Ausrüstung und Besatzung benötigten. Wir befahlen diesen Ṭālibs, sich darin binnen möglichst kurzer Zeit zu beeilen. Des Weiteren beriefen wir ein sieghaftes Heer und eine gesegnete zahlreiche Kriegsschar von den Almohaden - Gott möge ihnen Mächtigkeit verleihen - zusammen, an deren Spitze wir die Ṭālibs - Gott möge ihnen Mächtigkeit verleihen - gesetzt haben, denen wir die Befehligung dieses almohadischen Heeres anvertraut und welchen wir die Verantwortung für es übertragen haben. Diesen erwähnten Ṭālibs haben wir Gottesfurcht im Großen und Kleinen anempfohlen sowie

\footnotetext{
${ }^{279}$ Im mittelalterlichen arabischen Schrifttum wird ein emotionaler Zustand häufig durch das Bild ausgedrückt, man sei in das Gewand der jeweiligen emotionalen Verfassung gehüllt. Siehe hierzu die Einträge im Kapitel „Kleider und Gewänder“ im Anhang 2.
} 
befohlen, sich an die Sunna ${ }^{281} \mathrm{zu}$ halten, ihre vollkommenen Gebote genau zu beobachten und an den Bestimmungen und Richtlinien des Mängel behebenden herrscherlichen Waltens gegenüber den Untertanen festzuhalten. Ferner gaben wir ihnen die Anordnung, die körperliche und materielle Unversehrtheit allen Bewohnern jener Gebiete, seien es Stadt- oder Landbewohner, zuzusichern, ihrem militärischen Vorgehen die Warnung (vor den Folgen der antialmohadischen Umtriebe) sowie den Aufruf, vom antialmohadischen Handeln Abstand zu nehmen, vorauszuschicken und dies in einer solchen Weise zu verkünden, dass sowohl die nahen als auch die fernen Bewohner dieser Gebiete im gleichen Maße davon erführen. Dieser (obigen) Anordnung lag unsere Absicht zugrunde, einerseits die Rechtmäßigkeit des Vorgehens der Almohaden gegen die genannten Bewohner zu untermauern und andererseits ihnen (d. h. den Bewohnern) Billigkeit und Milde zuteil werden zu lassen. Nach diesem hat man sie alle, den Segen Gottes, Sein glückhaftes Eingreifen und Seinen Beistand zu ihren Gunsten erbittend, sich in Marsch setzen lassen, wobei der Beistand Gottes - lobgepriesen sei Er - und Sein - Preis sei Ihm - helfendes Eingreifen sie trugen, Sein - gewaltig ist Seine Macht den Erfolg bescherendes Wirken sie rechtleitete und die Zeichen (Seiner) Unterstützung ihnen den erfolgreichen Ausgang ihres Vorhabens ankündigten und verhießen.

Während dieser konkreten Schritte und im Laufe dieser glückhaften Maßnahmen war diesem Elenden das Warten zu lange geworden, was zur Folge hatte, dass seine Kopflosigkeit und Verwirrung zunahmen und er (weiterhin) darüber in Unwissenheit verharrte, worin seine Niedertracht ihn samt seiner Hoffnung hinabgestürzt hatte. Dies geschah, damit er sich noch mehr Sünden zuschulden kommen ließe und damit die ihm gewährte Frist (vor der Unterbindung seines Unwesens) größer würde. So kam es, dass er den Kampf allein aufzunehmen trachtend sich daran machte, Ortschaften und Siedlungen $\mathrm{zu}$ durchqueren ${ }^{282}$ sowie Anhöhen und Niederungen $\mathrm{zu}$ durchstreifen, überall durch seine Gewaltmaßnahmen Heimsuchung und Widerspenstigkeit um sich greifen machend. Dies machte er in seiner Dreistigkeit gegenüber Gott und in seiner Verschmähung des Allmächtigen, gemäß seiner Gewohnheit, andere zu drangsalieren, und aus seiner trügerischen Vorstellung heraus, die ihn in seinem Handeln

\footnotetext{
${ }^{280}$ Anspielung auf Sure 89, Vers 14 des Korans.

${ }^{281}$ Mit „Sunna“ werden Aussprüche und Handlungen Mohammeds bezeichnet, die nach seinem Tod zu gesetztlich verbindlichen Präzedenzfällen wurden und ab dem 9. Jahrhundert neben dem Koran die zweite Quelle des islamischen Rechtes bilden.

${ }^{282}$ Im arabischen Taxt (Mağmū' rasā'il muwaḥhidīya, S. 174) wird an dieser Stelle das Verb ,yataḥallal“ gebraucht, doch ,yatahallal“" ist hier wahrscheinlich gemeint.
} 
verblendete $^{283}$. Zum (glückhaften) Eingreifen Gottes zugunsten Seiner unbezwingbaren (almohadischen) Sache, welches den Almohaden unerwartet zuteil wurde, (ferner) zu Seinem zum Obsieg verhelfenden Beistand, welcher sich weit über die menschliche Kraft hinaus erstreckt (wörtl. welcher mit der menschlichen Kraft weder verbunden noch verknüpft ist), und zu Seiner machtvollen Hilfe, die weder durch Macht noch durch Kraft erlangt oder erwirkt werden kann, gehörte, dass er (d. h. der Mallorquiner) bei Constantine - Gott möge sie behüten - sein Lager aufschlagen ließ. Zu diesem geschilderten Eingreifen Gottes gehörte ferner, dass er Constantine beharrlich belagerte und bedrängte, dass er in seiner Begierde, diese Stadt zu bezwingen, der Absicht seines ihn zur Missleitung anstiftenden Verführers und seines Verblenders ${ }^{284}$ folgte und (dadurch) von seiner Hoffnung abgelenkt wurde, auf seine der Plünderung preisgegebene Insel ${ }^{285}$ und auf seine heimische Scholle zu fliehen, bis die Sache Gottes, welcher kein Fliehender $\mathrm{zu}$ entfliehen vermag und welche an Macht niemand $\mathrm{zu}$ übertreffen imstande ist, jäh über ihn hereinbrach, wobei dieser Mallorquiner in den Schlummer der Unachtsamkeit und Selbsttäuschung versunken war und der Belagerung der Stadt fortdauernd oblag.

Die Almohaden - Gott möge ihnen Mächtigkeit verleihen - setzten ihren tugendhaften Zug und ihr frommes und löbliches Streben indes fort. Sie verfolgten ihr vom göttlichen Beistand umgebenes Ziel, das einzig in der Erlangung des Wohlwollens Gottes lobgepriesen sei Er - bestand, und gelangten schließlich nach Miliana, der ersten Stadt der östlichen Gebiete ${ }^{286}$. Die Einwohner dieser Stadt sowie die in ihrer Nähe siedelnden Stämme ergaben sich den Almohaden, fanden Schutz in der Zufluchtnahme bei dieser glückhaften (almohadischen) Sache, sagten sich zugunsten Gottes - lobgepriesen sei Er - von der irrenden Rotte und vom gegen Ihn aufbegehrenden Satan los, erlahmten nicht bei ihren Reuebekundungen und ihren Bitten um Gnade und begehrten, dass von den Wolken der Verzeihung und Nachsicht über sie sämtliche reichlichen Regen spendenden Wolken sich ergießen mögen ${ }^{287}$. Sie baten ferner um Entschuldigung,

\footnotetext{
${ }^{283}$ Der arabische Satz an dieser Stelle (Mağmū` rasā’il muwahhidīya, S. 174) „wa-zannan kadūban

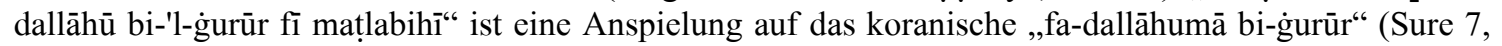
Vers 22).

${ }^{284}$ Der Widerpart Gottes ist mit diesen Bezeichnungen gemeint.

${ }^{285}$ Mallorca ist von den Almohaden erst 1203 erobert worden (Historia política del imperio almohade, Bd. 2, S. 398 ff.).

${ }^{286}$ Mit den „östlichen Gebieten“ ist in den almohadischen Briefen annähernd das Gebiet des Zentralen Maghreb gemeint.

287 Die entsprechende Passage im arabischen Original an dieser Stelle (Mağmūc rasā’il muwaḥhidīya, S. 175) lautet „wa-'stamțarū min suhub al-'afw wa-'l-iqāla kulla madār“, wobei höchstwahrscheinlich mit „madār“ „midrār“ gemeint ist. Siehe ferner die Einträge im Kapitel „Gnadenbezeigungen und Gunsterweise“ im Anhang 2.
} 
unterworfen gewesen zu sein (wörtl. im Griff der Unterwerfung gewesen zu sein) und sich in der Schlinge der Gefangenenfessel befunden zu haben. Die Almohaden nahmen ihre Reue an, ließen ihnen gegenüber Barmherzigkeit und Gnade walten und ermunterten sie, in einer solchen Weise den breiten Weg des Heils zu befolgen und sich im allen Anfechtungen standhaltenden Gehorsam und Treue zu üben, dass sie (d. h. diese Weise) ihnen das Wohl im Diesseits und die glückhafte Heimstätte im Jenseits einbringe. Die Elenden, die in dieser Stadt waren, stoben Rettung suchend auseinander und wurden (letztlich doch nur) zu den Orten ihrer Niederstreckung geschleift. Denn die Stämme, welchen sie auf ihrer Flucht begegneten, töteten sie allenthalben und übergaben diejenigen der Fliehenden, die der Tod vorerst verschont hatte, unterworfen, gedemütigt und in der Schlinge der Gefangenenfessel den Almohaden - Gott möge ihnen Mächtigkeit verleihen. Auf diese Weise konnte kein einziger von ihrer geringfügigen, verächtlichen und kleinen Schar den Almohaden entrinnen. Die (übrigen) Untertanen - Gott möge ihnen den Erfolg verleihen - folgten diesem (geschilderten) rechten Handeln: Sie setzten gefangen und schlugen in Eisen all diejenigen der Elenden, derer sie habhaft werden konnten (wörtl. bekleideten sie mit dem Kleid des Gefangensetzens und des Ineisenschlagens) und brachten diese Erniedrigten, Gedemütigten und Unterworfenen (wörtl. brachten sie, geführt an den Zügeln der Erniedrigung und getrieben mit den Riemen der Verächtlichkeit und Unterwürfigkeit) daraufhin $\mathrm{zu}$ den Almohaden - Gott möge ihnen Mächtigkeit verleihen.

Was die Ṭālibs der durch Gottes Beistand sieghaften (almohadischen) Flotte anbelangt, so waren sie mit den Almohaden - Gott möge ihnen Mächtigkeit verleihen - in Tilimsen - Gott möge alles Übel von ihm abwenden - zusammengekommen und hatten vereinbart, die (nächste) Zusammenkunft in Algier - Gott möge alles Übel von dieser Stadt abwenden - statthaben zu lassen. So glitten die durch Gottes Beistand getragenen Schiffe nach Algier und gelangten dorthin vermittels des Segens Gottes und der Glückhaftigkeit dieser machtvollen (almohadischen) Sache. Es gelang ihnen die Bezwingung dieser Stadt, und sofort löste sich ihr Unlösbares und ihre dichte pechschwarze Dunkelheit und ihre Finsternis lichteten sich durch die Lichter dieser erhabenen (almohadischen) Botschaft. Die Bewohner Algiers beeilten sich, die Tore der Stadt zu entriegeln und diejenigen des darin befindlichen Mobs der Missleitung und des Gesindels zu ergreifen, die zu ergreifen sie vermochten. Da ist dieser verfluchten Bande das Schlimme dessen, was ihnen letztlich bevorsteht, und ihres (ewigen) 
Aufenthaltsortes (im Jenseits) augenscheinlich geworden. Zu denjenigen, die man mit den Fesseln der Unterwerfung belegt hat und an deren demütig gesenkten Häuptern die Schlingen der Gefangenschaft zugezogen wurden, gehörte neben einem Cousin des irrenden Elenden auch eine Gruppe von angesehenen Persönlichkeiten seiner verfluchten Teufel sowie einige seiner einflussreichsten und führenden Gefährten - Gott möge die Almohaden all ihrer Gesamtheit habhaft werden lassen und den Almohaden durch die Ausmerzung dieser Feinde Seine Gnade erweisen - durch Seine Güte.

Die Šaihs und Notabeln von Algier berichteten den Almohaden, dass die Elenden in Biğāya vorhätten, die in ihrer Gewalt befindlichen Almohaden - Gott möge ihnen Mächtigkeit verleihen - nach Mallorca - Gott möge sie in die Hand der Almohaden geben - zu bringen. Als die Almohaden dies vernahmen, setzten sie eilends ihren Weg nach Biğāya fort, denn sie waren von Besorgnis ergriffen und wollten verhindern, dass diese Elenden ihre Hoffnung (auf die Verschiffung der Almohaden nach Mallorca) erfüllten und dazu übergingen, mittels Heimtücke und List dieses ihr Vorhaben in die Tat umzusetzen. Als sie nach Biğāya gelangten, sahen sie, dass die dort befindlichen beiden Brüder des Elenden darauf, was ihnen zweckmäßig erschien, großen Fleiß verwendet sowie sich äußerst angestrengt hatten, die nötigen Vorkehrungen und Vorbereitungen zu treffen. So schlugen sie ihre Zelte vor den Toren der Stadt auf, stellten ihre Wachposten an den Stadteingängen auf und ließen ihre der Niederlage geweihten Kriegsscharen die unterirdischen Gänge und (andere) Durchgänge besetzen. Doch niemand kann vor der Sache Gottes schützen noch vermag jemand, sie zu besiegen, ihr zu trotzen oder ihr zu widerstehen. Denn dies ist die Sache Gottes, der Gott Seinen Beistand wider alle Widersacher gewährt und welche Er alle Feinde und Gegner bezwingen lässt. Dies ist die Sache Gottes, zu welcher Seine Verheißung geschehen ist, dass sie einst über das herrschen werde, was sowohl im Osten als im Westen unserem Propheten - Friede sei über ihm - gehört $^{288}$. Als die gesegnete (almohadische) Flotte in die Nähe der Stadt gelangte, trat von den Ṭālibs - Gott möge ihnen den Erfolg bescheiden - Šaih Abū-Muhammad 'Abdallāh Ibn-Abī-Isḥāq - Gott möge ihm den erhabenen Rang gewähren - vor die Bewohner Biğāyas und hielt an sie Gott möge ihnen den Erfolg bescheiden - eine Ansprache, welche sie mit Zuversicht erfüllte und ihnen die Furcht (vor den Almohaden) benahm ${ }^{289}$. Er erklärte ihnen, dass

\footnotetext{
${ }^{288}$ Im Satz an dieser Stelle (Mağmū` rasā'il muwaḥhidīya, S. 177) ,al-mau'ūd bi-'l-istîlā' 'alā mā ruwīya li-nabīyinā [...] min al-mašāriq wa-'1-maġārib“ muss ,,ruwīya“ zu ,zuwīya“ korrigiert werden.

289 An dieser Stelle (Mağmū ${ }^{`}$ rasā'il muwaḥhidīya, S. 177) steht im arabischen Text „fa-hātaba ahl albalad [...] bimā basaṭa nufūsahum wa-makkana ta'sīsahum“, wobei höchstwahrscheinlich mit „ta'sīs“" eigtl. „ta’nīs“" gemeint ist.
} 
die Almohaden auf ihr Wohl bedacht seien und dass die Zusicherung ihrer aller körperlichen und materiellen Unversehrtheit den Almohaden aufgetragen worden sei. Danach hieß er die genannten Bewohner wieder ihre Häuser betreten und sich (den Almohaden gegenüber) gehorsam bezeigen. Und es kehrte $\mathrm{zu}$ den Bewohnern ihr Einsichtsvermögen wieder zurück, ihre Absichten und Vorsätze wurden unerschütterlich in der Frömmigkeit und ihr Inwendiges (wörtl. ihr Inneres und Verborgenes) war im Glauben und der unumstößlichen Überzeugung lauter geworden. Sie ergaben sich ohne Zaudern den Almohaden, stießen die mallorquinishen Elenden von sich, so wie etwa ein Verschmähender, Widerwillen Empfindender von sich stösst, und verzichteten auf die Parteiergreifung für die treulose und ungläubige Sache dieses Elenden zugunsten Gottes - gepriesen sei Er - und der Streiter für Seine mächtige Sache.

Der Unglaube hatte in Biğāya einige Kraft, durch welche sich diese Elenden hatten verblenden lassen, und den Rest des Dünkels, mit welchem gewappnet sie die almohadischen Angreifer - Gott möge ihnen beistehen - auf dem Schlachtfeld bekriegen zu können wähnten. Die almohadischen Angreifer - Gott möge ihnen Seine Unterstützung gewähren - traten den Mallorquinern entgegen, riefen Gott - Preis sei $\mathrm{Ihm}$ - um Seinen Beistand gegen diese Feinde an, leiteten ein in seiner Heftigkeit nicht $\mathrm{zu}$ überbietendes Gefecht gegen sie ein, bekriegten und bekämpften sie in vollkommenster Weise und haben Gott - lobgepriesen sei Er - in allen mit Schwert und mit Lanze geführten Kämpfen, welche Er sie ausfechten ließ, für wahrhaftig gehalten. Die (mallorquinischen) Frevler griffen die Almohaden ein um das andere Mal an und führten ununterbrochen ungestüme und heftige Attacken gegen sie durch. Doch all diesen Angriffen hielten die Streiter für die Sache Gottes unerschütterlich und tapfer stand und erwiesen sich bei allen Zusammenstößen als edel und ruhmvoll. Sie kämpften und fochten gegen diese Mallorquiner auf Leben und Tod und hielten diesen ihren Zweikampf für den kostbaren Schatz bei Gott ${ }^{290}$ und für die (am Tage des Jüngsten Gerichts nützliche) Rüstung. Schließlich gewährte Gott denjenigen Seinen Beistand, die Seine Sache verfechten ${ }^{291}$, und zerschnitt des Unglaubens Bande und Schlingen (d. h. tilgte ihn aus). Da ergriffen die Elenden - Gott möge ihnen den Misserfolg zuteil werden lassen - die Flucht, ohne sich um diejenigen von ihnen zu scheren, die (auf dem Schlachtfeld) zurückblieben, kein Mitleid mit denjenigen (ihrer Kämpfer) empfindend,

\footnotetext{
${ }^{290}$ Wahrscheinlich eine Anspielung auf Sure 3, Vers 171 „Sie sind froh über Gottes Gnade und Huld und (darüber) dass Gott die Gläubigen nicht um ihren Lohn bringt“.
} 
die $\mathrm{zu}$ fliehen nicht imstande waren, und sich nicht derjenigen (ihrer Anhänger) erbarmend, die zu ihrem Abscheu erregenden Davonjagen weder imstande noch fähig waren. Sie flohen, um sich ihrem Irrenden (wieder) anzuschließen, und hofften darauf, $\mathrm{zu}$ diesem ihren Elenden (wieder) zu stoßen. In dieser niederträchtigen Bande und widerwärtigen Rotte befanden sich auch die beiden erwähnten Brüder dieses (mallorquinischen) Frevlers. Zusammen mit den anderen davonjagenden Irrenden rannten auch sie davon und flüchteten zusammen mit ihren in die Flucht geschlagenen ungläubigen und sündigen Anhängern und Elenden. Gott wird ihre Gesamtheit ausmerzen und durch die Schwertklingen dieser mächtigen Sache ihre Befehlenden und ihre Befehligten austilgen, durch Seine Gnade.

Danach eilten die almohadischen Angreifer - Gott möge ihnen Seine Unterstützung gewähren - zur Stadt hin und drangen in sie ein. Sie bemächtigten sich der in Biğāya verbliebenen Ungläubigen und ergriffen sie, wobei diese Ungläubigen vor diesem Los kein (vorher gemachtes) Versprechen noch ein (vorher abgeschlossener) Vertrag bewahrte. Daraufhin eilten die Almohaden zu den Tâalibs - Gott möge ihnen Mächtigkeit verleihen - und zu den Almohaden - Gott möge ihnen den Erfolg bescheiden - , die mit den erwähnten Țālibs waren, und fanden vor, dass sie alle dank Gott im bestmöglichen Zustand der Unversehrtheit sich befanden, sich aller Gunstbezeigungen Gottes - lobgepriesen sei Er - und Seiner Gaben erfreuend und mittels Seines Beistandes und Seiner Obsorge ununterbrochenen Schutz und fortwährende Behütung genießend. Dabei fiel in die Hände der Almohaden - Gott möge ihnen Mächtigkeit verleihen - der Verirrte und Irrende namens Rašīd, der zu den Rädelsführern und Häuptlingen dieser Elenden gehörte, welcher ferner Anführer ihres unbilligen Wütens und ihres Unglaubens war und der ihre Meuterei angezettelt und das Feuer ihres Unwesens entfacht hatte. Die Almohaden fanden auch die gesamten Schiffe dieses Treulosen samt all ihren Kriegsgeräten und ihrer Ausrüstung vor. All diese Beute ließ Gott den Almohaden zufallen. Dadurch vermehrfachte Gott Seine Gunst gegenüber den Almohaden und ließ ihnen noch größere Güte zuteil werden.

Als Gott den Almohaden die Rückeroberung und Bezwingung Biğāyas ermöglicht hatte und als Er - lobgepriesen sei Er - durch die Lichter dieser mächtigen (almohadischen) Sache die Morgendämmerung und den Morgen dieser Stadt hat erstrahlen lassen, setzten sie eilends die Ṭālibs - Gott möge ihnen Mächtigkeit verleihen - des almohadischen Heeres von dieser erfreulichen Nachricht in Kenntnis und beeilten sich,

${ }^{291}$ Wahrscheinlich eine Anspielung auf Sure 47, Vers 7 des Korans „yā aiyuhā allad̄ina āmanū in tanṣurū 
ihnen mitzuteilen, was Gott ihnen an erquickenden und freudigen Begebenheiten zuteil werden ließ. Die erwähnten Ṭālibs erhielten dieses Schreiben, als sie gerade in die Nähe von Mattīğa - Gott möge Frieden dort währen lassen - gelangt waren. Die genannten Ṭālibs ihrerseits sandten eiligst dieses erwähnte (bei ihnen eingegangene) Schreiben an uns weiter, nachdem sie ihm ihr eigenes Schreiben hinzugefügt hatten, welches sowohl den Bericht über die ihnen (von Gott) gewährten Hilfe ${ }^{292}$ und Unterstützung bei der Durchführung ihrer Unternehmung enthielt als auch die euch bereits bekannt gemachte Darlegung dessen, was sie an Gottes Eingreifen und Seinem Beistand erfuhren und was $\mathrm{Er}$-gelobt sei Er - ihnen hat angedeihen lassen an edlem und gewaltigen Sieg sowie was Er - gewaltig ist Seine Macht - an ununterbrochenen und fortwährenden Erzeigungen Seiner Huld (zu ihren Gunsten) hat ein um das andere Mal geschehen lassen.

So blieb der Treulose und zum Verderben Verurteilte bei Constantine - Gott möge diese Stadt behüten - ausgeplündert und ausgeraubt, besiegt und von der Heimsuchung geschlagen. Seine Sünden und Verbrechen stürzten ihn ins Verderben hinab, seine Helfer und Anhänger ließen ihn im Stich und seine Verwandtschaft und seine Sippschaft gab ihn dem vorherbestimmten (tödlichen) Geschick und dem austilgenden fortraffenden Tod preis. Über ihn - Gott möge ihn mit Schmach bedecken - brach das Dunkle des Anfangs und des Endes seiner kreisenden [sic] Lebensfrist herein. Es war so, als ob ihn Gott zu einem Gefangenen oder einem Getöteten (in der Gewalt der Almohaden) gemacht hätte, denn er war nicht imstande, die Flucht zu ergreifen, und vermochte nicht, sich zu retten. Gott wird ihn bald die Qualen, die Er für ihn bereit hält, kosten lassen und ihn schmoren lassen mitten in Seiner grausamen Bestrafung und Strafe, durch Seine Gnade und Güte.

Wir haben euch - Gott möge euch den edlen Rang gewähren - in Kenntnis gesetzt über diese erquickenden Siegesmeldungen, dieses gütige und vortreffliche Wirken Gottes und über diesen gewaltigen Sieg, auf dass euer Anteil an der Freude darüber groß werde, ihr in eurem reichlichen Dank dafür ihrem Gewährer - gelobt sei Er - treffend seid und nicht innehaltet, Ihn - lobgepriesen sei Er - dafür zu loben, was Er die Feinde am Furcht erregenden Schrecken und am schlimmen $\operatorname{Tag}^{293}$ hat erfahren lassen. So

\footnotetext{
Allāh yanșurkum [...]“

${ }^{292}$ Im arabischen Original (Mağmū' rasā’il muwaḥhịīya, S. 179) steht an dieser Stelle ,wa-ardafūhū bikitābihim mu'limīn bi-mā laqūhū fĩ muhāwalatihim min at-tabšīr wa-'t-taisīr“. „Tabšīr“ scheint jedoch hier nicht in den üblichen bei Dozy und „Lisān al-'arab“ belegten Bedeutungen, sondern eher als Synonym zu „Taisīr“ gemeint zu sein.

${ }^{293}$ Siehe Sure 11, Vers 77.
} 
lasset diese Gunstbezeigungen (Gottes) durch euren Dank dafür fortwähren, kommt der Pflicht, sie zu verbreiten und ruchbar zu machen, in gebührender Weise nach und verkündet sie allenthalben und allerorten. Schicket die Kopien dieses Schreibens an alle Städte und Dörfer, lasset das Preisen Gottes - lobgepriesen sei Er - und die Dankesbezeigungen Ihm gegenüber euer In- und Auswendiges erfüllen und machet durch euren Gehorsam gegenüber der Sache Gottes - lobgepriesen sei Er - die Stätte eures dauerhaften Wohnens und euren Weilort im Schatten Seiner Sicherheit eben. Und Gott wird euch dabei die Gunst erweisen, welche zum Erfolg eures Anfangens und Beendens führen wird, durch Seine Gnade und Güte. Es gibt keinen anderen Gott außer Ihm. Allumfassender Friede, Gottes Barmherzigkeit und Seine Segen mögen euch zuteil werden.

Abgefasst am 6. Juli des Jahres 1185.

\subsection{Einleitung zum historischen Kommentar}

Als Yahyā Ibn-Ibrahīm, das Oberhaupt des berberischen Stammes Ğuddāla, um das Jahr 1036 von einer Pilgerreise nach Mekka zu seinem Stamm zurückkehrte, brachte er einen Prediger namens 'Abdallāh Ibn-Yasīn mit, der die bis dahin nur oberflächlich islamisierten Angehörigen dieses Stammes in der islamischen Lehre unterweisen sollte. Damit wurde eine historische Entwicklung eingeleitet, die letztlich in einen Kampfbund der berberischen Șanhāğa-Stämme Ğuddāla, Lamtūna, Banū-Wārit und Masūfa ${ }^{294}$ mündete und zur Entstehung einer religiös-politischen Bewegung führen sollte, deren Anhänger als Almoraviden (arab.: al-murābițūn ${ }^{295}$ ) bezeichnet wurden. Das Siedlungsgebiet dieser Șanhāğa-Stämme, welche das Rückgrat der späteren almoravidischen Bewegung bilden sollten, reichte vom Südwesten des heutigen Mauretaniens bis Südmarokko. Dem ursprünglichen Bund dieser Stämme schlossen sich im Laufe der Zeit andere berberische Șanhāğa-Stämme an, und unter der militärischen Führung von Yūsuf Ibn-Tāšufīn beherrschten die Almoraviden bis 1083 ein Gebiet, das sich von Südwesten des heutigen Mauretaniens bis Ceuta ertreckte und dessen östliche Grenze die Stadt Algier bildete.

\footnotetext{
${ }^{294}$ Vincent Lagardere erwähnt nur die ersten drei Stämme (Les Almoravides jusqu'au régne de Yūsuf Ibn-Tašfīn (1039-1106), S. 52) und Hans-Rudolf Singer zählt noch Masūfa dazu, ohne jedoch Banū-Wārit zu nennen (Der Maghreb und die Pyrenäeninsel bis zum Ausgang des Mittelalters, S. 295). Der Stamm Masūfa ist dennoch zu den Gründerstämmen zu zählen, weil er genau aufgrund dieser seinen Stellung beim Tod 'Alī Ibn-Yūsufs gegen seinen designierten Nachfolger Tašufīn aufbegehrte.

${ }^{295} \mathrm{Zu}$ dieser Bezeichnung und zu deren möglicher Enstehung siehe Ausführungen von V. Lagardere (Les Almoravides jusqu'au règne de Yūsuf b. Tāšfīn (1039-1106), S. 58 f.)
} 
Nach der Abschaffung des Omaiyadischen Kalifats von al-Andalus im Jahre 1031 ist eine Reihe von unabhängigen Kleinkönigreichen (arab.: at-țawā'if) entstanden, die sich einerseits untereinander bekämpften und andererseits den Angriffen der christlichen Königreiche ausgesetzt waren. Die Zahl dieser unabhängigen Königreiche hat sich in den nachfolgenden fünfzig Jahren auf insgesamt acht reduziert und einige von ihnen (z. B. Kleinkönigreiche von Toledo, Zaragoza, Badajoz, Sevilla und Cordoba) waren zu hohen Tributzahlungen gegenüber dem König von Kastilien, Alfons VI., verpflichtet. Es finden sich in den arabischen Quellen verschiedene voneinander abweichende Berichte darüber, wer von den Kleinkönigen von al-Andalus und aus welchen Gründen die Almoraviden darum bat, den Heiligen Krieg gegen die christlichen Königreiche der Iberischen Halbinsel zu führen ${ }^{296}$. Sicherlich bildete die Einnahme Toledos durch Alfons VI. im Jahr 1085 einen der Gründe für Yūsuf Ibn-Tāšufīn, mit seinem Heer nach al-Andalus überzusetzen. Bei dieser ersten Übersetzung brachte das almoravidische Heer zusammen mit den jeweiligen Kontingenten der Kleinkönige in der Schlacht bei Sagrajas (arab.: az-Zallāqa) Alfons VI. eine vernichtende Niederlage bei. Doch als Yūsuf Ibn-Tāšufīn ein zweites Mal um Beistand gebeten wurde und die Festung von Aledo im Jahr 1088 belagerte, traten die Querelen der Kleinkönige untereinander und ihre Bereitschaft, mit Christen zu kollaborieren, so deutlich zutage, dass Yūsuf den Entschluss fasste, sie allesamt $\mathrm{zu}$ entmachten und al-Andalus dem almoravidischen Reich einzuverleiben. Die meisten Kleinkönigreiche wurden zwischen 1090 und 1094 der almoravidischen Herrschaft unterworfen und die Einnahme Zaragozas im Jahr 1110 kann als Abschluss der Herrschaftsübernahme der Almoraviden in al-Andalus gelten. Seit ihrer Niederlassung in Tīnmalal bekämpften die Almohaden die Almoraviden und griffen sogar bereits im Jahr 1130 Marrakech vergeblich an. Diese Auseinandersetzung beschränkte sich zuerst auf vereinzelte Geplänkel und erst nach dem Tode 'Alī IbnYūsufs im Jahr 1143 gelang es den Almohaden, entscheidende militärische Erfolge zu erzielen. 1144 fiel Reverter, der Befehlshaber der christlichen Söldnertruppe und die militärische Stütze der Almoraviden, und im Jahr 1147 wurde Marrakech erstürmt und der letzte almoravidische Herrscher Ishạā Ibn-'Alī Ibn-Yūsuf getötet. Dieses Datum kennzeichnet das Ende der almoravidischen Herrschaft in Maghreb. Was die almoravidische Herrschaft in al-Andalus betrifft, so sind bereits die ersten antialmoravidischen Aufstände 1144 in Algarve ausgebrochen und 1146 kamen dort auf Bitte einiger lokaler Herrscher hin, die sich gegen die Almoraviden aufgelehnt hatten,

${ }^{296}$ Umfassende Zusammenstellung überlieferter Berichte arbischer Historiographen diesbezüglich findet 
die ersten almohadischen Kontingente an. Trotz dessen dauerte es weitere zehn Jahre, bis die almohadische Herrschaft dauerhaft auf den Großteil von al-Andalus ausgedehnt werden konnte. Mit Ausnahme der Baleareninseln kann man das gesamte Gebiet von alAndalus erst nach dem Jahr 1172 als dem almohadischen Reich eingegliedert bezeichnen, nämlich nach dem Tod von Ibn-Mardanī̌s, dem hartnäckigsten und stärksten Gegner der Almohaden in al-Andalus.

Was die Baleareninseln betrifft, so ist dort die almoravidische Präsenz seit dem Jahr 1116 belegt $^{297}$. Im Jahre 1126, wurde im Zuge der Unterwerfung eines antialmoravidischen Aufstandes auf Mallorca ein gewisser Muḥammad Ibn-Ġānīya mit der Statthalterschaft auf den Baleareninseln betraut, der dieses Amt bis zu seinem Tod behielt, und dem seine Söhne nachfolgten ${ }^{298}$. Dieser Muhammad sowie sein Bruder Yahyyā gingen aus der Ehe einer am almoravidischen Hofe hoch angesehenen Persönlichkeit vom Stamm Masūfa mit einer Verwandten Yūsuf Ibn-Tāšufīns namens Ġānīya hervor ${ }^{299}$. Da die berberischen Stämme bei der Filiation den Namen der Mutter und nicht, wie bei den arabischen Stämmen üblich, den Namen des Vaters angaben, trugen diese beiden Söhne den Namen Yaḥyā Ibn-Ġānīya und Muhammad Ibn-Ġánīya, deren Nachkommen ihrerseis die Banū-Ḡānīya heißen sollten. Die Dynastie der BanūGānīya sollte den Fall der Almoraviden in Maghreb und al-Andalus überdauern und bis 1203 auf den Baleareninseln Bestand haben.

Nach dem Sturz der almoravidischen Dynastie in Maghreb wurde Muhammad IbnGānīya unabhängiger Herrscher. Trotz dessen wurde die Freitagspredigt auf den Baleareninseln auch weiterhin im Namen der abbasidischen Kalifen gehalten. Viele der Almoraviden, die aus al-Andalus flohen, fanden bei diesem Herrscher Zuflucht ${ }^{300}$. Auf Muhammad folgte sein Sohn Ishāq Ibn-Muhammad im Jahr 1155/56 $6^{301}$ und „es waren zahlreich diejenigen, die von den flüchtigen Angehörigen des Lamtūna-Stammes und ihren Überlebenden zu ihm nach Mallorca gelangten, und er behandelte sie gütig und beschenkte sie nach Möglichkeit.، ${ }^{\text {(302 }}$ Mit diesen Helfern betrieb Ishāq Ibn-Muhammad Ibn-Ġānīya Seeräuberei und führte Plünderungszüge in christliche Gebiete durch. Die christliche Bevölkerung, die dabei gefangen genommen und auf die Baleareninseln

\footnotetext{
sich in „Les Almoravides jusqu'au règne de Yūsuf b. Tāšfīn (1039-1106)“ (S. 101 ff.)

${ }^{297}$ Les almoravides: le djihad andalou (1106-1143), S. 39 f., al-Fitan wa-'1-hurūb, Bd. 1, S. 229.

298 al-Fitan wa-'l-ḥurūb, Bd. 1, S. 229, Les Benou Ghânya, S. 4. 'Abd-al-Wāhịid al-Marrākuši überliefert in diesem Zusammenhang zwei andere, sehr abweichende Versionen der Ankunft Muhammads nach Mallorca (al-Mu '̌gib, S. 267 f.).

${ }^{299}$ Kitāb al-'ibar, Bd. 6, S. 390, al-Mư̌̆gib, S. 342.

${ }^{300}$ Les Benou Ghânya, S. 18.

${ }^{301}$ Alfred Bel, Les Benou Ghânya, S. 19.
} 
verschleppt wurde, hat man dann bei schweren Arbeiten und in der Landwirtschaft eingesetzt ${ }^{303}$. Anscheinend hat Ishāq Ibn-Muhammad Ibn-Ġānīya seinen Lebensunterhalt ziemlich aktiv auf diese Weise betrieben, wie es aus der Bemerkung hervorgeht, dass er „den ganzen Tag auf dem Gischt der Meeresfluten verbrachte und nach dem Einbruch der Dunkelheit die Festlandbewohner überfiel.“604 Diese Bemerkung wird durch einen Bericht al-Marrākušīs bestätigt: „Er wandte sich den Plünderungszügen $\mathrm{zu}$, ließ ihnen sein Interesse gelten und hatte keine andere Sorge als diese Plünderungszüge. In jedem Jahr überfiel er zweimal die Länder der Christen, machte Beute, nahm gefangen und brachte den Feinden schmerzlichste Verluste zu, bis sich die Hände seiner Gefährten mit Beutegütern gefüllt haben. Auf diese Weise wurde seine Macht groß und er eignete sich das Gebaren eines Königs an. “305 Der erwähnte Herrscher - so al-Marrākušī weiter - hat ferner Briefverkehr mit den Almohaden gepflegt sowie diesen immer wieder das Kostbarste an seinen Gefangenen und an seiner Beute geschenkt. Damit habe er sich seine Unabhängigkeit erkauft. Doch im Jahre 578 H. (1182/3) seien an Isḥāq Ibn-Muhammad Ibn-Ġānīya mehrere Briefe nacheinander mit der Aufforderung ergangen, sich den Almohaden zu unterwerfen, an welche sich die Warnung vor einer abschlägigen Antwort anschloss. Die daraufhin berufene Versammlung der Gefährten Isḥāq Ibn-Muḥammad Ibn-Gānīyas habe sich auf keine einmütige Antwort einigen können, und dieser almoravidische Herrscher habe die Entscheidung auf einen späteren Zeitpunkt verschoben und sich auf einen Plünderungszug begeben, bei dem er den Tod eines Märtyrers erlitten habe ${ }^{306}$.

4.3. „Ihr habt bereits erfahren [...] wie sich [...] dieser Elende von Mallorca [...] befand $[\ldots]^{\text {“" }}$

Ishāq Ibn-Muḥammad Ibn-Ġānīya hatte folgende Söhne ${ }^{307}$ : Muhammad, 'Alī, 'Abdallāh, Yahyā, al-Ḡāzī, Sīr, al-Manșūr, Ğabbāra, Tāšufīn, Ṭalhạ, 'Umar, Yūsuf und al-Ḥasan, von welchen die vier erstgenannten besonders hervorgehoben seien, da sie im Folgenden noch eine wichtige Rolle spielen werden.

\footnotetext{
302 al-Mu'̌̌̆ib, S. 269.

${ }^{303}$ Les Benou Ghânya, S. 23.

${ }^{304}$ Kitāb al-istibṣār fī 'ağāìb al-amșār, S. 159.

${ }^{305}$ al-Mư̌̆ib, S. 269. Ibn-Haldūn bestätigt diese seeräuberischen Aktivitäten (Kitāb al-'ibar, Bd. 6, S. 506).

306 al-Mu'ğib, S. 269 f. Dieser Version folgt auch Alfred Bel (Les Benou Ghânya, S. 24-25). Den Tod Isḥāq-Muḥammad Ibn-Ġānīyas noch zu Lebzeiten Abū-Ya'qūb Yūsufs (1163-1184) bestätigen auch IbnHaldūn (Kitāb al- 'ibar, Bd. 6, S. 506) und Ibn- Iḍārī al-Marrākušī (al-Bayān al-mug̣rib, S. 175).

${ }_{307}$ Kitāb al-'ibar, Bd. 6, S. 506-507. An einer anderen Stelle behauptet Ibn-Haldūn, Muhammad habe acht Söhne gehabt (Kitāb al-'ibar, Bd. 6, S. 391)?
} 
Auf Isḥāq Ibn-Muḥammad Ibn-Ġāniya, der den Aufruf, sich zum Almohadentum zu bekennen, bis auf weiteres verschoben und wenig später bei einem Plünderungszug den Tod gefunden hatte, folgte sein Sohn Muhammad Ibn-Ishạạq ${ }^{308}$. Dem Bericht Ibn-'Idārīs zufolge schickte Yūsuf Ibn-'Abd-al-Mu’min nach dem erwähnten Märtyrertod Ishāqs zu dessen Söhnen nach Mallorca einen gewissen 'Alī Ibn-Rubartair ${ }^{309}$, auf dass er sie zum Gehorsam gegenüber den Almohaden auffordere und an sie die Warnung davor überbringe, diese Aufforderung auszuschlagen. Dies sei gemäß der üblichen Vorgehensweise der Almohaden gegen die Meuterer geschehen, welche die muslimische Gemeinschaft verlassen hätten ${ }^{310}$. Diese Passage, die von ihrem Sinn her sowohl auf diejenigen Widersacher der Almohaden bezogen werden kann, die vorher von ihnen nicht unterworfen gewesen waren und es noch werden sollten, als auch auf diejenigen, die aus dem bereits bestehenden Untertanverhältnis zu den Almohaden heraus sich gegen diese aufgelehnt haben, könnte den Eindruck erwecken, die BanūGānīya seien einmal den almohadischen Kalifen botmäßig gewesen und hätten später aufgehört, es zu sein. In den überlieferten Quellen finden sich allerdings keine Anhaltspunkte, die diese Deutung des wiedergegebenen Abschnitts stützten. Eine etwas andere Deutung dieser Ereignisse geht aus dem Bericht Ibn-Haldūns hervor, dem zufolge Muḥammad Ibn-Isḥāq nach seinem Herrschaftsantritt mittels einer Gesandschaft dem almohadischen Kalifen (d. h. Yūsuf Ibn-'Abd-al-Mu'min) angeboten habe, sich ihm zu unterwerfen. Dieser Kalif habe daraufhin 'Alī Ibn-Rubartair, der bei diesem Autor fälschlicherweise 'Alī Ibn-Zuburtair heißt, nach Mallorca entsandt, um dieses Angebot zu sondieren ${ }^{311}$. In einem anderen Bericht des gleichen Autors heißt es, Yūsuf Ibn-'Abd-al-Mu'min habe 'Alī Ibn-Rubartair deswegen mit dem Aufruf an die Banū-Ġānīya, sich den Almohaden zu unterwerfen, nach Mallorca geschickt, weil Muḥammad Ibn-Isḥāq ihn darum schriftlich angegangen habe ${ }^{312}$. Diesen beiden Berichten Ibn-Haldūns ist die wohlgesinnte Haltung Muḥammad Ibn-Ishāass gegenüber den Almohaden und die Entsendung des erwähnten 'Alī Ibn-Rubartair gemeinsam und es fällt dabei auf, dass es nur Muḥammad Ibn-Isḥāq ohne seine Brüder ist, der die beschriebene Annäherung an die Almohaden einleitet. Interessanterweise berichtet Ibn-

\footnotetext{
${ }^{308}$ Kitāb al-ibar, Bd. 6, S. 391 und S. 507, Les Benou Ghânya, S. 25. 'Abd-al-Wāhid al-Marrākuš̄i zufolge hingegen sei noch zu Lebzeiten Ishāa Ibn-Muhammad Ibn-Ġānīyas sein Sohn 'Alī zu seinem Nachfolger ernannt worden und habe die Herrschaft nach dem Tod seines Vaters angetreten (al-Mu'ğib, S. 270).

${ }^{309}$ Sein Vater war jener Reverter, welcher der Befehlshaber der christlichen Söldnertruppe im Dienst der Almoraviden und die militärische Stütze dieser Dynastie war.

310 al-Bayān al-muġrib, S. 175.

${ }^{311}$ Kitāb al-'ibar, Bd. 6, S. 507 und stark verkürzt auf S. 391.
} 
Haldūn darüber, dass unmittelbar nach der Landung 'Alī Ibn-Rubartairs auf Mallorca die Brüder Muhammads dies missbilligt, ihn abgesetzt und eingekerkert hätten. 'Alī IbnIsḥāq, einer der Brüder Muḥammads, sei dann an seiner Statt zum Herrscher gewählt worden $^{313}$. Auf diese Weise erhärtet sich der Verdacht, dass Muḥammad Ibn-Isḥāq wahrscheinlich ohne Zustimmung seiner Brüder gehandelt hatte. Ein Indiz hierfür könnte auch sein, dass beispielsweise - wie oben geschildert - Isḥāq Ibn-Muhamamad Ibn-Ġāniya, als er vor die Wahl gestellt wurde, sich den Almohaden zu unterwerfen oder gegen sie Krieg zu führen, eine Versammlung berief, um über die angemessene Antwort zu beraten. Im Zusammenhang mit der im Hinblick auf ihre Tragweite nicht minder wichtigen Entscheidung Muḥammad Ibn-Isḥāqs, seine Bereitschaft, sich dem Almohadentum anzuschließen, in Marrakech bekannt geben zu lassen, wird eine solche Beratung in den überlieferten Quellen nicht erwähnt.

Was den almohadischen Gesandten anbetrifft, so hat man ihn dem Bericht Ibn- Iḍārīs zufolge nach seiner Ankunft mit allen Ehren empfangen ${ }^{314}$. Während der Verhandlungen, die 'Alī Ibn-Rubartair mit den Angehörigen dieser Dynastie führte, hätten diese angeordnet, seine Schiffe in Besitz zu nehmen und mit der almoravidischen Besatzung zu versehen. Die Banū-Ḡānīya hätten ferner 'Alī Ibn-Rubartair durch immer neue Versprechungen aufgehalten und seine Rückkehr hinausgezögert. Als bekannt wurde, dass Yūsuf Ibn-'Abd-al-Mu’min bei der Belagerung der Stadt Santarem den Tod gefunden hatte ${ }^{315}$, habe man 'Alī Ibn-Rubaratair unter Hausarrest gestellt. Dabei habe ein gewisser Rašīd eine wichtige Rolle gespielt. Danach seien die Banū-Ġānīya mit ihren almoravidischen Truppen nach Biğāya aufgebrochen ${ }^{316}$.

Damit wurde der sich anbahnende Konflikt von den Baleareninseln nach Ifrīqīya getragen, wo er verheerende Folgen sowohl für die Region als auch für die

\footnotetext{
${ }^{312}$ Kitāb al-ibar, Bd. 6, S. 509.

${ }^{313}$ Kitāb al-'ibar, Bd. 6, S. 391 und S. 507.

${ }^{314}$ Der Bericht Ibn- 'Idārīs lautet an dieser Stelle (al-Bayān al-muğrib, S. 175) wie folgt: „Und als er, d. h. 'Alī Ibn-Rubartair, in Mallorca an Land ging, empfing er, d. h. der Herrscher von Mallorca, ihn mit Ehren und gewährte ihm zum Schein große Gastfreundschaft. Er behandelte ihn großzügig, wobei sie, d. h. die Banū Gānīya, bereits die Absicht gefasst hatten, aufzubrechen und (Biğāya) zu überfallen. Trotz dieser Täuschungsmanöver des Herrschers von Mallorca erkannte 'Alī Ibn-Rubartair ihre wahre Absicht". Aus dieser Passage geht hervor, dass 'Alī Ibn-Rubartair höchstwahrscheinlich nicht von Muhammad Ibn-Ishāq empfangen wurde, denn die wohlgesinnte Haltung des Letzteren war - wie noch später zu sehen sein wird - aufrichtig, sondern von dessen Bruder 'Alī Ibn-Ishāa. Dafür spricht auch die Aussage Ibn Haldūns, Muhammad Ibn-Ishāq sei von seinen Brüdern sofort nach der Ankunft 'Alī Ibn-Rubartairs abgesetzt und eingesperrt worden (Kitāb al-'ibar, Bd. 6, S. 391).

315 Dieser Herrscher ist am 22. Juli 1184 seinen Verletzungen erlegen und sein Tod wurde bis 10. bzw. 11. August 1184 geheim gehalten. Erst einige Tage danach dürfte diese Nachricht Mallorca erreicht haben (Historia política del imperio almohade, Bd. 1, S. 321).

316 al-Bayān al-mugrrib, S. 175. Gleiche Abfolge der Ereignisse auch bei Ibn-Huldūn (Kitāb al- ibar, Bd. 6, S. 391f. und S. 507), allerdings ohne Erwähnung Rašīds.
} 
almohadische Herrschaft dort zeitigen sollte und letztlich zur Entstehung einer neuen, hafsidischen Dynastie geführt hat. Das letztliche Ausmaß und die Auswirkungen dieses Schrittes, die den Banū-Ġānīya selbst damals wohl kaum bewußt gewesen sein dürften, fasst sehr treffend 'Abd-al-Wāḥid al-Marrākušī zusammen: „In diesem Jahr 580 H. (1184) begaben sich die Mallorquiner, die Banū-Ġānīya, von Mallorca aus nach Biğāya, bemächtigten sich dieser Stadt und vertrieben die dort befindlichen Almohaden. [...] Dies war das erste Geschehnis, welches die Dynastie der Maṣmūda-Berber (d. h. das almohadische Reich) ins Wanken brachte. Es wirkt bis heute, nämlich das Jahr $621 \mathrm{H}$. (1224/25), nach. “6317

Was das weitere Schicksal von und Muḥammad betrifft, so enthält ,al-Bayān almugrrib“ ausführliche Informationen diesbezüglich. Demnach sei es 'Alī Ibn-Rubartair nach dem Aufbruch der kampffähigsten almoravidischen Kontingente nach Biğāya gelungen, die auf Mallorca befindlichen christlichen Gefangenen für sich zu gewinnen. Mit ihrer Hilfe habe er vermocht, an einem Freitag, als die Muslime mit ihren rituellen Waschungen beschäftigt gewesen seien, die Zitadelle der Stadt in seine Gewalt zu bringen und sich dort samt seinen Anhängern zu verschanzen. Die herbeigeeilte Bevölkerung habe zunächst die Zitadelle mit Katapulten und Schießbögen unter Beschuss genommen, da jedoch die Aufständischen die Nachkommen Ishạa IbnMuḥammad Ibn-Ġānīyas sowie die Familienangehörigen 'Alī Ibn-Isḥāq Ibn-Muḥammad Ibn-Ġānīyas als menschliche Schilde benutzt hätten, sei dieser Beschuss eingestellt worden und man habe Verhandlungen aufgenommen. Dabei habe 'Alī Ibn-Rubartair u. a. ausbedungen, dass Muhammad Ibn-Ishạā, der sich zu diesem Zeitpunkt im Norden der Insel aufgehalten habe ${ }^{318}$, in seiner Begleitung Mallorca verlassen dürfe. Nach der Übergabe der Zitadelle hätten sich 'Alī Ibn-Rubartair und Muhammad Ibn-Ishạa nach Marrakech begeben, wo dem Letzteren ein prachtvoller Empfang bereitet worden sei, und die gesamten christlichen Gefangenen seien heimgekehrt ${ }^{319}$.

\footnotetext{
${ }^{317}$ al-Mu ğib, S. 266 f.

${ }^{318}$ Im arabischen Text steht an dieser Stelle (al-Bayān al-mugrib, S. 184) „wa-kāna Abū-'Abdallāh IbnIshāa Ibn-Ġānīya taḥașṣana bi-aqșā al-ğazīra min siğn ihwwatihī 'alā mā kāna arādahū min al-ḩurūğ min alğazìra ilā al-amr“. Dieser Satz, der wahrscheinlich eine stark verkürzte Fassung eines längeren Satzes aus der zeitgenössischen almohadischen Quelle ,al-Mann bi-'l-imāma“ darstellt, ist in seinem ersten Teil nicht ganz eindeutig und kann vor dem Hintergrud des Berichts Ibn-Haldūns darüber, dass Muhammad Ibn-Ishāq nach der Ankunft des berühmten almohadischen Gesandten von seinen Brüdern entmachtet und eingekerkert worden sei, in folgender Weise übersetzt werden: „Abū-'Abdallāh (Muhammad) Ibn-Ishāq Ibn-Ġānìya verschanzte sich, nachdem er aus dem Gefängnis, in welches ihn seine Brüder gesperrt hatten, geflohen ist, ganz im Norden Mallorcas in der Absicht, die Insel zu verlassen und sich den Almohaden zu unterwerfen".

319 al-Bayān al-muğrib, S. 184. In ähnlicher Weise werden diese Ereignisse auch bei Ibn-Haldūn überliefert (Kitāb al-'ibar, Bd. 6, S. 399 und S. 509). Überraschenderweise findet sich jedoch bei diesem Autor noch ein dritter, von den erwähnten zwei stark abweichender Bericht darüber. Danach war es
} 
Vor dem Hintergrund dieser geschilderten Ereignisse stellt sich die Frage, wem denn die vielen pejorativen Bezeichnungen, von welchen am Anfang dieses Kapitels nur einige angeführt wurden und deren Adressat im Brief nicht namentlich erwähnt wird, gelten. Dem Brief nach habe der Herrscher von Mallorca anfangs seine Bereitschaft nur vorgetäuscht, sich dem almohadischen Kalifen $\mathrm{zu}$ unterwerfen, und habe nur eine günstige Gelegenheit abgepasst, dem Letzteren Schaden zuzufügen. Als sich diese günstige Gelegenheit ergeben habe, habe er sie ergriffen und Biǧāya überfallen. Schenkt man jedoch den beiden obigen Berichten Ibn-Haldūns Glauben, so war es von allen Söhnen Ishāā Ibn-Muḥammad Ibn-Ġānīyas nur Muḥammad, der die Anerkennung der Almohaden erwog und sie auch einleitete. Sowohl - der sehr glaubwürdige - Ibn-'Id̄ārī als auch Ibn-Haldūn berichten ferner darüber, dass Muhammad gerade wegen seiner proalmohadischen Haltung von seinen Brüdern abgesetzt und eingekerkert wurde. Weder bei Ibn-Ḩaldūn noch bei Ibn-'Idārī finden sich Hinweise darauf, dass irgendjemand von den übrigen Söhnen Isḥāq Ibn-Muḥammad Ibn-Ġānīyas nach der Entmachtung Muḥammads und vor der Einnahme Biğāyas eine ähnliche Intention gehabt oder bekundet hätte. In dieser Spanne hat es diesen beiden Autoren nach einen gewaltsam herbeigeführten Bruch in der Herrscherlinie der Banū-Ġānīya gegeben, was sich im Brief jedoch in keiner Weise widerspiegelt. Denn den Ausführungen des Briefes zufolge sei es derselbe Herrscher gewesen, der zunächst die Absicht vorgespiegelt, sich in die Gemeinschaft der Almohaden einreihen zu wollen, und später den Überfall auf Biğāya verübt habe. Die oben zitierten Quellenaussagen darüber, dass Muhammad IbnIshāa sich später in Begleitung 'Alī Ibn-Rubartairs nach Marrakech begab, sind ein gewichtiges Indiz dafür, dass die Absicht dieses gestürzten almoravidischen Herrschers, den Almohaden botmäßig zu werden, höchstwahrscheinlich aufrichtig gewesen ist. Vor diesem Hintegrund erscheint die Schlussfolgerung nahe liegend, dass der Adressat der Beschimpfungen - sicherlich fälschlicherweise und unbeabsichtigt - dennoch kein anderer als Muhammad Ibn-Ishāq war. Der Umstand, dass ausgerechnet dieser anscheinend treue Parteigänger der Almohaden im Brief mit wüsten Beschimpfungen überhäuft wird, rührt höchstwahrscheinlich davon her, dass die näheren

Muhammad Ibn-Ishāq, der diesen Aufstand mit Hilfe der Palastdienerschaft durchführte. Er habe danach die almohadische Herrschaft proklamiert und habe 'Alī Ibn-Rubartair nach Marrakech entsandt, der dort seine, d.h. Muhammads Unterwerfung überbringen sollte. Doch als die almohadische Flotte vor Mallorca aufgetaucht sei, um die Insel in Besitz zu nehmen, habe Muhammad es ihr verweigert und den Herrscher von Barcelona um militärische Unterstützung gebeten. Daraufhin habe sich die Bevölkerung der Insel aus Furcht vor Vergeltungsmaßnahmen der Almohaden gegen Muhammad erhoben, ihn vertrieben und seinen Bruder Tāšufīn zum Herrscher erhoben (Kitāb al-'ibar, Bd. 6, S. 515 f.). Diese Überlieferung erscheint 
Zusammenhänge der Geschehnisse auf Mallorca nach der Ankunft 'Alī Ibn-Rubartairs dort dem almohadischen Kalifen Ya'qūb al-Manșūr zum Zeitpunkt der Abfassung des Briefes Nr. 29 - noch - nicht bekannt waren. Diesem almohadischen Herrscher muss es daher als ein besonders heimtückischer Verrat vorgekommen sein, dass - wie er glaubte - Muḥammad Ibn-Isḥāq zuerst seine Kooperationsbereitschaft signalisierte, dann aber den prominenten almohadischen Abgesandten festhielt und $\mathrm{zu}$ guter Letzt die vorübergehende eingeschränkte Handlungsfähigkeit des almohadischen Reiches, die im Gefolge des unerwarteten Todes seines Vaters Yūsuf Ibn-'Abd-al-Mu’mins bei der vergeblichen Belagerung Santarems entstanden war, sich zunutzte machte, um Biğāya und weitere Städte des Zentralen Magheb in seine Gewalt zu bringen. Die ob dieser Heimtücke ausgelöste Entrüstung Ya`qūb al-Manșūrs kann vielleicht die selbst für die offiziellen almohadischen Briefe ungewöhnliche Häufung von Schimpfnamen, mit welchen der Herrscher von Mallorca, Muḥammad Ibn-Isḥāq, „,bedacht““ wird, erklären. Dass diese - aus der Sicht der Almohaden - Missetaten auf andere Söhne Ishāq IbnMuḥammad Ibn-Ġānīyas zurückgingen, dürfte erst bei der Ankunft 'Alī Ibn-Rubartairs in Marrakech und bereits nach der Abfassung des Briefes Nr. 29 klar geworden sein.

4.4. „In diesem geschilderten Zustand verharrte er, bis er die Klinge seines (eigenen) Todes ausgrub $[\ldots]^{\text {‘، }}$

Bei der Analyse des Briefes Nr. 9 wurden bereits einige allgemeine Feststellungen zu den in den almohadischen Briefen üblichen Bezeichnungen für „Feinde“ gemacht. Im Weiteren wird eine Zusammenstellung der im Brief Nr. 29 einschlägigen Benennungen gegeben $^{320}$.

,al-kāfir“ (S. 170), ,al-kāfir” (S. 172), ,al-kāfir“ (S. 172), d. h. „der Ungläubige”, ist im Koran in Sure 2, Vers 217 belegt.

„al-kafara” (S. 178), ,,al-kafara” (S. 178), d. h. „die Ungläubigen“. Obwohl dieser Plural im Koran nicht belegt ist, wird ein anderer Plural von ,al-kāfir“, nämlich ,al-kāfirūn“, an sehr vielen Stellen im Koran gebraucht. Siehe z.B. Sure 2, Vers 254, Sure 4, Vers 151, Sure 5, Vers 44 usw.

„al-ḡādir“ (S.170), d. h. „der Treulose“.

jedoch unglaubwürdig. Vgl. auch Ausführungen Huici Mirandas dazu (Historia política del imperio almohade, Bd. 1, S. 329).

${ }^{320}$ Die Seitenangaben hinter den angeführten arabischen Wörtern verweisen auf die Seiten des arabischen Originals „Mağmū` rasāìl muwaḥhidīya“. 


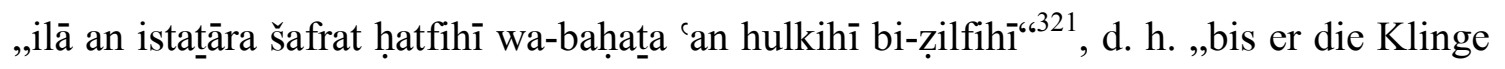
seines (eigenen) Todes ausgrub, mit seinem eigenen Huf sein Verderben aufscharrte“. Durch den Bezug des angeführten Satzes auf die arabische Redewendung „ḥatfahā tabhạ ḍa’n bi-aẓlāfihā‘‘322, d. h. „ihr Verderben scharren die Schafe mit ihren eigenen (gespaltenen) Hufen auf" wird der Herrscher von Mallorca einerseits entmenschlicht und gleichzeitig als den Schafen gleichwertig umschrieben. Dabei wird „das Schaf“ u. a. als ein Symbol für Feigheit und Kleinmütigkeit gebraucht, was u. a. folgende arabische Wendungen belegen: „Ahmmaq min ar-rahll ${ }^{323 ،, ~ d . ~ h . ~ „ b l o ̈ d e r ~ a l s ~ e i n ~ L a m m “, ~}$ „aḥmaq min an-na`̌̆a ‘alā al-ḥauḍ ${ }^{324 ،, ~ d . ~ h . ~ „, b l o ̈ d e r ~ a l s ~ e i n ~ S c h a f ~ a m ~ W a s s e r t r o g “, ~ „, m a n ~}$ șāra na ğatan akalahū aḍ-di'b ${ }^{325 ،, ~ d . ~ h . ~ „, w e r ~ z u ~ e i n e m ~ S c h a f ~ w i r d, ~ d e n ~ f r i s s t ~ d e r ~ W o l f ~}$ auf".

„al-la'̄in“ (S. 170), d. h. „der Verfluchte“, kommt im Koran nicht vor. Wohl aber ist „mal'ūnīn“, eine andere Form des Partizip Passiv vom arabischen Verb „lacana“ im Plural, in Sure 33, Vers 61 belegt.

„al-hā̄in“ (S. 170), d. h. „,er Verräter“, kommt im Koran im Plural in Sure 4, Vers 105, Sure 8, Vers 58 und Sure 12, Vers 52 vor.

„al-ḩāsir“ (S. 170) ,al-ḩāsir” (S. 172), d. h. „der zum Verderben Verurteilte“, ist im Koran im Plural in Sure 2, Vers 64; Sure 3, Vers 85; Sure 3, Vers 149 usw. belegt „,baqīyat al-ḥutāla al-ḡāwīya wa-su'r al-kufr ad-dātir“، (S. 170), d. h. „,er Überrest des irrenden Abschaums und das Überbleibsel des dahinschwindenden Unglaubens“, wobei „der Unglaube“ im Koran in Sure 2, Vers 108; Sure 2, Vers 217; Sure 3, Vers 52 usw. vorkommt.

,al-fāsiq“ (S. 171), ,al-fāsiq” (S. 178), d. h. ,der Frevler“, kommt im Koran in Sure 49, Vers 6 und Sure 32, Vers 18 vor. Die beiden Plurale davon „fussāq” (S. 171), „alfasaqa“ (S. 177) kommen im Koran zwar nicht vor, doch ist ,al-fāsiqūn“, ein weiterer möglicher Plural von ,al-fāsiq“, sehr häufig. Siehe z.B. Sure 2, Vers 99; Sure 3, Vers 82; Sure 3, Vers 110 usw.

„fuğğār” (S. 171), d. h. „die Hurer“, kommt im Koran in Sure 38, Vers 28; Sure 82, Vers 14; Sure 83, Vers 7 und ,al-fağara”, ein weiterer Plural ,al-fāğir” (S. 178), in Sure 80 , Vers 42 vor.

\footnotetext{
${ }^{321}$ Mağmū' rasā'il muwaḥhidìya, S. 170.

${ }^{322}$ Kitāb ğamharat al-amtāil, Bd. 1, S. 363.

${ }^{323}$ Kitāb ğamharat al-amtāl, Bd. 1, S. 392.

${ }^{324}$ Kitāb ğamharat al-amtāl, Bd. 1, S. 392.

325 al-Munğid fi 'l-luğa wa-'l-a 'lām, S. 1010.
} 
„,ii'āb al-gāara wa-kilābuhā” (S. 171), d. h. „Wölfe und Hunde der Überfälle“. Sowohl „Wolf“ als auch „Hund“ kommen im Koran vor und haben dort keinen pejorativen Sinn. ,auġād al-fitna wa-aušābuhā” (S. 171), d. h. „das Pack der Meuterei und ihr Gesindel“. „wa-tağamma'a lahū min ašbāhihī fi 'l-ğahāla wa-a'wānihī fì 'ḍ-ḍalāla auzā'، (S. 171 ff.), d. h. ,es scharten sich um ihn die Meuten der ihm in seiner Unwissenheit Ähnlichen und der ihm in seiner Missleitung Helfenden zusammen“. „Ğahāla” kommt im Koran in Sure 4, Vers 17; Sure 6, Vers 54; Sure 16, Vers 119 usw. und „dalāla” in Sure 2, Vers 16; Sure 2, Vers 175; Sure 4, Vers 44 usw. vor.

„aš-šaqī“ (S. 174), ,aš-šaqī” (S. 176), „šaqī” (S. 178), d. h. „der Elende”, kommt im Koran in Sure 11, Vers 105 vor.

„al-ašqiyā̄““ (S. 175), ,al-ašqīyā̄” (S. 176), ,,al-ašqīyā”” (S. 177), ,al-ašqīyāa““ (S. 176), „ašqīyā')“ (S. 178), ,al-ašqīyā”” (S. 178), ,al-ašqīyā̄““ (S. 178), d. h. „die Elenden“, ist im Koran nicht belegt, wohl aber dessen Singularform ,šaqi““ (s.o).

„al-firqa al-ġawìya“ (S. 175), d. h. „die irrende Rotte“.

„aš-šaițān al-marīd” (S. 175), d. h. ,gegen Gott aufbegehrender Satan“, kommt im Koran in Sure 22, Vers 3 vor.

„,aubāš aḍ-ḍalāla wa-aušābihā” (S. 176), d. h. „Mob der Missleitung und ihr Gesindel““. Siehe oben die Koranbelege zu ,aḍ-ḍalāla“.

„al-ġawī” (S. 176), ,,al-ġawi” (S. 178), d. h. „der Irrende“, kommt im Koran in Sure 28, Ver 18 vor.

„al-ğumla al-la'īma wa-'š-širdima adِ-damīma” (S. 178), d. h. „niederträchtige Bande und widerwärtige Rotte“. ,aš-Širdima“ kommt im Koran in Sure 26, Vers 54 vor.

„aḍ-ḍāll” (S. 178), d. h. „der Irrende“, ist im Koran nur im Plural ,aḍ-ḍallūn“ in Sure 3, Vers 90; Sure 15, Vers 56; Sure 56, Vers 51 usw. belegt.

Bei der erdrückenden Mehrheit dieser angeführten Bezeichnungen handelt es sich somit um Entlehnungen aus dem Koran. Hieraus sowie aus der Tatsache, dass sie den Rezipienten auch als solche bekannt waren, kann auf ihren hohen Bekanntheitsgrad geschlossen werden. Dies seinerseits hat sicherlich eine wesentliche Rolle bei der Rezeptionssteuerung gespielt, welche die Entwürdigung, Entwertung der Feinde der Almohaden zum einen und gleichzeitig die Legitimierung der Anhänger des Almohadentums zum anderen zur Folge hatte. Was die restlichen Bezeichnungen anbetrifft, so konnte ihr Ursprung nicht eindeutig ermittelt werden. Es ist jedoch nicht ausgeschlossen, dass sie ebenfalls einen hohen Bekanntheitsgrad hatten, der sich 
beispielsweise aus den verbreiteten und allgemein gekannten literarischen Texten gespeist haben konnte.

4.5. „Als dies geschah, nahm dieser Frevler Fühlung mit dem in Biğāya befindlichen Abschaum auf $[\ldots]^{\text {‘ }}$

Die Berichte arabischer Historiographen über den Ablauf des zu schildernden Überfalls auf Biğāya zeichnen sich durch ihre außerordentliche Kürze aus ${ }^{326}$. Eine Ausnahme bildet hierbei Ibn-'Idārī, dessen detaillierter Bericht darüber eine abgekürzte, auf einschlägige almohadische Vorlage zurückgehende Fassung $\mathrm{zu}$ sein scheint ${ }^{327}$. In folgender Weise lassen sich seine Ausführungen wiedergeben: Nach dem Bekanntwerden des unerwarteten Todes des zweiten almohadischen Kalifen Yūsuf Ibn'Abd al-Mu'min vor Santarem hätten die Banū-Gānīya den almohadischen Gesandten 'Alī Ibn-Rubartair festgesetzt und seien mit ihren Schiffen nach Biğāya aufgebrochen. Nachdem sie dort angelangt seien, hätten sie zuerst ein Boot vorausgeschickt, welches die Lage sondiert habe. Einige Bewohner der Stadt hätten dabei diese Ankömmlinge nach dem Grund ihrer unangemeldeten Ankunft gefragt, und die Letzteren hätten vorgegeben, Seeräuber zu sein, die sich hätten nur verproviantieren wollen. $\mathrm{Zu}$ diesem Zeitpunkt habe sich Saiyid Abū-Mūsa in Biğāya befunden, denn er hätte auf seinem Weg aus Ifrīqīya in dieser Stadt eine Zwischenstation gemacht ${ }^{328}$. Was den Saiyid Abu'r-Rabī' betrifft ${ }^{329}$, so sei er bereits davor nach Marrakech aufgebrochen und hätte sich noch nicht weit von der Stadt entfernt. Beide Saiyds seien nicht auf etwaige Angriffe vorbereitet gewesen und seit Jahren mit keiner Revolte gegen die almohadische Herrschaft konfrontiert worden. Am nächsten Tag seien die Mallorquiner in ihren Schiffen angekommen, wobei sie sehr gut bewaffnet gewesen seien. Dicht an die Stadtmauer Biğāyas herangesegelt hätten sie auf eine bestimmte Stelle dieser Stadtmauer Kurs gehalten. Denn diesem Überfall wäre ein geheimer Briefwechsel vorausgegangen zwischen den Mallorquinern auf der einen Seite und einer niederträchtigen und frevlerischen Gruppe von den Bewohnern Biğāyas auf der anderen, durch welchen die Letzteren den späteren Angreifern die Schwachstellen im

\footnotetext{
${ }^{326}$ Kitāb al-istibșār fị 'ağāàib al-amṣār, S. 131, al-Kāmil, Bd. 9, S. 166, al-Mu ǧib, S. 270, Kitāb al-'ibar, Bd. 6, S. 507, Ta'rīh ad-daulatain al-muwaḥhidìya wa-'l-ḥafșīya, S. 15, Kitāb ar-raud al-mi'ṭār, S. 82.

${ }^{327}$ Darauf deutet der proalmohadische Tenor dieser Vorlage hin, der sich in zahlreichen pejorativen Bezeichnungen für die Feinde der Almohaden sowie in der eindeutigen Parteinahme des Verfassers für die Bekenner des Almohadentums äußert.

${ }^{328}$ Laut Ibn-Haldūn war dieser Abū-Mūsa 'Umrān Ibn-'Abd al-Mu'min Statthalter von Ifrīqīya (Kitāb al(ibar, Bd. 6, S. 507).
} 
Verteidigungssystem der Stadt verraten und sie über die geringe Anzahl der wirklich mutigen abwehrfähigen Verteidiger in Kenntnis gesetzt hätten. Als die mallorquinischen Schiffe an dieser bestimmten Stelle angelangt seien, seien spontan und unorganisiert mehrere unbewaffnete Bewohner der Stadt dort zusammengeströmt. Dabei hätten sich in Biğāya einige almohadische Befehlshaber befunden, die, wäre es Gottes Wille gewesen, diesen Angriff abzuwehren vermocht hätten. Nachdem sich diese Verteidiger versammelt hätten, seien die mallorquinischen Schiffe zunächst fluchtartig zurückgesegelt, was jedoch nur ein Täuschungsmanöver gewesen sei, denn danach hätten sie plötzlich kehrtgemacht und sich mit großer Geschwindigkeit wieder genähert. Dabei habe man von den Schiffen aus eine große Menge von Pfeilen und Harpunen auf die Verteidiger abgeschossen, viele von ihnen seien dabei getötet worden und der Rest sei auseinander gestoben. Daraufhin hätten die Mallorquiner auf Wasser [unklar ${ }^{330}$ ] ausgebreitet, worauf die mallorquinischen Reiter in voller Ausrüstung die Schiffe hätten verlassen können. Als die Landung der Reiter und der Fußsoldaten abgeschlossen gewesen sei, seien sie alle zur Mauerbresche hingeeilt, von welcher die mit ihnen verschworenen Stadtbewohner sie in den geheimen Briefen vorher in Kenntnis gesetzt hätten. Durch diese Öffnung seien sie in die Stadt eingedrungen und hätten sie in Besitz genommen. Der in Biğāya befindliche Abū-Mūsa sei samt seinen Familienangehörigen gefasst und gefangen gesetzt worden ${ }^{331}$.

Es fällt hierbei auf, dass trotz der Ausführlichkeit dieser Schilderung der Einnahme Biğāyas auf Faktoren verwiesen wird, welche den überraschend schnellen Fall Biğāyas plausibel machen sollen ${ }^{332}$. So verweist der angeführte Bericht darauf, dass die beiden erwähnten Statthalter auf etwaige Übergriffe nicht vorbereitet gewesen seien, da sowohl Biğāya als auch Ifrīqīya bereits seit Jahren befriedet gewesen seien. Ferner wird auf die übernatürliche Ursache hingewiesen, deretwegen das Geschehene unausweichlich gewesen sei: Es sei der unabwendbare göttliche Ratschluss gewesen, dass Biğāya auf die geschilderte Weise überrannt werden sollte. Und schließlich wird einer Gruppe von deren Bewohnern die Schuld für das Gelingen des Überfalls gegeben, welche durch ihre Hinweise auf die besonders verwundbaren Stellen im Verteidigungssystem der Stadt

\footnotetext{
329 Abu-'r-Rabī' Ibn-'Abdallāh Ibn-'Abd-al-Mu'min ist Ibn-Hुaldūn zufolge Statthalter von Biğāya gewesen (Kitāb al-'ibar, Bd. 6, S. 392 und S. 507).

${ }_{330}$ An dieser Stelle (al-Bayān al-muğrib, S. 176) lautet der arabische Satz: ,wa-madda al-a`dā’ mațālic atțarā'id wa-wilāyatahā wa-ḩarağa al-fursān mustal'imīn ka-anna al-luğğa kānat țarīqahā“"? Es ist offensichtlich, dass ,wilāyatahā"“ hier nicht gemeint sein kann.

331 al-Bayān al-mug̈rib, S. $175 \mathrm{f}$.

${ }^{332}$ Ibn-al-Atīr behauptet sogar, dass die Stadt kampflos in Besitz genommen worden sei (al-Kāmil, Bd. 9, S. 166).
} 
sowie auf die geringe Zahl ihrer Verteidiger den Angreifern die rasche Eroberung der Stadt ermöglicht habe. Interessanterweise sprechen nur die almohadischen Quellen von der dem Angriff vorausgegangenen geheimen Kollaboration zwischen den Angreifern und einem - jeweils anders identifizierten - Teil der Bevölkerung von Biğāya: So hätten al-Marrākušī zufolge einige Notabeln Biğāyas Kontakt mit 'Alī Ibn-Isḥāq IbnMuhạmmad Ibn-Ġānīya aufgenommen und sich anerboten, ihm zur Herrschaft über die Stadt zu verhelfen ${ }^{333}$, ferner ist im anonymen „Kitāb al-istibșār fĩ 'ağāìb al-amṣār” davon die Rede, dass die Überlebenden der entmachteten Șanhāğa-Stämme (d. h. der Banū-Hammād) mit den Mallorquinern Fühlung aufgenommen hätten ${ }^{334}$, und schließlich ist es im $\mathrm{zu}$ analysierenden almohadischen Brief der Herrscher von Mallorca, der aus eigenem Antrieb den „Abschaum“ Biğāyas kontaktiert habe ${ }^{335}$. Hierbei springt wiederum in die Augen, dass es nach den beiden erstgenannten Quellen die in Biğāya Heimischen sind, die von sich aus darauf sinnen, sich der almohadischen Herrschaft $\mathrm{zu}$ entledigen und die entsprechenden Schritte einleiten, während dem almohadischen Schreiben nach diese Initiative vom mallorquinischen Herrscher allein ausgeht. Andere, nicht-almohadische Quellen erwähnen hingegen diese vorhergehende Kollaboration nicht ${ }^{336}$.

Was genaue Daten für diese Geschehnisse angeht, so gibt der zu analysierende Brief keinen Aufschluss darüber. Anderen Quellen zufolge scheint sich dieser Überfall am 13. November des Jahres 1184 ereignet zu haben ${ }^{337}$.

4.6. „Nach diesem begehrte er weitere Städte unter seine Botmäßigkeit zu zwingen, und seine verderbte Seele verleitete ihn dazu, sich auch der näheren Umgebung von Biğāya zu bemächtigen $[\ldots]^{\text {“‘ }}$

Mit diesen Worten wird das auf die gelungene Inbesitznahme Biğāyas folgende Vorgehen 'Alī Ibn-Ishāa Ibn-Muḥammad Ibn-Ġānīyass ${ }^{338}$ zusammengefasst. Allerdings wird mit diesem Satz ein nicht unwesentlicher Teil der im Anschluss an die Eroberung

\footnotetext{
${ }^{333}$ al-Mư̌̆̌ib, S. 270.

${ }^{334}$ Kitāb al-istibṣār fī 'ağāiib al-amșār, S. 131.

${ }^{335}$ Mağmū' rasā'il muwaḥhidìya, S. 171.

${ }^{336}$ Für Ibn-Haldūn (Kitāb al-'ibar, Bd. 6, S. 392 und S. 507) war der Überraschungseffekt für den Erfolg des Überfalls ursächlich. Ibn al-Atīr führt die mühelose Inbesitznahme Biğāyas ebenfalls zum einen darauf zurück und zum anderen auf die absolute Abwesenheit der almohadischen Garnison, die einige Tage zuvor mit dem Statthalter Biğāyas nach Marrakech aufgebrochen sei. Erst nach dieser Inbesitznahme hätten Angehörige der einstigen Dynastie der Banū-Ḥammād 'Alī Ibn-Ishāa IbnMuhammad Ibn-Ġānīya angeschlossen (al-Kāmil, Bd. 9, S. 166).

${ }^{337}$ Les Benou Ghânya, S. 42, Historia política del imperio almohade, Bd. 1, S. 323.

${ }^{338} \mathrm{Im}$ Folgenden wird auf die Angabe der vollständigen Filiation bei diesem Herrscher und bei seinem Bruder verzichtet.
} 
Biğāyas stattgefundenen Geschehnisse übergangen. Denn der Umstand, dass die nachfolgende Historie mit weiteren für die Almohaden unangenehmen Komplikationen verbunden war, geht z. B. aus dem folgenden Bericht Ibn-'Idārīs eindeutig hervor: „Nach dieser Einnahme Biğāyas ließ er (d. h. 'Alī Ibn-Ġānīya) dort seinen Bruder Yahyā und seinen Klienten Rašîd. Er selbst brachte sofort auf und eilte Saiyid Abu-'rRabī nach, den er an einem Ort namens Yalmilūl ${ }^{339}$ einholte. Die Saiyid Abu-'r-Rabīi begleitenden arabischen Stämme haben ihn im Stich gelassen und sind zum Feind (d. h. 'Alī Ibn-Ġānīya) übergelaufen. Mit ihnen griff 'Alī Ibn-Ġānīya den Saiyid Abu-'r-Rabīc an. Dieser floh nach der erlittenen Niederlage aus seinem Lager und konnte entweichen. Das Eigentum, die Famlienangehörigen sowie das Gepäck des geflohenen Saiyids fielen dabei 'Alī Ibn-Ġānīya zu, der dies alles nach Biğāya bringen ließ, wo es dem erwähnten Rašīd in Verwahrung gegeben wurde. Abu-'r-Rabī' ergriff die Flucht und einige seiner Männer erlitten dabei den Märtyrertod. Er selbst gelangte zunächst nach Algier, doch da er diese Stadt für nicht wehrhaft genug hielt, setzte er seine Flucht weiter nach Tilimsen fort, wo er, ohne seine Truppen und nachdem ihm alles genommen wurde außer seiner umfassenden Bildung (arab.: al-adab) und seinem Ruhm, beim almohadischen Statthalter, dem Saiyid Abu-'1-Hasan, (vorerst) geblieben ist.“340 Diese Ereignisse werden bei Ibn-Haldūn und Ibn-al-Ațir in ähnlicher Weise überliefert ${ }^{341}$. Der Brief hat also insofern Recht, als der mallorquinische Herrscher die nähere Umgebung Biğāyas unter seine Botmäßigkeit gezwungen hat. Doch dies wurde erst nach der Niederlage von Saiyid Abu-'r-Rabī` möglich. Die stark raffende Darstellungsweise des Briefes im eingangs angeführten Satz erweist sich somit als eine euphemistische Umschreibung für einen weiteren militärischen Erfolg 'Alī Ibn-Ġānīyas und Misserfolg der Almohaden, worüber allerdings die Adressaten des Briefes - wenn sie nur diese bekannt gegebene offizielle Sichtweise kannten - nichts erfahren konnten.

4.7. „So ging er um Algier, Miliana, Ašīr und Qal'at herum und kehrte dann nach Biğāya zurück."

\footnotetext{
${ }^{339}$ Dies ist eine der möglichen Lautgestalten für diesen im arabischen Original nicht vokalisierten Ortsnamen.

340 al-Bayān al-muğrib, S. 176 f.

${ }^{341}$ In einem Bericht Ibn-Huldūns heißt es, 'Alī Ibn-Ġānīya habe Abu-'r-Rabī' und den Statthalter von Qal'at Ban̄i-Hammād in die Flucht geschlagen, die sich beide danach nach Tilimsen zu Abu-'l-Hasan begeben hätten (Kitāb al-ibar, Bd. 6, S. 392). An einer anderen Stelle in seinem Werk jedoch habe diesem Autor zufolge 'Alī Ibn-Ġānīya bei seinem Überfall auf Biğāya sowohl Abu-'r-Rabī', als auch AbūMūsa gefangen genommen (Kitāb al-ibar, Bd. 6, S. 507). Die Schilderung Ibn al-Atīrs stimmt mit der obigen Darstellung Ibn- Iḍārīs überein und weicht von ihr insofern ab, als ihr zufolge der Statthalter von
} 
Die Schilderung des Briefes an dieser Stelle ist nicht eindeutig. Erst aus dem weiteren Verlauf seiner Ausführungen wird die mit diesem „Herumgehen“ eigentlich gemeinte Bedeutung klar. Die Frage, die sich dabei stellt, lautet: Handelt es sich beim „Herumgehen“ um einen geläufigen und der zeitgenössischen Zuhörerschaft wohl bekannten und verständlichen Euphemismus oder liegt hier die offizielle Absicht vor, durch Vermeidung der Nennung von - für die offizielle almohadische Seite - peinlichen Sachverhalten bei ihrem richtigen Namen bei den der Verkündung des Schreibens zuhörenden Adressaten eine bestimmte Wirkung zu erzielen? Was den genannten Euphemismus anbelangt, so ist die literarische Ausdrucksweise im Maghreb des Mittelalters noch unzureichend erforscht, als dass man diese Frage hätte eindeutig beantworten können ${ }^{342}$. Nichtsdestoweniger können folgende Beobachtungen Anhaltspunkte für eine mögliche Deutung liefern: Einige arabische Verben, die im Klassischen Arabisch die Bedeutung ,jemanden betrügen, täuschen, hintergehen“ haben, können in den mittelalterlichen westarabischen Quellen in der Bedeutung vorkommen ,eine Stadt bzw. einen Ort überfallen und in seine Gewalt bringen, sie in Besitz nehmen“. Dies trifft beispielsweise für die arabischen Verbalsubstantive wie ,al-

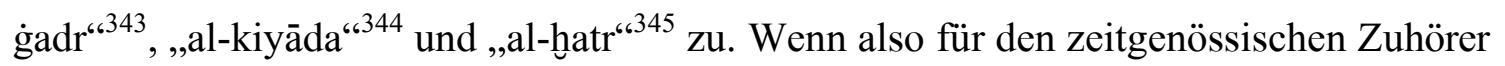
bei der Verlesung des Briefes Nr. 29 das verwendete arabische Verb für „herumgehen“ die Bedeutung oder auch die Konnotation gehabt hat, in hinterhältiger Absicht um ein Objekt herumzuschleichen, dann ist mit hoher Wahrscheinlichkeit davon auszugehen, das der Zuhörer den Satz, 'Alī Ibn-Ġānīya sei um die Städte des Zentralen Maghreb herumgegangen, dahingehend verstanden hat, dass der Letztere sich dieser Städte bemächtigt hatte. Es ist ferner möglich, dass für die Rezipienten des Briefes das „Herumgehen“' Alī Ibn-Ġānīyas, selbst wenn es sonst eine neutrale, über das Wörtliche nicht hinausreichende Bedeutung hatte, durch dessen Einbettung in einen Kontext, in welchem der Betreffende als Ausbund der Treulosigkeit, des Unglaubens und der Ruchlosigkeit dargestellt wird, im Text höchstwahrscheinlich die Bedeutung gehabt hat,

Biğāya nach der Niederlage mit seinen verbliebenen Truppen nach Marrakech sich begeben habe (alKāmil, Bd. 9, S. 166).

${ }^{342}$ Das „Supplément aux dictionnaires arabes“ Dozys aus dem Jahr 1881 bildet einen höchst wichtigen ersten Schritt auf dem Gebiet der lexikographischen Erfassung des mittelalterlichen arabischen Schrifttums. Zum besseren Verständnis von vielen arabischen Texten dieser Zeit bedarf es allerdings nicht nur eines Wörterbuchs, das die Übersetzung von einzelnen Lexemen enthält, sondern auch eines Nachschlagewerkes, das über die gemeinte Bedeutung von idiomatischen Wendungen, Metaphern und Allegorien der Texte des Mittelalters Aufschluss gäbe. Und eben ein solches Nachschlagewerk ist soweit meine Kenntnis reicht - nicht vorhanden.

343 al-Mann bi-'l-imāma, S. 288, Mağmū' rasā’il muwaḥhidīya, S. 173, al-Bayān al-mug̉rib, S. 175.

344 al-Mann bi-'1-imāma, S. 242, Raihānat al-kuttāb, Bd. 1, S. 299 f.

${ }^{345}$ Mağmū‘ rasā’il muwaḥhịīìa, S. 172. 
'Alī Ibn-Ġānīya sei um diese Städte eine günstige Gelegenheit für den Überfall abpassend herumgeschlichen. Somit wäre den Adressaten des Briefes u. a der Eindruck vermittelt, 'Alī Ibn-Ġānīya sei um die nichts ahnenden Stadtbewohner gekreist, bis sich ihm eine günstige Gelegenheit, diese zu überwältigen, geboten habe. Dies würde den Fall der Städte des Zentralen Maghreb durch die Heimtücke des Angreifers erklären und andere, eher ursächliche und theoretisch mögliche Faktoren wie z. B. die schlechte Verfassung von Verteidigungsanlagen, Kooperation der mit der almohadischen Herrschaft unzufriedenen Stadtbevölkerung, unadequates Verhalten der almohadischen Garnison usw. in den Hintergrund drängen bzw. ganz ausblenden.

Ibn-'Idārī berichtet, dass 'Alī Ibn-Ġānīya nach seinen anfänglichen Erfolgen Algier und Miliana erobert habe, in welchen er jeweils seinen Neffen Yahyā Ibn-Ṭalha und Yiddir Ibn-' $\bar{A})^{\prime}$ ¿̌̌a $^{346}$ ernannt habe ${ }^{347}$. Ibn-Haldūn fügt darüber hinaus hinzu, dass der erwähnte Herrscher bei seinem weiteren Eroberungszug westwärts abgesehen von Algier und Miliana noch die Städte Māzūna [sic] ${ }^{348}$ und Qal' 'at Banī-Ḥammād unterworfen habe ${ }^{349}$. Abschließend sei noch angemerkt, dass ein bemerkenswert beträchtlicher Teil des Briefabschnittes an dieser Stelle den Schilderungen der maßlosen Willkür gewidmet ist, welcher die mallorquinischen Angreifer und ihre Verbündeten die Bevölkerung in den unterworfenen Gebieten ausgesetzt hätten. Obwohl sich hierüber den überlieferten Quellen keine Hinweise entnehmen lassen, entbehrt diese Darstellung höchstwahrscheinlich doch nicht eines wahren Kerns, denn Wortbruch und Brutalität gegenüber Besiegten sowie der Bevölkerung von eingenommenen Orten seitens 'Alī Ibn-Ġānīyas als auch seines Bruders und späteren Nachfolgers Yahyā Ibn-Ġānīyas sind wohl belegt ${ }^{350}$.

4.8. „Nachdem uns [...] über das Unwesen dieses Frevlers berichtet wurde $[\ldots]^{“}$

Der Brief berichtet darüber, dass nach dem Bekanntwerden des almoravidischen Überfalls auf Biğāya und weiterer damit im Zusammehang stehender Ereignisse die

\footnotetext{
${ }^{346}$ So vokalisiert Huici Miranda diesen Namen (Historia política del imperio almohade, Bd. 1, S. 324), der bei Ibn-Haldūn sowohl als Badr Ibn-'Ā'iša (Kitāb al-'ibar, Bd. 6, S. 392 und S. 507) als auch als

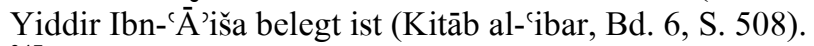

347 al-Bayān al-mugrib, S. 177. Damit stimmen auch fast vollständig die Angaben in „Kitāb al-‘ibar“ (Bd. 6, S. 392 und S. 507) überein, denn ihnen zufolge habe der ernannte Statthalter von Miliana Badr Ibn'Ā'iša geheißen.

348 A. Bel zufolge handelt es sich bei Māzūna in Wirklichkeit um Mūzaiya (Les Benou Ghânya, S. 45). Höchstwahrscheinlich ist Māzūna jedoch nicht eingenommen worden, denn laut Ibn- 'Id̄ārī hat Yiddir Ibn' $\bar{A}$ 'iša, nachdem er von 'Alī Ibn-Ġānīya zum Herrscher über Miliana ernannt wurde, Raids durchführen lassen, deren Ziel diese Stadt und ihr Umland war (al-Bayān al-muğrib, S. 178).

${ }^{349}$ Kitāb al- -ibar, Bd. 6, S. 392 f.

${ }^{350}$ Riḥlat at-Tiğānī, S. 14, 15, 136, 147, 162, 254, al-Kāmil, Bd. 9, S. 171, 233.
} 
almohadische Flotte und das almohadische Heer zur Rückeroberung von besetzten Städten entsandt wurden. Die ausführlichste Beschreibung sowohl dieser ersten Phase der almohadischen Unternehmung als auch ihres gesamten Verlaufs liefert - einmal mehr - Ibn-'Idārī. Seinem Bericht zufolge wurde mit dem Oberbefehl über die Flotte Šaih Abū-Muḥammad Ibn-Abī-Ishāa Ibn-Ğāmi`, der im Brief namentlich erwähnt wird, und über das Heer Saiyid Abū-Zaid Ibn-Abī-Hafṣ betraut ${ }^{351}$. Das almohadische Heer sei zunächst nach Fès gelangt und habe seinen Zug wegen schlechter Witterungsverhältnisse und unpassierbarer Wege zeitweilig unterbrechen müssen. Nach dem Ende der Regenfälle habe es seinen Marsch nach Tilimsen fortgesetzt, dessen Statthalter Abu-'1-Hasan die Verteidigungsanlagen dieser Stadt instand gesetzt und in den umliegenden Gebieten Wachen postiert habe. Miliana habe bei diesem Wiedereroberungszug die erste Etappe gebildet $^{352}$. Den Ausführungen des Briefes zufolge haben sich die Bewohner dieser Stadt den ankommenden Almohaden ergeben, die almoravidischen Besatzer haben dabei die Flucht ergriffen, wobei sie letztlich von den in der Umgegend siedelnden Stämmen aufgegriffen und den Almohaden überliefert wurden. Ibn-'I weicht insofern von der Darstellung des Briefes ab, als ihm zufolge die Bewohner dieser Stadt selbst seine Verfolgung aufgenommen haben. Die Bewohner eines Dorfes namens Umm al-'Alū, welches Yiddir Ibn- 'Ā'iša bei seiner Flucht erreicht habe, hätten ihm den Schutz, der seitens des Gastgebers dem Gast zu gewähren sei, angeboten. Man habe später Yiddir Ibn-'Ā'iša nach einem Gefecht am Flussufer überwältigt und zusammen mit seinen Gefährten zu den Almohaden gebracht. Der Befehlshaber der almohadischen Armee Saiyid Abū-Zaid habe daraufhin angeordnet, die restlichen Almoraviden [ $\mathrm{sic}^{353}$ ] am Fluss Cheliff umzubringen ${ }^{354}$. Ein interessantes Detail im Zusammenhang mit der Gefangennahme von Yiddir Ibn- 'Ā'iša überliefert Ibn-Haldūn, dem zufolge das almohadische Heer - und nicht die Bewohner der befreiten Gebiete - den flüchtigen almoravidischen Herrscher von Miliana verfolgt und ihn erst nach einem Gefecht mit Berbern, die ihm den nachbarschaftlichen Schutz gewähren wollten, habe ergreifen

\footnotetext{
${ }^{351}$ Dies wird auch von Ibn-Haldūn bestätigt (Kitāb al-ibar, Bd. 6, S. 393 und S. 507).

352 al-Bayān al-muğrib, S. 178.

${ }^{353}$ Dies scheint nahe zu legen, dass Yiddir Ibn- 'A' 'iša nicht umgebracht wurde. Ibn-Haldūn zufolge jedoch sei Yiddir Ibn-'Ā'iša nach seiner Gefangennahme getötet worden (Kitāb al-'ibar, Bd. 6, S. 393 und S. 508). Huici Miranda spricht an dieser Stelle - ohne Quellenangabe - davon, dass die Almohaden Yiddir Ibn-'Á'iša verschont und seine Gefährten geköpft hätten (Historia política del imperio almohade, Bd. 1, S. 325).

354 al-Bayān al-mugrrib, S. 178.
} 
können ${ }^{355}$. Stimmte dies, so müsste die allgemeine Aussage des Briefes, die um Miliana siedelnden Stämme hätten die fliehenden Almoraviden entweder umgebracht oder den Almohaden überliefert, relativiert werden.

Was die almohadische Flotte betrifft, so ist ihr dem Brief nach noch vor der Ankunft des almohadischen Heeres die Wiedereroberung von Algier gelungen. Darin wird an dieser Stelle explizit darauf hingewiesen, dass bei der Ankunft der almohadischen Flotte die Bewohner Algiers die Tore der Stadt entriegelt und Jagd auf die Angehörigen der almoravidischen Besatzung gemacht hätten ${ }^{356}$. Die almohadische Herrschaft sei in Miliana und Algier am gleichen Tag wiederhergestellt worden und man habe zu diesem Anlass die Trommeln rühren lassen ${ }^{357}$.

Die nächste Etappe des almohadischen Feldzuges bildete dem Brief nach Biğãya. Demnach wurde diese Stadt von der almohadischen Flotte allein zurückerobert. Die Ausführungen im Brief diesbezüglich weichen allerdings in einigen wesentlichen Punkten vom folgenden erhellenden Bericht Ibn-'Idāāīs darüber ab: „Der Flotillenadmiral namens Abu-'1-'Abbās aș-Ṣiqlīis8 war in einem Schiff mit einigen Bewohnern (Biğāyas) der almohadischen Flotte nach Biğāya vorausgesegelt. Die erwähnten Bewohner überbrachten der Bevölkerung der Stadt heimlich Briefe, welche die baldige Ankunft der Flotte und der gewaltigen Armee (der Almohaden) ankündigten. Als dann wie angekündigt die almohadische Flotte vor Biğāya erschien, erhob sich die Bevölkerung gegen die almoravidischen Besatzer und öffnete die Tore der Stadt. Die Besatzung der almohadischen Schiffe drang in die Stadt ein und plünderte viele ihrer Stadtteile aus. Der Šaih Abū-Muhammad Ibn-Ğāmi` hat jedoch diesen Missständen durch energisches und hartes Eingreifen sowie durch die Hinrichtung derer, die sich der Überfälle und der Plünderung schuldig gemacht hatten, ein Ende bereitet. ${ }^{6359}$ Dem Brief zufolge hingegen setzte die almohadische Flotte nach der Einnahme Algiers ihren Weg eiligst nach Biğāya fort, um den Plan der Mallorquiner, die in ihrer Gewalt befindlichen gefangen genommenen Almohaden nach Mallorca zu bringen, zu vereiteln. Dort angelangt habe sich der Befehlshaber der Flotte Šaih Abū-

\footnotetext{
${ }^{355}$ Kitāb al-ibar, Bd. 6, S. 393.

356 Über die Erhebung der Bevölkerung von Algier gegen die mallorquinischen Besatzer berichtet auch Ibn-Hुaldūn und fügt hinzu, Yahyā Ibn-Ṭalḥa sei danach Abū-Zaid übergeben worden (Kitāb al-'ibar, Bd. 6, S. 393).

${ }_{357}$ al-Bayān al-mugrib, S. 178.

${ }^{358}$ Die arabische Bezeichnung an dieser Stelle ,al-qā̄id“ ist - wie Dozy bemerkt - sehr verbreitet und sehr vage (Supplément aux dictionnaires arabes, Bd. 2, S. 425). Dem arabischen Text lassen sich keine Informationen über die konkreten Aufgaben von Abu-'l-'Abbās aṣ-Șiqlī entnehmen. Daher stellt „Flotillenadmiral“" keine genaue, sondern lediglich annähernde Übersetzung von ,al-qā’id“ dar.

359 al-Bayān al-muğrib, S. 178.
} 
Muḥammad 'Abdallāh Ibn-Abī-Ishạāq an die Bewohner der Stadt gewandt, ihnen die körperliche und materielle Unversehrtheit zugesichert und sie dafür gewonnen, beim bevorstehenden Zusammenstoss mit der mallorquinischen Besatzung nicht einzugreifen. Die Unterschiede zwischen diesen beiden Darstellungen sind überraschend: Die Schilderung von Ibn-'Idārī fußt wahrscheinlich auf einer zeitgenössischen almohadischen Quelle ,al-Mann bi-'1-imāma“ und müsste daher wenn nicht deckungsgleich, so doch weitgehend übereinstimmend mit derjenigen des Briefes sein, auch wenn Ibn-'Idārī nicht selten dazu neigt, den Text seiner Vorlage stark zu verkürzen $^{360}$. Aller Wahrscheinlichkeit nach war der ursprüngliche Bericht der Vorlage viel detailreicher und weitschweifiger als das, was nach der Redaktion Ibn-Id̄ārīs, der dadurch auch das Geschehen gleichzeitig gewichtete, übriggeblieben ist. Nichtsdestoweniger ist die Angabe höchst aufschlussreich, die Almohaden hätten den Boden für die Rückeroberung Biğāyas durch die Übermittlung von Schreiben an die Bevölkerung vorbereitet, sodass die später ankommenden almohadischen Schiffe nicht einfach unvermittelt aus dem Nichts auftauchten, wie es die betreffenden Sätze des Briefes glauben machen wollen ${ }^{361}$. Ob und wenn ja, wie sich diese beiden Schilderungen miteinander in Einklang bringen lassen können, lässt sich jedoch aufgrund fehlender Angaben diesbezüglich in anderen Quellen nicht eindeutig bestimmen.

Die beiden Brüder 'Alī Ibn-Ġānīyas und einige andere Mallorquiner konnten nach der erlittenen Niederlage zu ihrem Bruder, der Constantine erfolglos belagerte, fliehen ${ }^{362}$. Dabei ist Rašīd, der wie oben bereits erwähnt eine entscheidende Rolle bei dem Überfall auf Biğāya gespielt haben soll, gefangen genommen worden. Ferner berichtet der Brief darüber, dass die Almohaden und die Ṭālibs, die nach der Einnahme Biğāyas in Gefangenschaft der Mallorquiner geraten waren, nach der geschilderten Wiedereroberung dieser Stadt befreit werden konnten ${ }^{363}$. Dabei fällt die weitestgehende Anonymität, ja Gesichtlosigkeit der Befreiten auf. Dies ist überraschend, denn wie bei der Behandlung des Einfalls der Banū-Ġānīya im Zentralen Maghreb dargelegt wurde, handelte es sich bei diesen Gefangenen immerhin um sehr hochrangige Almohaden:

\footnotetext{
${ }^{360}$ Siehe z. B. den Bericht über den Zusammenstoss des almohadischen Kontingents mit den Truppen des Ibn-Mardanīš nahe Murcia in ,al-Mann bi-'l-imāma“, S. 195 ff., und dessen stark verkürzte Fassung in ,al-Bayān al-mugrrib“, S. 88 ff.

${ }^{361} \mathrm{Zu}$ diesen vorbereitenden, der militärischen Auseinandersetzung vorausgehenden Maßnahmen siehe auch die Ausführungen im nächsten Kapitel.

362 Diese Angabe des Briefes wird auch von Ibn-al-Atīr bestätigt (al-Kāmil, Bd. 9, S. 166). Ibn-Haldūn (Kitāb al-'ibar, Bd. 6, S. 393 und 508) und Ibn-'Idārī (al-Bayān al-muğrib, S. 178 f.) sprechen nur von einem Bruder 'Alī Ibn-Ġānīyas, nämlich Yahyā Ibn-Ġānīya.
} 
unter ihnen befanden sich der Statthalter von Ifrīqīya Abū-Mūsa samt seinen Gefährten und Familienangehörigen, die auf ihrem Weg nach Marrakech in Biğāya eine Zwischenstation eingelegt hatten, sowie die Familienangehörigen des Statthalters von Biğāya, die 'Alī Ibn-Ġānīya nach der Flucht des Saiyids Abu-'r-Rabī‘ gefangen genommen und zu Rašīd gesandt hatte. Schliesslich dürften auch die in Biğāya zum Zeitpunkt des Überfalls befindlichen almohadischen Funktions- und Würdenträger nicht unbehelligt geblieben sein. Vor diesem Hintergrund stellt sich die Frage nach dem Zweck dieser den almohadischen Briefen ganz allgemein eigenen Anonymität von Personen und nach der damit beabsichtigten und erzielten Wirkung bei den Rezipienten. Was diese Namenlosigkeit betrifft, so ist sie im vorliegenden Brief m. E. vor dem Hintergrund der allgemein zu beobachtenden Tendenz der almohadischen Schreiben zu sehen, die in ihnen geschilderten Abläufe zu simplifizieren und auf ein einfaches und einleuchtendes ereignisgeschichtliches Muster zu reduzieren. Denn die namentliche Nennung der befreiten Almohaden hätte - im sehr wahrscheinlichen Falle ihrer Bekanntheit - die Notwendigkeit nach sich gezogen, zu erklären, wie sie in Gefangenschaft der mallorqinischen Eindringlinge geraten sein konnten. Somit wäre auch die Erwähnung des Scheiterns Abu-'r-Rabī's in der Schlacht bei Yalmilūl sowie das Überlaufen der arabischen Stämme zu 'Alī Ibn-Ġānīya wohl unumgänglich geworden. Doch gerade diese näheren und für die offizielle Seite unliebsamen Zusammenhänge werden im Brief ausgespart. Die Adressaten des Briefes Nr. 29 müssen höchstwahrscheinlich ${ }^{364}$ dessen Ausführungen dahingehend verstanden haben, dass nur die in Biğāya zum Zeitpunkt der Ankunft 'Alī Ibn-Ġānīyas befindlichen almohadischen Funktions- und Würdenträger von den Angreifern gefasst und festgesetzt wurden.

4.9. „Die (übrigen) Untertanen [...] folgten diesem (geschilderten) rechten Handeln: Sie setzten gefangen und schlugen in Eisen all diejenigen der Elenden, derer sie habhaft werden konnten.“

\footnotetext{
${ }^{363}$ Dies wird auch von ,al-Bayān al-muġrib“ (S. 178) und ,al-'Ibar“ (Bd. 6, S. 393 und 508) bestätigt.

${ }^{364}$ Es wäre denkbar, dass man beim Bekanntwerden der Inbesitznahme Biğāyas und anderer Städte des Zentralen Maghreb in Marrakech die Untertanen davon in Kenntnis gesetzt haben konnte. Es ist jedoch kein offizieller almohadischer Brief weder in diesem noch in einem anderen Zusammenhang mit ähnlichem Inhalt überliefert. Die Rezipienten können auch keine Kenntnisse von im Brief geschilderten Ereignissen etwa durch heimkehrende almohadische Truppen besessen haben, da der Brief Nr. 29 unmittelbar nach der Rückeroberung Biğāyas verfasst, nach Marrakech gebracht und dann verbreitet worden ist, während die almohadische Armee sich noch für weitere Monate im Gebiet des Zentralen Maghreb aufhalten sollte.
} 
Mit diesem aus dem Zusammenhang mit der almohadischen Wiedereroberung der Stadt Miliana stammenden Satz soll auf die folgende Auffälligkeit des Briefes hingewiesen werden, nämlich auf die frappante Mühelosigkeit, mit welcher die almohadischen Flotte und Heer die Herrschaft sowohl über Miliana als auch über weitere Städte des Zentralen Maghreb wieder erlangt haben sollen. Im wesentlichen Maße soll die lokale Bevölkerung zu diesem scheinbar ungehinderten Ablauf der almohadischen Erfolge beigetragen haben, indem sie aktiv und spontan an der Vertreibung und Einbringung der fliehenden Angehörigen der mallorquinischen Garnisonen mitgewirkt habe. Bei Ibn'Idārī findet man indes eine sehr aufschlussreiche Passage, welche die erwähnte Mühelosigkeit sowie die aktive Teilnahme der einheimischen Einwohnerschaft in einen plausiblen Zusammenhang rückt: „Der Kalif Abū-Yūsuf al-Manșūr hat nach dem Ausrücken der almohadischen Truppen ihren jeweiligen Kommandeuren Schreiben an die Bewohner aller den Almohaden entrissenen Städte nachschicken lassen, in welchen man den Adressaten körperliche und materielle Unversehrtheit sowie Gnade und gütige Behandlung zusicherte. Als diese Kommandeure in die Nähe der zu befreienden Städte gelangten, sandten sie Spione mit diesen Schreiben heimlich voraus, welche nachts in diese Städte einsickerten und sich mit solchen ihrer Bewohner trafen, welche für die Zusicherung der körperlichen und materiellen Unversehrtheit in Betracht kamen ${ }^{365}$. Nachdem man den Inhalt dieser Schreiben den Letzteren zur Kenntnis gebracht hatte und als diese die Gewißheit hatten, dass sie keine Vergeltungsmaßnahmen seitens der Almohaden zu befürchten hatten und dass die Tore der Begnadigung und der Gnade vor ihnen weit aufgerissen waren, griffen sie die Feinde in ihrer Stadt an, lauerten ihnen bei ihrer Flucht auf und nahmen die meisten von ihnen gefangen. “366 Das Versprechen, alle Bewohner der zurückzuerobernden Orte gütig zu behandeln, wird im Brief lediglich allgemein mit „Ferner gaben wir ihnen (d. h. den ausrückenden Almohaden) die Anordnung, die körperliche und materielle Unversehrtheit allen Bewohnern jener Gebiete, seien es Stadt- oder Landbewohner, zuzusichern usw. “367 angedeutet. Im Brief wird von spontanen Parteinahmen der Stadtbewohner von Miliana und Algier für die Almohaden gesprochen: in Miliana sollen sich die Bewohner reuevoll ergeben haben, die Bewohner Algiers sollen bei der Ankunft der almohadischen Flotte sich beeilt haben, die Tore der Stadt zu entriegeln. Dabei werden sowohl das dem Angriff vorausgegangene Einsickern der almohadischen Spione als auch ihre geheime Agitation

\footnotetext{
${ }^{365}$ Dies ist m. E. der gemeinte Sinn der Passage „,wa-'ğtama'ū (aiy al-ğawāsīs) bihā (aiy bi-'l-bilād) ma'a man yūtaq bihī li-'l-aman“" an dieser Stelle.

366 al-Bayān al-mugirib, S. 178.
} 
verschwiegen. Erst die dank der oben zitierten Passage Ibn-'Idārīs mögliche Ausleuchtung dieses verkündigungstechnischen Aspekts gibt Aufschluss darüber, auf welche Weise die Zusicherung der körperlichen und materiellen Unversehrtheit in Wirklichkeit vonstatten ging, und erklärt, wie die Bewohner der zu „,befreienden“ Städte bei der Ankunft der almohadischen Armee und Flotte bei der Vertreibung und Verfolgung der almoravidischen Garnisonen - laut dem Brief - so koordiniert mitgeholfen haben konnten. Auch hier stellt sich die Frage danach, welche Wirkung die bewusste Nicht-Nennung von wichtigen Beweggründen der besetzten Bevölkerung, sich der Herrschaft der Almoraviden entledigen zu wollen, auf die Zuhörerschaft hatte.

Es fällt ferner das absolute Fehlen von Angaben über die jeweilige Zahlenstärke der almoravidischen Kontingente auf der einen und der entsandten almohadischen Truppen auf der anderen Seite im Brief auf. Anderen Quellen lassen sich kaum verlässliche Informationen darüber entnehmen ${ }^{368}$. Vor diesem Hintergrund gewinnen daher die Angaben Ibn-al-Atīrs insofern eine große Bedeutung, als sie über das numerische Verhältnis zwischen den gelandeten Almoraviden und der almohadischen Truppen Aufschluss geben. Dieser Historiograph berichtet nämlich darüber, dass 'Alī Ibn-Ġānīya mit ca. zweihundert Reitern und viertausend Fußsoldaten vor Biğāya gelandet sei. Er fügt am Ende seines Berichts hinzu, dass die aus Marrakech entsandte Armee zwanzigtausend Reiter und die almohadische Flotte sehr viele Menschen [sic] umfasst hätten $^{369}$. Aus dem - wohl nur annähernd stimmenden - Verhältnis zwischen zweihundert und zwanzigtausend resultiert die offenkundige mehrfache zahlenmäßige Überlegenheit der Almohaden den almoravidischen Angreifern gegenüber. Hinzu kommt, dass das erwähnte almoravidische Kontingent auf die eroberten Städte des Zentralen Maghreb verteilt wurde, während die almohadischen Truppen einem monolithen Block gleich vorrückten, was das ohnehin ungleiche Kräfteverhältnis zugunsten der Letzteren weiter verschoben haben dürfte. Auch ist mit großer Wahrscheinlichkeit anzunehmen, dass die in die betreffenden Städte eingeschleusten almohadischen Spione den für die Zusicherung der körperlichen und materiellen Unversehrtheit in Betracht kommenden Bewohnern die Menge der anrückenden

\footnotetext{
${ }^{367}$ Mağmū` rasā’il muwaḥhidīya, S. 174.

368 Ibn-Haldūn spricht von zweiunddreißig Schiffen, in welchen die Almoraviden von Mallorca aus aufgebrochen seien (al-'Tbar, Bd. 6, S. 393), ohne jedoch die Zahl der Kämpfer anzugeben. Ibn-al-Atīr erwähnt hingegen in diesem Zusammenhang nur zwanzig Schiffe (al-Kāmil, Bd. 9, S. 166). A. Bel hält die Zahl zweiunddreißig für glaubwürdig, folgt ansonsten den Angaben Ibn-al-Atīrs über die Truppenstärke der Almoraviden (Les Benou Ghânya, S. 41 f.).

369 al-Kāmil, Bd. 9, S. 166.
} 
Almohaden eindringlich geschildert haben ${ }^{370}$. Dies mag für die Bewohner zumindest einer der Beweggründe gewesen sein, gegen die zahlenmäßig unterlegenen almoravidischen Besatzer aufzubegehren. Abschließend sei darauf verwiesen, dass die Zuhörer das rasche Vorrücken und die nacheinander folgenden Erfolge der entsandten almohadischen Kontingente höchstwahrscheinlich nicht auf deren erdrückende numerische Überlegenheit zurückgeführt haben, weil sie ihnen kaum bewußt gewesen sein dürfte, sondern auf einen anderen Faktor, auf den der Brief explizit und mehrfach aufmerksam macht: das zum Obsieg der Almohaden verhelfende Eingreifen Gottes, welches den almohadischen Zug unausgesetzt begleitet haben soll.

\subsection{Zusammenfassung des historischen Kommentars}

Im Mittelpunkt des Briefes Nr. 29 steht die almohadische Unternehmung zwecks Rückeroberung einiger Städte des Zentralen Maghreb, die von den Angehörigen der auf den Baleareninseln überlebten Dynastie der Banū-Ġānīya in ihre Gewalt gebracht wurden. Aus dessen Schilderungen geht eine Ereignisabfolge hervor, die andere herangezogene Quellen in ähnlicher Weise dokumentieren. Bei der Bekanntgabe des Schreibens scheinen allerdings bestimmte Informationen nur in Form von Euphemismen an die Zuhörerschaft gelangt zu sein (s. Kapitel 4.7.). Ferner wurden die für die offizielle Seite unliebsamen Sachverhalte wie z. B. die Niederlage und Flucht des Statthalters von Biğāya bei Yalmilūl oder die Gewährung des Schutzes für Yiddir Ibn-' $\bar{A}$ 'iša seitens Angehöriger eines berberischen Stammes gänzlich ausgelassen.

Des Weiteren weist der Brief formale Merkmale auf, die sich auf seinen Wert als zeitgenossische historische Quelle eher mindernd auswirken. So ist das religiöse Moment im Brief dominierend: Die gesamte Unternehmung sei ausschließlich aus der Absicht entstanden, der Not der bedrängten Muslime abzuhelfen, und das göttliche Eingreifen zugunsten der Almohaden habe den Ablauf der Expedition in ihren einzelnen Etappen bestimmt. Auf der Textebene wird dieses Moment durch Koranzitate (s. Fußnoten Nr. 263, 266 und 276) bzw. Anspielungen auf solche (s. Fußnoten Nr. 261, 265, 267, 280, 283, 290, 291 und 293) und durch die aus dem Koran entlehnten Bezeichnungen für die Feinde der Almohaden (s. Kapitel 4.4.) geschaffen. Etwas weniger stark ausgeprägt als das religiöse ist das literarische Element, das durch eine

\footnotetext{
${ }^{370}$ Darauf lässt folgender Satz im Zusammenhang mit der almohadischen Rückeroberung Biğāyas schließen: „wa-dassū lahum kutuban bimā warā'ahum min al-usṭul wa-'l-ğuyūš al-wāṣila“ (al-Bayān almuġrib, S. 178), d. h. „Die erwähnten (zusammen mit Abu-'l-'Abbās aș-Ṣiqlī dem Gros der almohadischen Flotte vorausgesegelten) Bewohner überbrachten der Bevölkerung der Stadt heimlich Briefe darüber, wie gewaltig die anrückenden almohadischen Flotte und Heer seien.“
} 
klassische arabische Redewendung (s. Fußnote Nr. 264), ein bekanntes Zitat aus der vorislamischen Dichtung (s. Fußnote Nr. 274) und durch geläufige literarische Allegorien (s. Fußnoten Nr. 266, 269, 271, 279 und 287) konstituiert wird. Ferner ist der weitestgehend zeitlose Rahmen zu nennen, in welchem der mitzuteilende Inhalt des Briefes angesiedelt ist. Wie auch in anderen untersuchten Briefen kann man hier ebenfalls das Bestreben beobachten, Eroberungen als eine Kette rasch aufeinander folgender Ereignisse darzustellen ${ }^{371}$. Auch hier wird dieser Eindruck durch Weglassen jeglicher Zeitangaben bis auf das Abfassungsdatum vermittelt. Ferner konnte die weitgehende Ausblendung des kausalen Zusammenhangs zwischen den geschilderten Ereignissen festgestellt werden. Dies tritt besonders deutlich bei den Beteuerungen des Briefes zutage, die jeweilige Stadtbevölkerung habe bei der Vertreibung und Verfolgung der almoravidischen Besatzer spontan und aus eigenem Antrieb mitgewirkt. Die vorhergehende geheime Tätigkeit der almohadischen Agenten, die erst die Voraussetzungen für diese „Volkserhebungen“ geschaffen haben, bleibt unerwähnt. Man kann abschließend sagen, dass der Brief Nr. 29 die offizielle bzw. offiziell propagierte Sicht auf die geschilderten Ereignisse bekannt gibt und vor dem Hintergrund anderer überlieferter Quellenberichte als ein inhaltlich sehr tendenziöses Zeugnis mit ausgeprägter propagandistischer Ausrichtung verstanden werden kann.

\section{Zusammenfassung des Briefes Nr. 30}

Dieser aus der Region Nafzāwa abgesandte Brief, der vom 23. Oktober des Jahres 1187 datiert und im Namen des Befehlshabers der Gläubigen vor den Toren der Stadt Gabès abgefasst ist, richtet sich an die Ṭālibs, Almohaden, Šaihss und die gesamte Bewohnerschaft von Marrakech. Seinen Inhalt bildet der Bericht über den erfolgreichen Verlauf der almohadischen Unternehmung gegen ihre Feinde in Ifrīqīya (d.h. annähernd im Gebiet des heutigen Tunesiens). In folgender Weise wird dies geschildert: Die Adressaten haben bereits von den antialmohadischen Aktivitäten der asiatischen Söldner und der Mallorquiner in den Randbezirken Ifrīqīyas sowie von ihrem Plan, deren sämtliche landwirtschaftlichen Erzeugnisse zu vernichten, erfahren. Doch durch die rechtzeitige Ankunft der Almohaden dorthin kann dieses Vorhaben vereitelt werden. Von Tunis aus schlägt die almohadische Armee den Weg zu den erwähnten Aufrührern ein, welche, davon benachrichtigt, sich ebenfalls in Bewegung setzen. In Kairuan

\footnotetext{
${ }^{371}$ In der Tat erstreckten sich diese Abläufe über mehrere Monate: Biğāya wurde am 13. November 1184 von den Almoraviden eingenommen und am 22. Mai 1185 von den Almohaden wiedereobert (Historia política del imperio almohade, Bd. 1, S. 323).
} 
angelangt, richten die Almohaden an die erwähnten Feinde, die inzwischen in Wādī Rān angekommen sind, die Aufforderung, von ihrem Treiben Abstand zu nehmen. Ungeachtet dieser Aufforderung ziehen diese jedoch nach Gafsa, um dort den Almohaden gegebenenfalls eine Schlacht zu liefern. Die almohadische Armee nimmt ihre Verfolgung auf, und die Feinde ergreifen die Flucht nach Gabès. Auf ihrem Weg dorthin schlagen sie bei der Ortschaft namens Ḥamma Maṭmāṭa ihr Lager auf und rufen die Kämpfer des Stammes Sulaim zu Hilfe. Die sie verfolgenden Almohaden schlagen ebenfalls in der Nähe der genannten Ortschaft ihr Lager auf. Die Feinde werden bei einem darauf folgenden heftigen Gefecht geschlagen und erleiden auf ihrer Flucht hohe Verluste von den ihnen nachsetzenden Almohaden. Das almohadische Heer erreicht daraufhin Gabès. Als es dort anlangt, erbitten die Bewohner dieser Stadt die Zusicherung ihrer körperlichen und materiellen Unversehrtheit und bekennen sich wieder zum Almohadentum. Die in Gabès befindlichen Familienangehörigen und Vertrauten von Qarāqūš verschanzen sich in der Zitadelle der Stadt. Als man sich mit ihnen darauf einigt, dass man sie am Leben lässt, sie aber enteignet und bestimmte unter ihnen befindliche Frauen und Kinder versklavt, ergeben sie sich. Nach der Beschreibung der strategischen Wichtigkeit von Gabès und der zahlreichen Vorzüge dieser Stadt wird auf das göttliche Eingreifen bei dieser Unternehmung der Almohaden hingewiesen, da kein einziger von ihnen zu Schaden gekommen sei. Der Brief schließt mit der Aufforderung an die Adressaten, Gott für die geschilderten Erfolge der Almohaden gebührend zu danken, und die Kunde davon überall zu verbreiten.

\section{1. Übersetzung des Briefes Nr. 30.}

Vom Befehlshaber der Gläubigen, dem Sohn des Befehlshabers der Gläubigen, dem Enkel des Befehlshabers der Gläubigen - Gott möge ihnen Seinen Beistand leisten und ihnen Seine Unterstützung gewähren - an die Ṭālibs, Almohaden, Šaihs und die gesamte Bewohnerschaft von Marrakech - Gott möge ihren Erfolg und ihren erhabenen Rang mittels ihrer Ehrfurcht Ihm gegenüber währen lassen, Er möge sie Ihm in einer solchen Weise danken lassen, die demjenigen (d. h. Gott) gebührt, der diesen Erfolg (den Gläubigen) zuteil werden ließ, und Er möge euch die erquickenden Botschaften und die frohen Mitteilungen dieser mächtigen (almohadischen) Sache vernehmen lassen. Der Friede, die Gnade Gottes - gepriesen sei Er - und Seine Segen mögen euch zuteil werden ${ }^{372}$.

\footnotetext{
${ }^{372}$ Der darauf folgende einleitende Teil wurde bei der Übersetzung übergangen, s. Kapitel 8.2.
} 
Dieses unser Schreiben ergeht an euch - Gott möge euch von den frohen Mitteilungen dieser mächtigen Sache die erfreulichsten vernehmen lassen, Er möge euch durch das Unaufhörliche und Ununterbrochene dieser Botschaften in den Genuss des vortrefflichsten Gesammelten kommen lassen, Er möge euch durch ihr Eintreffen und Ankunft die fortwährenden und unabwendbaren Bezeigungen Seiner vollkommenen Güte erfahren lassen und Er möge euch Ihm, der sie euch zuteil werden ließ, dafür in einer solchen Weise danken lassen und Ihn, der sie zu euch geschehen ließ und sie gewährte, (für sie) in einer solchen Art lobpreisen lassen, dass dies (zu euren Gunsten) in den Schriften der Gnade ein unaustilgbares frommes Werk und ein Bittgebet verzeichnet sein lässt - aus dem Lager der Almohaden - Gott möge ihnen Mächtigkeit verleihen - vor den Toren der Stadt Gabès - Gott möge diese Stadt beschützen. Mit diesem unseren Schreiben empfehlen wir euch an, Gott zu fürchten, Seinen Willen zu befolgen, Ihn allein um Hilfe anzurufen und euch auf Ihn zu verlassen. Wir danken Gott - gepriesen sei Er - für Seine Gunstbezeigungen und Gnadenerweisungen, dank welchen die wahre Anbetung in diesen Landstrichen in ihrer Ganzheit wiederhergestellt wurde, die Wahrheit ihren erhabenen Rang wieder einnahm und das, was die Hände der Raubenden und der widerrechtlich an sich Reißenden erraft hatten, (dorthin) zurückgebracht wurde. Wir danken Ihm für Seine Gunstbezeigungen und Gnadenerweisungen, dank welchen alle Seiner (almohadischen) Sache Trotzenden und sich ihr Widersetzenden zu Boden gerungen, alle das Almohadentum Bekämpfenden und es Bekriegenden mit bösen Ränken ${ }^{373}$ erfasst und alle abtrünnigen, entflohenen Sklaven ${ }^{374}$ entseelt zurückgelassen wurden (wörtl. gleich dem weggehenden gestrigen Tag gelassen wurden). Wir danken Ihm ferner für Seine Gunstbezeigungen und Gnadenerweisungen, welche die almohadische Botschaft im weit nach oben sich erstreckenden Himmel ihrer Mächtigkeit erhöht haben, und welche ihre almohadischen Streiter, denen Gott beisteht, und ihre um der wahren Anbetung willen kämpfenden Anhänger, mit dem Nimbus des Sieges und der Sieghaftigkeit umhüllt, den hellleuchtenden Gestirnen ${ }^{375}$ gleich haben erstrahlen lassen sowie sie (d. h. diese genannten almohadischen Streiter und Anhänger) in der ihnen vertrauten Weise den

\footnotetext{
373 Anspielung auf Sure 35, Vers 43 des Korans, wo es heißt: „Aber von den bösen Ränken wird (schließlich) niemand anders erfasst als ihre Urheber" (Der Koran, S. 362)

374 Im arabischen Text steht an dieser Stelle (Mağmū' rasā'il muwaḥhidīya, S. 183) „'ubbāq“". Höchstwahrscheinlich ist damit „ubbāq“ gemeint.

${ }^{375}$ Mit dem an dieser Stelle (Mağmū` rasā'il muwaḥhidīya, S. 183) gebrauchten „ka-'n-nuğūm at-tawāqib“ scheint man Bezug zu nehmen auf einen bekannten Ausspruch Mohammeds „Aṣ̣ābī ka-'n-nuğūm biaiyihim iqtadaitum ihtadaitum“, d. h. meine Gefährten sind Gestirnen gleich, welchem unter ihnen ihr auch folgt, ihr werdet rechtgeleitet" (Nihāyat al-arab fī funūn al-adab , Bd. 3, S. 3).
} 
stetigen Beistand Gottes und Sein unaufhörliches zum Obsieg verhelfendes Eingreifen erfahren ließen und ihnen in all ihren Unternehmungen die fortdauernde Sieghaftigkeit und immerwährende Unterstützung (Gottes) angedeihen ließen.

Ferner, ihr - Gott möge euch den Erfolg verleihen und euch dabei Seine Hilfe gewähren, Ihm für Seine Hulderweisungen zu danken - habt bereits erfahren, dass diese Elenden, nämlich die asiatischen Söldner, und ihre Brüder in der Verirrung, diese Mallorquiner, in die Randbezirke dieser Gegenden Ifrīqīyas einfielen, sie mit Plünderungszügen überzogen und sich darüber einig wurden, die Erträge dieses Jahres in Ifrīqīya $\mathrm{zu}$ vernichten und $\mathrm{zu}$ verderben. Ihr habt auch erfahren, dass ihre trügerischen Begehrlichkeiten ihnen eingaben, sie könnten Ifrīqīya durch ihr räuberisches Unwesen lähmen und schwächen. Doch es hinderten sie daran, diese ihre Hoffnungen in Erfüllung gehen $\mathrm{zu}$ lassen, Gottes schützendes und abwehrendes Eingreifen und die Ankunft (der Almohaden) dorthin, die in einer Zeit statthatte, welche die Sieghaftigkeit für die Almohaden festgelegt hat, die zu einem Zeitpunkt erfolgte, zu dem zu erfolgen die Almohaden ihre Entschlossenheit und Eifer bewogen, und die genau dann geschah, als die aufrichtige Absicht und der Vorsatz (der Almohaden) einzig darauf gerichtet waren, Seinem Wort zum Obsieg zu verhelfen und den schwelenden Feuerfunken der Unwahrheit samt ihrem Unsteten auszutreten. Dank Gottes wundersamem Eingreifen gelangten wir nach Ifrīqīya just in dem Moment, als ihre Saat zur Reife gelangte. Auf diese Weise bewahrte Gott diese Saat davor, dass diese Elenden sie ausrauften, Er beschützte sie zugunsten ihrer rechtmäßigen Besitzer davor, dass diese Söldner und Mallorquiner sich darauf stürzten und sie verdürben, und Er ließ diese Saat zum reichlichen täglichen Brot Seiner dank Ihm sieghaften Anhänger werden, das ihnen durch deren Einigkeit und Eintracht nach ihren jeweiligen Bedürfnissen (wörtl. wohl abgewogen) zuteil wurde. Hingegen bewirkte das Scheitern der benannten Hoffnung dieser Elenden, dass sie sich verstreuten und uneinig wurden sowie einen solch heftigen Hunger leiden mussten, dass sie beinahe verhungert wären.

Diese meuternden Elenden, diese Ungläubigen, die dem Islam abgeschworen hatten (wörtl. die sich des Gewandes des Islam entledigt und entkleidet hatten ${ }^{376}$ ), diese Feigherzigen, die beim Treiben ihres Unwesens nur deswegen so dreist waren, weil niemand da war, der sie hätte wirksam in die Schranken weisen können ${ }^{377}$, dieser

\footnotetext{
${ }^{376}$ Die Aussage, man hänge einer Partei an bzw. man bekenne sich zu einer bestimmten Anschauung, kann durch das Bild zum Ausdruck gebracht werden, man sei in das Gewand dieser Partei bzw. dieser Anschauung gekleidet. Siehe hierzu die Belege im Kapitel „Kleider und Gewänder“ im Anhang 2.

377 An dieser Stelle des Textes (Mağmūc rasā’il muwaḥhidīya, S. 184) lautet der arabische Satz ,wa-'lğubanā' al-muğrūn fi 'l-ḩalā' wa-hum munfaridūn“. Hiermit scheint man Bezug zu nehmen auf die
} 
Abschaum, der sich zu dem Zwecke zusammenschloss und zusammendrängte, sein räuberisches Unwesen zu treiben, all diese ließ der Satan sich von Gott abwenden und irregehen, all diese verführte die verderbliche Habgier, welche sie vermeinen ließ, sie wären unbesiegbar, sie missleitete und ins Verderben stürzte. Als Gott - gepriesen sei Er - erlaubte, diese genannten Elenden auszumerzen, und als es Sein Ratschluss war, dass sie durch Seine siegreichen (almohadischen) Streiter unterworfen und aufgerieben werden sollten und dass dem Übel, welches dieser Elenden Lügenhaftigkeit und Schwindel $^{378}$ über die Gegenden Ifrīqīyas brachten, durch diese almohadischen Streiter abgeholfen werden sollte, fassten die Almohaden - Gott möge ihnen beistehen - den Entschluss, nach der Wohnstätte dieser Elenden aufzubrechen und sie inmitten ihrer Wohnorte zu überfallen ${ }^{379}$. Und nachdem sie Gott - gepriesen sei Er - darum angerufen haben, ihnen bei der Vernichtung und Austilgung dieser elenden Feinde beizustehen, brachen sie von Tunis - Gott möge diese Stadt beschützen - auf. Bei diesem ihren Aufbruch waren die Anzeichen ihres (bevorstehenden) Erfolges wahrhaftig, ihre Banner flatterten im Wind, das zum Obsieg der Almohaden verhelfende Eingreifen Gottes ankündigend, die Gesamtheit der ziehenden Almohaden war voller Zuversicht, dass Gott ihnen helfen werde, und Seine Beistandserweisungen ließen Hoffnungen auf Seine Gnade(nbezeigungen) in Erfüllung gehen. Bei diesem glückhaften Zug der Almohaden wurde keinerlei Bedeutung der Zahlenstärke noch der Bewaffnung beigemessen ${ }^{380}$, auf

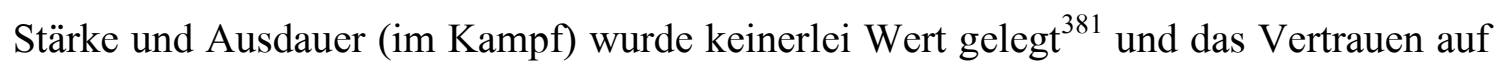
Kühnheit und Tapferkeit, welche die Menschen unerlässlich dünken und welche den Streitenden und den mit Schwert oder Lanze unerschrocken Kämpfenden eigen sind, war nicht vom geringsten Belang. Vielmehr wurde bei diesem Zug das Vertrauen der

\footnotetext{
idiomatische Redewendung „kull muğrin fi 'l-ḩalā' yusarr“, die auch als „kull muğrin fi 'l-ḩalā' mağĩd“ sowie „kull muğrin fi 'l-ḩalā' sābiq“ überliefert wird (Mağma' al-amtāl, Bd. 2, S. 135).

${ }^{378} \mathrm{Die}$ an dieser Stelle (Mağmū` rasā'il muwaḥhidīya, S. 184) gebrauchten Wörter ,zūr“ und ,ifk“ bedeuten jeweils „Lüge, Falschheit“ und „Lüge“ und entstammen dem koranischen Kontext, in welchem mit ihnen die Bedeutungen „Unglaube, Anfechtung der Wahrhaftigkeit der Botschaft Mohammeds und ihre Verschmähung" konnotiert werden.

${ }^{379}$ Anspielung auf den Ausspruch 'Alī Ibn-Abī-Ṭālibs: „Mā g̉uzīya qaum fī ‘uqr dārihim illā dallū“ (Mā 'ttafaqa lafẓuhū wa-'ḩtalafa ma'nāhū, S. 253), d. h. „Jede Gemeinschaft, die inmitten ihrer Wohnstätten überfallen wird, ist der Verächtlichkeit anheim gefallen“.

${ }^{380}$ Der arabische Satz an dieser Stelle (Mağmū' rasā'il muwaḥhidīya, S. 185) lautet ,wa-lam yakun aliltifăt fî hadihī al-ḥaraka as-sa'īda ilā 'adad wa-'udda“. „'Adad wa-'udda“ scheint ein idiomatischer Ausdruck zu sein, welcher in etwas abgewandelter Form bei Lisān-ad-Dīn Ibn-al-Ḩatị (Raihānat alkuttāb, Bd. 2, S. 254) bei der Schilderung der Ankunft des königlichen Zuges in der Stadt Purchena, und dies während einer Inspektionsreise durch die östlichen Gebiete des nasridischen Reiches im Jahre 1347, vorkommt: ,wa-qad baraza ahluhā fi 'l-'adīd wa-'l-'udda wa-'1-iḥtifāl allad̄ī qaduma bihī al-'ahd 'alā tụ̂l almudda“. Für beide dieser angeführten idiomatischen Ausdrücke gilt, dass „udda“ auch als „'idda“" vokalisiert und gelesen werden könnte.

${ }^{381}$ Im arabischen Satzsegment an dieser Stelle (Mağmū` rasā’il muwaḥhidīya, S. 185) ,wa-lā istiṭār biqūwa wa-lā šidda“" müsste ,,istiṭhār" m. E. zu ,istiẓhār" korrigiert werden.
} 
Almohaden auf Gott allein zu einem monolithen Ganzen, die aufrichtige Absicht (der Almohaden) wurde unverrückbar darin, nach dem Seinigen (und nicht nach dem Menschlichen) zu streben, und die Gewissheit, dass Gott - lobgepriesen sei Er - Sein Licht überall erstrahlen lassen und Seine Verheißung wahr machen wird, erfüllte die Almohaden. Und so ließ Gott alle Mutmaßungen (der Almohaden) wahr werden, Er ließ das Mannigfaltige und das Mannigfache Seiner wundersamen Beistandsleistungen augenscheinlich werden ${ }^{382}$ und ließ auf diejenigen, die sich von Seiner mächtigen (almohadischen) Sache abgekehrt und die Zuflucht in der sicheren Höhle des Gehorsams Ihm gegenüber verworfen hatten (wörtl. ihre Schlingen der Zufluchtnahme in der sicheren Höhle usw. abgestreift hatten), die durchbohrenden Todesgeschicke niederprasseln und sie mit Schmach in diesem diesseitigen Leben bedeckt sein, und wahrlich ist die Pein des Jenseits heftiger, wenn sie es nur wüssten ${ }^{383}$ !

Als diese Elenden merkten, dass die Bekenner des Almohadentums - Gott möge ihnen Mächtigkeit verleihen - zu ihnen unterwegs waren, dass die durch Gottes Beistand siegreichen Fahnen der Almohaden heranrückten und dass Gottes unabwendbares Strafgericht $^{384}$ sie nun von hinten und von vorne ereilt hatte, setzten sie sich in Bewegung, vom Wahn ihrer Lügenhaftigkeit geschlagen, sich ihrem eitlen Hochmut hinterher schleppend und an der Halsschlinge der Verächtlichkeit zu den Stätten ihrer Vernichtung hingezerrt. Sie stellten Mutmaßungen an, welche ihnen durch Gottes Allmacht letztlich nur den Tod einbringen sollten. Sie wähnten, alles weißlich Schimmernde sei eine Schnitte Fett ${ }^{385}$ und alles Dunkelfarbene sei eine Dattel ${ }^{386}$. Sie vermeinten, ihre falschen Vorspiegelungen würden ihnen immer nützlich sein, und sie ließen sich durch die ihnen gewährte Schonfrist, welche ihnen gegeben wurde, auf dass sie sich noch mehr Sünden zuschulden kommen ließen und auf dass ihre Ausmerzung heftiger würde, täuschen. Aber beim Suchen des Abendessens gerieten sie in die Wolfsfänge ${ }^{387}$, und der ihnen vorherbestimmte Tod führte sie an den Halfterriemen und

\footnotetext{
${ }^{382}$ Das Empfangen von etwas Erfreulichem wird im mittelalterlichen literarischen Schrifttum häufig durch das Bild zum Ausdruck gebracht, der Beschenkte nehme dieses Erfreuliche optisch wahr.

${ }^{383}$ Ein fast wörtliches Zitat aus dem Koran (Sure 68, Vers 33), denn das zu „Strafgericht“ gehörende Adjektiv lautet dort ,akbar“", während es im Text ,ašadd“" steht.

${ }^{384}$ Das an dieser Stelle (Mağmū' rasā’il muwaḥhidīya, S. 185) gebrauchte ,wa-anna ahd dat Allāh ar-rābīya atathum min warā’ihim wa-min baina aiydīhim“ ist eine Anspielung auf Sure 69, Vers 10 des Korans ,fa'asaū rasūl rabbihim fa-ahadahum ahֵdatan rābīyatan“.

${ }^{385}$ Anspielung auf die arabische Redewendung „mā kull baiḍā’ šaḥma“, d. h. „nicht alles weißlich Schimmernde ist eine Schnitte Fett" (Kitāb ğamharat al-amtāl, Bd. 2, S. 287).

${ }^{386}$ Anspielung auf die arabische Redewendung „mā kull saudā' tamra“, d. h. „nicht alles Dunkelfarbene ist eine Dattel“" (Kitāb ğamharat al-amtāl, Bd. 2, S. 287).

387 Arabische Redewendung (Kitāb ğamharat al-amtāl, Bd. 1, S. 514). Sie kommt auch in „Rasā’il wamaqāmāt andalusīya“" (S. 179) in einem der Briefe dès bekannten andalusischen Sekretärs Abū-'Abdallāh
} 
Stricken. Und so wurde ihnen statt der Gelegenheit zu plündern, die ihnen vorgeschwebt hatte, das Gallenbittere des Gefechts mit Schwertern und das Herbe des Kampfes mit Lanzen zuteil sowie die Hiebe mit den Spitzen der Scharfschneidigen (d. h. der Schwerter) und die Stiche mit den Eisenteilen der Biegsamen (d. h. der Lanzen), so dass ihre abgetrennten zerfleischten Körperteile und ihre weithin zerstreuten Gelenke zum Futter für Vögel und zum Fraß für Wölfe wurden (wörtl. zu Kröpfen der Vögel und zu Mägen der Wölfe) ${ }^{388}$.

Als die Almohaden - Gott möge ihnen Mächtigkeit verleihen - nach Kairuan gelangten - Gott möge diese Stadt beschützen - dünkte sie gut, an diese Elenden zunächst eine Warnung zu richten und die Rechtmäßigkeit ihres Vorgehens gegen diese Frevler zu untermauern sowie den Bestimmungen des geoffenbarten Gesetzes mit einem nachdrücklichen Aufruf an sie, sich Gott - gepriesen sei Er - , seinem Gesandten und dessen Botschaft unterzuordnen, Genüge zu leisten. Doch sie verschmähten und gering achteten die ihnen erwiesene Güte, sie missachteten diese Gnadenbezeigung, sie verkannten, wie groß diese ihnen zuteil gewordene Wohltat doch war, und wehrten sie ab. Darüber hinaus setzten sie den (almohadischen) Überbringer der Warnung fest, gemäß ihrer Gewohnheit der Ungläubigen handelnd, in der von ihnen bekannten Treulosigkeit und Heimtücke verharrend und (auf diese Weise) ihr (wahres) verdorbenes Wesen und ihre (nichtige) Sache in all ihrer Augenscheinlichkeit offenbarend. Dabei wussten sie nicht, dass der Stab des Almohadentums all das verschlingen würde ${ }^{389}$, was auch immer sie zaubern sollten, und dass das Vertrauen auf das Eintreffen der Verheißung Gottes die Almohaden mit Freude auf die Bezwingung dieser Feinde und auf deren Unterwerfung (wörtl. Unterwürfigkeit) erfüllte. Als die Almohaden - Gott möge ihnen Mächtigkeit verleihen - in Kairuan ihr Lager aufschlugen, befanden sich diese Elenden in der Nähe von Wādī Rān. Von dort brachen sie auf, gemäß ihrer Gewohnheit in Täuschung und Listanwendung handelnd, wobei der (ihnen vorherbestimmte) Tod, der sich ihrer bemächtigte und sie übermannte, ihnen ihr Einsichtsvermögen und ihre optische Wahrnehmungsfähigkeit benommen hatte. Vorher ließen sie ihre Anhänger glauben, sie würden dahineilen, um die Almohaden zu Boden $\mathrm{zu}$ ringen, und betrogen diese Unbedarften so mit den Blitzen ihrer Lügenhaftigkeit,

Ibn-Abi-'l-Hुișāl (gest. 1146) vor, dessen Briefsammlung laut 'Abd-al-Wāhid al-Marrākušī (al-Mu'ğib, S. 175) die andalusischen Literaten eingehend studierten und die darin enthaltenen Briefe nachahmten.

${ }^{388}$ Dieses Bild ist auch in der andalusischen Dichtung belegt. Siehe hierzu „al-Fitan wa-'l-hurūb“ (Bd. 3, S. 222)

389 Anspielung auf den Stab Moses', welcher bei einem Wettstreit mit den Zauberern Pharaos, in eine Schlange verwandelt, die Schlangen der Letzteren verschlang und Moses auf diese Weise zum Sieg verhalf (Qiṣaṣ al-anbiyā', S. 207 ff.). 
ihrer regenlosen Wolke ${ }^{390}$ und ihres Wahns. Doch nun flohen sie den verängstigt auseinanderstiebenden Straußenjungen gleichend davon, sie irrten in ihrer Furcht und Entmutigung ratlos ${ }^{391}$ zwischen [unklar ${ }^{392}$ ] der Nord- und Südwinde umher. Danach schlugen sie den Weg nach Gafsa ein - Gott möge diese Stadt wieder den Almohaden botmäßig machen - , gaben vor, sich dort dem Kampf (gegen die Almohaden) stellen zu wollen, und streuten das Gerücht aus, sie beabsichtigten die Almohaden - Gott möge ihnen Mächtigkeit verleihen - zu bekriegen, falls sie sich dorthin begeben sollten. Die Almohaden ihrerseits - Gott möge ihnen Mächtigkeit verleihen - folgten diesen ihren Feinden nach und kamen in die Nähe Gafsas. Sie zogen dorthin auf einem solchen Wege, von welchem diese Elenden niemals gedacht hätten, dass man ihn hätte einschlagen können, und welchen beschreiten zu können ihnen nimmer in den Sinn gekommen wäre ${ }^{393}$. Doch sie (d. h. die Feinde) bereuten bitterlich ihre Taten ${ }^{394}$. Alles, was sie sich da gedacht hatten, erwies sich als nichtig, und all ihre großtönenden Behauptungen entpuppten sich als leer. Stattdessen wurde ihr missachtenswerter Eifer dabei glühend, nach Gabès - Gott möge diese Stadt beschützen - zu fliehen. Die Todesgeschicke trieben sie dabei den Stätten ihrer Niederstreckung (bzw. ihrem Tod) behände entgegen, behinderten sie aufs Heftigste bei der Flucht, und der Satan ließ sie wähnen, sie seien dem gewachsen, was (in Wirklichkeit) ihre Kraft und ihr Vermögen überstieg. Auf diese geschilderte Weise gelangten sie nach Ḥamma Maṭmāța, wo ihre Todesstunde schlagen und ihrem Leben ein (jähes) Ende gesetzt werden sollte und wo ihre Füße erzittern sowie Niederungen und Anhöhen mit ihren staubbedeckten leblosen Körpern und ihren Schädeln übersät werden sollten. Bei dieser erwähnten Hamma Maṭmāta machten sie halt ${ }^{395}$ und riefen die Wegelagerer und Banditen des arabischen Stammes Sulaim zu Hilfe sowie auch all diejenigen der Verfechter des Eitlen von den arabischen Beduinen, die wie sie in der Missleitung befangen waren. So kam es, dass sie, indem sie sich gegenseitig um Beistand baten, den Regen von den regenlosen

\footnotetext{
${ }^{390}$ Das Bild einer regenlosen Wolke, im Text mit „hullab“ bezeichnet, kann im Arabischen Enttäuschung über einen nicht in Erfüllung gegangenen Wunsch konnotieren. Dieses Bild ist nicht selten in den almohadischen Briefen.

${ }^{391}$ An dieser Stelle (Mağmū' rasā’il muwaḥhidīya, S. 186) lautet das arabische Satzsegment ,wa-tāhū fī ğabrat al-ğaza' wa-'l-halac““. Mit „,̆abra“ könnte „haira“, d. h. „Verwirrung, Ratlosigkeit“, gemeint sein.

392 Das an dieser Stelle (Mağmū' rasā’il muwaḥhidīya, S. 186) gebrauchte Wort, durch Radikale Lām, Alif, Bā', Tā', Alif maqșūra konstituiert, konnte nicht ermittelt werden.

${ }^{393} \mathrm{Im}$ arabischen Satz an dieser Stelle (Mağmū' rasā’il muwaḥhidīya, S. 186 f.) „,wa-ahad̄ū ‘alā aṭ-ṭarīq lam yah̦tur bi-bāl al-ašqīyā' as-sulūk 'alaihā wa-lā iḥtalağa fī ṣudūrihim ihtidā' ilaihā" muss höchstwahrscheinlich ,ịtalağa“ zu ,ihtalağa“ korrigiert werden.

${ }^{394}$ Zitat aus dem Koran, Sure 7, Vers 149.

${ }^{395}$ In der Wendung an dieser Stelle (Mağmū' rasā’il muwaḥhịīiya, S. 187) „fa-alqaū bihā hịiānahum“ müsste „hịiānahum“ zu ,ğirānahum“ korrigiert werden.
} 
Wolken heischten und [unklar $\left.{ }^{396}\right]$. Durch Gottes Hilfe jedoch sollte sich ihre Tapferkeit in Feigheit und ihr Vorstürmen in Rückzug verkehren.

Die Almohaden - Gott möge ihnen Mächtigkeit verleihen - setzten indes ihren gesegneten Verfolgungszug fort, bis sie in die Nähe von Hamma Maṭātạ gelangten und dort ihr Lager aufschlugen. Dort verbrachten sie die Nacht, erneuerten ihre Absicht, die Feinde Gottes niederzukämpfen ${ }^{397}$, und ließen ihre Entschlossenheit (diesbezüglich) eisern werden. Als sie in der Frühe des nächsten Morgens, umgeben von Gottes Segen und Hilfe, das Licht der Morgendämmerung erblickten, waren sie zum Kampf bereit, sie hatten (bereits) ihre Panzerhemden für den bevorstehenden Schwertkampf angezogen und sich dafür gerüstet ${ }^{398}$. Ebenso hatten sie in einer den Muslimen zur Freude gereichenden Weise ihren jeweiligen Platz (innerhalb der almohadischen Armee) eingenommen und sich zu Armeeabteilungen formiert. Dann zogen die Almohaden gegen ihren Feind, und dabei unterstützte sie Gottes glückhaftes Eingreifen, Sein Beistand begleitete sie, die Übereignung ihres Lebens an Gott lenkte ihre Schritte und leitete sie recht, und ihre Demutsbezeigungen ${ }^{399}$ Gott gegenüber stärkten sie und verliehen ihnen Kraft. Hingegen ließ die Feinde Gottes ihre Kopflosigkeit dreist werden, ihre Verblendung hielt sie auf, damit sie ihren Tod fanden, und die Fügung Gottes vereitelte ihr Vorhaben, zu fliehen und zu entweichen. Sie schlossen sich zu einer Schwurgemeinschaft zu dem Zwecke zusammen, ihre der Niederlage geweihte Schar siegen zu lassen und ihre verachtenswerte und gedemütigte Partei sich in Reih und Glied aufstellen lassen, und sie bauten auf ihre Vortäuschung und Vorspiegelung ${ }^{400}$, die ihnen (doch nur) den Tod einbringen sollten. Doch kann etwa das Unwahre vor dem Wahren bestehen? Als die blitzschnellen almohadischen Kämpfer sich auf sie stürzten, und als diese Feinde durch den ungestümen almohadischen Schwertkampf in Bestürzung versetzt wurden und erkannten, dass die Streiter Gottes eines Sinnes waren, den Märtyrertod zu suchen und die Feinde Gottes niederzukämpfen, da erschauerten sie

\footnotetext{
${ }^{396}$ Das Satzsegment an dieser Stelle (Mağmū` rasā’il muwaḥhịīya, S. 187) „wa-hazza kullun minhum 'alaihī subhānahū wa-iqdāman“" ist unklar.

${ }^{397}$ Höchstwahrscheinlich eine Umschreibung für ,sich für den bevorstehenden Kampf rüsten“.

${ }^{398}$ Im arabischen Satz steht an dieser Stelle (Mağmū' rasā’il muwaḥhidīya, S. 187) ,,wa-'stalamū li-'1mumāṣa'a wa-talabbabū“, und mit ,istalamū“ ist höchstwahrscheinlich ,istal'amū“ gemeint.

399 „Șarf al-ḥaul wa-'l-qūwa ilaihī subhānahū““, d. h. dass die Almohaden durch Wiederholung der Formel „lā ḥaula wa-lā qūwa illā bi-'llāh“, d. h. keine Macht und keine Kraft außer bei Gott, die Allmacht Gottes bekannten.

${ }^{400} \mathrm{Im}$ arabischen Satz an dieser Stelle (Mağmū' rasā’il muwaḥhidīya, S. 188) werden die beiden Wörter ,at-tamwīh“ und ,at-tahyīl“" verwendet, die wörtlich übersetzt wurden. Es scheint jedoch, dass mit „tamwīh“ das Gegenteil von „șidq (al-qitāl)“, was in den almohadischen Briefen „ein ungestümer und heftiger Kampf" bedeutet, gemeint ist, so dass vor diesem Hintergrund „tamwīh“" sehr wahrscheinlich u. a. die Bedeutung ,halbherzig den Kampf gegen j-n führen, einleiten usw. und es dabei am für den Sieg unabdingbaren Einsatz ermangeln lassen“" hat.
} 
so, wie Wölfe beim Anblick der Löwen erschauern, denn wie sollten denn angesichts der anspringenden dickhälsigen Löwen die kleinwüchsigen Schafe (gelassen bleiben und) bestehen? Sie suchten ihr Heil in der Flucht, fügten sich dem Urteil der Schwertklingen und wähnten ihre Rettung darin, davonzujagen. Die Almohaden nahmen ihre Verfolgung auf und erschlugen sie in allen Senken und auf allen Hochgründen, rangen sie auf allen Anhöhen und in allen Niederungen zu Boden und streckten sie überall dort nieder, wo sie sich hinbegaben. Auf diese Weise traf ihr Wind auf einen Orkan $^{401}$, das, was sie hartes Holz wähnten, erwies sich als ein weiches ${ }^{402}$; ihre missgeleiteten Scharen brachten ihnen nichts als Verderben ein, das, was sie für ihre Rettung gehalten hatten, kehrte sich in ihren Tod um, und der Gewinn, den sie sich erhofft hatten, war in Wirklichkeit der Verlust ${ }^{403}$.

Die Almohaden - Gott möge ihnen Mächtigkeit verleihen - verfolgten sie diesen ganzen Tag und die nachfolgende Nacht, und eine große Zahl von den Köpfen ihrer Helden und Reiter wurde vor den Almohaden her transportiert ${ }^{404}$. Was die verschwindend geringe Zahl derjenigen dieser Feinde anbelangt, die dem Tod im letzten Moment doch noch entrinnen konnten ${ }^{405}$, so waren ihre Rufe „Wir sind verloren!“ und

\footnotetext{
${ }^{401}$ Eine fast wörtlich zitierte arabische Redewendung „In kunta rīhan fa-qad lāqaita i'ṣāran“, d. h. „bist ein Wind gewesen, so bist du jetzt einem Orkan begegnet“, womit gemeint ist, dass ein Starker auf jemanden trifft, der noch stärker ist (Kitāb ğamharat al-amtāl, Bd. 1, S. 31). Hinzu kommt, dass „Wind“ in der Bedeutung „Macht, Stärke“ auch koranisch belegt ist, siehe dazu Sure 8, Vers 46. Ferner kommt diese Redewendung in etwas abgewandelter Form in einem der Briefe von Abū-'Abdallāh Ibn-Abi-'1Huisāal (Rasā'il wa-maqāmāt andalusīya, S. 116) vor, den 'Abd-al-Wāhid al-Marrākušī zufolge ,fast sämtliche Bewohner von al-Andalus auswendig gelernt haben“ (al-Mu'ğib, S. 176). Das Interessante in diesem Zusammenhang ist, dass der genannte Brief an die in Valencia stationierten almoravidischen [!] Truppen adressiert war und sie in scharfen Worten dafür geißelte, bei einer Schlacht mit den Christen feige vom Schlachtfeld geflohen zu sein.

${ }^{402}$ An dieser Stelle (Mağmū' rasā'il muwaḥhidīya, S. 188) steht im Text „wa-sāạra nab`uhum bi-za`mihim marhan wa-'afāran“. „Nab““ ist die Bezeichnung eines Baumes, dessen Holz aufgrund seiner Härte bei der Schießbögenherstellung verwendet wurde. „Marh““ und „Afăr" sind Bezeichnungen von zwei Bäumen, deren Holz besonders gut Feuer fängt. Hinzu kommt, dass im mittelalterlichen literarischen Schrifttum die Aussage, das Holz einer Person sei fest, gut u. ä., zum Ausdruck gebracht werden konnte, der Betreffende sei stark, mächtig. Siehe zu dieser Vorstellung die im Kap. „Körperhaftigkeit bzw. Konkretheit des Abstrakten“ des Anhangs 2 zusammengetragenen Textbelege.

${ }^{403}$ Die beiden arabischen Wörter für „Gewinn“ und „Verlust“", „ribh““ und ,hasār", kommen im Koran vor und konnotieren dort „Gewinn des ewigen Lebens im Jenseits“ bzw. „,dessen Verlust“.

${ }^{404}$ Wörtliche Übersetzung des an dieser Stelle (Mağmū` rasā’il muwaḥịīiya, S. 188) nicht gänzlich eindeutigen arabischen Satzes „wa-sīqa al-'`adad al-ğamm min ru'ūs abțālihim wa-hailihim“, der auch die Übersetzung „Eine große Zahl der Anführer ihrer Helden und ihrer Reiterei wurde (gefangen genommen und) vor den Almohaden her getrieben“"zulässt. Zur Klärung des hier gemeinten Sinns könnte die Schilderung eines almohadischen Sieges bei Ibn-Haldūn beitragen, denn dort bedeutet die sehr ähnliche Formulierung ,wa-sīqa ra'suhū ilā Biğāya wa-nușiba bihā“" (Kitāb al-'ibar, Bd. 6, S. 508) eindeutig, dass der Kopf des getöteten almohadischen Widersachers nach Biğāya gebracht und dort zur Schau gestellt wurde.

${ }^{405}$ Mit der arabischen Entsprechung hier (Mağmū' rasā'il muwaḥhidīya, S. 188) „wa-'n-nāḡūna minhum bi-ğurai'at ad-daqan“ wird Bezug genommen auf die arabische Redewendung ,wa-aflata bi-ğurai'at addaqan“ (Kitāb ğamharat al-amtāl, Bd. 1, S. 115), welche auch als „mā aflattu minhū illā bi-ğurai'at ad̆daqan“ (al-Munğid fi 'l-lug̉a wa-'l-a'lām, S. 87) überliefert wird.
} 
„Wehe uns!“406 Das, was diese Feinde erlebten, zeigte ihnen das Wahre, die Tage ließen die einstige Prahlerei dieser Elenden sich verflüchtigen, sie ließen sie widerwärtige Heimsuchungen und Ungemach kosten und zeigten ihnen, wie die Vernichtung derjenigen, die der Sache Gottes trotzen, in mannigfaltiger Weise sich vollziehen kann. Nach der Vollstreckung dieser harten Strafe an ihnen ${ }^{407}$ haben sie keinen Ort mehr, der ihnen noch Zuflucht bieten könnte, unter ihnen gibt es dank Gottes Gnade niemanden mehr, der nicht der Austilgung zum Opfer gefallen wäre, und kein Feuer und keine Funken ihres räuberischen Unwesens werden, nachdem sie (in der geschilderten Weise) aufgerieben worden sind, jemals wieder aufflackern können ${ }^{408}$, mit Hilfe Gottes und dank Seiner Huld. Die Verfolgung des verbliebenen Abschaums dieser Feinde und die Ausmerzung derjenigen, die von der Unwissenheit dieser Feinde haben verblenden sowie durch die Fata Morgana der Stärke und durch die Lügenhaftigkeit der Missleitung von diesen Widersachern sich haben täuschen lassen, dauern in einer nicht nachlassenden Intensität an. Dieser verstreute Rest ist belanglos, und die Befreiung dieser Gegenden von ihren Schmutzflecken ist mit Gottes Macht unschwer. Nach dieser (geschilderten) Entsendung der Almohaden sind alle Überlebenden (dieser Feinde) vom Entsetzen übermannt ${ }^{409}$ und von Gram erfüllt.

Beim Anbruch des auf den Tag, an welchem Gott die Elenden erniedrigt und die Streiter (für Seine Sache) erhöht sowie ihnen den Sieg verliehen hatte, folgenden Tages, nämlich am 15. Oktober dieses Jahres ${ }^{410}$, gelangten die Almohaden nach Gabès - Gott möge diese Stadt beschützen. Bei ihrer Ankunft dorthin kamen die Bewohner dieser Stadt ihnen entgegen. Sie baten die eingetroffenen Almohaden demütig darum, ihnen Sicherheit zu gewähren und ihnen ihre körperliche und materielle Unversehrtheit zuzusichern, sie bekannten sich zum Almohadentum und zum (wahren) Glauben und baten darum, ihnen die Gaben dieser sich in Vergebung und Mildtätigkeit als großzügig erweisenden (almohadischen) Sache zuteil werden zu lassen. Und deswegen bescherte man ihnen Nachsicht und Zusicherung ihrer körperlichen und materiellen

\footnotetext{
${ }^{406}$ Mit „yad'ūna bi-tubūrihim wa-wailihim“ an dieser Stelle (Mağmū` rasā’il muwahhhidīya, S. 188) wird höchstwahrscheinlich auf die Beschreibung der Schlacht bei Badr angespielt, gemäß welcher der Satan, nachdem er die Mekkaner in den für sie äußerst verlustreichen Zusammenstoss mit Mohammed am genannten Ort buchstäblich getrieben hat, der zum Beistand der Muslime hineilenden Engelscharen ansichtig geworden unter lautem Stöhnen und mit den Rufen „Verloren (bin ich)!“ und „Wehe (mir)!“ (arab.: wa-da'ā (aiy al-iblīs) bi-'t-tubūr wa-'/-wail) vom Schlachtfeld flieht (Kitāb al-magāāzī, Bd. 1, S. 75). ${ }^{407}$ Anpielung auf Sure 73, Vers 16.

${ }^{408}$ Zur verbreiteten Vorstellung, eine Meueterei, Rebellion usw. habe etwas mit Feuer gemeinsam, siehe die im Kapitel „Meutereien und kriegerische Auseinandersetzungen“ des Anhangs 2 zusammen getragenen Belege.

${ }_{409}$ An dieser Stelle (Mağmū' rasā’il muwaḥhidīya, S. 189) steht im arabischen Text „manhūb al-fu'ād“ und es müsste wohl zu „manhūüb al-fu'ād“ korrigiert werden.
} 
Unversehrtheit, welche sie beruhigten und in ihre Häuser Ruhe und Frieden einkehren ließen. Auf diese Weise wandten sich die Bewohner dieser Stadt, umgeben von Sanftmut und Gerechtigkeit ihren neuen Lebenstagen und Lebensabschnitten $\mathrm{zu}^{411}$.

In Gabès befanden sich die Söhne Qarāqūšs und seine Familienangehörigen sowie eine Anzahl derjenigen, die sich bei seinen Plünderungszügen um ihn geschart und sich ihm angeschlossen hatten. Mit ihnen zusammen war eine Gruppe seines Abschaums, die Qarāqūšs vollstes Vertrauen genossen und deren Obhut allein er seine Anverwandten, Kinder und sein Eigentum anvertraute. All diese Erwähnten verschanzten sich in der uneinnehmbaren, weit in die Höhe reichenden und wehrhaften Zitadelle von Gabès, bereit, in ihr bis zum letzten Atemzug zu kämpfen. Die Kämpfer für die Sache Gottes umzingelten diese Zitadelle, und nachdem man sich (bei den Verhandlungen) auf die Zusicherung der körperlichen Unversehrtheit, die Wegnahme ihres gesamten Eigentums und ihrer Beutegüter und auf die Versklavung ihrer Frauen und Söhne sowie der Kinder derjenigen, die, seien sie nun tot oder geflohen, an der Schlacht (von Ḥamma Maṭmāța) teilgenommen haben, geeinigt hatte, gaben die Belagerten den Kampf auf. Qarāqūšs Familienangehörige und Kinder sowie sein ganzes Hab und Gut wurden (auf diese Weise) zur Beute der Almohaden sowie zum Eigentum und Besitz ${ }^{412}$ der (almohadischen) Gemeinschaft der Wahrheit.

Diese alte Stadt Gabès ist das Herz (wörtl. der Geist und der Sinn) dieser Gegenden Ifrīqīyas. Sie ist eine Festung, die die Gesamtheit der Gebiete Ifrīqīyas beschützt und deren Feinde abwehrt, und sie ist eine unbezwingbare Burg, die jeden Angreifer daran hindert, dort (d. h. in den genannten Gegenden Ifrīqīyas) sein Unwesen zu treiben. Diese Söldner - Gott möge sie zu Grunde richten - konnten nur deswegen das verüben, was sie verübten, weil es ihnen Gabès in ihre Gewalt zu bringen gelungen war, und sie konnten nur deswegen ihre Verblendung (durch ihre üblen Werke) konkrete Gestalt annehmen lassen, weil diese Stadt ihnen unterlag. Neben diesen reichlich vorhandenen nutzbringenden und vollkommenen nützlichen Dingen besitzt Gabès noch weitere Vorzüge, deren Vortrefflichkeit und Glanz die Herzen der Betrachter dieser Stadt mit Wonne erfüllen: In ihrem Inneren plätschert das wohlschmeckende Wasser sanft dahin, von ihr aus brechen Karawanen auf (wörtl. in ihr begegnen sich Reittiere und Reiter),

\footnotetext{
${ }^{410}$ Das heißt des Jahres 1187.

${ }^{411}$ Die Vorstellung, dass nach der Behebung eines Missstandes mit der Einkehr eines als vollkommen und erwünscht empfundenen Zustandes sozusagen die Jugendhaftigkeit Einzug hält, ist im mittelalterlichen Schrifttum belegt. Siehe hierzu die Einträge im Kapitel ,Jugendhaftigkeit“ im Anhang 2.

${ }^{412}$ Das hier (Mağmū' rasā’il muwaḥhidīya, S. 190) gebrauchte ,hawal“" wendet man vor allem auf die Sklaven an.
} 
sie ist eingebettet in üppig wachsende Gärten ${ }^{413}$ und Haine mit dicken Baumstämmen ${ }^{414}$, in welchen unterschiedliche Sorten der vorzüglichsten Früchte sowie Getreide gedeihen. Gott hat den Schandfleck dieser Stadt entfernt, indem Er in ihr die almohadische Herrschaft wiederhergestellt (wörtl. sie in die Perlenschnur des Almohadentums wieder eingereiht ${ }^{415}$ ), sie wieder zum Eigentum dieser glückhaften (almohadischen) Sache gemacht und sie diesem missleiteten Rädelsführer der Meuterei, diesem aufbegehrenden $\operatorname{Satan}^{416}$, entrissen hat. Dank dem glückhaften Eingreifen Gottes zugunsten der Almohaden, mit welchem niemand gerechnet und welches nur das absolute Vertrauen auf den Einen ${ }^{417}$, den Ewigen ${ }^{418}$, bewirkt hatte, ist von den Almohaden auch nicht einer (in der Schlacht) gefallen und ihre Zahl ist durch die Gnade Gottes nicht kleiner geworden. Zu den Merkmalen der Beständigkeit dieser mächtigen (almohadischen) Sache in einer in der Zeit unwandelbaren Weise und ihrer Erneuerung, zu den Zeichen ihrer fortwährenden Sieghaftigkeit und ihres fortdauernden Erstarkens und zu den Beweisen der Erfüllung der dem Almohadentum gegebenen Verheißung, es würde bis zum Tage des Jüngsten Gerichts bestehen und fortwähren, gehört, dass Gott den Kampf gegen die Gemeinschaften, die in der Anfangszeit des Islam bekämpft wurden, (bis auf unsere Zeit) aufgeschoben hatte und sich (nun) wider sie im Gewand der Botschaft des Imams (Muhammad Ibn-Tūmart) erhoben hat. Diese (genannten) Gemeinschaften sind folgende: die Perser, die Feueranbeter und die Frevler, nämlich die Träger des Schleiers ${ }^{419}$. Und darin sind für die Sanftmütigen lehrreiche Beispiele sowie die augenscheinliche Belehrung für die Einsichtigen und Verständigen enthalten.

Wir haben euch - Gott möge euch den Erfolg verleihen - über diese unaufhörlich währende Freude, diesen Sieg, der in sich das vollkommene Wohl birgt, und über den Obsieg, der den heftigen Durst der Seelen stillt und löscht, berichtet, auf dass euer Anteil daran groß wird und auf dass ihr in einer treffenden Weise Freude darüber empfindet und Gott - lobgepriesen sei Er - für das dankt, was Er die Feinde am austilgenden Entsetzen und am leidvollen $\mathrm{Tag}^{420}$ erfahren ließ. So danket - Gott möge euch den Erfolg verleihen - für Seine Gnadenerweise in der gebührenden Weise,

\footnotetext{
${ }^{413}$ Siehe Sure 78, Vers 16 des Korans.

${ }^{414}$ Siehe Sure 80, Vers 30 des Korans.

415 Siehe zu dieser Vorstellung die zusammengetragenen Belege im Kapitel „Halsketten, Zusammengefügtes u. ä.“ im Anhang 2.

${ }^{416}$ Siehe Sure 22, Vers 3 und Sure 4, Vers 117 des Korans.

${ }^{417}$ Dieser Beiname Gottes kommt an mehreren Stellen im Koran vor. Siehe z.B. Sure 13, Vers 16, Sure 14, Vers 48, Sure 38, Vers 65, Sure 39, Vers 4.

${ }^{418}$ Siehe dazu Sure 112, Vers 2 des Korans

${ }^{419}$ Damit sind die Almoraviden gemeint.

${ }^{420}$ Siehe Sure 11, Vers 77 des Korans.
} 
verbreitet sie und machet sie überall ruchbar, erfüllet eure Gegenden und Umgebungen mit ihrem Wohlgeruch $^{421}$ und machet sie überall bekannt! Sprechet bei euren Versammlungen und Treffen sowie in den gesamten Städten und ländlichen Gebieten über sie und erwähnet sie, so Gott will. Und Gott - lobgepriesen sei Er - wird euch zu solchen (Seiner Anbeter) machen, die für Seine Gnadenbezeigungen danken, von Seinen Gunsterweisungen sprechen und die durch das Loben Seines Namens lobgepriesen sei Er - die Gaben Seiner Großzügigkeit und Freigebigkeit geschehen lassen. Es gibt keinen anderen Gott außer Ihm. Edler Gruß, Gottes Gnade und Seine Segen mögen euch zuteil werden.

Abgeschickt aus Nafzāwa - Gott möge sie beschützen - am 23. Oktober des Jahres 1187.

5.2. „Ferner, ihr [...] habt bereits erfahren, dass diese Elenden, nämlich die asiatischen Söldner, und ihre Brüder in der Verirrung, diese Mallorquiner, in die Randbezirke dieser Gegenden Ifrīqīyas einfielen.“

Der im Obigen analysierte almohadische Brief Nr. 29 schliesst mit der Schilderung der Rückeroberung Biğāyas und der panikartigen Flucht der beiden Brüder 'Alī Ibn-Ġānīyas mit der almoravidischen Garnison nach der Niederlage, die sie vor den Mauern dieser Stadt erlitten hatten. Die Versprengten flohen zunächst zu 'Alī Ibn-Ġānīya, der Constantine einer zermürbenden, aber vergeblichen Belagerung unterwarf ${ }^{422}$. Nach deren Ankunft dort setzte 'Alī Ibn-Ġānīya die Katapulte in Brand und entwich mit ihnen zusammen in den Süden. Was die almohadische Armee betrifft, so gelangte sie nach Tīklāt ${ }^{423}$ drei Tage nachdem die almoravidischen Angreifer Constantine bereits verlassen hatten. Dort verbrachten die Almohaden zwei weitere Tage und nahmen am dritten Tag die Verfolgung der Mallorquiner auf. Doch angesichts der durch die Größe der almohadischen Armee sowie durch die Sperrigkeit des mitgeführten Trosses bedingten Langsamkeit des Zuges wurde die Verfolgung abgebrochen ${ }^{424}$.

\footnotetext{
421 Im mittelalterlichen literarischen Schrifttum ist die Vorstellung nicht selten, eine - meistens erfreuliche - Nachricht u. ä. sei in ihrem Bekanntwerden bzw. Bekanntgabe der Verbreitung eines Wohlgeruchs gleich. Siehe zu dieser Vorstellung die Belege im Kapitel „Wohlgerüche“ im Anhang 2.

422 al-Bayān al-muġrib, S. 179.

${ }^{423}$ Tīklāt war früher ein befestigter Ort von strategischer Bedeutung, dessen Ruinen sich heute in circa 1500 Meter Entfernung vom heutigen Dorf el-Kseur befinden (Historia política del imperio almohade, Bd. 1, S. 326, Fußnote Nr. 3). Angaben zu Tīklāt enthalten die jeweiligen Berichte von al-Idrīsī, der allerdings von Tāklāt spricht (Kitāb nuzhat al-muštāq fi 'hutirāq al-āfāq, S. 262) und al-Ḥimyarī (Kitāb arrauḍ al-mi'țār, S. 147).

424 al-Bayān al-mugrib, S. 179, Historia política del imperio almohade, Bd. 1, S. 326.
} 
'Alī Ibn-Ġānīya gelangte auf seiner Flucht zuerst nach dem südlichen Ğabal Aurās und später nach Ğarīd ${ }^{425}$. Dort konnte er die arabischen Stämme Riyāḥ und Ğušam um sich scharen und bezwang mit ihnen nach langer Belagerung Tawzar. Danach hat er Gafsa ${ }^{426}$ in Besitz genommen und sich nach Tripolis begeben, wo er in Qarāqūš einen Verbündeten im Kampf gegen die almohadische Herrschaft fand ${ }^{427}$. Einem Bericht IbnHaldūns lässt sich freilich folgender etwas abweichender Hergang dieser Geschehnisse entnehmen. Demnach habe 'Alī Ibn-Ḡānīya nach seiner Ankunft in Ğarīd zunächst Gafsa bezwungen und dann nach der vergeblichen Belagerung einer $\operatorname{Stadt}^{428}$ in der Region Qaṣṭilīya seinen Weg weiter nach Tripolis fortgesetzt, wo er in Qarāqūš einen Verbündeten gefunden habe. Die arabischen Stämme Riyāḥ, Ğušam, al-Ațbağ, BanūSulaim sowie Angehörige der berberischen Stämme Lamtūna und Massūfa hätten sich ebenfalls dieser antialmohadischen Allianz angeschlossen. 'Alī Ibn-Ġānīya habe später Qarāqūš bei der Belagerung und Bezwingung von Gabès beigestanden, das zur Residenzstadt des Letzteren geworden sei, und Qarāqūš habe seinerseits seine Unterstützung dem mallorquinischen Anführer gewährt zunächst bei der Wiedereroberung von Gafsa, das die mallorqinische Herrschaft vergeblich

${ }^{425}$ Im ausgehenden 12. Jahrhundert bezeichnete man mit „Bilād al-Ǧarīd“, wörtl. „Städte der Dattelpalmen“, ein weitläufiges, am Rande Ifrīqīyas gelegenes fruchtbares Gebiet, das reich an Datteln, Oliven und Früchten war und viele Städte umfasste (Kitāb al-istibșār fī 'ağă’ib al-amșār, S. 150). Zu diesem Gebiet gehörten auch die Regionen Qașțilìya, deren lokale Hauptstadt Tawzar war, und Nafzāwa (daselbst, S. 155ff.).

${ }^{426}$ Bei der Beschreibung der Flucht Qarāqūšs aus Ägypten im Kapitel 3.6. wurde darauf hingewiesen, dass mit ihm noch ein anderer Anführer von den asiatischen Söldnern namens Ibrāhīm Ibn-Qarātikīn geflohen war und dass sie sich später voneinander getrennt hatten. Was den Weg Ibrāhīm Ibn-Qarātikīns angeht, so berichtet at-Tiğānī davon, dass er zuerst die Absicht hatte, mit seinen Anhängern nach Maghreb zu ziehen, um dort in den Dienst der Almohaden zu treten. Die den Almohaden feindlich gesinnten Šaihs arabischer Stämme hätten ihn jedoch davon abgehalten und dazu bewegen können, nach alleiniger Herrschaft zu streben. Daraufhin habe er sich des Umlandes von Gafsa bemächtigt. Danach „schickte er jemanden zu Banu-'r-Rand und sie gaben Gafsa in seine Gewalt [...]. Es wurde (von Gott) vorherbestimmt, dass dieser erwähnte Ibrāhīm und sein Trupp in Gafsa von Ya'qūb Ibn-Yūsuf Ibn-'Abdal-Mu'min getötet wurden“ (Rihllat at-Tiğāāī, S. 114). Aus Gründen, die bei der Datierung der Einnahme Tripolis' durch Qarāqūš angeführt wurden, dürfte auch er zwischen zwischen 1185 und 1186, Herrscher über Gafsa geworden sein. Obwohl die näheren Umstände dieser Inbesitznahme Gafsas nicht bekannt sind, scheint die Angabe at-Tiğānīs, Ibrāhīm Ibn-Qarātikīn habe bis 1187 über Gafsa geherrscht, dafür zu sprechen, dass er sich mit 'Alī Ibn-G̈ānīya bei dessen Einfall in Ifrīqīya nach dem Abzug der almohadischen Armee im Jahr 1185 in der Weise arrangiert hatte, dass er im Namen des Letzteren die Herrschaft über Gafsa weiter ausgeübt hat. Im - vorerst wohl unlösbaren - Widerspruch zu den angeführten Angaben at-Tiğān̄is steht ein Bericht des anonymen „Kitāb al-istibșār fī 'ağă’ib al-amșār“ (S. 151), dem nach die Bewohner Gafsas seit der Niederschlagung der antialmohadischen Revolte im Jahr 1180 zunächst sich keine weiteren „Vergehungen“ zuschulden kommen ließen und im Jahr 1185 dem vorbeiziehenden 'Alī Ibn-Ġānìya die Herrschaft über die Stadt übertragen haben, der dort eine aus den asiatischen Söldnern zusammengesetzte Garnison ließ.

${ }^{427}$ Les Benou Ghânya, S. 55 f., Historia política del imperio almohade, Bd. 1, S. 330.

${ }^{428}$ Der Definition des anonymen Autors von „Kitāb al-istibșār fĩ 'ağăàib al-amșār" (S. 155 f.) zufolge umfasste die Region Qașțilīya Ende des 12. Jahrhunderts die Städte Tawzar, Nafṭa, Taqyūs und alHāmma. Der Name der Stadt, welche 'Alī Ibn-Ġānīya in der Region Qaștịiliya belagert hat, setzt sich aus den Radikalen Bā', Wāw, Rā', Qāf und ist in den vorhandenen Quellen nicht belegt. Sehr wahrscheinlich handelt es sich hier jedoch um einen Druckfehler und Tawzar könnte damit gemeint sein. 
abzuschütteln versucht habe, und später bei der Einnahme von Tawzar ${ }^{429}$. Wie auch immer der genaue Ablauf dieser Ereignisse im Einzenen gewesen sein mag, es kann als gesichert gelten, dass 'Alī Ibn-Ġānīya mit seinen Verbündeten die bedeutendsten Städte im Süden Ifrīqīyas in seine Gewalt bringen konnte. Die Eroberungs- bzw. Plünderungszüge Angehöriger der genannten antialmohadischen Allianz scheinen sich allerdings entgegen dem eingangs angeführten Satz des Briefes nicht lediglich auf den Süden beschränkt, sondern sich vielmehr auf das gesamte Gebiet von Ifrīqìya erstreckt $\mathrm{zu}$ haben. Denn die allgemeine Lage Ifrīqīyas in dieser Zeit fasste einmal ein Augenzeuge aus al-Mahdiya zusammen: „Es sind leblos die Gottesknechte und die einstigen Wohnstätten sind nun Wüsteneien.“" ${ }^{430}$ In einigen Fällen soll es auch zu regelrechten Massakern gekommen sein. So berichtet z. B. at-Tiğānī im Zusammenhang mit der Belagerung von Tawzar: „'Alī Ibn-Ġānīya und sein Bruder Yahyā belagerten einige Zeit Tawzar und holzten während der Belagerung den Palmenhain dieser Stadt ab. Wäre es nicht der Verrat einiger Stadtbewohner gewesen, wäre es ihnen nicht gelungen, Tawzar einzunehmen. Als sie dann Tawzar in Besitz nahmen, ließen sie diejeingen Bewohner unangetastet, die sich mit ihnen bei der Belagerung verschworen hatten. Was die übrigen Bewohner betrifft, so wurde ihnen ihr Eigentum weggenommen. Darüber hinaus haben die beiden Brüder ihnen weitere Zahlungen aufgebürdet, durch welche sich die Bewohner freikaufen sollten. Und so rief einer der Mallorquiner den Namen eines Stadtbewohners aus, und wenn sich jemand fand, der ihn freikaufte, so wurde der Betreffende freigelassen. Andernfalls jedoch wurde er umgebracht und in einen dort befindlichen Brunnen geworfen, der nach den Getöteten „Brunnen der Märtyrer“ genannt wurde.“431 Ein anderer, nicht minder grausamer Vorfall wird vom gleichen Autor im Zusammenhang mit der Einnahme der Ortschaft Manzil Baššaq ${ }^{432}$ überliefert. Bei der Belagerung dieser Ortschaft hätten deren Bewohner 'Alī Ibn-Ġānīya angeboten, gegen Zusicherung ihrer körperlichen und materiellen Unversehrtheit ihm die Stadttore zu öffnen, worauf er auch eingegangen sei. Als seine Anhänger jedoch Manzil Baššaq betreten hätten, hätten sie sich jedoch entgegen der Vereinbarung daran gemacht, die ganze Stadt auszuplündern und deren Bewohner bis auf die nackte Haut auszurauben. Die gesamte Bevölkerung habe ihr Heil in der Flucht gesucht und sei nach Tunis geflüchtet, wo sie zwischen den beiden

\footnotetext{
${ }^{429}$ Kitāb al-ibar, Bd. 6, S. 393 f.

${ }^{430}$ Rihlat at-Tiğānī, S. 14.

${ }^{431}$ Riḥlat at-Tiğānī, S. 162.

${ }^{432}$ Siehe Ausführungen von Bel (Les Benou Ghânya, S. 72 f., Fußnote 3) zu verschiedenen voneinander abweichenden Namen dieser Stadt in den arabischen Quellen.
} 
Mauern dieser Stadt eine Bleibe gefunden habe. Als der Winter eingebrochen sei, seien zwölftausend von ihnen dort vor Kälte und Regen umgekommen ${ }^{433}$. Aus der Tatsache, dass Manzil Baššaq weniger als eine Tagesreise von Tunis, dem Sitz des almohadischen Statthalters in Ifrīqīya, entfernt war, wird ersichtlich, dass der Aktionsradius der Mallorquiner weit über das Gebiet des Südens hinausreichte und dass sie auch im Norden Ifrīqīyas unbehelligt agieren konnten ${ }^{434}$. Diese antialmohadischen Aktivitäten hatten darüber hinaus auch ein religiöses Moment. So wird überliefert, dass 'Alī IbnĠānīya nach seinem Einfall in Ifrīqīya in den eroberten Gebieten die - nominelle abbasidische Herrschaft proklamiert und seinen Sohn in Begleitung seines Sekretärs zum amtierenden abbasidischen Kalifen an-Nāṣir Ibn-al-Mustadīī ${ }^{435}$ geschickt habe. Diese sollten dem Letzteren die Huldigung 'Alī Ibn-Gānīyas überbringen sowie ihn um Verstärkung und Unterstützung beim Kampf gegen die Almohaden bitten. Der Kalif habe die Huldigung angenommen und ein entsprechendes Schreiben an seinen nominellen Statthalter Șalāḥ-ad-Dīn Yūsuf Ibn-Aiyūb abfassen lassen, welcher seinerseits seinem früheren Untergebenen Qarāqūš mittels eines Schreibens angeordnet habe, 'Alī Ibn-Ġānīya zu unterstützen ${ }^{436}$.

5.3. „Dank Gottes wundersamem Eingreifen gelangten wir nach Ifrīqīya just in dem Moment, als ihre Saat zur Reife gelangte.“

Von der im vorangegangenen Kapitel skizzierten Bedrohung der almohadischen Herrschaft in Ifrīqiya wurde am almohadischen Hof in Marrakech seit dem Anfang des Jahres 582 H. (d. h. ab Ende März 1186) mehrmals berichtet ${ }^{437}$. Daraufhin wurde die Mobilisierung der Stämme angeordnet, und vor dem Aufbruch der almohadischen Armee besuchte Ya'qūb al-Manșūr das Grab des Mahdi Muhammad Ibn-Tūmart in Tīnmallal $^{438}$. Mitte Dezember 1186 verließ dann die almohadische Armee Marrakech ${ }^{439}$

\footnotetext{
${ }^{433}$ Riḥlat at-Tiğānī, S. 14. In einer sehr ähnlichen Weise überliefert auch Ibn-al-Atīi diesen Vorfall (alKāmil, Bd. 9, S. 171).

${ }^{434}$ Ibn-al-Atīr zufolge hat 'Alī Ibn-Ġānīya mit seinen Anhängern sogar mit Ausnahme von al-Mahdiya und Tunis das gesamte Gebiet von Ifrīqīya erobert (al-Kāmil, Bd. 9, S. 171), doch wird diese Angabe nicht von anderen überlieferten Quellen bestätigt.

${ }^{435}$ Dieser abbasidische Kalif hat von 1179 bis 1225 geherrscht.

${ }^{436}$ Kitāb al-'ibar, Bd. 6, S. 396 und stark verkürzt und unvollständig bei Ibn-al-Atīi (al-Kāmil, Bd. 9, S. 171).

${ }^{437}$ al-Bayān al-muġrib, S. 185.

${ }^{438}$ Der Besuch des Grabes des Mahdi in Tīnmallal erfolgte oft vor militärischen Unternehmungen und diente neben anderen Ritualen dem Zweck, das dominierende religiöse Moment - aus der offiziellen Sicht: den wahrhaftigen islamischen und ausschliesslichen legitimen Charakter - der almohadischen Herrschaft den Untertanen vor Augen zu stellen. Vgl. al-Muwaḥhidūn fi 'l-Ġarb al-Islāmī, S. 249.

${ }^{439}$ al-Bayān al-muğrib, S. 186, al-Anīs al-mutrib, S. 287. Abweichende Zeitangaben, die Ibn-al-Atīr (alKāmil, Bd. 9, S. 171) und Ibn-Haldūn (Kitāb al-'ibar, Bd. 6, S. 396) überliefern, sind unwahrscheinlich. Siehe hierzu Ausführungen Huici Mirandas (Historia política del imperio almohade, Bd. 1, S. 331).
} 
und trat den Zug nach Ifrīqīya an, der in seinen ersten Etappen über die Städte Rabat, Fès und Taza verlaufen sollte ${ }^{440}$. Dabei habe al-Manșūr an alle almohadischen Statthalter von Städten, welche auf dem Weg der Armee zu ihrem Zielort lagen, die Anweisungen ergehen lassen, die Verkehrswege instand zu setzen, Brücken an entsprechenden Stellen zu errichten sowie genügend Lebensmittel- und Futtervorräte anzulegen. Diese Anweisungen schlossen die Entschuldigung etwaigen Unvermögens der betreffenden Statthalter, das für die almohadische Armee Nötige zur Verfügung zu stellen, aus. Auf ihrem Zug nach Ifrīqīya hätten sich daher die Almohaden fortbewegt, als wären sie in ihren besten Wohnstätten, und hätten sich eines ihnen bis dahin nicht gekannten Masses an Überfluss und Genussfülle erfreut ${ }^{441}$. Diese besonders im letzten Teil sicherlich etwas übertriebenen Ausführungen Ibn-I Idārīs sind u. a. insofern interessant, als sie im Hinblick auf den logistischen Aufwand bei den Feldzügen der Almohaden nach entlegenen Gebieten des Reiches große Gemeinsamkeiten mit dem Bericht Ibn-al-Atīrs über den Marsch der almohadischen Armee nach Ifrīqīya im Jahr 1159 unter der Leitung von 'Abd-al-Mu'min aufweisen ${ }^{442}$.

Ibn-'Idārī berichtet ferner, dass als die Almohaden in die Nähe Constantines gelangt sind, die Mallorquiner und asiatischen Söldner sich beeilt haben, sich zu formieren und ihre Anhänger um sich zu scharen. Als die almohadische Armee danach weiter in Richtung ihres Zielortes gezogen sei, habe man die Vorhut dieser antialmohadischen Allianz nahe Kairuan gesichtet. Ya'qūb al-Manșūr habe die Feinde mit einem sofortigen Angriff überrumpeln wollen, man sei jedoch bei der daraufhin abgehaltenen Beratung mit den almohadischen Weziren und Šaihs zum Schluss gelangt, dass man den Weg nach Tunis fortsetzen und den Truppen dort erst eine Ruhepause gönnen sollte ${ }^{443}$. Das Datum der Ankunft der almohadischen Armee in Tunis ist nicht überliefert, doch es ist sicherlich davon auszugehen, dass der Marsch von Marrakech nach Tunis mehrere

\footnotetext{
${ }^{440}$ al-Bayān al-mugrib, S. 186 f. Die gleichen Etappen zählt auch Ibn-Haldūn auf (Kitāb al-cibar, Bd. 6, S. 509).

441 al-Bayān al-muġrib, S. 186.

442 Ibn-al-Atīr beschreibt die Vorbereitungen, die 'Abd-al-Mu'min nach der Ankunft in Marrakech der Überlebenden des Massakers von Zawīla traf, folgendermaßen: „Er (d. h. 'Abd-al-Mu'min) hieß diese Menschen unterbringen und zahlte ihnen zweitausend Dinar aus. Danach ordnete er an, große Wasserschläuche, (kleinere) Lederschläuche und all das anzufertigen, was die Soldaten bei ihren Märschen benötigen. Er schrieb an alle seine Gouverneure im Westen [...] und befahl ihnen, die Getreideerträge zu speichern, es (d. h. das Getreide) an der Ähre zu lassen und in den Sammelstellen aufzubewahren. 'Abd-al-Mu'min befahl ihnen ebenfalls, Brunnen an den Wegen auszuheben. Sie befolgten all das, was er ihnen beauftragt hatte, und sammelten das Getreide drei (nachfolgende) Jahre lang, brachten es dann zu den Sammelstellen und verschlossen sie mit Lehm. Und so ragten diese Sammelstellen den Hügeln gleich in die Höhe. [...] Die Fürsorge 'Abd-al-Mu'mins gegenüber den almohadischen Kämpfern war so umfassend, dass sie bei ihrem Vorbeiziehen an Saatfeldern keine einzige Ähre beschädigten (al-Kāmil, Bd. 9, S. 63).

${ }^{443}$ al-Bayān al-muğrib, S. 187.
} 
Monate in Anspruch genommen hat. Was die Größe der almohadischen Armee anbelangt, so ist Ibn-al-Atīr der einzige unter den arabischen Historiographen, der ihre Menge mit zwanzigtausend Reitern beziffert ${ }^{444}$. Diese Angabe, gegen die zwar Vorbehalte angebracht scheinen $^{445}$, ist jedoch für die Analyse der nachfolgenden Auseinandersetzungen mit den Mallorquinern samt deren Anhängern von keinem großen Belang, da die Zahl der Letzteren nicht überliefert ist und somit keine Schlüsse auf das zwischen den sich bekriegenden Parteien bestehende Kräfteverhältnis möglich sind. Abschließend sei noch angemerkt, dass der Brief allgemein von der Ankunft der almohadischen Armee nach Ifrīqīya spricht, ohne dabei Tunis, wo die Almohaden letztlich absteigen, zu erwähnen.

5.4. „Und nachdem sie Gott [...] darum angerufen haben, ihnen bei der Vernichtung und Austilgung dieser elenden Feinde beizustehen, brachen sie von Tunis [...] auf.“

Der Verlauf dieser almohadischen Unternehmung im Einzelnen wird von Ibn-'Id̄ārī dokumentiert, dessen Bericht die ausführlichste überlieferte Schilderung der nachfolgenden Ereignisse enthält und in einigen wesentlichen Punkten von der Darstellung des Briefes abweicht. Dies ist höchst erstaunlich, scheint doch der Bericht dieses Autors eine verkürzte Fassung einer zeitgenössischen offiziellen almohadischen Schilderung dieser Ereignisse darzustellen ${ }^{446}$ und müsste aus diesem Grunde eigentlich mit der Darstellung des Briefes weitestgehend übereinstimmen ${ }^{447}$. Ibn-'Id̄ārī nach hat also al-Manșūr einige Zeit nach der Ankunft der almohadischen Armee in Tunis Saiyid Abū-Yūsuf Ibn-Abì-Ḥaf̣̣ mit der Befehligung eines großen almohadischen Kontingents betraut und es gegen die Feinde entsandt. Als dieses Kontingent die von 'Alī Ibn-Ġānīya und seinen Anhängern kontrollierten Gebiete erreicht habe, seien sie in der Morgendämmerung des 24. Juni des Jahres 1187 zu ihren Feinden aufgebrochen ${ }^{448}$.

\footnotetext{
444 al-Kāmil, Bd. 9, S. 171.

${ }^{445}$ Es fällt auf, dass dieser Autor die gleiche Zahl der almohadischen Reiter auch bei der Schilderung der Rückeroberung von Biğāya im Jahr 1185 nennt (al-Kāmil, Bd. 9, S. 166).

${ }^{446}$ Dafür, dass ,al-Mann bi-'l-imāma“ Ibn-'Idārī als Vorlage gedient hat, sprechen folgende gewichtige Indizien: an vielen Stellen behält Ibn- Id̄ārī die chronikhafte Struktur seiner Vorlage bei, sein Sprachgbrauch lehnt sich stark an denjenigen Ibn-Ṣāhib-aș-Ṣalāts an und der Blick auf einige Passagen in „al-Bayān al-muggrib“ ergibt, dass wir in ihnen abgekürzte Abschnitte aus „al-Mann bi-'1-imāma“ vorliegen haben; dies trifft beispielsweise für die Seiten 63 f., 65, 67, 78, 88 f. und 94 ff. in ,,al-Bayān almugrib“ und die jeweils ihnen entsprechenden Seiten 65 ff., 74, 112 f., 149 f., 195 f. und 231 ff. in ,alMann bi-'l-imāma“" zu. 'Izz-ad-Dīn 'Umar Mūsā ist aufgrund der vielen Übernahmen Ibn-'Idārīs der Meinung, dass ,al-Bayān al-muğrib“ die Lücke in ,al-Mann bi-'l-imāma“, die durch den verloren gegangenen dritten Teil dieser almohadischen Chronik entstanden ist, zu schließen hilft (al-Muwaḥhidūn fi 'l-Ğarb al-Islāmī, S. 19).

${ }^{447}$ Siehe einen ähnlichen Fall im Kapitel 4.8.

${ }^{448}$ Huici Miranda versteht den dieser Beschreibung zu Grunde liegenden arabischen Text dahingehend, dass die im Folgenden geschilderte Schlacht an diesem Tag stattgefunden habe (Historia política del
} 
Unmittelbar vor der Schlacht von 'Umra, einer nahe Gafsa gelegenen Ebene, hätten die Almohaden keine Einigkeit untereinander gehabt ${ }^{449}$, hätten der Kampfentschlossenheit ermangelt und seien nicht vollständig für den Kampf gerüstet gewesen. Denn sie wären die Nacht zuvor durchgereist ${ }^{450}$, hätten sich bei ihrem Zug kaum gestärkt und ihr Tross wäre trotz unausgesetzten Vorwärtsziehens ihnen nicht nachgekommen. Die feindlichen Stämme hätten die Positionen am Rande des Schlachtfeldes bezogen, von wo aus sie beim Abschießen der Pfeile ihre Ziele hätten nicht verfehlen können. Die asiatischen Söldner hätten dann die Kampfhandlungen eingeleitet. 'Alī Ibn-Rubartair habe mit seiner Schar einen Reiterangriff vorgetragen, sie seien dabei von einem Platzregen von Pfeilen überschüttet worden, einige seiner Kämpfer seien dabei sofort niedergestreckt worden, und diesen Anführer selbst habe man, nachdem er zu Fuss zu kämpfen gezwungen worden sei und seine Reiter teils niedergestoßen, teils niedergestochen worden seien, gefangen genommen. Ein anderer almohadischer Kommandeur namens Abū-'Alī Ibn-Yūmūr sei mit einer Schar von arabischen Beduinen dem Beispiel 'Alī Ibn-Rubartairs gefolgt, diese hätten ihn jedoch gleich am Anfang der Attacke im Stich gelassen und er sei ebenfalls schwer verletzt gefangen genommen worden. Das Gefecht sei sehr heftig gewesen, eine große Zahl von ranghohen Almohaden habe dabei den Tod gefunden und die gemeinen almohadischen Krieger hätten sich als feige erwiesen. Beim Einbruch der Dunkelheit hätten sich die verbliebenen Almohaden bis auf die Mitte ihrer Nachhut zurückgezogen und seien völlig entkräftet gewesen. Unmengen von Pfeilen seien auf sie niedergeprasselt, sie seien einem Ring gleich inmitten der sie umdrängenden Feinde gewesen und wären, auf zersplitterten Lanzenresten und abgetrennten Körperteilen von gefallenen Almohaden stehend, von allen Seiten den tödlichen Hieben und Stichen ausgesetzt gewesen. In dieser Situation hätte der Mut die Almohaden verlassen und sie hätten die Flucht ergriffen. Der über das almohadische Kontingent mit dem Oberbefehl betraute Saiyid Abū-Yūsuf Ibn-Abī-Hafṣ sei mit seinen Gefährten ebenfalls geflohen. Was die Feinde betrifft, so seien sie auf dem Schlachtfeld geblieben und hätten sich der Plünderung hingegeben. Diejenigen der Almohaden, die zur Flucht nicht fähig gewesen seien, hätten zunächst in Gafsa Zuflucht gefunden, wo

\footnotetext{
imperio almohade, Bd. 1, S. 333). Der Autor von „Kitāb ar-rauḍ al-mi'țār“ (S. 414), der an dieser Stelle seiner Schilderung den Bericht aus „al-Bayān al-muġrib“ zusammenfasst, gibt ebenfalls dieses Datum für die Schlacht an. Die vorliegende Edition von ,al-Bayān al-mugirib” legt m. E. jedoch nahe, dass es zu diesem Zusammentreffen erst am nächsten Tag bzw. an einem der nächsten Tage gekommen ist.

${ }^{449}$ Laut Ibn-al-A tīr (al-Kāmil, Bd. 9, S. 171) hat eine auf der Seite der Almohaden in den Kampf ziehende Gruppe der asiatischen Söldner diese verraten.
} 
sie von Qarāqūš und seinen Gefährten vorerst unbehelligt gelassen worden seien. 'Alī Ibn-Ġānīya hätte jedoch danach verkünden lassen, sie gütig behandeln zu wollen, und als die versprengten Almohaden sich bei ihm eingefunden hätten, habe er sie alle umbringen lassen. Was den gefangen genommenen 'Alī Ibn-Rubartair betrifft, so habe er einige seiner Wächter dafür gewinnen können, ihm bei seiner Flucht zu helfen. Als jedoch 'Alī Ibn-Ġānīya davon erfahren habe, habe er ihnen Geld gegeben, auf dass sie diesen verrieten. Als dies geschah, hätten sie ihm 'Alī Ibn-Rubartair überliefert, der dann zu Tode gefoltert worden sei. Auch Abū-'Alī Ibn-Yūmūr sei umgebracht und dessen Leiche am Eingangstor Gafsas aufgehängt worden ${ }^{451}$. Auf diese für die Almohaden sehr verlustreiche Weise ist also die erste Begegnung des entsandten Kontingents mit 'Alī Ibn-Ġānīya und seinen Verbündeten ausgegangen. Was die versprengten Almohaden betrifft, die nicht in Gafsa Schutz gesucht hätten, so seien sie bei ihrer Flucht nach einigem Umherirren entkräftet nach Tunis gelangt. Diese erlittene Niederlage habe sich weithin herumgesprochen und soll Ya'qūb al-Manșūr für lange Zeit den Schlaf geraubt haben ${ }^{452}$. Ein interessantes Detail überliefert in diesem Zusammenhang al-Ḥimyarī, dem zufolge Ya'qūb al-Manșūr hat verkünden lassen, von der Bestrafung dieser in Tunis anlangenden Almohaden abzusehen, und zu ihnen die ranghöchsten Ṭālibs geschickt habe, die dem almohadischen Kontingent zugestoßene Widerwärtigkeit bagatellisieren sollten ${ }^{453}$. Im Gefolge dieser Ereignisse hat, so Ibn'Idārī weiter, der almohadische Kalif mit den Vorbereitungen für eine weitere, viel breiter angelegte Unternehmung begonnen, welche er diesmal persönlich leitete ${ }^{454}$. Das almohadische Heer habe Anfang September Tunis verlassen und den Weg nach Kairuan eingeschlagen. Dort angelangt, habe al-Manșūr an seine Gegner die Aufforderung gerichtet, sich den Almohaden zu unterwerfen, begleitet von der Warnung, diese zu missachten. Die Adressaten seien jedoch darauf nicht eingegangen. Von Kairuan aus,

\footnotetext{
${ }^{450}$ Dem Text nach also, sind die Almohaden in der Morgendämmerung aufgebrochen und kommen am Schlachtfeld an, nachdem sie nachts sich fortbewegt haben. Dies legt m. E. nahe, dass die Almohaden nicht am 24., sondern frühestens erst am 25. Juni mit ihren Feinden zusammen gestossen sind.

${ }^{451}$ al-Bayān al-mugrib, S. 188 f. Der Verlauf dieser Schlacht wird sehr kurz in groben Zügen auch in ,,alKāmil“ (Bd. 9, S. 171), „al-Mu' '̌̆ib“ (S. 273), „Riḥlat at-Tiğānī“ (S. 136 und S. 162), „Kitāb al-'ibar“ (Bd. 6, S. 396 f. und 509 f.) überliefert. Eine interessante Schilderung dieser Ereignisse findet sich auch in „Kitāb ar-rauḍ al-míțār“ (S. 414), welche zum größten Teil aus den jeweiligen teils wörtlich übernommenen, teils leicht abgewandelten und verkürzten Passagen aus ,al-Bayān al-muġrib“ und „Rihlat at-Tiğānī“ hierüber besteht und darüber hinaus weitere Details enthält, wie z.B., dass 'Alī IbnRubartair von den asiatischen Söldnern gefangen genommen wurde oder dass 'Alī Ibn-Ġānīya an die erwähnten Bewacher zweitausend Dinare gezahlt hat.

452 al-Bayān al-muğrib, S. $189 \mathrm{f}$.

${ }^{453}$ Kitāb ar-rauḍ al-mi'țār, S. 414.

${ }^{454}$ Sowohl at-Tiğānī (Riḥlat at-Tiğānī, S. 136) als auch al-Himyarī (Kitāb ar-rauḍ al-míṭār, S. 201 und S. 414) betonen an dieser Stelle, dass al-Manșūr die geschilderten Maßnahmen allein und ohne vorherige Beratung mit den ranghöchsten Almohaden veranlasst habe.
} 
wo die Almohaden einige Tage zugebracht hätten, habe sich das Heer wieder in Marsch gesetzt, sei schließlich in die Nähe von Ḥamma Maṭmāṭa gelangt, einer in der Nähe von Gabès gelegenen Ortschaft, und in einer Entfernung von zwei Meilen ${ }^{455}$ von ihr abgestiegen. Die Kriegsscharen 'Alī Ibn-Ġānīyas, die zu diesem Zeitpunkt in den Randbezirken von Ḥamma Maṭmāṭa gelagert hätten, hätten diese räumliche Nähe der Almohaden mit großer Gelassenheit zur Kenntnis genommen und sich dadurch nicht weiter stören lassen ${ }^{456}$. Im Morgengrauen des nächsten Tages habe al-Manșūr den Almohaden befohlen, sich für die Schlacht zu rüsten und gegen die Feinde vorzurücken. Dabei hätten mehrere hochrangige almohadische Funktionsträger ihm angeboten, an seiner Statt zu kämpfen, während er im Heerlager bleiben und an der Schlacht nicht direkt teilnehmen sollte. Alle, die ihn darauf ansprachen, habe der Kalif nicht einmal ausreden lassen und habe unbeirrt an seinem Vorhaben, persönlich die Schlacht zu leiten, festgehalten ${ }^{457}$. Alle nachfolgenden überlieferten Quellen stimmen im Hinblick auf den Ausgang der nachfolgenden Schlacht miteinander überein und weichen insofern voneinander $\mathrm{ab}$, als sie zum Teil große Unterschiede bezüglich deren Verlaufs im Einzelnen aufweisen. So berichtet Ibn-'Idārī, dass die Sichtverhältnisse an diesem Tag wegen eines dichten Nebels sehr schlecht gewesen sind. Als dann die Sonne aufgegangen sei und die gewaltigen Mengen des almohadischen Heeres, den nacheinander rollenden Meereswogen gleich, sichtbar geworden seien, hätten die Gegner die Flucht ergriffen. Die in den vordersten Reihen vorrückenen Almohaden hätten die davonjagenden Widersacher, die durch die jähe Richtungsänderung ihrer Armee nun in ihren hintersten Reihen sich wiedergefunden hätten, eingeholt und sie alle rasch niedergemetzelt ${ }^{458}$. Was die beiden Anführer der antialmohadischen Allianz angeht, 'Alī Ibn-Ġānīya und Qarāqūš, so sei es ihnen gelungen, vom Schlachtfeld zu fliehen $^{459}$.

Anderen Berichten zufolge habe Ya'qūb al-Manșūr nach der Ankunft der almohadischen Armee in der Nähe von Hamma Maṭmāṭa einen Kavallerietrupp entsandt, welcher die jeweiligen Siedlungsorte der arabischen Stämme, die mit 'Alī IbnGānīya verbündet gewesen seien, überfallen und ausgeplündert habe. Als die

\footnotetext{
${ }^{455}$ Eine Meile betrug zwei Kilometer (W. Hinz: Islamische Maße und Gewichte, S. 63).

${ }^{456}$ al-Bayān al-muğrib, S. 190 f.

457 al-Bayān al-muğrib, S. 191.

458 al-Bayān al-muğrib, S. 191.

459 al-Bayān al-muggrib, S. 191, Riḥlat at-Tiğānī, S. 136, Kitāb al-'Ibar, Bd. 6, S. 397 und S. 510, Kitāb arrauḍ al-mi'ṭār, S. 201 und S. 414, Ta'rīh ad-daulatain al-muwaḥhidīya wa-'1-ḥafșiya, S. 16. In ,al-Mu'ǧgib” (S. 273), „Kitāb al-istibṣār fī 'ağā'ib al-amșār” (S. 159) und ,al-Mu’nis fī-ahbbār Ifrīqīya wa-Tūnis“ (S. 120) wird unter den Fliehenden nur 'Alī Ibn-Ġānīya erwähnt.
} 
betroffenen arabischen Stämme davon erfahren hätten, hätten sie 'Alī Ibn-Ġānīya verlassen. Auf diese Weise sei die Schlachtordnung in der gesamten Armee der Mallorquiner und der asiatischen Söldner durcheinander geraten ${ }^{460}$. Den überlieferten Darstellungen der Schlacht lassen sich hiermit zwei Umstände entnehmen, welche beim Sieg der Almohaden in der Schlacht bei Ḥamma Maṭmāṭa nicht unerheblich, vielleicht sogar ausschlaggebend gewesen sind: Es ist die zahlenmäßige Gewaltigkeit und Überlegenheit der almohadischen Armee einerseits sowie das durch das geschickte taktische Manöver Ya'qūb al-Manșūrs verursachte Ausscheren einiger wichtiger Verbündeter 'Alī Ibn-Ġānīyas kurz vor der Schlacht andererseits.

Nachdem im Obigen die Ereignisse nach der Ankunft der almohadischen Armee in Tunis anhand überlieferter Quellen nachgezeichnet wurden, soll im Folgenden auf die Darstellung des Briefes eingegangen werden. Dabei stellt man fest, dass daraus eine sehr abweichende Abfolge dieser Geschehnisse hervorgeht. Denn den einschlägigen Ausführungen nach bricht die gesamte almohadische Armee - und nicht erst ein almohadisches Kontingent unter dem Oberbefehl von Saiyid Abū-Yūsuf Ibn-Abì-Hafạ von Tunis nach Kairuan auf. Dort fordern sie ihre Feinde auf, sich zum Almohadentum $\mathrm{zu}$ bekennen. Die Letzteren lehnen diese Aufforderung ab und ziehen nach einigem Umherirren schließlich nach Gafsa. Als die almohadische Armee ihnen nach Gafsa folgt, fliehen sie weiter. Bei Ḥamma Maṭmāṭa kommt es schließlich zu einer Schlacht, in welcher die Bekenner des Almohadentums den Sieg davontragen. Auf diese sehr vereinfachte Abfolge lassen sich die Ausführungen des Briefes reduzieren. Frappierend ist dabei die offensichtliche Tatsachverdrehung, die in keinem der in der vorliegenden Arbeit analysierten Briefe so weit geht: Die belegte Entsendung des almohadischen Kontingents unter der Leitung von Saiyid Abū-Yūsuf Ibn-Abī-Ḥafṣ sowie die verlustreiche Niederlage der Almohaden in der Schlacht bei 'Umra werden gänzlich ausgelassen. Stattdessen wird fälschlich behauptet, die gesamte almohadische Armee breche gleich von Tunis auf, ziehe zu ihren Feinden über Kairuan bis Gafsa und verfolge sie später nach Ḥamma Maṭmāța. Ferner wird im Brief behauptet, die Almohaden hätten bei ihrem Zug keinerlei Bedeutung der numerischen Stärke noch ihrer Bewaffnung beigemessen, was höchstwahrscheinlich als wirklichkeitsfern zu beurteilen ist. Denn erstens weist der oben wiedergegebene Bericht Ibn- Idāāīs auf die numerische Überlegenheit der almohadischen Armee explizit hin und zweitens erscheint es wenig wahrscheinlich, dass nach der schweren Niederlage bei 'Umra Ya'qūb al-

\footnotetext{
${ }^{460}$ Kitāb ar-rauḍ al-micṭār, S. 201, 414, Rihlat at-Tiğānī, S. 136.
} 
Manșūr mit - der Darstellung des Briefes nach - so wenig Wirklichkeitssinn in den nächsten Kampf gezogen ist. Wenn man ferner das Augenmerk auf die Schilderung der Schlacht im Schreiben richtet, so fällt zweierlei auf: Dem eigentlichen Schlachtgeschehen bzw. Schlachtverlauf ist im Vergleich zu anderen Passagen ein relativ kleiner - nur einige Zeilen umfassender - Abschnitt gewidmet; als Ursache für den Sieg der Almohaden wird das Eingreifen Gottes zugunsten Seiner almohadischen Gemeinschaft sowie die Feigherzigkeit der Feinde hingestellt. Der genannte Abschnitt ist ansonsten in sehr allgemeinen Zügen gehalten, so dass es nicht möglich ist, daraus Anhaltspunkte $\mathrm{zu}$ gewinnen, die die Information anderer Quellen diesbezüglich zu gewichten helfen könnten. Man kann daher schlussfolgern, dass im Brief nur einzelne und keineswegs zufällig ausgewählte Fragmente dessen vorliegen, was anhand anderer überlieferter Darstellungen ermittelt werden konnte, und dass diese einzelnen Bruchstücke, in einer tendenziösen Weise zusammengefügt, ein zwar für die Almohaden sehr vorteilhaftes, aber im Grunde wirklichkeitsfernes Abbild der stattgefundenen Ereignisse bieten.

5.5. „Als die blitzschnellen almohadischen Kämpfer sich auf sie stürzten [...] da erschauerten sie so, wie Wölfe beim Anblick der Löwen erschauern [... $]^{\text {“. }}$

Folgende Bezeichnungen sind im vorliegenden Brief den Feinden der Almohaden vorbehalten:

„al-ašqīyā')“ (S. 183), ,al-ašqīyāa““ (S. 184), ,al-ašqīyāa‘“ (S. 185), d. h. „,die Elenden“, ist im Koran zwar nicht belegt, dafür aber dessen Singular ,aš-šaqīy“ in Sure 11, Vers 105; Sure 19, Vers 4; Sure 19, Vers 32 usw.

„ihwwānihim fi 'ḍ-ḍalāla“ (S. 183), d. h. „,ihre Brüder in der Missleitung“, wobei ,aḍḍalāla“ im Koran in Sure 2, Vers 16; Sure 4, Vers 44; Sure 7, Vers 30 usw. vorkommt. Das Gesagte gilt auch für „man wāfaqahum 'alā ḍalālatihim“ (S. 187), d. h. „die wie sie in der Missleitung befangen waren“, und „zūr ḍalālatihim“ (S. 189), d. h. „Lügenhaftigkeit derer Missleitung“.

„al-kafara” (S. 184), d. h. „die Ungläubigen“, kommt im Koran in Sure 80, Vers 42. Daneben sind daselbst sehr zahlreiche weitere Ableitungen der arabischen Wurzel „KaFaRa“" belegt.

"al-aubāšs" (S. 184), d. h. "der Pöbel”.

„wa-lammā adina Allāh tacālā bi-halkihim wa-qaḍā bi [...] irāḥat hadihī al-ğihāt mimmā dahāhā min zūrihim wa-ifkihim“ (S. 184), d. h. „Als Gott - gepriesen sei Er - erlaubte, 
diese genannten Elenden auszumerzen, und als Sein Ratschluss es war, [...] dass dem Übel, welches dieser Elenden Lügenhaftigkeit und Schwindel über die Gegenden Ifrīqīyas brachten, durch diese almohadischen Streiter abgeholfen werden sollte [...]“. „Zūr“", d. h. „Falschheit, Lüge“, als auch ,ifk“, d. h. „Lüge“, sind koranisch belegt und haben dort die Bedeutung „Unglaube“. Siehe zu ,zūr“ Sure 22, Vers 30; Sure 25, Vers 72; Sure 25, Vers 4 und zu „ifk“ Sure 24, Vers 11; Sure 25, Vers 4; Sure 34, Vers 43 usw. Interessant ist ferner im obigen Zitat der Gebrauch von ,irāḥa“, das wörtlich „die Gewährung von ar-rāḥa“ bedeutet, wobei „ar-rāḥa“ u. a. den Sinn „körperliches Wohlbefinden (nach erlittener Krankheit), Genesung“ haben kann. Hiermit wäre durch „,irāhaa“, in diesem Kontext in der Bedeutung „das Herbeiführen der Heilung von einer Krankheit“, Bezug auf die auch in den almohadischen Quellen häufige Vorstellung genommen, Missstände seien Krankheiten vergleichbar. Siehe hierzu die Einträge im Kapitel „Krankheiten und Übel“" des Anhangs 2.

„fa-'arradū ta'rīd ar-ri'āl 'an ar-ri'āl““ (S. 186), d. h. „,doch nun flohen sie den verängstigt auseinanderstiebenden Straußenjungen gleichend davon“. Strauße gelten als Ausbund der Feigheit in der arabischen Kultur, wie es aus der folgenden klassischen Wendung hervorgeht: „Ağban min an-na‘āma“, d. h. ,ängstlicher als ein Strauß“461

„kufr“ (S. 186), d. h. „Unglaube“, kommt im Koran in Sure 3, Vers 90; Sure 4, Vers 137; Sure 5, Vers 64 und an zahlreichen anderen Stellen vor.

„hiyāna“ (S. 186) ist im Koran in Sure 8, Vers 58 und Sure 8, Vers 71 belegt. ,wa-tazalzalū tazalzula adِ-di'āb min al-āsād wa-annā tastaqirr li-saṭat al-luyūt al-ğgulb qulūb an-niqād“ (S. 188), d. h. „da erschauerten sie so, wie Wölfe beim Anblick der Löwen erschauern, denn wie sollten denn angesichts der anspringenden dickhälsigen Löwen die kleinwüchsigen Schafe (gelassen bleiben und) bestehen?“ Die hier gebrauchten Bezeichnungen für Tiere sind im Koran nicht belegt. Das arabische Wort für „kleinwüchsige Schafe“, „an-naqad“, ist in der Wendung „Adall min an-naqad““462, d. h. „unterwürfiger als ein kleinwüchsiges Schaf“, belegt. Darüber hinaus kann wie erinnerlich $^{463}$ die Bezeichnung „das Schaf“ in den arabischen Redewendungen oft verwendet werden, um die Dummheit des geschilderten Objekts zum Ausdruck zu bringen. „Löwe“ war in der westarabischen Dichtung als Symbol der Tapferkeit und des Siegreichtums verbreitet gewesen ${ }^{464}$.

\footnotetext{
${ }^{461}$ Hayāt al-hayawān al-kubrā, Bd. 2, S. 359.

${ }^{462}$ Kitāb ğamharat al-amtāl, Bd. 1, S. 469.

${ }^{463}$ Vgl. Kapitel 4. 4. der vorliegenden Arbeit.

${ }^{464}$ Siehe hierzu die entsprechenden Belege in ,al-Fitan wa-'l-hurūb“ (Bd. 3, S. 26 ff.).
} 
„ğahāla“ (S. 189), d. h. „Unwissenheit, Unglaube“, kommt im Koran in Sure 4, Vers 17; Sure 6, Vers 54; Sure 16, Vers 119 usw. vor.

Die Zusammenstellung der obigen Bezeichnungen ergibt, dass ihr überwiegender Teil aus dem Koran entlehnt ist. Ferner konnten auch Entlehnungen aus der Tierwelt festgestellt werden, die in der westarabischen Dichtung sowie in den klassischen arabischen Redewendungen belegt sind. Dies lässt auf den hohen Bekanntheitsgrad dieser Bezeichnungen schließen.

5.6. „Dank dem glückhaften Eingreifen Gottes zugunsten der Almohaden [...] ist von den Almohaden auch nicht einer (in der Schlacht) gefallen [...]“

Dieser Satz des Briefes mutet sonderbar an, denn bei aller Bagatellisierung der almohadischen Rückschläge und der Vertuschung ihrer Niederlage auf dem Schlachtfeld bei 'Umra kann er von den zeitgenössischen Rezipienten nicht auch nur als annähernd zutreffend verstanden worden sein. Solche Behauptungen sind in den almohadischen Briefen indes nicht selten. Im Folgenden seien weitere Beispiele hierfür angeführt:

Im undatierten almohadischen Brief Nr. 22 wird über die kriegerische Auseinandersetzung zwischen den christlichen Eindringlingen und den sie verfolgenden almohadischen Kontingenten in der Region Fạ̣ṣ Hilāl in al-Andalus berichtet. Die Schilderung des Kampfes enthält folgenden Satz: ,wa-lam yunal minhum (aiy min almuwaḥhidīn) nail wa-lam yuqam li-'l-kafara fī ğānibihim mail“465, d. h. in freier Übersetzung „keiner der (am Kampf teilnehmenden) Almohaden war zu Schaden gekommen und die Ungläubigen haben ihnen keinerlei Verlüste zugefügt“،. Der gemeinte Sinn dieser im arabischen Original - aus heutiger Sicht zumindest mehrdeutig bis beliebig interpretierbaren Passage wird vor dem Hintergrund eines weiteren almohadischen Briefes deutlich, der die gleiche Begebenheit schildert und dieselbe Aussage in folgender, diesmal eindeutiger Weise formuliert: „wa-azhara subḥānahū bāhir al-āyāt fĩ salāmat ğamī'ihim (aiy al-muwaḥhidīn) máa liqā’ had̄ā alğam` al-kabīr [...] fa-lam yuṣab minhum aḥad“466, d. h. „Er (Gott) - Lob sei Ihm - hat Seine wunderbaren Wunderzeichen augenscheinlich werden lassen im Hinblick auf die Unversehrtheit aller (an der Schlacht beteiligten) Almohaden, denn obwohl sie mit einer zahlreichen (christlichen) Kriegsschar zusammenstießen [...] ist auch nicht einer von ihnen versehrt worden.“

\footnotetext{
${ }^{465}$ Mağmūc rasā’il muwaḥhidīya, S. 124.
} 
Der undatierte Brief Nr. 37 enthält die Schilderung des almohadischen Feldzuges nach Ifrīqīya im Jahr 1205 zwecks Befriedung dieser entfernten Provinz. Dabei kommt es im Brief wird darauf explizit hingewiesen - zu einer äußerst blutigen Schlacht zwischen einem almohadischen Kontingent und einer aus den almoravidischen Truppen Mallorcas und den Angehörigen einiger arabischer Beduinenstämme Ifrīqīyas zusammengesetzten Kriegsschar. Bei der Beschreibung des Schlachtverlaufs wird u. a. Folgendes ausgeführt: „fa-kānat bainahum al-muḍāraba nafaqa fîhā sūq al-qitāl wa'zdaḥamat fỉhā ar-riǧāl ‘alā ar-riğāl wa-'n-nișāl ‘alā an-niṣāl wa-fĩ kull dalik lā yamassu al-muwaḥhidīn qidh““467, d. h. „zwischen ihnen (d. h. den Almohaden und ihren Feinden) entbrannte ein heftiger Kampf, in dessen Getümmel (miteinander kämpfende) Männer sich auf (getöteten) Männern drängten und Schwertklingen sich über Schwertklingen türmten. In alledem traf die Almohaden kein einziger Pfeil“،.

Bei der Beschreibung des Ausgangs der bekannten Schlacht bei Las Navas de Tolosa im Jahr 1212, bei der die von Alfons III. von Kastilien befehligten vereinigten christlichen Truppen der almohadischen Armee eine vernichtende Niederlage beigebracht haben, heißt es: „fa-kānat 'āqibat al-yaum 'alā al-ḩuṣuṣ li-ahl aṣ-ṣulbān wa-'l-'āqiba al-muṭlaqa hīya li-ahl al-islām wa-'l-īmān wa-tahạğaza al-farīqān wa-'l-muslimūn 'azīza ğawānibuhum maḥrūsa bi-qudrat Allāh katā’ibuhum lam tuṣib al-ḥarb minhum aḥadan wa-lā naqașat lahum 'adadan““468, d. h. „Das Ergebnis dieses einen Schlachttages war zugunsten der Anbeter des Kruzifixes, das letztliche Ergebnis war jedoch zugunsten der Muslime und der Gläubigen. Sieghaft haben die muslimischen Kämpfer das Schlachtfeld verlassen, ihre Kriegsscharen waren dank der Allmacht Gottes unversehrt, im Schlachtverlauf ist nicht einer von ihnen zu Schaden gekommen und ihre Zahl ist nicht geringer geworden".

Vor dem Hintergrund der angeführten Passagen hat Aḥmad 'Azzāwī, der Herausgeber einer weiteren, umfänglicheren Sammlung der offiziellen almohadischen Briefe, durchaus Recht, wenn er bei einer ähnlich lautenden Beteuerung in einem almohadischen Schreiben anmerkt, dass die fälschliche Behauptung, keiner bzw. nur wenige Almohaden hätten bei den Zusammenstößen mit ihren Widersachern den Tod gefunden, in den almohadischen Schriftstücken üblich ist ${ }^{469}$. Die Frage, die sich hierbei stellt, lautet, was haben die Rezipienten unter solchen Wahrheitsverdrehungen verstanden. Lag für sie darin lediglich eines der allgemein bekannten, dem offiziellen

\footnotetext{
${ }^{466}$ Mağmū'a ğadīda, Bd. 1, S. 133.

${ }^{467}$ Mağmūe rasā’il muwaḥhidīya, S. 257.

${ }^{468}$ Mağmū'a ğadīda, Bd. 1, S. 270.
} 
almohadischen Schrifttum eignenden Stilmittel vor, über dessen formelhaften Charakter und Floskelhaftigkeit sie wohl Bescheid wussten? Oder nahmen sie in derartigen Übertreibungen einen Bezug auf einen bestimmten Aspekt des islamischen bzw. almohadischen Gedankengutes wahr? Folgende Beobachtungen könnten zur Klärung dieser Frage beitragen. Bereits im Koran ist die Vorstellung feststellbar, dass diejenigen Gläubigen, die im Kampf um der Sache Gottes willen gefallen sind, nicht tot, sondern lebend seien. So heißt es in Sure 3, Vers 169 f.: „Und halte nicht diejenigen, die um der Sache Gottes willen getötet wurden, für tot. Sie leben (im Gegenteil) ${ }^{470}$ und werden bei ihrem Herrn wohl versorgt, erfreut darüber, was Gott sie an Seiner Gnade hat erfahren lassen“. Auch in der späteren islamischen Geschichtsschreibung ist dieser Gedankengang belegt: Im langen detailreichen Bericht al-Wāqidīs über den Verlauf der berühmten Schlacht bei Badr zwischen Mohammed samt seinen Anhängern einerseits und den Mekkanern andererseits findet sich eine Passage, welche die gleiche Kernaussage des angeführten Koranzitats enthält. Dieser zufolge erreicht die Mutter und die Tochter von Ḥārita Ibn-Surāqa, die in Medina zurückgebliebenen waren, die Nachricht von dessen Tod auf dem Schlachtfeld von Badr. Die Mutter schwört dabei, ihren gefallenen Sohn nicht zu betrauern, bis Mohammed nach Medina zurückgekehrt sei und sie ihn nach dem jenseitigen Schicksal ihres Sohnes gefragt habe. Sollte diesem das Paradies zuteil geworden sein, so werde sie ihn gar nicht beweinen, sollte er jedoch dem Feuer anheimgefallen sein, so werde sie wehklagen. Als Mohammed nach Medina zurückkehrt, fragt ihn die Mutter nach dem jenseitigen Los ihres getöteten Sohnes, worauf sie die Antwort erhält, dass das Paradies aus mehreren Gärten bestehe und dass sich ihr Sohn im obersten davon befinde ${ }^{471}$. Auf diese Weise wird ersichtlich, dass sowohl der Koran als auch die Überlieferung zum Leben Mohammeds bereits deutlich formulierte Ansätze für die obige Vorstellung enthalten, welcher Muhammad IbnTūmart einem Bericht von Ibn-Abī Zar zufolge letztlich eine sehr konkrete, buchstäblich greifbare Form verleiht. Trotz allen Vorbehalten, die gegenüber den Überlieferungen dieses Autors angebracht erscheinen mögen ${ }^{472}$, enthält der nachfolgend zitierte Abschnitt aus seinem Werk zweifelsohne einen wahren Kern, allein aufgrund der bloßen Tatsache, dass er inhaltlich mit den einschlägigen Aussagen des Korans und der Prophetenvita übereinstimmt. „Als Beispiel für die Listigkeit Muhammad IbnTūmarts und für die Leichtigkeit, mit welcher er der Menschen Blut vergoss, sei

\footnotetext{
${ }^{469}$ Mağmū'a ğadīda, Bd. 1, S. 86, Fußnote Nr. 28.

${ }^{470}$ Sinngemäß widerholt sich diese Aussage auch in Sure 2, Vers 154.

${ }^{471}$ Kitāb al-maġāzī, 1. Bd., S. 94.
} 
Folgendes berichtet: Einmal ließ er eine Gruppe seiner Anhänger verscharren und dabei wurde einem jeden von ihnen in seiner Grube ein Loch zum Atmen gelassen. Er sagte dann zu den Verscharrten: ,Als man euch fragen wird, sagt, dass ihr wahrhaftig das gefunden habt, was euer Gott euch verheißen hat, nämlich vermehrfachten Lohn für den Kampf gegen die Lamțūna-Stämme und die hohen Rangstufen (im Jenseits), in deren Genuss ihr durch euren Märtyrertod gekommen seid. Befiehlt dann den Fragenden, sie sollen unermüdlich gegen ihre Feinde kämpfen, denn das, wozu sie ihr rechtgeleiteteter Imam (Ibn-Tūmart) gerufen hat, ist wahr.' Er fuhr dann fort: ,Nachdem ihr dies gesagt habt, werde ich euch wieder befreien und ich werde euch am meisten von allen anderen ehren und achten. 'Dies gelobte er der erwähnten Gruppe seiner Anhänger. Der Anlass für die beschriebene Maßnahme war, dass beim Zusammenstoß zwischen den Truppen der Almohaden und der Armee der Almoraviden die Kämpfe zwischen den beiden Parteien heftig waren und viele der Almohaden dabei getötet wurden. Dies hat die almohadischen Stämme und Sippen geängstigt. Deshalb griff er (d. h. Ibn-Tūmart) zu dieser Maßnahme, um ihnen den Tod und die Verwundungen ihrer Angehörigen nicht so schrecklich erscheinen zu lassen. Dann kam er eines Nachts zum Schlachtfeld mit diesen seinen Anhängern und verscharrte sie (auf die beschriebene Weise) zwischen den getöteten Almohaden. Dann ging er weit nach Mitternacht in das almohadische Lager und rief den almohadischen Šaihs: ,O ihr Almohaden! Ihr seid die Partei Gottes, die Streiter für Seinen wahren Glauben und die Verfechter der Wahrheit! So kämpft unermüdlich gegen euren Feind, denn ihr seid auf dem Weg der Wahrheit und ihr erkennt wohl die Rechtmäßigkeit eurer Sache! Und solltet ihr Zweifel bezüglich dessen haben, was ich euch sage, so geht hin zum Schlachtfeld und fragt eure Brüder, die heute gefallen sind, und sie werden euch über die Vorzüge eures Kampfes gegen eure Feinde und über den großen jenseitigen Lohn dafür berichten!` Dann ging er mit ihnen zum Schlachtfeld und rief mit lauter Stimme: ,O ihr Märtyrer! Was hat Gott - mächtig ist er und erhaben - euch zuteil werden lassen, sagt es uns!' Und sie antworteten: ,Wir haben bei Gott - erhaben ist er - gefunden, was kein Auge (jemals zuvor) gesehen, was kein Ohr gehört und was sich kein Mensch vorgestellt hatte!‘ Als die versammelten Šaihs dies hörten, kehrten sie zu ihren jeweiligen Angehörigen und Stämmen zurück und sagten: ,Wir haben die Antwort unserer Brüder, die in der Schlacht gefallen sind, gehört und was ihnen an der Güte Gottes - erhaben ist er - und an Seinem reichlichen Lohn zuteil geworden ist.' Und so sind diesem Betrug alle Menschen aufgesessen. Was

\footnotetext{
${ }^{472}$ Historia política del imperio almohade, Bd. 1, S. 11.
} 
Muḥammad Ibn-Tūmart betrifft, so kehrte er zurück und stopfte die Löcher zum Atmen bei seinen in der Erde liegenden Anhängern zu und sie alle sind so verscharrt erstickt. Dies tat er, damit sie später nach ihrer Befreiung nicht ihren Nächsten hätten anvertrauen können, was er mit ihrer Hilfe gemacht hat.“473

5.7. „Diese alte Stadt Gabès ist das Herz (wörtl. der Geist und der Sinn) Ifrīqīyas.“

Wenn man Beschreibungen anderer Städte in „Mağmū' rasā’il muwaḥhidīya“ betrachtet, stellt man fest, dass sie alle als absolut unerreichbar und uneinnehmbar dargestellt werden und dass bei deren Schilderung mit Superlativen nicht gegeizt wird. Die konkreten Erscheinungsbilder der jeweiligen Städte bleiben dabei meistens trotzdem unscharf. Mehr noch, den almohadischen Briefen ist ein mehr oder minder einheitliches Schilderungsmuster der befestigten Städte eigen. Im Folgenden seien die einschlägigen Schilderungen aus „Mağmū` rasā’il muwaḥhidīya“ angeführt:

In folgender Weise wird Constantine im Brief Nr. 8 vom 10. November 1152 geschildert: „,wa-kāna ma'ammuhum [...] balad Qusanțīna [...] li-kaunihī bi-ḥait lā yunāl bi-qudrat al-mahlūq wa-aina yasta'lī bi-imtinācihī ‘alā kull malhūụ bi-‘ain al-muhạaraba au marmūq، ${ }^{674}$, d. h. „Der Ort, an welchen sie sich begaben [...] war die Stadt Constantine [...] Denn diese Stadt befand sich in einer solchen Höhe, wo sie durch Menschenkraft nicht erlangt (d. h. bezwungen) werden konnte und von wo aus sie dank ihrer Unnahbarkeit voller Hochmut auf alle Lebewesen feindselig hinabschaute“. Und

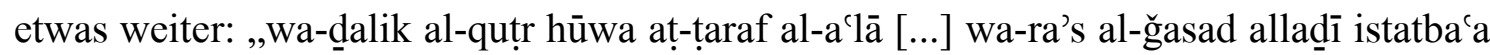
ba`ḍhū ba`ḍan wa-'statlā‘ ${ }^{` 475}$, d. h. „Was diese befestigte Stadt anbelangt, so ist sie der höchste Gipfel [...] sowie der Kopf des Körpers, dessen Glieder zum vollendeten Ganzen zusammengefügt sind“. Der Blick auf einige arabische geographische Quellen ergibt, dass die angeführte Passage im Hinblick auf ihre Kernaussage im Wesentlichen zutreffend ist, denn die einzigartigen Uneinnehmbarkeit und Wehrhaftigkeit Constantines werden auch dort bezeugt ${ }^{476}$.

Im Brief Nr. 16 vom September 1157 wird über die kriegerischen Unternehmungen der Ṭālibs von Granada in al-Andalus berichtet, in deren Verlauf ihnen die Rückeroberung der Städte Almeria, Baeza und Ubeda glückt. Auch viele nicht namentlich genannte

\footnotetext{
473 al-Anīs al-muțrib, S. 234.

${ }^{474}$ Mağmū' rasā’il muwaḥịidīya, S. 24.

${ }^{475}$ Mağmū' rasā'il muwaḥhịidìa, S. 26.

${ }^{476}$ Kitāb al-muġrib fī dikr bilād Ifrīqīya wa-'l-Mag̉rib, S. 63, Kitāb mu'ğam al-buldān, 4. Bd, S. 98-99, Kitāb nuzhat al-muštāq fi 'hutirāq al-āfāq, S. 266, Kitāb al-istibṣār fī 'ağā'ib al-amșār, S. 165-166, Kitāb arrauḍ al-mi'ṭār, S. 480 f.
} 
befestigte Orte sollen dabei wiedererobert worden sein: ,wa-'nfataḥa atnā'a dِalik min alḥuṣūn al-mumtani`a wa-'l-ma'āqil al-murtafi'a mā kāna ya'zub 'an al-auhām wa-lā yaqrub li-tanāwul al-ğaiš al-luhām, atlācun tuzāhiim a'nān as-samā’ bi-manākibihā‘‘477, $\mathrm{d}$. h. „Dabei wurden auch wehrhafte Burgen und hohe Festen (von den granadinischen Ṭālibs) erobert, deren Zahl die Vorstellungskraft überstieg und die selbst ein gewaltiges Heer zu unterwerfen nicht imstande gewesen wäre. Diese (d. h. Burgen und Festen) waren Hügel ${ }^{478}$, die so weit in den Himmel ragten, dass sie mit ihren Schultern die Wolken wegdrängten“.

Im undatierten almohadischen Brief Nr. 20, der zu einem nicht eindeutig bestimmbaren Zeitpunkt abgefasst wurde und die Schilderung der almohadischen Unternehmung zur Niederschlagung einer Rebellion in Gafsa enthält, findet sich eine weitschweifige Schilderung dieser Stadt, aus der nur einige relevante Passagen hier zitiert seien: „wawaḍ 'uhū (aiy wạ̣ ' qaṣr Gafṣa) min al-intihā' fi 'l-ḥaṣāna wa-tağāwuz fi 'l-mana'a wa-'1watāqa bi-ḥait lā yuṣhị muṣáabuhū wa-lā yatamahhad illā li-had̄ā al-amr al-'azīz markabuhū wa-hūwa rūḥ had̄ā al-iqlīm wa-ma'nāhū ${ }^{479}$ wa-quṭbuhū allad̄i tadūr 'alaihī rahāhū ${ }^{\text {‘480 }}$, d. h. „,die Lage Gafsas ist von unübertreffbarem Befestigungsgrad und von solch außerordentlichem Grad an Uneinnehmbarkeit und Festigkeit, dass dieses störrige Reittier $^{481}$ unbezähmbar ist und dass außer dieser erhabenen (almohadischen) Sache niemand sonst dessen Rücken zu besteigen vermag. Gafsa ist lebenswichtig für diese Region (wörtl. ist ihr Geist und ihr Sinn) und stellt eine Achse dar, um welche sich der Region Mühlstein dreht“. Diese Aussage kann anhand überlieferter geographischer Werke nicht bestätigt werden, denn diese enthalten zwar manchmal sehr detaillierte Beschreibungen Gafsas, aber keine Hinweise auf die herausragende Wehrhaftigkeit dieser Stadt ${ }^{482}$.

Das almohadische Schreiben Nr. 32 vom 14. Januar 1188 berichtet seinen Adressaten über den siegreichen Abschluss der Belagerung Gafsas, das u. a. in folgender Weise geschildert wird: „fatḥ had̄ā al-ablaq al-fard wa-'1-marqab al-mutağāwiz fi 'l-ḥaṣāna kull

\footnotetext{
${ }^{477}$ Mağmūc rasā'il muwaḥhidīya, S. 79.

478 Siehe zu der Vorstellung, eine zu unterwerfende Stadt sei ein hoher Berg die im Kapitel "Festungskonzepte" des Anhangs 2 zusammengetragenen Textbelege.

${ }^{479}$ Hier springt in die Augen, dass dieselbe Formulierung nur leicht abgewandelt bei der Schilderung von Gabès gebraucht wurde: „wa-hadihī al-madīna al-`atīqa rūh hadihī al-ğihāt al-ifrīqīya wa-ma'nāhā““ (Mağmūc rasā'il muwaḥhidīya, S. 190), mir der das vorliegende Kapitel überschrieben ist.

${ }^{480}$ Mağmū' rasā'il muwạ̣hidìya, S. 111.

${ }^{481}$ Zur Vorstellung, eine zu bezwingende Stadt sei ein störriges Reittier, siehe die Belege des Kapitels „Bezwingungen, Inbesitznahmen von Festungen und Siege allgemein“ im Anhang 2.

${ }^{482}$ Kitāb al-muġrib fī dikr bilād Ifrīqīya wa-'1-Mag̉rib, S. 47, Kitāb mu'ğam al-buldān, 4. Bd., S. 151, Kitāb nuzhat al-muštāq fi 'hutirāq al-āfāq, S. 277 f., Kitāb al-istibṣār fī 'ağāìb al-amṣār, S. 150 ff., Kitāb ar-rauḍ al-mi'țār, S. 477 ff.
} 
hadd wa-'1-'alam al-bādihh wa-'1-ḩașm al-aladd“4483, d. h. „Unterwerfung dieser einzigartigen Festung und dieser Burg, die in ihrer Uneinnehmbarkeit das Maß des Vorstellbaren übersteigt, dieses hochragenden Bergs ${ }^{484}$ und dieses Erzfeindes“. Im weiteren Verlauf wird ausgeführt: „wa-cāda ilā al-muwaḥhịīīn [...] had̄ā al-ma'qil alašib wa-qufl hadihī al-bilād al-mumtani` al-mustaṣ íb wa-ğāmiḥuhā allad̄ī lā yanqād lirā’ị̣ wa-lā yuṣ̣ib [...] ḥāddat al-burūğ abrāğuhū, arbā fi 'l-abā' 'alā kull ḥiṣn wa-ḥawā min ḍurūb al-ḥaṣāna kull ma`nā lā tu'addīhī al-'ibāra wa-fann““485, d. h. „Und auf diese Weise ist diese unbesiegbare Festung, das wehrhafte und unbezwingbare Bollwerk dieser Landstriche und dieses störrige Reittier ${ }^{486}$, das sich weder von einem Bändiger zur Gefügigkeit zwingen lässt noch sich zahm zeigt, auf diese Weise ist also diese Festung den Almohaden [...] wieder botmäßig geworden [...] Ihre hochragenden Türme und Mauerzinnen berühren sich mit den Sternbildern und sie übertrifft an ihrer Unnahbarkeit alle anderen Burgen. Diese Festung hat für jede erdenkbare Art der Wehrhaftigkeit die jeweilige (konkrete) Entsprechung, die man in Worte zu fassen nicht imstande ist, und Form.“

Den Gegenstand der Schilderung des Briefes Nr. 34 vom 31. Juli 1190 bildet der Verwüstungszug der almohadischen Armee im Westen der Iberischen Halbinsel, bei dem das landwirtschaftlich genutzte Umland von Santarem vernichtet und weitere Festungen überfallen und ausgeplündert wurden. Die Festung Torres-Novas wird dabei wie folgt beschrieben: „,tumma nahaḍū ilā qal'a li-'l-a'dā' tusammā Ṭurruš 'alā haḍba munīfat al-marāqib musāmīya li-'l-kawākib qad inqaṭa'at hạāâtuhā wa-ba'udat qaḍafātuhā min kull al-arğā' wa-'l-ğawānib [...] la-qad kānat min al-mana'a bi-ḥait lā turām wa-lā yuhtaḍam al-mutawaqqil fỉhā wa-lā yustaḍām wa-lā taţbut li-muhāribihā liwu'ūrat marāqibihā wa-ğawānibihā al-aqdām lau lā su'ūd had̄ā al-amr ‘ُ487, d. h. „danach setzten die Almohaden ihren Zug nach Torres-Novas fort. Diese Festung liegt auf einer Anhöhe, die hoch emporragt und mit den Sternen um die Höhe wetteifert. Dieser Anhöhe Abhänge fallen senkrecht nach unten ab und ihre Gipfel reichen von jeder Seite her betrachtet weit in den Himmel hinein [...] Diese Festung war von solcher Wehrhaftigkeit, dass sie uneinnehmbar war; derjenige, der in ihr Zuflucht fand, war vor allen Übergriffen und Anschlägen (von außen) sicher und die Füße der Stürmenden

\footnotetext{
${ }^{483}$ Mağmū‘ rasā’il muwaḥhidīya, S. 202.

${ }^{484}$ Siehe zu dieser Metapher die Textbelege im Kapitel "Festungskonzepte" des Anhangs 2.

${ }^{485}$ Mağmū' rasā’il muwaḥhidīya, S. 207.

${ }^{486} \mathrm{Zu}$ dieser Metapher siehe die Einträge des Kapitels „Bezwingungen, Inbesitznahmen von Festungen und Siege allgemein" im Anhang 2.

${ }^{487}$ Mağmū' rasā'il muwaḥhidìya, S. 223 f.
} 
fanden aufgrund der Unebenheit ihrer Mauern und Wachttürme keinen festen Halt. Die Sieghaftigkeit dieser (almohadischen) Sache war aber größer“.

Der Brief Nr. 35 vom 6. August 1196 schildert ebenfalls einen Verwüstungszug der almohadischen Armee durch das von Christen beherrschte Gebiet der Iberischen Halbinsel und enthält folgende Passage zur Festung Montánchez, der sich die Almohaden dabei bemächtigen: „wa-hūwa ḥiṣn yatalaffa' bi-'1-'anān wa-yaqtaḍ̣̣ aṭțā'ira bi-'s-sinān [...] 'alā țaud qad sāfara fi 'l-ğauw muqtariban [ sic $\left.^{488}\right]$ wa-lam yarḍa bi'l-ğibāl akfā'an wa-lā bi-'l-basīṭa muntasaban““489, d. h. „Diese Festung (erstreckt sich weit in den Himmel hinein und) hüllt sich in die Wolken ein, sie durchbohrt die Vögel mit ihren Mauerzinnen und [...] sie ist auf einem hohen Berg gelegen, der so weit in die Höhe ragt (wörtl. der bei seinem Streben nach auswärts so weit in den Himmel gegangen ist), dass er andere Berge nicht als ihm ebenbürtig und die Erde nicht als seinen Urgrund anzuerkennen gewillt ist." Aber auch die in der Umgebung der genannten Festung befindlichen befestigten Orte werden zumindest im Hinblick auf ihre Wehrhaftigkeit sehr ähnlich beschrieben: „wa-kāna yuğāwiruhā min macāqil al-kafara mā lam yulhạaq fi 'l-mana`a bi-ġāyatihā‘ ${ }^{‘ 490}$, d. h. „die im Umland von Montánchez gelegenen befestigten Orte der Ungläubigen waren im Hinblick auf ihre Uneinnehmbarkeit unübertroffen.“

Auch wenn man einräumt, dass die oben angeführten arabischen Quellen die unbezwingbaren Verteidigungsanlagen von Constantine betonen, fällt dabei doch auf, dass die oben zitierten Passagen jede der geschilderten Festungen, Städte usw. als absolut unbesiegbar beschreiben, auch solche Orte, auf die diese Beschreibungen zumindest im dargestellten übertriebenen Maß - ganz offensichtlich nicht zugetroffen haben.

Es wurde eingangs bereits angemerkt, dass bei solchen allgemeinen Beschreibungen das konkrete Erscheinungsbild der geschilderten Orte häufig trotzdem nicht erkennbar wird. Interessant ist nun, dass man sich dabei einer eingrenzbaren Menge an entsprechenden Ausdrücken bedient zu haben scheint, die zum einen in verbreitete Metaphern und Allegorien gefasst sind und zum anderen aufgrund ihres weitest gehend allgemeinen Charakters auf nicht nur eine konkrete Stadt angewendet werden konnten, sondern auf mehrere. Folgendes aufschlussreiches Beispiel soll das Gesagte veranschaulichen. In einer bereits mehrfach zitierten geographischen Quelle aus der Feder eines

\footnotetext{
${ }^{488}$ Es ist m. E. sehr wahrscheinlich, dass hier nicht „muqtariban“, sondern „mugtariban“ gemeint ist.

${ }^{489}$ Mağmū' rasā'il muwaḥhidīya, S. 231.

${ }^{490}$ Mağmū' rasā'il muwạ̣ḥidīya, S. 232.
} 
proalmohadischen anonymen Autors „Kitāb al-istibṣār fĩ 'ağā’ib al-amșār“ findet sich unter anderem die Beschreibung der Stadt Gabès. Den Angaben über die geographische Lage, Verteidigungsanlagen und Einrichtugen sowie landwirtschaftliche und textile Erzeugnisse dieser Stadt folgt am Ende des betreffenden Abschnitts eine allgemeine Passage über ihre strategische Wichtigkeit für die gesamte Region sowie ihre lokale Bedeutung. Diese in allgemeinen Worten gehaltene Passage ist nun mit derjenigen identisch, die wir bei der Übersetzung des Briefes Nr. 31 im Zusammenhang mit Tawzar noch kennenlernen werden ${ }^{491}$. Dies lässt die Vermutung als nahe liegend erscheinen, dass es sich bei den allgemeinen Ortsschilderungen in den almohadischen Briefen eher um austauschbare literarisierte Versatzstücke handelt, die weniger den Sinn haben, die konkreten architektonischen und sonstigen Charakteristika eines Objektes zu benennen, sondern vielmehr seine absolute Unbezwingbarkeit der Zuhörerschaft vor Augen zu stellen. Dies, eingebettet in die Schilderung der letztlich doch gelungenen Bezwingung dieses Objekts durch die Almohaden, diente leicht erkennbaren propagandistischen Zwecken, zumal fast jede Eroberung als ein rasch und mühelos vonstatten gegangener Vorgang dargestellt wird.

\subsection{Zusammenfassung des historischen Kommentars}

Der Brief Nr. 30 berichtet über die almohadische Unternehmung nach Ifrīqīiya gegen die „Mallorquiner“ sowie gegen die asiatischen Söldner und die mit ihnen verbündeten arabischen Beduinenstämme. Im Verlaufe der Analyse konnte festgestellt werden, dass der im Brief überlieferte Ablauf der Ereignisse erheblich von demjenigen der höchstwahrscheinlich zeitgenössischen almohadischen Berichte abweicht. In besonders Aufmerksamkeit erregender Weise wurde die Niederlage des almohadischen Kontingents nahe Gafsa ausgelassen und die so entstandene Lücke in der Abfolge der stattgefundenen Ereignisse durch bewusste Wahrheitsverdrehung geschlossen (siehe hierzu Kapitel 5.4.). Der Schwerpunkt der Schilderung liegt auf der Betonung des gottgewollten Charakters der gesamten Unternehmung, auf dem unterstützenden Eingreifen Gottes zugunsten der Almohaden sowie auf der vollkommenen Fügung der Letzteren in den göttlichen Willen. Insgesamt lässt sich feststellen, dass der kausale

\footnotetext{
${ }^{491}$ Die betreffende Passage in „Mağmū` rasā’il muwaḥhidīya“ (S. 197) und „Kitāb al-istibṣār fī 'ağā'ib alamșār" (S. 113) lautet ,ḥāḍirat hadā al-iqlīm al-caẓìm wa-quṭuhū wa-rūhuhū wa-qalbuhū wa-markaz dā'iratihī allad̄ī 'alaihī yastadīr [bzw. yadūr] muhịtụūù wa-bi-'l-istinād ilaihī yatamahhad raḥbuhū“،, d. h. „Tawzar bzw. Gabès sticht als die (lokale) Hauptstadt und das Zentrum dieses weitläufigen Gebiets hervor und bildet den Geist und das Herz sowie den Mittelpunkt der Drehscheibe dieser Region, die (d. h. Region) sich rund um diesen Mittelpunkt herum ordnet und deren (d. h. der Region) Anlehnung an ihn in ihren Weiten Frieden und Sicherheit obwalten lässt".
} 
Zusammenhang der im Brief bekannt gegebenenen Ereignisse ausgeklammert bleibt. Dies trifft zum einen für das scheinbar unvermittelte Auftauchen der „Mallorquiner“ und der asiatischen Söldner zu, die gleichsam aus dem Nichts kommend zerstörungswütig in die friedliche Idylle Ifrīqiìyas eingefallen seien, für die Motive dieser Eindringlinge sowie für den Erfolg der Almohaden auf dem Schlachtfeld nahe Hamma Maṭmāța. Beim zuletzt genannten Punkt konnten Faktoren ermittelt werden, die für den Sieg der almohadischen Truppen wesentlich waren und die im gewissen Widerspruch zur Darstellungsweise des Briefes stehen (siehe hierzu Kapitel 5.4.).

Darüber hinaus weist der Brief folgende formale Merkmale auf. Wie bereits erwähnt, ist das religiöse Moment im Brief dominierend: Auf der Textebene wird es durch Koranzitate und -entlehnungen (s. Fußnoten Nr. 373, 378, 383, 384, 394, 401, 403, 407, 413, 414, 416, 417, 418 und 420) sowie durch die koranisch geprägten Bezeichnungen für die Feinde der Almohaden (s. Kapitel 5.5.) geschaffen. Minder stark ausgeprägt ist ferner das literarische Element, das durch klassische arabische Redewendungen bzw. Anspielungen auf solche (s. Fußnoten Nr. 377, 385, 386, 387, 401 und 405) sowie durch den literarisch-figurativen Sprachgebrauch konstituiert wird (siehe Fußnoten Nr. 376, 388, 402, 408, 411, 415 und 421). Auch beim Brief Nr. 30 fällt der weitestgehend zeitlose Rahmen in die Augen, in welchem sein Inhalt angesiedelt ist. Denn auch hier sind abgesehen von seinem Abfassungsdatum keine weiteren chronologisch relevanten Angaben enthalten, so dass bei einem öffentlichen Verlesen bei der Zuhörerschaft der falsche Eindruck entstanden sein muss, die geschilderten Ereignisse seien rasch aufeinander folgend in nahtlosen Übergängen vonstatten gegangen ${ }^{492}$. Ebenfalls nicht der Wirklichkeit entsprechend ist die Behauptung des Briefes, bei der Schlacht bei Ḥamma Maṭmāṭa sei keiner der almohadischen Kämpfer gefallen, wobei es hier - wie im Kapitel 5.6. gezeigt wurde - sich eher um einen impliziten Bezug mit religiösem Gehalt zu handeln scheint.

Vor diesem Hintergrund ist die Schlussfolgerung möglich, dass erst die Einbettung des Briefes in einen größeren, durch weitere einschlägige Berichte gestützten Überlieferungsrahmen seinen historischen Gehalt freizuschälen sowie das durch die historisch-kritische Analyse Gesicherte vom Imaginären zu entflechten erlaubt.

\footnotetext{
492 Um sich den zeitlichen Rahmen zu vergegenwärtigen, seien folgende Daten genannt: am 17. Dezember 1186 setzt sich das almohadische Heer von Marrakech aus in Marsch nach Ifrīqīya, am 24. Juni 1187 kommt es zur Schlacht bei 'Umra, am 14. Oktober tragen die Almohaden den im Brief bekannt gegebenen Sieg bei Hamma Maṭmāța davon und am 23. Oktober 1187 wird der Brief Nr. 30 vor den Toren von Gabès abgefasst.
} 


\section{Zusammenfassung des Briefes Nr. 31}

Dieser Brief, datiert vom 5. November des Jahres 1187 und abgefasst im Namen des Befehlshabers der Gläubigen vor den Toren Gafsas, ist an die Ṭālibs, Almohaden, Šaihs und die gesamte Bewohnerschaft von Tunis adressiert. In folgender Weise wird darin über die Fortsetzung der almohadischen Unternehmungen in Ifrīqīya nach der Einnahme von Gabès berichtet: Nach den militärischen Erfolgen der Almohaden gegen die Mallorquiner und die asiatischen Söldner in der den Adressaten bereits bekannt gegebenen Art und Weise setzt sich die almohadische Armee von Gabès nach Ğarīd in Marsch. Nach ihrer Ankunft dort werden die beiden Gebiete Nafzāwa und Qaș̣̂ilīya von den Almohaden wieder in Besitz genommen. Beim Anrücken der almohadischen Armee erheben sich die Bewohner von Tawzar, Taqyūs, al-Hamma und Nafța gegen die in ihren Städten befindlichen Garnisonen der erwähnten almohadischen Gegner, töten einige von ihnen und bringen andere zu den Almohaden. Einer in Tawzar von diesen Widersachern befindlichen Gruppe gelingt es, nachts in die Wüste zu entweichen. Ihr in der Stadt zurückgelassener Besitz fällt den Almohaden anheim. Die Rückkehr der Bewohner der genannten Städte zum Almohadentum bringt ihnen gütige Behandlung seitens der Almohaden und allumfassendes Wohl ein. An dieser Stelle schildert der Brief in allgemeinen Worten die große Ausdehnung sowie die Fruchtbarkeit der Gegend von Ğarīd und weist darauf hin, welch zentrale und wichtige Stellung Tawzar unter den übrigen Städten dieses Gebiets einnimmt. In folgender Weise wird der Bericht fortgesetzt: Von Tawzar aus bricht die almohadische Armee nach Gafsa auf, wo sich die asiatischen Söldner samt ihren Anhängern verschanzt haben und in ihrem Vertrauen auf die Wehrhaftigkeit der Stadt den Almohaden zu widerstehen gedenken. Die Almohaden nehmen die Belagerung Gafsas auf. Am Tage der Ankunft der almohadischen Armee dorthin treffen bei ihnen die Gesandten Qārāqūšs ein und übermitteln seinen Wunsch, sich in den Dienst der Almohaden zu stellen. Am nächsten Tag treffen auch die Boten eines gewissen Abū-Zaiyāns ein, eines früheren Gefährten Qārāqūšs, der nach seiner Trennung vom Letzteren Herr über Tripolis geworden ist, und überbringen die Nachricht, dass er sich zum Almohadentum bekannt habe. Auf diese Weise ist nun die gesamte Region wieder den Almohaden botmäßig und befriedet. Der Brief schließt mit der Aufforderung, die bekannt gegebenen almohadischen Erfolge nah und fern zu verkünden und Gott für sie danken.

\section{1. Übersetzung des Briefes Nr. 31.}


Vom Befehlshaber der Gläubigen, dem Sohn des Befehlshabers der Gläubigen und dem Enkel des Befehlshabers der Gläubigen - Gott möge ihnen Seinen Beistand zuteil werden lassen und ihnen Seine Unterstützung gewähren - an die Țālibs, Almohaden, Šaihs und die gesamte Bewohnerschaft der Stadt Tunis - Gott möge mittels ihrer Furcht (vor Ihm) ihren edlen Rang fortdauern lassen, Er möge ihnen dabei beistehen, Ihm für all das zu danken, was Er ihnen an Seiner Güte hat zuteil werden lassen, und Er möge durch die fortwährenden Siege dieser mächtigen (almohadischen) Sache und durch ihre aufeinander folgenden Siegesmeldungen ihre Freude nicht aufhören lassen. Der Friede, die Gnade Gottes und Seine Segen mögen euch zuteil werden ${ }^{493}$.

Dieses unser Schreiben - Gott möge euch von so vielen Siegen dieser mächtigen Sache und von ihren [unklar ${ }^{494}$ ] sowie von so vielen ihrer löblichen Verdienste beim Beistand der wahren Gottesanbetung und ihrer vortrefflichen Unternehmungen erfahren lassen, dass all dies eure Gegenden mit dem angenehmen und duftenden Wohlgeruch ihrer (d. h. der mächtigen Sache) Hilfe ${ }^{495}$ erfüllt und dass all dies euch die Freude bereitende Kunde davon, welche nicht als langweilig empfunden werden kann, unaufhörlich vernehmen lässt. Gott möge ferner euch von den erwähnten Siegen, Verdiensten und Unternehmungen erfahren lassen, auf dass all dies euch dazu veranlasst, (Gott) in einer solchen Weise zu danken, die in gebührender Weise das würdigt, womit euch Gott an der Zufluchtnahme (wörtl. Anlehnung) bei Seiner siegreichen Gemeinschaft und an Seinem Wirken beschert hat - erfolgt an euch aus dem Lager der Almohaden - Gott möge ihnen Mächtigkeit verleihen - vor den Toren der Stadt Gafsa - Gott möge diese Stadt den Almohaden botmäßig machen. Mit diesem Schreiben empfehlen wir euch an, Gott zu fürchten, gemäß Seinem Willen zu handeln, Ihn um Hilfe anzuflehen und euch auf Ihn allein zu verlassen. Ferner empfehlen wir euch damit das unumstößliche Wissen darum an, dass Gott die Unternehmungen dieser mächtigen Sache einiges in sich bergen ließ, womit Er Seine Anbeter auf die Probe stellt und wodurch Er die Hoffnungen derjenigen in Erfüllung gehen lässt, die alle Absicht und allen Vorsatz ausschließlich

\footnotetext{
${ }^{493}$ Der darauf folgende einleitende Teil wurde bei der Übersetzung übergangen, s. Kapitel 8.2.

${ }^{494}$ An dieser Stelle steht im arabischen Satz (Mağmū' rasā’il muwahhịidiya, S. 194) ein Wort, das folgende Radikale konstituieren: Nūn, Šin, Rā’. Der Blick auf den einleitenden Teil einiger almohadischer Schreiben der vorliegenden Sammlung ergibt, dass in diesem Teil nicht selten „futūh", d. h. „Siege“, in Verbindung mit „bašā’ir“, d. h. „erfreuliche Nachrichten, Siegesmeldungen“, vorkommt. Siehe hierzu S. 100, 200, 250 der Sammlung. Möglicherweise ist hier „bišar“, das synonym zu,,bašāiir“ gebraucht zu werden scheint, gemeint, das an mindestens noch einer Stelle (Mağmū` rasā’il muwaḥhidīya, S. 28) in dieser Bedeutung vorkommt.

${ }^{495}$ An dieser Stelle (Mağmū' rasā’il muwahhịidīya, S. 194) wird ein durch die Radikale 'Ain, Wāw, Nūn konstituiertes Wort gebraucht, das als „'Aun“ vokalisiert werden kann, obwohl es hier m. E. nicht passt. Andere Vokalisierungsmöglichkeiten sind zwar möglich, ergeben in diesem Zusammenhang jedoch keinen Sinn.
} 
auf das Vertrauen auf Ihn (allein) gegründet haben (wörtl. ihre Absicht und ihren Vorsatz im Vertrauen auf Ihn geläutert haben), all ihr Streben und Streiten in der Hoffnung auf die Entlohnung im Jenseits um Seine Gunst bemüht Gott unterordnen ${ }^{496}$, (ferner) voller Ergebenheit sich dem gefügt haben, was Gott zugunsten Seiner mächtigen Sache beschieden hat (wörtl. warfen ergeben ihren Zügel und ihren Halfterstrick in die Hand der Zufriedenheit mit dem, was Gott für Seine mächtige Sache erwählt hatte), und gewusst haben, dass Gott - gewaltig ist Seine Macht - Seine (almohadische) Sache nie preisgibt und Seine Verheißung immer in Erfüllung gehen lässt. Dieses genannte Einige ließ Gott die Unternehmungen dieser mächtigen Sache in sich bergen, auf dass die Gläubigen an ihrem Glauben (noch mehr) wachsen, diejenigen, die an Gott als dem Herrn und an Mohammed als dem Propheten Genüge haben, an ihrer Fügsamkeit und an ihrem Gehorsam zunehmen sowie in Bezug auf Seine Verheißung, dass Seine (almohadische) Botschaft obsiegen und Sein Wort die Oberhand gewinnen werde, eine solche Zuversicht haben, dass, entfernte man die (das Verborgene abschirmende) Hülle, dies ihr unumstößliches Wissen nicht mehren würde, und dass sie (eingedenk dieser Zuversicht) weder ein Zeichen noch einen Beweis für das verlangen, was in ihren Herzen unerschütterlich ist und was sie in ihrem Inneren empfinden. Gott möge uns zu solchen (Seiner Anbeter) gehören lassen, die durch ihr vollkommenes in- und auswendiges Danken Seine Gunstbezeigungen fortwähren lassen, durch Seine Huld und Güte.

Diesem gesegneten Feldzug - Gott möge euch den Erfolg verleihen - lag (ausschließlich) das Bestreben zugrunde, die Übeltäter zu bezwingen, die Missetäter und die Frevler zu unterwerfen sowie der Pflicht, welche Gott auferlegt hat, nachzukommen, nämlich das Wahre zu beschützen und der wahren Gottesanbetung zum Obsieg zu verhelfen. Und so ließ Gott - lobgepriesen sei Er - bei diesem Feldzug Seine Beistandserweisungen geschehen, die alles bis dahin Gewohnte in den Schatten stellten und die gewaltigsten Siege und das als Wunsch Vorstellbare übertrafen. Diese Beistandserweisungen Gottes entsprachen allem Wunsch danach, dass die gefügigen und fügsamen Hoffnungen ${ }^{497}$, welche - gehen sie in Erfüllung ${ }^{498}$ - das allumfassende

\footnotetext{
${ }^{496}$ Wohl eine Anspielung auf Sure 3, Vers 171 „,Sie sind froh über Gottes Gnade und Huld und (darüber) dass Gott die Gläubigen nicht um ihren Lohn bringt“".

497 Wörtliche Übersetzung von ,,al-āmāl al-muṣhiba al-munqāda“ im arabischen Text (Mağmūc rasā’il muwaḥhidīya, S. 195). Im mittelalterlichen literarischen Schrifttum ist nicht selten der Vergleich der zu bezwingenden Festung, Stadt u.ä. mit einem störrigen Reittier, das zu zähmen bzw. zu besteigen der Eroberung dieser Festung gleichkommt. Der Vergleich mit einem widerspenstigen Reittier konnte auch auf andere Zusammenhänge ausgeweitet werden und hatte dann die Bedeutung ,ein bestimmtes Etwas in Gestalt eines Reittieres - sei jemandem gefügig“", d. h. dieser jemand beherrscht bzw. besitzt es und ist
} 
Wohl und das vollkommene Glück bringen, wahr werden mögen. Diese Beistandserweisungen waren (ferner) umgeben vom unaufhörlichen Wachstum und der Augenscheinlichkeit der Zunahme, welche (den Almohaden) zuteil wurden. All dies erquickte die Gläubigen (wörtl. heilte die Brüste der Gläubigen), ließ die Vermutungen der das unumstößliche Wissen Besitzenden sich bewahrheiten, erwies das Vertrauen auf den Herrscher der Welten als wahr und kündigte an, dass die einstige Belohnung (im Jenseits) den Gottesfürchtigen und den Wohltätigen zuteil werden wird ${ }^{499}$. Als Gott erhaben ist Er - durch die Vernichtung und Ausrottung der Widersacher Seine Gunst (den Almohaden) erwiesen hatte, als Sein Ratschluss, dass diese Feinde von den Streitern für Sein Wort unterworfen und bezwungen werden sollten, erfolgt war, als Er sie (d. h. diese Feinde) der Strafe ihres Verlustes und ihrer üblen Heimstatt zugeführt hatte und als $\mathrm{Er}$ diesen Landstrich von deren bösartigen Beimischungen ${ }^{500}$ und zusammengewürfelten Scharen befreit hatte - und dies in einer Weise, deren Schilderung unser (vorher an euch ergangenes) Schreiben enthielt und deren ausführliche Beschreibung ihr von unseren Gesandten an euch und aus unserem Brief kennt - , brachen die Almohaden - Gott möge ihnen Mächtigkeit verleihen - von Gabès - Gott möge diese Stadt vor allem Übel bewahren - auf und drangen in die nahe dieser Stadt gelegene Wüste ein, um so nach Ğarīd zu gelangen. Dabei zogen sie auf Wegen, die kein Heer jemals zuvor beschritten hatte, die noch nie ein Bewohner genutzt hatte ${ }^{501}$ und die sich in der Unendlichkeit verlieren (wörtl. die keinen Durchgang vor sich haben weder für den Ankommenden noch den Weggehenden). Die Almohaden durchzogen dabei Gegenden, wo die Erde aufhörte und wo die kahle Wüste sich unendlich weit

sein Nutznießer. So heißt es in (Raihānat al-kuttāb wa-nuğ`at al-muntāb, Bd. 1, S. 290) „maqām maḥall ahīnā alladī [...] markab al-'izza al-qa'sā' li-hidmatihī fi 'l-iṣbāḥ wa-'l-imsā' ğanīb“, (Mağmū'a ğadīda, Bd. 1, S. 489) „,fa-innā katabnāhū (aiy hadāa al-ḩiṭāb) kataba Allāh lakum auḍah al-a'māl sadādan wa-ṣawāban wa-'arrafakum asmaḥ al-āmāl inqiyādan wa-iṣ̣āban“, was in freier Übersetzung so viel wie „Wir haben dieses unser Schreiben an euch geschrieben - Gotte möge euch die rechten und richtigen Taten eingeben und eure Hoffnungen ohne Aufschub in Erfüllung gehen lassen (wörtl. „euch Hoffnungen zuteil werden lassen, die im Hinblick auf ihre Fügsamkeit und Gefügigkeit nicht zu übertreffen sind")“" heißt.

${ }^{498}$ Im arabischen Text steht an dieser Stelle (Mağmū' rasā'il muwaḥhidīya, S. 195), ,al-āmāl [...] al-ğārīya 'alā idlālihā fī 'umūm al-ḩair wa-'ntizāam as-sa‘āda“, wobei „,idlāl““ - in seiner lexikographisch erfassten Bedeutung - hier nicht zu passen scheint. Vielleicht ist mit „idlāl““,id̄lāl“, d. h. „Zähmung, Bändigung“, gemeint, denn dann würde es der Vorstellung entsprechen, die in der vorangegangenen Fußnote erklärt wurde.

${ }^{499}$ Siehe dazu Sure 7, Vers 128 oder Sure 28, Vers 83 des Korans.

500 Das an dieser Stelle (Mağmū' rasā’il muwaḥhidīya, S. 195) gebrauchte arabische Wort „,išābāt“" bezeichnet vor allem flüssige Beimischungen, wie z.B. von Wasser in der Milch. In den almohadischen Briefen ist der Vergleich von antialmohadischen Erhebungen mit der Beschmutzung von Wasserbecken häufig. Siehe hierzu die Belege im Kapitel „Wasserbecken u. ä.“ im Anhang 2. Vor diesem Hintergrund ist sehr wahrscheinlich, dass für den zeitgenössischen Rezipienten die „Beimischungen“ die Bedeutung ,antialmohadische Bestrebungen“ gehabt haben.

${ }^{501}$ In „Kitāb al-istibṣār fī 'ağā'ib al-amṣār“ (S. 159) findet sich bei der Angabe dieses Absatzes folgende Lesart: „lā 'alama fīhā li-'ābir“, d. h. „es gab in ihr keine Wegzeichen für den Reisenden“. 
erstreckte; es quoll kein Wasser dort aus dem Boden hervor noch spendeten ${ }^{502}$ es die Wolken. Und so ist doch das Beschreiten ${ }^{503}$ dieser Wüstenwege eines der bewunderungswürdigen Wunderwerke und eines der Wunderzeichen dieser (almohadischen) Sache, deren kriegerische Unternehmungen gegen ihre Feinde (durch Gottes Beistand) immer erfolgreich verlaufen, deren augenscheinliche Beweise die Verständigen mahnen, deren Banner durch Gottes Eingreifen siegreich ist und deren Bestand Gott Fortdauer verliehen hat.

Als die Almohaden - Gott möge ihnen Mächtigkeit verleihen - in den erwähnten Gegenden eintrafen, wetteiferten die Siege in ihrem Hineilen (zu den Almohaden) miteinander, die Perlen der Städte ${ }^{504}$ der Region Ğarīd auf ihre (d. h. der Siege) Perlenschnur aufreihend und ihr wahrhaftiges Versprechen an die Streiter um der Wahrheit willen und an deren Helfer erfüllend. Die Regionen Nafzāwa und Qașțīlìya ${ }^{505}$ - Gott möge sie vor allem Übel bewahren - wurden dem Pöbel der Meuterei und ihrer [unklar ${ }^{506}$ ] entrissen. Die Städte der Region Nafzāwa sowie Tawzar, Taqyūs, al-Hamma und Naftạ ${ }^{507}$ ergaben sich den Almohaden (wörtl. warfen ihre Zügel von sich), erbaten von dieser erhabenen Botschaft die ihr innewohnende Gnadenbezeigung und erflehten durch ihre aufrichtigen Reuebekundungen die weithin bekannten Milde und Barmherzigkeit dieser almohadischen Botschaft. Sie (d. h. die genannten Städte) bewiesen, dass sie an der wahren Gottesanbetung festgehalten hatten und weder in Zeiten des Friedens noch in Zeiten des Krieges von ihrem Glauben und von ihrer unumstößlichen Überzeugung abgefallen waren. Daraufhin wurde den Bewohnern der genannten Städte seitens dieser mächtigen (almohadischen) Sache an der Zusicherung

\footnotetext{
${ }^{502}$ Der arabische Satz an dieser Stelle (Mağmū' rasā’il muwaḥhidīya, S. 195) lautet „,wa-lā mā’a yanba` fi 'l-arḍ wa-lā yastaqirr min șaub as-sahāb“. Das Verb ,yastaqirr“", hier lässt die partielle Vokalisation des Editors keine andere Lesart zu, ist m. E. in diesem Zusammenhang unverständlich. Deswegen wurde der zweite Teil des angeführten Satzes sinngemäß übersetzt.

${ }^{503}$ Bei „wa-inna salakūhā la-min al-'ağā'ib“ an dieser Stelle (Mağmū' rasā'il muwaḥhidīya, S. 195) handelt es sich offensichtlich um einen Druckfehler: ,salakūhā“ müsste zu „sulūkahā“، korrigiert werden.

${ }^{504}$ An dieser Stelle des arabischen Originals (Mağmū` rasāỉil muwaḥhidīya, S. 195) wird ,,al-aqtār alğarīdìya“ gebraucht. Das arabische Wort „quțr“, dessen Plural „aqțār“ ist, kann u. a. sowohl die Bedeutung „Stadt“ - zum Beispiel in „Mağmū' rasā’il muwaḥhidīya“ (S. 12, 79) - als auch Teilgebiet eines größeren Gebiets - beispielsweise in „Kitāb al-istibșār fí 'ağā'ib al-amsāā“ (S. 155) - gebraucht werden. Beide Bedeutungen ergäben in der betreffenden Passage Sinn.

${ }^{505}$ Nafzāwa und Qașțīlìya bildeten laut „Kitāb al-istibṣār fī ‘ağāìb al-amsāār“ (S. 155 ff.) Teilgebiete der Region Ğarīd. Darüber hinaus gab es im Teilgebiet Nafzāwa die gleichnamige Stadt, siehe hierzu „Kitāb al-istibșār fī ‘ağā'ib al-amșār““ (S. 158) sowie „Kitāb mưğam al-buldān“ (Bd. 4, S. 799), „Kitāb al-mug̣rib fī dikr bilād Ifrīqīya wa-'i-Mağrib“ (47 f.) und „Kitāb ar-rauḍ al-mi'țār“ (S. 578 f.). In den zwei zuletzt genannten Werken wird Nafzāwa ausschließlich als Stadt beschrieben.

${ }^{506}$ Das an dieser Stelle (Mağmū' rasā'il muwaḥhidìya, S. 195) gebrauchte Wort wird durch die Radikale Wāw, 'Ain, Dāl konstituiert und ergibt hier keinen Sinn. Vielleicht ist damit „Waġd“, d. h. Schurke, gemeint, wobei unklar bliebe, warum es im Singular gebraucht wird.

${ }^{507}$ Laut „Kitāb al-istibṣār fī 'ağā'ib al-amṣār““ (S. 155 ff.) setzt sich aus den genannten Städten das Teilgebiet Qaṣṭilìya zusammen.
} 
der körperlichen und materiellen Unversehrtheit das zuteil, was ihren Gegenden Ruhe (bzw. Frieden) bescherte, ihre Hoffnung auf die Güte dieser großen (almohadischen) Sache (ihnen gegenüber) erfüllte und sie in den Genuss des Segens dieses allumfassenden Wohls, das bei ihnen Einzug hielt, kommen ließ. Die Bewohner dieser Städte fielen über die bei ihnen befindlichen Elenden her, töteten einen Teil von ihnen und legten den anderen Teil in Fesseln. Sie zerstreuten dieser Elenden niederträchtige Scharen weithin und verjagten sie und sie führten diese Elenden durch die Zermürbung $^{508}$ [sic] ihrer bösen Seelen hin zu dem Brand, dessen Glut und dessen Lohen in ihrer Heftigkeit nicht nachlassen. Und jedes Mal wenn die Almohaden - Gott möge ihnen Mächtigkeit verleihen - an einer der erwähnten Städte - Gott möge sie vor allem Übel bewahren - vorbeizogen, brachten deren Bewohner eine große Schar der gefesselten und der übrig gebliebenen Elenden $\mathrm{zu}$ ihnen, und dann hieben die geschärften Schwerter der letzteren Köpfe ab und ihre Nieren wurden auf die geraden langen Lanzen gereiht.

In Tawzar befand sich eine verachtungswürdige Gruppe dieser Elenden. Einige von ihnen brachen im Dunkel der Nacht auf (wörtl. hüllten sich in einen Teil des Nachtdunkels ein ${ }^{509}$ ) und ergriffen die Flucht vor dem Tod, wobei sie letztlich (anstatt von dem Tod fort) in den Tod hinein rannten. Sie drangen bei ihrer Flucht tief in die Verderben bringende Wüste ein und waren dabei dem entflohenen Vieh ähnlich. Gott wird noch die Boten der grausamen Bestrafung $\mathrm{zu}$ ihnen und $\mathrm{zu}$ denen ihres Abschaums, deren Todesstunde Er aufgeschoben hat, hineilen lassen und ihnen nach Seiner Gewohnheit mit den Händen der Streiter dieser mächtigen (almohadischen) Sache die Kelche ${ }^{510}$ des augenblicklich eintretenden Todes gewaltsam einflößen, in Seiner Gnade und Güte. Die geflohenen Elenden ließen (in Tawzar) ihr gesamtes Hab und Gut sowie auch all das, was sie an Hausrat und Wertgegenständen besessen hatten. Auf diese Weise ließ Gott ${ }^{511}$ all das, was diese Elenden an Beutegütern erraft hatten, als Beute den Almohaden zufallen und gab die Anverwandten, Söhne und die Familienangehörigen der Geflohenen in ihre Gewalt. Die Widerwärtigkeiten (des

\footnotetext{
${ }^{508}$ Der arabische Satz an dieser Stelle (Mağmū̌ rasā’il muwaḥhidīya, S. 196) lautet „,wa-yūridūnahum biirhāq nufūsihim al-ḩabīta sa īran lā yahbū ittiqāduhū wa-harīquhū“. Es ist m. E. wahrscheinlich, dass mit „,irhāq“ hier „,izhāq“ gemeint ist. Dann hieße es „,und dadurch, dass sie (d. h. die Bewohner) diese Elenden erschlugen, führten sie diese Elenden hin usw.“ Mit der angeführten Passage scheint auf die Sure 11, Vers 98 Bezug genommen zu werden.

${ }^{509}$ Siehe zu dieser Vorstellung die Textbelege im Kapitel „Zeitangaben“ des Anhangs 2.

${ }^{510}$ Siehe zu dieser verbreiteten Allegorie die unter der Überschrift „Trinkbecher als Symbol des Todes und der Schlacht“ gesammelten Textbelege im Kapitel „Körperhaftigkeit bzw. Konkretheit des Abstrakten“ des Anhanges 2.
} 
Schicksals) haben (somit) an diesen Feinden (zahlreiche) Exempel statuiert, die warnenden Lehrbeispiele haben sie der bewunderungswürdigen Wunder und Wunderzeichen gewahr werden lassen und das Geschick ließ die ihnen gewährte Schonfrist, welche mit ihrem Tod (wörtl. Entziehung ihres widerwärtigen Odems) endet, bis zur aufgeschriebenen Todesstunde (dafür) und Zeit fortbestehen, durch die Kraft und Macht Gottes.

Was diese Städte der Region Ğarīd anbetrifft, so brachten die (vorherigen) Schilderungen ihre Eigenschaften nur annähernd zum Ausdruck und gaben nicht ihren wirklichen (vortrefflichen) Zustand wieder. Derjenige, dem über diese Städte berichtet wird, vermag nicht, sich ein genaues Bild von ihnen zu machen, das sich in seiner ganzen Klarheit (nur) ihrem Betrachter darbietet. Das äußerste Maß in der ausdrucksstarken Schilderung, mag sie noch so vortrefflich sein, erweist sich letztlich doch als ungenügend, um das Wesen dieser Städte zu beschreiben. Das direkte Schauen hat ergeben, dass diese Region Ğarīd ein weitläufig nach allen Seiten hin sich erstreckendes Gebiet ist mit weit reichenden Mittel- und Randbezirken, dass sie nützliche Dinge, Lebensmittel und Gaben im Überfluss hat sowie reich an Hainen mit dicken Baumstämmen ${ }^{512}$ und üppig wachsenen Gärten ${ }^{513}$ ist. All ihre Städte können sich selbst versorgen (und sind somit nicht von den Lieferungen von außerhalb abhängig), verfügen über ein ausreichendes $\mathrm{Ma}$ an landwirtschaftlichen Erzeugnissen und sind aufgrund der Fülle der verschiedenen Getreidesorten (in jeder einzelnen von ihnen) nicht auf andere Städte angewiesen. Vielmehr ist es so, dass die Städte dieser erwähnten Region durch die Lieferungen ihrer landwirtschaftlichen Erzeugnisse und verschiedenartigen Früchte für andere Ortschaften lebensnotwendig sind. Unter den genannten Städten sticht Tawzar - Gott möge diese Stadt vor allem Übel behüten - als die (lokale) Hauptstadt und das Zentrum von Ğarīd hervor und bildet den Geist und das Herz sowie den Mittelpunkt der Drehscheibe dieser Region, die (d. h. Region) sich rund um diesen Mittelpunkt herum ordnet und deren (d. h. der Region) Anlehnung an ihn in ihren Weiten Frieden und Sicherheit obwalten lässt. Dadurch, dass sich diese Region wieder in die Gemeinschaft dieser großen (almohadischen) Sache eingereiht hat, wurde die Ordnung in ihren Städten wiederhergestellt, Sicherheit und Ruhe kehrten (wieder) ein, die Schmutzflecken des Unglaubens wurden aus diesen Gegenden entfernt und

\footnotetext{
511 Obwohl „Gott“ hier nicht erwähnt wird, erscheint es in der Übersetzung sinnvoll, „Gott“ als das Subjekt des Satzes aufzufassen, da zumal der Satz nur so grammatisch stimmig ist.

${ }^{512}$ Siehe Sure 80, Vers 30 des Korans.

${ }^{513}$ Siehe Sure 78, Vers 16 des Korans.
} 
seine Überreste wurden ausgetilgt, durch die Macht und Kraft Gottes und durch Seine Gnade und Güte.

Die Almohaden - Gott möge ihnen Mächtigkeit verleihen - setzten ihren gesegneten Zug von Tawzar - Gott möge diese Stadt vor allem Übel behüten - nach Gafsa - Gott möge diese Stadt wieder den Almohaden botmäßig machen - fort. Dort trafen sie auf die schmachbedeckte Schar der elenden asiatischen Söldner und auf ihre Anhänger. Deren aller Herzen waren von ihren Gelüsten übermannt, und sie waren alle vom Teufel verführt und verleitet ${ }^{514}$, der ihnen eingeflüstert hatte, sie könnten es mit den Unbezwingbaren aufnehmen (und sie bezwingen) ${ }^{515}$, ihnen wesenlose Versprechungen gemacht und ihre Begehrlichkeiten geweckt hatte. So zeigten sie sich (vor den eingetroffenen Almohaden) wehrhaft, schickten sich zum Abwehrkampf und Verteidigungsgefecht an und ließen sich durch ihre in den Himmel hineinragenden Mauerzinnen täuschen. Doch diese mächtige (almohadische) Sache können keine steil aufgerichteten Berge ${ }^{516}$ noch hohe Festungen aufhalten! Und so gingen die Almohaden - Gott möge ihnen Mächtigkeit verleihen - entschlossen dazu über, dieses Bollwerk zu belagern und zu umzingeln. Sie riefen Gott - lobgepriesen sei Er - darum an, ihnen bei seiner Bezwingung beizustehen, und baten Ihn - gepriesen sei Er - darum, ihnen Seine Unterstützung und Sein (den Almohaden zur Sieghaftigkeit verhelfendes) Wirken zuteil werden zu lassen, wie Er dies immer tat. Mit Gottes Macht wird die Eroberung dieser Feste den mindesten Kraftaufwand erfordern, leicht erlangbar sein, unschwer durchzuführen und mit geringster Anstrengung zu bewerkstelligen sein, mit Gottes Kraft und Macht.

Am Tage, an welchem die Almohaden ihr Lager vor Gafsa aufschlugen, trafen bei ihnen die Gesandten Qarāqūšs mit einem Brief von ihm ein, in welchem er demütig seinen Wunsch äußerte, sich dem Almohadentum anzuschließen, sich dieser glückhaften (almohadischen) Sache unterwarf (wörtl. die Hand der Unterwürfigkeit demütig nach dieser glückhaften Sache ausstreckend ${ }^{517}$ ) und bekannt gab, dass er, würde man seine Reue annehmen und seinem Wunsch entsprechen, zu den Almohaden - Gott möge

\footnotetext{
${ }^{514}$ Hiermit wird wahrscheinlich auf die Geschehnisse im Vorfeld der Schlacht bei Badr zwischen den Mekkanern und Mohammed angespielt. Denn der islamischen Überlieferung zufolge habe der Teufel die heidnischen Mekkaner unablässig in diese Schlacht, deren für die Letzteren unrühmlicher Ausgang ihnen bereits in sicheren Zeichen vor dem Velassen Mekkas verkündigt worden sei, und wider ihre anfänglichen Bedenken getrieben (Kitāb al-maḡāzī, 1. Bd., S. 31, 38 f., Sīrat Ibn-Ishāà, S. 285). Siehe dazu auch Kapitel 6.4.

${ }^{515}$ Höchstwahrscheinlich eine Anspielung auf Sure 8, Vers 48 des Korans.

${ }^{516}$ In den almohadischen Briefen ist die Vorstellung nicht selten, eine befestigte Stadt sei u. a. einem Berg gleich. Siehe hierzu die Belege im Kapitel „Festungskonzepte“ im Anhang 2.
} 
ihnen Mächtigkeit verleihen - gehorsam und gefügig stoßen werde. Am nächsten Tag kamen bei den Almohaden die Gesandten Abū-Zaiyāns an und überbrachten einen Brief, in welchem er mitteilte, dass er sich an den hohen Berg dieser großen (almohadischen) Sache und an ihren Pfeiler anlehne, (ferner) die Zusicherung der körperlichen und materiellen Unversehrtheit und die Sicherheitsgewährung begehre und (des Weiteren) in ihrer (d. h. der almohadischen Sache) erhabensten Höhle und in ihrer Festung Zuflucht nehme. Dieser erwähnte Abū-Zaiyān ist einer der Anführer der asiatischen Söldner, ist im Hinblick auf sein Gewicht bei ihnen mit Qarāqūš vergleichbar und hat Anteil an dessen Macht. Er hatte sich von Qarāqūš abgespalten aufgrund seiner Abneigung, mit dem Letzteren gemeinsame Sache zu tun, und aus seinem Entschluss heraus, sich von ihm lösen. Er (Abū-Zaiyān) setzte sich in den Besitz von Tripolis - Gott möge diese Stadt vor allem Übel behüten - samt Umgebung und ließ dort das Almohadentum proklamieren. Auf diese Weise - Gott sei gedankt dafür wurden all diese Städte den Almohaden wieder botmäßig, reihten sich abermals in die almohadische Gemeinschaft ein und kehrten in den Schoss (wörtl. Besitz) dieser erhabenen und mächtigen (almohadischen) Botschaft zurück. Sie (d. h. diese Städte) kamen wieder zur Besinnung nach den Krankheiten ${ }^{518}$, von welchen sie befallen waren, und genasen (wörtl. entschlüpften) vom unheilbaren Übel der Meuterei und von ihrem inkurablen Leiden. So ist der Wunsch (der Almohaden) danach, in diesen Städten Frieden und Ordnung einkehren und in diesen Gegenden Sicherheit und Ruhe obwalten $\mathrm{zu}$ lassen, in Erfüllung gegangen, durch die Gnade Gottes, des Besitzers der Gnadenerweise und Huldbezeigungen.

Wir haben euch - Gott möge euch den Erfolg verleihen - von diesen zahlreichen Siegen berichtet, deren Bedeutsamkeit groß ist, die das Danken und das Loben außerstande gesetzt haben, für sie gebührend Dank und Lob zum Ausdruck bringen zu können, die (ferner) aufgrund der wundersamen Sieghaftigkeit und des (militärischen) Erfolgreichtums (der Almohaden) das Gewohnte in den Schatten gestellt haben, auf dass ihr an diesen Siegen teilhabt, sie in den nahen und fernen Gegenden ruchbar macht, denjenigen - groß ist Seine Macht - , der sie gewährt hat, erneut für sie lobpreist sowie demjenigen, der sie möglich gemacht hat und sie beshieden hat, gebührend dankt. Gott

\footnotetext{
517 Siehe zu dieser weit verbreiteten Vorstellung die zusammengetragenen Textbelege im Kapitel „Gefühle (Gefühlsbezeigungen, Empfindungen)“ im Anhang 2.

${ }_{518}$ In den almohadischen Briefen ist die Vorstellung verbreitet, Landstriche, Städte usw., die den Almohaden unbotmäßig geworden sind bzw. der almohadischen Herrschaft entrissen wurden, seien von einer schwer heilbaren Krankheit befallen, die zu heilen, d. h. die almohadische Herrschaft dort wiederherzustellen, es gelte. Siehe hierzu ferner die Belege im Kapitel „Krankheiten und Übel“ im Anhang 2.
} 
- gelobt sei Er - möge euch dabei Seinen Beistand erweisen, Er, welcher über euch das Mehrfache und das Unaufhörliche Seiner Gunstbezeigungen sich ergießen lässt, durch Seine Huld und Güte. Es gibt keinen anderen Gott außer Ihm. Der Frieden, Gnade Gottes - gelobt sei Er - und Seine Segen mögen euch zuteil werden.

Abgefasst am 5. November des Jahres 1187.

6.2. „Die Städte der Region Nafzāwa sowie Tawzar, Taqyūs, al-Hamma und Nafṭa ergaben sich den Almohaden [...]".

Über diese Teiletappe der Fortsetzung der almohadischen Wiedergewinnung der Gebiete von Ifrīqīya finden sich in den überlieferten arabischen Quellen kaum Angaben. Ibn-al-Atīr geht gleich nach dem kurzen Hinweis auf die Wiedereroberung von Gabès nach dem Sieg der Almohaden bei Ḥamma Maṭmāṭa zur Beschreibung der Belagerung Gafsas über ${ }^{519}$. Diese Abfolge überliefert auch az-Zarkašī, dem zufolge die Bewohner von Gabès von sich aus sich beeilt hätten, die in ihrer Stadt befindlichen Almohaden $\left[?^{520}\right]$ Yacqūb al-Manșūr auszuliefern, welche hiernach nach Marrakech gebracht wurden $^{521}$. Für 'Abd-al-Wāhid al-Marrākušǐ, der irrtümlicherweise diese Unternehmung mit derjenigen zur Befreiung Biğāyas im Jahr 1185 zur einen Expedition vereint, ist die auf Ḥamma Maṭmāta folgende Etappe die Belagerung Gafsas ${ }^{522}$. Ibn-Haldūn fügt nach Gabès und vor Gafsa Tawzar in die Reihe der almohadischen Inbesitznahmen und erwähnt die in der Kapitelüberschrift genannten Taqyūs, al-Ḥamma und Nafța ebenfalls nicht $^{523}$. Allen diesen Angaben ist die weitest gehende Knappheit gemeinsam und sie gehen selten über mehr als eine beiläufige Bemerkung hinaus. Keine wesentliche Ausnahme bildet auch die diesbezügliche Passage bei Ibn-'Idārī, in der lediglich sehr allgemein davon gesprochen wird, dass Ya'qūb al-Manșūr nach dem bekannten Ausgang der Schlacht bei Hamma Maṭmāṭa das gesamte Gebiet von Ğarīd zurückeroberte, indem er dessen Städte eine nach der anderen wieder in Besitz nahm ${ }^{524}$. Tawzar, so scheint es, ist mit Waffengewalt wieder in den Besitz der Almohaden gebracht worden ${ }^{525}$. Was die Rolle der Bevölkerung dieser Städte bei der Vertreibung der almohadischen Widersacher betrifft, so ist in der betreffenden Schilderung des

\footnotetext{
${ }^{519}$ al-Kāmil, Bd. 9, S. 171.

${ }^{520}$ Es handelt sich hierbei offensichtlich um einen Fehler, und Familienangehörige und Anhänger von Qarāqūš sind an dieser Stelle sicherlich gemeint, denn ihre Deportation nach Marakech ist belegt (siehe hierzu Riḥlat at-Tiğānī, S. 103 f., Kitāb al-'ibar, Bd. 6, S. 397, al-Kāmil, Bd. 9, S. 171).

${ }^{521}$ Tārrīh ad-daulatain, S. 16.

522 al-Mu ǧib, S. 272 ff.

${ }^{523}$ Kitāb al-'ibar, Bd. 6, S. 397 und S. 510.

524 al-Bayān al-muġrib, S. 192.
} 
Briefes Folgendes auffallend: Demnach werden bei der Ankunft der Almohaden in der Region Ğarīd die zu ihr gehörenden Teilgebiete Nafzāwa und Qaṣṭīlīya den Meuterern entrissen, und zwar dadurch, dass die Städte dieser beiden Teilgebiete um Gnade bittend sich den Almohaden ergeben; die erbetene körperliche und materielle Unversehrtheit wird den Bewohnern gewährt und erst dann gehen sie dem Brief zufolge daran, mit Waffengewalt gegen die in ihren Orten stationierten Feinde der Almohaden vorzugehen, sie zu vertreiben, gefangen zu setzen und den Almohaden auszuliefern. Ist im Brief wirklich diese Abfolge der Ereignisse gemeint, so bedeutet dies streng genommen, dass der Kontakt der Bewohner der betreffenden Städte mit den Almohaden zustande gekommen war, noch bevor sich die Letzteren vor den Mauern von Tawzar, Taqyūs, alHamma und Nafta usw. eingefunden haben. Wenn man an ein sehr ähnliches Wiedereroberungsmuster bei der almohadischen Expedition zur Befreiung der Städte des Zentralen Maghreb zurückdenkt, so ist die Möglichkeit nicht von der Hand zu weisen, dass auch hier die der almohadischen Armee vorauseilenden Agenten den Boden für solche koordinierten „Selbstbefreiungsaktionen“ vorbereitet haben, indem sie den Bewohnern der noch wiederzugewinnenden Städte - heimlich - die körperliche Unversehrtheit zugesichert und sie somit für die Kooperation mit den anrückenden Almohaden gewonnen haben ${ }^{526}$. Der Grund für die Bereitschaft der Bevölkerung dieser sowie anderer Städte der Region zur aktiven Teilnahme an der Vertreibung der antialmohadischen Garnisonen kann aber auch nicht zuletzt in den Gräueltaten gelegen haben, die 'Alī Ibn-Ġānīya und seine Anhänger, wie z. B. im Kapitel 5.2. beschrieben, in Tawzar verübt haben.

6.3. „Am Tage, an welchem die Almohaden ihr Lager vor Gafsa aufschlugen, trafen bei ihnen die Gesandten Qarāqūšs mit einem Brief von ihm ein $[\ldots]^{“}$

Der Name Qarāqūš kommt in „Mağmū̌ rasā’il muwaḥḥidīya““ an insgesamt drei Stellen vor: zweimal im Brief Nr. 30 im Zusammenhang mit der Inbesitznahme von Gabès, bei der wie erinnerlich seine Familie den Almohaden als Beute zugefallen war, und einmal im eben angeführten Zitat. Über den genauen Zeitpunkt des Einfalls dieses Söldners in Ifrīqīya, an dessen Anfang die Unterwerfung von Ğabal Nafūsa und Tripolis gestanden hat und über den die überlieferten Quellen widersprüchliche, schwerlich miteinander in Einklang zu bringende Angaben enthalten, wurden im Kapitel 3.6. einige Überlegungen angeführt. Ohne noch einmal die gesamte Problematik des nicht mit letzter Sicherheit

\footnotetext{
${ }^{525}$ Kitāb al-'ibar, Bd. 6, S. 397 und S. 510.
} 
zu ermittelnden Datengerüstes der Ereignisgeschichte dieser Region in jenem Zeitraum aufzurollen, sei lediglich auf den für das Verständnis der Ausführungen des Briefes Nr. 31 unerlässlichen ereignisgeschichtlichen Hintergrund hingewiesen. Qarāqūš bringt Tripolis in seine Gewalt, verbündet sich später mit 'Alī Ibn-Ġānīya und unterwirft bei den nun gemeinsamen Plünderungszügen Gabès, das er zu seiner Residenz macht und dort seine Familie und seine Schätze unterbringt ${ }^{527}$. Zum Zeitpunkt der almohadischen Wiedergewinnung Ifrīqīyas im Jahr 1187 befanden sich also Tripolis und Gabès seit einigen Jahren - höchstwahrscheinlich ununterbrochen ${ }^{528}$ - in der Gewalt Qarāqūšs und seine Herrschaft in diesen beiden Städten wird unmittelbar vor und nach seiner und 'Alī Ibn-Ġānīyas Flucht im Gefolge der Niederlage bei Hamma Maṭātạ durch die Vertrauenspersonen an seiner Statt aufrechterhalten worden sein.

Die Wiedereinnahme von Gabès erfolgte laut dem Brief Nr. 30 dergestalt, dass die Bewohner dieser Stadt den anrückenden Almohaden entgegengeeilt und sich ergeben haben. Die Familienangehörigen und Anhänger von Qarāqūš hätten sich zunächst in der Zitadelle verschanzt und den Widerstand erst dann aufgegeben, als ihnen die körperliche Unversehrtheit zugesichert worden sei. Bei der Ankunft der Gesandten Qarāqūšs nach Gafsa, der wohlgemerkt, nachdem er nur mit knapper Not dem Tod bei Hamma Maṭmāta entrinnen konnte ${ }^{529}$, gerade irgendwo in den Weiten der hinter Tawzar liegenden Wüste auf der Flucht war, befanden sich also seine Familienangehörigen in der Gewalt der Almohaden. Über ihr weiteres Schicksal lässt sich der Sammlung „Mağmū` rasā’il muwaḥhidīya“ nichts Näheres entnehmen. Anderen Quellen zufolge wurde die Familie dieses Anführers der asiatischen Söldner nach Marrakech gebracht ${ }^{530}$ und laut at-Tiğānī verlief ihr Weg nach Maghreb über Tunis. Obwohl man nicht sagen kann, wann genau die Überführung der Familie Qarāqūšs nach Marrakech erfolgte, so scheint doch sehr wahrscheinlich, dass zum Zeitpunkt des Eintreffens seiner Gesandten bei Gafsa seine Angehörigen sich wohl noch in Tunis befanden. Dies ist der Hintergrund, vor dem wir die angeführte Kapitelüberschrift betrachten müssen und vor dem sicherlich auch der Entschluss Qarāqūšs, mit den Almohaden Fühlung aufzunehmen, herangereift sein dürfte. Der Wunsch Qarāqūšs, sich unter die Herrschaft der Almohaden zu stellen, scheint indes keinen langen Bestand gehabt zu haben. Denn

\footnotetext{
${ }^{526}$ Siehe hierzu die Wiedergabe des Berichts von Ibn- Iḍārī im Kapitel 4.9.

${ }^{527} \mathrm{Zu}$ diesem groben Ablauf lassen sich die jeweiligen Berichte in „Riḥlat at-Tiğānī““ (S. 103, 113) und „Kitāb al-'ibar“ (Bd. 6, S. 394 ff.) zusammenfügen.

${ }_{528}$ Im Zusammenhang mit Gabès enthalten die Quellen keine Hinweise auf dessen Gegenteil und bei Tripolis wird dies in „Riḥlat at-Tiğānī“ (S. 243 f.) bezeugt.

${ }^{529}$ Kitāb al-'ibar, Bd. 6, S. 397.

${ }^{530}$ Riḥlat at-Tiğānī, S. 103 f., Kitāb al-cibar, Bd. 6, S. 397, al-Kāmil, Bd. 9, S. 171.
} 
sein Abfall vom Almohadentum wird von den im Folgenden zu erörternden Berichten bezeugt, aus welchen allerdings nicht eindeutig hervorgeht, ob er nur einmal der almohadischen Sache abgeschworen hat. Im folgender Weise lässt sich der einschlägige Bericht at-Tiğānīs hierüber wiedergeben: Als Yacqūb al-Manșūr die Familienangehörigen Qarāqūšs, die sich den Almohaden nach der Einnahme von Gabès egeben hatten, nach Tunis hat bringen lassen, hat sich dieser Söldner im Jahr 586 H. / 1190 den Almohaden unterworfen. Dies fand statt nachdem sein Verbündeter 'Alī IbnĠānīya starb und sein Bruder Yaḥyā Ibn-Ġānīya zu seinem Nachfolger wurde. Qarāqūš begab sich daraufhin nach Tunis, wo er einige Zeit die Gastfreundschaft des Statthalters dieser Stadt genossen hat. Von dort entwich er jedoch schon bald nach Gabès. Mittels Anwendung einer List bemächtigte er sich dieser Stadt, tötete einige ihrer Einwohner und zog seinen Übertritt zum Almohadentum zurück. Als Nächstes lud er die Stammesältesten des arabischen Stammes Dabbāb nach Gabès ein und ließ sie umbringen. Nach der Einnahme von Gabès zog er gegen Tripolis, das bei seiner ersten Ankunft in diese Region seine Autorität anerkannt hatte, ihm später jedoch unbotmäßig geworden war. Nun gelangten Tripolis und Gabès wieder in seine Gewalt ${ }^{531}$.

Wenn nun die obige Zeitangabe dieses Berichts stimmt, so hieße es, dass obwohl Qarāqūš den Ende Oktober bzw. Anfang November 1187 vor Gafsa abgestiegenen Almohaden seinen Wunsch hat überbringen lassen, sich in ihren Dienst zu stellen, die praktische Umsetzung dieses Schrittes jedoch noch zwei bis drei Jahre in Anspruch genommen hat. Was ein weiteres mögliches Szenario betrifft, nämlich dass er kurz nach der Bekanntgabe des erwähnten Wunsches den Schritt dazu vollzogen, bei der nächsten günstigen Gelegenheit - z. B. nach dem Abrücken der almohadischen Truppen westwärts - dem Almohadentum den Rücken gekehrt hatte, um später wieder einmal sich zum Almohadentum zu bekennen und ihm abermals abzuschwören, so gibt es dafür nach aktueller Quellenlage keine Anhaltspunkte. Aus der folgenden Passage aus „Kitāb al-istibṣār fỉ ‘ağā’ib al-amṣār“ geht u. a. ebenfalls hervor, dass Qarāqūš im Zeitraum von seiner Kooperationsbekundung mit den Almohaden im Jahr 1187 bis 1190 sich nur einmal zum Almohadentum bekannt hat: „Und der Prüfer ${ }^{532}$ fügte ergänzend hinzu, dass in dieser erwähnten Stadt Tripolis ein asiatischer Söldner namens Qarāqūš war, der, nachdem er sich dem Almohadentum gegenüber verschlossen und abweisend gezeigt

\footnotetext{
${ }^{531}$ Riḥlat at-Tiğānī, S. 104; diese Angaben werden im Wesentlichen auch auf S. 244 wiederholt. IbnHaldūn übernimmt die wiedergegebenen Ausführungen at-Tiğānīs (Kitāb al-'ibar, Bd. 6, S. 398).

532 Es gehört zur eigenartigen Struktur dieses Werks, dass nach den geographischen und historischen Angaben des Verfassers der so genannte ,an-nāzirir“ ergänzend im Sinne der almohadischen Deutung des Geschilderten in Erscheinung tritt.
} 
hatte, sich an den hohen Berg dieser mächtigen (almohadischen) Sache - Gott möge ihren Bestand fortwähren lassen - angelehnt und sich ausschließlich den Almohaden und den (vom Almohadentum her strömenden) Gunsterweisen zugewandt hat. Einst unterstützte er diesen elenden Irrenden, den das Meer von der Insel Mallorca - Gott gebe sie in die Gewalt der Almohaden - herangespült hatte ${ }^{533}$, und bei all den blutigen Zusammenstössen (mit den Almohaden) bewahrte ihn (das ihm zugeteilte diesseitige und jenseitige) Gelingen bis zum Tode des elenden Irrenden unversehrt. Danach reihte sich Qarāqūš in die Partei der Bekenner der Einsheit Gottes ein, bezwang Tripolis und vertrieb Abū-Zabā al-Fārisī von dort, der die Herrschaft über diese Stadt an sich gerissen hatte. $\left[{ }^{534}\right]$ Als der Kalif Abū-Yūsuf (Ya'qūb al-Manșūr) im Jahr 583 H. (1187/88) nach Ifrīqīya zog, um ihre Städte zu befreien, ließ ihm dieser Abū-Zabā alFārisī unterwürfig seinen demütigen Wunsch danach überbringen, Frieden zu schließen und in den Genuss der Gnade zu kommen. Später jedoch fiel er $\mathrm{ab}^{535}$ und setzte sich in den Besitz von Tripolis. Dort herrschte er solange, bis Qarāqūš sich den Almohaden anschloss und dieser sein Übertritt zum Almohadentum sich als aufrichtig erwies. Qarāqūš verjagte ihn - wie oben gesagt wurde - aus Tripolis und schickte ihn in Fesseln geschlagen (nach Marrakech), wo er im Jahr 586 H. / 1190 angekommen ist. Und wir sind jetzt im Monat Rağab des Jahres 587 H. / 25 Juli bis 24 August des Jahres 1191 und die Botschaft des Almohadentums und der Rechtleitung gilt uneingeschränkt im gesamten Wüstengebiet, von Tripolis bis hin zu den Städten Ġāna und Kaukau ${ }^{536}$

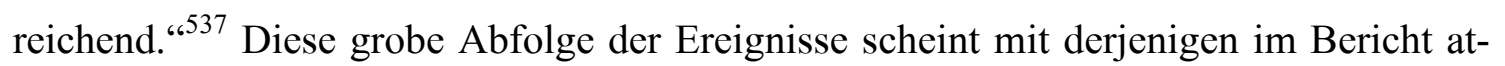
Tiğānīs übereinzustimmen: Qarāqūš stösst nach dem Tode seines Mitstreiters 'Alī IbnGānīya zu den Almohaden und bringt dann Tripolis wieder in seine Gewalt. Die beiden zitierten Überlieferungen weichen jedoch im Hinblick auf die Gesinnung Qarāqūšs bei seiner Ankunft nach Tripolis wesentlich voneinander ab: Für at-Tiğānī ist er zu diesem Zeitpunkt dem Almohadentum bereits abtrünnig geworden, während der anonyme Autor von „Kitāb al-istibṣār fī 'ağā'ib al-amșār“" daran festhält, er hänge dieser religiöspolitischen Auffassung an. Man kann heute nur mutmaßen darüber, worauf dieser Unterschied zurückgehen mag und welcher der beiden Bewertungen eher Glauben

\footnotetext{
${ }^{533}$ D. h. 'Alī Ibn-Ġānīya.

${ }^{534}$ Nachdem der Verfasser an dieser Stelle auf den Namen Abū-Zabā al-Fārisīs eingeht, erklärt er im Folgenden die näheren Umstände seiner Machtergreifung in Tripolis.

535 Das arabische ,tumma nakata“ an dieser Stelle meint genau genommen ,später löste er das UntertanVerhältnis, das er zu dem almohadischen Kalifen zuvor eingegangen war, einseitig auf“.

${ }^{536} \mathrm{Zu}$ diesen beiden Städten siehe „Kitāb al-muğrib fī dikr bilād Ifrīqīya wa-'l-Mag̀rib“ (S. 328 ff. und S. 335 der Übersetzung, Fußnote Nr. 2) sowie „The new Islamic dynasties“ (S. 122 ff.).

${ }^{537}$ Kitāb al-istibșār fị 'ağāìb al-amṣār, S. 110 f.
} 
geschenkt werden kann. Der weitere Verlauf der Ereignisse legt jedoch nahe, dass atTiğānī doch Recht haben könnte. So wird überliefert, dass es nach der Wiedereinnahme von Tripolis durch Qarāqūš zu einem schweren Zerwürfnis zwischen ihm und dem neuen Anführer der Mallorquiner Yaḥyā Ibn-Ġānīya gekommen ist. Die einzelnen Etappen der darauf folgenden Ereignisse lassen sich dahingehend zusammenfassen, dass Qarāqūš im Gefolge des Bruchs mit Yahyā Ibn-Ġānīya sowohl Tripolis als auch Gabès an den Letzteren verlor und schließlich von ihm in Waddān, wo er vorläufigen Schutz gefunden hatte, belagert und umgebracht wurde ${ }^{538}$. Die Tatsache, dass Qarāqūš bei seinen Auseinandersetzungen mit Yahyā Ibn-Ġānīya nicht auf die Unterstützung oder auch den Schutz der Almohaden zurückgreifen konnte, verleiht der Aussage at-Tiğānīs, er habe seinen Übertritt zum Almohadentum zurückgezogen, Glaubwürdigkeit.

Nun gilt es, unser Augenmerk auf die wenigen Überlieferungen über Abū-Zaiyān zu richten. Laut dem Brief Nr. 31 gelangen seine Gesandten in das almohadische Lager vor Gafsa einen Tag nach denjenigen des - irgendwo hinter Tawzar auf der Flucht befindlichen - Qarāqūš und geben bekannt, er sei zum Almohadentum übergetreten, habe Tripolis seiner Herrschaft unterworfen und dort das Almohadentum proklamiert. Wenn man die entsprechende Passage des Briefes, die obigen Ausführungen in „Kitāb al-istibṣār fī 'ağāàib al-amṣār" über den treulosen Abū-Zabā al-Fārisī, der sich zuerst den Almohaden unterworfen und später jedoch sich zum unabhängigen Herrscher über Tripolis aufgeschwungen habe, und den Bericht at-Tiğānīs über die zeitweilige Unbotmäßigkeit Tripolis' gegenüber Qarāqūš alle in Beziehung miteinander setzt, so drängt sich unweigerlich der Schluss auf, dass es sich bei Abū-Zaiyān und Abū-Zabā al-Fārisī um ein und dieselbe Person handelt. Höchstwahrscheinlich wird auch mit der Aussage in „Kitāb al-istibṣār fĩ 'ağā’ib al-amṣār“, Abū-Zabā al-Fārisī habe beim Aufenthalt Ya'qūb al-Manșūrs in Ifrīqīya um Friedensschluss und um Genuss der Gnade dieses Herrschers demütig gebeten auf die Überbringung des im Brief Nr. 31 erwähnten Schreibens von Abū-Zaiyān Bezug genommen.

Wenden wir uns an dieser Stelle kurz den Herrschaftsverhältnissen in Ifrīqīya vor und nach der Niederlage der Almohaden bei 'Umra zu: Qarāqūš, Gewaltherrscher über Tripolis und Gabès, zieht mit 'Alī Ibn-Ġānīya, dem Herrscher über die Gesamtheit Ifrīqīyas bis auf Tunis und al-Mahdiya ${ }^{539}$, in die Schlacht bei Hamma Maṭmāṭ. Selbstverständlich lässt dabei dieser asiatische Söldner in den beiden Städten

\footnotetext{
538 Riḥlat at-Tiğānī, S. 104 ff. In „Kitāb al-'ibar“ (Bd. 6, S. 398) findet sich eine auf diesem zusammengefassten Bericht von at-Tiğānī aufbauend stark verkürzte Fassung dieser Ereignisse.

${ }^{539}$ Historia política del imperio almohade, Bd. 1, S. 331 und Kapitel 5.2. oben.
} 
Vertrauenspersonen an seiner Statt. Nach dem bekannten Ausgang des Zusammenstosses fliehen die beiden Anführer, und die Almohaden gehen zur schrittweisen Rückeroberung Ifrīqīyas über. Dabei fällt Gabès als nächste Stadt und bald gibt Abū-Zaiyān bekannt, er habe Tripolis, das bis dahin Qarāqūš gehörte, seiner Gewalt unterworfen. Bei der Beschreibung dieses Anschlusses von Tripolis an den Herrschaftsbereich der Almohaden wird sowohl im zu analysierenden Brief als auch in „Kitāb al-istibṣār fī 'ağāìb al-amṣār" das arabische Verb „,istabadda“ gebraucht, das in diesem Zusammenhang aufschlussreich sein könnte. Gemeinhin werden heute für „,istabadda“ Bedeutungen ,ganz in Besitz nehmen, ergreifen, erfassen, überwältigen; despotisch, tyrannisch, autokratisch herrschen“540 angegeben; in einer Quelle aus dem 12. Jahrhundert hat es die neutrale Bedeutung „die Herrschaft über eine Stadt übernehmen“6541 und in Supplément Dozys findet man dazu Folgendes: „istabadda calā as-sultān ou 'alā ad-daula, en parlant du premier ministre, accaparer toute l'autorité du souverain $[. . .]^{\text {“5 } 542}$ Mit anderen Worten, ,istabadda“ konnte u. a. den spezifischen Sinn gehabt haben, ein ranghoher Untertan des Herrschers treibe den Ausbau der in seinen Händen konzentrierten Macht so weit voran, dass sie sich schließlich mit derjenigen des Herrschers deckt und somit zur prakischen Entmachtung des Letzteren führt. Auf die in Tripolis im Gefolge der Schlacht bei Ḥamma Maṭmāṭa entstandene Situation übertragen ergäbe diese spezifische Bedeutung - sofern sie hier wirklich gemeint ist - eine interessante Erklärungsmöglichkeit: Abū-Zaiyān, eine der ranghohen Vertrauenspersonen Qarāqūšs, wirft sich die Flucht seines Oberherren nutzend zum Herrscher über Tripolis auf und lässt seine nunmehrige Herrschaft mittels Bekenntnisses zum Almohadentum legitimieren, was ihm die Beibehaltung der Position sichert. Über die Aktivitäten dieses Söldners nach seinem in „Kitāb al-istibṣār fī ‘ağā’ib al-amṣār“ bezeugten Abfall vom Almohadentum nach dem Abzug der almohadischen Armee bzw. nach der Errichtung seiner kurzfristigen Gewaltherrschaft in Tripolis bis zu seiner oben erwähnten Entmachtung durch Qarāqūš im Jahr 1190 lässt sich dem überlieferten Quellenmaterial nur so viel entnehmen, dass er sich mit Yahyā Ibn-Ġānīya zusammen getan und an dessen Plünderungszügen teilgenommen zu haben scheint ${ }^{543}$.

\footnotetext{
${ }^{540}$ Arabisches Wörterbuch für die Schriftsprache der Gegenwart, S. 68.

${ }^{541}$ Kitāb al-iktifā' fī ahbār al-ḩulafā', S. 99.

542 Supplément aux dictionnaires arabes, Bd. 1, S. 55.

${ }^{543}$ In einer Passage, die at-Tiğānī aus dem Werk eines anderen Autors zitiert, ist davon die Rede, dass Yaḥyā Ibn-Gānīya und ein gewisser Abū-Ziyād al-Mağribī - zweifelsohne eine weitere der vielen überlieferten Namensvarianten des uns bekannten Abū-Zaiyān (siehe hierzu den Kommentar des Herausgebers auf S. 15, Fußnote Nr. 1) - die nahe Tunis gelegene Ortschaft Manzil Baššaq ausplündert
} 
Die jeweiligen Übertritte von Qarāqūš und Abū-Zaiyān zum Almohadentum erweisen sich beide im Lichte der obigen Berichte kaum mehr als ein taktisches Manöver. Die wahren Motive und der eigentliche Hintergrund für diesen scheinbaren Gesinnungswandel sind der betreffenden Passage des Briefes allerdings nicht zu entnehmen, der im hochtrabenden und floskelhaften Stil seinen Adressaten die Version eines aufrichtigen Bekenntnisses der beiden Söldner zum Almohadentum glaubhaft machen will. Ferner ist hier die Parallele zum Šaih Abū-Sirḥān Mas'ūd Ibn-Sultāan IbnZimām unübersehbar, der, wie im Kapitel 3.6. beschrieben, nach seiner scheinbar aufrichtigen Einwilligung, nach dem Äußersten Maghreb umgesiedelt zu werden, später nach Ifrīqīya entweicht und dort bis ins greise Alter hinein gegen die almohadische Herrschaft kämpft.

6.4. „Diesem gesegneten Feldzug [...] lag (ausschließlich) das Bestreben zugrunde, die Übeltäter zu bezwingen $[\ldots]^{\text {“ }}$

Folgende Bezeichnungen sind den Feinden der Almohaden im Brief vorbehalten:

„al-mu'tadīn“ (S. 194), d. h. „die Übeltäter“, kommt im Koran - neben den ebenfalls belegten Formen ,al-mu'tadī" und ,al-mu'tadūn“ - in Sure 2, Vers 190; Sure 5, Vers 87; Sure 6, Vers 119 usw. vor.

„al-cābitīin“ (S. 194), d. h. „Missetäter“.

„al-mufsidīn“ (S. 194), d. h. „Frevler“, ist im Koran - neben den Formen ,al-mufsid““ und ,al-mufsidūn“ - mehrfach belegt. Siehe Sure 2, Vers 60; Sure 3, Vers 63; Sure 5, Vers 64 usw.

„wabaš al-fitna“ (S. 195), d. h. „Pöbel der Meuterei“.

„al-ašqīyā̄““ (S. 196, 197), d. h. „die Elenden“, ist im Koran nicht belegt, wohl aber dessen Singularform in Sure 11, Vers 105.

„ka-šārid al-an‘ām“ (S. 196), d. h. „dem entflohenen Vieh ähnlich“. Wie bereits im Kapitel 2.7. ausgeführt, ist „das Vieh“ an mehreren Stellen im Koran belegt und manchmal wird mit dieser Bezeichnung zum Ausdruck gebracht, das mit „das Vieh“ bezeichnete Objekt sei missgeleitet. Der Blick auf die klassischen arabischen Redewendungen im genannten Kapitel ergab ebenfalls eine sehr negativ besetzte Assoziation. 
„adnās al-kufr“" (S. 197), d. h. „Schmutzflecken des Glaubens“. „Unglaube“ ist im Koran, z.B. Sure 2, Vers 108; Sure Sure 3, Vers 52; Sure 5, Vers 41 usf., mehrfach belegt.

Interessant ist der folgende Satz im arabischen Original: „fa-alfaū bihā ğumla damīma min ašqīyā' al-ag̉zāz wa-atbā' ihim qad rāna 'alā qulūbihim hawāhum wa-'staġwāhum aššaițān wa-'stahwāhum wa-sauwala lahum mugāalabat al-gullāb fa-wa'adahum gurūran wa-mannāhum“6544, d. h. „Dort trafen sie auf die schmachbedeckte Schar der elenden asiatischen Söldner und auf ihre Anhänger. Deren aller Herzen waren von ihren Gelüsten übermannt, und sie waren alle vom Teufel verführt und verleitet, der ihnen eingeflüstert hatte, sie könnten es mit den Unbezwingbaren aufnehmen (und sie bezwingen), ihnen wesenlose Versprechungen gemacht und ihre Begehrlichkeiten geweckt hatte.“ Dieser Satz setzt sich aus insgesamt drei aus ihrem jeweiligen Kontext gelösten koranischen Zitaten zusammen, wobei zwei von ihnen leicht abgewandelt wurden: „rāna 'alā qulūbihim“ - Sure 83, Vers 14, ,ka-'l-lad̄i istahwathū aš-šayāṭ̂nn fi 'larḍ ḥairān“ - Sure 6, Vers 71 und ,yaciduhum wa-yumannīhim wa-mā ya iduhum aššaitān illā gurūran“" - Sure 4, Vers $120^{545}$.

Eine Anmerkung verdient abschließend noch die Passage des Briefes, die von der nächtlichen Flucht einer Gruppe der almohadischen Widersacher aus Tawzar spricht. Denn diese enthält einen auffallenden Widerspruch: Anfangs wird verkündet, die Widersacher hätten zwar den Almohaden entrinnen können, seien dabei allerdings in den Tod hinein gerannt; etwas weiter jedoch wird prophezeit, die Entflohenen würden noch später sicherlich den gewaltsamen Tod erleiden. An mindestens zwei weiteren Stellen in „Mağmū' rasā’il muwaḥhịīya““ wird die Flucht von Personen geschildert, die mit ihrem jähen Tod geendet habe. So heißt es im Brief Nr. 16 im Zusammenhang mit dem Tod des christlichen Königs, der zusammen mit Ibn-Mardanīš nach dem vergeblichen Versuch, Almeria zu entsetzen, panikartige Flucht ergriffen habe: „farra min al-maut wa-fi 'l-maut waqa'a wa-'ttasa'a al-harq 'alā ar-rāqii ${ }^{c 546}$ fa-mā rafā wa-mā raqa $^{c} a^{، 547}$, d. h. „Er floh von dem Tod und fand dabei den Tod, und so ist der Riss, den einer stopfen wollte, noch größer geworden, sodass er weder ausgebessert noch gestopft hat“". Im Brief Nr. 29 wird u. a. mitgeteilt, dass beim Vorrücken der almohadischen

\footnotetext{
${ }_{544}^{54}$ Mağmūc rasā'il muwaḥhidīya, S. 197.

${ }^{545}$ Die Übersetzung der angeführten Zitate weicht teilweise erheblich von derjenigen Parets ab, sie ist jedoch dem Kontext des Briefes geschuldet.

${ }^{546}$ „Ittasa'a al-ḩarq 'alā ar-rāqi i“‘ ist eine bekannte arabische Redewendung (Kitāb ğamharat al-amtāl, Bd. 1, S. 160).

${ }^{547}$ Mağmū' rasā'il muwaḥhidīya, S. 77.
} 
Armee im Zentralen Maghreb zwecks Wiedergewinnung der von 'Alī Ibn-Ġānīya besetzt gehaltenen Städte die almoravidische Garnison der Stadt Miliana ihr Heil in der Flucht gesucht habe: „wa-farra al-ašqīyā' alladīna kānū bihā (aiy bi-Milyāna) 'alā wuğūhihim wa-sārū munğarrīn ilā mașāri` ḥutūfihim fa-qatalahum al-qabā’il alladīna ‘alā tarīqihim bi-kull sabīl“‘548, d. h. „Die Elenden, die in dieser Stadt waren, stoben Rettung suchend auseinander und wurden (letztlich doch nur) zu den Orten ihrer Niederstreckung geschleift. Denn die Stämme, welchen sie auf ihrer Flucht begegneten, töteten sie allenthalben“. Auch in der mittelalterlichen arabischen Literatur ist dieses Bild nicht unselten. Und vor diesem Hintergrund ließe sich die aufgezeigte Widersprüchlichkeit des angeführten Abschnitts über die Flucht aus Tawzar auflösen, denn es scheint sich hierbei um die Wiedergabe eines der Topoi des Schrifttums jener Zeit zu handeln und nicht um eine für die historische Analyse in Betracht kommende Quellenaussage.

\subsection{Zusammenfassung des historischen Kommentars}

Die im Mittelpunkt des Briefes Nr. 31 stehenden Ereignisse wurden in den herangezogenen Quellen nur am Rande berücksichtigt. Dort, wo die weitschweifige Schilderung im Brief uns die almohadische Sicht auf das Geschehene bekannt gibt, beschränkt sich das überlieferte Quellenmaterial auf kaum mehr als eine beiläufige Bemerkung. Aus dieser Perspektive heraus betrachtet, könnte der Brief einen willkommenen Mosaikstein darstellen, der die Ereignisgeschichte Ifriqyias im in Frage kommenden Zeitraum zu rekonstruieren helfen könnte. Allerdings verflicht sich in seinen Schilderungen das Faktische in inniger Weise mit dem propagandisisch begründeten Immaginären, so dass eigentlich erst ein solides Überlieferungsfundament diese beiden Elemente zu entflechten erlauben würde. So enthält das Schreiben zwar pathetische Passagen über die Wiedereroberung der Städte der Region Ğarīd, ihre faktische Durchführbarkeit konnte jedoch erst der Rückblick auf ein anderes, sehr ähnliches Wiedereroberungsmuster der Städte des Zentralen Maghreb (s. Kapitel 6.2. und 4.9.) plausibel erklären. Das Gleiche scheint auch für die Beschreibung des Weges der Almohaden von Gabès nach Ğarīd zuzutreffen, der äußerst unwegsam und gefährlich gewesen sein soll. Im Kapitel 2.3. wurden bereits ähnliche Zitate aus anderen almohadischen Schreiben zusammen getragen und es wurde die Vermutung geäußert, dass es sich hierbei mehr um ein stilistisches Mittel, als um eine im Sinne einer

\footnotetext{
$\overline{{ }^{548} \text { Mağmūc rasā’il muwaḥhidīya, S. } 175 .}$
} 
historischen Analyse relevante Aussage handelt. Die beiden namentlich genannten Personen sind im Brief Qarāqūš und Abū-Zaiyān. Der in hochtrabenden Worten geschilderte Wunsch Qarāqūšs, zum Almohadentum überzutreten, bzw. der tatsächlich vollzogene Übertritt Abū-Zaiyāns erscheinen im Lichte der ermittelten späteren Handlungsweise dieser beiden Personen lediglich als ein Täuschungsmanöver mit dem Zweck, die unmittelbar bevorstehende Konfrontation mit den Almohaden abzuwenden. Hier drängt sich die Parallele zum aus dem Brief Nr. 29 bekannten Šaih Abū-Sirḥān Mas'ūd Ibn-Sulțān Ibn-Zimām (s. Kapitel 3.6.) auf, dessen Motive in den betreffenden Passagen ebenfalls überschwänglich als aufrichtig gelobt werden.

Auch im vorliegenden Schreiben sind die koranische und die literarische Schicht miteinander eng verwoben. Die erste manifestiert sich darin, dass allen Schritten der Almohaden der göttliche Wille zu Grunde gelegen und dass alles Geschehen dank göttlichem Eingreifen sich zugunsten der Almohaden gestaltet habe. Auf der Textebene gelangt es mittels Koranzitate und -bezüge (s. Fußnoten Nr. 496, 499, 508, 512, 513 und 515) sowie mittels koranisch geprägter Bezeichnungen für die Feinde der Almohaden (s. Kap. 6.4.) zum Ausdruck. Die zweite Schicht wird durch den allegorischen Sprachgebrauch konstituiert (s. Fußnoten Nr. 497, 498, 500, 509, 510, 516, 517 und 518). Was die bereits in anderen Zusammenhängen genannte Zeitlosigkeit der Schilderung betrifft, so ist sie im Brief Nr. 31 weniger augenfällig, da die bekannt gegebenen Ereignisse sich innerhalb kurzer Zeit abgespielt haben.

\section{Zusammenfassung des Briefes Nr. 32}

Dieser Brief, datiert vom 14. Januar des Jahres 1188 und abgefasst im Namen des Befehlshabers der Gläubigen, ist an die Țālibs, Almohaden, Šaihss, Notabeln und die gesamte Bewohnerschaft von Marrakech adressiert. Er berichtet in folgender Weise über den siegreichen Abschluss der Belagerung Gafsas: Die Adressaten wissen bereits von einigen militärischen Erfolgen der Almohaden in Ifrīqīya, die nun in der Eroberung Gafsas ihren Höhepunkt erreichen. Es haben sich in dieser Stadt allerlei Räuber und Sünder zusammengerottet, die trotz zahlreicher Warnzeichen von ihrem Unwesen nicht haben Abstand nehmen wollen. Die Almohaden unterbreiten bei ihrer Ankunft dorthin das Angebot, ihnen Leben zu schenken und Gnade walten zu lassen, wenn sie sich ergäben, welches die Belagerten jedoch ausschlagen. Die Almohaden beschließen daraufhin, Gafsa mittels Kriegsmaschinen zu bezwingen. Es werden Maßnahmen zur Sicherung von Verkehrswegen in der Umgebung getroffen, und von überall her werden 
Lebensmittel in das Lager der Almohaden gebracht. Die Almohaden beginnen mit dem Zusammenbau der erwähnten Kriegsmaschinen, die innerhalb kürzester Zeit fertig gestellt werden. Die Belagerten lassen auch angesichts dieser Vorbereitungen keine Anzeichen von Reue erkennen. Dann kommen die erwähnten Maschinen zum Einsatz, und Gafsa wird unter Beschuss genommen, was den Verteidigern Verluste und den Mauern der Stadt großen Schaden zufügt. Der inzwischen einsatzbereite Belagerungsturm wird an die Mauern der Stadt geschafft, und die Stadt wird von ihm aus beschossen. Später gelingt es den Almohaden, den der Stadtmauer vorgelagerten Bereich der Festung zu erstürmen und einen seiner Türme in Brand zu setzen. Da sehen die Belagerten die Aussichtslosigkeit weiteren Widerstandes ein und ergeben sich. Allen Belagerten wird mit Ausnahme der Mallorquiner Leben geschenkt. Als die asiatischen Söldner auch für ihre mallorquinischen Verbündeten körperliche Unversehrtheit ausbedingen wollen, setzt man ihnen auseinander, dass ihr eigenes Leben von der Auslieferung der genannten Mallorquiner abhänge. Die Letzteren werden also ausgeliefert, und die Almohaden fallen über sie her. Mit der Bezwingung Gafsas gelangt die Unternehmung der Almohaden zu ihrem Abschluss, und von den asiatischen Söldnern ist niemand mehr in dieser Gegend geblieben, der den Almohaden hätte unbotmäßig werden können, denn diejenigen, die dazu fähig wären, sind entweder gefallen oder befinden sich nun in der Gewalt der Almohaden.

Die Almohaden beschließen ferner, die Mauern von Gafsa, die aufgrund ihrer als unüberwindbar geltenden Höhe die Stadt so oft zum Zentrum von antialmohadischen Meutereien haben werden lassen, niederzureißen. Jedem Stamm wird ein bestimmter Teil der Mauer zugeteilt, und ihre Schleifung wird binnen weniger als eines Tages durchgeführt.

\section{1. Übersetzung des Briefes Nr. 32.}

Vom Befehlshaber der Gläubigen, dem Sohn des Befehlshabers der Gläubigen und dem Enkel des Befehlshabers der Gläubigen - Gott möge ihnen Seinen Beistand gewähren und ihnen Seine Unterstützung zuteil werden lassen - an die Ṭālibs, Almohaden, Šaihs, Notabeln und die gesamte Bewohnerschaft von Marrakech - Gott möge mittels ihrer Furcht (vor Ihm) ihren Erfolg und ihren edlen Rang währen lassen und Er möge bei ihnen (in unaufhörlicher Abfolge) nacheinander Siege dieser großen (almohadischen) Sache und ihrer Siegesmeldungen kund werden lassen, deren zuletzt verkündete die ihnen vorausgegangenen an Zahl übertreffen und deren Abschließendes edel und deren 
Letztes vorzüglich sind. Der Friede, die Gnade Gottes - gepriesen sei Er - und Seine Segen mögen euch zuteil werden ${ }^{549}$.

Dieses unser Schreiben - Gott möge euch so viele der unaufhörlich aufeinander folgenden Siegesmeldungen und der fortwährend verkündeten Siege dieser obsiegenden und sieghaften (almohadischen) Sache vernehmen lassen, dass sie eure Zeiten mit Freude überfluten und ihr demjenigen, der sie (den Almohaden) angedeihen ließ, laut zu danken anhebt; Gott möge euch so viele der unaufhörlich nacheinander folgenden Siege und Siegesmeldungen dieser (almohadischen) Sache vernehmen lassen, dass durch sie euer Flehen und demütiges Bitten vor ihrem Gewährer, Er möge die genannten Siege und Siegesmeldungen fortdauern lassen, lang wird, dass sie euch (ferner) solche Frieden und Ruhe bescheren, durch welche eure Wohnstätten und Häuser wieder bevölkert werden, und dass durch sie euer mit Überfluss gesegnetes Leben und euer Weilen im Schatten der Sicherheit und auf der Aue der Sanftmut an Annehmlichkeit zunehmen ergeht aus der Stadt Gafsa - Gott möge sie befrieden - an euch. Mit diesem Schreiben empfehlen wir euch an, Furcht vor Gott - gepriesen sei Er - zu haben, Seinem Willen Folge zu leisten, Ihn um Beistand anzurufen und auf Ihn (allein) zu vertrauen. Wir lobpreisen Gott - gepriesen sei Er - für all das, was er (den Almohaden) hat zuteil werden lassen, nämlich dafür, dass Er den Streitern für die wahre Gottesanbetung und den Verfechtern Seiner Sache Sieghaftigkeit verliehen hat und sie die Oberhand hat gewinnen lassen sowie dafür, dass Er die Wege gerade gemacht ${ }^{550}$, den (richtigen) Entscheidungen Gewicht verliehen ${ }^{551}$, Wünsche wahr gemacht und die Unternehmungen (der Almohaden) sich als glückhaft erweisen lassen hat. Wir lobpreisen Gott ferner dafür, dass Er die Gegner niedergezwungen und Feinde zerschlagen, Seiner mächtigen (almohadischen) Sache, wo auch immer sie sich hinbegab, (die von Ihm gewährten) Gelingen und Erfolg zu unzertrennlichen Gefährten bestellt und sie (d. h. die almohadische Sache) in allem, was sie in Angriff nahm und wovon sie abstand, in das Gewand der glückhaften Fügung und der Rechtleitung gekleidet hat ${ }^{552}$ sowie (Sein mehrfaches zum Obsieg verhelfendes) Eingreifen mit ihren (d. h. der almohadischen Sache) Unternehmungen aufs engste verknüpft hat, wobei die

\footnotetext{
${ }^{549}$ Der darauf folgende einleitende Teil wurde bei der Übersetzung übergangen, s. Kapitel 8.2.

${ }^{550}$ Die arabische Wendung hier (Mağmūc rasā’il muwaḥhidīya, S. 201) lautet „tasdīd al-madāhib“. Dazu muss angemerkt werden, dass „,madhab“ und dessen Plural „madāhib“ früher u. U. „Schritte, Maßnahmen bzw. Anordnungen eines Herrschers gegenüber seinen Untertanen“ bedeuten konnte. Sollte hier diese spezifische Bedeutung gemeint sein, dann müsste die Übersetzung lauten „das (durch Gottes Beistand) rechte Handeln (der almohadischen Herrscher)“

${ }^{551}$ Beim an dieser Stelle (Mağmū' rasā’il muwaḥhidīya, S. 201) stehenden ,ta’bīd al-ārā’‘ handelt es sich wohl um einen Druckfehler und ,ta’yīd al-ārā'“ ist wahrscheinlich gemeint.
} 
Sieghaftigkeit - Gott sei gedankt dafür - die Erlangung und das Erreichen der Ziele der almohadischen Sache immer gewährleistete.

Des Weiteren - Gott möge all euren Vorsätzen Erfolg und all eurem Handeln im Gehorsam Ihm gegenüber Glückhaftigkeit verleihen - ist bereits vorher unser Schreiben an euch ergangen, welches einiges von dem enthielt, was Gott - gepriesen sei Er während dieser glückhaften (militärischen) Unternehmung (den Almohaden) hat angedeihen und zuteil werden lassen, welches (ferner) summarisch darüber berichtete, dass es Gottes Ratschluss und Fügung waren, dass Seine Feinde bezwungen wurden. Dieses erwähnte Schreiben berichtete (des Weiteren) im Allgemeinen über Seine Obsorge, mit welcher Er - lobgepriesen sei Er - diese große (almohadische) Sache sichtbar umgeben hatte. Diese gewaltigen Siege und großen Gnadenerweise, diese reichlichen Gaben und edlen Gunstbezeigungen - Gott möge euch den Erfolg verleihen - hat Er darin gipfeln lassen, dass diese einzigartige Festung ${ }^{553}$ und diese Burg, die in ihrer Uneinnehmbarkeit das Maß des Vorstellbaren übersteigt, und dass dieser hochragende Berg und dieser Erzfeind, der jeden, der ihn niederzuzwingen und zu bekriegen sucht, mit [unklar ${ }^{554}$ ] abwehrt, (den Almohaden) unterlag. Wie wir euch bereits mitgeteilt haben, beherbergte diese (genannte) Festung allerlei Hurer. Es befanden sich in ihr Meuten und zusammengewürfelte Scharen, welche sich alle zwecks Meuterei zusammengerottet haben, Grünschnäbel und Verschwörer, die sich allesamt zum Aufbegehren verleiten ließen, sowie Diebe, welche der Streit und der Zwist in der Absicht, ihrem räuberischen Unwesen zu frönen, haben sich zusammenfinden und Buße und Reue verschmähen lassen. Sie gebärdeten sich wie toll in ihrem Aufbegehren, leisteten dem Satan voller aufopferungsvoll Gehorsam und wollten von ihrem Abfall (vom Glauben) und ihrer Abkehr nicht ablassen, selbst dann nicht, als ihnen das Wahre kund geworden war und die Tage sie vor ihrer Wandelbarkeit gewarnt hatten. In ihrem Trotz verharrten sie an den Orten des Verderbens. Man wollte sie rechtleiten, doch sie

\footnotetext{
${ }^{552}$ Siehe hierzu die im Kapitel „Kleider und Gewänder“ des Anhangs 2 zusammengetragenen Textbelege.

${ }^{553}$ Das hier (Mağmū' rasā'il muwaḥhidìya, S. 202) gebrauchte ,al-Ablaq al-fard“" kommt in einem Gedicht des frühislamischen Dichters al-A ‘̌āā (Kitāb ğamharat al-amtāl, Bd. 1, S. 257) sowie in der Redewendung „tamarrada al-Mārid wa-'azza al-Ablaq“, d. h. „die Festungen Mārid und al-Ablaq haben sich als uneinnehmbar erwiesen“ (Kitāb ğamharat al-amtāl, Bd. 1, S. 257, Nihāyat al-arab fī funūn aladab, Bd. 1, S. 385) vor.

${ }^{554}$ Im arabischen Original steht an dieser Stelle (Mağmū ${ }^{`}$ rasā’il muwaḥhidìya, S. 202) „,bi-alsinatin luddin“, d. h. „mit streitsüchtigen Zungen“. Sofern hier kein Druckfehler vorliegt, ist nicht auszuschließen, dass mit dieser Bezeichnung Lanzen gemeint sind, mit welchen sich die Belagerten gegen die Angreifer zur Wehr setzten. Denn der Vergleich der Schneiden von Speerspitzen mit dem scharfen Zungenrand der Schlangen geht z. B. auch aus dem folgenden Zitat hervor: „burūğ min al-hatịy fīhā kawākibun lahā min qulūb al-muğrimīn manāzilu [...] ka-anna šad̄ā aṭāfihā idِ taraffa'at šad̄ā alsun alḥaiyāt ḥina tuṣāwilu“ (Kitāb at-tašbīhāt, S. 200), wobei „šad̄ā“ im arabischen Kommentar mit ,al-ḥadd wa-'l-hidda“ erklärt wird.
} 
zogen Blindheit der Rechtleitung vor und überschritten in unüberbietbarer Weise das Maß darin, sich durch ihre hohen Mauern täuschen $\mathrm{zu}$ lassen und auf die unüberbrückbaren Umfassungsgräben zu vertrauen. Trotz alledem ließ man ihnen die Behandlung zuteil werden, die diese große (almohadische) Sache immer zuteil werden zu lassen pflegt: Man mahnte sie (vor dem militärischen Vorgehen gegen sie) dazu, von ihrem Handeln Abstand zu nehmen, man rief sie dazu auf, den rechten Weg zu beschreiten, und man ließ ihnen gegenüber derartige Milde walten und sicherte ihnen in einer solchen Weise ihre körperliche Unversehrtheit sowie die ihres Besitzes und ihrer Familienangehörigen zu, dass dies die Gläubigen mit Freude und die unumstößliche Gewissheit Besitzende mit Behagen erfüllt sowie die Gefügigen und die Folgsamen erquickt haben würde. Doch [unklar ${ }^{555}$ ], ihre wesenlose Hoffnung verleitete und verführte sie und ihr Trotz behielt die Oberhand über ihr Urteilsvermögen, da sie böse waren. So verharrten sie weiterhin in ihrem Aufbegehren und in ihrer Widerspenstigkeit und warfen ihre Schlüssel und Stricke ${ }^{556}$ ihrem sie missleitenden Verführer und ihrem Satan zu (d. h. folgten ergeben dem Satan).

Wir unsererseits ersparten den Almohaden - Gott möge ihnen Mächtigkeit verleihen die Mühe, gegen diese Elenden zu kämpfen, und erachteten ihr Leben für zu wertvoll, als dass wir sie diese Frevler bekriegen ließen. Statt dessen gelangten wir zu der Überzeugung, dass der Einsatz von zusammenbaubaren Belagerungsmaschinen gegen diese Feinde größere Wirkung dabei entfalten würde, die Belagerten zu zermürben und sie niederzuzwingen, und mit Gottes Hilfe zu ihrer rascheren Vernichtung und Ausmerzung führen würde. Also machte man sich daran, den Aufenthalt der Almohaden - Gott möge ihnen Mächtigkeit verleihen - vorzubereiten, nämlich Wege sowie Pfade und Gänge zu sichern und gegen alle eventuellen Unwägbarkeiten (wörtl.

\footnotetext{
555 An dieser Stelle (Mağmū' rasāìil muwaḥhidīya, S. 203) lautet der arabische Satz „fa-aṣammahum al'ain wa-a'māhum"?

${ }^{556}$ Der Gebrauch des Wortes ,ašṭān“ im arabischen Satz an dieser Stelle (Mağmūc rasāiil muwaḥhidīya, S. 203) „fa-alqaū bi-maqālīdihim wa-aštānihim ilā muğwīhim al-muḍill wa-šaitānihim“ mutet auf den ersten Blick etwas merkwürdig an. Im arabischsprachigen Schrifttum des Mittelalters ist die Vorstellung nicht selten, das Bekunden bestimmter Gefühle, Einstellungen sowie das Erflehen von Gunsterweisen erfolge dadurch, dass jemand - so wörtlich - die Hand oder den Hals eines Gefühls, einer Einstellung usw. ausstreckt. Siehe hierzu die Belege im Kapitel „Gefühle (Gefühlsbezeigungen, Empfindungen)“ im Anhang 2. Was das eingangs angeführte Zitat anbelangt, so ist es möglich, dass ,aštān“ in diesem Kontext die Bedeutung „Hände“ bzw. „Arme“ hat, denn in eben dieser Bedeutung kommt auch das Synonym von ,aštān“, nämlich ,,asbāb“, im folgenden Zitat vor: „wa-'qtahamū (aiy al-muwaḥhidūn) assitāra 'alaihim (aiy 'alā ahl Gafṣa) wa-dahulūhā 'anwatan 'alā șudūrihim [...] wa-'aḍ̣athum al-ḥarb hunāk bi-anyābihā fa-maddat al-ḥutūf 'alaihim bi-asbābihā'“ (Mağmū' rasā'il muwaḥhidìya, S. 108) - hier ist die Bedeutung „Hände“ bzw. „Arme“ gemeint, da die genannten Todesgeschicke sowie Unheile allgemein früher als Lebewesen aufgefasst und mit den den Tieren eigenen Körperteilen wie Armen, Klauen oder Reißzähnen ausgestattet wurden. Vor dem Hintergrund ist es möglich, dass durch den Gebrauch von „aštān" die Feinde der Almohaden auf die gleiche Stufe mit den Unheilen gestellt werden.
} 
Weghindernisse und unheilvolle Vorfälle), vor welchen sich jeder Reisende (wörtl. der Gehende und der Kommende) fürchtet, Vorkehrungen zu treffen. Und so wurden (den Almohaden) reichlich $[\ldots]^{557}$ von überall her zuteil, Lebens- und Nahrungsmittel standen ihnen durch das Hineilen des Hineilenden und das Hinbringen des Hinbringenden im Überfluss zur Verfügung und die Almohaden - Gott möge ihnen Mächtigkeit verleihen - entbehrten nicht aller Annehmlichkeiten des Lebens, eines unaufhörlichen Flusses an Kost und der äußeren Umstände, die für sie alles Wohl enthielten. Gott ließ dabei den Lohn für ihr Fasten und Fastenbrechen um ein Mehrfaches wachsen. Die Almohaden ihrerseits hielten die Zeit ihres Grenzdienstes (vor der belagerten Festung) für die vortrefflichste Zeit ihres Lebens und erachteten sie für die vortrefflichsten Werke und nützlichsten Schätze bei Gott ${ }^{558}$ - gepriesen sei Er -. Man fing damit an, die genannten Belagerungsmaschinen in all ihren unterschiedlichen Arten und Formen zusammenzubauen, man brachte ihre jeweiligen Kampfeigenschaften zur größtmöglichen Entfaltung und war darum bemüht, dass diese Belagerungsmaschinen die vollkommenste Einsatzbereitschaft aufwiesen, die sie jemals gehabt hatten. Und so stand eine solch immense Anzahl dieser Kriegsgeräte schließlich zum Einsatz bereit, dass sie weit über alle Vermutung darüber, wie viele davon möglich gewesen wären, hinausging. Ihre Gesamtheit wurde in nicht überbietbarer Schnelligkeit und Raschheit fertig gestellt, und der Zweck, den man mit dem Zusammenbau dieser Kriegsmaschinen verfolgt hatte, sollte - wie immer - mit der Sieghaftigkeit dieser glückhaften (almohadischen) einhergehen.

Während der Arbeiten (an den genannten Kriegsgeräten) dachten wir, dass sich diese Meuterer besinnen, von ihrem Irrtum ablassen und ihm abschwören würden sowie sich von ihrem Befangensein in der Missleitung und ihrem Verharren in der Unwissenheit abbringen und zur Reue bewegen lassen könnten. Denn dann würde man ihnen allen die umfassende Milde erwiesen haben und die sich auf ihre Gesamtheit erstreckende Gnade würde ihren heftigen Durst mit dem Wasser des ununterbrochen herabströmenden und reichlich niederprasselnden Regens gelöscht haben. Doch stattdessen wurden sie von Übermut $^{559}$ und Dünkel übermannt, die sie dem Verderben preisgeben sollten. Und

\footnotetext{
557 Hier (Mağmūe rasā’il muwaḥhidīya, S. 203) verweist E. Lèvi-Provençal darauf, dass im handschriftlichen Original an dieser Stelle circa die Hälfte der Zeile fehlt.

${ }_{558}$ Wahrscheinlich eine Anspielung auf Sure 3, Vers 171 ,Sie sind froh über Gottes Gnade und Huld und (darüber) dass Gott die Gläubigen nicht um ihren Lohn bringt".

559 Der arabische Text lautet hier (Mağmū' rasā'il muwaḥhidīya, S. 204) „fa-rāna 'alā qulūbihim mā ardāhum min al-ihmāl wa-'l-iğtirār", wobei ,ihmāl“" eher „Verschmähung der von den Almohaden gewährten Frist bzw. der Möglichkeit, von der geschilderten Gehorsamsaufkündigung abzulassen“"
} 
wenn über jemanden das Urteil, ihm werde die Höllenpein zuteil, ausgesprochen wurde, kannst du etwa jemanden aus dem Feuer befreien? ${ }^{560}$ Ihre Verirrung und Kopflosigkeit nahmen zu, sie klammerten sich mit noch größerer Kraft an ihrer Missleitung fest und missachteten und verschmähten die ihnen sowohl im Diesseits als auch im Jenseits zufallenden Vorteile noch mehr. Dabei drängte die Verheißung Gottes darauf, diese Elenden für das, was sie verübt hatten, auszutilgen und sie das Unbekömmliche der Sünden, welche sie sich aufgebürdet haben und sich haben zuschulden kommen lassen, kosten zu lassen. Sie wähnten dabei, ihre Burgen könnten sie gegen Gott feien, doch $[\ldots]^{561}$.

Derweil hat man mit dem Einsatz der erwähnten Kriegsmaschinen begonnen, und es wurden Katapulte in Stellung gebracht, die so gewaltig waren, dass deren felsblockartige Wurfgeschosse (selbst) einen Berggipfel zu zermalmen imstande waren und jeder, der von ihnen getroffen wurde, weder genesen noch sich erholen konnte. Alltäglich rissen diese Wurfgeschosse mehrere der belagerten Feinde in den Tod und zerstörten ganze Teile der Stadtmauer. Die aufgefahrenen Wurfgeschütze ließen über die Belagerten die ewige Pein ${ }^{562}$ und Feuersbrunst niedergehen und von ihnen her trafen diese Feinde Blitzschläge, deren Last an todbringendem Unheil ihre ruchlosen Seelen und feigen Herzen ${ }^{563}$ nicht $\mathrm{zu}$ tragen vermochten. Eine gewisse Zeitlang fügten diese Katapulte den Belagerten Verluste zu, rafften die Beschützer (der Festung) fort und brachten die (darin befindlichen) Gebäude zum Einsturz. Die belagerten Elenden wurden unaufhörlich von allen Seiten her (durch die Wurfgeschütze) beschossen, und sie (d. h. die Wurfgeschütze) haben Abschnitte der (niedrigen) Umfassungsmauer (arab.: al-ǧidār ${ }^{564}$ ) dem Erdboden gleichgemacht, eine klaffende Bresche in die Stadtmauer (arab.: al-aswār ${ }^{565}$ ) geschlagen, eine Anzahl von hochragenden Türmen sowie Häusern zerstört und den Belagerten ihre (bevorstehenden) Vernichtung und Ausmerzung angekündigt. Das Ausmaß der Zerstörung, welche die genannten

bedeutet. Darüber hinaus bildet der erste Teil des angeführten arabischen Satzes den Anfang von Vers 83, Sure 14 des Korans.

${ }^{560}$ Vers 39, Sure 19 des Korans.

561 An dieser Stelle (Mağmūc rasā’il muwaḥhidìya, S. 204) fehlen laut E. Lèvi-Provençal im handschriftlichen Original infolge eines Risses zwei oder drei Wörter.

562 Siehe Vers 37, Sure 9 des Korans.

563 „Qulūbuhum al-manḥūba“ an dieser Stelle (Mağmū` rasā’il muwaḥhidīya, S. 204) müsste höchstwahrscheinlich zu ,qulūbuhum al-manhūba“ korrigiert werden.

564 Der Abgleich dieser Passage mit dem weiter unten wiedergegebenen und u. a. auf diesen Belagerungsverlauf Bezug nehmenden Bericht Ibn-'Idārīs ergibt, dass der Letztere diese niedrige Mauer als ,,as-sitāra as-suflā" bezeichnet.

${ }^{565}$ Sowohl mit „sūr“ als auch mit dessen Plural „,aswār“ wird im Brief die Stadtmauer Gafsas bezeichnet, wie es eindeutig aus dem letzten Abschnitt des Briefes hervorgeht (Mağmū‘ rasā’il muwaḥhidīya, S. 209 f.). 
Wurfgeschütze anrichteten, und ihre Wirksamkeit waren von einer einzigartigen, in den verstrichenen Zeiten nicht gekannten Gewaltigkeit. Dieses Ausmaß und diese Wirksamkeit waren ausschließlich ${ }^{566}$ durch die segensreiche Kraft dieser (almohadischen) Sache möglich, die in ihrer Erneuerung und in ihrem Wachstum beständig ist und deren Entfaltung sowie deren Unternehmungen sowohl im einzelnen als im großen von der Obsorge Gottes - gepriesen sei Er - um diese (almohadische) Sache zeugen sowie davon, dass Gott dieser Sache bei ihren Feldzügen beisteht, ihre Entscheidungen die richtigen sein lässt, ihren Anhängern zum Obsieg verhilft und ihrem Banner den Sieg verleiht.

Als einer der Belagerungstürme fertig und einsatzfähig war, als man sie mit verschiedenen Waffen umgürtet und versehen sowie mit unterschiedlichen sackleinenen Schutztüchern ${ }^{567}$ behängt und bedeckt hatte, wurde er an die Festung herangerückt, um den Graben aufzufüllen und so den Weg (der Almohaden) zur Vernichtung und Auslöschung dieser Feinde zu ebnen. Dabei brachten die Almohaden - Gott möge ihnen Mächtigkeit verleihen - auf den ersten Anhieb den Umfassungsgraben und die Stadtmauer in ihre Gewalt ${ }^{568}$, und Gott ließ die Annahme und Vermutung der Belagerten, sie seien unbezwingbar, sich als nichtig erweisen. Da ließ der Tod die Feinde das Bittere seiner Ereilung kosten und das in aller Heftigkeit entbrannte Gefecht ließ sie das zermalmende Sichdrehen des Mahlsteins samt seinem Auffangbeutel ${ }^{569}$ erfahren. Das entbrannte Gefecht führte ihnen in aller Deutlichkeit die (schmerzliche) Wirklichkeit ihrer Austilgung und Ausmerzung vor Augen und gab ihnen die NichtZuträglichkeit ihrer Weiden der Verirrung ${ }^{570}$ und die Unrühmlichkeit dessen, worin diese Weiden letztlich enden, kund. Als der gesegnete (erwähnte) Turm an die Belagerten mühelos herangerückt wurde, überdeckte er die Feinde vollends und war einem Adler gleich, der seine langen geschmeidigen Fittiche ausgebreitet hatte. Dieser

\footnotetext{
${ }^{566}$ Der arabische Satz an dieser Stelle (Mağmūc rasā’il muwạ̣hidīya, S. 205) lautet „wa-kāna lahā min 'aẓim al-atar wa-karīm al-ġanā' mā lam yu'had fī sālif al-azmān wa-'l-ānā' wa-lā tayassara bi-barakat alamr al-mutțarid at-tağaddud wa-'n-namā' ad-dāll bi-tașarruf hāāātihī wa-tațauwur maāhuidihī fī ğuz'iyātihī wa-kulliyătihī ‘alā mā li-Allāh tacālā bihī min al-i'tinā“‘, nach „,wa-lā tayassara“ müsste „,illā“ stehen, denn sonst wäre alles, was auf ,ausschließlich“ folgt, verneint.

${ }^{567}$ Im arabischen Text wird an dieser Stelle (Mağmū‘ rasā’il muwaḥhidīya, S. 205) ein durch die Konsonanten „Hुā', Yā̄, Sīn“ konstituiertes Wort gebraucht. Die Annahme liegt nahe, dass damit eigentlich, haiš‘ gemeint ist.

568 Diese Behauptung steht im Widerspruch zur Schilderung des weiteren Verlaufs des Kampfes, denn erst nach der Auffüllung des Stadtgrabens gelingt es den Almohaden später, lediglich zum vorderen Außenbereich der Festung vorzudringen.

569 Zitat aus dem bekannten Gedicht von Zuhair Ibn-Abī-Sulmā (circa 530-627). Siehe dazu „Šarh alqașā̄id as-sab` aṭ-ṭiwāl al-ğāhilīyāt"“ (S. 268).

${ }_{570}$ Siehe hierzu die Belege im Kapitel „Seiten und die geographische Verfasstheit von seelischen und emotionalen Zuständen“ im Anhang 2.
} 
Adler stürzte daraufhin auf sie hinab und der Himmel über ihnen erfüllte sich mit Getöse (wörtl. Gebrüll ${ }^{571}$ ). Von diesem Belagerungsturm aus wurde auf sie der augenblicklich eintretende Tod und das übelste aller Unheile hinabgeschnellt, und es verhielt sich mit dieser Festung und dem Turm so wie mit einem Jagdfalken und der $\left[\right.$ unklar $^{572}$ ], über welcher der Jagdfalke laut pfeifend rüttelte. Beim Anblick des erwähnten Belagerungsturms blieb bei den Widersachern der Almohaden kein Zweifel mehr darüber bestehen, dass sie dem Tode geweiht waren und keinerlei Hoffnung auf Überleben hatten und dass dieser Turm die wenigen Lebensfunken und die letzten Zuckungen ${ }^{573}$, welche in ihnen nach dem Beschuss mit den Wurfgeschützen noch übrig geblieben waren, endgültig zum Erlöschen bringen würde. Den Almohaden - Gott möge ihnen Mächtigkeit verleihen - gelang es, als eine Art Einleitung zum durch diesen Turm den Belagerten Bevorstehenden den Graben auf das Niveau der Erdoberfläche aufzufüllen, sie drangen daraufhin zur der Stadt vorgelagerten niedrigen Umfassungsmauer (arab.: as-sitāra ${ }^{574}$ ) vor und steckten den Turm von Ibn-Zawāğ, welcher Krone und Kranz dieser Stadt bildet, oben in Brand. Da entbrannten in diesen Feinden lodernd und lichterloh die Flammen des Entsetzens und der Furcht ${ }^{575}$, und es vollzog sich durch Gottes Gnade rasch der (von Ihm gewährte) Sieg über sie. Als die Belagerten erkannten, dass die Wogen des unabwendbaren Strafgerichtes Gottes sich um sie herum aufgetürmt hatten ${ }^{576}$ (wörtl. dass der Baldachin des Strafgerichtes Gottes sie von allen Seiten umringt) und dessen (d. h. des Strafgerichtes) Schlingen (wörtl. Halsketten) sich um ihren Hals gelegt haben, dass dessen schreckliche Geschehnisse und furchtbare Todesgeschicke sie ereilt haben, dass die todbringenden Donner- und Blitzschläge dieses Strafgerichtes sie mit furchtbaren Heimsuchungen und austilgenden

\footnotetext{
${ }^{571}$ Der arabische Satz an dieser Stelle (Mağmū' rasā'il muwaḥhidīya, S. 205) lautet „fa-raġā fauqahum saqf as-samā̄" Interessant ist in diesem Zusammenhang, dass in der andalusischen Dichtung das Geräusch, das beim Abschießen des Pfeiles erzeugt wurde, u. a. mit dem Gebrüll einer Kamelin verglichen werden konnte. Siehe hierzu ,al-Fitan wa-'l-hurūb“ (Bd. 3, S. 125).

572 An dieser Stelle (Mağmū' rasā’il muwahhịīìa, S. 205) steht im arabischen Text „,nabāt al-mā̄“?

${ }^{573} \mathrm{Im}$ arabischen Nebensatz an dieser Stelle (Mağmū' rasā’il muwaḥhidīya, S. 205) ,wa-annahū (aiy alburğ al-mubārak) yasta'șil mā as'arathū al-mağānīq fīhim min ramaq wa-ḡādarat min dimā'، ist m. E. nicht „dimā̄“ sondern ,damā̄" gemeint.

${ }^{574}$ Genau diese Bedeutung ist im folgenden Zitat: „yuhīt bi-hadā as-sūr (aiy bi-sūr Tarābulus) al-ān fasīl āhar aqșar minhū 'alā al-'āda fī dalik yusammūnahū as-sitāra“ (Riḥlat at-Tiğānī, S. 240) belegt. Dozy erklärt „sitāra“ u. a. mit „,mur extérieur, parapet, un mur faible qui couvre un homme“ (Supplément aux dictionnaires arabes, Bd. 1, S. 632).

${ }^{575}$ Die Intensität von Gefühlen wurde häufig anhand des Bildes vom Feuer zum Ausdruck gebracht. Siehe hierzu die im Kapitel „Gefühle (Gefühlsbezeigungen, Empfindungen)“ des Anhangs 2 zusammengetragenen Belege.

${ }^{576}$ Der arabische Satz an dieser Stelle (Mağmū' rasāìl muwaḥhidīya, S. 206) „wa-'indamā taḥaqqaqū anna aḥdat Allāh ar-rābīya aḥāta bihim surādiquhā" setzt sich aus zwei koranischen Zitaten zusammen: aus „fa-'așaū rasūl rabbihim fa-ahadahum ahdatan rābīyatan“ (Sure 69, Vers 10) und ,innā a'tadnā li-'zzāàimīn nā̀ran ahạța bihim surādiquhā"“ (Sure 18, Vers 29).
} 
Unheilen überdeckt haben und dass die schützenden Gräben und Mauern ihres unbezwingbaren Berges ihrer Gewalt entrissen worden waren, als sie also all dies erkannten, da beugten sie ihre Köpfe voller Unterwürfigkeit und Demut nieder, bekundeten ihre Reue und aufrichtige Gesinnung (gegenüber den Almohaden) und suchten ihr Heil in der Rückkehr zum Almohadentum. Es erschallte ihr lautes Rufen und Heischen, man möge ihre Reue annehmen, urplötzlich brachen sie kreischend in Bitten danach aus, man möge sich ihrer erbarmen und ihnen gegenüber Milde walten lassen $^{577}$, und laut schreiend und Hände ausstreckend erbaten sie von dieser mächtigen (almohadischen) Sache, ihnen Gnade zu erweisen, und erkannten, dass die alles umfassende Gnade dieser almohadischen Sache größer ist als die Sünden ihrer Sünder und Missetaten ihrer Missetäter. Und so ließ man den Belagerten ihre (d. h. der almohadischen Sache) Gnade widerfahren, welche so groß ist, dass sie von all jenen erfahren werden kann, die um Verzeihung bittend Buße tun, es wurde ihnen allen Vergebung zuteil, welcher alle teilhaftig werden können, die sich reumütig (dem Almohadentum) wieder zuwenden, und es erstreckte sich auf sie ihre (d. h. der almohadischen Sache) Gunst, deren Schatten für diejenigen, welche sie suchen und sie begehren $^{578}$, niemals schrumpfen. Man sicherte ihnen die vollkommene körperliche Unversehrtheit zu, die (nach dem Zustand der Benommenheit, in welchem sie sich durch die erwähnten Entsetzen und Furcht beim Beschuss befanden) ihre Körper und ihre hinterlistigen Seelen hat wieder zu sich kommen lassen, sie ihr von Unstetheit beherrschtes Urteilsvermögen und ihr der Missleitung verfallenes Einsichtsvermögen wiedererlangen ließ und sie begreifen machte, dass Milde und Gnade (gegenüber besiegten Feinden) dieser erhabenen (almohadischen) Botschaft eigen sind, auch dann, wenn sie (ihre Feinde) packt und wenn sie obsiegt ${ }^{579}$.

Diese Zusicherung der körperlichen Unversehrtheit wurde der Gesamtheit der asiatischen Söldner und ihrer Anhänger sowie allen Bewohnern und der Allgemeinheit Gafsas gewährt, sie schloss ebenfalls sämtliche Stammesangehörigen und Landbewohner ein, die (zu diesem Zeitpunkt) dort waren. Davon ausgenommen wurden

\footnotetext{
${ }^{577}$ Das im arabischen Satz an dieser Stelle (Mağmūc rasā’il muwaḥhidīya, S. 206) „wa-ahalla bi-'1istirhām wa-'l-istiṣfāḥ dā'īhim wa-munādīhim“ gebrauchte Verb ,ahalla“ drückt genau genommen das erste Schreien des Neugeborenen aus, so dass durch den Gebrauch dieses Verbs den Gegnern der Almohaden implizit ihre Mündigkeit abgesprochen wird.

${ }^{578}$ Im arabischen Satz an dieser Stelle (Mağmū` rasā'il muwaḥhidīya, S. 206) „wa-ġamarahum mannuhū allad̄i lā yataqallas li-mustafyi’ zā'ib afyā’uhū wa-ẓilāluhū““ müsste vermutllich „,zācib“ zu „rāgib“ korrigiert werden.

${ }^{579}$ Im letzten Teil des arabischen Satzes an dieser Stelle (Mağmūc rasā’il muwaḥhidīya, S. 206) „wa'arrafathum anna šīmat hadihī ad-da'wa al-'alīya al-ihsān wa-'l-isğāḥ wa-in kānat al-mudrika wa-'l-ḡālīya“" müsste vermutlich nicht, ,ḡālīya“, sondern ,g̈āliba“ gelesen werden.
} 
jedoch die abgefallenen Abtrünnigen und die Irrenden Mallorcas. Diese Mallorquiner hatten sich ehemals mit ihnen (d. h. mit den asiatischen Söldnern) zusammengerottet und verbündet, und sie hatten sich mit ihnen $\mathrm{zu}$ einer Gemeinschaft zusammengeschlossen. Als sie (d. h. diejenigen, denen die körperliche Unversehrtheit zugesichert wurde) für sich die genannte Zusicherung erbaten und sie vereinbarten, brachten sie auch die Zusicherung der körperlichen Unversehrtheit für die Mallorquiner zur Sprache. Man erwiderte ihnen jedoch, dass ihnen selbst das Leben nur dann geschenkt werde, wenn sie die erwähnten Mallorquiner auslieferten, dass die Gnade dieser großen (almohadischen) Sache den genannten Abtrünnigen aufgrund des Unmaßes ihrer Freveltaten nicht zuteil werden könne und dass das wahrhafte Urteil Gottes es sei, dass der Genannten Gliedmaßen zerfleischt und ihre Köpfe zermalmt werden sollen. Als also den Bittenden jegliche Zweifel diesbezüglich benommen wurden, lieferten sie ihre Gefährten aus, sagten sich von ihnen los und ergriffen die Möglichkeit, ihr flackerndes Lebenslicht weiterflackern zu lassen durch die Übergabe dieser mallorquinischen Elenden. Was diese Letzteren betrifft, so waren sie eine große Menge, überaus zahlreiche Schar und dichte Masse. Nach diesem fielen die Almohaden - Gott möge ihnen Mächtigkeit verleihen - in einer solchen Weise über sie her, dass sie (durch das Ungestüme ihres Herfallens über diese Feinde) ihren Rachedurst gestillt und die Glut ihres entbrannten Zornes gelöscht haben sowie ihre Belohnung haben zunehmen, ihre Freude sich vervielfachen und ihren Frohsein anschwellen lassen. Und auf diese Weise ist diese unbesiegbare Festung, das wehrhafte und unbezwingbare Bollwerk dieser Landstriche und dieses störrige Reittier ${ }^{580}$, das sich weder von einem Bändiger zur Gefügigkeit zwingen lässt noch sich zahm zeigt, auf diese Weise ist also diese Festung den Almohaden - Gott möge ihnen Mächtigkeit verleihen - wieder botmäßig geworden. Ihre (d. h. Gafsas) Mauern reichen in den Himmel hinein, die sie Anstürmenden vermögen ihren Seiten nichts abzutrotzen, ihre hochragenden Türme und Mauerzinnen berühren sich mit den Sternbildern und sie übertrifft an ihrer Unnahbarkeit alle anderen Burgen. Diese Festung hat für jede erdenkbare Art der Wehrhaftigkeit die jeweilige (konkrete) Entsprechung, die man in Worte zu fassen nicht imstande ist, und Form. Hätte ein Dürstender in ihr seinen Durst stillen wollen, so brauchte er lediglich seine Hand auszustrecken, und schon hätte er das kristallklare Wasser direkt aus den Regenwolken geschöpft. Ohne die segensreiche Kraft dieser (almohadischen) Sache, die (d. h. almohadische Sache) jeden Widerstand zu brechen vermag, hätte die Störrigkeit

${ }^{580}$ In den almohadischen sowie nasridischen Briefen ist der Vergleich einer Festung mit einem störrigen 
dieses Bollwerkes niemals überwunden noch seine Widerspenstigkeit gezähmt werden können und ohne diese segensreiche Kraft wären diejenigen, die dieses Bollwerkes Gipfel erklommen und sich hinter seinen hohen Mauern verschanzt hatten, nie in den Staub der (umliegenden) flachen kahlen Sandböden und der weiten Ebenen hinabgestoßen worden. Den Menschen waren die Schutzmauer dieser Stadt und ihr Graben schon seit lange verstrichenen Zeiten Anlass für ihren Übermut und sie (d. h. die genannten Schutzmauer und Graben) hatten den Hochmut der Bewohner Gafsas über lange Jahre und viele Jahrzehnte hinweg genährt, so dass die Gesamtheit dieser Einwohnerschaft im Laufe der Zeit in die irrtümliche Vorstellung verfiel, dass ihre Stadt in irgendeiner Weise zu bekämpfen nicht möglich sei, dass die Hoffnung auf ihre Bezwingung sich nie erfülle und dass die Absicht sie zu besiegen nimmer verwirklicht werden könne. Doch Gott offenbarte an Gafsa solche Seiner mächtigen (almohadischen) Sache eigenen Wunderzeichen, dass dank ihnen die Zuversicht, diese Stadt werde nicht bezwungen, als unbegründet und der Ruf Gafsas, uneinnehmbar zu sein, als Schall und Rauch sich erwiesen haben. Gott hat vielmehr sich bewahrheiten lassen, dass diese Botschaft des Mahdi auf ihrem Weg zum Sieg (wörtl. zum Gewünschten) keinen ernstzunehmenden Hindernissen, selbst wenn sie gewaltig sein sollten, noch abwehrenden Schirmen begegnet. Die Einnahme dieser Festung stellte etwas derart Außergewöhnliches dar, dass es die Festigung des Glaubens von denjenigen, deren Glaubenskraft nachgelassen hatte, bewirkte und zur Folge hatte. Diejenigen, die im Besitz der Sehkraft und des Einsichtsvermögens sind, gelangten zur unumstößlichen Überzeugung, dass die Unternehmungen dieser mächtigen (almohadischen) Sache des Lehrreichen nicht entbehren sowie immer das Erwachen und Wiedererlangen des Einsichtsvermögens bewirken und dass sie über sich abwechselnde Zeitabschnitte und einander nachfolgende Zeitspannen hinweg die Verständigen erwachen und sich besinnen lassen.

Mit der Einnahme Gafsas fand diese gesegnete Unternehmung ihren vortrefflichen Abschluss, es hat sich in ihrem Verlauf offenbart und ist augenscheinlich geworden das großartige Eingreifen Gottes zugunsten Seiner Streiter, denen Er Sieghaftigkeit schenkt, und jeder Gläubige ersah und erkannte die gnadenreiche Obsorge Gottes um sie (d. h. Seine Streiter). In all diesen Gegenden ist niemand mehr von den asiatischen Söldnern geblieben, der es noch vermocht hätte, die Glut der Meuterei zu entfachen oder sie anzuzetteln, denn dieser gesegnete Feldzug hat am Tage des größten Sieges ihre 
Tapferen und Angesehenen unwiederbringlich fortgerafft und durch die Bezwingung von Gabès und Gafsa ihre zäh Kämpfenden und Heldenmutigen bezwungen. All ihre Massen, ihre Mutigen und Tapferen wurden zum Eigentum ${ }^{581}$ der Almohaden - Gott möge ihnen Mächtigkeit verleihen - und zu ihren Sklaven, und es sammelte sich bei ihnen (d. h. bei den Almohaden) zahlreiche Schar, beträchtliche Menge und gewaltige, unendliche Anzahl dieser Söldner. Gott hat allen Meutereien dieser Landstriche ein endgültiges Ende gesetzt ${ }^{582}$ und Er hat die Lügen und die Verzerrungen zunichte gemacht, mit welchen der aufbegehrende Irrende ${ }^{583}$ in diesen Gegenden die Schwachen lange täuschen konnte. Das lichte Zeichen des Wahren aber und sein strahlend heller Morgen sind jedem, der Augen und Herz hat, augenscheinlich geworden. Das Geradebiegen (d. h. die Beseitigung sämtlicher Erscheinungsformen des Aufbegehrens gegen die Almohaden) hat Sicherheit über die Gesamtheit dieser Gegenden ausgebreitet, dieser Landstriche Krummes gerade gemacht (d. h. Gerechtigkeit dort wieder obwaltend gemacht), die erwähnten Gebiete von der beschwerlichen und drückenden Last der Heimsuchungen befreit und in ihnen ihren üblichen Zustand des Friedens und der Ruhe wiederhergestellt. Im Verlaufe des im obigen Geschilderten stürmten eure Brüder, die Almohaden - Gott möge ihnen Mächtigkeit verleihen - derart gegen ihre Feinde an, sie eilten in einer solchen Weise hin, ihre Widersacher mit dem Schwert in der Hand zu bekämpfen und ihnen (auf dem Schlachtfeld) entgegenzutreten, und dürsteten so sehr danach, ihre Gegner entseelt zu Boden sinken zu lassen ${ }^{584}$ und ihr Blut zu vergießen, dass dies alles der Lauterkeit ihrer Absichten, der Unbescholtenheit ihrer Vorsätze und ihrer inneren Beweggründe sowie ihrer absoluten Verinnerlichung des Gehorsams (wörtl. dem Gleichsein ihres Inwendigen und ihres Auswendigen in Bezug auf den Gehorsam) gegenüber Gott - gepriesen sei Er - entsprach. Und Gott gepriesen sei Er - wird die Belohnung für ihr selbstloses Streiten sicher aufbewahren, Er wird das, was sie im Laufe dieser gesegneten Unternehmung an ihren (im Jenseits) Gewinn bringenden Taten vollbrachten, ihnen zum Nutzen gereichen sowie ihnen die

\footnotetext{
${ }^{581}$ Mit dem hier gebrauchten „hawal“ bezeichnet man vor allem den Besitz an Sklaven.

${ }^{582} \mathrm{Im}$ arabischen Satz an dieser Stelle (Mağmū' rasāìil muwaḥhidīya, S. 208), „wa-ạhaba Allāh kull mā kāna bi-hadihī al-bilād min atar al-fitan wa-ġain“ ist sehr wahrscheinlich nicht „ǵ̀in“, sondern ,'ain“" gemeint, da ,atar" und ,'ain" häufig zusammen vorkommen und zum Ausdruck bringen, dass das, worauf sie bezogen werden, in seiner Ganzheit einer bestimmten - sehr oft auf sein Verschwinden hinauslaufenden - Wirkung unterliegt.

${ }^{583}$ Mit an dieser Stelle (Mağmūc rasā'il muwaḥhidīya, S. 208) gebrauchten „'awīyuhā al-marīd“ ist vermutlich ,g̉awīyuhā al-marīd“ gemeint; das Adjektiv „marīd“ ist koranisch (s. Sure 22, Vers 3; Sure 4, Ver 117) geprägt.

${ }^{584}$ Im arabischen Satz an dieser Stelle (Mağmūc rasā’il muwaḥhidīya, S. 209), ,wa-ẓahara min ihwānikum al-muwaḥhidīn [...] min [...] at-ta'aț̣uš ilā irhāq nufūsihim (aì nufūs a'dā’ihim) wa-irāqat dimā'ihim [...]“, ist wahrscheinlich ,izhāq“, d. h. ,,jemanden erschlagen“, statt ,irhāq“ gemeint.
} 
Früchte ihres erfolgreichen Strebens und ihrer frommen Werke sowohl in Diesseits als auch in Jenseits zuteil werden lassen, durch Seine Gnade und Freigebigkeit.

Wir haben euch - Gott möge euch den Erfolg gewähren - diese Siegesmeldungen und diese sowohl in Bezug auf ihren Anfang als auch auf ihren Abschluss gewaltigen Siege mitgeteilt, auf dass eure Freude über sie groß wird, auf dass ihr unaufhörlich Gott gepriesen sei Er - für Seine umfassende Güte und Seine überreichliche Gnade lobpreist und Ihn - Preis sei Ihm - darum bittet, euch das Danken für Seine Hulderweise, welche zu würdigen nur das überschwängliche Loben eines Lobenden und das gesamte Danken eines Dankenden vermögen, und für Seine Gnadenbezeigungen, die aufzuzählen oder zu beziffern weder ein Zählender noch ein Beziffernder jemals imstande sind, einzugeben. Und Gott - gepriesen sei Er - wird euch zu solchen (Seiner Anbeter) machen, die durch das vollkommene Loben Seine überflutende Güte und Seine fortwährende Freigebigkeit fortbestehen lassen, durch Seine Gnade ${ }^{585}$. Es gibt keinen Gott außer Ihm.

Die Mauern dieser Stadt - Gott möge euch den Erfolg zuteil werden lassen - bescherten ihren Bewohnern seit jeher (nichts anderes als) Kümmernis, sie brachten ihre Bevölkerung (lediglich) in Versuchung und führten (nur) dazu, dass sie von jedem Unruhestifter, der auf Meuterei und Schutz hinter ihren Mauern sann, heimgesucht wurden. Doch so manche Wonne birgt Widerwärtiges in sich, so manches Wohlbefinden kann sich zu nicht nachlassendem Schmerz und Gebrechen wandeln und so mancher Zustand, welchen man das Leben wähnt, kann sich in Wirklichkeit als Tod erweisen. Deswegen beschlossen die Almohaden - Gott möge ihnen Mächtigkeit verleihen - einmütig, die Bewohner Gafsas von dem Übel ihrer Mauern zu erlösen, dem unersprießlichen und schadenverursachenden Einfluss dieser Mauern auf sie ein Ende zu setzen sowie sie (höchstwahrsch. Gafsa ${ }^{586}$ ) in Bezug auf die Festigung des Friedens in ihr und auf die Sicherung ihres Fortbestandes anderen Städten gleich zu machen. Also wiesen die Almohaden einem jeden ihrer Stämme jeweils einen Abschnitt der Mauer zu und verwandelten sie in einem oder gar weniger als einem Tage in ein wallendes Meer aus Sand. Und eines der größten Lehrbeispiele sowie eines der gewaltigsten Wunderzeichen dieser vornehmen (almohadischen) Sache war, dass die Schleifung der Mauern Gafsas binnen dieser genannten Zeit durchgeführt werden

\footnotetext{
585 Im arabischen Satz an dieser Stelle (Mağmū` rasā'il muwaḥhidīya, S. 209) „wa-Allāh tacālā yağ'alukum mimman istadāma bi-'š-šukr al-atamm dūna iḥsānihī as-sābig [...]“ handelt es sich bei ,dūna“ offensichtlich um einen Fehler und es wurde bei der Übersetzung übergangen.

${ }^{586}$ Dem weiteren Verlauf des Satzes nach müsste mit „,sie“ an dieser Stelle (Mağmūc rasā'il muwahhịidiya, S. 209 f.) Gafsa gemeint sein, wobei der Übergang von „die Mauern“ zu „Gafsa“ - auf beide wird im arabischen Text mit dem gleichen Personalsuffix ,hā"“ verwiesen - nahtlos ist.
} 
konnte, denn dies hätte man nicht einmal binnen sehr langer Zeit für möglich gehalten. Gott wird die Gesamtheit der Menschen (vor allem Übel) bewahren durch das (Missstände behebende) Walten dieser universalen und vollkommenen (almohadischen) Sache. Es gibt keinen Gott außer Ihm. Edler Friede, die Gnade Gottes und Seine Segen mögen euch zuteil werden.

Abgefasst am 14. Januar des Jahres 1188.

\subsection{Zusammenfassung der überlieferten Quellenzeugnisse}

Wie auch im Falle des analysierten Briefes Nr. 31 wird der Verlauf der Bezwingung Gafsas in den überlieferten arabischen Quellen wenn überhaupt, dann höchstens nur am Rande berücksichtigt. Im Folgenden werden die überlieferten Angaben zusammengefasst, die zwar aufgrund ihrer Kürze und Allgemeinheit für sich allein keine hinlängliche Basis für die Überprüfung der Aussagen des Briefes bieten, aber zu einem Ensemble zusammengefügt vor dem Hintergrund der Ausführungen des Briefes doch interessante Schlüsse erlauben. Wie bereits im Kapitel 6.2. erwähnt, vereint 'Abdal-Wāhid al-Marrākušī irrtümlicherweise die gesamte almohadische Unternehmung in Ifrīqīya mit derjenigen zur Befreiung Biğāyas im Jahr $1185 \mathrm{zu}$ einem Ereignis und berichtet nur sehr allgemein darüber, dass die Bevölkerung Gafsas bei dieser Expedition die almohadische Herrschaft für beendet erklärt und diejenige der Mallorquiener anerkannt habe. Bei der nachfolgenden Belagerung Gafsas hätten die Almohaden die Stadt erstürmt und viele ihrer Bewohner geschlachtet ${ }^{587}$. Ibn-al-Atîr zufolge habe alManșūr Gafsa drei Monate lang belagert und in dieser Zeit die Bäume des umliegenden Haines abholzen und das Umland zerstören lassen. Die asiatischen Söldner hätten dann um die Gewährung der Sicherheitsgarantie für sich und für die Bewohner der Stadt gebeten, und Yáqūb al-Manșūr habe dieser Bitte entsprochen. Die in Gafsa befindlichen Mallorquiner seien umgebracht und die Mauern der Stadt niedergerissen worden $^{588}$. Laut at-Tiğānī haben die Bewohner Gafsas infolge der zermürbenden Belagerung der Stadt al-Manșūr um Gnade gebeten, der ihnen ihre körperliche Unversehrtheit zugesichert hat mit der Auflage, dass sie über ihr gesamtes Eigentum nur noch als Pächter ${ }^{589}$ verfügen durften und dass alle in Gafsa befindlichen ortsfremden

\footnotetext{
${ }^{587}$ al-Mư̌̆ ǧib, S. 274.

588 al-Kāmil, Bd. 9, S. 171.

589 So müsste wohl der arabische Satz „fa-šārațahum 'alā ta'mīn ahl al-balad fī anfusihim hāṣṣatan watabaqqī amlākihim bi-aidīhim 'alā ḥukm al-musāqāat" (Riḥlat at-Tiğānī, S. 138) verstanden werden, wenn man von Freytags Erklärung für das Verb ,sāqā" ausgeht: , [...] Palmas vitesve colendas dedit alicui pro quadam proventus parte“ (Lexicon arabico-latinum, Bd. 2, S. 330), d. h. „den Weinberg für einen Teil des Ertrages verpachten“".
} 
Pesonen und Anhänger der almohadischen Gegner (arab.: al-ḥušŭ $d^{590}$ ) sich dem noch zu fällenden Urteil über sie fügen und sich ergeben sollten. Nachdem man diese Bedingungen akzeptiert hätte, hätten außer den Frauen alle die Stadt verlassen und sich vor ihren Mauern versammelt. Den Bewohnern Gafsas unter den Versammelten sei danach erlaubt worden, in die Stadt wieder zurückzukehren. Was die übrigen ortsfremden Personen, Anhänger der Gegner der Almohaden sowie die Versprengten betroffen habe, unter denen auch Ibrāhīm Ibn-Qarātqīn befunden habe, so seien sie vorerst eingesperrt worden. Nach der Verrichtung des Nachmittagsgebets habe alManșūr da, wo er bei der Belagerung immer gesessen hätte, Platz genommen, die Eingesperrten seien dann $\mathrm{zu}$ ihm gebracht worden und er habe ihre Schlachtung angeordnet $^{591}$. Differenziertere Angaben über die Gruppen, die nach dem Fall Gafsas verschont bzw. nicht verschont wurden, bietet indes Ibn-Haldūn, in dessen Werk zwei voneinander unabhängige Berichte über diese Ereignisse enthalten sind: Dem einen zufolge habe sich Gafsa einige Tage nach der Aufnahme der Belagerung ergeben, alManșūr habe den Stadtbewohnern und den arabischen Beduinen, die mit Qarāqūš verbündet waren, die Sicherheitsgarantie gewährt ${ }^{52}$ und die Mallorquiner sowie ihre Anhänger $^{593}$ umbringen lassen ${ }^{594}$; bei der zweiten Überlieferung wird darauf hingewiesen, dass nach dem Fall der Stadt die Anhänger der Banū-Ġānīya und Ibrāhīm Ibn-Qarātikīns hingerichtet worden seien. Den Einwohnern Gafsas sei ihre körperliche Unversehrtheit mit der Auflage zugesichert worden, dass sie über ihr Eigentum hätten nur noch als Pächter verfügen dürfen ${ }^{595}$.

Von den zusammengefassten Quellezeugnissen setzt sich der Bericht Ibn-'Idārīs aufgrund seiner Ausführlichkeit und Länge deutlich ab. Ihm liegt vermutlich auch dieses Mal die diesbezügliche Passage aus „al-Mann bi-'1-imāma“ zu Grunde, die Ibn'I bildet dieser wiedergegebene Text den mit Abstand ausführlichsten überlieferten Bericht und weist trotz der eindeutig proalmohadischen Gesinnung des Autors der Vorlage einige wesentliche und aufschlussreiche Abweichungen zu den Schilderungen

\footnotetext{
${ }^{590}$ Das Wort „ḥušŭd“ scheint in diesem Kontext speziell die Anhänger der Mallorquiner zu meinen, wie es aus den jeweiligen noch zu zitierenden Berichten von Ibn-Haldūn und Ibn- Id dārī hervorgehen wird.

${ }^{591}$ Rihlat at-Tiğānī, S. 138.

${ }^{592}$ Was implizit zu meinen scheint, dass auch die übrigen asiatischen Söldner, die zumindest mit Qarāqūš verbündet waren, verschont wurden.

${ }^{593}$ Diese Bedeutung von „hušūd“ geht aus dem Satz an dieser Stelle „wa-qatala sā’ir al-mulattamīn waman kāna ma'ahum min al-hušǔd".

${ }^{594}$ Kitāb al-'ibar, Bd. 6, S. 510.

${ }^{595}$ Kitāb al-'ibar, Bd. 6, S. 397. Az-Zarkašĩ gibt allem Anschein nach diesen Bericht Ibn Hualdūns verkürzt wieder (Tầrīh ad-daulatain, S. 16).
} 
des Briefes auf. In folgender Weise lässt sich der Bericht Ibn-'Idāāīs wiedergeben: Ya'qūb-al-Manșūr habe sein Lager anfangs dort aufschlagen lassen, wo auch sein Vater (d. h. Yūsuf Ibn-'Abd-al-Mu'min) bei der Belagerung Gafsas sein Lager hätte aufschlagen lassen. Später jedoch, als die nötigen Mittel eingetroffen seien und die Kampfbereitschaft der Almohaden, die Belagerten zu bekriegen, glühend geworden sei, habe er an einer anderen Stelle Position bezogen. Dort sei für ihn ein Beobachtungsturm aus Holz errichtet worden, von dem aus er das Schlachtgeschehen und die Arbeiten im Lager der Almohaden habe überblicken können. Dann habe man die gesamten Wurfgeschütze der Almohaden rund um die Stadt dicht nebeneinander aufgestellt und mit dem Beschuss Gafsas begonnen, der den Belagerten große Verlüste zugefügt habe. Bei diesen Wurfgeschützen habe es sich um die gewaltigsten und wirksamsten gehandelt, die verfügbar gewesen seien. Unmengen von Wurfgeschossen seien gegen die Stadtmauer geschleudert worden bis sie in aufstiebenden feinen Staub verwandelt und samt der (die Stadt umgebenden und der Stadtmauer vorgelagerten) niedrigen Mauer (arab.: as-sitāra) dem Erdboden gleich gemacht worden sei ${ }^{597}$. Danach habe man einen aus sieben Schichten bestehenden und weit in die Höhe ragenden Belagerungsturm errichtet und mit den almohadischen Kriegern und mit Kriegsgeräten beladen. Er sei dann fast geräuschlos in Bewegung gesetzt worden und sei gleich einer Schlange dahingeglitten. Er sei geradewegs auf sein Ziel zubewegt worden, ohne dabei zu holpern noch in den Grund zu sinken. In seinem Inneren sei dann heftig in die Trompeten geblasen worden, die Trommeln daselbst seien gerührt worden und im gesamten Heerlager der Almohaden seien laut die Rufe „Gott ist groß!““ und „Es gibt keinen Gott außer dem Gott!“ ertönt. Der Turm sei an die Stadtmauer geschafft worden, und er habe aufgrund seiner gewaltigen, pyramidenähnlichen Größe die Stadt überragt. Derweil hätten die Almohaden den Stadtgraben an der Stelle, die der beim Beschuss in die Mauer geschlagenen Bresche gegenüber gelegen habe, auf das Niveau der Erdoberfläche aufgefüllt und es sei auf diese Weise ein breiter, in die Stadt hinein führender Weg entstanden, auf dem man habe ungehindert in die Stadt eindringen und sie verlassen können. Am auf den Tag, an dem der Belagerungsturm an Gafsa hingeschafft worden sei, folgenden Tag hätten die Almohaden an dieser Stelle angegriffen. Über die verstreuten Stadtmauerreste hätten sie versucht, zur Bresche zu

\footnotetext{
${ }^{596}$ Darauf lässt jedenfalls eine gewisse Sprunghaftigkeit seiner Schilderung schließen.

${ }^{597}$ An dieser Stelle liegt entweder die Übertreibung des Originaltextes oder die verzerrende Wiedergabe Ibn-'Idārīs vor, denn aus dem weiteren Verlauf wird klar, dass durch den Beschuss nur an einer Stelle der Stadtmauer lediglich eine Bresche entstanden ist, durch welche die Almohaden dann vergeblich in die Stadt einzudringen versuchten.
} 
gelangen. Ihr Aufstieg habe sich jedoch als äußerst schwierig erwiesen, da die aufgetürmten durch den Beschuss herausgelösten Mauerteile sowie die zu Pulver zermahlenen Steine, die zuvor mittels Wurfgeschütze gegen die Wand geschleudert worden wären, den Weg versperrt hätten. Viele der angreifenden Almohaden seien dabei ausgerutscht, und aufgrund der Unpassierbarkeit dieses Weges sei dieser Erstürmungsversuch gescheitert. Hinzu sei gekommen, dass die Verteidiger der Stadt sich hinter den Stadtmauerresten versteckt gehalten hätten, die verbliebene Mauer als Schutzschild benutzt und den Almohaden aufgelauert hätten. Dann (d. h. beim Herannahen der Almohaden) seien sie auf die almohadischen Angreifer aus ihren Verstecken hinabgestürzt und hätten sich den Vorteil zunutze gemacht, dass sie sich oberhalb von ihnen befunden hätten. An diesem Tag hätten sich die Almohaden unverrichteter Dinge zurückgezogen, fest entschlossen, am nächsten Tag ihre Feinde vernichtend zu schlagen. Als die Verteidiger Gafsas erkannt hätten, dass ihre Stadt nun der Plünderung preisgegeben sei und dass sie alle dem Tod geweiht seien, hätten sie bei der abgehaltenen Versammlung der Stadtmächtigen darüber beraten, einen Brief an den almohadischen Herrscher zu überbringen und so ihr Leben zu retten. Man habe sich darauf geeinigt, die Notabeln Gafsas sowie die einflussreichen Vertreter der verschiedenen Gruppen dieser Stadt in das almohadische Lager zu entsenden. Beim Einbruch der Dunkelheit, als die Mitglieder der Gesandtschaft vor den Übergriffen des gemeinen Volkes sicher gewesen seien $^{598}$, hätten die Unterhändler die Stadt durch die Bresche verlassen, nachdem ihnen die Erlaubnis gewährt worden sei, zum almohadischen Lager zu kommen. Sie seien in die Nähe des Zeltes der Nachhut gelangt, nachdem sie es wie vorher erwähnt worden sei ${ }^{599}$ erkannt hätten [sic]. Der Kalif alManșūr habe Platz genommen, um in Bezug auf ihren Brief eine Entscheidung zu fällen, und habe seine bedeutendsten Verwandten sowie seine Berater kommen lassen. Man habe daraufhin die Bedingungen besprochen, die die Belagerten im Falle der Übergabe der Stadt gestellt hätten, und sei der Meinung gewesen, die von ihnen für diesen Fall geleisteten Verpflichtungszusagen $\mathrm{zu}$ akzeptieren ${ }^{600}$. Die Bitte $^{601}$ der Gesandten, auch den Mallorquinern sowie dem diese unterstützenden

\footnotetext{
${ }^{598}$ Dies ist m. E. der gemeinte Sinn von ,wa-aminū min inbisāṭ al-āmma 'alaihim wa-'mtidādihim ilaihim bi-'l-istitālāt"“ an dieser Stelle des Textes (al-Bayān al-muğrib, S. 195).

599 Das, worauf hier Bezug genommen wird, scheint bei der Zusammenfassung des Textes durch Ibn'Idārī ausgelassen worden zu sein.

${ }^{600}$ Dies ist wohl der Sinn des arabischen Satzes ,wa-takallamū fī šurūṭihim wa-ragibū fī tatmīm rubūṭhim“ an dieser Stelle (al-Bayān al-muğrib, S. 195).
} 
zusammengewürfelten Pöbel (arab.: al-aubāš al-munḍăfinn) die körperliche Unversehrtheit zuzusichern, diese hätten die Almohaden jedoch abgelehnt. Die Unterhändler seien nach Gafsa mit der folgenden Sicherheitszusage zurückgekehrt: Den asiatischen Söldnern sowie den Bewohnern Gafsas sei die körperliche und materielle Unversehrtheit zugesichert worden; alle sonstigen in der Stadt befindlichen Personen hätten sich zu ergeben und sich dem noch zu fällenden endgültigen Urteil über sie zu fügen gehabt. Am nächsten Morgen seien alle Menschen aus der Stadt geströmt, um Ya'qūb al-Manșūr zu begrüßen, und es sei niemand in der Stadt außer den Frauen geblieben, die „Gott ist groß!““ und „Es gibt keinen Gott außer Ihm!“ rufend angstvoll das Urteil über ihre Männer abgewartet hätten. Als sie alle draußen versammelt gewesen seien, hätten die Almohaden sie nach ihrer jeweiligen Zugehörigkeit in Gruppen aufgeteilt. Man habe dann die Bewohner Gafsas ausgesondert, die ihnen gewährten gütige Behandlung und Begnadigung verkündet und sie ihres Weges ziehen lassen. Was die versprengten Kämpfer, die zusammengewürfelten Scharen sowie diejenigen betroffen habe, die sich dem noch zu fällenden Urteil über sie gefügt hätten, so sei ihr Todesurteil gefällt worden und man habe sie im Belagerungsturm eingesperrt $^{602}$. Ya'qūb al-Manșūr und die Versammelten hätten sich hiernach zurückgezogen. Nach der Verrichtung des Nachmittagsgebets habe der Kalif auf seinem Beobachtungsturm Platz genommen und angeordnet, die Eingesperrten aus dem Belagerungsturm zu holen und sie alle zu schlachten ${ }^{603}$. Diese seien dann gruppenweise zu ihren Hinrichtungsstätten getrieben und auf ihre Gesichter, Körperseiten und Rücken niedergestoßen worden. Die Bevölkerung Gafsas habe der Tötung zugeschaut. Die Leichen der Geschlachteten habe man dann in den Umfassungsgraben Gafsas geworfen und der Gestank der verwesenden Körper habe sich in der ganzen Gegend verbreitet. Nach diesem habe Ya'qūb al-Manșūr sein Zelt wieder dort aufschlagen lassen, wo er es am Anfang hätte aufschlagen lassen. Er habe Abschnitte der Stadtmauer allen im Heerlager befindlichen Almohaden zuteilen lassen, und die Letzteren hätten diese dann binnen zwei Tagen in aufstiebenden feinen Staub verwandelt. Die gesamten

\footnotetext{
601 Das im Satz an dieser Stelle „fa-lam yus'afū fī ta'mīn al-mayūrqiyīn wa-'l-aubāš al-munḍāīn““ gebrauchte arabische Verb „as'afa“" wird von Dozy u. a. mit „,consentir à quelqu'un demande ou desire“ erklärt (Supplément aux dictionnaires arabes, Bd. 1, S. 655).

${ }^{602}$ Seltsamerweise werden an dieser Stelle des Textes die asiatischen Söldner nicht mehr erwähnt. Möglicherweise wurden sie bei der Zusammenfassung der Vorlage ausgelassen.

${ }^{603}$ Das hier gebrauchte arabische Wort „dabh"“ wird auch von at-Tiğānī (Riḥlat at-Tiğānī, S. 138) und 'Abd-al-Wāhid al-Marrākušī (al-Mu'ğib, S. 274) gebraucht.
} 
Wurfgeschütze und Belagerungsvorrichtungen habe man in Brand gesetzt, und die Almohaden seien dann (nach Tunis) abgezogen ${ }^{604}$.

7.3. „Da entbrannten in diesen Feinden lodernd und lichterloh die Flammen des Entsetzens und der Furcht.“

Wenn wir nun die wenigen Aussagen der überlieferten Quellen denjenigen des Briefes gegenüberstellen, so ergeben sich daraus folgende Beobachtungen.

Den Ausführungen des Briefes nach hat nach dem andauernden Beschuss mit den Wurfgeschützen und der Nivellierung des Stadtgrabens vor allem das heftige Vorstürmen der Almohaden, in dessen Verlauf der Turm des Ibn-Zawāğ in Brand gesteckt worden ist, eine veritable Panik unter den Belagerten ausgelöst und nichts anderes als dies hat sie in die Knie gezwungen. Die oben zusammengefassten Berichte legen jedoch nahe, dass diese Unterwerfungsbereitschaft der in der Stadt Umzingelten auch durch andere Faktoren bewirkt wurde. Wie erinnerlich weist Ibn-al-Atīr darauf hin, das während der Belagerung die Bäume des umliegenden Haines Gafas abgeholzt wurden. Der anonyme Autor „Kitāb al-istibșār fî ‘ağā'ib al-amṣār“ schildert mit großer Detailfreude diesen Hain, in dem neben Datteln und Oliven sämtliche Obstsorten Äpfel, Granatäpfel, Zitronen, Bananen, Datteln und Pistazien - von einzigartig hoher Qualität angebaut worden sind. Pistazien seien in die gesamte Ifrīqīya sowie nach Maghreb, al-Andalus und Ägypten exportiert worden ${ }^{605}$. Yāqūt al-Hamawī nennt darüber hinaus noch Feigen und Weintrauben und fügt hinzu, dass Kairuan mit Obst aus Gafsa versorgt worden ist ${ }^{606}$. Ferner berichtet Abu-'1-Fidā' (gest. 1331) unter Berufung auf Ibn-Sa'̄id al-Maġribī (gest. 1286 oder $1274^{607}$ ), dass Gafsa die einzige Stadt im gesamten Maghreb gewesen ist, in der Pistazienbäume wuchsen ${ }^{608}$. Vor dem Hintergrund dieser Aussagen liegt der Schluss nahe, dass der in „Kitāb al-istibṣār fī

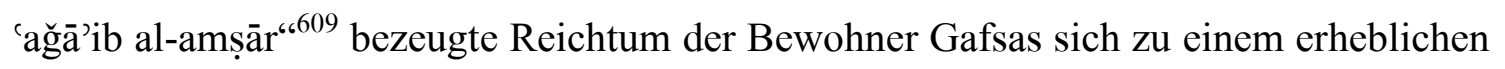
Teil aus den Erzeugnissen des umliegenden Haines und deren Vertrieb gespeist hat. Die von Ibn-al-Atīr erwähnte Abholzung muss somit u. a. für die gesamte Stadt die Vernichtung eines wichtigen Teils ihrer wirtschaftlichen Existenzgrundlage bedeutet haben. Eine annähernde Vorstellung vom Ausmaß des angerichteten Schadens

\footnotetext{
${ }^{604}$ al-Bayān al-muġrib, S. 194 - 196.

${ }^{605}$ Kitāb al-istibsāār fī ‘ağā'ib al-amṣār, S. 153 f.

${ }^{606}$ Kitāb mu'ğam al-buldān, Bd. 4, S. 151.

${ }^{607}$ Geschichte der arabischen Litteratur, S I, S. 576

${ }^{608}$ Géographie d'Aboulféda, Bd. 2, Teil 1, S. 197.

${ }^{609}$ Kitāb al-istibṣār fī 'ağā'ib al-amṣār, S. 154.
} 
verschafft uns at-Tiğānī, dem zufolge bei dieser Bezwingung Gafsas der Großteil des Dattelpalmenbestades der Stadt vernichtet worden sei, weil al-Manșūr geschworen hätte, an jedem Tag der Belagerung tausend Dattelpalmen fällen zu lassen ${ }^{610}$.

Sowohl der Brief als auch der Bericht Ibn-I Idārīs sprechen ferner davon, dass beim Beschuss mit den Katapulten eine Bresche in die Stadtmauer geschlagen wurde. Dabei wirkt die Erwähnung der Bresche im Brief fast nebensächlich und bleibt im weiteren Verlauf der Beschreibung unerwähnt. Die sich daran anschließende Passage des Schreibens handelt von der Heranschaffung des Belagerungsturmes bis an den Umfassungsgraben Gafsas heran sowie davon, dass die Almohaden dabei sofort den Stadtgraben und die Stadtmauer in ihre Gewalt gebracht hätten. Nach der Schilderung der für die Belagerten aüßerst hohen Verluste wird wiederum die bereits genannte Heranschaffung des Belagerungsturmes erwähnt und die Schilderung konzentriert sich im Folgenden auf die Tod bringende Unterbeschussnahme Gafsas von diesem Turm aus sowie auf seinen die Umzingelten in Schrecken versetzenden Anblick. Die nachfolgende Darstellung des anschließenden Furcht einflößenden Ansturmes der Almohaden nach der Auffüllung des Umfassungsgrabens ist so aufgebaut, als habe sein Zweck darin bestanden, den Turm von Ibn-Zawāğ in Brand zu stecken, was bei den Eingekreisten die Einsicht, weiteren Widestand aufzugeben, bewirkt habe. Die zuvor geschlagene Bresche spielt bei dieser Darstellung des Briefes keine Rolle und dient höchstens zur Hervorhebung der gewaltigen Durchschlagskraft der almohadischen Wurfgeschütze. Im Bericht Ibn-'Idārīs hingegen kam dieser Maueröffnung eine zentrale Bedeutung zu, denn auf sie nämlich seien die almohadischen Angreifer zugestürzt bei ihrem ergebnislosen Versuch, dadurch gewaltsam in die Stadt einzudringen. Außerdem wirkt die wahre Bedeutung des Turmes von Ibn-Zawāğ im Brief etwas überhöht. Dies legt das folgende Zitat des anonymen Autors von „Kitāb al-istibṣār fĩ ‘ağā’ib al-amṣār“ nahe, der als einziger unter den arabischen Geographen diesen Turm einer kurzen Erwähnung würdigt, die bei der sonst recht ausführlichen und detailreichen Schilderung Gafsas bemerkenswerterweise beiläufig ausfällt: „(nach der Niederreißung der Stadtmauer) sind nur deren Grundmauern übrig geblieben, und der nahe davon gelegende Turm, der Turm des Ibn-Zawāğ, ist Zeuge des weit in die Vergangenheit reichenden Erbauungsdatums dieser Mauer und ihrer einstigen großen Bedeutung. “611 Angesichts der auffallenden Beiläufigkeit dieser Bemerkung scheinen Zweifel durchaus

\footnotetext{
${ }^{610}$ Rihlat at-Tiğānī, S.139.

${ }^{611}$ Kitāb al-istibṣār fī 'ağā'ib al-amṣār, S. 151 f.
} 
angebracht, dass dieser Turm, zumal außerhalb der Stadt gelegen, wirklich - wie im Brief behauptet wird - „die Krone und Kranz“ Gafsas gebildet hat.

Die Situation, in der sich die Belagerten nach dem vereitelten almohadischen Erstürmungsversuch beim Einbruch der Dunkelheit befanden, und somit der Hintergrund für die Entscheidung, sich zu ergeben, mögen also wie folgt ausgesehen haben: Gafsa sieht sich der Übermacht einer zahlenmäßig weit überlegenen feindlichen Armee gegenüber, die nicht nur große Sachschäden in der Stadt, sondern auch empfindlichen wirtschaftlichen Schaden außerhalb davon tagtäglich - falls nötig ad infinitum - anrichten kann; was die Stadtmauer, den noch einzig verbliebenen Schutz, betrifft, so hat sie eine große Bresche, durch welche die Angreifer nächstes Mal mit einem heftigeren, besser koordinierten und massiven ${ }^{612}$ Angriff versuchen würden einzudringen.

\section{4. „Diese Zusicherung der körperlichen Unversehrtheit wurde der Gesamtheit der} asiatischen Söldner und ihrer Anhänger sowie allen Bewohnern und der Allgemeinheit Gafsas gewährt [...]“

In hochtrabenden und sehr allgemeinen Worten schildert der Brief die Zusicherung der körperlichen Unversehrtheit gegenüber asiatischen Söldnern, Einwohnern Gafsas sowie allen Stammesangehörigen und Landbewohnern, die sich zu diesem Zeipunkt in der Stadt befanden. Die Beschreibung der Verschonung bzw. der Nicht-Verschonung der einzelnen in Gafsa eingeschlossenen Personengruppen im Brief weicht in einem nicht unwesentlichen Punkt von der Darstellung Ibn-'Idārīs ab. Im Brief ist davon die Rede ist, dass die Belagerten bei ihrer Zusammenkunft mit den Almohaden die körperliche Unversehrtheit für sich erbitten und deren Gewährung auch für die Mallorquiner zur Sprache bringen. Das Letztere wird von den Almohaden mit dem Hinweis darauf, es sei Gottes Urteil, dass die Mallorquiner einen grausamen Tod sterben sollen, kategorisch abgelehnt. Vor dem Hintergrund der Ausführungen Ibn-'Id̄ārīs hieße es mit anderen Worten, dass bereits bei den Gesprächen mit den Unterhändlern der Eingekreisten über die vertragliche Fassung der noch bevorstehenden Kapitulation unmissverständlich festgelegt wurde, dass die Inbesitznahme Gafsas durch die Almohaden unausweichlich

\footnotetext{
612 Die Belagerung Gafsas bildete nach dem almohadischen Sieg bei Hamma Maṭmāṭa und der Inbesitznahme der Städte Nafzāwa, Tawzar, Taqyūs und al-Hamma die abschließende Etappe der almohadischen Unternehmung nach Ifrīqīya. Mit anderen Worten, zur Bezwingung Gafsas hätten theoretisch die gesamten almohadischen Verbände eingesetzt werden können. Andererseits konnte die Stadt auch keine auswärtige Hilfe erwarten, denn Qarāqūš hatte sich formal den Almohaden unterworfen und sein Gefährte 'Alī Ibn-Ġānīya befand sich auf der Flucht.
} 
zur Tötung der darin befindlichen Banū-Ḡānīya und ihrer Anhänger führen würde. Und genau darin liegt der wesentliche Unterschied zum Bericht Ibn-'Idārīs: diesem zufolge weigern sich die versammelten ranghohen Almohaden nämlich, die an sie von den Unterhändlern Gafsas herangetragene Bitte, auch den Mallorquinern Sicherheitsgarantien zuzusagen, eindeutig zu beantworten; die diesbezügliche endgültige Entscheidung wird auf den Zeitpunkt erst nach der Einnahme der Stadt aufgeschoben. Mit anderen Worten, durch keine Festlegung auf eine eindeutige und unmissverständlich interpretierbare Antwort wurde den Mallorquinern implizit ihre mögliche Begnadigung in Aussicht gestellt und somit die Hoffnung, am Ende doch mit dem Leben davonkommen zu können, genährt. Denn wie sonst sollte man den Satz verstehen, die Mallorquiner sollten sich dem Urteil, das noch gefällt werde, fügen und zusammen mit allen anderen sich ergeben?

\subsection{Zusammenfassung des historischen Kommentars}

Der Brief Nr. 32 enthält den ausführlichsten überlieferten Bericht über die Rückeroberung Gafsas, die den Abschluss der almohadischen Unternehmung zur Befriedung Ifriqiyas gebildet hat. Wie auch im Falle des Briefes Nr. 31 bilden die Angaben in den herangezogenen Quellen über dieses Ereignis keine ausreichende Basis für die Überprüfung des historischen Gehaltes des überwiegenden Teils der Aussagen des Briefes. Trotz ihrer Kürze einerseits und ihres manchmal proalmohadischen Tenors andererseits erlauben sie dennoch, einige Darstellungen des Briefes vor einem wirklichkeitsnäheren und besser nachvollziehbaren Hintergrund $\mathrm{zu}$ betrachten. So werden die Motive der Belagerten, den Widerstand aufzugeben und zu kapitulieren, dank den zitierten Berichten über die groß angelegte Vernichtung des für das Wirtschaftsleben Gafsas bedeutsamen Palmenbestandes, über das sachliche Verhandeln über die Kapitulationsbedingungen und über die implizite Inaussichtstellung der körperlichen Unversehrtheit den Mallorquinern gegenüber in einen logischen Zusammenhang gerückt, der im Brief zugunsten einer Deutung weitgehend getilgt ist, der gemäß die Wundersamkeit der Siege und der Segensreichtum dem Almohadentum nun mal innewohnend seien. Vor diesem genannten Hintergrund konnte ferner der von Ibn-'Id̄ārī überlieferte Rückschlag der Almohaden erkannt werden, bei ihrem Versuch, durch die Bresche in die Stadt einzudringen, abgewehrt worden zu sein, der jedoch im Brief durch die Überhöhung der bei diesem Vorstoß erzielten Erfolge und durch die stark raffende und abstrakte Darstellungsweise der nachfolgenden Ereignisse in den 
almohadischen Sieg umgedeutet wurde. Interessant, doch nicht weiter verfolgbar sind des Weiteren Berichte darüber, dass die Einwohner Gafsas faktisch enteignet wurden, was im krassen Widerspruch zu den Ausführungen des Briefes über die der Bevölkerung zuteil gewordenen Segnungen seitens der Almohaden stünde. In diesen Zusammenhang gehört ebenfalls die Tötung der mallorquinischen Gegner der Almohaden vor den Augen der versammelten Stadtbewohner, die in den Quellen als „Schlachtung“613 bezeichnet wird und welche at-Tiğān̄̄ als ein regelrechtes Schlachtungsritual schildert ${ }^{614}$. Nach formalen Gesichtspunkten betrachtet springt, wie bereits oft beobachtet, die weitgehende Zeitlosigkeit der beschriebenen Geschehnisse in die Augen. Dies äußert sich im weitest gehenden Fehlen von zeitrelevanten Angaben, was beim öffentlichen Verlesen den Zuhörern den Eindruck vermittelt haben musste, der vorgetragene Inhalt habe sich binnen kürzester Zeit abgespielt. Dabei erstreckten sich die bekannt gegebenen Vorgänge in Wirklichkeit über anderthalb Monate ${ }^{615}$. Im Zusammenhang mit dem Umgang der almohadischen Schreiben mit der Zeit ist bemerkenswert, dass den von Ibn-'Idāāī und at-Tiğānī angegebenen zwei Tagen ${ }^{616}$ für die Schleifung der Stadtmauer im vorliegenden Brief ein bzw. weniger als ein Tag gegenübersteht.

\section{Abschließende Betrachtungen}

\subsection{Thematische Gliederung}

Wollte man ausgehend von der Sammlung „Mağmūc rasā'il muwaḥhidīya“ den thematischen Schwerpunkt ermitteln, der die almohadischen Schreiben allgemein kennzeichnet, so wäre das Ergebnis dahingehend $\mathrm{zu}$ formulieren, dass ihre überwiegende Mehrheit Siegesmeldungen bzw. Berichte über den erfolgreichen Verlauf der militärischen Auseinandersetzungen der Almohaden mit ihren Widersachern sind. Dies stünde in zweifacher Hinsicht in einem auffälligen Gegensatz zu den offiziellen Briefen der Sammlung „Raiḥānat al-kuttāb wa-nuğ`at al-muntāb“ aus der Zeit des nasridischen Sultanats (1232 - 1492): denn darin machen die Siegesmeldungen allgemein den kleinsten Teil aus; davon ist ferner die überwiegende Zahl der Siegesberichte an die souveränen muslimischen Herrscher und nicht an die Allgemeinheit gerichtet. Mit der Veröffentlichung der „Mağmū'a ğadīda“ ist jedoch eine wesentliche Korrektur der oben ausgehend von „Mağmū̌ rasā’il muwaḥhidīya“

\footnotetext{
${ }^{613}$ Rihllat at-Tiğānī, S. 138, al-Bayān al-muğrib, S. 195, al-Mu ğib, S. 274.

${ }^{614}$ Rihlat at-Tiğānī, S. 139.

${ }^{615}$ Historia política del imperio almohade, Bd. 1, S. 338.
} 
gegebenen thematischen Aufschlüsselung der almohadischen Briefe möglich, denn in der neuen Briefsammlung machen die Verlautbarungen über erfolgreiche militärische Unternehmungen den kleinsten Teil aus. Vor diesem Hintergrund stellt sich die Frage: Warum haben in das handschriftliche Original, das Lévi-Provençal 1941 herausgab, vornehmlich Briefe Eingang gefunden, die Siegesmeldungen und Schlachtbeschreibungen enthalten? Es ist mit hoher Wahrscheinlichkeit davon auszugehen, dass für den Besitzer bzw. für die Besitzer des handschriftlichen Bandes bei der Auswahl der zu berücksichtigenden Briefe bestimmte Kriterien ausschlaggebend waren. Die Vermutung drängt sich auf, dass eines dieser Kriterien in der sprachlichen Schönheit der darin überlieferten Briefe bestanden hat. In diese Richtung weist zumindest der Eingriff des Besitzers im abschließenden Abschnitt eines der Briefe in „Mağmū` rasā’il muwaḥhidīya“, der mit dem lapidaren Hinweis „Hier hört der schönste Teil des Schreibens auf “617 die Schilderung abrupt enden lässt. Ferner spricht auch die folgende formale Auffälligkeit für die eben geäußerte Vermutung: abgesehen von einigen wenigen Ausnahmen werden die in den Briefen vorkommenden Personen nicht mit ihrem Namen angegeben, sondern sehr häufig lediglich durch „fulān“, d. h. „,[Herr] Soundso", umschrieben. Diese Angabeweise von Personen ist auch in der für die Sekretäre $^{618}$ verfassten Enzyklopädie „Șubḥ al-a šā fĩ șinā`at al-inšā̄“‘ weit verbreitet, in der u. a. zahlreiche repräsentative Proben von offiziellen Schreiben aus unterschiedlichen Epochen und geographischen Gebieten zu verschiedenen Anlässen zusammengefasst sind und womit den Adressaten vor allem über die formalen und sprachlichen Eigentümlichkeiten der angeführten Texte Aufschluss gegeben werden sollte. Die genannte Auffälligkeit ist auch in der oben erwähnten Sammlung „Raihānat al-kuttāb wa-nuğcat al-muntāb“ sehr häufig, welche aus der Feder des wohl berühmtesten Sekretärs und Wezirs der nasridischen Dynastie, Lisān-ad-Dīn Ibn-alHatị̂b (1313-1374), stammt. Darin findet man nicht nur den Wortlaut der offiziellen nasridischen Schreiben, sondern auch einleitende Teile zu Schriften und Werken dieses Autors, die er für sprachlich besonders gelungen erachtet und sie deswegen den späteren Sekretären - wohl zur Nachahmung - zur Verfügung gestellt hat. Interessant ist in diesem Zusammenhang, dass Ibn-'Idārī bei der Schilderung der almohadischen Unternehmung zur Unterwerfung des Zentralen Maghreb im Jahre 1152 abschließend bemerkt, 'Abd-al-Mu'min habe von Abū-Ğa'far Ibn-'Aṭ̂ya ein in sprachlicher Hinsicht

\footnotetext{
${ }^{616}$ Riḥlat at-Tiğānī, S. 139, al-Bayān al-mug̉rib, S. 196.

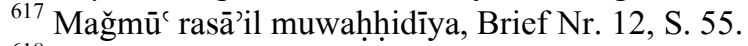

${ }^{618}$ Izbrannye sočinenija, Bd. 4, S. 412.
} 
schönes Schreiben mit der Schilderung der Einnahme Biğāyas an die Bewohner von Maghreb und al-Andalus abfassen lassen, in dessen sprachlicher Ausgestaltung dieser ein unnachahmlich hohes Niveau erreicht habe ${ }^{619}$. Und eben dieser Brief scheint in „Mağmū` rasā’il muwaḥhidīya“ überliefert zu sein ${ }^{620}$. Abschließend kann man also festhalten, dass in der Sammlung „Mağmū rasā’il muwaḥhịīiya“ offizielle Schreiben vorliegen, die für das ästhetische, in Maghreb und al-Andalus im Mittelalter vorherrschende Empfinden in sprachlicher Hinsicht als besonders schön galten und von welchen alle $\mathrm{e}^{621}$, die Berichte über die militärischen Erfolge der Almohaden enthalten, u. a. an die Allgemeinheit gerichtet sind.

\subsection{Der Aufbau der almohadischen Briefe}

Alle Briefe der Sammlung weisen ein einheitliches formales Aufbaumuster auf, das sich grob in drei Teile gliedern lässt: der einleitende erste Teil, die eigentliche Inhaltsmitteilung und der Abschluss. Der erste Teil enthält gewöhnlich die Nennung des almohadischen Herrschers, in dessen Namen der jeweilige Brief verfasst ist, sowie des Adressaten bzw. der Adressaten; mittels der obligatorischen Wendung „Und nun zum Eigentlichen!“ (arab.: ammā ba'd) wird die Überleitung geschaffen zum Segment mit den Lobpreisungen Gottes (arab.: al-hamdala), der Nennung Mohammeds, dem zugewandt die Absender des Briefes ihre Gebete verrichten sollen (arab.: at-taṣlïya) ${ }^{622}$, und den an Gott gerichteten Bitten, am Mahdi der Almohaden Muhammad Ibn-Tūmart Wohlgefallen zu haben (arab.: at-tardìya).

In den späteren Briefen ${ }^{623}$ wird die eben genannte, zuvor Muhammad Ibn-Tūmart vorbehaltene Eulogie „Gott möge an ihm Wohlgefallen haben“ auf den Nachfolger des Mahdi 'Abd-al-Mu'min ausgeweitet, und für den jeweils amtierenden almohadischen Kalifen wird der göttliche Segen (arab.: $a d-d u^{c}(\bar{a})$ herabgefleht. In den almohadischen

\footnotetext{
${ }^{619}$ al-Bayān al-muğrib, S. 47.

${ }^{620}$ Mit endgültiger Gewissheit kann man dies nicht sagen, da beim Brief Nr. 8 Abū-'Aqīl 'Atīya Ibn'Ațìya, der Bruder Abū-Ğa'far Ibn-'Ațìyas, als Verfasser angegeben ist (Mağmū' rasā'il muwaḥhidīya, S. 22). Der darauf folgende Brief Nr. 9 wird jedoch mit der Bemerkung des Kompilators eingeleitet: „Und dieser Brief stammt ebenfalls aus der Feder des erwähnten Abū-Ğa'far Ibn-'Ațìa" (Mağmū' rasā'il muwahhidiya, S. 26). Dies, verbunden mit der Tatsache, dass auch der almohadische Brief Nr. 7 von Abü-Ğa'far Ibn-'Ațiya im Rahmen der gleichen almohadischen Unternehmung in den Zentralen Maghreb verfasst wurde (Mağmū' rasā'il muwaḥhidìya, S. 17), spricht für die Urheberschaft des Letzteren auch beim Brief Nr. 8 .

${ }^{621}$ Dies trifft bis auf die Briefe Nr. 22, 36 und 37, bei welchen der einleitende Teil fehlt, für die Briefe Nr. $8,9,16,20,21,29,30,31,32,33,34,35$ zu.

${ }^{622}$ In den Briefen Nr. 1, 2, 5, 6, 8, 9, 10, 12, 13, 14, 15, 16, 17, 18, 19, 20, 21, 22, 23, 26, 32, 35 und 36 wird das Gebet auch den Familienangehörigen und Gefährten Mohammeds zugewandt verrichtet. Hierbei kann die Formulierung der Eulogie leicht variieren, denn sowohl „nuṣallī ‘alā [...] ālihī wa-ṣaḥbihī“ (S. 1) als auch ,șallā Allāh [...] 'alā ālihī“" (S. 242), d. h. Gott möge ihnen zugewandt beten, kommt vor.

${ }^{623}$ In „Mağmū' rasā'il muwaḥhidìya“ ab dem Brief Nr. 20.
} 
Briefen späteren Abfassungsdatums kommt es zur folgenden interessanten Unterbrechung in der Abfolge der genannten Elemente und zur wiederholten, zweiten Aufgreifung von „Hamdala“ und „Taṣlìya“. So heißt es z.B. im einleitenden Teil vom Brief Nr. 20: „Vom Befehlshaber der Gläubigen [...] an die Ṭālibs, Almohaden, die Ältesten und Notabeln der Stadt Cordoba, sowie auch an all ihre Bewohner [...]. Euer eingedenk loben wir Gott, außer Dem es keinen anderen Gott gibt, und danken Ihm für Seine Gaben und Wohltaten. Unsere Gebete verrichten wir Mohammed zugewandt, Seinem auserwählten Propheten und Gesandten. Gelobt sei Gott, der diese erhabene (almohadische) Botschaft unterstützte, ihr beistand, sie machtvoll machte und obsiegen ließ. $[\ldots]^{624}$ Die Gebete seien Muhammad zugewandt verrichtet, seinem Propheten und Gesandten usw. “625

Die mit leichten Abwandlungen formulierte, sinngemäß jedoch immer gleich bleibende Wendung „Dieses unser Schreiben an euch“6626 kennzeichnet den Abschluss des ersten einleitenden Teils und gleichzeitig den Übergang zur eigentlichen Inhaltsmitteilung. Beim Blick beispielsweise auf den einleitenden Teil der offiziellen nasridischen Schreiben der Sammlung „Raiḥānat al-kuttāb wa-nuğ`at al-muntāb“ springt der wesentliche Unterschied in die Augen, der unüberbrückbar zwischen diesen und den almohadischen Briefen besteht. Denn in den Ersteren ist dieser erste Teil zur unveränderlichen Abfolge von „Hamdala“, „Taṣlīya“, „Tarḍīya“ und „Du(ā)‘“ erstarrt, wobei die beiden ersten Eulogien jeweils Gott und Mohammed gewidmet sind, die dritte, also „Tarḍīya“, jedoch den Familienangehörigen und Weggefährten Mohammeds und die vierte dem jeweiligen Adressaten vorbehalten sind. Die auffallende Eingliederung des Mahdi in den almohadischen Schriftstücken in die Reihe der als kanonisch betrachteteten, obligatorischen Elemente einer jeden offiziellen Verlautbarung und noch dazu mit einer Eulogie ausgestattet, mit der unter anderen historischen Bedingungen nur den in verwandschaftlicher und sonstiger Hinsicht Mohammed Nahestehenden Hochachtung gezollt wurde, ist indes keineswegs zufällig und wurzelt in der almohadischen Imamatslehre, die Muhammad Ibn-Tūmart ausführlich dargelegt hat ${ }^{627}$. Diese lässt sich wie folgt zusammenfassen: Der Begründer des Almohadentums ging davon aus, dass Gott in allen verstrichenen Zeiten den

\footnotetext{
${ }^{624}$ Hieran schließt sich eine Passage mit der Beschreibung der Siege, welche die Almohaden über ihre Feinde dank göttlichem Eingreifen davongetragen hätten.

${ }^{625}$ D. h. es folgen hierauf die üblichen, eben bennanten Elemente der Einleitung.

${ }^{626}$ Im arabischen Text werden an dieser Stelle Wendungen wie „fa-inna kitābunā ilaikum“, ,wa-hād̄ā kitābunā ilaikum“ gebraucht.

${ }^{627}$ Le Livre de Mohammed Ibn Toumert, S. 245 ff.
} 
Menschen Imame ${ }^{628}$ gegeben habe, welche die in Sünde und Unwissenheit verweilende Welt mit dem Lichte der Gerechtigkeit hätten erfüllen und in ihr der Wahrheit zum Obsieg verhelfen sollen. $\mathrm{Zu}$ solchen Imamen, die als Garanten des Fortbestandes der Himmel und der Erde beschrieben werden, hätten Adam, Noah, Abraham, David, Jesus, Muhammad und seine Nachfolger Abū-Bakr und 'Umar gehört ${ }^{629}$. Danach habe sich jedoch die Welt mit Ungerechtigkeit und Tyrannei erfüllt, und die Finsternis der Unwissenheit und des Unglaubens sei über sie hereingebrochen. In diesem Zustand habe die Welt verweilt, bis er, der Mahdi, erschienen sei, den Gott mit den Attributen der Rechtleitung ausgezeichnet und ihm versprochen habe, dass er die bestehenden ungerechten Verhältnisse der Welt zugunsten der Wahrheit verändern würde, „,bis diese Verhältnisse auf den Wegen der Rechtleitung geordnet sind und sich fest auf dem Pfade der Gottesfurcht befinden. “630 Durch das Auftreten des Mahdi würde die Falschheit verschwinden, und er würde die Welt durch das Versprechen Gottes und durch Seine Gnade wieder mit rechter Glaubenspraxis, Wahrheit und Gerechtigkeit erfüllen. Hierauf folgt dann eine längere Passage, in der das dargelegte Geschichtskonzept noch weiter vereinfacht bzw. auf die Wirklichkeit der Rezipienten mit allen für sie daraus resultierenden Obliegeneheiten übertragen wird. Nach der längeren eindringlichen Mahnung, dass es Pflicht sei, über den Mahdi Gewissheit zu haben, ihm zu gehorchen, ihm zu glauben, ihn als den Mahdi anzuerkennen, sich seinem Urteil zu fügen, ihn in allen religiösen Angelegenheiten als die höchste Autorität zu befragen, ihm nachzufolgen usw. sowie der Betonung der Unerlaubtheit allen Gegenteils hiervon, wird die genannte Vereinfachung in folgende Fassung gebracht: „Seine (d. h. des Mahdi IbnTūmart) Handlungsweise ist die Handlungsweise Gottes und Seines Gesandten, seine Sache ist die Sache Gottes und Seines Gesandten, ihm zu gehorchen heißt Gott und Seinem Gesandten zu gehorchen, sich ihm unterzuordnen heißt, sich Gott und Seinem Gesandten unterzuordnen, sich ihm anzuschließen heißt, sich Gott und Seinem Gesandten anzuschließen, in seiner Huld zu stehen heißt, in der Huld Gottes und Seines Gesandten zu stehen, ihm zu folgen heißt, Gott und Seinem Gesandten zu folgen, und

\footnotetext{
${ }^{628}$ Das arab. Wort „imām“ ist hier nicht in der heute geläufigen Bedeutung „Imam, Vorbeter“ zu verstehen. Im mittelalterlichen Sprachgebrauch konnte es u. a. den Sinn „der unter seinesgleichen Vortrefflichste, der im Hinblick auf sein Wissen, Können usw. Unübertreffliche“ haben. Hier ist damit jemand gemeint, der in vollendeter Unbescholtenheit und frei von Unwahrheit, Missleitung, Verwerflichkeit, Ungerechtigkeit usw. über die Menschen herrscht und sie rechtleitet. Vgl auch T. Nagel: Geschichte der islamischen Theologie, S. 58.

${ }^{629}$ Obwohl 'Utmān und 'Alì in dieser Reihe nicht namentlich genannt sind, zählt sie Ibn-Tūmart implizit trotzdem dazu, wie es aus seiner Aussage darüber hervorgeht, dass dieses Zeitalter der Gerechtigkeit noch dreißig Jahre nach dem Tode des Propheten, also bis zum Jahr 661 gedauert habe. (Le Livre de Mohammed Ibn Toumert, S. 249).
} 
ihn zu verehren (arab.: ta'żim ḥurumātihi) heißt, Gott und Seinen Gesandten zu verehren. “631

Man kann angesichts dieser Ausführungen unschwer erkennen, wie sehr die eingangs skizzierte Abfolge der Eulogien im einleitenden Teil der almohadischen Briefe mit diesem gedanklichen Hintergrund übereinstimmt. Dieses almohadische Geschichtskonzept schlägt sich darüber hinaus im gesamten ersten Teil der offiziellen almohadischen Verlautbarungen nieder. Im Folgenden sei die Übersetzung des einleitenden Teils des Briefes Nr. 30 angeführt, dessen hier vorgelegte Fassung sich im Hinblick auf den Inhalt als auch den Aufbau in den meisten almohadischen Siegesmeldungen von „Mağmū` rasā’il muwaḥhịīiya“ wiederholt:

„Euer eingedenk loben wir Gott, außer dem es keinen anderen Gott gibt, und preisen Ihn für Seine Gaben und Gnadenbezeigungen. Unsere Gebete verrichten wir unserem Herrn Mohammed zugewandt, Seinem auserkorenen Propheten und Gesandten.

Preis sei Gott, der Seine Verheißungen in Erfüllung gehen ließ, Seinen Streitern und Knechten Sieghaftigkeit gewährte, den Anhängern der Wahrheit und den um ihretwillen Kämpfenden Mächtigkeit verlieh und mittels der Mächtigkeit Seiner obsiegenden Sache (d. h. des Almohadentums) und Seiner erfolgreichen und sieghaften Partei die zahlreichen Scharen der Unwahrheit mit Schmach bedeckt sein ließ. Preis sei Ihm, der bei der Gewährung Seines umfassenden Sieges und Seines gewaltigen Obsieges zugunsten Seiner großen (almohadischen) Sache ihr das Erneute und Jüngste Seines glückhaften Eingreifens zuteil werden ließ und der die Vorhaben und Vorsätze des Almohadentums mit (Seinem) Beistand und (Seiner) Hilfe sowie mit (Seiner) allgegenwärtigen Unterstützung und dem (von Ihm) ermöglichten Triumph untrennbar verknüpft hat. Gepriesen sei Er, der dem Almohadentum in all seinen Unternehmungen und bei all seinen Angriffen und Belagerungen in der gewohnten und wohl bekannten Weise den Weg ebnete und das Los aller almohadischen Widersacher und der dem Almohadentum Trotzenden das vernichtende Ungestüme des Almohadentums und die Oberhand der almohadischen Botschaft, deren ganze Tatkraft auf den Obsieg der wahren Gottesanbetung gerichtet ist, sein ließ. Gelobt sei Er, der durch das, was Er dem

\footnotetext{
${ }^{630}$ Le Livre de Mohammed Ibn Toumert, S. 251.

${ }^{631}$ Le Livre de Mohammed Ibn Toumert, S. 252. Man könnte einwenden, dass dieses Versprechen Gottes nur an Ibn-Tūmart erfolgt sei und sich somit nicht auf seinen Nachfolger 'Abd-al-Mu'min und später auf dessen Nachkommen ertsrecke. Dieses logische „Problem“ wurde dadurch gelöst, dass man auch 'Abd-alMu’min, Abū-Ya'qūb Yūsuf, Ya'qūb al-Manșūr und Muhammad an-Nāșir Imame hieß. In den Briefen Nr. 34 (S. 219) und Nr. 35 (S. 229), die zu Lebzeiten Ya'qūb al-Manșūrs geschrieben wurden, werden nur 'Abd-al-Mu'min und Yūsuf als Imame bezeichnet. Im Brief Nr. 37 (S. 249), der zu Lebzeiten Muhammad
} 
Almohadentum an Sieghaftigkeit, Bezwingungsmacht und Obsieg gewährte, seinen Feinden das Rückgrat brach und sie austilgte, die Ersten und Letzten ${ }^{632}$ dieser Feinde in den Flammen der Pein, deren Feuerung Er lodern machte, schmoren ließ, welchen (d. h. den Feinden) Er in der Mitte der Hölle ${ }^{633}$ das Schmerzliche und Entsetzliche Seiner gewaltigen Strafe vorbehalten hat, und welche (d. h. Feinde) Er zu einem belehrenden Beispiel für diejenigen, die sich belehren lassen, und zu einem warnenden Zeichen für die Reumütigen und Einsichtigen gemacht hat, auf dass all diejenigen erwachen, welche diese mächtige (almohadische) Sache zu verschmähen und sie in Abrede zu stellen gedacht haben. Ferner auf dass dies zu einem unumstößlichen Beweis dafür wird, dass Gottes Obsorge dem Almohadentum gilt und dass Seine Unterstützung und Sein Beistand dem Almohadentum gegenüber fortdauern, damit sich die Wiederholung dessen sich erübrigt und die Gläubigen, welchen Gott den Erfolg verliehen hat, die Gewißheit darüber erlangen, dass G o t $\mathrm{t}$ - Lob sei Ihm - die Sterne der Almohaden hat erglänzen lassen, dass E $\mathrm{r}$ die Verdienste des Almohadentums und es als Ganzes erhaben sein ließ, dass E r zu ihm das Mehrfache Seines zum Obsieg verhelfenen Eingreifens sowohl in der verstrichenen als auch in der gegenwärtigen Zeit hat geschehen lassen und dass E r dem Almohadentum vorherbestimmt hat, bis zur Stunde der Auferstehung siegreich und unbezwingbar zu sein und ewiglich zu bestehen.

Alle Gebete seien Mohammed zugewandt verrichtet, Seinem auserkorenen Propheten und Seinem vornehmsten und auserwählten Gesandten, durch dessen Berufung Gott Seine Erhabenheit über menschliche Attribute und Seine Einsheit offenkundig gemacht hat, durch dessen umfassendes Prophetentum Er der Gesamtheit der Erdbewohner bekannt gemacht hat, dass geheiligt und lobgesungen zu werden allein I h m gebührt, und welchen (d. h. Mohammed) Er vor allen anderen dadurch ausgezeichnet hat, dass Er ihn am Tage des Jüngsten Gerichts zum Fürsprecher machen wird und dass Er ihn an jenem kommenden Tage zum Leben auferweckt und ihn den vornehmen und löblichen Rang innehaben lässt. Und so ließ Mohammed seine Glaubensgemeinschaft und seine Botschaft, welche alle anderen religiösen Riten und Glaubensrichtungen ablöst, sich erstrecken auf die Gesamtheit der Erdbewohnerschaft sowie auf deren Herren und Beherrschte. Mohammed füllte mit der ausschließlichen Geltung seiner Botschaft und mit ihrer ununterbrochenen Fortdauer bis zum Tage des Jüngsten Gerichts die Tihāma-

\footnotetext{
an-Nāṣirs verfasst wurde, werden alle almohadischen Kalifen, also auch Ya'qūb und Muhammad eingeschlossen, als ,rechtleitende Imame“ bezeichnet.

${ }_{632}$ Anspielung auf die Sure 7, Verse 38 und 39.

${ }^{633}$ Koranischer Ausdruck, siehe Sure 44, Vers 47 oder Sure 37, Vers 55.
} 
als auch die Neğdregionen ${ }^{634}$ dieser Welt aus, und er gab ein wahrhaftes Versprechen, dass seine Glaubensgemeinschaft einst über die Hügel und Niederungen ${ }^{635}$ der gesamten ihm von Gott anheim gegebenen bevölkerten Landschaften dieser Erde herrschen werde.

Gott möge am unfehlbaren Imam und am mit göttlichen Erkennungszeichen ausgestattenen Mahdī Wohlgefallen haben, durch dessen Licht Gott die Leuchte des Islam und seinen Pfeiler aufgerichtet hat, durch welchen Er das einst geoffenbarte Gesetz wieder zur Geltung hat gelangen lassen; Gott möge am unfehlbaren Imam und Mahdī Wohlgefallen haben, welcher die Finsternis ausgetilgt und der wahren Gottesanbetung zur ihrer vollkommensten Entfaltung verholfen hat. Gottes Ratschluss war es, dass seine erhabene Botschaft und die den Weg der Rechtleitung führenden und auf ihm wandelnden Worte seiner Sendung die Zerstreuung und Zerteilung des Unwahren zur Folge haben sollten sowie auch die Rückkehr des Islam nach seiner zweiten Fremdheit ${ }^{636}$ und nach seiner Entblößung.

Gott möge am vortrefflichsten Nachfolger des Mahdi und an seinem an Gottesfurcht und an Rechtleitung nicht zu übertreffenden Gefährten, an unserem Herrn, dem Befehlshaber der Gläubigen Wohlgefallen haben, dessen Vermächtnis Gott (nach dem Hinscheiden des Mahdi) das Amt des Nachfolgers des Mahdi und die aus diesem Amt erwachsenden Obliegenheiten sein ließ und den Er auserwählt hat, die Festigung und Ausbreitung Seiner erhabenen (almohadischen) Sache vollkommen zu machen. Er (d. h. der Befehlshaber der Gläubigen) folgte dem edlen Beispiel des Mahdi, nahm die Sache Gottes wahr, dabei seinen ganzen Fleiß darauf verwendend, sie voranzutreiben ${ }^{637}$, und äußerste Anstrengungen unternehmend, ihr zum Obsieg zu verhelfen, bis das Wort des

\footnotetext{
${ }^{634}$ Zum arabischen Satz an dieser Stelle (Mağmū' rasā'il muwaḥhidīya, S. 181) „wa-'amara bi-wuğūbihā wa-ilzāmihā wa-'țịādihā ilā yaum ad-dīn wa-'ntiẓāmihā tahā’im al-'ālam wa-nuğūdahā“ muss folgendes angemerkt werden: „Nağd“, dessen Plural „nuğūd“ lautet, bedeutet im Arabischen allgemein „Hochgrund“ und bezeichnet gleichzeitig die im Deutschen als „Nedschd“ bekannte Region der Arabischen Insel, welche von Anhöhen geprägt ist. Die Region namens „Tihāma“, dessen im Text gebrauchter Plural „tahā’im“ allerdings nicht belegt ist, bezeichnet den schmalen ebenen Küstenstreifen im Westen der Arabischen Insel.

${ }^{635}$ Der im arabischen Satz an dieser Stelle (Mağmū' rasā’il muwaḥhidīya, S. 181) gebrauchte Plural „wuhūd“" ist in „Lisān al-'arab“ nicht belegt.

636 „Gurbat al-islām“ geht auf einen Ausspruch Mohammeds zurück, den Muhammad Ibn-Tumart im eigens diesem Thema gewidmeten Kapitel über die einst eintretende zweite „Fremdheit des Islam“, der bereits einmal am Anfang fremd gewesen sei, zitiert. Siehe hierzu „Le Livre de Mohammed Ibn Toumert“ (S. 266 f.)

${ }^{637}$ Im arabischen Text steht an dieser Stelle (Mağmū' rasā'il muwaḥhidìya, S. 182) ,wa-nahaḍa bi-amr Allāh bādilan fī tamšìyat haddihī wa-bālig̉an fī nuṣratihī mağhūdahü“،, was m. E. keinen Sinn ergibt. Ferner bleibt das zu „,bādilan“ gehörende Objekt unerwähnt und das den almohadischen Briefen so sehr eigene Stilmittel, das Mitzuteilende mindestens zweimal mit anders lautenden, von ihrem Sinn her jedoch ähnlichen Worten bzw. Sätzen zu wiederholen, gelangt nicht zur Anwendung. Daher ist es nicht
} 
Mahdi sich so weit wie die Horizonte reichen ausgebreitet hat und bis seine einzig wahre Rechtleitung und seine Botschaft in den nahen und fernen Landstrichen der Erde Geltung erlangt haben.

Gesegnet sei sein makelloser Sprößling und sein dem reinen Geschlecht und dem reinen Geblüt entstammender Sohn, unser Herr, der Imam, der Befehlshaber der Gläubigen, Sohn unseres Herrn, des Kalifen, des Imams, des Befehlhabers der Gläubigen, der ihn für das Innehaben seines Ranges erwählt hat, ihn mit dessen Gewändern bekleidet hat und ihm durch seine Auserwählung und Auserkiesung ${ }^{638}$ das Glückhafte und das Löbliche seines höchsten Ranges hat angedeihen lassen. Gesegnet sei er, dem sein Vater bei der Fortsetzung seiner Sache (bis zu ihrer Vollkommenheit hin), bei ihrer Festigung und Stärkung sein (in allen Lebenslagen) sich als recht und zutreffend erweisendes Urteilsvermögen vererbt (wörtl. beschenkt ${ }^{639}$ ) hat samt seiner Sieghaftigkeit, die seine (d. h. seines Sohnes) siegreichen Fahnen und Banner begleitet, und samt seinem Erfolgreichtum, der die Gewährung des Beistandes Gottes ihm gegenüber zeitigt und von den Gottes wahrhaften Verheißungen die gegenwärtigen und die noch kommenden in Erfüllung gehen lässt sowie von Seiner umfassenden Gnade und Seiner unermeßlichen Macht die mehrfache Erweisung Seiner Wohltaten bewirkt und die Sieghaftigket Seiner mächtigen (almohadischen) Sache noch lange, lange Zeit fortdauern lässt, nämlich solange Tage in ununterbrochener Reihe einander nacheilen und Monate und Jahre aufeinander folgen.“

Abschließend sei noch angemerkt, dass die obige Zusammenfassung der Imamatslehre, die ein um das andere Mal in jedem offiziellen almohadischen Brief verkürzt laut verkündet wurde, auch insofern äußerst interessant ist, als sie ein tieferes, über das Wörtliche hinausgehendes Verständnis des spezifischen almohadischen Sprachgebrauchs erlaubt. Die im offiziellen almohadischen Schrifttum häufig anzutreffende Formulierungen wie „reuige Umkehr zu Gott“, „Buße“, „Abfall vom Islam“ und dergleichen mehr haben für die zeitgenössischen Adressaten vor diesem gedanklichen Hintergrund die Untertänigkeit gegenüber den Almohaden bzw. das Gegenteil davon konnotiert ${ }^{640}$. Erst vor diesem Hintergrund hellt sich ferner der u. a. beabsichtigte, propagandistisch relevante Zweck der vielen koranisch geprägten

unwahrscheinlich, dass der angeführte Satz ursprünglich wie folgt lautete: „wa-nahaḍa bi-amr Allāh bādilan fī tamšìyatihī ğaddahū wa-bālig̉an fī nuṣratihī mağhūdahū“،.

${ }^{638}$ Im arabischen Original an dieser Stelle (Mağmū' rasā'il muwaḥhidīya, S. 182) steht „min iștifā'ihī wa-

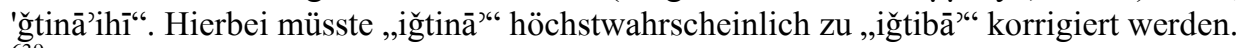

${ }^{639}$ Das an dieser Stelle gebrauchte arabische Verb „habā“ (Mağmū' rasā’il muwaḥhidīya, S. 182) ist als „habā" gelesen und übersetzt worden.

${ }^{640}$ Siehe hierzu auch Kapitel 2.2. 
Bezeichnungen für die Widersacher der Almohaden auf: auch auf dieser Ebene sollte die almohadische Herrschaft ein um das andere Mal sakralisiert und legitimiert und die Gegner als schlechthin un-islamisch diffamiert werden.

\subsection{Verbreitungsweise}

Die Bekanntgabe der almohadischen Verlautbarungen an die Allgemeinheit war strikt mündlich. Erfreulicherweise besitzen wir heute authentische Berichte aus der Feder IbnṢāḥib-aṣ-Ṣalāts, der nicht nur Zeitgenosse der Geschehnisse, von denen die unten zu zitierenden Briefe handeln, sondern auch - nachweislich in mindestens einem Fall Augenzeuge ihrer Verbreitungsweise war. Die Ausführungen dieses Autors geben somit sehr genau Aufschluss darüber, wie und in welchem Rahmen die Bekanntgabe der almohadischen Schreiben vonstatten ging, und sind insofern einzigartig, als dieser „formale“ Aspekt in den sonstigen Überlieferungen kaum Beachtung gefunden hat.

Nach der Einnahme al-Mahdiyas von 'Abd-al-Mu'min bei der almohadischen Unterwerfung Ifrīqīyas im Jahr 1160 habe man nach Sevilla einen Brief mit der Beschreibung dieses almohadischen Sieges gebracht, dem ein Gedicht beigefügt gewesen sei ${ }^{641}$. „Daraufhin befahl unser $\operatorname{Herr}^{642}$, der mächtigte Befehlshaber AbūYa'qūb, der später der Befehlshaber der Gläubigen wurde, allen in Sevilla befindlichen Menschen und Ṭālibs, diesen überbrachten almohadischen Brief zu kopieren, auswendig zu lernen und dessen Inhalt weiterzuerzählen. Er wies ferner darauf hin, dass dieser Brief auf Anordnung des Kalifen persönlich verfasst wurde. Die Menschen leisteten seinem Befehl Folge und flehten Gott in ihren Bittgebeten darum, die Macht und die Herrschaft des Befehlshabers der Gläubigen fortdauern zu lassen. Der Brief und die ihm beigefügten Verse wurden verlesen, man hat sie von den Moscheekanzeln herab verkündet, und sowohl die in Sevilla befindlichen Stadt- als auch Landbewohner haben all diese Siegesmeldungen vernommen. Anschließend sandte man diese frohen Meldungen an die Untertanen und Stämmen, und die Boten schwangen sich auf ihre Pferde und sprengten rasch mit den Sieg verkündenden Versen dieses Briefes hin zu den umliegenden Gebieten und Dörfern. Und der Schall der wahren und aufeinander folgenden Mitteilungen dieses Briefes gellte in den Ohren aller Ungläubigen. Gott sei Preis dafür! Unser Befehlshaber und Herr befahl, anlässlich dieser Siegesmitteilungen, an welchen aller Augen Gefallen fanden und welche für die angstvoll durchwachten

\footnotetext{
${ }^{641}$ al-Mann bi-'l-imāma, S. 70 ff.

${ }^{642}$ Den Titel ,,as-saiyid“" trugen im Almohadenreich die männlichen Nachkommen 'Abd-al-Mu'mins.
} 
Nächte angemessene Belohnung waren ${ }^{643}$, die Trommeln zu rühren, dank welchen die Bekanntgabe der Botschaft zu großem Genuss wurde. Er (d. h. Abū-Ya'qūb Yūsuf) ließ ferner die Almohaden, die gesamten Menschen in Sevilla sowie das dort stationierte almohadische Kontingent dreißig Tage lang speisen. Während dieser Zeit der Speisung wurden die Trommeln gerührt, allgemeine Freude dauerte fort, die Dichter trugen ihre Beglückwünschungen in Gedichten vor und machten die Freude vollkommen mit den aufrichtigen Wünschen. “644

Auf das von 'Abd-al-Mu'min eingegangene Schreiben habe Abū-Ya'qūb Yūsuf seinerseits ein Antwortschreiben abfassen lassen, das aus einem Text in Prosa sowie einem Gedicht bestanden habe ${ }^{645}$. Darauf sei von 'Abd-al-Mumin ein weiteres Schreiben überbracht worden, das er nach dem Abschluss der Unterwerfung von Ifrīqīya bei seiner Rückkehr nach Maghreb in seinem Lager bei Constantine im Mai des Jahres 1160 habe abfassen lassen und das die Bestätigung seiner Rückkehr sowie den Sieg der Almohaden über Gafsa und das Bekenntnis der Banū-Sulaim zum Almohadentum enthalten habe. Diesem Brief sei auch ein Gedicht beigefügt gewesen $^{646}$. „Beim Eingang dieses Schreibens samt dem Siegesmitteilungen enthaltenden Gedicht [von 'Abd-al-Mu'min] wurden die Almohaden mit Freude erfüllt und erlangten die unumstößliche Gewissheit über den Beistand Gottes [zugunsten der Almohaden] und Sein nahes Eingreifen zur Sieghaftigkeit der Almohaden. Dieses Schreiben wurde von den Moscheekanzeln herab verlesen, und die darin enthaltenen Siegesmitteilungen wurden mehrfach den Untertanen und den Stämmen verkündet. Die Menschen, die Taàlibs, die Almohaden und die gesamten Angehörigen der Unterschicht fertigten Abschriften von diesem erwähnten beigefügten Siege verkündenden Gedicht an, lernten es auswendig, verwahrten es, versahen es mit einem Schutzumschlag und fügten es ihren Gedichtsammlungen hinzu. Diese Siegesmeldungen erquickten mit ihrer [sprachlichen] Vortrefflichkeit unseren mächtigsten und verehrten Herrn Abū-Ya'qūb Yūsuf - Gott möge Wohlgefallen an ihm finden - sowie die gesamten Almohaden Gott möge ihnen Seinen Beistand angedeihen lassen - in Sevilla und im Umland. Diese

\footnotetext{
${ }^{643}$ Dies scheint der Sinn des arabischen Textes an dieser Stelle ,wa-amara al-amīr as-saiyid bi-qar` attubūl 'alā hadihīi al-masārr allatī istaladِdat bihā al-muqal wa-ḥamidat (aiy al-muqalu) gìābāt al-karā“" (alMann bi-'l-imāma, S. 74) zu sein.

644 al-Mann bi-'l-imāma, S. 74-75. In ,al-Bayān al-muğrib“ (S. 65) findet sich eine verkürzte Fassung dieses Berichts.

${ }^{645}$ al-Mann bi-'l-imāma, S. 75.

${ }^{646}$ al-Mann bi-'l-imāma, S. 77 f.
} 
Siegesmeldungen wurden ihm verkündet ${ }^{647}$, die einzelnen Koranverse ihrer Suren in vollkommener und vollendeter Weise rezitiert und die darin enthaltenen belehrenden Beispiele vorgetragen ${ }^{648}$. “

Nach der Entsendung von almohadischen Truppen nach al-Andalus und ihrem Sieg über Ibn-Mardan̄̄š samt seinen Anhängern in der Nähe von Murcia im Jahr 1165 wurde an den Palast des almohadischen Kalifen in Marrakech ein Brief mit der Schilderung des Sieges sowie der damit im Zusammenhang stehenden Geschehnisse gesandt ${ }^{649}$. Bei der Ankunft der Boten mit dem genannten Schreiben habe sich der Verfasser von ,al-Mann bi-'l-imāma“" vor dem kalifalen Palast befunden und Ausschau nach Neuigkeiten über den Verlauf dieser almohadischen Unternehmung gehalten ${ }^{650}$. „In diesem Moment betraten die Boten mit der Siegesmeldung den Hof des kalifalen Palastes ohne vorhergehende Benachrichtigung oder Ankündigung, und in ihren Händen hielten sie die zusammengerollten Banner von Ibn-Mardan̄̄̌s. Alle Menschen erschraken zunächst, da die Boten ohne Ankündigung und ohne Erlaubnis eintraten, doch dann erkannten sie an den lauten Freudenschreien dieser Boten, dass sie die Siegesmeldung überbrachten. Da brach die Gesamtheit der Menschen in Rufe ,Gott ist groß!‘ und ,Es gibt keinen anderen Gott außer dem Gott!‘ aus, die Trommeln wurden gerührt und die Freude darüber war unaufhörlich. Der Befehlshaber (d. h. Abū-Ya'qūb Yūsuf) befahl sogleich allen dort befindlichen Ṭālibs und den übrigen Menschen, in den Palast einzutreten, um der Verlesung dieses die Siegesmeldung und den Obsieg der Almohaden verkündenden Schreibens beizuwohnen. Der Rechtsgelehrte namens Abū-Muhammad al-Malaqī las es anschließend den Versammelten vor. Danach wurde dieses Schreiben in der Großen Moschee (von Marrakech) der Gesamtheit der Menschen vorgelesen. “651 Diesem Brief sei ein Gedicht beigefügt gewesen, das der Befehlshaber Abū-Ya'qūb Yūsuf danach bei seiner Zusammenkunft mit einigen hohen almohadischen Würdenträgern habe vorlesen $\operatorname{lassen}^{652}$.

Im Jahre 1167 sei ein antialmohadischer Aufstand, den ein gewisser Sab` Ibn-Munahfād im Norden des heutigen Marokkos organisiert hätte, niedergeschlagen worden ${ }^{653}$. „Nach der Beendigung dieser vom Sieg gekrönten erwähnten almohadischen Unternehmung

\footnotetext{
${ }^{647}$ Im arabischen Satz an dieser Stelle (al-Mann bi-'l-imāma, S. 82) „wa-ğulibat ladaihī mahāāin șūwarihā" ist sehr wahrscheinlich nicht „ğulibat", sondern ,ğulīyat" gemeint.

6́48 al-Mann bi-'l-imāma, S. 82.

${ }^{649}$ Historia política del imperio almohade, Bd. 1, S. $226 \mathrm{f}$.

${ }^{650}$ al-Mann bi-'l-imāma, S. 200 f.

651 al-Mann bi-'l-imāma, S. 201. Eine stark verkürzte Fassung dieses Berichts findet sich auch in ,,alBayān al-muğrib“ (S. 90).

${ }^{652}$ al-Mann bi-'l-imāma, S. 209.
} 
befahl der mächtigste, der, an dem man das Wohlgefallen hat, und der gerechteste Befehlshaber, den Erfolg dieser Unternehmung mit diesem (nachfolgenden) Brief bekannt zu geben. Er ließ allen Almohaden, Ṭālibs und Šaihs sowohl in Maghreb als auch in al-Andalus den Verlauf dieser Unternehmung und ihren überwältigenden Sieg, der die innigsten Hoffnungen der Hoffenden in Erfüllung gehen lässt, sowie den Tod des Elenden, des Irrenden namens Sab Ibn-Munahfāad ${ }^{654}$, und seine Kreuzigung verkünden ${ }^{655}$ ،

Im Jahre 1168 habe Abū-Ya'qūb Yūsuf beschlossen, der bis dahin nach dem Tode seines Vaters ${ }^{656}$ nur den Titel „Befehlshaber“ getragen hätte, sich mit dem vollständigen Titel, d. h. „Befehlshaber der Gläubigen“, anreden und den Huldigungseid ihm gegenüber erneut ablegen zu lassen. Ein diese Entscheidung bekannt gebendes Schreiben sei daraufhin an den almohadischen Statthalter von Sevilla mit der Anordnung ergangen, allen in dieser Stadt sowie in al-Andalus befindlichen Almohaden diesen erneuten Huldigungseid abzunehmen. Der erwähnte Statthalter habe seinerseits eine Abschrift des bei ihm eingegangenen Schreibens an den Statthalter von Granada gesandt $^{657}$. „Abū-'Abdallāh (d. h. der almohadische Statthalter von Granada) ließ die Gesamtheit der Menschen in Granada sich versammeln und das eingegangene kalifale Schreiben wurde in seinem Beisein ${ }^{658}$ ihnen allen von den Kanzeln herab verlesen. Sowohl Stadt- als auch Landbewohner erlangten Kenntnis über den Inhalt dieses Briefes und beeilten sich, den Huldigungseid abzulegen und den Titel „Befehlshaber der Gläubigen“" anzuerkennen, und ihnen allen wurde somit die Wonne des Glücks (wörtl. sie rochen den Wind des Glücks) durch diese ihre Zustimmung zuteil ${ }^{659}$ “،

Fast allen angeführten Berichten ist gemeinsam, dass die eingegangenen Schreiben in den Moscheen verlesen wurden. Wenn man die Möglichkeiten der Nachrichtenübermittlung jener Zeit berücksichtigt, so mag Moschee als Verküdigungsort der offiziellen Verlautbarungen nahe liegend gewesen sein, um einer möglichst großen Zahl der Untertanen etwas bekannt zu geben. Doch abgesehen von diesem praktischen Gesichtspunkt hatte die Wahl dieses islamischen sakralen Baus noch

\footnotetext{
${ }^{653}$ al-Mann bi-'l-imāma, S. 231 f.

${ }^{654}$ In ,,al-Bayān al-mugrrib“ (S. 95) wird der Name dieses Aufständischen als Sab` Ibn-Mun`aqād und in „Kitāb al-'ibar“ (Bd. 6, S. 498) als Sab` Ibn-Munaġfād überliefert.

${ }_{655}$ al-Mann bi-'l-imāma, S. 233.

${ }^{656}$ 'Abd-al-Mu'min ist im Frühjahr 1163 gestorben (Historia política del imperio almohade, Bd. 1, S. 208 f.).

${ }^{657}$ al-Mann bi-'l-imāma, S. 258 f.

${ }^{658}$ Im Satz des arabischen Originals an dieser Stelle (al-Mann bi-'l-imāma, S. 259) ,wa-quri'a 'alaihim alkitāb al-karīm bi-maḥ̣aratin fauqa al-manābir“ ist höchstwahrscheinlich nicht „bi-maḥ̣aratin“, sondern „bi-maḥ̣arihī" gemeint.
} 
eine weitere Wirkung zur Folge: in der Moschee, diesem Versammlungs- und Anbetungsort der Muslime, in dem während der Gottesdienste Abschnitte aus dem Koran rezitiert werden, eben dort wurden auch von den Kanzeln herab die almohadischen Briefe verlesen, deren Inhalt in den almohadischen Quellen bezeichnenderweise als in Koransuren gefasst beschrieben wird, die sich aus Koranversen zusammengesetzt hätten ${ }^{660}$; auch im Hinblick auf ihre stilistische Form der häufige Gebrauch der Reimprosa - als auch auf ihre Wortwahl - siehe hierzu z. B. die Bezeichnungen für Feinde in den Kapiteln 2.7., 4.4., 5.5. und 6.4. sowie die Belege für eingeflochtene Koranzitate und -bezüge in den jeweiligen Zusammenfassungen des historischen Kommentars - suchte man mit diesen offiziellen Schriftstücken bewußt in die formale wie sprachliche bzw. semantische Nähe des islamischen Offenbarungstextes zu gelangen.

\subsection{Endergebnis und Ausblick}

Die almohadischen Briefe bilden einen wichtigen Mosaikstein, der das geschichtliche Bild des Maghreb im Mittelalter zu ergänzen hilft. Allerdings sind sie erst vor dem Hintergrund anderer überlieferter Quellenaussagen verständlich und bewertbar. Historische Geschehnisse verflechten sich in ihnen in innigster Weise mit den von offizieller Seite veranlassten propagandistisch motivierten Darstellungen, sodass eine objektive Unterscheidung zwischen Geschichtlichem und Fiktivem nur auf einer soliden Grundlage der historischen Überlieferung möglich sein kann, die im erforderlichen Maße häufig nicht gegeben ist.

Um die almohadischen Briefe in ihrem geschichtlichen Kontext - und somit ihre Funktion - besser zu verstehen, muss man berücksichtigen, dass sie einen wesentlichen Teil, vielleicht sogar den Grundpfeiler des offiziellen almohadischen Nachrichtenwesens bildeten. Vor dem Hintergrund der Tatsache, dass in jener Zeit die Informationen ausschließlich mündlich übermittelt wurden, wird die Bedeutung der almohadischen Schriftstücke für die Herrscher in Marrakech verständlich, die unter

\footnotetext{
${ }^{659}$ al-Mann bi-'l-imāma, S. 259.

660 al-Mann bi-'l-imāma, S. 82. Ferner konnte die Allegorie, man habe die Koransuren und -verse einer Siegesmeldung oder einer Dankesbekundung rezitiert, die neutrale Bedeutung haben, man habe diese Siegesmeldung oder Dankesbekundung laut vorgetragen bzw. geäußert (al-Mann bi-'l-imāma, S. 79, Mağmū'a ğadīda, Bd. 1, S. 284). Darüber hinaus ist in den almohadischen Briefen der Ausdruck ,,al-āyāt al-baiyināt", d. h. die klaren Koranverse bzw. Wunderzeichen, nicht selten und er konnte in Verbindung mit anderen Adjektiven vorkommen. Damit werden überwiegend die angeblich ob ihrer Gewaltigkeit an Wunder grenzende militärische Erfolge der Almohaden konnotiert, die ihnen dank göttlichem Eingreifen zuteil geworden sein sollen (Mağmū' rasā’il muwaḥhidīya, S. 19, 23, 39, 72, 80, 105 und 210).
} 
stetigem hohem Legitimationsdruck stehend ${ }^{661}$ sich sowohl mit religiös motivierten als auch mit anders bedingten Aufständen auseinanderzusetzen hatten. Nicht zufällig wurden die Briefe unmittelbar nach den in ihnen geschilderten Geschehnissen verfasst und rasch $^{662}$ den Adressaten übermittelt. In den gleichen Zusammenhang gehört auch die in vielen an die Allgemeinheit adressierten Schreiben deutlich formulierte Bestrebung, einen möglichst großen Streuungsgrad dieser Schrifstücke zu erreichen ${ }^{663}$ und ihren Inhalt einer möglichst großen Zahl von Untertanen bekannt zu geben ${ }^{664}$. Die almohadischen Briefe waren also in zeitlicher Hinsicht die ersten Informationsquellen, die den Untertanen die offizielle Perspektive vermittelten und ihre Sicht auf die mitgeteilten Ereignisse somit nachhaltig prägen sollten. Andere Informationen wie auch Details der bereits feierlich bekannt gegebenen offiziellen schriftlichen Mitteilungen können später, etwa nach der Rückkehr der almohadischen Armee durch ihre Angehörigen an die Bevölkerung gelangt sein, doch muss man davon ausgehen, dass dies bei den militärischen Unternehmungen der Almohaden etwa in den Zentralen Maghreb oder nach Ifrīqìya erst Monate nach der ersten Verlesung bzw. nach den ersten Verlesungen $^{665}$ möglich gewesen war.

Die Bekanntgabe der almohadischen Briefe war nach heutigem Quellenstand ein feierlich-religiöser Akt. Die entsprechenden Überlieferungen diesbezüglich lassen dies eindeutig erkennen ${ }^{666}$. Allein der Ort der Verlesung muss sich bestimmend auf den mitzuteilenden Inhalt ausgewirkt haben. Denn es ist kaum vorstellbar, dass in diesem feierlich-religiösen Rahmen almohadische Rückschläge und Niederlagen hätten laut und freimütig verkündet werden können. In diesem Zusammenhang erscheint es angebracht,

\footnotetext{
${ }^{661}$ Wie im Kapitel 8.2. beschrieben, musste nach den Vorstellungen Ibn-Tūmarts mit der almohadischen Machtergreifung das Zeitalter der Gerechtigkeit und der Billigkeit eintreten, und an diesem Anspruch mussten sich die almohadischen Machthaber messen lassen. Alle Briefe der Sammlung „Mağmū` rasā’il muwahhidìya" an die Allgemeinheit stellen in ihrem einleitenden Teil diesen Anspruch ihren Rezipienten deutlich vor Augen und lassen keine Anzeichen dafür erkennen, dass er an seiner Aktualität zumindest zum Ende der Herrschaft von Muhammad an-Nāsir (1199 - 1213) etwas verlor.

${ }^{662}$ In ,al-Mann bi-'l-imāma“ wird berichtet, wie der almohadische Briefzuträger (arab.: ar-raqqās) einen in Ifrīqīya abgefassten kalifalen Brief zu seinen Adressaten in Sevilla und Granada schnellstmöglich brachte (S. 77 f.).

${ }^{663}$ So findet sich - zusätzlich zu den im vorangegangenen Kapitel zitierten almohadischen Schriftstücken - im abschließenden Teil der Briefe Nr. 20, 22, 26, 27, 28, 29, 30, 33, 34 und 37 die allgemeine Aufforderung an die Empfänger, den bekannt gegebenen Inhalt nah und fern zu verkünden, wobei die Briefe 28, 29 und 33 hiervon daneben den ausdrücklichen Aufruf enthalten, diese Mitteilungen schriftlich, d. h. durch Anfertigung und Verschickung von Kopien, dem jeweiligen Umland zukommen zu lassen.

${ }^{664}$ al-Muwaḥhidūn fi 'l-Ġarb al-Islāmī, S. 164.

${ }^{665}$ Dabei muss man berücksichtigen, dass in den überlieferten Siegesmeldungen an die Allgemeinheit im abschließenden Teil fast immer Aufrufe sich finden, von den eingegangenen Siegesmeldungen Abschriften zu machen und an alle benachbarten Orte zu senden. Nimmt man diese Aufforderungen ernst, so heißt es, dass in einer Stadt, Ortschaft usw. mehrere auf dasselbe Ereignis Bezug nehmende Siegesmeldungen verlesen werden konnten.
} 
auf folgende Beobachtung, auf die bereits im Verlauf der Arbeit kurz hingewiesen wurde, etwas näher einzugehen: Bei der Analyse der Briefe Nr. 30 und $32^{667}$ wurde festgestellt, dass die wiedergegebenen entsprechenden Berichte Ibn- Idāāīs in einigen wesentlichen Punkten von den Darstellungen der almohadischen Briefe abweichen. Dies war vor dem Hintergrund der Vermutung umso bemerkenswerter, als der genannte Autor sich bei seinen Berichten auf die nur partiell überlieferte Chronik ,al-Mann bi-'1imāma“" stützte. Auch wenn der endgültige Beweis, dass in den beiden betreffenden Fällen diese Chronik und kein anderes Werk Ibn-'Idārī als Vorlage gedient hatte, nicht stichhaltig erbracht werden kann ${ }^{668}$, so kann zumindest als erwiesen gelten, dass der Verfasser der Abschnitte, die Ibn-'Idārī entlehnt bzw. verkürzt wiedergibt, eindeutig proalmohadischer Gesinnung war ${ }^{669}$. Wir haben also in den Briefen Nr. 30 und $32 \mathrm{zu}$ zwei unterschiedlichen Begebenheiten je zwei ursprünglich almohadische Überlieferungen, die zum einen in den almohadischen Briefen und zum anderen in den von Ibn- 'Idārī zitierten Berichten auf uns gekommen sind, und beide lassen sich trotz, oder besser vielleicht: gerade wegen der Ausführlichkeit, mit der in ihnen die Geschehnisse nachgezeichnet werden, nicht ohne weiteres in eine übereinstimmende Abfolge von Ereignissen einfügen. Für den aufgezeigten Sachverhalt bietet sich folgende Erklärungsmöglichkeit an. Da die almohadischen Briefe für die öffentliche Bekanntgabe einer möglichst großen Anzahl von Menschen bestimmt waren, musste das Bekanntzugebende zu einleuchtenden, in ihrem Verlauf einfachen Ereignismustern verdichtet werden, um dem öffentlichen Charakter des laut Vorgetragenen und der Vielzahl der Anwesenden Rechnung zu tragen: Das zu Schildernde wurde dementsprechend $\mathrm{zu}$ als wesentlich erscheinenden und einprägsamen Höhepunkten gerafft und das Übrige mit anscheinend den eigenen Topoi ${ }^{670}$ weitgehend folgender proalmohadischer und religiöser Rhetorik ${ }^{671}$ verallgemeinert. Nicht zuletzt darin scheint die Auslassung aller Elemente, die die genannten Ereignismuster mit - aus offizieller Sicht - unnötigen, zu sehr ins Detail gehenden Darstellungen hätten überladen und letztlich verwischen können, sowie die Überzeichnung von Motiven,

\footnotetext{
${ }^{666}$ Siehe Kapitel 8.3.

${ }^{667}$ Siehe Kapitel 5.4. und 7.3.

${ }^{668}$ Siehe hierzu Fußnote Nr. 446 im Kap. 5.4.

${ }^{669}$ Der proalmohadische Grundtenor der von Ibn-'Idārī zitierten Berichte spiegelt sich beispielsweise in den jeweiligen Bezeichnungen für die almohadischen Gegner, für ihr Handeln sowie für die Anhänger des Muhammad Ibn-Tūmart wider; diese Bezeichnungen lehnen sich stark an den in den almohadischen Briefen üblichen Sprachgebrauch (al-Bayān al-muggrib, S. 188 ff., 193 f.) an.

${ }^{670}$ Siehe dazu die in den Kapiteln 2.3., 5.6. und 6.4. zusammen getragenen Belege.

${ }^{671}$ Siehe dazu die in den Kapiteln 2.7., 4.4., 5.5. und 6.4. zusammen getragenen Quellenangaben zu den Bezeichnungen für die almohadischen Gegner.
} 
Handlungsweisen und Eigenschaften der Almohaden bzw. ihrer Gegner begründet zu liegen. Bei der Vorlage Ibn-'Idārīs hingegen handelte es sich um ein historiographisches, als Chronik konzipiertes Werk über das almohadische Reich, in dem die Ereignisgeschichte jener Epoche als offizielle Dynastiegeschichte, die aller Wahrscheinlichkeit nach nicht für den öffentlichen Vortrag gedacht war, - von einem durch und durch proalmohadischen Grundton bestimmt - ausführlich behandelt wurde.

Bei der obigen Analyse von einigen Briefen wurde sichtbar, wie offensichtliche Rückschläge sowie andere „Unrühmlichkeiten“ der almohadischen Truppen auf dem Schlachtfeld stillschweigend übergangen bzw. in ihren Sieg umgedeutet wurden ${ }^{672}$; die bei diesen Schreiben festgestellte, sie charakterisierende vereinfachende Verdichtungstendenz, von der im eben voraufgegangenen Absatz gesprochen wurde, konnte nur so lange ohne sich in größere Widersprüche zu verwickeln angewandt werden, wie die Almohaden in den kriegerischen Auseinandersetzungen mit ihren Widersachern letztlich doch den Sieg davonzutragen vermochten. Einen gänzlich anderen, aber nicht minder aufschlussreichen Fall bildet nun die folgende offizielle almohadische Darstellung der Schlacht bei Las Navas de Tolosa, auf die bereits im Kapitel 5.6. hingewiesen wurde. Im Jahre 1212 kam es zwischen den vereinigten christlichen Truppen unter der Führung von Alfons VIII. von Kastilien und dem von Muḥammad an-Nāṣir befehligten almohadischen Heer zu dieser folgenreichen Schlacht, in welcher dem Letzteren eine vernichtende Niederlage beigebracht wurde. Muhammad an-Nāṣir (1199-1213) hat danach ein Schreiben mit der Schilderung dieser Ereignisse abfassen lassen, von welchem längere Abschnitte u. a. bei Ibn-'Idārī überliefert sind. Ein großer Teil hiervon ist der Beschreibung der Ankunft von christlichen Verbündeten samt „unzähligen Scharen ihrer Truppen“ aus ganz Europa nach Toledo gewidmet ${ }^{673}$. Das eigentliche Schlachtgeschehen nimmt hingegen einen geringen Teil ein und ist sehr allgemein gehalten. In den wenigen diesbezüglichen Zeilen ist u. a. davon die Rede, dass das Ergebnis dieses einen Schlachttages zwar zugunsten der Christen, das letztliche Ergebnis jedoch zugunsten der Muslime gewesen sei. Daran schließen sich Beteuerungen an, dass die Almohaden sieghaft, unversehrt und ohne dass ein einziger

\footnotetext{
${ }^{672}$ Siehe hierzu Kapitel 4.6., 5.4. und 7.3.

${ }^{673}$ Die diesbezüglichen Ausführungen des Briefes schildern die unbezifferbar gewaltigen Mengen der christlichen Truppen, im Vergleich zu denen - so der suggerierte Eindruck - die almohadischen Kontingente sich zahlenmäßig unterlegen ausnehmen. Huici Miranda (Historia política del imperio almohade, Bd. 2, S. 427) hält die maximal hunderttausend almohadischer und sechzigtausend christlicher Kämpfer für am ehesten wahrscheinlich. Daraus folgt, dass die im Brief gezeichneten Kräfteverhätnisse genau umgekehrt gewesen sein dürften.
} 
von ihnen gefallen wäre das Schlachtfeld verlassen hätten ${ }^{674}$. Den Abschluss des Briefes bildet der folgende Satz: „Dies haben wir euch mitgeteilt, auf dass ihr diese Begebenheit in ihrer Wirklichkeit und dieses üble Geschehnis in seinem Wesen begreift und auf dass ihr wisst, dass von den Almohaden keiner zu beklagen war und weder viele noch wenige von ihnen zu Schaden gekommen sind.“675 Dabei legt die geäußerte Absicht, die Adressaten den ungünstigen Schlachtverlauf in seiner eigentlichen Wirklichkeit begreifen zu lassen, nahe, dass der Ausgang der Kämpfe bei Las Navas de Tolosa schon vorher bekannt geworden ist und dass die offizielle Darstellung im Brief den nachherigen Versuch bildet, zur Niederlage Stellung zu nehmen und diese irgendwie zu erklären, d. h. mit der almohadischen Doktrin in Einklang zu bringen. Dies geschieht vor allem mit dem Hinweis darauf, dass kriegerische Auseinandersetzungen nun mal Gottes Fügung gemäß mit wechselndem Erfolg geführt würden und dass Muslime auch in den Zeiten Mohammeds sowie seiner Nachfolger nicht immer als Sieger aus ihren Kämpfen hervorgegangen seien ${ }^{676}$. Der Zweck dieses Schriftstücks scheint somit darin bestanden zu haben, den Adressaten die offizielle Sichtweise glaubhaft zu machen. In diese Richtung weist auch der Kommentar von 'Abd-al-Mun'im al-Himyarī, mit dem der Autor von „Kitāb ar-raự al-mi'ṭār“ interessanterweise die Zusammenfassung der Ereignisse bei Las Navas de Tolosa in seinem Werk abschließt: „,an-Nāṣir hat bei seiner Rückkehr (vom Schlachtfeld) nach Sevilla die Menschen durch ein Schreiben beschwichtigt, dessen Inhalt gehaltlose rhetorische Floskeln waren. “677

Dem genannten feierlich-religiösen Verlesungsrahmen auf der einen entspricht auf der anderen Seite die sprachliche Form der Briefe, die sich durch ihren sehr anspruchsvollen, gehobenen Stil auszeichnet und sich in ihrer Wortwahl am koranischen Offenbarungstext orientiert. Wenn man die überlieferten almohadischen Schriftstücke aus der Zeit vor der gewaltsamen Entmachtung der Almoraviden und diejenigen aus der Zeit danach betrachtet, so erkennt man einen deutlich spürbaren qualitativen Unterschied. Die frühen almohadischen Schreiben lassen sich unter diesem Gesichtspunkt dahingehend beschreiben, dass sie nach keinem einheitlichen Aufbaumuster gestaltet sind und in sprachlicher Hinsicht noch recht schlicht, ja schmucklos wirken. Diese Beschaffenheit äußert sich in direkter konkreter Sprache,

\footnotetext{
674 al-Bayān al-mugìrib, S. 263 ff.

675 al-Bayān al-muğrib, S. 265.

676 al-Bayān al-muġrib, S. 265.

${ }^{677}$ Der Satz an dieser Stelle ,wa-lamma 'ntahā an-Nāṣir ilā Išbīlìya annasa al-bilād bi-hitāō katabahū ilaihim zahrafahū al-kātib" (Kitāb ar-raud al-mi'tāa, S. 416) wirkt im letzten Teil unvollständig und wahrscheinlich ist ihm die Variante vorzuziehen, die sich in der Edition eines Teils dieses Werkes durch E. Lévi-Provençal findet: ,[...] bi-zuhrufihī al-kādib“ (daselbst, Fußnote Nr. 2).
} 
einfacher Wortwahl und dem weitestgehenden Fehlen von später so häufigen Allegorien, klassischen Redewendungen und literarischen Ausdrücken ${ }^{678}$. Die genaue Art und Weise des Übergangs von den Briefen der Almohaden als einer Gemeinschaft, die den Almoraviden die Macht zu entringen suchte, hin zu den Verlautbarungen der neuen Machthaber in Marrakech sind noch nicht erforscht. Umso interessanter ist daher die folgende, - wahrscheinlich - erste offizielle an 'Abd-al-Mu'min adressierte almohadische Siegesmeldung, auf die im Folgenden kurz eingegangen wird.

Einige Zeit nach der Erstürmung Marrakechs im Jahr 1147 durch die Almohaden kam es zu einem Aufstand gegen die neuen Herrscher im Maghreb, der in der Region Sūs ausbrach und von einem gewissen al-Māsī angeführt wurde. Über diesen Aufständischen lässt sich einem Bericht Ibn-'Idārīs nur soviel entnehmen, dass dieser gemeiner Herkunft war und sich seinen Lebensunterhalt als Walker in Salè verdiente, bevor er als Anführer eines antialmohadischen Aufstandes in Erscheinung trat und die Rechtleitung für sich beanspruchte (arab.: fa-'dda'ā al-hidāyaa ${ }^{679}$ ). Bei seinem Auftreten hätten sich ihm viele berberische Stämme angeschlossen, mit deren Hilfe er das gegen ihn entsandte almohadische Kontingent habe vernichtend schlagen können ${ }^{680}$. Auf dem Höhepunkt der Erhebung hätten bis auf Marrakech und Fès alle Städte des Äußersten Maghreb die almohadische Herrschaft abgeschüttelt. Letztlich jedoch sei es dem zweiten almohadischen Kontingent gelungen, unter der Führung des Abū-Hafṣ 'Umar Ibn-Yạ̣yā, eines langjährigen Gefährten der ersten Stunde von Muḥammad IbnTūmart, die Aufständischen in die Flucht zu schlagen und ihren Anführer zu töten ${ }^{681}$. In jener für das junge Almohadenreich schicksalhaften Stunde sollte Abū-Ğa'far Aḥmad Ibn-'Ațiya zum ersten almohadischen Schreiber berufen werden. Huici Miranda zufolge war Abū-Ğacfar Ahmmad Ibn-'Ațiya Schreiber des Ibrāhīm Ibn-Tāšfīn Ibn-'Alī ${ }^{682}$ gewesen, der in den Wirren der almohadischen Erhebung zum almoravidischen Herrscher in Marrakech ausgerufen wurde, kurze Zeit später jedoch aufgrund seines jungen Alters zugunsten seines Onkels Ishạā Ibn-'Alī abgesetzt worden zu sein scheint $^{683}$. Laut Ibn-'Idārī und Ibn-al-Abbār war er jedoch Schreiber von Ishāa Ibn-

\footnotetext{
${ }^{678}$ Mit literarischen Ausdrücken sind hier in Abgrenzung zu idiomatischen Redewendungen einzelne Wörter gemeint, die im als klassisch angesehenen literarischen Schrifttum belegt sind. Hierzu gehören beispielsweise Bezeichnungen für „gewaltige Armee“ (arab.: 'aramram), „Lanzen“ (arab.: al-hattî) u.ä.

${ }^{679}$ Er soll auch als der Mahdi dieser Region bekannt gewesen sein (Kitāb ar-rauḍ al-micțār, S. 522)

680 'Abd-al-Mun'im al-Ḥimyarī zufolge sind von ihm sogar mehrere almohadische Kontingente, die zur Niederschlagung des Aufstandes entsandt wurden, in die Flucht geschlagen worden (Kitāb ar-rauḍ almi țār, S. 522).

${ }^{681}$ al-Bayān al-muġrib, S. $30 \mathrm{f}$.

${ }^{682}$ Historia política del imperio almohade, Bd. 1, S. 150.

${ }^{683}$ Historia política del imperio almohade, Bd. 1, S. 142.
} 
${ }^{C} A 1{ }^{684}$. Die jeweiligen Berichte dieser beiden Autoren über Abū-Ğa'far Aḥmad Ibn'Ațiya lassen sich dahingehend zusammenfassen, dass er nach dem Fall Marrakechs untertauchte und sich bei der Entsendung des oben erwähnten zweiten almohadischen Kontingents gegen al-Māsī als Bogenschütze verdang. Nach dem bekannten Ausgang der Schlacht habe Abū-Ḥaṣ 'Umar Ibn-Yahyā nach jemandem Ausschau gehalten, der ein Schreiben über den Sieg der Almohaden an 'Abd-al-Mu'min abfassen sollte, und sei dabei auf den ehemaligen almoravidischen Schreiber aufmerksam gemacht worden ${ }^{685}$. Längere Abschnitte dieser almohadischen Siegesmeldung sind u. a. in Ibn-al-Abbārs Schrift zur Entschuldigung der Schreiber überliefert ${ }^{686}$. Auffallend an diesem Schreiben ist, dass in ihm bereits die Charakteristika deutlich ausgeprägt sind, die bei der Übersetzung und im Verlaufe der vorliegenden Analyse von anderen almohadischen Schriftstücken festgestellt wurden: häufiger Gebrauch von Reimprosa, koranische Zitate, koranisch geprägte Bezeichnungen sowohl für die Feinde als auch für deren „Vergehen“, Gebrauch von Allegorien, idiomatischen Wendungen sowie von literarischen Ausdrücken.

Diese in die Augen springende weitestgehende stilistische wie sprachliche Ähnlichkeit mit den in dieser Untersuchung übersetzten späteren Briefen an die Allgemeinheit hebt sich, wie oben erwähnt, von den wenigen erhaltenen almohadischen Briefen aus der Anfangszeit als aber auch von den überlieferten offiziellen almoravidischen Verlautbarungen ab. Was die zuletzt genannte Gruppe angeht, so waren im handschriftlichen Band, dem wie im Vorwort erwähnt Lévi-Provençal den überwiegenden Teil der almohadischen Briefe für die Sammlung „Mağmūc rasā’il muwaḥhidīya min inšāà kuttāb ad-daula al-mu’minīya“ entnommen hat, unter anderem insgesamt zweiundzwanzig almoravidische Schreiben enthalten ${ }^{687}$. Diese Zahl erlaubt uns nur bedingt, die Wesenszüge der almoravidischen Schriftstücke erschöpfend herauszuarbeiten. Nichtsdestominder lassen sich ihnen bereits beim ersten Hinsehen zwei wichtige Charakteristika entnehmen: es sind die bezeichnenden Kürze und Prägnanz sowie die strenge Fixierung auf die eigentliche Mitteilung ${ }^{688}$, die ihnen

\footnotetext{
${ }^{684}$ al-Bayān al-mugirib, S. 31, I'tāb al-kuttāb, S. 226.

${ }^{685}$ al-Bayān al-muğrib, S. 31, I'tāb al-kuttāb, S. 226.

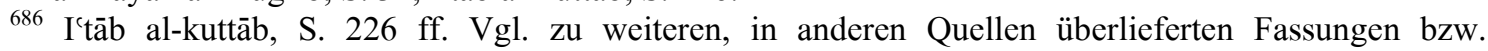
Fragmenten dieses Schreibens „Mağmū'a ğadīda“ (Bd. 1, S. 56 ff.)

${ }^{687}$ Diese almoravidischen Schriftstücke wurden von Mahmūd 'Alī Makkī im Jahr 1959 in der eigens ihnen gewidmeten Untersuchung „Watāì ta'rīhīya ğadìda“ mit historischem Kommentar sowie mit Angaben zu den jeweiligen almoravidischen Schreibern versehen und veröffentlicht.

${ }^{688}$ Vgl. Watāìiq ta'rīhīya ğadīda, S. 120. Ansonsten sind auch hier die den almohadischen Schreiben eigentümlichen Merkmale festzustellen: Gebrauch von Reimprosa, Verwendung der koranischen Zitate und der einschlägigen koranisch geprägten Bezeichnungen für die Almoraviden als auch für ihre Feinde,
} 
eignen. Ihr weiterer formaler Grundzug besteht ferner darin, dass sich bei diesen überlieferten Briefen der einleitende erste Teil auf ein kurzes „Unser Schreiben [... $\left.{ }^{68}\right]$ ergeht an Euch aus der Stadt Soundso $\left[\ldots{ }^{690}\right]^{“,}$, beschränkt, woran sich nahtlos die eigentliche Inhaltsmitteilung anschließt ${ }^{691}$. Wohlgemerkt stammen zwanzig dieser Schriftstücke, die einen Zeitraum von 1106 bis 1129 abdecken ${ }^{692}$, aus der Feder der Schreiber aus al-Andalus, die es an den Höfen der dortigen Kleinkönige zu Ruhm und Ansehen gebracht hatten ${ }^{693}$. Diese Briefe sind also nur insofern als almoravidisch zu bezeichnen, als sie auf Veranlassung von 'Alī Ibn-Yūsuf Ibn-Tāšufīn, des zweiten, von 1107 bis 1143 regierenden almoravidischen Herrschers, abgefasst wurden. In ihrer sprachlichen Ausgestaltung spiegeln sie nicht so sehr das fachliche Potenzial der andalusischen Schreiber wider ${ }^{694}$, sondern vielmehr das Bild, das die almoravidischen Auftraggeber von sich und ihrem Reich nach außen zu vermitteln bestrebt waren. Und dieser den überlieferten Schriftstücken zu Grunde liegende politische Wille scheint ihnen das spezifisch almoravidische Gepräge verliehen zu haben ${ }^{695}$.

Abschließend sei noch auf den auffälligen Unterschied hingewiesen, der zwischen den einleitenden Teilen der almohadischen und almoravidischen Briefe besteht. Während die neuartige, auf die tiefgreifende Reform des Islam hinstrebende almohadische Botschaft ihren wortreichen und -gewaltigen Ausdruck bereits in der Einleitung der almohadischen Schriftstücke findet ${ }^{696}$, bleibt diese religiöse Dimension ganz im Einklang mit dem Selbstverständnis der almoravidischen Herrscher, nur Statthalter der abbasidischen Kalifen zu $\operatorname{sein}^{697}$ und somit an die bestehende religiöse Tradition lediglich anzuknüpfen, in den genannten Verlautbarungen dieser Dynastie ausgespart.

\footnotetext{
literarische Entlehnungen und Allegorien. Diese genannten formalen Elemente sind jedoch im Allgemeinen dem Grundsatz der Prägnanz und Bündigkeit unterworfen.

${ }^{689}$ Darauf folgt eine kurze Eulogie.

${ }^{690}$ An dieser Stelle wird - sofern überliefert - das Abfassungsdatum angegeben (Watā'iq ta'rīhīya ğadīda, S. 120).

${ }^{691}$ Vgl. Kapitel 8.2., in dem der einleitende Teil der almohadischen Schreiben umrissen wurde.

${ }^{692}$ Watāìiq ta'rīhìya ğadīda, S. 113.

${ }^{693}$ Watāōiq ta'rīhìya ğadīda, S. 114.

${ }^{694}$ Laut 'Izz-ad-Dīn 'Umar Mūsā hatten alle Schreiber, die in der Regierungszeit 'Abd-al-Mu'mins tätig waren, ehemals entweder im Dienste der Almoraviden oder der Hammādiden gestanden. Hierbei seien alle almoravidischen Schreiber Andalusier gewesen (al-Muwaḥhidūn fi 'l-Ġarb al-Islāmī, S. 163). Dies ist insofern interessant, als dass der im Brief Ahmad Ibn-'Atịyas deutlich sichtbare Umschwung zum Wortreichen und Überschwenglichen hin, der die almohadischen offiziellen Verlautbarungen später auszeichnen sollte, sich bei nahtloser Weiterbeschäftigung der einstigen almoravidischen Schreiber vollzogen zu haben scheint.

${ }^{695}$ Maḥmūd 'Alī Makkī (Watāìiq ta'rīhīya ğadīda, S. 121) nennt dieses Gepräge „Einfachheit, Schlichtheit" (arab.: al-basāta).

${ }^{696}$ Vgl. Kapitel 8.2.

${ }^{697}$ vgl. al-Muwaḥhidūn fi 'l-Ġarb al-Islāmī, S. 111.
} 
Doch wenden wir uns an dieser Stelle noch einmal dem Brief Abū-Ğa'far Aḥmad Ibn'Ațīyas nach dem almohadischen Sieg über al-Māsī zu. Dem in dieser Arbeit oft zitierten Ibn- Iḍārī verdanken wir einen kurzen Bericht über die Wirkung, welche diese Siegesmeldung entfaltet haben soll: „Und er (d. h. Abū-Hafṣ 'Umar Ibn-Yahyā) schickte diese Siegesmeldung an den Kalifen 'Abd-al-Mu'min. Als diese überbracht wurde, wurde sie in der von 'Abd-al-Mu'min abgehaltenen Sitzung verlesen und hat alle anwesenden Tālibs, Rechtsgelehrten, Schreiber, herausragende Männer und Dichter in Bewunderung versetzt. 'Abd-al-Mu'min befand sie aufgrund ihrer unübertreffbar vollendeten Schilderungen für vortrefflich. Ihre sprachliche Reinheit, mitreißende Ausdrucksstärke und ihre bewunderungswürdigen Allegorien haben alle Anwesenden in ihren Bann geschlagen. Das einmütige Urteil derjenigen, die sich durch ihre Sprachgewalt auszeichnen, war, dass dieses Schreiben in seiner Vollendung unübertreffbar war. Diese Siegesmeldung bescherte Abū-Ğa'far Ahmad Ibn-'Ațīya Aufstieg, Ansehen und Ruhm. “698 Vor dem Hintergrund der Tatsache, dass - wie oben erwähnt - bereits in diesem ersten Schreiben deutlich die Wesenszüge der späteren an die Allgemeinheit adressierten almohadischen Schriftsstücke ausgeprägt sind, die ebenfalls dem Kriterium der sprachlichen Vollendung und der Wirkungskraft auf die Zuhörer folgen, drängt sich die Vermutung auf, dass diese erste Siegesmeldung für die sprachliche Ausgestaltung von späteren Verlautbarungen an die Allgemeinheit maßgebend war.

Bei der obigen Schilderung der Revolte von al-Māsī im Jahr 1147 ist erwähnt worden, dass diese - zumindest vordergründig - religiös motiviert war: dieser Aufständische erklärte sich zum Mahdi und war mit diesem Anspruch so erfolgreich, dass in der gefährlichsten Etappe der von ihm angeführten Erhebung Ibn-'Idārī zufolge nur die Städte Marrakech und Fès in der Gewalt der Almohaden übrigblieben ${ }^{699}$. Der genannte al-Māsī war indes nicht der einzige, der den Anspruch auf die einzig wahre Rechtleitung erhob. Erinnert sei in diesem Zusammenhang auch an Aḥmad Ibn-al-Husain Ibn-Qasī, der, nachdem er Anhänger eines Sufiordens um sich geschart hatte, sich gegen die almoravidische Herrschaft im Westen der Iberischen Halbinsel auflehnte. Auch er erhob den Anspruch, der Mahdi zu sein, bevor die Almohaden in al-Andalus Fuß gefasst haben ${ }^{700}$. Vor diesem ereignisgeschichtlichen Hintergrund wird verständlich, warum im einleitenden Teil der almohadischen Briefe nachdrücklich betont wird, dass Ibn-Tūmart

\footnotetext{
${ }^{698}$ al-Bayān al-mugirib, S. 31.

${ }^{699}$ al-Bayān al-muğrib, S. 31.

700 al-Fitan wa-'l-hurūb, Bd. 1, S. 202.
} 
d e r Mahdi sei. Diese thematische Vorgabe ist bereits in den Sätzen, die sich an die im Kapitel 8.2. zitierten Ausführungen Ibn-Tūmarts über das heilbringende Wirken der Imame anschließen, deutlich formuliert: „Es ist Pflicht, von all diesem überzeugt zu sein, an all dies zu glauben, sich daran zu halten solange die Welt besteht, sowie auch es ruchbar zu machen, zu verkünden, zu verbreiten, zu lehren und zu festigen. Es ist eine Pflicht, dass all dies im Herzen jedes Kleinen und Großen, Freien und Sklaven, jedes Mannes und jeder Frau unerschütterlich wird.“701 Genau diesen Zweck erfüllen die Siegesmitteilungen enthaltenden almohadischen Schreiben an die Allgemeinheit: in ihrer Einleitung wird den Zuhörern das almohadische Geschichtskonzept verkündet, ihr Inhalt kündigt im Einklang damit den Anbruch des Zeitalters der Gerechtigkeit und der Billigkeit sowie die machtvolle Bezwingung der Widersacher an, und in ihrem abschließenden Teil wird dazu aufgerufen, den bekannt gemachten Inhalt nah und fern ruchbar zu machen.

Wenn man die in der Einleitung zu dieser Untersuchung formulierte Frage nach dem historischen Gehalt der offiziellen almohadischen Schriftstücke an dieser Stelle im Lichte des bisher Gesagten neu aufwirft, so muss man sie dahingehend beantworten, dass der historische Gehalt der Briefe, die Siegesmitteilungen enthalten und an die Allgemeinheit adressiert sind, als gering einzuschätzen ist. Denn obgleich diese Verlautbarungen sowohl im Hinblick auf ihr Aufsetzungsdatum als auch auf die Tatsache, dass ihre Abfasser Augenzeugen der darin bekannt gegebenen Ereignisse waren, unmittelbare und direkte Geschichtszeugnisse darstellen, hat sich die anfängliche Erwartung, in ihnen eine an neuen Fakten reichhaltige Quelle zu finden, nicht erfüllt. Wir haben es, wie aus den obigen Briefanalysen hervorgeht, mit den direkten Zeugnissen für das Bestreben der almohadischen Herrscher zu tun, den Untertanen eine im Einklang mit der almohadischen Doktrin stehende und die almohadische Herrschaft legitimierende und sakralisierende Perspektive zu vermitteln, und diesem höchsten herrscherlichen Bestreben ist der Inhalt der analysierten Verlautbarungen strikt untergeordnet. Viele ereignisgeschichtlich relevante Informationen und Angaben sind in diesen Schriftstücken darüber hinaus durch vereinfachende, sie dem öffentlichen Vortrag anpassende und das Geschilderte allgemein überzeichnende Tendenzen nicht selten in den Hintergrund gedrängt, sodass erst ein solides Überlieferungsfundament es erlauben würde, das Faktische von Fiktivem trennen zu können ${ }^{702}$.

\footnotetext{
${ }^{701}$ Le Livre de Mohammed Ibn Toumert, S. 252.

${ }^{702}$ Von dieser Einschätzung sind allerdings diejenigen almohadischen Schreiben auszunehmen, die nicht für den öffentlichen Vortag konzipiert und an einen bestimmten Empfänger - sei es der almohadische
} 
Doch unter einem anderen Gesichtspunkt stellt die Sammlung „Mağmū ${ }^{c}$ rasā’il muwaḥhidīya" sehr wohl eine äußerst reichhaltige und einzigartige Quelle dar und kann in zweifacher Hinsicht zu höchst interessanten Erkenntnissen führen: Zum einen fügt sie sich als ein wichtiger Teil in das Korpus des überlieferten almohadischen offiziellen Schrifttums ein, das an hochsprachlichen mittelalterlichen Allegorien und an abstrakter Ausdrucksweise allgemein äußerst reich ist. Für die davon ausgehende systematische „Vereindeutigung“ des aus heutiger Sicht immensen Bedeutungsreichtums des literarisch-figurativen Sprachgebrauchs der almohadischen Epoche ist somit eine gute Grundlage gegeben. Deren erschöpfende Erhellung würde ferner im nächsten Schritt ganz allgemein dazu beitragen, über die almohadische Epoche hinaus Zugang zum einschlägigen mittelalterlichen Schrifttum des Maghreb und al-Andalus' zu verschaffen und es zu erschließen.

Der der Sammlung „Mağmūc rasā’il muwaḥḥidīya“ abgewinnbare hohe Erkenntniswert besteht auf der anderen Seite darin, dass sie neben ,al-Mann bi-'l-imāma“ und „Mağmū'a ğadīda“ die unentbehrliche Grundlage für alle Versuche bildet, in die spezifische offizielle almohadische Terminologie vorzudringen und viele der „verwaltungstechnischen“ Begriffe des almohadischen Reiches aufzuhellen. Folgendes einfaches Beispiel soll das Gemeinte veranschaulichen: In den almohadischen Schreiben kommt häufig der Ausdruck ,,an-naẓar al-ğamīl“ vor. Ihn wörtlich mit „der schöne Blick“ zu übersetzen, wäre schlicht falsch wie irreführend. Denn das arabische Verb „naẓara“ in Verbindung mit der Nennung des Herrschers wird häufig in der Bedeutung „das kalifale Augenmerk auf etwas in Mängel, Missstände behebender Absicht richten“ verwendet; dementsprechend hat dann das Substantiv ,an-naẓar“ häufig den Sinn „kalifale Verfügungsgewalt“ bzw. „die kalifalen Verfügungen““703. Zusammen mit diesem Substantiv kommt häufig das Adjektiv „ğamīl“ vor, womit vor allem die Bedeutung ,herrscherlich, kalifal“ konnotiert wird ${ }^{704}$. Und erst die Kenntnis dieses Zusammenhangs versetzt uns in die Lage, das mit „an-naẓar al-ğamīl“ für den zeitgenössischen Zuhörer bzw. Leser Gemeinte zu verstehen ${ }^{705}$. Eine fundierte

\footnotetext{
Herrscher oder einer seiner Untertanen - adressiert waren sowie die ganz konkrete kalifale Anordnungen enthaltenden Schreiben an die Allgemeinheit. Diese Schriftstücke - hat man ihren eigentlichen Inhalt von den das Verständnis erschwerenden rhetorischen Floskeln freigeschält - weisen einen viel größeren historischen Gehalt auf.

${ }^{703}$ Darüber hinaus kann sowohl „an-nazar“ als auch „nazara“ weitere, jeweils kontextuell bedingte Bedeutungen haben.

${ }^{704} \mathrm{Im}$ offiziellen nasridischen Schrifttum des 14. Jahrhunderts hatte interesanterweise das arab. Adjektiv „karīm“ diese Konnotation.

${ }_{705}$ Auch die genauen Konnotationen von Adjektiven wie „sa`īd“, „mubārak“, „karīm“ und vielen anderen müssten erst noch ermittelt werden.
} 
Erschließung der almohadischen Verwaltungssprache kann ferner eine solide Grundlage für weiterführende Versuche bilden, in den administrativen Sprachgebrauch anderer westarabischer Dynastien vorzudringen ${ }^{706}$.

Abschließend sei auch auf eine offen bleibende Frage hingewiesen, deren Beantwortung uns wichtige Einblicke in die Natur des zwischen den almohadischen Herrschern und der beherrschten Bevölkerung bestehenden Verhätnisses erlauben könnte. In der heutigen Maghrebforschung wird stillschweigend vorausgesetzt, dass die Bevölkerung des Maghreb im 12. Jahrhundert so weit arabisiert gewesen sei, dass die Sprache der offiziellen Verlautbarungen der Almohaden zwar nicht als Alltagssprache gegolten habe, zumindest aber so weit vertraut gewesen sei, dass man sie ohne weiteres hätte verstehen können. Aussagen arabischer Quellenzeugnisse legen jedoch eine Relativierung dieser Annahme nahe und lassen erkennen, dass der Beherrschungsgrad der Sprache der islamischen Offenbarung bei der Bevölkerung des Maghreb davon entfernt war, als muttersprachlich bezeichnet zu werden. Ein Hinweis auf diesen Sachverhalt lässt sich z. B. der Passage des almohadischen Briefes Nr. 23 entnehmen, wo es heißt, diejenigen, die die westliche Sprache (arab.: al-lisān al-garbı̄) verstünden und sprächen, sollen den Abschnitt über die Einsheit Gottes lesen, auswendig lernen, ohne Anstoss vortragen können ${ }^{707}$, es unablässig lesen und wiederholen ${ }^{708}$. Auch der zugegebenermaßen wohl überspitzte - folgende Bericht von Ibn-Abī-Zar über die Beherrschung des Arabischen gerade bei den Rezipienten, an die sich die in dieser Untersuchung behandelten Briefe u. a. explizit richten, weist in die gleiche Richtung: „Und für ein weiteres Beispiel für seine (d. h. Ibn-Tūmarts) Listanwendung und den geschickten Umgang (mit den Angehörigen von berberischen Stämmen) lässt sich Folgendes anführen. Einmal waren seine Versuche, einer Gruppe von den MasmudaBerbern die erste Sure des Korans beizubringen, wegen der unzulänglichen Beherrschung des Arabischen (arab.: al-uğma) von Letzteren vergeblich geblieben. Also hat er diese Sure in einzelne Wörter aufgeteilt und einem jeden Mann [der betreffenden Gruppe] jeweils eines dieser Wörter als Namen gegeben. Danach ließ er sie auf dem Boden in einer Reihe Platz nehmen und sagte zum ersten von ihnen: Dein Name ist ,Preis sei Gott‘, zum zweiten: ,dem Herrscher‘, zum dritten: ,der Welten` usw. bis zum Schluss der Sure. Danach sagte er zu ihnen: ,Gott wird keinem einzigen eurer

\footnotetext{
${ }^{706}$ Als besonders aufschlussreich würde sich hierbei der Vergleich mit den nasridischen Briefen der Sammlung „Raihānat al-kuttāb wa-nuğ at al-muntāb“ von Lisān-ad-Dīn Ibn-al-Hatị̂b erweisen.

707 Dies ist wohl der gemeinte Sinn von ,an [...] yafuṣṣūhū“ an dieser Stelle (Mağmū ${ }^{c}$ rasā’il muwaḥhidìya, S. 132).

${ }^{708}$ Mağmūc rasā'il muwaḥhidīya, S. 132.
} 
Gebete Gehör schenken, außer ihr reiht bei jedem Niederwerfungsablauf (arab.: arrak a) diese Namen in der richtigen Abfolge aneinander'. Auf diese Weise machte er es ihnen leichter, und sie konnten sich die erste Koransure einprägen ${ }^{709}$ “ "Auch wenn man einräumt, dass Ibn-Abī-Zar hier das sprachliche Vermögen einiger berberischer Gruppen in Arabisch untertreiben mag, so steht es doch in einem auffallenden Gegensatz $\mathrm{zu}$ den an die Allgemeinheit gerichteten almohadischen Briefen, die anspruchsvolle literarische Zeugnisse darstellen und sich durch ein hohes sprachliches Niveau auszeichnen. Die Häufung von im mittelalterlichen literarischen Schrifttum verbreiteten Allegorien, die relativ dichte Streuung von Zitaten und einzelnen Begriffen aus dem Koran, die Verwendung von einzelnen Wörtern und Redewendungen aus der vor- und frühislamischen Dichtung bei gleichzeitigem beinahe vollständigem Fehlen von westarabischen Dialektwörtern ${ }^{710}$ und nicht zuletzt die Überlieferung von Briefen in einer Sammlung, deren massgebliches Kriterium für die Aufnahme der - zumindest almohadischen - Schriftstücke in ihrer sprachlichen Vorzüglichkeit bestanden zu haben scheint $^{711}$, zwingen darüber hinaus zum Schluss, dass nur das sprachlich, religiös und literarisch gebildete Publikum imstande gewesen war, diese Texte zu verstehen. Dies wirft jedoch die Frage auf, wie dieser Widerspruch zwischen der für das Verständnis der almohadischen Briefe an die Allgemeinheit erforderlichen Kenntnis der klassischen arabischen Sprache und ihrer tatsächlichen Beherrschung bei der autochthonen Bevölkerung plausibel erklärt werden kann.

\section{Anhang 1}

Inhaltsverzeichnis und Zusammenfassung der siebenunddreißig almohadischen Briefe

1. An die Tāālibs und die Gesamtheit der Almohaden von Ceuta:

Mitteilung über seine Rückkehr nach erfolgreicher Niederschlagung eines antialmohadischen Aufstandes.

2. An Qāḍī Qāsim:

Bestätigung der Ankunft seiner Gesandten und Annahme seiner Entschuldigung.

3. An die Țālibs und die gesamte Bewohnerschaftvon Tāsgart:

\footnotetext{
709 al-Anīs al-mutrib, 235.

710 Das einzige - soweit meine Kenntnis reicht - maghrebinische Dialektwort in „Mağmū` rasā’il muwaḥhidīya“ ist „murūs“ im Brief Nr. 20, S. 104.

${ }^{711}$ Siehe hierzu das Kapitel 8.1.
} 
Bericht über den Besuch von Tinmallal und die Zusammenkunft mit den Gesandten der Ṭālibs von Tāsgart dort.

4. An Ibn-Ġānīya:

Bestätigung des Erhalts der Nachricht über sein Bekenntnis zum

Almohadentum.

5. An die Ṭālibs von Ceuta:

Bestätigung des Eingangs ihres Briefes und kurze Wiedergabe des Berichts über ihre Unternehmung gegen Almeria sowie andere Anweisungen.

6. An die Šaihs von Cordoba:

Bestätigung des Eingangs ihres Huldigungsschreibens.

7. An alle Bewohner von Constantine:

Aufruf zum Almohadentum.

8. An die Tāalibs von Tilimsen und die Gesamtheit der Almohaden dort:

Mitteilung über die Inbesitznahme von Constantine.

9. An den Šaih Abū-Muhammad Wasnār und die gesamten Bewohner von Marrakech: Mitteilung über den Abschluss der Unternehmung in den Zentralen Maghreb und den Sieg über die arabischen Stämme in der Schlacht bei Setif.

10. An den Šaih Abū- 'Abdallāh Muḥammad Ibn-Sa'd:

Aufruf zum Almohadentum.

11. (Ohne Adressaten):

Mitteilung über den misslungenen Aufruhr der beiden Brüder des Mahdi und ihre Hinrichtung.

12. An die Ṭālibs von Tilimsen:

Mitteilung über die Aufteilung der Almohaden in drei Schichten.

13. An die Tālibs von Ceuta und Tanger sowie ihre gesamte jeweilige

Bewohnerschaft:

Mitteilung über die Ernennung Muhammads zum Nachfolger seines Vaters.

14. An die Țālibs und die gesamte Bewohnerschaft von Ceuta:

Mitteilung über die Einsetzung der Söhne 'Abd-al-Mu'mins zu Statthaltern über einige Gebiete des Reiches.

15. An die Tāalibs und die gesamte Bewohnerschaft von Ceuta:

Bericht über die „Aufarbeitung“ eines antialmohadischen Vorfalls.

16. An die Ṭālibs und die gesamte Bewohnerschaft von Biğāya: 
Bericht über die Wiedereroberung der Städte Almeria, Baeza und Ubeda durch die Țālibs von Granada.

17. An die Tāalibs und die gesamte Bewohnerschaft der Stadt Soundso:

Bericht über den Besuch des Grabes von Mahdi Muhammad Ibn-Tūmart und über weitere damit im Zusammenhang stehende Ereignisse.

18. (Ohne Adressaten):

Eingangsbestätigung des Schreibens mit der Schilderung der Unternehmungen gegen den Feind der Almohaden.

19. An die Tālibs und Almohaden von Granada:

Mitteilung über die Entscheidung, auf Gibraltar eine Stadt zu bauen, sowie über die Einnahme von Gafsa.

20. An die Tâalibs und die gesamte Bewohnerschaft von Cordoba:

Bericht über den Verlauf der Einnahme Gafsas.

21. An die Tāalibs und die gesamte Bewohnerschaft von Ceuta:

Bericht über den erfolgreichen Abschluss des Feldzuges gegen den Stammesverband Banū Riyāh und den Aufbruch einiger seiner Stämme nach Maghreb.

22. (Ohne Adressaten)

Bericht vom Sieg der Almohaden über die Christen bei Fạ̣ṣ Hilāl.

23. An die Ṭālibs von Biğāya:

Anordnungen darüber, wie die religiösen Belange zu regeln und Übertretungen zu ahnden sind.

24. An den Šaih Abū-Sa ̄̄o und Šaih̆ Abū-Sac̄id Yahlluf Ibn-al-Ḥasan:

Mitteilung über den Aufbruch der almohadischen Armee zur Unterwerfung von aufbegehrenden Șanhāğa-Stämmen und über die Entsendung almohadischer Truppen zum Schutze Sevillas.

25. An Ibn-Mardanīš:

Aufruf zum Almohadentum.

26. An die Tāalibs und die gesamte Bewohnerschaft von Cordoba:

Mitteilung über den Aufbruch der Riyāh-Stämme nach al-Andalus zwecks Teilnahme an den militärischen Unternehmungen dort.

27. An die Tāalibs und die gesamte Bewohnerschaft von Granada:

Mitteilung über die Huldigung der Almohaden ihm gegenüber mit dem Aufruf, sich dieser Huldigung anzuschließen und andere an ihr teilhaben zu lassen. 
28. An die Țālibs und die gesamte Bewohnerschaft von Sevilla:

Befehl, das Trinken, Ausschenken und den Verkauf von Arrope gänzlich zu unterbinden.

29. An die Tāālibs und die gesamte Bewohnerschaft Sevillas:

Bericht über die Unternehmung der Almohaden gegen den Herrscher von Mallorca und die Befreiung Biğāyas sowie anderer Städte.

30. An die Țālibs und die gesamte Bewohnerschaft von Marrakech:

Mitteilung über den Sieg der Almohaden bei Ḥamma Mațmāṭa und die Einnahme von Gabès.

31. An die Tālibs und die gesamte Bewohnerschaft von Tunis:

Mitteilung über die Befriedung der Region Ğarīd und die Aufnahme der Belagerung Gafsas.

32. An die Tâalibs und die gesamte Bevölkerung von Marrakech:

Bericht über den Verlauf der Bezwingung Gafsas.

33. An die Ṭālibs und die gesamte Bevölkerung von Marrakech:

Bericht über den Abschluss des Feldzuges und Ankündigung der Rückkehr der Almohaden aus Ifrīqīya.

34. An die Țālibs und die gesamte Bewohnerschaft von Ceuta:

Bericht über die Unternehmung der Almohaden im Westen von al-Andalus.

35. An die Tāâlibs und die gesamte Bewohnerschaft von Fès:

Bericht über den Verwüstungszug der Almohaden in das von Christen beherrschte Gebiet der Iberischen Halbinsel.

36. (Ohne Adressaten):

Bericht über die Eroberung der Insel Mallorca durch die Almohaden.

37. (Ohne Adressaten):

Bericht über den Verlauf der Unternehmung zur Befreiung Ifrīqīyas und die Belagerung al-Mahdiyas sowie über die Niederlage des „Mallorquiners“.

Anmerkung zur Zusammenfassung ${ }^{712}$ : Bei den nachfolgenden Zusammenfassungen werden die Begebenheiten und Mitteilungen der almohadischen Briefe ihrem Wortlaut nach in allgemeinen Zügen wiedergegeben. Es wird nicht versucht, den historischen Gehalt dieser Briefe herauszukristallisieren, sondern lediglich ihren Inhalt

${ }_{712}$ Lévi-Provençal hat in seinem Aufsatz „Un recueil de lettres officielles almohades: une étude diplomatique et historique“ (in: Hespéris. Archives berbères et bulletin de l'institut des hautes études 
nachzuerzählen, ganz so, wie ihn die Adressaten dieser almohadischen Schreiben verstanden haben dürften.

Die in der Regierungszeit von 'Abd-al-Mu’min (1130-1163) abgefassten Briefe.

Der 1. Brief.

Dieser undatierte Brief, abgefasst in Marrakech im Namen des Befehlshabers der Gläubigen, richtet sich an die Țālibs sowie an alle Almohaden der Stadt Ceuta. Darin wird von der Rückkehr der Almohaden dorthin nach dem erfolgreichen Abschluss eines Feldzuges zwecks Niederschlagung eines antialmohadischen Aufstandes berichtet. An die Beschreibung der Gewaltigkeit der von den almohadischen Kriegern erlangten Löhne und der zahlreichen Segensmanifestationen des Mahdi schließen sich mehrere Aufrufe religiösen Charakters an.

Der 2. Brief.

Dieser undatierte Brief, abgefasst in Marrakech im Namen des Befehlshabers der Gläubigen, ist an eine Person namens Abu-'l-Qāsim Muḥammad Ibn-al-Ḥāğğğ, der als Rechtsgelehrter und Richter amtiert, adressiert. Darin wird von der Ankunft des Bruders, des Sohnes und des Gefährten des erwähnten Adressaten und ihrer Huldigung gegenüber dem almohadischen Herrscher berichtet. Abu-'1-Qāsim Muhammad Ibn-alHạğğg wird entschuldigt, an diesem Besuch nicht teilgenommen zu haben, und sein stellvertretend für ihn geleistetes Treuegelöbnis dem almohadischen Herrscher gegenüber wird angenommen. Daran schließen sich die Zusicherungen seitens des almohadischen Machthabers an, dem genannten Adressaten wohlwollende Behandlung zuteil werden zu lassen. Die Aufrufe, Gott für Seine Gaben zu danken und frommen Lebenswandel zu führen, schließen den Brief ab.

Der 3. Brief.

Dieser undatierte Brief, abgefasst im Namen des Befehlshabers der Gläubigen, ist an die Ṭālibs der Region Șinhāğa Tāsğart sowie an ihre Šaihs, Notabeln und ihre gesamte Bewohnerschaft adressiert. Darin wird von der Reise der Almohaden nach Tīnmallal und von ihrem Zusammentreffen dort mit den Gesandten aus Șinhāğa Tāsgarart berichtet. Dem Verlauf des Berichts nach tragen die Letzteren dem almohadischen Herrscher ihre 
Anliegen, die nicht näher bestimmt werden, vor und sollen nun bei ihrer Rückkehr nach Șinhāğa Tāsgarart die Bevölkerung von den in Bezug auf diese Anliegen angeordneten Anweisungen in Kenntnis setzen. Des Weiteren, so der Brief weiter, befindet sich im Anhang die Abschrift eines anderen Briefes, der Empfehlungen religiösen Charakters enthält und welcher an alle almohadischen Gebiete ergangen ist. Aufrufe religiösen Charakters und Ankündigung künftiger Segen bilden den Abschluß dieses Briefes.

\section{Der 4. Brief.}

Dieser Brief, der vom 27. August des Jahres 1148 datiert ist und im Namen des Befehlshabers der Gläubigen in Marrakech abgefasst ist, ist an Abū-Zakariyā' Yahyā Ibn-'Alī adressiert. Diesem Brief nach berichten die in al-Andalus ${ }^{713}$ befindlichen Ṭālibs über die wohlwollende Haltung des Adressaten dem Almohadentum gegenüber und über ihren ständigen Kontakt zu ihm. Des Weiteren haben sie den almohadischen Herrscher über das Bekenntnis Abū-Zakariyā' Yahyā Ibn-'Alīs zum Almohadentum unterrichtet. Nach Eingang der erwähnten Briefe wird dieses Bekenntnis auch bekräftigt von einer in Marrakech eingetroffenen und nicht namentlich genannten Person, und all dies wird vom almohadischen Herrscher mit Genugtuung zur Kenntnis genommen. Daran schließen sich einige, vornehmlich auf die Aussprüche Mohammeds gestützte Ausführungen über die Legitimität der almohadischen Bewegung und über ihren gottgewollten Charakter an. Nach den Zusicherungen, diesen Schritt des Adressaten des Briefes zu seinem Nutzen gereichen zu lassen, wird im Brief auf das Beispiel des Stammes Massūfa hingewiesen, der bereits seit einiger Zeit dem Almohadentum anhängt und dafür reichlich belohnt wurde. Ein weiterer Hinweis erfolgt auf den Šaih Abū-Zakariyā’ Yaḥyā Ibn-Ishāa Ibn-Ibrāhīm, der samt seinen Söhnen und Verwandten ebenfalls inzwischen zur treuen Anhängerschaft des Almohadentums zählt und sich dafür seitens der Almohaden respektvoller Behandlung erfreut. Der Brief schließt mit der Beschreibung mannigfaltiger Vorteile, derer sich jemand vom Format AbūZakariyā’' Yahyā Ibn-'Alīs durch sein Bekenntnis zum Almohadentum sicher sein kann.

\section{Der 5. Brief.}

Dieser undatierte Brief, im Namen des Befehlshabers der Gläubigen in Marrakech abgefasst, ist an die Țālibs von Ceuta adressiert. Er enthält die Bestätigung des

\footnotetext{
officielles" enthaltenen Briefe zusammengefasst und mit einem kurzen historischen Kommentar versehen. ${ }^{713}$ Mit der Bezeichnung al-Andalus meinte man den Teil der Iberischen Halbinsel, der von Muslimen beherrscht wurde.
} 
Eingangs des Schreibens, das die genannten Ṭālibs nach Marrakech geschickt haben, und lässt sich wie folgt zusammenfassen: In seinem ersten Teil wird der Bericht dieser Ṭālibs an den almohadischen Herrscher über ihren Überfall auf die Stadt Malaga resümiert. Demnach hat ihn ein gewisser Abū-Muhammad 'Abdallāh Ibn-Sulaimān zusammen mit seinen Gefährten von Ceuta aus durchgeführt. Im Verlaufe dieses Überfalls drangen die Almohaden in die Stadt ein, töteten einige christliche Verteidiger und erbeuteten bei ihrem Rückzug die im Hafen befindlichen christlichen Schiffe. Daran schließt sich die Bestätigung an, dass der almohadische Herrscher einen von diesen Tạalibs angesprochenen Sachverhalt, von dem im Schreiben mit dem erwähnten Bericht die Rede war und der nicht weiter präzisiert wird, zur Kenntnis genommen hat. Des Weiteren wird bestätigt, dass der Abschnitt des Schreibens über die Zusammenarbeit eines gewissen Ibn-Miqdāms bei dem Überfall auf Almeria sowie auch weitere Abschnitte ebenfalls zur Kenntnis genommen wurden. Den abschließenden Teil des Briefes bildet der Aufruf, über Maßnahmen, die zur Unterbindung des Lebensmittelhandels mit Malaga und einigen anderen Städten führen, zu reflektieren und diese dann dem almohadischen Herrscher mitzuteilen bzw. vorzuschlagen, um von ihm dann die entsprechende Verfügung diesbezüglich zu erhalten. Ferner wird der Befehl erteilt, an den mit den erwähnten Städten diesen Handel Treibenden die Todesstrafe zu vollstrecken.

Der 6. Brief.

Dieser Brief, datiert vom 11 Juni des Jahres 1149, ist vom Befehlshaber der Gläubigen an den Šaih Soundso sowie auch an die Gesamtheit der Šaihs von Cordoba adressiert. Er enthält die Bestätigung des Eingangs ihres Huldigungsschreibens beim almohadischen Herrscher und kündigt die ihnen daraus erwachsenden Vorteile sowohl im Diesseits als auch im Jenseits an. Darauf folgen Aufrufe religiösen Charakters und Ankündigung von weiteren umfassenden diesseitigen und jenseitigen Vorteilen. Daran schließt sich die Erwähnung der Ankunft von drei namentlich genannten Šaihs von Cordoba, ihrer Huldigung und die Bestätigung, dass sie dem almohadischen Herrscher Nachrichten, die nicht weiter präzisiert werden, überbrachten.

\section{Der 7. Brief.}

Dieser Brief, datiert vom 27. August des Jahres 1152 und abgefasst in der Stadt Biğāya im Namen des Befehlshabers der Gläubigen, richtet sich an die Šaihs, Notabeln und die 
gesamte Bewohnerschaft der Stadt Constantine. Ihm nach beschließen die Almohaden nach der Eroberung der östlichen Gebiete ${ }^{714}$, die genannte Bewohnerschaft zum Gehorsam Gott gegenüber und Seinem Gesandten zu mahnen, d. h. sich zum Almohadentum zu bekennen. Diese Mahnung wird nebst Aufrufen religiösen Charakters u. a. von Warnungen davor, sie zu missachten, begleitet. Diesen Warnungen wird durch die Schilderung verhängnisvoller Folgen, welche die Verschmähung derartiger Aufforderungen für nicht namentlich genannte lokale Herrscher gehabt hat, Nachdruck verliehen. Darauf folgt der Hinweis auf das nachstrebenswerte Beispiel des Šaihss Abū-Muhammad Maimūn Ibn-'Alī Ibn-Hamdūn und seines Bruders Abū'Abdallāh Muḥammad Ibn-'Alī Ibn-Hamdūn, die sich samt ihren Verwandten bereits zum Almohadentum bekannt haben, und auf die ihnen daraus erwachsenden Vorteile. Der Brief wird mit dem Hinweis auf die Abschaffung der nicht-koranischen Steuern und Abgaben in den von den Almohaden in Besitz genommenen Gebieten sowie auf die strikte Anwendung der schariatischen Normen abgeschlossen.

\section{Der 8. Brief.}

Dieser Brief, datiert vom 10. November des Jahres 1152 und abgefasst in Biğāya im Namen des Befehlshabers der Gläubigen, richtet sich an die Ṭālibs und die Gesamtheit der Almohaden von Tilimsen und ist, wie es aus seinen Hinweisen hervorgeht, einer der Briefe, die im Rahmen des von den Almohaden im Jahre 1152 unternommenen Feldzuges zur Unterwerfung des Zentralen Maghreb geschrieben wurden. Anfangs erfolgt eine kurze Schilderung der Flucht des ḥammādidischen Herrschers AbūZakariyā’ Yahyā Ibn-al-'Azīz bi-'llāh Ibn-al-Manșūr Ibn-an-Nāṣir samt seinen Familienangehörigen aus Biğāya nach Constantine. Daran schließt sich die Beschreibung der Entsendung einiger almohadischer Einheiten nach der Bezwingung der Stadt Qal'at Banī-Ḥammād zur Eroberung Constantines. Nach der Aufnahme der Belagerung dieser Stadt beschließen deren Bewohner, eine Delegation an den almohadischen Herrscher $\mathrm{zu}$ entsenden, die sich ihm unterwerfen und ihn um die Sicherheitsgarantie bei der Kapitulation bitten soll. Er willigt in diese Bitte ein und Constantine wird von den Almohaden friedlich in Besitz genommen. Der Brief schließt mit der Beschreibung der außerordentlichen Bedeutung der eingenommenen Stadt für die gesamte Region.

\footnotetext{
${ }^{714}$ Mit den ,östlichen Gebieten“ meint man in den almohadischen Briefen und Quellen annähernd das Gebiet des Zentralen Maghreb, das vom als „Ifrīqīya“ bezeichneten Gebiet unterschieden wird. Siehe zu
} 
Der 9. Brief.

Dieser Brief, datiert vom 26. Juni des Jahres 1153 und abgefasst im Namen des Befehlshabers der Gläubigen in Tilimsen, ist an den Šaih Abū-Muhammad Wasnār, an seine Gefährten von den Ṭālibs sowie an die Šaihss, Notabeln und die gesamte Bewohnerschaft von Marrakech adressiert. Laut diesem Brief ist er ebenfalls eines der Schreiben, die im Rahmen der militärischen Unternehmung der Almohaden in den Zentralen Maghreb abgefasst wurden. Darin ist die Schilderung der Schlacht zwischen den Almohaden und den arabischen Beduinen sowie auch der damit im Zusammenhang stehenden Ereignisse enthalten. Folgender Ablauf dieser Geschehnisse geht aus dem Brief hervor: Bei der Unterwerfung des Zentralen Maghreb werden die arabischen Stämme in die Wüste abgedrängt und die almohadischen Truppenverbände lagern nach ihrem Sieg über die Städte Qal'at Banī-Hammād und Constantine kampfbereit in naher Entfernung von ihnen. Die erwähnten Stämme schicken dem almohadischen Herrscher, der sich zu diesem Zeitpunkt mit dem Gros der almohadischen Armee auf dem Weg in den Äußersten Maghreb in Mattīğa aufhält, Loyalitätserklärungen zu und mobilisieren gleichzeitig alle arabischen Stämme, die sowohl in Ifrīqīya als auch in den bis nach Alexandrien reichenden Gebieten siedeln. Als die genannten almohadischen Verbände sich in Marsch nach Marrakech setzen ${ }^{715}$, verfolgen sie die zusammengescharten arabischen Stämme auf Schritt und Tritt, so dass die Almohaden, in der Umgebung von Sétif angelangt, sich dem Kampf gegen ihre Verfolger zu stellen beschließen und dies dem almohadischen Herrscher mitteilen. Der Letztere schickt Verstärkung, welche noch vor der Schlacht die verfolgten Truppenverbände der Almohaden erreicht. Beim nachfolgenden Zusammenstoß erleiden die arabischen Stämme eine vernichtende Niederlage und fliehen vom Schlachtfeld. An die Beschreibung dieser Ereignisse schließen sich die Ausführungen über die Verfolgung der versprengten Stämme und die Gewaltigkeit der den Almohaden dabei zufallenden Beute an. Nach der Ankündigung der baldigen Ankunft dieser almohadischen Truppenverbände in Tilimsen schließt der Brief mit dem Aufruf, Gott für diesen Sieg der Almohaden zu danken und die enthaltenen Mitteilungen nah und fern ruchbar zu machen.

dieser geographischen Einteilung die Berichte in ,al-Mu'ğib fī talhīṣ aḩbār al-Mag̉rib“, S. 273 und 298 sowie in „Mağmū' rasā'il muwaḥhidīya“, S. 18 und 33 ff.

715 Zur nicht ganz eindeutigen Passage des arabischen Originals an dieser Stelle siehe Kapitel 2.3. der vorliegenden Arbeit. 
De 10. Brief ${ }^{716}$.

Dieser Brief, datiert vom 9. September des Jahres 1153 und abgefasst im Namen des Befehlshabers der Gläubigen, ist an den Šaih Abū-'Abdallāh Muhammad Ibn-Sa'd adressiert. Er enthält einen Aufruf an den genannten Adressaten, sich zum Almohadentum zu bekennen. Dies geschieht u. a. durch die Aufforderungen, sich die Vergänglichkeit des irdischen Seins zu vergegenwärtigen, sowie durch die Aussicht auf die vielfältigen, aus dem Bekenntnis zum Almohadentum erwachsenden Vorteile. Weiterhin werden dem Adressaten am Beispiel von lokalen Herrschern in al-Andalus einerseits die Vorteile der Annahme des Almohadentums und andererseits die Folgen der Verschmähung der almohadischen Botschaft in Erinnerung gebracht. Der Brief schließt mit dem Aufruf, das Vorgehen, das sich der obige Šaih gegen die Bewohnerschaft von Valencia und Lorca bei ihrer jeweiligen Unterwerfung den Almohaden gegenüber sich hat zuschulden kommen lassen, künftig zu unterlassen.

\section{Der 11. Brief.}

Der Adressat bzw. die Adressate dieses undatierten Briefes, der im Namen des Befehlshabers der Gläubigen in Marrakech abgefasst wurde, ist aufgrund seiner Unvollständigkeit - sein einleitender Teil fehlt - unbekannt. Seinen Inhalt bildet der Bericht über den misslungenen Versuch der beiden Brüder des Mahdi Muhammad IbnTūmart, in Marrakech gegen den amtierenden almohadischen Herrscher zu rebellieren. In folgender Weise wird der Ablauf der Geschehnisse, die letzlich in die genannte Meuterei münden, geschildert: Seit dem Anfang versuchen die Almohaden vergebens, die beiden Brüder des Mahdi, die als Ausbund der Begriffsstutzigkeit und Bösartigkeit beschrieben werden, zum frommen Lebenswandel anzuhalten. Diese jedoch ziehen es vor, sich mit Sündern und Verbrechern zu umgeben, und gehen sogar so weit, vom Almohadentum abzufallen. Trotz milder Behandlung der Almohaden ihnen gegenüber fallen sie immer wieder in ihr sündhaftes Treiben zurück. Beim Feldzug der Almohaden in den Zentralen Maghreb zetteln sie eine Verschwörung an, die jedoch aufgedeckt wird. Die beiden Brüder werden verhaftet, während anderen Verschwörern eine harte Strafe zuteil wird. Einige Zeit danach beschließen die Almohaden, diese Brüder samt ihren Familienangehörigen in Fes anzusiedeln. Als sich die Almohaden später in Rabat

\footnotetext{
716 Diesen Brief hat Lévi-Provençal (Un recueil de lettres officielles almohades: étude diplomatique et historique, S. 4, Fußnote Nr. 11) der aus der mamlukischen Zeit stammenden Enzyklopädie „Șubḥ al-a šāā fī șinā'at al-inšă’’ entnommen und der Sammlung beigefügt.
} 
einfinden, um die Huldigung zu vollziehen ${ }^{717}$, ergreifen die beiden Brüder des Mahdi diese Gelegenheit, fliehen nach Marrakech und rebellieren, unterstützt von ihren Anhängern, gegen die almohadische Herrschaft. Dieser Versuch scheitert jedoch am Widerstand der Bewohnerschaft von Marrakech und die beiden Anführer werden umgebracht. Der Brief weist darauf hin, dass zum Zeitpunkt seiner Abfassung die Ahndung der Mitverschwörer immer noch andauert. Der Brief schließt mit dem Dank an Gott für die Gewährung des Sieges den Almohaden, gefolgt vom Aufruf, Gott dafür zu danken.

Der 12. Brief.

Dieser undatierte Brief ist im Namen des Befehlhabers der Gläubigen abgefasst und richtet sich an die Ṭālibs von Tilimsen. Er enthält den Bericht über die Zusammenkunft almohadischer Stämme in Marrakech und die Aufteilung der Almohaden in drei Schichten. In folgender Weise wird dies geschildert: Vermittels zahlreicher Schreiben ruft der almohadische Herrscher seine Untertanen dazu auf, von bestimmten zu missbilligenden Praktiken Abstand $\mathrm{zu}$ nehmen und sich ausschließlich an das (gesetzlich) Erlaubte zu halten. Dann richtet er sein Augenmerk auf die Untertanen in seiner Umgebung, an die er sich im erwähnten Sinne richtet. Nach seiner Ankunft in Marrakech werden alle (sic) Almohaden aufgerufen, sich dort einzufinden. Mit den dorthin gelangenden almohadischen Stämmen werden Aufklärungsgespräche geführt, aus welchen die Beteiligten geläutert hervorgehen. Als die Gesamtheit der Almohaden in Marrakech angekommen ist, beginnt man mit ihrer Aufteilung in insgesamt drei Schichten. Dabei gehören der ersten Schicht die Almohaden an, die dem Mahdi Muḥammad Ibn-Tūmart gehuldigt haben und an der Schlacht bei Buhaira (1130) teilgenommen haben. Die zweite Schicht soll aus denjenigen bestehen, die sich zum Almohadentum im von der Schlacht bei Buhaira bis zur Einnahme von Oran (1145) reichenden Zeitraum bekannt haben. Was die dritte und letzte Schicht anbetrifft, so sind ihr all diejenigen zuzurechnen, die sich in die Gemeinschaft der Almohaden nach der Eroberung Orans im Jahre 1145 eingereiht haben bzw. sich noch einreihen werden.

Hiernach endet der Brief unvermittelt mit dem Hinweis, dass an dieser Stelle der schönste Teil des Briefes zu Ende sei.

\section{Der 13. Brief.}

${ }^{717}$ Der Brief erläutert nicht, wem die Almohaden huldigen, und die Kenntnis, wem diese Huldigung 
Dieser undatierte Brief, abgefasst in Rabat im Namen des Befehlshabers der Gläubigen, ist an die Tâalibs von Ceuta und Tanger sowie an die Gesamtheit ihrer jeweiligen Almohaden, Šaihs, Notabeln und die Allgemeinheit adressiert. Den Gegenstand dieses Briefes bildet die Ernennung des Sohnes des Befehlhabers der Gläubigen (d. h. 'Abd-alMu'mins) namens Muhammad zum Nachfolger seines Vaters: Seit langer Zeit bereits weisen die arabischen und die șanhāğitischen Stämme des Ostens auf ihren Wunsch hin, Muhammad zu ihrem Herrscher bzw. Statthalter zu haben. Bei ihrer letzten Ankunft beim almohadischen Herrscher, bei der eigentlich Gespräche über ganz andere Themen hätten stattfinden sollen, tragen sie das erwähnte Anliegen mehrmals vor. Vor ihrer Rückkehr bestehen sie besonders nachdrücklich auf ihrem Wunsch, so dass der almohadische Herrscher sich genötigt sieht, darüber mit den in Rabat befindlichen almohadischen Šaihs, Țālibs und Schatzmeistern der Provinzen (arab: 'ummāl' ${ }^{18}$ ) zu beratschlagen. Die versammelten Almohaden äußern jedoch ihrerseits den Wunsch, Muhammad möge zum Herrscher über sie ernannt werden, und sind sich über den daraus resultierenden Nutzen für die almohadische Bewegung einig. Dieser Wunsch der Almohaden wird auch bei den darauf folgenden Treffen wiederholt zum Ausdruck gebracht und findet auch sonst die allgemeine Zustimmung der Almohaden. Angesichts dieser Einmütigkeit wird Muhammad als dem künftigen Herrscher gehuldigt.

\section{Der 14. Brief.}

Dieser Brief, datiert vom 5. Mai des Jahres 1156 und abgefasst im Namen des Befehlshabers der Gläubigen in Rabat, ist an die Tāalibs, Šaihs, Notabeln und die gesamte Bewohnerschaft der Stadt Ceuta adressiert und setzt sie über die Ernennung der Söhne der herrschenden Dynastie zu Statthaltern über einige Provinzen des Reiches in Kenntnis: Die arabischen und șanhāğitischen Stämme des Ostens, angesichts der Proklamation Muhammads zum Nachfolger seines Vaters, äußern den Wunsch, einer der Brüder Muhammads möge in ihren Gebieten die Funktion des Statthalters ausüben. Als die almohadischen Šaihs, Țālibs und Schatzmeister der Provinzen davon erfahren, sind sie sich darüber einig, diesem Wunsch zu entsprechen. Als dies geschieht, haben die Bewohner sämtlicher Gebiete den innigen Wunsch, ihre Regierungsangelegenheiten ebenfalls den Söhnen des Befehlhabers der Gläubigen anzuvertrauen. Die Ṭālibs von Tilimsen äußern sich in diesem Sinne, und das findet die Zustimmung der Almohaden.

\footnotetext{
gegolten hat, wird vorausgesetzt.

${ }_{718}$ Laut 'Izz-ad-Dīn 'Umar Mūsā waren „'ummāl“ zuständig für die „Finanzangelegenheiten“ in den almohadischen Provinzen (al-Muwaḥhịīn fi 'l-Ġarb al-Islāmī, S. 170).
} 
Die almohadischen Šaihs, Ṭālibs und Schatzmeisetr des Gebietes, das als ,al-Ġarb alwasat“ ${ }^{6719}$ bezeichnet wird, beratschlagen darüber, wie die Angelegenheiten dort in der bestmöglichen Weise gestaltet werden können, und gelangen zur Überzeugung, dass es für dieses Gebiet gut sei, wenn ihm einer der Brüder Muhammads vorstehe und wenn der Stamm Ġumāra sowie die Stadt Ceuta samt ihrem Umland in die Zuständigkeit dieser erwähnten Verwaltungseinheit falle. Bei den darauf folgenden Beratungen gelangen die Ṭālibs von Ceuta mit anderen Ṭālibs zum Schluss, dass wenn die Angelegenheiten des Stammes Ġumāra und anderer um Ceuta und Tanger siedelnder Stämme sowie der Städte Algeciras, Tarifa und Malaga samt ihrem jeweiligen Umland auch weiterhin in Ceuta geregelt werden, es einer Person bedürfe, welche mit diesem Aufgabenbereich betraut werde. Einer der Brüder Muhammads wird dafür erbeten. Der almohadische Herrscher stimmt all diesen Entscheidungen der Almohaden zu und bestimmt für jeden seiner Söhne almohadische Würdenträger, die ihnen bei der Wahrnehmung seiner Aufgaben zur Seite stehen sollen.

\section{Der 15. Brief.}

Dieser Brief, datiert vom 26. Juli 1156 und abgefasst in Namen des Befehlshabers der Gläubigen in Marrakech, ist an die Ṭālibs, Šaihs, Notabeln und die gesamte Bewohnerschaft von Ceuta adressiert. Er nimmt Bezug auf einen nicht näher umrissenen Fall des Ungehorsams in den almohadischen Reihen und berichet wie folgt über die Maßnahmen zwecks seiner Aufarbeitung: Nach der Bestrafung des Schuldigen werden mit den Almohaden Aufklärungsgespräche in den über mehrere Tage sich hinziehenden Versammlungen geführt, und alle Almohaden zeigen sich reumütig. Nach einiger Zeit treten nicht namentlich genannte Šaihss, Notabeln, Ṭālibs und Schatzmeister der Provinzen vor den Befehlshaber der Gläubigen, und nach zahlreichen Ermahnungen und Predigten bitten sie unterwürfig um Verzeihung und bekunden weinend ihre Zerknirschung. Sie werden über diejenigen aus den Reihen der Almohaden aufgeklärt, welche sie zur Uneinigkeit verführen. Man fordert sie auf, Buße zu tun, aufrichtig zu sein und warnt sie davor, mit all jenen zu verkehren, die auf die Uneinigkeit der Almohaden untereinander sinnen. Die erwähnten Almohaden geloben, all diesem Genüge zu leisten. Es wird ferner allen Almohaden befohlen, miteinander Frieden zu

\footnotetext{
${ }^{719}$ Es geht aus dem Text nicht hervor, welches Gebiet damit gemeint ist. Der Gebrauch der Bezeichnung „Ġarb“ in „Kitāb ahbār mahdī Ibn-Tūmart wa-'btidā' daulat al-muwaḥhidīn“ (S. 65, 111) legt nahe, dass damit das nördliche Marokko gemeint ist, die Städte Fès und Meknès inbegriffen. Es ist möglich, dass mit „a-G̈arb al-wasat?" entweder nur ein Teil von „G̈arb“ oder aber ein sich damit deckendes Gebiet gemeint ist.
} 
schließen, untereinander Nachsicht walten zu lassen und sich gegenseitigen Beistand zu leisten. Mit einigen Segenswünschen und dem Aufruf, den erwähnten Almohaden im Hinblick auf die Nachsicht miteinander und auf die Festigung der Bande der Gemeinschaft nachzueifern, schließt der Brief.

Der 16. Brief.

Dieser Brief, abgefasst im Namen des Befehlshabers der Gläubigen in Marrakech im Zeitraum vom 8. bis 17. September des Jahres 1157, ist an die Ṭālibs, Šaihs, Notabeln und die gesamte Bewohnerschaft von Biğāya adressiert. Darin ist der Bericht über einige Ereignisse in al-Andalus enthalten, deren Abfolge wie folgt beschrieben wird: Bereits mehrmals sind aus al-Andalus Bitten um Beistand gegen seinen Feind, der es immer heftiger bedrängt, überbracht worden. Als die Entscheidung getroffen wird, dem Treiben des erwähnten Feindes Einhalt zu gebieten, gelangt man zur Überzeugung, dass bei der bevorstehenden Unternehmung der Stadt Almeria die größte Bedeutung zukommt. Zur gleichen Zeit kehren die Țālibs von Granada in diese Stadt zurück ${ }^{720}$. In Granada angekommen, setzen sie jedoch ihre Reise bis nach Almeria fort. Als sie in der Umgebung von Almeria eintreffen, greifen sie die sich dort aufhaltenden Ungläubigen an und erstürmen wenig später die Stadt. Einigen Ungläubigen gelingt es, sich in der Zitadelle der Stadt zu verschanzen. Als Ibn-Mardanīš von diesen Ereignissen erfährt, eilt er zusammen mit dem christlichen König nach Almeria, um die Stadt zurückzuerobern. Einige Zeit nach der Ankunft dort mit ihren jeweiligen Truppen, werden sie jedoch von solch gewaltigem Entsetzen ergriffen, dass sie eilendst die Flucht ergreifen und die in der Zitadelle Umzingelten im Stich lassen. Daraufhin gelingt den Ṭālibs die Bezwingung der erwähnten Zitadelle. Noch vor dieser Flucht haben die genannten Ṭālibs den almohadischen Herrscher über das Eintreffen der Truppen von Ibn-Mardanīš und des christlichen Herrschers informiert, und so setzt sich das almohadische Heer nach Almeria in Bewegung. Unterwegs wird jedoch die erwähnte Flucht Ibn-Mardanīšs und des mit ihm verbündeten christlichen Königs bekannt, und die almohadische Armee kehrt um. Die fliehenden Scharen von Ibn-Mardanīš und des christlichen Herrschers gelangen derweil nach Granada, das sie vergeblich belagern, und wo ihnen durch Ausfälle der granadinischen Garnison Verluste zugefügt werden. Angesichts dieser Situation ergreift der christliche Herrscher die Flucht und findet in der Nähe von Baeza den Tod. Als die Țālibs, die Almeria erobert haben, davon erfahren,

\footnotetext{
${ }^{720}$ Dem Kontext nach kehren sie aus Marrakech nach Granada zurück.
} 
eilen sie nach Baeza, welche sie kampflos in Besitz nehmen und deren christliche Garnison nach Ubeda flieht. Die Țālibs nehmen ihre Verfolgung auf und bemächtigen sich auch dieser Stadt.

Weiter enthält der Brief Ausführungen darüber, welch große strategische Bedeutung Baeza bei den Beutezügen und Einfällen der Christen in das Gebiet von al-Andalus gehabt hat, und weist darauf hin, dass die Ṭālibs nach den geschilderten Ereignissen den almohadischen Herrscher über ihren Ablauf in Kenntnis setzen. Der Brief schließt mit den Hinweisen auf den gottgewolten Charakter der beschriebenen Ereignisse.

Der 17. Brief.

Dieser Brief, datiert vom 13. November des Jahres 1157 und abgefasst im Namen des Befehlshabers der Gläubigen in Marrakech, ist an die Țālibs, Šaihss, Notabeln und die gesamte Bewohnerschaft der Stadt Soundso sowie ihres Umlandes adressiert. Er enthält den folgenden Bericht über den Besuch des Grabes des Mahdi und über die damit im Zusammenhang stehenden Ereignisse: Mit den almohadischen Šaihss, Notabeln, Ṭālibs und Hāfiẓs bricht der almohadische Herrscher auf, die Gegenden der Almohaden zu besuchen und mit den Almohaden dort zusammenzutreffen. Unterwegs finden Zusammenkünfte und Gespräche mit den Stämmen Ğadmīwa, Maṣmūda, Ğanfīsa, Rağrāğa und Ḥāḥa statt. In der Nähe von Ḥāḥa kommt es zum zufälligen Treffen mit den Stämmen Ğazūlat al-Kust, die sich gerade auf dem Weg nach Marrakech, der almohadischen Hauptstadt, befinden, um dort die Sicherheitsgarantie für ihr Leben und Gunsterweisungen ihnen gegenüber zu erflehen. Es wird ihren Wünschen entsprochen und nachdem sie dem almohadischen Herrscher Treue schwören, verabschieden sich von den Almohaden. Über as-Sūs gelangen die Almohaden nach Tārūdānt, wo sie von den Stämmen von as-Sūs empfangen werden. Von dort aus setzen sie ihre Reise nach İ̆̄illīz fort, wo sie einige Tage in der dort befindlichen Moschee ${ }^{721}$ verbringen und Renovierungsarbeiten zwecks besseren Schutzes dieser Moschee gegen die Gewitter durchführen. Während ihres von Koranrezitationen begleiteten Aufenthaltes dort,

\footnotetext{
${ }^{721}$ Im arabischen Text (Mağmū' rasā'il muwaḥhidīya, S. 86) wird dies wie folgt ausgedrückt: „fa-nuzila 'an al-akwār wa-tuburrika bi-d̄alika al-masğid al-mu'aẓẓam wa-'l-ḡār wa-dīna bi-ta'ẓīm dِalika al-mašhad al-karīm“, wörtl. „man stieg von den Satteln ab, und man erlangte Segen mittels dieser verehrungswürdigen Moschee und Höhle und zollte Hochachtung diesem geheiligten Ort". HuiciMiranda hält ,al-masğid al-mu'az̧zam“ und ,al-ḡār“ für zwei voneinander zu unterscheidende Orte (Historia política del imperio almohade, Bd. 1, S. 181). Aufgrund der grammatischen Struktur des arabischen Satzes jedoch sowie der Tatsache, dass die genannte Höhle bereits bei dem Aufenthalt des Mahdi dort im Jahr 514 H. (2. April 1120-21. März 1121) eine Tür o.ä. hatte (in „Kitāb ahbār al-mahdī Ibn-Tūmart“, S. 73, ist von „,bāb al-ḡār" die Rede), ist es sehr wahrscheinlich, dass sich die obigen ,almasğid al-mu'ažz̧am“, ,al-ḡār" und ,al-mašhad al-karīm“" auf das gleiche Objekt beziehen.
} 
treffen bei den Almohaden die Šaihs des Stammes Harğa ein, denen man die Erfüllung ihrer Hoffnungen und Nachsicht zuteil werden lässt. In Ānsā angelangt, wird die almohadische Prozession von den Stämmen von Tīmallal und Hintāta sowie anderen dort siedelnden Stämmen begrüßt. Angesichts des herannahenden Winters beschließen die Almohaden, ihre Reise mit dem Besuch des Grabes von Muhammad Ibn-Tūmart abzuschließen. Als sie auf dem Weg dorthin sich in der Entfernung einer Tagesreise von Ānsā befinden, treffen bei ihnen die Gesandten der Stämme Ğazūla, Haskūra und der Stämme von al-Kust ein und bitten zerknirscht über ihre früheren Vergehen um Verzeihung. Zur gleichen Zeit strömen alle anderen Stämme sowie die gesamten Bewohner dieses Gebietes zu den Almohaden. Die Almohaden führen mit den erwähnten Gesandten religiöse Aufklärungsgespräche und die Letzteren bringen ihren Wunsch zum Ausdruck, dem almohadischen Herrscher Treue zu geloben. Die Vertreter der genannten Stämme treffen bei den weiterziehenden Almohaden unaufhörlich ein bis die Letzteren Tinsilt erreichen. Als der Zug der Almohaden nach Tinmallal gelangt, kommt bei ihnen eine große Abordnung an, die sich aus den Notabeln der erwähnten Stämme zusammensetzt, Rettung ${ }^{722}$ erflehend und durch die Heiligkeit des Grabes von Mahdi Schutz suchend. Nach dem Besuch des Grabes kehren die Almohaden nach Marrakech zurück.

Der 18. Brief.

Bei diesem Antwortschreiben, das vom 11. August des Jahres 1158 datiert ist und im Namen des Befehlshabers der Gläubigen in Marrakech abgefasst wurde, ist der Adressat $^{723}$ nicht erwähnt. Es enthält die Eingangsbestätigung des Briefes, in welchem seine Absender, d.h. die Empfänger des vorliegenden Antwortschreibens, ihn über ihre erfolgreichen Unternehmungen gegen den ungläubigen Feind und der ihnen dabei zuteil gewordenen Unterstützung in Bezug auf den Proviantnachschub informiert haben. Die

\footnotetext{
${ }^{722}$ An dieser Stelle (Mağmū' rasā'il muwaḥhidīya, S. 91) steht im arabishen Origunal ,yargabūn fi 'lislām wa-yatawassalūn bi-ḥurmat dِalika al-maqām“. Dabei kann mit „Islām“ sowohl die Religion Islam als auch, von der Grundbedeutung der Wurzel „SaLiMa“, d. h. „unversehrt, heil sein“, ausgehend, der Infinitiv vom 4. Stamm gemeint sein, der wörtlich „unversehrt, heil machen, retten“ bedeutet. Ferner geht aus den almohadischen Briefen hervor, dass „Islam“ und „Almohadentum“ gleichgesetzt werden, so dass alle, die sich nicht zum Almohadentum bekennen, nicht als „wahre“ Muslime betrachtet werden. Siehe hierzu z.B. (Mağmū' rasā’il muwaḥhidīya, S. 184) „kāna haulā' al-ašqīyā' al-mutamarridūn wa-'l-kafara al-munhali'ūn min taub al-islām al-mutağarridūn“ oder (daselbst, S. 196) „wa-tatallabat (aiy bilād Nafzāwa wa-Tauzar wa-Taqyūs wa-'l-Hamma wa-Nafța) min hadihī ad-da'wa al-'alīya ma'lūm minnatihā [...] wa-ḥaqqaqat annahā lam tubaddil dīnahā wa-lā fāraqat īmānahā wa-yaqīnahā“‘.

${ }^{723}$ Mit dem arabischen Personalpronomen ,antum“ werden in den almohadischen Briefen sowohl einzelne Personen als auch Personengruppen angeredet. Es ist wahrscheinlich, dass der vorliegende Brief an eine Personengruppe adressiert ist.
} 
genannten Unternehmungen finden die Zustimmung des almohadischen Herrschers. Der Brief schließt mit Ermahnungen religiösen Charakters.

Der 19. Brief.

Dieser Brief, datiert vom 4. Dezember des Jahres 1159 und abgefasst im Namen des Befehlshabers der Gläubigen vor den Toren der von den Almohaden belagerten alMahdia, ist an die Ṭālibs und Almohaden von Granada adressiert und berichtet wie folgt über das Vorhaben, auf Gibraltar eine Stadt zu bauen: Trotz seines Aufenthaltes in Ifrīqiya ist der almohadische Herrscher der Gegenden von al-Andalus eingedenk und stets auf ihr Wohl bedacht. So beschließt er, eine Stadt auf Gibralatar bauen zu lassen, der eine wichtige Rolle bei der Verteidigung von al-Andalus zukommen soll. $\mathrm{Zu}$ diesem Zweck entsendet er zwei almohadische Šaihs, die das Vorhaben in die Wege leiten sollen. Die genannten Adressaten werden aufgefordert, mit anderen andalusischen Šaihss, den Ṭālibs von Sevilla samt ihren Gefährten mit den beiden Ankommenden auf Gibraltar zusammenzutreffen und einen für die Gründung der Stadt geeigneten Ort zu bestimmen. An den Šaih Abū-Ḥafṣ ist ein Brief ergangen und er wird nach Möglichkeit dort eintreffen. Auch ein anderer Šaih wurde bereits schriftlich aufgefordert, sich nach Gibraltar zu begeben. Die beiden entsandten Šaihs überbringen die Vorstellungen des almohadischen Herrschers, die den künftigen Überlegungen zugrundeliegen sollen.

Als dieser Brief bereits abgeschickt werden sollte, wird die Nachricht von der Bezwingung Gafsas sowie der damit zusammenhängenden Kontaktaufnahme mit den arabischen Beduinenstämmen von Gabès überbracht. Das Schreiben, das diese letzteren Geschehnisse schildert, wird dem vorliegenden Brief beigefügt. Was die almohadische Armee betrifft, so wird sie sich demnächst in Marsch nach Marrakech setzen. Die Adressaten werden aufgefordert, die Nachricht von der Rückkehr sowie von der Einnahme Gafsas allen Almohaden zukommen zu lassen.

Der 20. Brief $^{724}$.

Dieser undatierte Brief ist im Namen des Befehlshabers der Gläubigen in Gafsa abgefasst und ist an die Ṭālibs, Almohaden, Šaihs, Notabeln und die gesamte Bewohnerschaft Cordobas adressiert. Seinen Inhalt bildet der folgende Bericht über die Eroberung Gafsas und die damit im Zusammenhang stehenden Ereignisse: Der

724 In „Mağmū'a ğadīda“ (Bd. 1, S. 144-161) finden sich zwei der Handschrift „al-`Ațā’ al-ğazīl““ entnommene almohadische Briefe, die die Bezwingung Gafsas schildern und als Datum ihrer Abfassung 
Anführer von Gafsa lehnt sich gegen die almohadische Herrschaft auf, so dass sich die Almohaden zum Durchgreifen dagegen veranlasst sehen. Zu diesem Zweck werden die in Biğāya befindlichen Ṭālibs sowie die in Biğāya und Ifrīqīya stationierten Truppenkontingente der Almohaden nach Gafsa vorausgeschickt, um den genannten Anführer mit seinen Anhängern dazu zu mahnen, von ihrem Handeln Abstand zu nehmen. Die Letzteren missachten diese Mahnung. Das Gros der almohadischen Armee schlägt währenddessen den Weg nach Gafsa über Kairuan ein. Nach der Ankunft dort wird die Belagerung Gafsas aufgenommen, und die sich rund um die Stadt befindenden Anpflanzungen werden beseitigt, was den Almohaden eine dichte Umzingelung der Stadt ermöglicht. Es werden Katapulte eingesetzt, und angesichts ihrer Wirksamkeit beschließen die Almohaden, weitere Katapulte zu bauen. Zu dieser Zeit begibt es sich, dass Christen Bauholz zu den Küsten Ifrīqiyas transportieren, welches die Almohaden für den erwähnten Bau verwenden. Unmittelbar vor der Fertigstellung dieser Kriegsmaschinen wird an die Belagerten eine letzte Warnung gerichtet, welche ebenfalls ignoriert wird. Beim folgenden Angriff auf die Stadt gelingt es den Almohaden, ihren vorderen Bereich zu erstürmen. Daraufhin bieten die Belagerten gegen eine Sicherheitsgarantie für ihr Leben den Almohaden die Kapitulation an, worauf die Letzteren eingehen. Nach der Schilderung der Grausamkeiten, mit welchen der erwähnte Anführer zusammen mit seinen Anhängern gegen die Bewohnerschaft von Gafsa gewütet habe sowie des allgemeinen Sittenverfalls dieser Stadt fährt der Brief mit der Beschreibung der Vorzüge und anderer bewunderungswürdiger Eigenschaften Gafsas fort. Der Brief weist ferner darauf hin, dass die wiklichen Zustände in Gafsa dem almohadischen Herrscher infolge verzerrender Berichterstattung lange unbekannt blieben, ohne dabei konkreten Personen die Schuld dafür zu geben. Mit dem Aufruf, die beschriebenen Siege der Almohaden überall zu verkünden, schließt der Brief.

\section{Der 21. Brief.}

Dieser Brief, datiert vom 23. April des Jahres 1160 und abgefasst im Namen des Befehlshabers der Gläubigen in der Nähe von Mattīğa, ist an die Ṭālibs, Šaihs, Notabeln und die gesamte Bewohnerschaft von Fes adressiert. Er setzt die erwähnten Adressaten wie folgt vom Sieg der Almohaden über den arabischen Stammesverband Banū-Riyāḥ in Kenntnis: Im vorhergegangenen Schreiben hat man bereits die Adressaten über die Erfolge des almohadischen Feldzuges gegen die arabischen Stämme Ifrīqīyas 
unterrichtet, der allerdings zum damaligen Zeitpunkt noch nicht gänzlich abgeschlossen war. Nun ergeht an die genannten Empfänger das nächste Schreiben, nachdem der erwähnte Stammesverband ausgemerzt wurde. Seine Angehörigen hatten die Wahl, entweder sich den Almohaden zu unterwerfen oder gegen sie aufzubegehren. Diejenigen unter ihnen, welche die Flucht vorzogen, wurden umgebracht, diejenigen aber, die auf das Angebot der Almohaden eingingen, verschonte man. Zum Zeitpunkt der Abfassung dieses Briefes treffen die ersten Abteilungen der almohadischen Armee ein $^{725}$, berichten vom genannten Sieg und kündigen eine außerordentlich reiche Beute an. Durch das Bekenntnis des Anführers der Banū-Muhammad, eines Stammes von den Banū-Riyāḥ, zum Almohadentum lassen die Almohaden diesem Stamm gegenüber Gnade walten. Die Banū-Muhammad sind nun aufgebrochen, um nach Maghreb auszuwandern. Auch ein anderer Stamm der Banū-Riyāḥ, die Ğušam, hat ebenfalls den Weg nach Maghreb eingeschlagen. Was die Stämme al-Ațbağ und Zugiba anbelangt, so sind ihre Notabeln bei den Almohaden eingetroffen, ihre Reue bekundend, Sicherheitsgarantie für ihr Leben heischend und sich $\mathrm{zu}$ bessern versprechend. Nach diesem Feldzug der Almohaden nach Ifrīqīya ist die Gesamtheit ihrer lokalen Herrscher besiegt. Der Brief schließt mit der Aufforderung, sich über diese frohen Botschaften zu freuen und sie zu verbreiten.

\section{Der 22. Brief.}

Dieser undatierte Brief ${ }^{726}$, abgefasst im Namen des Befehlshabers der Gläubigen in der Residenzstadt Soundso, nennt keine Adressaten und setzt sie in folgender Weise vom Sieg der Almohaden über Christen in al-Andalus in Kenntnis: Wärend des Aufenthaltes des almohadischen Herrschers in al-Andalus wird bekannt, dass einige Christen der Stadt Avila und ihres Umlandes nach al-Andalus unterwegs sind. Dort angelangt, durchqueren sie zwischen Cordoba und Sevilla den Guadalquivir und erbeuten in der Nähe von Ecija zahlreiche Schafherden. Von dort aus schlagen sie über La Campiña den Weg nach Montoro ein. Als die Almohaden davon erfahren, entsenden sie gegen die christlichen Eindringlinge eine Abteilung der almohadischen Armee nach, welcher sich später der Šaih Abū-Ḥaṣ mit anderen Almohaden anschließt. Gemeinsam nehmen sie nun die Verfolgung auf, und schon bald wird der Sieg der Almohaden verkündet. Die

\footnotetext{
identisch.

${ }^{725}$ Dem Kontext nach in Mattī̌̆a.

${ }^{726}$ Lévi-Provençal (Un recueil de lettres officielles almohades: étude diplomatique et historique, S. 49) korrigiert die ursprüngliche Zuordnung dieses Briefes und datiert ihn in die Regierungszeit des Nachfolgers 'Abd al-Mu'mins, Abū Ya'qūb Yūsuf.
} 
Almohaden kehren nach Abschluss dieser Unternehmung mit dem Kopf des christlichen Anführers und den christlichen Bannern zurück und berichten über die Abfolge der Ereignisse. Ihrem Bericht zufolge kommt es in der Region Fạ̣s Hilāl zur Schlacht, aus welcher die Almohaden als Sieger hervorgehen. Bei ihrer Flucht vom Schlachtfeld hätten die Christen die erbeuteten Schafherden und die von ihnen verschleppten Muslime zurückgelassen. Eine außerordentlich hohe Zahl von Christen sei in der Schlacht gefallen und die Natur selbst habe zugunsten der Almohaden in das Kampfgeschehen eingegriffen.

Ferner weist der Brief darauf hin, dass dem geschilderten Sieg der Almohaden noch zahlreiche andere folgen werden und beschreibt den erbärmlichen Zustand der Christen nach ihrer Niederlage. Der Brief schließt mit der Aufforderung, Gott für den Erfolg der Almohaden gebührend zu danken und diesen Sieg allenthalben zu verkünden.

\section{Der 23. Brief.}

Dieser Brief, datiert vom vom 2. März des Jahres 1161 und abgefasst im Namen des Befehlshabers der Gläubigen in Rabat, ist an die Țālibs von Biğāya adressiert. Er besteht aus zwei thematischen Teilen. Im ersten wird das almohadische Konzept des Weltgeschehens, d. h. die Mission des Mahdi und die der Almohaden nach seinem Hinscheiden, kurz zusammengefasst. ${ }^{727}$ Der zweite Teil enthält Anordnungen darüber, wie die religiösen Belange in den von den Almohaden beherrschten Gebieten zu regeln und etwaige Übertretungen der schariatischen Normen zu ahnden sind. Dieser zweite Teil wird mit dem Hinweis auf das Verharren der Menschen im Irrtum und im sündigen Handeln und auf die daraus seitens der Almohaden resultierenden Maßnahmen dagegen eingeleitet. An erster Stelle wird das Bekenntnis zur Einsheit Gottes erwähnt. Daran schließt sich der Befehl an diejenigen, die die „westliche Sprache“ beherrschen, das in dieser Sprache verfasste Kapitel über die Einsheit Gottes ${ }^{728} \mathrm{zu}$ lesen, auswendig zu lernen und es ständig zu üben. Die Ṭālibs der Präsenz ${ }^{729}$ erhalten einen ähnlich lautenden Befehl bezüglich des Kapitels über die Grundlagen der almohadischen Lehre,

\footnotetext{
727 Diese almohadischen Vorstellungen sind in einem von Muhammad Ibn-Tūmart verfassten Buch „A`azzu mā yuṭlab“ bzw. „Le livre de Mohammed Ibn Toumert, Mahdi des Almohades“, S. 251 ff. (Hrsg. von I. Goldziher, Alger 1903) überliefert.

${ }^{728}$ Der Kontext legt hier nahe, dass es sich bei diesem Kapitel sowie bei anderen erwähnten Abschnitten um die Passagen der von Muhammad Ibn-Tūmart verfassten Schrift handelt, in der er seine theologischen und religiösen Ansichten darlegt.

${ }^{729}$ Diese Bezeichnung geht auf Emil Fricaud zurück, der in seinem Artikel „Les talaba dans la société almohade“ (Al-Qantara 1997, Bd. 18, S. 331-387) Belege dafür anführt, dass mit „Ṭalabat al-hadar“ die Ṭālibs der ständigen Präsenz beim jeweiligen almohadischen Herrscher in Abgrenzung von „Ṭalabat almuwạ̣hidīn" gemeint sind.
} 
und die gesamte Bewohnerschaft habe das gleiche mit der genau festgelegten Passage eines weiteren Kapitels zu tun. Darauf folgen die Aufrufe, für die Verrichtung der kanonischen Gebete zu sorgen, das gemeine Volk die erste Sure des Korans samt einigen anderen Suren auswendig lernen $\mathrm{zu}$ lassen und an denjenigen, die die vorgeschriebenen Gebete verabsäumen, die Todesstrafe $\mathrm{zu}$ vollstrecken. Die Entrichtung der Zakāt-Steuer soll durchgesetzt werden und diejenigen, die die Entrichtung dieser Steuer verweigern, sollen ebenfalls mit der Todesstrafe geahndet werden. Ferner wird befohlen, die Aufmerksamkeit auf die alkoholhaltigen Getränke zu richten, diejenigen Feindseligkeiten auszusetzen, die sie verkaufen, konsumieren oder verwenden, und solche dieser Getränke zu vernichten, die berauschende Wirkung haben. Wer sich aber dieses Vergehen zuschulden kommen lässt, so ist er auch des Todes. Des Weiteren sollen auch Versammlungsorte, an welchen Musikinstrumene vorhanden sind, von den Adressaten entdeckt und ihre Betreiber sollen aufgescheucht werden. Auch in Bezug auf die Wucherer, auf die dem Ğihād Ferbleibenden, auf die Stämme, die im Umgang miteinander die islamischen Normen missachten und sich wie Unwissende benehmen, sowie auf Heuchler sind einschlägige koranische Strafen anzuwenden.

Der Brief weist auf die bereits früher erfolgte Zusendung eines Exemplars des Buches vom Mahdi hin, aus welchem die Adressaten ersehen sollen, welche Strafe Gott für andere Frevler festgesetzt hat. Dieses Buch soll als die einzige Quelle der Rechtleitung und des unumstößlichen (religiösen) Wissens dienen. Ferner sollen die Taalibs den Menschen das Bekenntnis zur Einsheit Gottes beibringen und es sie samt einigen anderen Koransuren auswendig lernen lassen.

Die in der Regierungszeit von Yūsuf Ibn-'Abd-al-Mu'min (1163-1184) abgefassten Briefe.

Der 24. Brief.

Die Adressaten dieses undatierten Briefes, der im Namen des Befehlshabers Yūsuf Ibn'Abd-al-Mu'mins abgefasst ist, bilden sein Bruder, der Šaih Abū-Sa'̄̄d, und der Šaih Abū-Sa īd Yahluf Ibn-al-Hasan. Er beinhaltet die folgende Mitteilung über die Entsendung eines Teils der almohadischen Armee nach Sevilla: Der almohadische Herrscher beschließt, gegen die Abtrünnigen der Șanhāğa-Stämme militärisch vorzugehen, und die zu den Beratungen diesbezüglich berufene Versammlung der 
Almohaden einigt sich über den Aufbruch aller Almohaden in Begleitung der almohadischen Šaihs und Hạfiẓs zur erwähnten Unternehmung. Dieses almohadische Heer ist bereits ausgerückt. Noch vor der genannten Versammlung beratschlagten die Šaihs der Ṭālibs darüber, einen Almohaden namens Ismā̄̄il mit den Almohaden und arabischen Beduinen nach Sevilla zum Schutze dieser Stadt zu entsenden. Die darüber beratenden Šaihs der Ṭālibs beschlossen einmütig diese Entsendung und man war bereits im Begriff, sie erfolgen $\mathrm{zu}$ lassen, doch wegen des beginnenden Monats Ramaḍān wurde sie bis zu dessen Ende aufgeschoben. Da dieser Monat nun zu Ende ist, wird die erwähnte almohadische Verstärkung unmittelbar nach der Absendung des vorliegenden Schreibens nach Sevilla aufbrechen.

\section{Der 25. Brief.}

Dieser Brief, datiert vom 29 Mai des Jahres 1169 und abgefasst im Namen des Befehlshabers der Gläubigen in Marrakech, ist an den Šaih Abū-'Abdallāh Muhammad Ibn-Sa'd adressiert und enthält einen Aufruf an ihn, sich zum Almohadentum zu bekennen. Er weist folgenden Aufbau auf: Am Anfang erfolgt die Schilderung die Erlösung der Welt aus ihrer Sündhaftigkeit und Unwissenheit durch den Propheten Mohammed. Er hat demnach die Verfälschung der wahren Gottesanbetung und den allgemeinen Sittenverfall nach seinem Tod und demjenigen seiner Gefährten prophezeit. Diese wahre Gottesanbetung werde erst durch das Erscheinen eines unfehlbaren Imams, dessen Merkmale sowie die Zeit und der Ort seines Auftretens er genau beschrieben hat, wiederhergestellt. Diese Prophezeiung hat sich erfüllt und der angekündigte Imam ist tatsächlich erschienen, unterstützt von seinem Gefährten, dem Befehlshaber der Gläubigen (d. h. 'Abd-al-Mu'min), welcher der Botschaft des Mahdi zum umfassenden Obsieg verholfen hat. An diese Ausführungen schließt sich der Aufruf an, das Almohadentum anzunehmen und sich die jenseitigen Vorteile zu vergegenwärtigen, die aus dem Bekenntnis zum Almohadentum erwachsen. Die Ablehnung der almohadischen Botschaft jedoch kommt der Ablehnung der koranischen Offenbarung und der Leugnung der Aussagen der Gottesgesandten gleich. Nach der erneuten Erwähnung zahlreicher aus dem Bekenntnis zum Almohadentum resultierender Nutzen wird der Adressat aufgefordert, des tragischen Schicksals der Gegner der Almohaden zu gedenken. Ferner wird darauf hingewiesen, dass, obwohl der Adressat ehemals einen ähnlichen Aufruf missachtet habe, ihm, leiste er diesmal der Einladung zum Almohadentum Folge, die vorzügliche Behandlung seitens der Almohaden sicher ist. 
Der Brief schließt mit damit, dass der Šaih Abū-Hafṣ, der mit dem almohadischen Heer nach al-Andalus ausgerückt ist, die Anweisung erhalten hat, die Gebiete des Adressaten nicht zum Schauplatz der Kampfhandlungen zu machen solange seine Antwort auf das vorliegende Schreiben nicht eingegangen ist, und dass von eben dieser Antwort das weitere Vorgehen der almohadischen Armee abhängen wird.

\section{Der 26. Brief.}

Dieser Brief, datiert vom 4. März des Jahres 1181 und abgefasst im Namen des Befehlshabers der Gläubigen in Tunis, richtet sich an die Tālibs, Almohaden, Notabeln und die gesamte Bewohnerschaft Cordobas und teilt den genannten Adressaten den Aufbruch arabischer Beduinenstämme Ifrīqīyas nach al-Andalus zwecks Teilnahme an den militärischen Unternehmungen der Almohaden dort mit. In folgender Weise wird dies geschildert: Während der Entsendung der Almohaden zu den Küstenregionen Ifrīqīyas, die nach dem erfolgreichen Abschluss eines Feldzuges dorthin erfolgt, werden die Šaihs und die angesehenen Persönlichkeiten der Stämme des Stammesverbandes Banū-Riyāḥ versammelt, es werden mit ihnen religiöse Aufklärungsgespräche geführt und man ruft sie dazu auf, die Christen in al-Andalus zu bekriegen und $\mathrm{zu}$ diesem Zweck dorthin umzusiedeln. Begeistert willigen die Versammelten in diesen Aufruf ein, und die gesamten arabischen Stämme dieser Region brechen bald unter Aufsicht von Ṭālibs und Hāfiẓs nach al-Andalus auf. Einer derjenigen, die den unterbreiteten Vorschlägen freudig zustimmen, ist Šaih Abū-Sirhāan Mas`ūd Ibn-Sulțān Ibn-Zimām, der samt all seinen Familienangehörigen als einer der ersten die Auswanderung nach Maghreb antritt. Nach dem Abzug dieser Stämme ist niemand mehr von den arabischen Beduinen in Ifrīqīya geblieben. Des Weiteren wird ein vorher erfolgter ähnlicher Aufruf an die Sulaim-Stämme erwähnt, die in den um Tripolis und östlich und südlich davon befindlichen Gegenden siedeln. Von diesen erwartet man nun, dass sie wie die RiyāhStämme nach al-Andalus ziehen. Der Brief schließt mit der Aufforderung, diese Mitteilungen $\mathrm{zu}$ verkünden und sie bei den Zusammenkünften der Almohaden zu verbreiten.

Die in der Regierungszeit von Ya'qūb Ibn-Yūsuf Ibn-'Abd-al-Mu’min (1184-1199) abgefassten Briefe.

Der 27. Brief. 
Dieser Brief, datiert vom 16. August des Jahres 1184 und abgefasst im Namen des Befehlshabers in Sevilla, richtet sich an die Țālibs, Almohaden, Šaihss, Notabeln und die gesamte Bewohnerschaft Cordobas und berichtet in folgender Weise über die Huldigung der Almohaden diesem genannten Herrscher gegenüber: Unaufhörlich ist an den Befehlshaber der Gläubigen (d. h. an den Vater des diesen Brief absendenden almohadischen Herrschers) seitens der Almohaden und arabischer Stämme der Wunsch herangetragen worden, seinen Sohn zum Befehlhaber der Gläubigen zu ernennen. Der genannte Herrscher versprach immer wieder die Erfüllung dieser Bitte in der dafür rechten Zeit. Als recht erweist sich nun die Zeit nach dem erfolgreichen Abschluss einer militärischen Unternehmung wider die Feinde, an der die Almohaden besonders zahlreich teilgenommen haben. Sie alle werden über den obigen Wunsch der genannten Almohaden und der arabischen Stämme in Kenntnis gesetzt, und die Versammelten greifen ihn voller Begeisterung einmütig auf. Ihrem Wunsch wird entsprochen und das Huldigungszeremoniell wird vollzogen. Die Benachrichtigung der Adressaten darüber erfolgt nun, auf dass sie sich dieser Huldigung anschließen, sie allenthalben verkünden und die Gesamtheit der Bewohner ihrer Region an dieser Huldigung teilhaben lassen. Die geschilderten Ereignisse machen einen Zusatz bei der Freitagspredigt notwendig, der dem vorliegenden Schreiben beigefügt ist, und in Form von Kopien nun an sämtliche umliegenden Gebiete verschickt werden soll.

\section{Der 28. Brief:}

Dieser Brief, datiert vom 4. Januar des Jahres 1185 und abgefasst im Namen des Befehlshabers der Gläubigen in Marrakech, ist an die Ṭālibs, Almohaden, Šaihs, Notabeln und die gesamte Bewohnerschaft von Sevilla adressiert. Er enthält den Befehl, das Trinken, Ausschenken und den Verkauf von Arrope ${ }^{730} \mathrm{zu}$ unterbinden, und enthält eine Anweisung an die Adressaten, die zakāt al-fịtr ${ }^{731}$ dem Šaih Abū-Makārim zu übergeben. In folgender Weise wird im Brief das Verbot von Arrope begründet: Im Umgang mit diesem Getränk haben sich die Menschen Missbilligenswertes sowie Nachlässigkeit zuschulden kommen lassen, und Verkauf sowie Genuss von Arrope mit berauschender Wirkung haben stattgefunden. Trotz riguroser Maßnahmen dagegen, welche auch die Todesstrafe nicht ausschließen, halten die Menschen an dieser Unsitte fest und verabsäumen es, sich zu bessern. Dabei war, dem Beispiel des rechtgeleiteten

\footnotetext{
${ }^{730}$ Ein alkoholhaltiges Getränk, siehe hierzu ,al-Mann bi-'l-imāma“ (Fußnote Nr. 1, S. 113 ff.).

731 Es handelt sich hierbei um eine am Ende des Fastenmonats Ramaḍān zu leistende Spende von Lebensmitteln.
} 
Kalifen ${ }^{\prime} \mathrm{Umar}^{732}$ folgend und in Übereinstimmung mit den schariatischen Bestimmungen diesbezüglich, der Genuss solchen Arropes nicht verboten, der lange genug gekocht wurde und die Konsistenz eines Farbstoffes aufwies. Doch als die Verstöße gegen diese Auflagen bekannt werden und es feststeht, dass die Menschen die ihnen gemachten Zugeständnisse in Bezug auf dieses Getränk missverstanden haben, wird das gänzliche Verbot von Arrope beschlossen. Beim Eintreffen dieses Schreibens sind sämtliche Bestände dieses Getränks zu vernichten, dessen Ausschänken sind zu verwüsten und anderen, im Einklang mit der Scharia stehenden Zwecken zuzuführen. Ferner sollen all diejenigen hart bestraft werden, bei denen es entdeckt wird, und ohne Ansehen der Personen sind all jene gemäß der Scharia zu ahnden, bei welchen der Mundgeruch von Arrope festgestellt wird. Dies ist überall zu verkünden, und darüber hinaus sind vom vorliegenden Schreiben Kopien anzufertigen und an die umliegenden Gegenden zu senden.

Am Ende des Briefes findet sich eine kurze Anweisung, die zakāt al-fiṭr dem Šaih AbūMakārim zu übergeben, der sie seinerseits an die Armen und Bedürftigen verteilen werde.

Der 29. Brief.

Dieser Brief, datiert vom 6. Juli des Jahres 1185 und abgefasst im Namen des Befehlshabers der Gläubigen in Marrakech, ist an die Ṭālibs, Almohaden, Šaihss, Notabeln und die gesamte Bewohnerschaft Sevillas adressiert. Den Inhalt des Briefes bildet der folgende Bericht über die erfolgreiche Unternehmung der Almohaden gegen den Herrscher von Mallorca ${ }^{733}$, der zusammen mit seinen Anhängern einige Städte des Zentralen Maghreb in seine Gewalt gebracht hat: Die Adressaten wissen bereits über die vom erwähnten mallorquinischen Herrscher vorgetäuschte Bereitschaft, den Almohaden zu gehorchen und zu dienen, wobei er doch in Wirklichkeit auf Feindschaft sann. So nimmt er mit dem Pöbel von Biğāya Fühlung auf und bemächtigt sich mit dessen Hilfe

\footnotetext{
${ }_{732}$ Gemeint ist hier der zweite rechtgeleitete Kalif 'Umar Ibn-al-Huațāb (634-644).

${ }^{733}$ Mit diesem nicht namentlich genannten Herrscher ist der almoravidische Herrscher über Mallorca Alī Ibn-Ġānīya gemeit, der im Jahre 1184 samt seinen Familienangehörigen und Anhängern von Mallorca aus die Stadt Biğãya überfiel und so eine lange Reihe von blutigen und anhaltenden militärischen Auseinandersetzungen mit den Almohaden in Ifrīqīya einleitete. Als er vermutlich im Jahre 1188 starb, folgte ihm sein Bruder Yahyā Ibn-G̈ānīya (gest. 1237) nach, der den Krieg gegen die Almohaden fortsetzte und nach 1200 fast die Gesamtheit des Gebietes von Ifrīqīya beherrschte, bis er im Jahre 1205 im Laufe einer almohadischen Unternehmung in die Flucht geschlagen wurde (siehe die Zusammenfassung des Briefes Nr. 37) und später durch das tatkräftige Vorgehen des hafsidischen Herrschers aus Ifrīiiya gänzlich verdrängt werden konnte. Diese almoravidischen Herrscher werden im weiteren Verlauf in Anlehnung an den für sie in den almohadischen Briefen üblichen Namen als „Mallorquiner" bzw. „mallorquinische Herrscher" bezeichnnet.
} 
dieser Stadt. Als er in Biğāya Fuß fasst, strömen zu ihm von überall her allerlei Frevler und Meuterer hin. Dieser Machtzuwachs weckt seine Begehrlichkeiten auch in Bezug auf andere Gebiete, und er bringt die Städte Algier, Miliana, Ašīr und Qal'at BanīHammād in seine Gewalt, wonach er nach Biğāya zurückkehrt. Die Bevölkerung der unterworfenen Gebiete setzt der genannte Herrscher der Entehrung aus, er enteignet sie nach seinem Belieben und erlegt ihr erdrückende Abgaben auf. Auch von seinen Anhängern muss die Bevölkerung Erniedrigungen und Übergriffe erleiden. Angesichts dieser Erfolge wähnt er nun, das gesamte Gebiet beherrschen zu können, und begibt sich nach Constantine, das er vergeblich einzunehmen sucht. Als die Almohaden von alledem Kenntnis erlangen, rüsten sie sich zum Feldzug. Einige Tâalibs werden mit der Aufgabe betraut, die Flotte eiligst klarzumachen. Anderen Tāalibs wird die Befehlsgewalt über das ausrückende almohadische Heer übertragen, und man gibt ihnen neben Empfehlungen religiösen Charakters die Anweisung, den Bewohnern der unterworfenen Gebiete Sicherheitsgarantie für ihr Leben zu gewähren sowie ihren militärischen Aktionen die Aufforderung vorausgehen zu lassen, sich den Almohaden zu unterwerfen. Was den Herrscher von Mallorca anbelangt, so durchstreift er derweil die Gegenden. Dabei erweist es sich für die Almohaden als vorteilhaft, dass er sein Lager bei Constantine aufschlagen lässt, das er unablässig, aber erfolglos belagert und somit von der Flucht nach Mallorca abgelenkt wird. Indes erreicht das almohadische Heer Miliana, dessen Bewohner in reuiger Umkehr dem Almohadentum sich wieder zuwenden. Die Angreifer zerstieben dabei in alle Richtungen, werden jedoch von den in der Umgebung siedelnden Stämmen teils umgebracht, teils gefangen genommen und den Almohaden überliefert. Den Ṭālibs der almohadischen Flotte, die sich gemäß einer vorher getroffenen Abmachung mit der almohadischen Armee in Algier hätten treffen sollen, gelingt es, diese Stadt mit der alleinigen Unterstützung ihrer Einwohner in Besitz zu nehmen. Dabei werden der Cousin des Herrschers von Mallorca sowie einige seiner Gefährten gefasst. Von den Šaihs der Stadt erfahren die Almohaden, dass die in Biğāya gefangen gehaltenen Almohaden von den Angreifern nach Mallorca gebracht werden sollen. Deswegen setzt die almohadische Flotte eiligst ihren Weg nach Biğāya fort. In der Nähe dieser Stadt angelangt, hält Šaih Abū-Muhammad 'Abdallāh Ibn-Abī-Isḥāq eine Ansprache an ihre Bevölkerung und gewinnt sie für die Almohaden. Ein heftiges Gefecht entbrennt daraufhin vor den Mauern der Stadt zwischen den almohadischen Kämpfern und den mallorquinischen Angreifern, welche schließlich in die Flucht geschlagen werden. Die Almohaden betreten die Stadt, finden ihre gefangenen gesetzten 
Brüder unversehrt vor und bemächtigen sich der Schiffe des mallorquinischen Herrschers. Sie benachrichtigen von diesem Sieg die Țālibs der inzwischen bei Mattīğa angelangten almohadischen Armee, die ihrerseits diese Benachrichtigung um den Bericht über ihre militärischen Erfolge erweitern und an den almohadischen Herrscher weiterschicken. Was den Herrscher von Mallorca bei Constantine anbetrifft, so ist er, verlassen von all seinen Verwandten und Helfern, dem Tode geweiht.

Der Brief schließt mit der Aufforderung, Gott für die Siege der Almohaden gebührend zu danken, diese Mitteilungen überall zu verkünden und die vom vorliegenden Brief angefertigten Kopien an die Gebiete in der Umgebung zu verschicken.

\section{Der 30. Brief.}

Dieser aus der Region Nafzāwa abgesandte Brief, der vom 23. Oktober des Jahres 1187 datiert und im Namen des Befehlshabers der Gläubigen vor den Toren der Stadt Gabès abgefasst ist, richtet sich an die Ṭālibs, Almohaden, Šaihss und die gesamte Bewohnerschaft von Marrakech. Seinen Inhalt bildet der folgende Bericht über den erfolgreichen Verlauf der almohadischen Unternehmung gegen ihre Feinde in Ifrīqīya ${ }^{734}$ : Die Adressaten haben bereits von den antialmohadischen Aktivitäten der asiatischen Söldner und der Mallorquiner in den Randbezirken Ifrīqīyas sowie von ihrem Plan, deren sämtliche landwirtschaftlichen Erzeugnisse zu vernichten, erfahren. Doch durch die rechtzeitige Ankunft der Almohaden dorthin kann dieses Vorhaben vereitelt werden. Von Tunis aus schlägt die almohadische Armee den Weg zu den erwähnten Eindringlingen ein, welche, davon benachrichtigt, sich ebenfalls in Bewegung setzen. In Kairuan angelangt, richten die Almohaden an die erwähnten Feinde, die inzwischen in Wādī Rān angekommen sind, die Aufforderung, von ihrem Treiben Abstand zu nehmen. Ungeachtet dieser Aufforderung ziehen diese nach Gafsa weiter, um dort den Almohaden gegebenenfalls eine Schlacht zu liefern. Die almohadische Armee nimmt ihre Verfolgung auf, und die Feinde ergreifen daraufhin die Flucht nach Gabès. Auf ihrem Weg dorthin schlagen sie bei einer Ortschaft namens Hamma Maṭāta ihr Lager auf und rufen die Kämpfer des Stammes Sulaim zu Hilfe. Die sie verfolgenden Almohaden schlagen ebenfalls in der Nähe der genannten Ortschaft ihr Lager auf. Die Feinde werden bei einem heftigen Gefecht geschlagen und erleiden auf ihrer Flucht hohe Verluste von den ihnen nachsetzenden Almohaden. Das almohadische Heer erreicht daraufhin Gabès. Als es dort ankommt, erbitten die 
Bewohner dieser Stadt für sich um eine Sicherheitsgarantie und bekennen sich wieder zum Almohadentum. Die in Gabès befindlichen Familienangehörigen und Vertrauten von Qarāqūšs ${ }^{735}$ verschanzen sich in der Zitadelle dieser Stadt. Als man sich mit ihnen darauf einigt, dass man sie am Leben lässt, sie aber enteignet und bestimmte unter ihnen befindliche Frauen und Kinder versklavt, ergeben sie sich. Nach der Beschreibung der strategischen Wichtigkeit von Gabès und der zahlreichen Vorzüge dieser Stadt wird auf das göttliche Eingreifen bei dieser Unternehmung der Almohaden hingewiesen, da kein einziger von ihnen zu Schaden gekommen sei. Der Brief schließt mit der Aufforderung an die Adressaten, Gott für die geschilderten Erfolge der Almohaden gebührend zu danken, und die Kunde davon überall zu verbreiten.

\section{Der 31. Brief.}

Dieser Brief, datiert vom 5. November des Jahres 1187 und abgefasst im Namen des Befehlshabers der Gläubigen vor den Toren Gafsas, ist an die Ṭālibs, Almohaden, Šaihs und die gesamte Bewohnerschaft von Tunis adressiert. In folgender Weise wird darin über die Fortsetzung der almohadischen Unternehmungen in Ifrīqīya nach der Einnahme von Gabès berichtet: Nach den militärischen Erfolgen der Almohaden gegen die Mallorquiner und die asiatischen Söldner in der den Adressaten bereits bekannt gegebenen Art und Weise setzt sich die almohadische Armee von Gabès nach Ğarīd in Marsch. Nach ihrer Ankunft dort werden die beiden Gebiete Nafzāwa und Qasțilīya von den Almohaden wieder in Besitz genommen. Beim Herannahen der almohadischen Armee erheben sich Bewohner von Tawzar, Taqyūs, al-Hamma und Nafṭa gegen die in ihren Städten befindlichen feindlichen Garnisonen, töten einige von ihnen und bringen andere zu den Almohaden. Einer in Tawzar von diesen Feinden befindlichen Gruppe gelingt es, nachts in die Wüste zu entweichen. Ihr in der Stadt zurückgelassener Besitz fällt den Almohaden als Beute zu. Die Rückkehr der Bewohner der genannten Städte zum Almohadentum bringt ihnen gütige Behandlung seitens der Almohaden und allumfassendes Wohl ein. An dieser Stelle schildert der Brief in allgemeinen Worten die große Ausdehnung sowie die Fruchtbarkeit der Gegend von Ğarīd und weist darauf hin, welch zentrale und wichtige Stellung Tawzar unter den übrigen Städten dieses

\footnotetext{
${ }^{734}$ Mit der Bezeichnung „Ifrīqīya“ ist ein dem heutigen Tunesien annähernd entsprechendes Gebiet gemeint.

${ }_{735}$ Qarāqūš war ein Söldner, der im 12. Jahrhundert zusammen mit anderen asiatischen Söldnern aus Ägypten in Libyen eingefallen ist. Ca. ab dem Jahr 1185 kämpfte er auf seiten 'Alī Ibn-Gānīyas gegen die Almohaden in Ifrīqīya, später jedoch zerbrach diese Allianz, er floh nach Westlibyen und wurde im Jahre 1213 von Yahyā Ibn-Ġānīya umgebracht. Relativ zahlreiche Angaben zu dieser Person sind vornehmlich in der Reisebeschreibung ,Riḥlat at-Tiğānī“ enthalten.
} 
Landstrichs einnimmt. In folgender Weise setzt der Brief seinen Bericht fort: Von Tawzar aus bricht die almohadische Armee nach Gafsa auf, wo sich die asiatischen Söldner samt ihren Anhängern verschanzt haben und in ihrem Vertrauen auf die Wehrhaftigkeit der Stadt den Almohaden zu widerstehen gedenken. Dort angelangt nehmen die Almohaden die Belagerung Gafsas auf. Am Tage der Ankunft der almohadischen Armee dorthin treffen bei ihnen die Gesandten Qārāqūšs ein und übermitteln seinen Wunsch, sich in den Dienst der Almohaden zu stellen. Am darauf folgenden Tage treffen die Boten eines gewissen Abū-Zaiyāns ein, eines früheren Gefährten Qārāqūšs, der nach seiner Trennung vom Letzteren die Herrschaft über Tripolis an sich gerissen hat, und überbringen die Nachricht, dass er sich zum Almohadentum bekannt habe. Auf diese Weise ist nun die gesamte Region wieder den Almohaden botmäßig und befriedet.

Der Brief schließt mit der Aufforderung, die in ihm bekannt gegebenen Erfolge nah und fern zu verkünden und Gott für sie danken.

\section{Der 32. Brief.}

Dieser Brief, datiert vom 14. Januar des Jahres 1188 und abgefasst im Namen des Befehlshabers der Gläubigen, ist an die Tāalibs, Almohaden, Šaihs, Notabeln und die gesamte Bewohnerschaft von Marrakech adressiert und berichtet in folgender Weise über den siegreichen Abschluss der Belagerung Gafsas: Die Adressaten wissen bereits von einigen militärischen Erfolgen der Almohaden in Ifrīqīya, die nun in der Eroberung Gafsas ihren Höhepunkt erreichen. Es haben sich in dieser Stadt allerlei Räuber und Sünder zusammengerottet, die trotz zahlreicher Warnzeichen von ihrem Unwesen nicht haben Abstand nehmen wollen. Die Almohaden unterbreiten bei ihrer Ankunft das Angebot, ihnen Leben zu schenken und Gnade walten zu lassen, wenn sie sich ergäben, welches die Belagerten jedoch ausschlagen. Die Almohaden beschließen daraufhin, Gafsa mittels Kriegsmaschinen zu bezwingen. Es werden Maßnahmen zur Sicherung von Verkehrswegen in der Umgebung getroffen, und von überall her werden Lebensmittel in das almohadische Lager gebracht. Die Almohaden beginnen mit dem Zusammenbau der erwähnten Kriegsmaschinen, die innerhalb kürzester Zeit fertig gestellt werden. Die Belagerten lassen auch angesichts dieser Vorbereitungen keine Anzeichen von Reue erkennen. Dann kommen die erwähnten Maschinen zum Einsatz, und Gafsa wird unter Beschuss genommen, der den Verteidigern Verluste und den Mauern der Stadt große Schäden zufügt. Einer der inzwischen einsatzbereiten 
Belagerungstürme wird an die Mauern der Stadt geschafft, und die Stadt wird von ihm aus beschossen. Später gelingt es den Almohaden, den vorderen Bereich der Festung zu erstürmen und einen seiner Türme in Brand zu setzen. Da sehen die Belagerten die Zwecklosigkeit weiteren Widerstandes ein und ergeben sich. Allen Belagerten, mit Ausnahme der Mallorquiner, wird Leben geschenkt. Als die asiatischen Söldner auch für ihre mallorquinischen Verbündeten körperliche Unversehrtheit ausbedingen wollen, setzt man ihnen auseinander, dass ihr eigenes Leben von der Auslieferung der genannten Mallorquiner abhänge. Die Letzteren werden also ausgeliefert, und die Almohaden fallen wuterbrannt über sie her. Mit der Bezwingung Gafsas gelangt die Unternehmung der Almohaden zu ihrem Abschluss, und von den asiatischen Söldnern ist niemand mehr in dieser Gegend geblieben, der gegen den Almohaden hätte noch unbotmäßig werden können, denn diejenigen, die dazu fähig wären, sind entweder gefallen oder befinden sich nun in der Gewalt der Almohaden.

Die Almohaden beschließen ferner, die Mauern von Gafsa, die aufgrund ihrer als unüberwindbar geltenden Höhe diese Stadt so oft zum Zentrum von antialmohadischen Meutereien haben werden lassen, niederzureißen. Jedem Stamm wird ein bestimmter Teil der Mauer zugeteilt, und ihre Schleifung wird binnen weniger als eines Tages durchgeführt.

\section{Der 33. Brief.}

Dieser Brief, datiert vom 9. Mai des Jahres 1188 und abgefasst im Namen des Befehlshabers der Gläubigen in Abī-Sa ${ }^{1} \bar{i} d$, richtet sich an die Ṭālibs, Almohaden, Šaihs, Notabeln und die gesamte Bewohnerschaft von Marrakech. In folgender Weise setzt er seine Adressaten vom Abschluss des Feldzuges der Almohaden nach Ifrīqīya und von ihrer baldigen Rückkehr in Kenntnis: Die Empfänger sind bereits über die gewaltigen Siege der Almohaden informiert worden, dank welchen Ifrīqīya nun befreit und befriedet ist. Es wurde ihnen ebenfalls über die asiatischen Söldner berichtet, welcher sich die Almohaden nach der Bezwingung der beiden Städte Gabès und Gafsa bemächtigt haben. Sie alle, nachdem ihnen seitens der Almohaden Gnade und gütige Behandlung zuteil wurde, haben sich in den Dienst des Almohadentums gestellt und haben die Auswanderung nach Maghreb angetreten. Die Almohaden hingegen beschließen, ihre eigene Rückkehr noch bis zum Ende der Erntezeit aufzuschieben. Danach brechen die Almohaden nach Mahdia auf, und die beiden Stämme des Stammesverbandes Banū-Sulaim, 'Auf und aš-Šarīd, reihen sich in die Gemeinschaft 
der Almohaden ein. Nun, da Ifrīqīya befriedet ist, wenden die Almohaden ihre Aufmerksamkeit den westlichen Gegenden zu und brechen nach Maghreb auf.

Der Brief schließt mit der Aufforderung, Gott für die Sieghaftigkeit der Almohaden bei ihren Unternehmungen in Ifrīqīya zu danken, und kündigt die Bereitschaft der zurückkehrenden Almohaden an, am Ğihād teilzunehmen.

\section{Der 34. Brief.}

Dieser Brief, datiert vom 31. Juli des Jahres 1190 und abgefasst im Namen des Befehlshabers der Gläubigen in Sevilla, ist an die Ṭālibs, Almohaden, Notabeln, Šaihss und die gesamte Bewohnerschaft von Ceuta adressiert. In folgender Weise wird darin von den Unternehmungen der Almohaden gegen die Christen im Westen von alAndalus berichtet: Die Almohaden beschließen die Durchführung eines Feldzuges gegen den Ungläubigen der Iberischen Halbinsel und rufen arabische Stämme sowie die Stämme der Untertanen zur Teilnahme auf. Derweil werden die Christen der Iberischen Halbinsel angesichts der bevorstehenden Ankunft der almohadischen Armee von Entsetzen ergriffen und versuchen, durch Kontaktaufnahme mit den in ihrer jeweiligen Umgebung befindlichen Ṭālibs Friedensverträge mit den Almohaden zu erwirken. Der Herrscher von Kastilien bittet um die Erlaubnis, durch seine Gesandten seinen Wunsch danach übermitteln $\mathrm{zu}$ dürfen, den Almohaden $\mathrm{zu}$ dienen, worin die Letzteren einwilligen. Das almohadische Heer setzt sich in Marsch und noch vor seiner Ankunft in Qaṣr al-Mağāz treffen die Gesandten dieses erwähnten Herrschers in Sevilla mit den dort befindlichen Ṭālibs zusammen und übermitteln seinen Wunsch, sich in den Dienst des Almohadentums zu stellen. Der mit diesem König verwandte Herrscher von Leon äußert seinerseits den Wunsch, den zwischen ihm und den Almohaden bestehenden Friedensvertrag zu verlängern, der ihm erfüllt wird. Die Almohaden beschließen daraufhin, in die Gebiete des christlichen Herrschers Ibn-ar-Rīq ${ }^{736}$ einzufallen. Sie setzen sich in Bewegung und erreichen über Cordoba den Fluss Tejo, nach dessen Übersetzung sie nach Santarem gelangen. Nach der Verwüstung der diese Stadt umgebenden Gärten und Ackerfelder setzten die Almohaden ihren Weg nach Torres fort, einer auf einem hohen Berg gelegenen Festung, deren Einwohner nach einem blutigen Gefecht die Almohaden darum bitten, ihren Wohnort samt ihren

\footnotetext{
${ }^{736}$ Dieser Herrscher wird im Text namentlich nicht genannt, lediglich sein Spottname „Ibn-ar-Rīq“, wörtlich „Sohn des Speichels“, kommt im Brief vor. Mit „Ibn-ar-Rīq“ meinten arabische Geschichtsschreiber Alfonso Enriquez, den ersten König von Portugal und den Begründer der gleichnamigen Dynastie. Nach seinem Tod im Dezember des Jahres 1185 benutzten Muslime weiterhin diesen Spottnamen auch für seine Nachkommen. Mit „Ibn-ar-Rìq“ ist hier sein Sohn Sancho I gemeint.
} 
Familienangehörigen verlassen $\mathrm{zu}$ dürfen. Ihrem Wunsch wird entsprochen und den Almohaden fallen die in der Stadt zurückgelassenen Pferde, Waffen und andere Besitztümer als Beute zu. Nach der vollständigen Zerstörung dieser Festung gelangt das almohadische Heer nach Tumar, welche das gleiche Schicksal wie Torres ereilt. Während der Belagerung von Tumar schwärmen die Streifscharen der Almohaden in alle Richtungen aus und vernichten die gesamten landwirtschaftlich genutzten Flächen, wobei die Ungläubigen, hinter den Mauern ihrer befestigten Städte verschanzt, alledem tatenlos zusehen. Auch ihr König, Ibn-ar- Rīq, hält sich während dieser Zeit in Santarem versteckt und meidet jede Begegnung mit den Almohaden. Aufgrund der Tatsache, dass die almohadische Armee auf ihrem Weg in das christliche Gebiet gemächlich gezogen ist und dass die Feinde rechtzeitig über diesen Zug informiert wurden und sich auf den bevorstehenden Angriff vorbereitet haben, indem sie die Ernte eingetragen und die nötigen Sicherheitsmaßnahmen getroffen haben, sehen sich die Almohaden letztlich außerstande, sich länger in den christlichen Gebieten aufzuhalten, und treten den Rückzug an.

Der Brief schließt mit dem Aufruf, Gott für die geschilderten Erfolge der Almohaden überschwänglich zu danken.

\section{Der 35. Brief.}

Dieser Brief, datiert vom 6. August des Jahres 1196 und abgefasst im Namen des Befehlshabers der Gläubigen in Sevilla, ist an die Tāalibs, Almohaden, Šaihs und die gesamte Bewohnerschaft von Fès adressiert. In folgender Weise berichtet er über den Verlauf der Unternehmung der Almohaden in das von Christen beherrschte Gebiet der Iberischen Halbinsel: Nach der erfolgreichen Unternehmung der Almohaden gegen Ibnar-Rīq hat er sich nach Kastilien geflüchtet und seine Gesandten überbringen den Almohaden mehrmals seinen Wunsch, mit ihnen einen Friedensvertrag zu schließen. Die Almohaden ignorieren ihn jedoch und lassen vielmehr erkennen, dass sie im Begriff sind, einen neuen Verwüstungszug durchzuführen. Dann setzt sich die almohadische Armee in Marsch und erreicht die Festung Montánchez, wobei den Almohaden noch vor der Ankunft dort der Sieg über sie beschieden wird [sic]. Von dort aus setzen die Almohaden ihren Weg nach Trujillo fort, dessen Bewohner, sobald sie von der heranrückenden almohadischen Armee informiert werden, die Flucht ergreifen. Ihrem Beispiel folgen ebenfalls die Einwohner von Santa Cruz, und die Almohaden hinterlassen in dieser Stadt eine Garnison und treffen Maßnahmen zur ihrer 
Wiederbesiedlung. Die Almohaden setzen sich in Bewegung, setzen zum anderen Ufer von Tejo über und betreten das christliche Gebiet. Die erste Stadt, zu der sie sich dann begeben, ist Plasencia, zu dessen Aufbau Ibn-ar-Rīq einige Jahre verwendet und in ihm seine Untertanen aus dem Norden angesiedelt hat. Die Bevölkerung dieser Stadt flieht und es bleibt lediglich eine beträchtliche Zahl ihrer Verteidiger zurück. Sie verschanzen sich zuerst in der Zitadelle, finden dann, als diese den Almohaden anheimfällt, Zuflucht in einem Turm und ergeben sich am nächsten Tag den Almohaden. Nach der Verwüstung dieser Stadt setzen die Almohaden ihren Weg nach Talavera fort und verheeren dessen Umland samt den dort befindlichen Gärten und Äckern vollständig. Unterwegs vernichten die Almohaden das reife Getreide und ziehen an blühenden Ortschaften vorbei, deren Bewohner sie angesichts der herannahneden almohadischen Armee verlassen haben und eiligst in die entferntesten von Christen beherrschten Gegenden geflohen sind. Daraufhin schlagen die Almohaden den Weg nach Toledo ein. Dort angelangt, verwüsten sie das Umland dieser Stadt. Dann überschreiten die Almohaden Tejo und verwüsten das Anwesen dieses christlichen Herrschers, in welches er sich zurückzuziehen pflegte. Während dieser Unternehmungen geht der Herrscher von Leon, der mit dem König von Kastilien verwandt ist, die Almohaden darum an, sich in ihren Dienst stellen zu dürfen, und erklärt sich bereit, sein Herrschaftsgebiet den Almohaden zur Durchführung eines Angriffs auf diesen kastilischen König zur Verfügung zu stellen. Es wird zu diesem Zweck ein almohadisches Heer in sein Gebiet entsandt, das dem Feind der Almohaden große Verluste zufügt. Nach diesen Erfolgen treten die Almohaden den Rückzug an. Eine Tagesreise von Toledo entfernt belagern die Almohaden zwei befestigte Orte, von welchen der eine eine große Zahl von Verteildigern sowie von den Kreuzfahrern beherbergt. Beide Festungen werden bezwungen, ihre Verteidiger versklavt und es werden dort almohadische Garnisonen zurückgelassen.

Der Brief schließt mit der Aufforderung, Gott für den gewährten Beistand zu danken und verweist darauf, dass weitere Informationen über die geschilderten Ereignisse von den Notabeln der Adressaten zu erbeten seien, da sie an diesen Unternehmungen teilgenommen hätten.

Die in der Regierungszeit von Muhammad an-Nāṣir (1199-1213) abgefassten Briefe.

Der 36. Brief. 
Dieser undatierte Brief ist im Namen des Befehlshabers der Gläubigen abgefasst und nennt keinen bestimmten Adressaten. Den Gegenstand seiner Schilderung bilden die almohadische Eroberung der Insel Mallorca und die damit im Zusammenhang stehenden Ereignisse: Nach der Ausmerzung der Almoraviden im Maghreb und alAndalus retten sich einige von ihnen auf die Baleareninseln. Es erfolgen an sie mehrere Aufrufe, sich den Almohaden zu unterwerfen, welche sie jedoch missachten. Nachdem es den Almohaden gelingt, Ibiza und Menorca einzunehmen, erbeten die auf Mallorca verbliebenen Almoraviden eine Sicherheitgarantie für ihr Leben, welche die Almohaden ihnen gewähren. Einige Zeit später jedoch bringen diese Almoraviden Mallorca wieder in ihre Gewalt. Als dies geschieht, wird das almohadische Heer nach Mallorca entsandt, das diese Insel nach sieben Nächten heftiger Kämpfe, an welchen auch die Bewohnerschaft der Insel auf seiten des gelandeten Heeres teilnimmt, unter die Botmäßigkeit der Almohaden bringt.

Ferner berichtet der Brief über das Anbrechen des Zeitalters der Gerechtigkeit und des Lichtes, welches diese Eroberung für alle Bewohner der Insel bedeute sowie auch darüber, dass dadurch ein großer Sieg über die christlichen Küstenkönigreiche erlangt sei. Daran schließt sich die Zusicherung an, dass das Unwesen des in Ifrīqīya sich aufhaltenden Almoraviden bald ein Ende haben werde. Die Anrufungen Gottes und die Bitte, er möge auch weiterhin den Almohaden beistehen, bilden den Abschluss dieses Briefes.

\section{Der 37. Brief.}

Dieser undatierte Brief nennt keine Adressaten und wurde vor der Toren der Stadt alMahdia abgefasst. In folgender Weise wird darin über die Unternehmungen der Almohaden in Ifrīqīya gegen den Mallorquiner und seine Anhängerschaft berichtet: Die Adressaten wurden bereits durch ein vorangegangenes Schreiben darüber in Kenntnis gesetzt, dass Tunis und das Gebiet von Ğarīd bei der Ankunft der almohadischen Armee in Ifrīqìya wieder den Almohaden botmäßig geworden sind. Als die Almohaden sich in Marsch nach Kairuan setzen, ergreift der Mallorquiner ${ }^{737}$, der sich zu jenem Zeitpunkt vor dieser Stadt befand, die Flucht und verschanzt sich in Gafsa. Doch nach einiger Zeit sieht er sich gezwungen, diese Stadt angesichts der heranrückenden Almohaden zu verlassen. Indes gelangen die Almohaden nach Gabès und entsenden von dort aus zwecks seiner Verfolgung ein Korps, das jedoch das Entweichen des Mallorquiners 
nicht verhindern kann. Währenddessen gelangt $\mathrm{zu}$ den in Gabès verbliebenen Almohaden eine Delegation von Notabeln der Stadt Tripolis, die ihre Loyalität dem Almohadentum gegenüber bekunden und mitteilen, dass ihre Stadt, die der mallorquinische Herrscher zu seinem Zufluchtsort erwählt hat, nun wieder den Almohaden botmäßig ist. In Begleitung eines almohadischen Ṭālibs kehren sie dann nach Tripolis zurück. Danach wird der Schutz von Gabès einer almohadischen Garnison anvertraut, und das Gros des almohadischen Heeres begibt sich nach al-Mahdia, dessen Belagerung es aufnimmt. Nach Verstreichen einiger Zeit taucht der mallorquinische Widersacher im Gebiet von Ğarīd auf und es gelingt ihm, einige Angehörige von Zug̉ba und aš-Šarīd, der beiden Unterstämme des arabischen Stammes Banū-Sulaim, für seine Sache zu gewinnen, so dass sie sich in die Schar seiner Anhängerschaft einreihen und sie somit auf eine beträchtliche Zahlenstärke anwächst. Es wird ein almohadisches Korps gegen ihn entsandt, das Abū-Muhammad Ibn-Abī-Ḥafṣ, der Sohn des Gefährten des Mahdi der ersten Stunde, befehligt. Es kommt zu einer äußerst blutigen Schlacht, aus welcher die Almohaden letztlich als Sieger hervorgehen. Den Almohaden wird eine reiche Beute zuteil und sie befreien die Taalibs und andere Almohaden, die sich in Gewalt der Mallorquiner befunden haben. Dem mallorquinischen Herrscher gelingt es, schwer verletzt zu entweichen.

Was die arabischen Beduinen anbetrifft, so bekunden sie im Gefolge der erwähnten Schlacht ihre Unterwürfigkeit gegenüber den Almohaden. Ebenfalls nach der Schlacht ist bei den Almohaden der Šaih Abū-Sirhān Mas'ūd Ibn-Sulțān Ibn-Zimām ${ }^{738}$ angetroffen, für seine Familien- und Stammesangehörigen die Erlaubnis erflehend, sich in die Gemeinschaft der Almohaden einreihen zu dürfen.

Daran schließen sich die Ausführungen des Briefes darüber, dass Ifrīqīya nun von der abbasidischen Propaganda gereinigt und gänzlich, abgesehen von al-Mahdia, deren Einnahme unmittelbar bevorstehe, befreit ist. Aufrufe, die im Brief enthaltenen erfreulichen Mitteilungen zu verbreiten, Gott für sie zu danken sowie Anrufungen Gottes um seine Gnade und Beistand bilden den Abschluss dieses Briefes.

\footnotetext{
${ }^{737}$ Hier ist mit dem „Mallorquiner“ Yahyā Ibn-Gānīya, der Bruder und Nachfolger des im Jahre 1185 verstorbenen 'Alī Ibn-G̈ānīyas gemeint.

${ }^{738} \mathrm{Zu}$ dieser Persönlichkeit siehe die Zusammenfassung des Briefes Nr. 26.
} 


\section{Anhang 2}

Belegsammlung für den figurativen Sprachgebrauch

Einleitende Bemerkung: Dieser Anhang bildet einen kleinen Auszug aus dem „Glossar der westarabischen Begriffe samt deren Belegstellen“, mit dessen Erarbeitung ich im Laufe meiner Beschäftigung mit den almohadischen Briefen im Rahmen meiner Doktorarbeit begonnen habe. Dies erschien mir notwendig, da ich bei der Lektüre von offiziellen almohadischen Schreiben sowie anderen gattungsverwandten arabischen Texten zweierlei festgestellt habe: zum einen war die gemeinte Bedeutung von vielen Wörtern im mittelalterlichen Schrifttum nicht eindeutig klar, sodass ich da, wo das „Supplément aux dictionnaires arabes“ von Dozy nicht weiterhalf, selbständige lexikographische Erschließung der relevanten - u. a. mittelalrabischen - Quellentexte betreiben musste; zweitens, auch wenn man das Wörtliche von westarabischen offiziellen arabischsprachigen Schriftstücken und literarischen Werken präzise zu übersetzen imstande war, blieben deren eigentliche Aussagen, deren bezweckter Sinn oft nicht in eindeutiger Weise verständlich, und dies aufgrund der die erwähnte Textgattung so sehr kennzeichnenden und sie im buchstäblichen Sinne des Wortes durchwirkenden metaphorischen und allegorischen Ausdrucksweise. Wollte man also so mein Gedankengang weiter - die unüberschaubare Fülle von Interpretationsmöglichkeiten dieser Texte zugunsten der einen intendierten oder vielmehr: der für den zeitgenössischen Rezipienten in Frage kommenden Interpretation auflösen, war eine Belegsammlung von am häufigsten verwendeten Metaphern und Allegorien samt deren erschlossenen Bedeutungen unerlässlich. Erst eine solche Sammlung würde mich in den Stand setzen, die verwirrende Fülle der aus heutiger Sicht möglichen Interpretationsmöglichkeiten bzw. die Interpretationsbeliebigkeit von Texten der genannten Gattung einzugrenzen und im zweiten Schritt eine eindeutige Aussage darüber $\mathrm{zu}$ treffen, was der zeitgenössische Rezipient mit den zahlreichen Umschreibungen dieser Originaltexte sehr wahrscheinlich assoziiert und darunter verstanden hat. Erst mit diesem Wissen wäre es möglich, stichhaltige Schlüsse auf den historischen Gehalt der almohadischen Briefe $\mathrm{zu}$ ziehen und somit die diese Doktorarbeit bestimmende Frage möglichst präzise zu beantworten. Dies war der gedankliche Hintergrund, vor dem mein Entschluss zur Sammlung und Erschließung der nachfolgenden Textbelege gereift war. Die vorliegende Sammlung stellt somit einen Versuch dar, systematisch die figurative Ausdrucksweise von literarischen und 
historischen arabischen Texten des Mittelalters und ansatzweise zu erhellen und somit zu ihrem tieferen Verständnis beizutragen.

Im Verlaufe dieser Beschäftigung wurde deutlich, dass die Art und Weise, wie in den genannten Texten Abstrakta durch Bezugnahme auf konkrete Sachverhalte zum Ausdruck gebracht werden, in Ansätzen zum einen bereits im klassischen arabischen Wortschatz angelegt ist ${ }^{739}$. Zum anderen ließen sich bei der Durchsicht der Sammlungen von arabischen Redewendungen bereits Vorläufer von Allegorien feststellen, die uns in den Texten der genannten Gattung später begegnen ${ }^{740}$. Diese Erkenntnis führte letztlich zur Erforschung der Bedeutungsvielfalt des arabischen Wurzelbestandes und der arabischen Redewendungen im Hinblick auf die grundsätzliche Frage, welchen konkreten Hintergrund die Formulierung von abstrakten Sachverhalten hat.

\section{Verzeichnis der Kapitelüberschriften}

Festungskonzepte

Krankheiten und Übel

Heere

Bezwingungen, Inbesitznahmen von Festungen und Siege allgemein

Nasen als Sinnbild des Hochmuts bzw. der Auflehnung und Ungehorsams

Niederlagen

Naturerscheinungen

Gnadenbezeigungen und Gunsterweise

Wasserbecken u. ä.

Gefühle (Gefühlsbezeigungen, Empfindungen)

Kleider und Gewänder

Wohlgerüche

Zeitangaben

Halsketten, Zusammengefügtes u.ä.

Jugendhaftigkeit

Mögliche Rezeptionssteuerungsmechanismen

Nutznießung anhand des Bildes von Euterzitzen

Bauten

Vollendetheit und Vollkommenheit

${ }^{739}$ Siehe Kapitel „Gnadenbezeigungen und Gunsterweise“ unten. 
Meutereien und kriegerische Auseinandersetzungen

Fahnen

Schönheit und Vortrefflichkeit

Schießscheiben und Geschossfänge

Die Rennbahnen

Seiten und die geographische Verfasstheit von seelischen und emotionalen Zuständen

Mögliche Umschreibungen fürs Gelingen

Die Gänzlichkeit eines Sachverhaltes bzw. Objekts

Wege und Pfade

Wirtschaftlichkeit und Kommerziellität des mittelalterlichen Sprachgebrauchs

Umkreisen und Umfliegen des Erstrebten

Bücher, Schriften und Register

Das Motiv des Schattens

Körperhaftigkeit bzw. Konkretheit des Abstrakten

Licht und Finsternis

Farbenpracht

Vorislamisches Brauchtum

\section{Festungskonzepte}

Vergleich einer Festung mit einem Falken ${ }^{741}$ : (Mağmū'a ğadīda, Bd. 1, S. 266) „wakāna al-ma'qil al-ma'rūf bi-Šalbațra [...] marqab ad-dauw wa-'uqāb al-ğauw al-`alam almuṭill ‘alā al-a'lām“, (Raihānat al-kuttāb, Bd. 1, S. 147) „fa-innahū (aiy hịṣn Ašir) alğārih al-muhalliq wa-'1-bāzī al-muṭill wa-'l-yad al-muhkama wa-'d-dā' ad-dafīn muqiḍ̣ al-maḍāğic“, (Raihānat al-kuttāb, Bd. 1, S. 149) „,wa-lağa’a ilā al-ḥiṣn man kāna bihī alhāmīya fa-ḩalafahum al-muslimūn [...] wa-qātalū dalika al-‘uqāb al-marūm“, (Raiḥānat al-kuttāb, Bd. 1, S. 368 f.) ,(bei der Beschreibung des Verwüstungszuges des kastilischen Königs im muslimischen Gebiet) wa-kam ḥimā maṣūn bihā qad istabāḥhū [...] wa-muṣallā naṣaba fỉhī tamātilahū al-muḍilla wa-'uqāb ḥiṣn hāḍa ğanāḥahū wa-atfā miṣbāḥhahü“. Interessanterweise wird bei dem Beschuss Gafsas durch die almohadischen Truppen im Jahr 1187 der Belagerungsturm, der dabei eingesetzt wurde, wie folgt beschrieben „fa-aṭalla (aiy a-burğ al-mubārak) ‘alā arğā'ihim iṭlāl al-fathā̄`‘. (Raiḥānat

\footnotetext{
${ }^{740}$ Siehe Kapitel Gefühle (Gefühlsbezeigungen, Empfindungen) unten.

${ }^{741}$ Vor dem Hintergrund der arabischen Redewendung „Amna' min 'uqāb al-ğauw“ (Mağma' al-amtāl, Bd. 2, S. 323) liegt die Vermutung nahe, dass die nachfolgenden Belege die Uneinnehmbarkeit der Festungen implizieren.
} 
al-kuttāb, Bd. 1, S. 162), ,inna madīnat Ǧaiyān [...] manbit aš-šauka wa-`uqāb al-qawāeid al-muġtașaba li-'1-muslimīn“.

Der Vergleich einer befestigten Stadt mit einem hohen Berg: (Raihānat al-kuttāb, Bd. 1, S. 503) „wa-ḩalaṣnā gilāban bi-ḥāl infirād [...] ḥattā awaynā min madīnat Wādī Āš ilā al-ğabal al-cāṣim min al-ḥādit al-qāṣim“, (Ṣubḥ, Bd. 7, S. 101) ,wa-hīya (aiy al-madīna al-fulānīya) allatī a'yat riyāḍatuhā kull rā’ị̣ wa-sahirat bi-kull qā'id bi-qunūnihā rābị̣“", (Ṣubḥ, Bd. 7, S. 69) ,amțākum as-sa'd șahwatahā wa-aḥallakum at-taufĩq rabwatahā min gair muṭāwalat hiṣār wa-lā istinfād wus` wa-'qtidār wa-lā tasauwur ğidār", (Mağmūc rasā'il muwaḥhịīya, S. 202) „fatḥ had̄ā al-ablaq al-fard wa-'l-marqab al-mutağāwiz fi 'lḥaṣāna kull ḥadd wa-'l-'alam al-bādih wa-'l-ḩaṣm al-aladd (aiy fatḥ Qafṣa)“ - hier ist der Vergleich mit einem Berg insofern interessant, als auch das Almohadentum in „Mağmū rasā’il muwaḥhidīya“ als „haḍba“ bezeichnet wird. Was „al-marqab“ betrifft, so kann es u. a die Bedeutung ,eine befestigte Stadt“ haben, wie es aus den folgenden zwei Zitaten hervorgeht: (Mağmū'a ğadīda, Bd. 1, S. 266) ,wa-kāna al-ma'qil al-márūf bi-Šalbaṭra [...] marqab ad-dauw wa-'uqāb al-ğauw al-'alam al-muṭill 'alā al-a'lām“ und (Mušāhadāt, S. 80) „qultu Šalubrānīya [...] marqab mutawaqqil wa-ḡāyat țā’ir wamumtana' at-tâ̄irir“; (Mağmūc rasā’il muwaḥhịidīya, S. 206) ,wa- indamā taḥaqqaqū (aiy al-muḥāṣarīn bi-Gafṣa) anna aḥdat Allāh ar-rābīya [...] țaraqathum bi-'l-ḥawādit an-nukr wa-'l-manāyā al-ḥumr țawāriquhā [...] wa-anna hạ̣batahum al-manī‘a qad mulikat 'alaihim aswāruhā wa-ḩanādiquhā“‘, (Raihānat al-kuttāb, Bd. 1, S. 137) ,('inda istīlā' almuslimīn ‘alā hịṣn Qanīṭ) fa-tasallama al-muslimūn al-yaum at-tānī qaṣabatahū [...] watasannamat rāyāt an-naṣr haḍbatahū“". Gerade aus dieser Vorstellung heraus, eine befestigte Stadt sei u. a. ein hoher Berg, lassen sich die folgenden Zitate erklären: (Mağmū' rasā’il muwaḥḥidīya, S. 255) „tumma 'aiyannā 'askaran yuqīm bi-Qābis ḥāfiẓan li-ğanābihā wa-mu’taminan li-šicābihā [!] wa-māni'an li-'l-'adūw min tawalluğ bābihā“،, (Raihānat al-kuttāb, Bd. 1, S. 168) „wa-tarakūhā (aiy al-muslimūn madīnat Ğayān) auhaš min al-qafr [...] marșūfat as-sikak bi-'1-ğutat wa-'1-ašlā' [...] murafrifa fauqahā 'aṣā’ib al-qašācim mutazāhima 'alā ši ābihā wa-niqābihā aḍ-ḍibā'c“, (Raiḥānat alkuttāb, Bd. 1, S. 189 f.) ,wa-bādarnā ramaq al-ḥuṣūn al-muḍāáa [...] sākinuhā bā'is wa'l-a'ṣam fị šacbātihā min al-'iṣma ā'is“،, (Raihạānat al-kuttāb, Bd. 1, S. 165) „(beim Angriff der Muslime auf Jaen) fa-lā tarā illā hāwīyan min dِurā šurfa tahlifuhū ğumla au šahīdan yatazāḥam 'alā mawāqifihī lumma au tanīya tufra` au šicāran yusmac“ sowie (Raihānat al-kuttāb, Bd. 2, S. 300 f.) ,illā anna al-'adūw țawā dail burūdihā (aiy burūd madīnat Runda) wa-ġaṣaba bunaiyātihā [...] wa-aḍāqa ḩāriğahā wa-ḩaffaḍa macāriğahā“‘ 
- wörtl. „der Feind hat ihre zu besteigenden Hänge bzw. ihre Leiter niedrig gemacht, und ihre Ersteigung, d. h. Bezwingung, ist somit leicht geworden“. In den Zusammenhang „,der Berg“ ist auch „Dirwa“ einzuordnen: (Ṣubh, Bd. 7, S. 39) ,(bei der Schilderung der Belagerung einer Festung) wa-mā zilnā mundu kān an-nuzūl ‘alā had̄ā al-ḥiṣn nata'arraf fîhī min maḩāìl an-nuğh [...] mā a'tạāā [fa] țalağ al-yaqīn bi-annā nafșim 'urwatahū wa-nafra' dirwatahū, (al-Mann, S. 204) „wa-lammā wașala al-'askar al-muntaẓar min Ġarnāṭa aḩaḍnā fi 'l-ḥaraka ilā an intahainā ilā ḥiṣn Qaliya fa-sā'ata aliṭlāl 'alaihī nazala ahluhū min dirwatihī tā'ibīn ābīn [wa-la'alla al-maqșūd hunā ā'ibīn]“ - „nazala 'an dirwa“ steht hier für „sich ergeben, j-s Herrschaft anerkennen und vom weiteren Widerstand abstehen“, (Mağmū rasā’il muwaḥhidīya, S. 171) „fa-yassarū lahū (aiy li-'l-mayūrqī) șahwatahā (aiy șahwat Biğāya) wa-a ānūhū 'alā tasannum diriwatihā“‘ sowie (Qalā'id al-'iqyān, S. 116) ,wa-ahbaranī annahū sāyarahū ilā Šantarīn qāṣīyat arḍ al-islām as-sāmīya aḍ-durā wa-'1-a'lām“ - hier wird der Plural - ähnlich wie bei „marāqib“ - für die Umschreibung von „Höhe“ gebraucht.

Vergleich des inneren Bereichs von befestigten Städten, Gebäuden oder sogar Gegenden mit dem heiligen Bezirk: (Raiḥānat al-kuttāb, Bd. 2, S. 286) „fa-ḥimāhā (aiy ḥimā Mālaqa) man̄̄ ḥarīz“ - „unbezwingbar, uneinnehmbar“, (Mušāhadāt, S. 81) „ḥaramuhā (aiy ḥaram madīnat Barğa) amīn wa-ḥusnuhā bādin wa-kamīn“, (Mağmūc rasā’il muwaḥhidīya, S. 111) ,wa-kāna šurrād al-‘arab [...] yasnidūna fīmā yazīgùunahū min 'inādihim wa-yuhāwilūnahū min iḍrārihim wa-ifsādihim ilā manī‘ hịmāhū (aiy ḥimā Gafṣa)“،, (Raihānat al-kuttāb, Bd. 1, S. 164) „wa-'stağannū (aiy al-ḥāmīya) bi-ḥimā alabrāğ al-mašīda“, (Raiḥānat al-kuttāb, Bd. 1, S. 166 ff.) „wa-lağa’a al-fall al-maḥrūb [...] ilā hịmā al-qala‘āt al-mašīda“, (Mağmūc rasā’il muwaḥhidīya, S. 232) „Šantaqrūs [...] ḥiṣn bi-'l-ğiha [...] minhū tafattaḥat abwābuhā wa-tawazza'at aslābuhā wa-ustubịha bi-'lġadr ḥimāhā““, (al-Mann, S. 242), ,(nach dem Sieg über die Aufständischen, die sich auf einem Berg verschanzt hatten) wa-had̄ā al-ğabal hūwa alladīi kāna ablaqahum al-fard almumtani' 'alā man rāmahū al-musta'ṣi qadīman 'alā man kādahū fa-qad istaftaḥa mamnū uhū wa-ḩalat min aẓ-ẓālimīn rubū'uhū“ - hier wird „hịmā“، in ihrer Bed. als „heiliges, für Fremde nicht betretbares Gebiet“" mit „mamnū'uhū" umschrieben.

$\mathrm{Zu}$ verbreiteten Vergleichen von befestigten Städten mit einer schönen Frau oder einem störrigen Reittier, siehe das Kapitel „Bezwingungen, Inbesitznahmen von Festungen und Siege allgemein“.

\section{Krankheiten und Übel}


(Riḥlat at-Tiğānī, S. 318) ,fa-aqamnā bi-ẓāhir had̄ā al-ḥiṣn [...] ilā an wağadtu hiffa min al-marad" - Krankheit wird als etwas Belastendes, Beschwerendes empfunden und die Genesung von ihr demnach als eine Entlastung im wörtlichen Sinne des Wortes. Diese Vorstellung schwingt sicherlich mit in (Mağmū' rasā’il muwaḥhidīya, S. 259) „qadima Abū Sirḥān [...] yarsif fĩ qaid haramihī wa-yaṭlub liman warā’ahū [...] min qubūl had̄ā al-amr al-'azīm wa-dimamihī‘‘.

„Krankheit“ dient ferner dazu, z. B. den subjektiv empfundenen Zustand eines häufig politischen Misstandes zum Ausdruck zu bringen: (Mağmū' rasā’il muwaḥhidīya, S. 101) „wa-tawașṣala (aiy muntazī Gafṣa) ilā as-saicy fi 'l-arḍ bi-'l-fasād bi-sababihim (aiy bi-sabab al-a'rāb) wa-tarākaḍū ğamī'an fĩ maidān al-'ait [...] wa-'nhamakū fi 'stiḥlāl almahārim ğur’atan 'alā Allāh wa-bag̉yan fa-ta‘aiyana ḥasm dā’ihim“, (Mağmū` rasā’il muwaḥhidīya, S. 216) „(nach dem erfolgreichen Abschluss der almohadischen Unternehmung gegen Banū Ġānīya und Qarāqūš in Ifrīqīya) fa-'inda mā abra’a Allāh tacālā suqm hadihī al-bilād wa- tilālahā wa-ra'aba ta’yahā wa-aṣlaḥa ihtilālahā“،, (Qalāid al-iqyān, S. 49) „wa-hūwa (aiy yaum az-Zallāqa) yaum šafā al-islām ba'd mā ašfā“, (Raiḥānat al-kuttāb, Bd. 1, S. 129) ,wa-naltamis minhū (aiy min had̄ā al-mulk) cilāğ had̄ā al-quṭr iḍā iḍțarabat țabā'icuhū“ - hier „,von dieser merinidischen Dynastie erhoffen wir Beistand immer dann, wenn die geordneten politischen Verhältnisse in al-Andalus ins Wanken geraten“, (Raihānat al-kuttāb, Bd. 2, S. 41),,(nach dem Tod des kastilischen Königs bei der Belagerung Gibraltars) wa-talāḥaqa binā al-fursān min Ğabal al-Fath [...] fa-'ĥtabarat [wa-'l-maqșūd hunā fa-ahbarat] bi-'nfirāğ aḍ-ḍīq wa-'rtifā' al-'̄àiq lahā 'an at-țarīq wa-bur’ ad-dā’ alladī ašraqa ar-rīq““. In den alm. Briefen werden häufig Städte, Orte usw. als von Krankheit befallen bezeichnet, die den Almohaden unbotmäßig geworden sind: (Mağmū' rasā’il muwaḥhidīya, S. 80) „(nach der Wiederinbesitznahme von Almeria, Baeza und Ubeda durch die Almohaden) wa-'1-ān [...] istarāḥat al-Andalus min dā'ihā al-'uḍāl“, (Mağmū̄ rasā’il muwaḥḥidīya, S. 101) (bei der Schilderung der Planung der almohadischen Führung, bei einem Feldzug nach Ifrīqīya Gafsa zurückzuerobern) „wa-kāna min qaṣdinā fỉhā (aiy fị hadihī al-ḥaraka) wa-irādatinā bihā an-naẓar fī amr hadihī al-madara wa-izāḥat cillatihā“, (al-Mann, S. 235) ,(vor der Niederschlagung eines antialmohadischen Aufstandes im Gebirge Kawākib) wa-'nbanat (aiy an-nīya) 'alā ḥasm al-adwā' an-nāzila bi-had̄ā al-Mag̉rib min hadihī al-firaq allatī fāraqat al-ğamā'a“. Und schliesslich kann „Krankheit“ für die Umschreibung des Schadens dienen, der einem Objekt zugefügt wird: (Qalā’id al-iqyān, S. 61) „fa-aqāmū (aiy al-murābiṭun) 'alaihā ('alā Qurțuba) šuhūran [...] yusāwirūnahā musāwarat al- 
arāqim wa-yubākirūnahā bi-dā’ min al-ḥișār fāqim“ - d. h. „brachten der Stadt große Schäden während der Belagerung bei“.

Die Charaktereigenschaften, die als nicht tugendhaft empfunden werden, können als Krankheiten beschrieben werden: (Maqāmāt al-Ḥarīīī, S. 289) „wa-a ciddū li-'r-riḥla i'dād as-su'adā' wa-'ddari'ū ḥulal al-wara` wa-dāwū 'ilal aṭ-ṭamac“, (Maqāmāt al-Ḥarīīin, S. 379) (in der Geschichte mit dem Kauf eines jungen Sklaven, der durch die Anspielung auf den Verkauf Josephs auf seinen wahren freien Status implizit hinweist und sich später, beim Verlassen des Marktes als freier Bürger erweist) „wa-inna fīmā šaraḥtumāhū (aiy antumā ar-rāwī wa-'l-g்ulām) la-dalīlan 'alā anna had̄ā al-g̉ulām qad nabbahaka fa-mā ir`awaita wa-naṣaḥaka fa-mā wa'aita fa-'stur dā' balahika wa-'ktumhū wa-lum nafsaka wa-lā talumhū“‘

\section{Heere}

Die Gewaltigkeit der Heere z.B. anhand des Bildes der wogenden Gewässer: (al-Fitan wa-'l-ḥurūb, Bd. 3, S. 10) ,yasīl 'alā al-basīṭa minhū (aiy min al-ğaiš) sail 'ubābāhū alḥawādit wa-'š-šu'ūn“ - hier Vergleich des Heeres aufgrund seiner Menge mit einem Strom, (Raiḥānat al-kuttāb, Bd. 1, S. 174) „wa-'qtaḥamnāhū (aiy al-ğisr) tağrī fauqahū suyūl al-ḥušūd wa-našr an-naml gaaur al-maḥ̣ūr wa-lā al-mamdūd (wa-'l-arğah annahū al-ma'dūd)“, (al-Fitan wa-'l-ḥurūb, Bd. 3, S. 28) ,wa-yā rubba ğaišin li-'l-'adūw ka'annahū 'ubāb ḩị̣amm țamā yatadaffa'u“, (Qalā'id al-'iqyān, S. 59) ,fa-mā amsā (aiy alMu'tamid Ibn-'Abbād 'inda ḥiṣārihī li-qașabat Mālaqa) illā gaašīyahū lailuhā (aiy lail alkatība) wa-sāla 'alaihī sailuhā“, (Qalā'id al-ciqyān, S. 59) „wa-wağğaha ilaihā (aiy ilā Mālaqa) ğaišahū al-mutazāḥim al-afwāğ al-mutalāṭim al-amwāğc،, (Qalā'id al-iqyān, S. 59) „fa-ahrağa (aiy Bādīs Ibn-Ḥabbūs) min hịnihī katībatahū allatī kānat tarmī bi-'zzabad".

Andere Umschreibungsmöglichkeiten für gewaltige Heerscharen: (al-Fitan wa-'1-ḥurūb, Bd. 3, S. 10) „fī ğaḥfalin ka-sawād al-lail murtakim lakin asinnatuhū șārat lahū šuhuban“, (Mağmū'a ğadīda, Bd. 1, S. 265), „fa-atat minhum umam lā ya lamuhum illā Allāh [...] wa-ğā'ū ka-amwāğ al-baḥr fĩ ğuyūš lā yuṭill 'alā miṣbāḥihā as-sārī“.

Schlachten Schlacht als Stute bzw. als Weib: (Qalā'id al-iqyān, S. 58) ,fa-saqaṭa alhabar (aiy bi-anna Bādīs Ibn-Ḥabbūs ğarā fī maidān lahwihī ḥattā istaufāhū) 'alā alMu'taḍid bi-'llāh mulaqqih al-ḥarb wa-muntiğ aṭ-ṭa'n wa-'ḍ-ḍarb“, (al-Fitan wa-'l-ḥurūb, Bd. 3, S. 15) „fĩ kull haiğā' laqqạ̣at (aiy al-ḥarbu) nafsahā bi-'1-maut fa-'stag̉nat 'an alfạ̣l - katīrat an-nasl wa-lakinnahā aqța' mā fi 'l-baṭn li-'n-nasl', (Raqm al-ḥulal, S. 65) 
„wa-'ḍṭaraba al-amr wa-ğalla al-ḩațb [wa] laqiḥat [au luqqiḥat] fi 'l-fi'atain al-ḥarb“, (alFitan wa-'l-ḥurūb, Bd. 3, S. 37) ,tamharu arwāḥ al-'idā bị̣̄uhū iḍā arādat min hurūbin nikāḥ“ - „arādat“ bezieht sich hier auf „bị̣̣“, (al-Fitan wa-'1-ḥurūb, Bd. 3, S. 37) „wamā waladat sūdu al-manāyā wa-ḥumruhā 'alā al-kurh ḥattā kānat ṣawārimuka fạ̣lan“.

\section{Bezwingungen, Inbesitznahmen von Festungen und Siege allgemein}

Verbreitet ist der Vergleich einer befestigten Stadt mit einem störrigen Reittier, und daraus resultiert die Vorstellung, man bezwinge Festungen, indem man sie gleich Reittieren besteige bzw. abrichte und bändige. Hierzu folgende Beispiele: (Ṣubḥ, Bd. 7, S. 101) ,wa-hīya (aiy al-madīna al-fulānīya) allatī a'yat riyāḍatuhā kull rā’ị̣ wa-sahirat bi-kull qāiid bi-qunūnihā rābị̣““, (Raihāanat al-kuttāb, Bd. 2, S. 29) „Biğāāya [...] amtākum as-sa'd șahwatahā wa-ạ̣kama at-taufīq rabwatahā“،, (Mağmū̄ rasā’il muwaḥhidīya, S. 111) ,wa-waḍ 'uhū (aiy haḍā qaṣr Gafṣa) min al-intihā' fi 'l-ḥașāna watağāwuz fi 'l-mana'a wa-'l-wațāqa bi-ḥait lā yuṣhị muṣ́abuhū wa-lā yatamahhad illā lihad̄ā al-amr al-'azīz markabuhū“, (Raiḥānat al-kuttāb, Bd. 1, S. 261) „wa ra’ā (aiy al'adūw) annahū iḍā fāzat bi-furḍat al-mağāz (aiy bi-Ǧabal al-Fatḥ) qidāḥuhū wa-lāna lahū min al-ğabal bi-ṭūl al-ḥiṣār ğimāḥuhū“،, (Șubḥ, Bd. 7, S. 39) ,(bei der Schilderung der Belagerung einer Festung) wa-mā zilnā mundِu kān an-nuzūl 'alā had̄ā al-ḥiṣn nata'arraf fīhī min mahā̄il an-nuğh [...] mā a ț̣ānā [fa] talağ al-yaqīn bi-annā nafṣim 'urwatahū wa-nafra' dirwatahū wa-lam yazal al-'azm yudallil šimāsahū wa-yuqallil nāsahū [ilā āhirihī]“, (Raihānat al-kuttāb, Bd. 1, S. 517) ,ammā ba'd ḥamd Allāh [...] muyassir aṣ-ṣa ${ }^{\complement} b$ ba`d ibā'ihī wa-'l-kafîl bi-taqrīb al-farağ wa-idnā’ihī'،, (Raiḥānat alkuttāb, Bd. 1, S. 148) „wa-'staharnā Allāh fĩ qaṣdihī (aiy qaṣd ḥiṣn Ašir) wa-sa'alnāhū al-i'āna 'alā fatḥihī wa-taisīr șa'bihī“, (Raihānat al-kuttāb, Bd. 1, S. 174) „(vor den Toren Ubedas angelangt äußern die Muslime folgenden Wunsch) fa-qulnā allahumma sahhil lanā șacbahā wa-asfil kacbahā wa-'ğcalhā li-'ibādik anfālan“.

Interessant ist das folgende Zitat (Mağmū' rasā’il muwaḥhidīya, S. 255) „wa-sa'alnā Allāh [...] fī tathīr buq'atihā (aiy buq'at al-Mahdīya) wa-taḍlīl mana'atihā“‘, denn es entspringt zwar der Vorstellung, eine zu erobernde Festung sei einem widerspenstigen Reittier gleich, benennt aber nur deren einen Bestandteil „tadlīi““ und ersetzt das erwartete ,șacbahā“" durch „mana'a“".

Nicht unüblich ist ferner auch der Vergleich einer Frau, derer man sich bemächtigen will, mit einem störrigen Reittier. (Maqāmāt al-Ḥarīrī, S. 485) (als Abū-Zaid as-Sarūğ̄̄ einen jungen Mann um die Beschreibung der jeweiligen Vorzüge von Frauen mittleren 
Alters und von Jungfrauen bittet) ,wa-ammā at-taiyib fa-'1-mațīya al-mudallala“ und wenig später in der gleichen Angelegenheit (Maqāmāt al-Ḥarīī, S. 487) „fa-qultu (aiy Abū-Zaid as-Sarūğī) kuntu samictu anna al-bikr ašaddu ḥubban [...] fa-qāl [...] waiḥaka a mā hīya al-muhra al-abīya al-'inān wa-'1-mațìya al-batịya al-ị̣̂ān wa-'z-zanda almuta'assira al-iqtidāḥ wa-'l-qal'a [!] al-mustaṣ'aba al-iftitāḥ tumma inna [...] riyāḍatahā 'anā' wa-'alā hibratihā gišāà wa-țālamā ahzzat al-munāzil [!]“ - wohlgemerkt kommen hier „mațìya“, „d_allala“, ,abīy“, die in anderen Zusammenhängen bei der Beschreibung der belagerten Städte gebraucht werden, zusammen mit „al-qal'a“" und „nizāl“ vor.

Hochzeitsrituale u. ä.: Befestigte Städte können mit schönen Ehefrauen, schmucken Bräuten usw. verglichen werden: (Raihāānat al-kuttāb, Bd. 1, S. 231) „wa-kunnā qad ittaṣala binā anna maqāmakum ḩaṭaba madīnat Biğāya fa-alqat al-maqād“", (Mušāhadāt, S. 94) ,illā anna [...] manāzilahā (aiy manāzil madīnat Lauša) li-nazā’il al-ğund nāzila wa-'uyūn al-'adūw li-țag̉rihā aš-šanīb muġāzila“, (Mušāhadāt, S. 95) ,illā annahā (aiy madīnat DQkwwān) lā tadfa' 'an qurțihā wa-siwārihā bi-aswārihā wa-lā tamna' naz' ṣidārihā bi-ğidārihāa“, (Rasā’il wa-maqāmāt andalusīya, S. 131) „fa-qalladnāka [...] taqlīdan ğama'nā laka bihī baina al-wilāyatain wa-mallaknāka bihī amr al-karīmatain“, (al-Fitan wa-'l-ḥurūb, Bd. 3, S. 38) ,(nach der Ermordung des Statthalters) fa-armalahā (aiy armala aš-šahsu al-mauṣūf al-madīna) bi-'s-saif tumma a ārahā min an-nār ațāōb alḥidād 'alā al-faqd“", (al-Fitan wa-'l-ḥurūb, Bd. 1, S. 234) „,(nach der Einnahme Gafsas durch al-Manșūr im Jahre 1187 unter Einsatz von Katapulten) lammā zanat (aiy Gafṣa) wa-hīya taḥta al-amr muḥṣana ḥaṣabtumūhā ittibāca aš-šar bi-'l-ḥaṣab“, (Raiḥānat alkuttāb, Bd. 2, S. 254) „(Buršāna) qal'a sāmīyat al-ğalāl muhattama bi-'l-kawākib“ - eine Frau, deren Finger mit den in Sterne gefaßten Ringen geschmückt sind, (Qalā’id al'iqyān, S. 46) „wa-kānat Qurțuba muntahā amalihī (aiy amal al-Mu'tamid Ibn-'Abbād) [...] wa-mā zāla yahutubuhā bi-mudāhalat ahlihā wa-muwāṣalat wālīhā id lam yakun fĩ munāzalatihā fā'id“, (Qalā'id al-'iqyān, S. 59) „fa-lammā aṭalla 'alaihā (aiy al-Mưtamid Ibn-'Abbād 'alā Mālaqa) a'țathū șafqatahā wa-amțathū șahwatahā illā qaṣabatahā fainnahā imtana'at bi-tāèifa min as-sūdān al-maḡāriba lam yarḍaū sifāḥahā wa-lā amḍaū nikāḥahā“‘, (al-Fitan wa-'1-ḥurūb, Bd. 3, S. 37) „wa-'aḍrā’a min bikr al-futūḥ iftaḍaḍtahā wa-laisa lahā illā bi-ḥukm al-waġā 'aqdu“. Es kommt ferner vor, dass die zu bezwingende Festung mit einer Braut verglichen wird, die ein hohes Brautgeld verlangt, d. h. das Blut vieler Stürmender vergossen werden muss, bevor sie eingenommen werden kann: (Mağmū'a ğadīda, Bd. 1, S. 243) ,hatabnāhā (aiy al-Mahdīya) fa-arādat at-tanbīh 'alā qadrihā wa-'t-taufîr fî iğlā' mahrihā [...] fa-tamanna'at tamannu'a al- 
maqșūrāt fi 'l-ḩiyām“ (vgl. auch Raihānat al-kuttāb, Bd. 1, S. 221). Vor diesem Hintergrund wird erst das folgende Zitat verständlich (Mağmū' rasā'il muwaḥhidīya, S. 232) ,,ahl Šantaqrūs wa-hīya al-qal'a al-ḥasība fi 'l-imtināe al-mağlūwa 'alā minaṣṣat alyafā̄“, denn sowohl „mağlūwa“ - man denke an „ğalwa“ - als auch „minașṣa“ entstammen dem Sprachgebrauch des Hochzeitsrituals. - Das Bild mit der auf ihrem Brautstuhl sitzenden Braut kann aber auch als eine Umschreibung für die Augenfälligkeit, Klarheit eines Objektes bzw. Sachverhaltes gebraucht werden, denn (21. almor. Briefe, S. 179) „wa-qad kāna al-amīr [...] taqaddama lanā baina yadaiy dalika bi-ğalā' tilka al-aḥwāl fĩ manāṣṣihā“ - hier „der Amīr Soundso hatte bereits vorher diese Zustände (ahwāl) in aller Ausfühlichkeit dargelegt und geschildert“; (Raihānat al-kuttāb, Bd. 1, S. 364) ,wa-hadihīī al-bilād al-andalusīya [...] hīya 'udda liaslāfikum (aiy li-aslāf min ḥukkām Banī Marīn) al-kirām ilā macādihim [...] wa-ṣaḥîfat a'mālihim az-zakīya wa-minașṣat ātārihim al-mulūkīya“. - Die Braut, derer man sich bemächtigen will, kann auch als Grundlage für eine längere Beschreibung der betreffenden Festung dienen (die ausdruckstärkste mir bekannte Schilderung dieser Art findet sich in „Mağmū'a ğadīda“, S. 242 f.). (Raihānat al-kuttāb, Bd. 1, S. 165) „(bei der Beschreibung des Straßenkampfes nach der Erstürmung Jaens) wa-duhilat [...] wa-ğāza fursānuhā fi 's-sikak yaṭīūn min ḍaiqa ilā uhrā wa-'1-muslimūn ya'huudūn 'alaihim alfūwahāt wa-yasūqūnahum (wa-yurwā yasbuqūnahum) ilā al-mutamannicāt“ - dem Verlauf der Schilderung nach ist die Variante „yasbuqūn“ vorzuziehen, und m.E. sind mit „al-mutamannicāt“, eigtl. „(begehrte) spröde und abweisende Frauen“, Gebäude gemeint, in welchen die fliehenden Feinde sich zu verschanzen hofften, woran sie die ihnen zuvorkommenden Muslime hindern. Wohlgemerkt wird das „tamanna'a“ häufig im Zusammenhang mit spröden und sich verschließenden Frauen gebraucht, so z.B. in (Raiḥānat al-kuttāb, Bd. 1, S. 233) ,wa-in kānat (aiy madīnat Biğāya) qad abdat nifāran wa-tīhan wa-'āwadat 'ādat tağannīhā fa-'t-tīh min 'ādat al-gāàda wa-'t-tamannu' min šìmat al-karīma“. (Raihānat al-kuttāb, Bd. 1, S. 196) „,fa-lam yablug al-`afā min madīna ḥāfila wa-'aqīla fị ḥulal al-maḥāsin rāfila mā balag̉a min hadihī al-bā'isa“, (Raiḥānat al-kuttāb, Bd. 2, S. 25) „raḥalnā 'anhā (aiy 'an Qurțuba) wa-qad ințawainā min i'fā aktar tilka azzurūc 'alā hamm [...] id kāna 'ādil al-mațar yakaff alsinat an-nār 'an al-mubālag̀a fi 'Itihāmihā [...] wa-nihāb siwārihā“، - hier ,der Braut bzw. der Frau ihr Armband abreißen, ihrer äußeren Schönheit durch Gewaltanwendung Abbruch tun, d. h. der Stadt Verluste zufügen“. 
Das Bild vom störrigen Reittier kann auch allgemein auf Feinde bezogen werden: (Mağmū' rasā'il muwaḥhịīìa, S. 28) ,fa-qad kāna șun` Allāh fi 'ftitāḥ hadihīi al-bilād aš-šarqīya 'alā mā taqaddama dikruhū min at-tanāsuq wa-'t-tatābu' wa-taḍlīl aṣ-ṣa $b$ wataqrīb aš-šāsi““ - wohlgemerkt wird hier „taḍlīl aṣ-ṣa‘b“ und „taqrīb aš-šāsic“ synonym zueinander gebraucht und bed. allgemein ,jemanden bzw. etwas bezwingen“, (Mağmū' rasā’il muwaḥhidīya, S. 29) ,fa-'ādat had̄ā al-amr al-'azīz hīya al-iḥtimāl wa-'l-iğmāl wa-'r-rifq bi-'1-ğuhhāl wa-muqābalat al-ba'īd aṣ-ṣacb bi-'t-taqrīb wa-'1-ishāl“ - ,al-ba'īd“ und ,aș-ṣa $\mathrm{b}^{\mathrm{a}}$ " sind hier diejenigen, die der almohadischen Botschaft nicht wohlwollend bzw. feindlich gegenüberstehen, (Mağmū' rasā’il muwaḥhidīya, S. 213 f.) „,(nach der Befriedung Ifrīqīyas) wa-mā dalika illā yusr Allāh tacālā fī had̄ā al-amr al-'azīz arg̉ama lahū bihī šumm al-macātis wa-adalla li-rahbatihī wa-haibatihī kull ğāmih șāmis“, (Mağmū' rasā’il muwaḥhịidīya, S. 125) „fa-innahū (aiy had̄ā al-fatḥ) li-'l-futūḥ al-āzifa miftāh [...] limā ušriba fīhī aulīyā' Allāh [...] min rīḥ al-fatḥ wa-'staḥlaū min mudāmat an-naṣr wa-tawaț̣a'a lahum min țarīq az-ẓafar ar-raum wa-tadallala lahum [min] markab ar-rūm“.

Das Bild von einem störrigen Reittier und dessen Besteigung, kann auch auf andere Zusammenhänge übertragen werden und hat dann die Bedeutung „ein bestimmtes Etwas - in Gestalt eines Reittieres - sei dem benannten Nutznießer untertan, zu Diensten“. So heißt es in (Raiḥānat al-kuttāb, Bd. 1, S. 290) „maqām maḥall ahīnā allad̄ī [...] markab al-'izza al-qa'sā' li-ḩidmatihī fi 'l-iṣbāḥ wa-'l-imsā' ğanīb“, (Mağmū'a ğadīda, Bd. 1, S. 489) ,fa-innā katabnāhū (aiy had̄ā al-ḩiṭāb) kataba Allāh lakum aựạ̣ al-a māl sadādan wa-ṣawāban wa-'arrafakum asmaḥ al-āmāl inqiyādan wa-iṣhāban“, (Șubḥ, Bd. 7, S. 99) „,wa-Allāh yudīm li-'l-maqām al-wātiqiē mā 'auwadahū min tawālī as-su'ūd wa-'ț̣irādihā wa-iṣhāb al-āmāl wa-'nqiyādihā““ - hier „Eintreffen und Inerfüllunggehen von Hoffnungen“, (Raihānat al-kuttāb, Bd. 1, S. 128) „wa-'d-du'ā’ li-maqāmikum al-asmā bi-'izz yudill maṣāiib al-amānī min ba'd mașāìib aš-šimās“; (Raihānat al-kuttāb, Bd. 1, S. 343) ,wa-hūwa (ya'nī Ibn-Marzūq) [...] fāris al-manābir yurauwiọ și ābahā wa-yafrac hiḍābahā“. Im übertragenen Sinn ist auch das Zitat zu verstehen (Raihānat al-kuttāb, Bd. 1, S. 217) „wa-'r-riḍā 'an șaḥbihī [...] alladīn rāọū și āb an-naṣr ba'd al-ğimāḥ“ - hier „welche Siege ertrotzt haben“. Weiteres Bsp. in einer anderen Bed. (Rasā’il wamaqāmāt andalusīya, S. 135 f.) (bei der Ernennung eines neuen Statthalters von Valencia) „fa-aṭīiuhū kamā furiḍa 'alaikum fi 'l-makrūh wa-'l-maḥbūb wa-'nḍammū ‘alaihī rāšidīn mus'ifīn inḍimām al-ğawārih 'alā al-qulūb [...] ğa'alakum Allāh mimman aṣhaba fi 'l-qiyād wa-ağāba dā'ī ar-rašād“. (Qalā'id al-'iqyān, S. 37) „wa-aḩbaran̄̄ 
[fulān] annahū dahala 'alaihī (aiy 'alā al-Mu'tamid Ibn-'Abbād) fî lailatin qad tanā assurūr manāmahā wa-'mtatā al-ḥubūr gāaribahā wa-sanāmahā [...] wa-satara bayāẹ alamānī sawādahā“ - d. h. „Nacht, in welcher die Versammelten den Vergnügungen frönten“

Nasen als Sinnbild des Hochmuts bzw. der Auflehnung und des Ungehorsams ${ }^{742}$ (Raḥānat al-kuttāb, Bd. 1, S. 220) „šamaḩat (aiy Tilimsān) bi-anf al-ḥașāna wa-'1ibāya“", (Mağmū' rasā’il muwaḥhịīiya, S. 218) „wa-al-ḥamd li-'llāh allad̄ī arg̉ama lihad̄ā al-amr al-'azīz šumm al-ma'ātiss“, (Raihānat al-kuttāb, Bd. 1, S. 174) „fa-qulnā allahumma sahhil șábahā (aiy șa bo madīnat Ubeda) wa-asfil kacbahā wa-'ğ̣alhā li'ibādik anfālan [...] wa-'qța` 'amālatahā li-yadaiy al-ḩarāb wa-'ṣra` ānāf mabānīhā assāmīya fi 't-turāb“, (Riḥlat at-Tiğān̄i, S. 339) ,ilā an ustu'ṣilū 'an āḩirihim wa-kabbahum al-ḥatf 'alā ğibāhihim wa-manāhnirihim“, (Mağmū' rasā’il muwaḥhidīya, S. 213 f.) „(nach der Befriedung Ifrīqīyas) wa-mā dalika illā yusr Allāh tacālā fĩ had̄ā al-amr al‘azīz arg̉ama lahū bihī šumm al-ma'āțis wa-adalla li-rahbatihī wa-haibatihī kull ğāmih šāmis“

\section{Erleichterung nach durchlittener Not}

Die Vorstellung, dass die Erleichterung nach durchlittener Not etwas mit „Aufdecken“ gemeinsam hat, ist nicht unüblich. Das bekannteste Beispiel hierfür ist etwa der Titel des bekannten Werkes von at-Tanūh̄i ,al-Farağ ba'd aš-šidda“, weitere Beispiele sind: (Raihānat al-kuttāb, Bd. 1, S. 141) „wa-'1-yusr bi-fạ̣l Allāh țārid al-azmāt ba'd mā qa'adat wa-kāšif aš-šadā’id ba'd mā ar'adat wa-abraqat", (Raiḥanat al-kuttāb, Bd. 1, S. 213) „wa-'ṣ-ṣalāt 'alā saiyidinā wa-maulānā [...] allad̄ī tadāraka al-ḩalīqa bi-hadyihī fakašafa balāyāhā“‘, (Raiḥānat al-kuttāb, Bd. 1, S. 376) „wa-man yu’ammal min almislimīn li-raf ${ }^{\Upsilon}$ ar-ridā’ wa-kašf al-balwā“. Dabei legt „Aufdecken“ nahe, dass Not etwas Bedeckendes darstelle. Dies schwingt in mindestens zwei folgenden Bezeichnungen für „Not, Unglück“ mit, nämlich ,at-ṭāmma“ und ,al-ġamm“.

\section{Gnadenbezeigungen und Gunsterweise}

Die Vorstellung, dass jemand mit etwas beschenkt wird, wird sehr häufig mittels des Bildes des dahinströmenden Wassers zum Ausdruck gebracht ${ }^{743}$ : (Maqāmāt al-Harīī̄, S.

\footnotetext{
${ }^{742}$ Diese Vorstellung ist bereits in den folgenden Wendungen belegt: „Anf fi 's-samā' wa-'st fi 'l-mā' (Mağma` al-amtāl, Bd. 1, S. 21) und ,amna' min anf al-asad“" (al-Munğid fi 'l-lug̉a wa-'l-a' lām, S. 1009)
} 
233) ,țumma afāọa (aiy al-wālī) 'alaihimā hil'atain wa-waṣalahumā bi-niṣāb min al'ain“, (Mağmū' rasā’il muwaḥhidīya, S. 96) ,kataba Allāh lakum [...] barakat almawāhib allatī hīya min baḥr 'aṭ̂̄'ihī mustamadda“, (Riḥlat Ibn-Baț̣uṭ̣a, S. 388) „waba'ata ma'ahū anğād al-fursān [...] wa-adarra 'alaihim al-arzāq wa-wassa'a lahum aliqtạ̄a“, (Raihānat al-kuttāb, Bd. 1, S. 128) ,wa-raḥmatuhū li-man bihā (aiy bi-amṣār alAndalus) min al-muslimīn kafîla bi-'nsikāb an-na'mā wa-ḍahāb al-ba's“, (Mağmūc rasā'il muwaḥhịīiya, S. 2) ,al-futūḥ allatī zahara bihā min āyāt al-mahdīy [...] al-'ağab al-'uğāb wa-fāḍa min barakātihī al-faiḍ al-munsāb wa-darrat bihā al-arzāq““.

Eng damit hängt die Vorstellung zusammen, die Gnadenbezeigungen und Gunsterweise einer höherstehenden Entität ergössen sich auf die Begnadeten gleich dem Regen einer Wolke: (Raihānat al-kuttāb, Bd. 1, S. 263) „mararta (aiy as-sulțān an-naṣrī Yūsuf) 'alā wa'd min al-ġait bainahā (aiy baina at-tugūur) fa-manẓaruhā ba'd al-'ubūs bahīğ“', (Raihānat al-kuttāb, Bd. 1, S. 255 f.) „wa-kānat al-bilād aš-šarqìya qad ahllafathā alguyūt wa-'adat 'alaihā li-'l-'adūw al-luyūt [...] wa-šakat ilā sa'ādat maqdaminā ma'arrat al-qaḥat fa-ạina Allāh fī inğāz al-wa'd wa-qarrabat ġarīma al-ġamām fi 'l-maqām a'wānu ar-ra'd““, (Raihāanat al-kuttāb, Bd. 1, S. 128) „wa-'r-riḍā 'an ālihī wa-aṣhābihī [...] guyūt an-nadā wa-luyūt al-ba's“،, (Mağmū' rasā’il muwaḥhidīya, S. 224) ,wa- indamā 'aḍ̣̣athum al-ḥarb aḍ-ḍarūs [...] maddū aiydīhim ilā rạ̣mat had̄ā al-amr allad̄i lā yatawaqqaf 'an mustamṭirihā wākif saḥābihā'،, (Mağmū` rasā’il muwaḥhidīya, S. 56) „fa-antum bi-ri'āyat Allāh wa-kalā'atihī fī ğawānib al-amana rāti'ūn [...] tastadirrūn ahlāfa an-ni'am istidrāran wa-tastamṭirūn min barakāt had̄ā al-amr al-mubārak samā' midrāran“, (Raihānat al-kuttāb, Bd. 2, S. 29) „wa-faḍl Allāh hāmīyatun dīyamuhū“, (Ṣubḥ, Bd. 7, S. 96) „'abd bābihī (aiy bāb al-maqām al-'alīy) al-ašraf wa-mamlūk iḥsānihī al-asaḥh al-ậraf“, (Mağmū` rasā’il muwaḥhidīya, S. 47) „wa-iyākum min ‘ibādihī al-cārifîn bi-mawāqi` an-ni`am“ - hier in Anlehnung an „mawāqi` as-sahāā", (Mağmū' rasā’il muwaḥhịīya, S. 117) „wa-anba’at (aiy al-'asākir al-manșūra) bimā arsala Allāh fì ğamīc bilād Ifrīqīya min samāc al-aman al-munsakib al-munsāb“, (Maqāmāt al-Ḥarīrī, S. 265) ,(fī waṣf al-wālī) manāẓim šarafihī ta’talif wa-šu’būb ḥibā'ihī yakif wa-nā'il yadaihī fạḍ wa-šuḥh qalbihī gāạ wa-ḩilf sahā’ihī yuḥtalab“, (Maqāmāt al-Ḥarīrī, S. 408) ,qāla (aiy al-fatā) innahū (aiy aš-šaiḩ) mud șafira min almāl wa-munīya bi-'l-imḥāl yasūmunī an atalammaz bi-'s-su'āl wa-astamṭir suḥb annawāl“". Auch das genaue Gegenteil, nämlich dass jemand anderen statt Gunstbezeigungen Widerwärtigkeiten zuteil werden lässt, kann mittels der gleichen

$\overline{{ }^{743} \text { Diese Vorstellung ist bereits in einigen arabischen Wurzeln bzw. deren Ableitungen angelegt. Vgl. }}$ 
Allegorie ausgedrückt werden: (Ṣubḥ, Bd. 7, S. 72) „fa-qad kāna (aiy al-malik al-qaštālī ḥīna muḥāṣaratihī li-Ğabal al-Fatḥ) sadda al-mağāz bi-asāṭ̄lihī wa-kātara kalimat alḥaqq bi-abāṭ̂lihī wa-ramā al-ğazīra al-andalusīya bi-šu’būb šarrihī'،, (Raihānat al-kuttāb, Bd. 1, S. 368) „wa-ramā (aiy at-tạḡìya al-qaštālī) hadihīī al-bilād as-sāḥilīya bi-šu’būb šarrihī‘. Vor dem Hintergrund der aus den Wolken der Freigebigkeit sich ergießenden Regenflüsse lässt sich das folgende Zitat besser verstehen (Raqm al-ḥulal, S. 110) „qatalathū (aiy al-amīr an-naṣrī) ru'asā' ğundihī wa-ġurasā' faḍlihī wa-rifdihī“ - hier „diejenigen, denen seine Gnaden- und Gunsterweise zuteil wurden“

Erfahrung des Gedeihlichen oder des Abträglichen anhand des Bildes der Wasserquellen bzw. Wasserbecken: (Raiḥānat al-kuttāb, Bd. 1, S. 487) ,ammā ba'd ḥamd Allāh allaḍī [...] albasa dِātakum aṭ-tāhira min al-cāfiya atwāban wa-sauwag̉a alislām min al-istibšār bi-iqbālihā (aiy bi-iqbāl d dātikum) mawārida cidāanan“ - hier synonym zu „'arrafa“", (Șubḥ, Bd. 7, S. 68) „kataba Allāh lakum min fạ̣lihī aufar alaqsām wa-aufāhā wa-auradakum min mawārid 'ināyatihī a'ḍab al-ğimām wa-aṣfāhā“", (Ṣubh, Bd. 7, S. 96) „abqāhū Allāh (aiy abqā Allāh al-maqām al-'alīy) wāridan min mašāric at-ta’yīd a'dabahā“‘, (Raihạānat al-kuttāb, Bd. 1, S. 341) ,al-maqām allad̄ī [...] yanābī‘ ğūdihī maurūda“, (al-Bayān al-mug̉rib, S. 175) „,wa-ẓill al-hudna fī tilka al-bilād mamdūd wa-mā' al-'āfiya bihā maskūb wa-maurūd wa-'1-'aiš ka-'1-ạ̣lām wa-'d-dunyā taḥīya wa-salām“, (Raiḥānat al-kuttāb, Bd. 1, S. 343) ,wa-'qtadainā bikum wa-bisalafikum fī tarfī` qadrihī (aiy fī tarfī` qadr Ibn-Marzūq) wa-sauwag̉nā li-mustafīd al'ilm maurid ifādatihī“،, (Raihạanat al-kuttāb, Bd. 1, S. 69) ,amara bihī (aiy bi-ẓahīr) [...] al-amīr fulān li-walīhī fi 'llāh alladị kasāhū min ğamīl i'tiqādihī hulalan wa-auradahū min 'aḍb riḍāhū manhalan“, (Maqāmāt al-Ḥarīrī, S. 122) ,wa-qad nāğatnī al-qarūna bian tūğad 'indakum al-ma ūna wa-ādanatnī firāsat al-ḥaubā' bi-annakum yanābī' alhibā̄`“. - „Tränken“ kann aber auch in einem völlig anderen Zusammenhang in der Bedeutung ,ein Ort, an dem der Tod als Getränk gereicht wird, d. h. das Schlachtfeld“ gebraucht werden: (Ṣubḥ, Bd. 7, S. 75) „wa-qad waṣala kitābukum [...] tu'arrifūn mā atāḥa lakum al-laṭîf al-ḩabīr [...] wa-annakum min ba'd al-kā'ina [...] ğahhaztum alğuyūš al-muhtāra [...] wa-lam yakun illā an ḥamīya waṭīs an-nizāl wa-rağafat al-arḍ lihaul az-zalzāl [...] wa-aurada al-ḩail mawārida at-ṭicān al-iqdāmu fa-kāna li-ḥizbikum aẓ-ẓuhūr“، Dies hängt sicherlich eng mit der häufigen Vorstellung zusammen, der Kampf sei ein gegenseitiges Reichen von Kelchen, sowie auch mit der Vorstellung, der Betreffende sterbe, indem ihm der Todeskelch gereicht bzw. eingefösst wird: (Raihānat 
al-kuttāb, Bd. 1, S. 155) „„ummma 'ātaū (aiy al-muslimūn) man taḥaṣṣana bi-'l-qaṣaba ku'ūs al-qitāl“ - Die Erfahrung des Erquicklichen anhand des Bildes des Meeres: (Maqāmāt al-Ḥarīīi, S. 123) ,yā qaum innī min unās ġanaū dahran wa-ğafn ad-dahr 'anhum gadị̣̄ [...] fa-gaaiyaḍat minhum șurūf ar-radā bihār ğūd lam nahalhā tag̣ị̣̄“". (Maqāmāt al-Ḥarīrī, S. 419), „țmma innī šaih tariba ba`d al-itrāb wa-'adima al-i'šāa [...] qașadtuka min maḥalla nāziḥa wa-ḥāla rāziḥa āmul min baḥrik duf́atan“".

Der Geiz wird dementsprechend auf folgende Weise ausgedrückt: (Maqāmāt al-Ḥarīrī, S. 122) „wa-ādanatnī firāsat al-ḥaubā’ bi-annakum yanābī‘ al-ḥibā’ fa-naḍ̣ara Allāh imra'an abarra qasamī wa-ṣaddaqa tawassumī wa-naẓara ilaiy bi-‘ain yuqḍīhā al-ğumūd wa-yuqadِdīhā al-ğūd“, (Maqāmāt al-Ḥarīrī, S. 420) „wa-iyāk an taqbiẹ rāḥak 'amman imtāḥak [...] fa-wa-Allāhi mā mağad man ğamad“, (Maqāmāt al-Ḥarīrī, S. 422) ,wa-'ssamḥ fi 'n-nās mạ̣būb halā'iquhū wa-'1-ğāmid al-kaff mā yanfakk mamqūtan“

\section{Wasserbecken u.ä.}

Der allegorische Gebrauch von Wasserbecken, die von Beimischungen gereinigt werden, kann u. a. aussagen, die Herrschaft in einem bestimmten Gebiet sei wiederhergestellt bzw. - häufig politische - Misstände seien dort beseitigt worden, und insofern besteht hierduch weitgehende Ähnlichkeit zum allegorischen Gebrauch von „Krankheiten“ (vgl. das entsprechende Kapitel oben): (al-Mann, S. 293) „fa-ta`tariḍ min ahl hadihìī al-Maġārib šawāgib yutîiruhā al-ğuhhāl [...] fa-lā yasa` ihmāluhā [...] qiyāman bi-ḥaqq ad-dīn wa-tawaqqīyan min istišrā' aš-šarr wa-tawaffur asbāb al-fitna fa-yanșarif ilaihā min al-iltifāt wa-'l-qaṣd li-ḥasm 'ilalihā wa-ibrā' adwā'ihā mā yuqašši ' gayābātihā wa-yuṭhhir aqdāāahā““ - „hā““ bezieht sich hierbei auf ,šawāġib“, (al-Mann, S. 290 ff.) „fîhā (aiy fi 's-sana al-mu'arraḩa) hada'at al-fitan fi 'l-'udwa wa-ṣalaḥat al-buldān wa'rtafa'at al-ḥurūb wa-rahușat al-as'ār wa-dānat al-auṭār wa-'nqaṭa'at fitnat aḍ-ḍullāl alğuhhāl ahl al-ğibāl [...] fa-ṣafat li-amīr al-mu’minīn [...] mašārib hadihī al-ğibāl min alfitan“ - d. h. diese Berge wurden befriedet und waren den Almohaden wieder botmäßig geworden, (Mağmū' rasā’il muwaḥhidīya, S. 258) ,(nach dem Abschluss des Feldzuges zur Befreiung Ifrīqīyas im Jahr 1203) wa-hadihīi Ifrīqīya qad ḩalat min al-wasāwis wanaqīyat min al-adnās wa-ṣafat min šawā’ib al-arğāas“, (Mağmū' rasā’il muwaḥhidīya, S. 111) „wa-qad tafarrag̉a bi-fạ̣l Allāh an-naẓar fī maṣāliḥ hadihī al-arğāà wa-ḩalā attaqwīm li-imāṭat mā ẓahara fîhā min nawāši' al-i'tidā' wa-'nṣarafa at-tasdīd li-ṭạ̣r aššawā'ib 'an mašārib ahlihā wa-'1-aqd̄ā’‘, (al-Mann, S. 293) „wa-mā fati’a al-ištiḡāl bihad̄ā al-Ġarb yuliẓz bi-arğā'ihī wa-yaštamil ‘alā ğawānibihī wa-yataḩallal zawāyāhū wa- 
yunazẓim aucārahū wa-suhūlahū ḥattā șaffā Allāh mašāribahū wa-ḩallaṣa min aš-šaub mašări'aū“ - „,bis Gott diesen Westen befriedet und die almohadische Herrschaft dort wiederhergestellt hat“; (al-Mann, S. 235) „fa-innā katabnāhū [...] min manzil almuwaḥhiidīn [...] bi-dāḩil ğabal al-Kawākib [...] wa-qad kunnā bimā li-'llāh 'alainā min 'ahd al-qiyām bi-ḥuqūq haḍā al-amr al-'azīz wa-'l-hiyātạ li-arğāàihī wa-'d-dedabb 'an

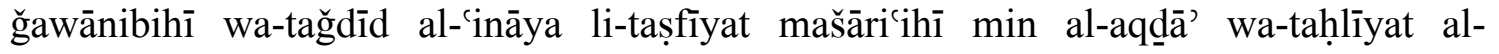
muḥauwimīn 'alaihā min ahl al-ahwā' [..] tawağğahnā lahā bi-'l-ḥaraka al-mubāraka“ interessanterweise beziehen sich ,arğāa“", ,ğawānib“ und „mašāri““ auf ,al-amr al-'azīz“ und nicht wie in den Zitaten davor auf ein geographisches Gebiet.

\section{Gefühle (Gefühlsbezeigungen, Empfindungen)}

Das Bezeigen von Gefühlen, Haltungen usw. wird häufig mit dem Bild, jemand streckt die Hand oder den Hals eines Gefühls aus, wiedergegeben ${ }^{744}$ : (Raihānat al-kuttāb, Bd. 1, S. 349) „tadֵkurūn anna man hunālikum min qaumihī basaṭū yad ar-rag̉ba ilā maqāmikum fī an yağtami` šamluhum bi-'l-mad̄kūr“, (Șubḥ, Bd. 7, S. 97) „wa-inna alhitāāb al-karīm [...] warada 'ala 'l-'abd [...] fa-tanāwalahū al-mamlūk bi-yamīn iğlālihī wa-i'zāmihī“, (Raiḥānat al-kuttāb, Bd. 2, S. 286) „Mālaqa [...] tulqī lahā yad al-istislām maḥāsin bilād al-islām“ - hier „,sich geschlagen geben, j-s Vorzüge anerkennen“, (Mağmū` rasā’il muwaḥhidīya, S. 206) ,wa-'indamā tahaqqaqū anna [...] hạ̣batahum alman̄̄'a qad mulikat 'alaihim aswāruhā wa-ḩanādiquhā maddū a'nāq al-istikāna wa-'lhuựū' wa-abdaū șafahāât al-ināba wa-'n-nuhūu'“, (Mağmū' rasā’il muwaḥhidīya, S. 108)

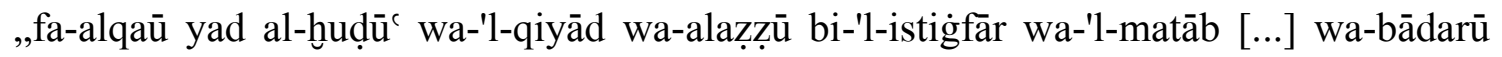
bi-irsāl ašyāḩihim [...] rāgèibīn fĩ qubūl al-ināba wa-'t-tauba māddīn li-ṭalab al-amān aidī al-istih̆d̄ā’ wa-'̣̣-ḍarā'a“, (Mağmū' rasā’il muwaḥhidīya, S. 44) „wa-kāna lahum min aulīyā’ihim fi 'l-ġaiy man [...] yamidd ilā wa'dihim al-makdūb akuff al-iqtị̣ā' wa-'listihbbār [wa-lacallahū al-intiğāz]“, (Mağmūc rasā’il muwaḥhidīya, S. 29) ,id lā murāda min ahl ad-dunyā illā tauba yuṣaddiqūnahā wa-'aqīida bi-'l-īmān yuhạqqiqūnahā wa-yad bi-'ț-țăca yamiddūnahā ilā aš-šarī̌a wa-yulqūnahā“".

Dem Ausstrecken von Armen sowie dem Recken von Hälsen kann auch - im wörtlichen Sinne des Wortes - das Hinschnellen von Schlüsseln einer bestimmten Einstellung u. ä. entsprechen: (Raihạānat al-kuttāb, Bd. 2, S. 16) „Allāh [...] allad̄ī nulqī ilā at-tawakkul 'alaihī maqālīd al-i'timād wa-namudd ilā inğādihī aidī al-i'tidād“ - d. h. ,auf Seinen

\footnotetext{
${ }^{744}$ Diese Vorstellung begegnet uns bereits in der Redewendung „hadihī yadī laka“ (Mağma' al-amtāl, Bd. 2, S. 388), womit die Unterwerfung unter den Willen dessen, demgegenüber sie ausgesprochen wird, zum Ausdruck gebracht wird.
} 
Beistand allein vetrauen wir“. „Maqālīd“ ist dabei um synonyme oder ähnliche Wörter erweiterbar: (Mağmū' rasā’il muwaḥhidīya, S.203) „fa-alqaū (aiy a'dā’ al-muwaḥhidīn) bi-maqālīdihim wa-ašțānihim ilā mug̉wīhim al-muḍill“ - möglicherweise hat in diesem Kontext „aštān”“ die Bed. „Hände“ bzw. „Arme“, denn in eben dieser Bed. kommt auch das Synonym von „ašțān“, nämlich ,asbāb“, im folgenden Zitat vor (Mağmūc rasā’il muwaḥhidīya, S. 108) „wa-'qtaḥamū (aiy al-muwaḥhidūn) as-sitāra 'alaihim (aiy ‘alā ahl Gafṣa) wa-dahualūhā 'anwatan 'alā șudūrihim [...] wa-'aḍḍathum al-ḥarb hunāk bianyābihā fa-maddat al-ḥutūf 'alaihim bi-asbābihā" - hier liegt die Bed. „Hände“ bzw. „Arme“ nahe, da die genannten „Todesgeschicke“ als Lebewesen aufgefasst werden, siehe hierzu die entsprechenden Einträge im Kapitel „Körperhaftigkeit bzw. Konkretheit des Abstrakten“. Keine negative, sondern neutrale Bedeutung hat „sabab“ hingegen im folgenden Zitat, wo es synonym zu „yad“ gebraucht worden zu sein scheint: (Șubḥ, Bd. 7, S. 107) „(bei der Beglückwünschung von Abū-'Inān Fāris zur Einnahme Tilimsans, die ihm Ibn-al-Hatịb aus Chella zukommen ließ) wa-in lam yubāšir al-`abdu al-yad al'ālīya bi-hadāa al-hanā' wa-[lam]-yatamattal baina yadaiy al-ḩilāfa al-'aẓima as-sanā wa's-sanā' wa-[lam] yamudd bi-sabab al-bidār ilā tilka as-samā' fa-qad bāšara bihī (aiy bi'1-hanā’) al-yad allatī yahinn maulaiy li-tadakkur taqbīlihā““. Das „,von-sich-Schleudernder-Schlüssel“ für sich allein kann die Bedeutung ,sich ergeben, den weiteren Widerstand aufgeben“ haben: (Mağmū rasā’il muwaḥhidīya, S. 175) ,ilā an waṣalū (aiy al-muwaḥhidūn) Milyāna [...] fa-alqā ahluhā wa-qabā'iluhā ilaihim bi-'l-maqālīd“"- hier synonym zu ,istaslamū“. Identische Bedeutung kann die gleiche Wendung haben, wenn man „die Schlüssel“ durch „die Zügel“ ersetzt: (Mağmū` rasā’il muwaḥhidīya, S. 195 f.) „wa-ustunqidatat Nafzāwa wa-Qasṭîlīya [...] min wabaš al-fitna [...] wa-alqat bilād Nafzāwa wa-Tauzar wa-Taqyūs wa-'1-Hamma bi-azimmatihā“. Mit „die Zügel“ scheint auch „die Macht über etwas bzw. Beherrschung einer Sache“ konnotiert zu werden, denn (Raihạānat al-kuttāb, Bd. 2, S. 400) „wa-hūwa al-ān qāḍi al-ğamā'a wa-imāmuhā wa-qaiyim aš-šarī‘a allatī fĩ yadaihī zimāmuhā“‘.

Auch die Vorstellung, man binde die Hand eines bestimmten Gefühls bzw. einer Haltung an ein Objekt, kann zum Ausdruck bringen, dass man dieses Gefühl bzw. diese Haltung gegenüber einem Objekt hegt bzw. ihm entgegebringt: (Mağmū'a ğadīda, Bd. 1, S. 203) „(bei der Schilderung der Ergebnisse der Schlacht von Alarcos) wa-inna min aẓhar al-āyāt [...] ḥuṣūl al-ma‘āqil allatī kāna al-kafara šaddū 'alaihā yad aḍ-ḍanāna wașarafū ilaihā himmat al-'ināya wa-'ṣ-șiyāna“ - „Festungen, die dem Feind außerordentlich viel wert waren“, (Raihānat al-kuttāb, Bd. 1, S. 343) „wa-'qtadainā 
bikum wa-bi-salafikum fī tarfī‘ qadrihī (aiy qadr Ibn-Marzūq) wa-sauwag̉nā li-mustafīd al-'ilm maurid ifādatihī wa-šaddadnā 'alaihī yad al-ig̉tibāt fì ibdā'ihī wa-i'ādatihī'“, (Raihānat al-kuttāb, Bd. 1, S. 65) „wa-šadda (aiy as-sultān an-naṣī) yad al-ig̣tibāṭ 'alā qurbihī (aiy qurb šaih al-guzāt) mustamniḥan minhū bi-'r-rai'y as-sadīd wa-mustanidan min wuddihī ilā ar-rukn aš-šadīd“ - ,j-n unüberbietbar wohlwollend behandeln“; (Mağmū' rasā'il muwaḥḥidīya, S. 8) ,wa-antum [...] aulā man šadda 'alā had̄ā al-amr [...] yad al-mutamassik wa-aḥalla nafsahū baḥbūḥat had̄ā al-mansik" - hier in der Bed. „sich zum Almohadentum bekennen“.

Die Ehrlichkeit und Echtheit von Gefühlen wird anhand des Bildes von einer Quelle mit lauterem und wohlschmeckendem Wasser zum Ausdruck gebracht: (Raiḥānat al-kuttāb, Bd. 1, S. 187) „wa-auğaba at-tárīf bihī (aiy bi-'l-fath) wudd fī sabīl Allāh atyaab min al'aḍb az-zulāl wa-ḩulūṣ yataḍā'af 'alā marr al-aiyām wa-'l-layāl'،, (Raiḥānat al-kuttāb, Bd. 1, S. 129) „wa-'indanā li-maqāmikum al-'alī wudd șafat mawāriduhū al-'aḍba wamašāri uhū““, (Raihạnat al-kuttāb, Bd. 1, S. 259) „wa-wuddunā fīhī (aiy fi 'l-maqām) taṣfū 'alā kadar az-zamān šarā'i'uhū'،, (Raihạnat al-kuttāb, Bd. 1, S. 288) „fa-qad 'alima al-ġā’ib wa-'š-šāhid [...] mā 'indanā lakum min al-ḥubb alladī ṣafat minhū al-mawārid“. Häufig wird die Aufrichtigkeit, Ehrlichkeit und Echtheit von Gefühlsbezeigungen, Einstellungen und dgl. mittels des Bildes eines Weges zum Ausdruck gebracht: (Raiḥānat al-kuttāb, Bd. 1, S. 374) „fa-aurainā fi 'š-šukr zandan wa-auḍaḥnā fi 'ț-tanā' qaṣdan“ - hier „, den Betreffenden überschwenglich und aufrichtig loben“. Ähnliche Bed. hat auch die Wendung „waḍaha al-madhab“ in ihren vielen Variationen: (Raihānat al-kuttāb, Bd. 1, S. 539) „wa-'l-i'timād 'alaikum ba'd Allāh watīq as-sabab wāḍih almadhab“, (Raihạanat al-kuttāb, Bd. 1, S. 534) „wa-'staufainā mā qarrarahū maqāmukum al-a lā bi-muqtaḍa al-wudd al-karīm al-wāḍih al-mad̄āhib“, (Raiḥānat al-kuttāb, Bd. 1, S. 529) „wa-lā zā’ida bi-faḍl Allāh [...] illā wudd yastaḥkim sababuhū wa-tašaiyu' yattaḍiḥ madhabuhū“, (Raihānat al-kuttāb, Bd. 1, S. 519) „fa-qābalnā delik bi-'š-šukr allad̄ī yattaṣil sababuhū wa-yattaḍih madhabuhū“, (Raiḥanat al-kuttāb, Bd. 1, S. 389) „wa-li-'t-tašaiyu’ fī sultạnikum al-'alī sabīl lā yaltabis“،, (Raihānat al-kuttāb, Bd. 1, S. 414) „wa-'indanā li-uhūwatikum al-karīma tašaiyu` wāḍiḥa mad̄āhibuhū“", (Raihạānat alkuttāb, Bd. 1, S. 69 f.) „yaḥūhū ilā hidmatihī at-ta'mīl wa-yabū' [?] bihī al-ḥubb allad̄ī waḍaḥa minhū as-sabīl““.

Die Vorstellung, dass die Heftigkeit und die Intensität von Gefühlen (wie z.B. Liebe, Hass, Trauer usw.) sowie von Gefühlsbezeigungen mit dem Feuer etwas Gemeinsames habe, ist häufig und ist auch europäischen Sprachen nicht fremd: (Raiḥānat al-kuttāb, 
Bd. 1, S. 299 f.) ,wa-sauwala lahum (aiy li-'r-rūm) aš-šaițān kiyādat tagir al-Iskandarīya [...] li [...] yaḥūlū baina al-muslimīn wa-baina maḥaț̣ auzārihim wa-ḥağğghimim wamazārihim wa-bait rabbihim allad̄ī yuṭ̂i’ūn bi-ziyāratihī min aš-šauq kull ḥarīq“", (Raihānat al-kuttāb, Bd. 1, S. 144) „,wa-arsalū (aiy an-naṣārā) min ad-dumū̄ muznan wa-šaqqū ğuyūbahum asafan wa-ạ̣ramū qulūbahum talahhufān“, (Mağmū‘ rasā’il muwaḥhidīya, 225) „wa-'l-kafara munḥağizūn fī ḥuṣūnihim al-ašība [...] yaḥnūn ḍulū'ahum 'alā ğạ̣īm al-ḥasra al-muḍṭarima al-multahiba“", (Raihạnat al-kuttāb, Bd. 1, S. 192) ,fa-ubīhat minhā (aiy min madīnat Uțīira) aḍ-dimār wa-aḩadahā ad-damār [...] wa-šufìyat min dimā’ ahlihā aḍ-ḍulū' al-ḥirār“،, (Rasā’il wa-maqāmāt andalusīya, S. 81) „wa-fī baqā'ika mā yafsah al-mağāl wa-yadfa' al-auğāl wa-ya'fī 'alā atr al-lau'a wayusakkin uwār tilka ar-rau'a“, (Mağmū'a ğadīda, Bd. 1, S. 252) „wa-'ağğala almuwaḥhịūn ilaihim (aiy ilā a'dā’ihim) fa-waradū Qābis wa-'l-aṛ̣ tuḥraq min ba'sihim“, (Mağmūc rasā’il muwaḥhịīìa, S. 44) „wa-țaraqa al-ašqīyā’ al-mad̄kūrīn min qāṣimat zuhūrihim mā țaraqa wa-'šta'alat lahā (aiy li-'l-bai'a) nār al-ḥasad baina ḍulū'ihim fa'Itahaba šuwāẓuhā wa-'ḥtaraqa“, (Mağmūc rasā’il muwaḥhidīya, S. 232) „fa-'qtadaḥa fīhā (aiy fī ma'āqil al-kafara) zand al-istiḩāra 'alā al-hadm wa-'l-'imāra“", (Raiḥ̄anat al-kuttāb, Bd. 1, S. 374) „fa-aurainā fi 'š-šukr zandan wa-auḍaḥnā fi 't-ţanā' qaṣdan“, (Raiḥ̄ānat alkuttāb, Bd. 1, S. 474) „,fa-innanā bi-ḥasab al-wudd al-watīq 'aqduhū al-mūrā zanduhū“،, (Maqāmāt al-Ḥarīrī, S. 89 f.) „ra’aitu gulāman [...] wa-qad i'talaqa šaih bi-rudnihī yadda'̄̄ annahū fataka bi-'bnihī [...] wa-'l-ḩiṣām bainahumā mutațāyir aš-šarār", (Maqāmāt al-Ḥarīrī, S. 160) ,laḥaẓtu fī bacọ maṭāriḥ al-bain [...] fityatan [...] wa-hum fī mumārāt muštaddat al-hubūb wa-mubārāt muštaț̣at al-ulhūb“. Diese Intensität kann auch mittels der Schärfe eines Schwertes wie folgt umschrieben werden: (Raiḥānat alkuttāb, d. 1, S. 305) ,wa-al-ḥamd li-'llāh kamā hūwa ahluhū fa-lā fạ̣la illā fac̣lahū wa'indanā i'tidād karīm lā zāla yurhaf fĩ sabīl Allāh ḥadduhū wa-nartaqib fỉ 'z-ẓuhūr 'alā

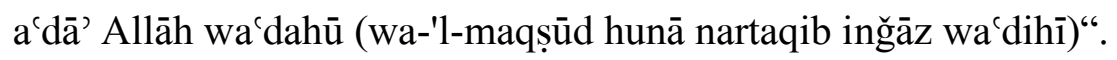

Emotionale Ergriffenheit: (Riḥlat Ibn-Ğubair, S. 200) „tumma tamādā (aiy al-ḩațīb) fī wa' ẓihī ilā an aṭāra an-nufūs hišyatan wa-riqqatan wa-tahāfata 'alaihī al-a'āğim mu'linīn bi-'t-tauba wa-qad țāšat albābuhum wa-dahalat 'uqūluhum“, (daselbst, S. 203) „wa-mā zannuk bi-mauqif yunāğā bi-'t-taudī‘ fīhī saiyid al-auwalīn wa-'l-āharīn [...] innahū lamauqif tanfaṭir lahū al-af'ida wa-tațīš bihī al-albāb at-tāàita al-mutta’ida“ - „tâšat alalbāb“ ist demnach durchaus positiv belegt, und es bezeichnet hier einen Zustand, der von heftigen Emotionsausbrüchen gekennzeichnet ist und in welchem die betreffende Person seinen Emotion nachgebend die ihr eigene Gesetztheit und würdevolles 
Auftreten „abstreift“. Auch andere, sonst negativ konnotierte Begriffe wie „sakra“ z. B. können in einem bestimmten - häufig religiösen - Kontext eine positive Bedeutung annehmen, denn (Riḥlat Ibn-Ğubair, S. 224 ff) „wa-gāadara (aiy al-ḩațīb ba`d hiṭbatihī) al-kull mutanaddiman 'alā nafsihī muntahiban [...] wa-kull minhum ba'du min sakratihī mā șaḥā"، Allgemein fällt auf, dass als besonders gelungen solche Predigten gelten, die den Zuhörer in einen Zustand der starken emotionalen Erregung versetzen, in welchem er seine gewohnte Gesetztheit verliert und in Tränen ausbricht, so heißt in Raihānat alkuttāb (Bd. 2, S. 367) „wa-hūwa al-ān huaṭị bihā yuharrik al-ğāmi` wa-yuqarriz almasāmic wa-yursil min al-ğufūn al-madāfic“‘.

Ausdruck von Gefühlszuständen mittels Werkzeuge: (Mağmū̌ rasā’il muwaḥhidīya, S. 45) „fa-qaṣadūhū (aiy qaṣada ahuwān al-mahdī wa-atbācuhum aš-šaih Abā-Ḥaf̣̣ 'Umar Ibn-Tafrāḡīn) 'inda huurūğihī ilā al-ğāmic wa-qad a'adda li-ṣalāt aṣ-ṣubḥ 'uddat al-muhbit al-ḩāši` [...] wa-'rtadā min at-ṭamānīna ridā’ as-sākin bi-qarārihā ar-rātic““.

$\mathrm{Zu}$ weiteren Konzepten von emotionalen Empfindungen siehe die entsprechenden Zitate im Kap. „Kleider und Gewänder“.

\section{Kleider und Gewänder}

Ein Zustand - hierzu gehören z. B. Gefühlszustände sowie körperliche Zustände, charakterliche Verfasstheit, Haltungen gegenüber anderen - kann durch das Bild, man sei in das Kleid o.ä. einer bestimmten seelischen oder auch körperlichen Verfassung „eingehüllt‘“, wiedergegeben werden ${ }^{745}$ : (Maqāmāt al-Harīīī, S. 289) „wa-a ciddū li-'rriḥla i'dād as-su'adā’ wa-'ddari'ū ḥulal al-wara““, (Maqāmāt al-Ḥarīrī, S. 198 f.) „'unīytu mud [...] 'araftu qabīlī min dabīrī bi-an uṣgìi ilā al-cizạăt [...] li-ataḥallā bi-maḥāsin alahllāq“, (Raiḥānat al-kuttāb, Bd. 2, S. 254) „wa-ṭala'cnā Buršāna [...] fa-ḥaiyatnā bibawākir al-ward wa-naḍat 'annā burūd al-bard“, (Maqāmāt al-Ḥarīrī, S. 352) „fa-lammā qaḍainā aṣ-ṣalāt [...] baraza šaih bādī al-laqwa bālī al-kiswa wa-'l-qūwa“, (Maqāmāt alHarīrī, S. 185) „ilā an 'arāhū (aiy Abā-Zaid as-Sarūḡī) maraḍ imtadda madāhū wa'araqathū mudāhū ḥattā kāda yaslubuhū taub al-maḥyā“, (Raiḥānat al-kuttāb, Bd. 1, S. 469) „fa-innanā lammā warada rasūlunā [...] munbi'an 'ammā kāna alamma bi-ahīnā [...] tumma bimā manna Allāh bihī min mưāfăt al-mağd bi-mucāâtihī wa-i ādatihī min libās aṣ-ṣị̣ḥa ilā afụal 'ādatihī“", (Raiḥānat al-kuttāb, Bd. 1, S. 487) ,ammā bacd ḥamd Allāh

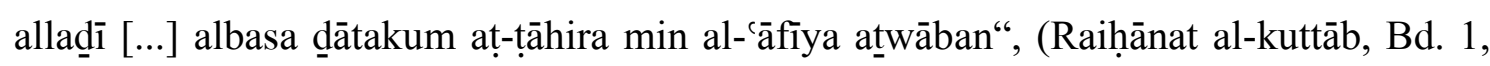

\footnotetext{
${ }^{745}$ Diese Vorstellung ist bereits in den folgenden Redewendungen belegt: „Labistu lahū ğilda an-namir“ (Mağma' al-amtāl, Bd. 2, S. 180), „man labisa ya'san 'alā mā fātahū wadda'a badanahū (Mağma' al-
} 
S. 196) „fa-lam yablug al-'afā min madīna ḥāfila wa-'aqīla fị ḥulal al-mahạāin rāfila mā balag̉a min hadihī al-bā'isa allatī [...] ḍafat 'alā a'ṭāfihā malābis al-ḩiḍlān“, (Raiḥānat alkuttāb, Bd. 1, S. 194) ,fa-dāfa'ū (aiy al-muslimūn) man aṣhara ilaihim min al-fursān [...] ḥattā ahğarūhum fí 'l-balad wa-salabūhum libās al-ğalad“, (Maqāmāt al-Ḥarīīî, S. 109) „,tumma innī sa-anfī mā rābakum wa-astasill al-ḥaḍar alladīi nābakum“ - „ich, d. h. AbūZaid as-Sarūğī, werde euch eure Bedenken benehmen“; (Mağmū' rasā’il muwaḥhidīya, S. 80) „wa-'rtāḥat (aiy al-Andalus) bi-nafầis al-yumn wa-'1-amān fī malābis al-ḥusn wa'l-ị̣sān wa-'1-ifụāl“, (Maqāmāt al-Ḥarīrī, S. 292) „alhamakum Allāh aḥmad al-ilhām wa-raddākum ridā’ al-ikrām“, (Ṣubḥ, Bd. 7, S. 71) ,ammā ba'd ḥamd Allāh [...] mutadārik hadihī al-umma al-muḥammadīya bi [...] ar-raḥma allatī maddat 'alā an-nufūs wa-'l-amwāl wa-'l-ḥurumāt wa-'l-ạ̣wāl ḍāfī ruwāqihā““ - hier „,die Gnade Gottes, die auf das Aufgezählte sich erstreckt, es in den Kreis ihrer ersprießlichen Wirkung einschliesst“", (Raihānat al-kuttāb, Bd. 1, S. 172) „wa-qāmū (aiy āl Muḥammad) bisunnatihī [...] ḥattā danat al-ġuṣūn li-'l-qātịf wa-'ḩtālat al-milla min tịyāb al-'izz fī abhā al-mațārif“, (Maqāmāt al-Ḥarīrī, S. 286) „wa-sa'aitu wa-mā wanaitu ilā an ḥaṣala 'indī al-bait fa-lammā naqaltu ilaihī qandī [...] 'uğt ilā al-ḥammām 'alā al-atar fa-amaṭ̂ 'annī wa'țā' as-safar“" - synonym zu „wa-'rtaḥt min ta'ab as-safar“", (Maqāmāt al-Ḥarīrī, S. 497 f.) (als der Erzähler in einer kalten und dunklen Nacht von einem gastfreundlichen Beduinen zu anderen Reisenden, die sich am Feuer wärmen, geleitet wird) „wa-ahad̄tu ma’ḩadahum fi 'l-iștịiā' wa-wağadtu bihim wağd at-țamil bi-'ṭ-ṭilā' wa-lammā an sarā alḥaṣar wa-'nsarā al-ḩaṣar utīnā bi-mawā'id ka-'l-hālāt"“ - wörtl. als das bzw. unser Kleid des Frostes ausgezogen war, d. h. als die Kälte aus dem Körper gewichen war, (Maqāmāt al-Ḥarīrī, S. 475) ,fa-qāla (aiy Abū Zaid as-Sarūğī) li-yasrū 'ank hammuka fa-rubba ah lam talidhū ummuka fa-'nsarā inda dalik išfāqī wa-sarā al-wasan ilā āmāqī“, (Maqāmāt al-Ḥarīrī, S. 381) „qāla al-Ḥāriț Ibn-Hammām fa-wadda'tuhū (aiy Abā Zaid as-Sarūḡī) lābisan taub al-ḩağal wa-'1-ḥazan“, (Raihānat al-kuttāb, Bd. 2, S. 41) „wa-'ağğalnā ta'rīfakum bihī (aiy bi-ḩabar maut al-malik al-qaštālī wa-hūwa muhāṣir li-Ğabal al-Fatḥ) sā'at iğtilā’ihī wa-taḥaqquq anbāihī li-tasḥabū lahū ațāb alğadal ḍāîyatan“.

Reichliches Maß an etwas kann mittels langer schleppender Gewänder bzw. Schleppen umschrieben werden, die das betreffende Objekt habe bzw. nachschleife: (Raiḥānat alkuttāb, Bd. 1, S. 537) ,wa-lā zā'ida bi-faḍl Allāh subḥānahū illā al-ḩair al-munsaḥib alburūd“", (Raihānat al-kuttāb, Bd. 1, S. 123) ,ilā an qāma bi-'l-amr [...] amīr al-muslimīn 
bi-wāğib al-ḥaqq șāḥib aḍāl al-'afāf wa-'ṭ-țahāra“ - ,etwas, hier z.B. sittliche Eigenschaften, im reichlichen Maße besitzen“, (Raihānat al-kuttāb, Bd. 1, S. 128) „famawāhib 'ināyatihī subhānahū li-ahl hadihīi al-amṣār 'alā marr al-a'ṣār ḍāfiyat al-libās“ „sind überreichlich“, (Maqāmāt a-Ḥarīrī, S. 115) „wa-huựtu as-suyūl wa-ruḍtu al-huuyūl li-ğarr duyūl aṣ-ṣibā wa-'l-marạ"“ - hier ,frönen, schwelgen, in vollen Zügen genießen“, (Raihānat al-kuttāb, Bd. 1, S. 449) „wa-Allāh yaṣil lakum asbāb as-sacāda aḍ-ḍāfiya al-aḍāal“; (Raihānat al-kuttāb, Bd. 2, S. 257) „wa-'staqbalnā arḍan šabīhatan bi-'ṣ-ṣaḥrā' [...] saḥabat 'alainā bihā as-saḥā'ibu fuḍūla aḍ-dail wa-ṭaffafa al-ġamāmu fi 'l-kail““, (Raihānat al-kuttāb, Bd. 1, S. 127) „maqām maḥall abīnā [...] abqāhū Allāh [...] yasḥab aḍāl cizzihī fī kull silm wa-ḥarb“; (Mağmū'a ğadīda, Bd. 1, S. 373) „wa-ḩarağa al-la'̄n walad al-ḡādir wa-hūwa fĩ dail al-hawān yacturc“. (Raihānat al-kuttāb, Bd. 2, S. 402) „naša'a bi-Sabta baina 'ilm yuqaiyiduhū [...] wa-ṭahāra yasḥab mațārifahā““. Bemerkenswert ist, dass in den angeführten Beispielen „dail wa-mā ma'nāhū“ und „saḥaba wa-mā ma'nāhū“ fast immer zusammen vorkommen. (Qalā’id al-'iqyān, S. 61) „fa-aqāmū (aiy al-murābiṭun) 'alaihā (aiy 'alā Qurțuba) šuhūran wa-arhaū min muhạșaratihā wa-'t-taḍyìq 'alaihā sutūran“ - d. h. belagerten und bekriegten Cordoba heftigst.

Auch die Aussage, man hänge einer Partei an bzw. man bekenne sich zu einer bestimmten Anschauung, kann auf die oben beschriebene Weise erfolgen: (Mağmū̌ rasā'il muwaḥhịīya, S. 2) ,wa-inna an-ni'ma [...] bi-haḍihī al-futūḥ al-'amīma al-'āmma šāmilatun 'alā man aḩaḍa bi-had̄ā al-amr al-'azīz wa-dān wa-tazaiyā bi-ḥullatihī (aiy biḥullat al-amr) al-bahīya wa-'zdān“, (Mağmūc rasā’il muwaḥhịīìya, S. 184) „wa-kāna haulā' al-ašqīyā' al-mutamarridūn wa-'l-kafara al-munḩali'ūn min taub al-islām almutağarridūn“; (al-Mann, S. 290 f.) ,fīhā (aiy fi 's-sana al-mu'arraḩa) hada'at al-fitan fi 'l-'udwa wa-ṣalaḥat al-buldān wa-'rtafa'at al-ḥurūb [...] wa-'nqaṭa'at fitnat aḍ-ḍullāl alğuhhāl ahl al-ğibāl [...] fa-ṣafat li-amīr al-mu'minīn [...] mašārib hadihī al-ğibāl min alfitan wa-ġasala al-amr al-'azīz wa-'l-qahr bi-țā'atihā tịyābahā min danas an-nifāq wa-'ddaran“.

\section{Wohlgerüche}

Das Ruchbarwerden von Nachrichten sowie ganz allgemein das Bekanntwerden von sehr häufig erfreulichen - Inhalten kann als Verbreitung von Gerüchen umschrieben werden: (Raihạanat al-kuttāb, Bd. 1, S. 177) „wa-'l-ğihāt bi-šad̄ā al-fatḥ tata'atṭar“, 
(Raihāanat al-kuttāb, Bd. 1, S. 240) „wa-bašā'ir tasrī fi 'l-āfāq masrā an-nasīm“, (Raihānat al-kuttāb, Bd. 2, S. 372) „wa-'uqidat 'alā ḥubbihī (aiy 'alā ḥubb fulān) aḍ-

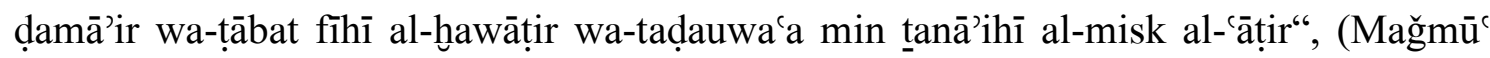
rasā’il muwaḥhidīya, S. 191) „(im abschließenden Teil des Briefes) „wa-'f́amū arğā'akum bi-raiyāhā (aiy bi-raiyā an-ni'am) al-'abiq wa-natrihā'،, (Raiḥānat al-kuttāb, Bd. 1, S. 519) ,antum aulā man nuthifuhū bi-țỉb raiyāhā (aiy raiyā al-bišāra) wa-nuṭlic 'alaihī ğamīl muhaiyāhā“‘.

Genuß des Genehmen als sinnliche Wahrnehmung von Wohlgerüchen: (al-Mann, S. 237) „(nach dem Sieg über die antialmohadischen Aufständischen) wa-aqāma almuwaḥhidūn [...] bi-a lā dalik al-ğabal yaumain yataqarraun baqāyāhum wayatatabba'ūn qilālahum wa-yağma'ūn aslābahum wa-yanka'ūn fīhim mutanassimīn min 'awā’id Allāh al-ğamīla nawāsim takmīl al-fatḥ“ - hier „sich einer Sache erfreuen“, (Qalā'id al-'iqyān, S. 46) „fa-aqāmū lailatahum (aiy fī had̄ā al-mağlis) mā țaraqahum naum wa-lā 'arāhum 'an ṭīb al-lidِdāt su'm“،, (37 alm.Briefe, S. 216) ,arat as-sa'āda liqabā'il 'Auf wa-'ššSarīd min Sulaim [...] muhaiyāhā wa-anšaqathum rā'iḥatahā al-'abiqa wa-raiyāhā“, (Ṣubḥ, Bd. 7, S. 98) „fa-kullamā wafada 'alaihī (aiy 'alā al-'abd) min ṣaḥāifihā (aiy min șaḥāîf al-matāāba al-wātiqīya) al-mukarrama wāfid [...] fa-qad ğaddada az-zamān 'indahū yadan garrā’ wa-aṭla'a 'alaihī badran wa-afādahū min alibtihāğ mā ya'mur al-ḩalad wa-yanšur nasīm al-istibšār id̄ā sakana wa-rakad“, (Raiḥānat al-kuttāb, Bd. 1, S. 129) „wa-'l-alsun bi-šukrihā (aiy bi-šukr al-masarra) mādiha wa-'nnufūs fi 'ntišāq rayāhā wa-mu'ātā muhaiyāhā taṣil al-yaum al-gāāī bi-'1-laila al-bāriḥa“ hier „Wonne empfinden über eine Sache“, (al-Mann, S. 243) „wa-miqdār had̄ā al-fatḥ al-muṣannaf wa-'n-naṣr al-mufannan [...] wazn mīzānihī mā lā taqūm bihī aqwāl alqā̄ilīn wa-lā yablug hạīiatahū iṭnāb al-muṭnibīn li-annahū ğāàa min nafaḥāt raḥmat Allāh tacālā allatī tuṣīb bihā man yašā' min 'ibādihī‘

\section{Zeitangaben}

Die Zeit, zu welcher jemand etwas unternimmt, kann dadurch umschrieben werden, dass der Betreffende das Reittier bzw. den Reittierrücken einer bestimmten Zeit bzw. Stunde besteigt: (Raiḥānat al-kuttāb, Bd. 1, S. 131) „rakibat ilaihā (aiy ilā tilka almadīna) as-sarāyā ẓahr al-lail““, (daselbst, Bd. 1, S. 169) „wa-alfainā qāṭinahā qad wallā haraban wa-'ttaḩada al-lail ğamalan“, (al-Bayān al-muġrib, S. 179) „wa-'1-'adūw qad alqā a bā’ahū wa-ḩaffafa rạ̣lahū wa-farraqa rağlahū wa-šammara li-'l-firār dailahū wa'ttaḩada al-lail ğamalan". 
Diese Zeitangaben können auch mittels der Vorstellung ausgedrückt werden, der Betreffende sei mit der jeweiligen Zeit umhüllt: (Mağmū rasā’il muwaḥhidīya, S. 196) „wa-kānat bi-Tūzar minhum ğamā'a damīma fa-'ddara'a ba'ḍuhum al-lail wa-farrū“", (Maqāmāt al-Ḥarīrī, S. 474) „fa-'rta'tu li-iẓlāl aẓ-ẓalām wa-'qtihāàm ğaiš Ḥām wa-lam adri a akfitu adِ-dail wa-artabiṭu am ag̉tamidu al-lail wa-ahtabiṭu“, (Maqāmāt al-Ḥarīrī, S. 298 f.) „fa-kaifa aflatta wa-'alā aiy wașfaik ağfalt fa-qultu ittaḩadtu al-lail qamīṣan wa-adlağtu fīhī ḩamīṣan“.

\section{Halsketten, Zusammengefügtes $u$. ä.}

Das Bild der Halskette - auch als ein Sinnbild für Vollkommenheit nicht unüblich -, bei deren Auseinanderreißen ihre einzelnen Perlen verstreut bzw. bei deren Zusammensetzung diese Perlen aneinandergereiht werden, ist im literarischen Schrifttum im Maghreb des Mittelalters häufig. Nicht selten wird durch das Auseinanderreißen der Kette zum Ausdruck gebracht, etwas, z.B. eine Festung, Stadt und dgl., kündige einem Herrscher den Gehorsam auf oder aber, bei der Zusammensetzung, werde ihm botmäßig. Eng damit hängt auch die häufig implizite Vorstellung zusammen, eine befestigte Stadt, Gegend usw. sei eine der Halskettenperlen. Hierzu folgende Beispiele: (Raihānat al-kuttāb, Bd. 2, S. 70) „waqaddamahū (aiy qaddama as-sulțān al-andalusī) [...] šaiḩa al-g̉uzāt al-muğāhidīn [...] bimadīnat Mālaqa [...] uht ḥaḍrat mulkihī wa-țānīyat ad-durra at-țamīna min silkihī wadār salafihīi“, (Mağmū' rasā’il muwaḥhịīiya, S. 190) „(nach der Rückeroberung von Gabès durch die Almohaden) wa-qad țahharahā (aiy madīnat Qābis) Allāh bi-'ntiẓāmihā fĩ silk at-tauhịid wa-i'ādatihā ilā hadāa al-amr as-sa'îd“", (Qalāid al-iqyān, S. 64) „walammā tamma fi 'l-mulk amaduhū (aiy amad al-Mu'tamid Ibn-'Abbād) [...] nāzalathū ğuyūš amīr al-muslimīn wa-mahallātuhū wa-ẓāharathū fasāṭituhū wa-miẓallātuhū ba'damā natarat ḥuṣūnahū wa-qilā'ahū“ - hier „nachdem diese almoravidischen Heere dem al-Mu'tamid Ibn-'Abbād seine Festungen usw. entrissen hatten“, (Raihānat alkuttāb, Bd. 1, S. 368) „,wa-dahama (aiy al-'adūwu) al-ğiha allatī bādarat ilā al-i'tiṣām biḥimā mulkikum wa-'l-intizāam fị silkikum“, (Raiḥānat al-kuttāb, Bd. 1, S. 138) „wa-mā yuğāwiruhū (aiy mā yuğāwir hịịna Qanīt) min al-ḥuṣun bi-sababihī (aiy bi-sabab hịị̣n Qanīt) in šā’a Allāh yantatir silkuhū wa-yatayassar mulkuhū“ - hier ,wird (der Herrschaft des Feindes) entrissen und wird Euch botmäßig“ oder (daselbst) „wa-hūwa (aiy hịṣn Qanīt) mabda’ al-ḥuṣun allatī fĩ silkikum ar-rafī‘ bi-ḥaul Allāh tantaẓim“, (Kitāb a'māl al-a lām, S. 243) „wa-lammā istaulā malik Qaštāla Iḍuunš Ibn-Farḍiland 
'alā madīnat Ṭulaiṭila dār mulk ar-rūm wa-'alā at-tağr al-ğaufī wa-'ntaẓamat lahū albilād“ - ,als ihm die Städte botmäßig wurden“, (Mağmū' rasā’il muwaḥhịidìya, S. 74 f.) „wa-aqāma al-muwaḥhidūn bi-ẓāhirihā (aiy bi-ẓāhir al-qaṣaba allatī tạ̣aṣṣana fīhā alkafara) al-muṭill [...] masrūrīn bi-rafa'at al-ḥ̄āl wa-'1-mahall mustabširīn bi-'ntitāar dalik an-naẓm al-munhall““ - hier „sich freuend auf die bevorstehende Inbesitznahme dieser Zitadelle“, welche wohlgemerkt nicht mehr mit einer Perle, sondern mit einer ganzen Perlenschnur gleichgesetzt wird. Weiteres Bsp., das sich auf die gleiche Begebenheit bezieht, (Mağmū' rasā’il muwaḥhidīya, S. 75) ,wa-lammā ittaṣala bi-Ibn-Mardanīš mā hālahū min had̄ā an-naba' [...] ra'ā an yanhaḍ bi-ğumlatihī al-bā'isa 'alā nīyat al-giyāt wa-mubādarat hailihī qabl al-intiqāọ wa-'l-intikāt (aiy qabl intiqāọ wa-'ntikāt an-naẓm al-mutamattil fi 'l-qaṣaba al-maḍkūra)“, (Raihạnat al-kuttāb, ohne Beleg) „(bei der Schilderung der Wiedereinverleibung einer ehemals den Muslimen botmäßigen Stadt, die danach christlich geworden und nun durch Muslime wieder erobert werden konnte) 'arrafnākum mā an'ama Allāh [...] min fath Burg̉a fa-aṣbaḥa aš-šaml ğamī'an wa-'1mantūr manzuūman wa-'s-sabīl qaṣdan wa-'l-furqa ğam'an“" - nota bene, dass hier das Verhältnis ,Zusammengefügtsein vs. Zerstreutsein“ gleich dreifach thematisiert wird.

Vor dem Hintergrund der angestellten Überlegungen wird meiner Meinung nach das folgende Beispiel verständlich: (Mağmūc rasā’il muwaḥhidīya, S. 195) (bei der Wiedereroberung der Städte Ifrīqīyas durch die Almohaden bei ihrem Feldzug dorthin im Jahr 1187) „wa-'indamā šārafa al-muwaḥhidūn [...] al-ğihāt al-maḍkūra ğāàat alfutūḥ tubārī fĩ šaddihā wa-tunaẓẓim laālī’ al-aqțār al-ğarīdīya fị (iqdihāa - auch hier der Vergleich einer Stadt mit einer Halskettenperle.

Auch die Tatsache, dass jemand im Dienste eines Königs steht, kann durch das Bild der Halskette ausgedrückt werden: (Raiḥānat al-kuttāb, Bd. 2, S. 403) „wa-kataba (aiy fulān) 'an ba'ḍ mulūkihā ('an mulūk al-bilād al-andalusīya) wa-'ntaẓama fĩ sumūtịā arrafī‘a wa-sulūkihā“ - hier ,der beschriebene Literat stand im Dienst einiger Herrscher als Schreibers".

Konzepte der Wohl- und Miss-stände: Die gleiche Halsketten-Vorstellung kann allgemein auch einen „unperfekten, nicht-wünschenswerten und misslichen Zustand“ bzw. dessen Gegenteil zum Ausdruck bringen: (Raihānat al-kuttāb, Bd. 1, S. 262) „munșarifain 'an muhaiyam at-ṭāgīya ba'da mā qūwiḍat riḥāluhū wa-ḥālat hāâhū waḥumma halākuhū wa-'ntatarat aslākuhū“، - hier wird auf den infolge der grassierenden Seuche eingetretenen Tod des christlichen Herrschers bei der Belagerung Gibraltars Bezug genommen. Vor dem Hintergrund dieser Überlegungen liegt die 
Schlussfolgerung nahe, dass das Zusammengefügtsein eines - meistens abstrakten Objektes bzw. Sachverhaltes dessen als vollendet, vollkommen und unter Umständen als gottgewollt empfundene Verfasstheit zum Ausdruck bringt, während die Auflösung des zusammenhaltenden Moments dieses Objekts und infolgedessen seine Auflösung einen Missstand im weitesten Sinne des Wortes ausdrückt, denn (Raqm al-ḥulal, S. 108) „qāma (aiy auwal mulūk banī Naṣr) wa-šaml ad-dīn fị šatāt wa-'r-rūm tastaulī 'alā alğihāt fa-nu'iša ad-dīn bihī (aiy bi-auwal mulūk banī Naṣr) lammā 'atara wa-nuẓima assilk wa-qad kāna intatara“ - daraus ersieht man gleich drei Konzepte des als vollkommen empfundenen Zustandes: erstens, Gemeinschaft statt Trennung und Zerstreuung, zweitens, das Sich-Erheben nach dem Stolpern und schließlich drittens, das Zusammengefügtsein gleich den Perlen einer Halskette, (Ṣubh, Bd. 7, S. 75) „(bei der Beglückwünschung wahrsch. des merinidischen Machthabers zur Einnahme Beğāyas) wa-qad waṣala kitābukum alladīi akkada as-surūr wa-așṣalahū wa-ağmala muqtaḍā al-bušrā wa-faṣṣalahā [...] tưarrifūn mā atāḥa lakum al-laṭif al-ḩabīr wa-'1walīy an-naṣīr min aṣ-ṣun` allad̄i ittasaqa niẓāmuhū“ - ,in diesem Schreiben setzen Sie uns über das vollkommene Eingreifen Gottes zu Ihren Gunsten in Kenntnis“. Das Halsketten-Konzept wird auch im folgenden Zitat thematisiert: (Mağmū'a ğadīda, Bd. 1, S. 458) „wa-innā katabnāhū (aiy had̄ā al-hitāo) kataba Allāh lakum wa-li-aḥwālikum intiẓāman wa-'Iti’āman“ - hier „Gott möge euch zu eurem Wohl verhelfen und eure Lebensumstände zu eurem Besten fügen“; (Raiḥānat al-kuttāb, Bd. 1, S. 305) „wa-lā zā’ida bi-faḍl Allāh al-laṭịf al-ḩabīr illā [...] as-surūr li-'l-islām 'alā yadikum bi-ğam` aššatīt wa-naẓm an-natīir“ - hier bed. es sinngemäß, dass der erwähnte Herrscher dem Islam aus dem politischen Miss-stand, in dem er sich befunden hatte, wieder zum vollendeten Wohl-Stand verholfen hat, (Mağmū'a ğadīda, Bd. 1, S. 489), ,adāma Allāh ṣalāh aḥwālihim wa-'ntiẓām umūrihim“ - beachtenswert ist hier die Parallele zum obigen Beleg in (Mağmū'a ğadīda, Bd. 1, S. 458), denn daraus geht m.E. hervor, dass „șalāḥ“ und „intiẓām wa-mā ma`nāhū“ bedeutungsgleich sein können. (Mağmū'a ğadīda, Bd. 1, S. 494) ,wa-an ta lamū [...] annakum mūfaun min naẓarinā al-ağmal (wafi 'l-aṣl li-ağmal) mā lā yagibbukum minhū niẓām al-umūr wa-sadād al-anḥā’“, (Mağmū'a ğadīda, Bd. 1, S. 485) „kataba Allāh lakum ihtiyāran yaḥfaz nizāàm umūrikum“.

Es ist ferner interessant, dass im nachfolgenden Zitat die Vorstellung, etwas Problemhaftes werde in einer vollkommenen Weise gelöst, dem Bild einer lückenlos zusammengefügten Halskette entspringt und somit eher sich aus dem genauen Gegenteil 
unseres Konzeptes von (Problem-)Lösung“ speist: (Mağmū'a ğadīda, Bd. 1, S. 497) „hutṭat al-qaḍā' allatī tuqām bihā bainakum al-ạ̣kām wa-yattasiq bi-iğrā'ihā 'alā alqawānīn ad-dīnīya li-ğamī an-nawāzil an-niẓām“ - „durch das Innehaben des Richteramtes in der mit den islamischen Prinzipien im Einklang stehenden Weise werden die Streitfälle in vollkommener Weise gelöst“.

\section{Jugendhaftigkeit}

Der Wohl-Stand, die als vollkommene empfundene Verfassung eines beschriebenen Objekts kann auch dadurch umschrieben werden, dass es als (wieder) jugendhaft geschildert wird: (Mağmū'a ğadīda, Bd. 1, S. 336) „fa-innahū la-fatḥ min al-futūḥ allatī [...] taṣluḥ bihā aḥwāl wa-tašibb a'māruhā““, (Raihānat al-kuttāb, Bd. 1, S. 205) „,(nach der Wiedereroberung Algeciras durch Muslime) ,fa-cādat al-madīna li-ạ̣san aḥwālihā wa-sakanat min ba'd ahwālihā wa-cādat al-ḥālīya ilā amwālihā wa-rağaca ilā al-quṭr šabābuhū“, (Raiḥānat al-kuttāb, Bd. 1, S. 367 f.) ,wa-lammā ra’ā at-ṭāgīya [...] anna daulat al-islām qad ista'nafat šabābahā wa-anna Allāh fataḥa li-hadihī al-ğazīra bāban [...] šariha ilā iṭ̂ā’ nūr Allāh allad̄ī wa'ada bi-itmāmihī“, (Mağmū'a ğadīda, Bd. 1, S. 456) „wa-ladainā min istiṣhāb an-naẓar al-asadd fī umūrikum [...] mā narğū an yư̄è ilaikum ğiddat az-zamān“, (Raihānat al-kuttāb, Bd. 2, S. 389) ,,(fulān) šācir yunfiq min as-si`a [...] 'ānā an-naẓm wa-zamanuhū ka-mitlihī gulām wa-dahruhū tạ̣ìya wa-salām“، - das Verb „‘ānā (y'ānī mu'ānānatan)“ hat hier die Bed. „sich mit etwas beschäftigen, etwas studieren“, (Mağmū' rasā’il muwaḥhịīya, S. 15) „(nach dem Eingang der Huldigung aus Cordoba) wa-'staqbilū [...] bi-'l-a'māl al-barra 'umran ğadīdan“, (Mağmūc rasā’il muwaḥhịīìa, S. 80) „mubaiyinīn bi-annahā (aiy al-futūḥ) [...] muttaṣila fī 'unfuwānihā ğārīya fī maidānihā mil’a 'inānihā“،, (Mağmū' rasā’il muwaḥhidīya, S. 250) ,wa-an ta lamū anna da'wat al-imām al-mahdī [...] bihā ğaddada Allāh raya‘ān al-ḥaqq wa-hūwa hašìm“ - hier ist allerdings das Verhältnis ,jung vs. alt bzw. vertrocknet" bezogen auf die Pflanzenwelt.

\section{Mögliche Rezeptionssteuerungsmechanismen}

Es ist möglich, dass in bestimmten Zusammenhängen der Rezipient eines literarischen Textes häufig vorkommende Wendungen in bestimmten Zusammenhängen erwartet. So z.B. ist beim öffentlichen Verlesen eines Briefes über den erfolgreichen Feldzug ins Feindesland beim Zuhörer die Erwartung der Anwendung von gängigen Metaphern und Allegorien vorhanden. Nun besteht die Kunst des mittelalterlichen „Kātibs“ u. a. auch 
darin, dass er den Sinn der erwarteten Wendungen zwar nicht verändert, ihn jedoch auf unterschiedliche Weisen wiederzugeben imstande ist. Folgendes Bsp. soll das Gesagte veranschaulichen: Häufig kommt bei Ibn-al-Ḩațỉb sowie in den almohadischen Briefen die Wendung „'azā’im māḍīya“ bzw. ,al-‘azm al-māḍī“, d. h. „eiserner Kampfeswillen“, vor. Bei der Schilderung der Vorbereitungen für den Feldzug gegen die Stadt Jaen sagt er aber „wa-abramnā al-ḥazm allad̄i šaḥad̄a at-tawakkul garbahū“, hier wurde einerseits „ḥazm“ statt „'azm“ genommen und andererseits das Adjektiv „al-māḍī“ umschrieben, ohne dass der Sinn verändert worden wäre - obgleich er durch „at-tawakkul“, d. h. „,das ausschließliche Vertrauen auf Gott allein“, eine Erweiterung erfahren hat. Weiteres Bsp. hierfür (Raiḥānat al-kuttāb, Bd. 1, S. 164), „(nach der Ankunft des muslimischen Heeres bei Jaen) wa-aṣharat ilainā ḥāmīyat al-'adūw dābbatan 'an al-ḥauza mublīyatan min dūna al-'arșa mutamarrisatan bi-sur'ān al-muqaddimāt wa-rūwād manāzil al-maḥallāt" hier ist mit „sur`ān al-muqaddimāt wa-rūwād manāzil al-maḥallāt“ eigtl. „țalī'a“ gemeint. Was „mutamarrisa“ betrifft, so liegt hier m.E. eine Umschreibung vom Verb „i'taraka“ vor, dessen Ableitung ,al-mu'tarak“ samt seiner Bedeutung vor dem geistigen Auge des Rezipienten entstehen lassen sollte. Weiteres Bsp. (Raiḥānat al-kuttāb, Bd. 1, S. 165) „wa-bādarnā al-hay'a wa-qad hazzat rīḥ an-naṣr 'aḍabāt ar-rāyāt" - hier wird auf die häufige Wendung ,a lām hāfiqa“, mit welcher die Sieghaftigkeit auf dem Schlachtfeld ausgedrückt wurde, angespielt. Oder anstatt „li-fulān adab tāait“ sagt Ibnal-Ḩațīb (Raiḥānat al-kuttāb, Bd. 2, S. 374) „lahū adab muḥtakam [wa-lacallahū muḥkam] wa-manī` al-hiḍāb wa-'ṣ-șūwāa“. Weitere Beispiele sind: (Raihānat al-kuttāb, Bd. 1, S. 459) „(nach der Bekanntgabe der Niederschlagung eines antimerinidischen Aufstandes in Granada) kullamā qadaḥa al-ḩilāf zandan aṭfa’a sa'dukum šu latahū“", (Raqm al-ḥulal, S. 109) ,aṭfa'a mā' saifihī al-uwār wa-'stanzalat 'azmatuhū at-tūwār" hier wird auf die häufige Vorstellung Bezug genommen, die „fitna“ sei ein Feuer, dessen Löschung mit der Niederschlagung dieser „fitna“ gleichzusetzen sei. Siehe auch die Einträge im Kapitel „Meutereien“.

\section{Nutznießung anhand des Bildes von Euterzitzen}

Häufig ist die Vorstellung, das für jemanden wichtige Etwas, welches er nutzt bzw. von welchem er profitiert oder zehrt, sei eine Euterzitze bzw. weibliche Brust, an der er saugt. (Mağmū'a ğadīda, Bd. 1, S. 252) ,țumma 'aṭafū (aiy al-muwaḥhịīñ) min hunālikum 'alā Nafzāwa li-yataqauwatū min tamrātihā wa-yastadirrū raitamā tașiluhum amdāduhum ahlāfahā‘‘, (Mağmū' rasā’il muwaḥḥidīya, S. 56) „fa-antum bi-ri'āyat Allāh 
wa-kalā'atihī fī ğawānib al-amana rāti ūn [...] tastadirrūn ahlāfa an-ni'am istidrāran“, (Mağmū'a ğadīda, Bd. 1, S. 334) „fa-‘ammat al-bušrā mawāsiṭ hadihī al-ğihāt waatrāfahā wa-ṭafiqat al-bilād tartaḍi` tady al-amana wa-ahlāfahā“،, (Raihānat al-kuttāb, Bd. 1, S. 195) „wa-halakat bi-mahlak hadihī al-umm (aiy Ğaiyān) banāt kunna yartaḍi na tadyahā al-ḥawāfil wa-yastautirūn ḥiğrahā al-kāfil'“, (Mağmū'a ğadīda, Bd. 1, S. 454) „wa-innā katabnāhū kataba Allāh lakum [...] 'ārifa tastadirrūn ahlāfahā““, (Maqāmāt a-Harīrī, S. 265) ,(fî̀ waṣf al-wālī) manāẓim šarafihī ta’talif wa-šu’būb ḥibā’ihī yakif wa-nā'il yadaihī fậ̣ wa-šuḥh qalbihī gāọ wa-hilf sahā’ihī yuhtalab“.

Bei intransitivem Gebrauch kann damit auch die Reichlichkeit des einem Empfänger Zugutekommenden zum Ausdruck gebracht werden: (Raihānat al-kuttāb, Bd. 1, S. 284) „wa-anna rikābakum istaqarra bi-madīnat Marrākuš [...] ḥait [...] al-huutṭa al-fasīḥa ya yā 'an bulūg madāhā aṭ-ṭair wa-'1-ğibāya ad-dārrat al-ahllāf“ - hier „die Steuereinnahmen sind reichlich“, (Raihānat al-kuttāb, Bd. 1, S. 425) „fa-innanā warada 'alainā kitābukum [...] yunšì sahạ̄'ib al-ālā' hāmīyat ad-dirar“, (Raihānat al-kuttāb, Bd. 1, S. 437) ,wa-lā zā’ida bi-faḍl Allāh subhānahū illā al-ḩair al-wākif ad-dirar“. Interessant ist das folgende Zitat (Raihānat al-kuttāb, Bd. 2, S. 10) „fa-ya'lam Allāh annanā [...] lā ğuliba ilainā habar illā ahdaināhū cinda halb darrihī wa-rakkaḍnā țirfahū ba`d taqlībihī wafarrihī“ - denn hier scheint „halb darrihī“ die Bedeutung zu haben „durch Kenntnisnahme der erfreulichen Botschaft erquickt werden“. Darüber hinaus kann die obige Vorstellung auch einen negativen Sinn, nämlich ,jemanden ausnutzen, ihn schinden“, haben: (Mağmū' rasā’il muwaḥhidīya, S. 253) „wa-bainamā hūwa (aiy aššaqīy al-mayūrqī) yasūm ar-ra'̄iya bihā (aiy bi-Qābis) hasfan [...] wa-yastadirr makāsibahā al-qadīma wa-'l-ḥadīta dar'an fa-ḍar'an wa-ḩilfan fa-hilfan“, (Mağmūc rasā’il muwaḥhidīya, S. 28) „wa-man yartaḍi ašțurahā (aiy ašṭur al-bilād aš-šarqīya) min al-a'rāb [...] qad qadafathum al-ġalaba ilā ṣaḥrāìhā“‘.

\section{Bauten}

Der Islam als religiöse Auffassung oder auch die islamische Gemeinde können mit dem hohen Erbauten, Errichteten, sei es ein Steinbau oder ein Zelt, verglichen werden: (Raihānat al-kuttāb, Bd. 2, S. 9) ,ar-riḍa 'an ālihī wa-aṣhābihī alladīna rafa'ū min millatihī al-ḥanīfĩya arkānan wa-šaiyadū min macālim da`watihī bunyānan“, (Raihānat al-kuttāb, Bd. 1, S. 270) „wa-'r-riḍā 'an ālihī wa-aṣhābihī [...] alladīn rafa'ū qubbat millatihī madīdat aṭț̣nub sāmīyat al-`amūd“, (Raihānat al-kuttāb, Bd. 1, S. 128) ,wa-'r-

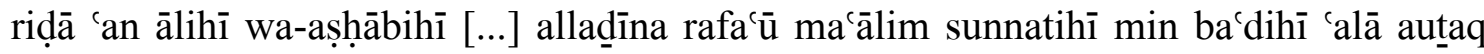


asās“, (Maqāmāt al-Ḥarīīī, S. 288) ,arsala (aiy Allāh) Muhammadan li-'l-islām mumahhidan wa-li-'l-milla muwațtidan“ - hier „um ein festes Fundament für die Stiftung der islamischen Gemeinde zu legen“, (Raiḥānat al-kuttāb, Bd. 1, S. 266) ,ammā ba'd ḥamd Allāh [...] allad̄ī man tawakkala 'alaihī wa-lağa'a ilaihī fa-qad awā ilā az-ẓill az-ẓalīl (wa-yurwā ayḍan: al-ḥiṣn al-ḥaṣīn) wa-'r-rukn aš-šadīd“, (Raiḥānat alkuttāb, Bd. 1, S. 135) „wa-'indanā [...] min at-tawakkul 'alaihī (aiy 'alā Allāh) ḥiṣn ḥaṣinn ilaihī fi 'š-šadā’id al-i'tișām“. Aus der Vorstellung, Islam sei ein hoher Bau, resultiert, dass die (absolute) Höhe dieses Baus mit der Sieghaftigkeit des Islam gleichbedeutend sei: (Raihānat al-kuttāb, Bd. 2, S. 17) „ḥattā bauwa'ū al-islām fi 'l-qawā'id aš-šahīra wa'l-bilād wa-arg̉amū unūf ahl al-ğaḥd wa-'l-ilhạād fa-aṣbaḥa rafīcu ad-dīn rafíca al-'imād“, (Raihānat al-kuttāb, Bd. 1, S. 439) ,,ammā ba`d ḥamd Allāh [...] ğāmic kalimāt al-islām li-yarfac qawācidahū wa-yu'līhā“،. Auch andere religiöse Auffassungen können als Bauten gedacht werden: (Raiḥānat al-kuttāb, Bd. 2, S. 33) „wa-hūwa subḥānahū almarğūw fĩ ḥusn al-'uqbā wa-'l-ma'āl wa-naṣr qubbat al-hudā 'alā qubbat aḍ-ḍalāl'“ und vor diesem Hintergrund wird das folgende Zitat besser verständlich (Mağmūc rasā’il muwaḥhidīya, S. 28) ,wa-'asākir al-muwaḥhidīn [...] ḥarịṣūn 'alā ġazwihim (aiy gazw al-'arab alladīn qaḍafathum al-g̉alaba ilā șaḥrā' al-bilād al-mašriqīya) fī 'uqr mawāqifihim wa-marāqib intizā'ihim [...] nāẓirūn ilā munša’āt hayāl aḍ-ḍālīn“.

Lobenswerte und erstrebenswerte Eigenschaften, Charakteristika und Attribute als Bauten: (Raihānat al-kuttāb, Bd. 1, S. 266) ,wa-'ṣ-ṣalāt 'alā saiyidinā [...] dī al-qadr arrafī‘ wa-'l-'izz al-makīn wa-'1-mağd al-mašīd“, (Raiḥānat al-kuttāb, Bd. 1, S. 416) „kataba Allāh lakum sa'dan tāabit al-arkān wa-cizzan sāmīya al-makān wa-mağdan watīi al-bunyān“, (Maqāmāt al-Ḥarīrī, S. 364) ,wa-ḥāditātin qara'at marwatī wa-qauwaḍat mağdī wa-bunyānahū“, (Raiḥānat al-kuttāb, Bd. 1, S. 65) „wa-man lahū bi-d̄ātihī wasalafihī 'ulūw aš-ša’n [...] wa-'l-ḥasab al-watīq al-bunyān“, (Maqāmāt al-Ḥarīīî, S. 265) „(fī waṣf al-wālī) manāẓim šarafihī ta’talif wa-šu’būb ḥibā’ihī yakif“, (Raiḥānat alkuttāb, Bd. 1, S. 290) ,maqām maḥall ahīnā alladīi [...] qubbat al-faḩr qad uḥkima minhā 'alā mağdihī al-ġarr [wa-'l-aṣaḥh hunā al-ag̉arra] wa-fạ̣lihī al-g̉amr taṭnībun“ - d. h. „țunnibat qubbat al-faḩr 'alā mağd had̄ā al-maqām wa-fạ̣lihī“‘ oder mit anderen Worten „qubbat al-faḩr aṣluhā mağd maqām al-maḥall wa-fạ̣luhū“، Diese Aussage, der nach alle Vortrefflichkeit (fahr) in dem Ruhm und in der Güte der marinidischen Dynastie gegründet sei, impliziert darüber hinaus, dass die merinidische Dynastie der Inbegriff dieser Vortrefflichkeit sei. (Maqāmāt al-Ḥarīīī, S. 133) „yā sādatan fi 'l-macāī lahum mabānin mašīda“, (Raiḥānat al-kuttāb, Bd. 1, S. 354) „kataba Allāh lakum 'izzatan 
mušaiyadat al-binā̄‘،, (Maqāmāt al-Ḥarīrī, S. 413), ,yā aiyuhā al-qāḍ̄i allad̄ī 'ilmuhū waḥilmuhū arsah min Raḍwā (wa-Raḍwā ğabal bi-qurb al-Madīna)“, (Raiḥānat al-kuttāb, Bd. 1, S. 230) ,al-'azā'im al-qā'ima 'alā asās al-yaqīn 'amaduhā“. Gefühle als Bauwerke: (Raihānat al-kuttāb, Bd. 1, S. 245) „wa-naḥnu 'alā mā ta'lamūna min alwudd allad̄ī istaqarrat arkānuhū“،, (Raiḥānat al-kuttāb, Bd. 1, S. 506) „fa-baina salafinā wa-salafikum al-karīm min al-wudd ar-rāsih̆ al-bunyān“; (Raihānat al-kuttāb, Bd. 1, S. 474) „fa-innanā bi-ḥasab al-wudd al-wațīq 'aqduhū al-mūrā zanduhū“ - die konzeptionelle Ähnlichkeit zwischen „Strick“ und „Bau“ geht aus der arab. Erklärung für „naqaḍa“ hervor, denn diese lautet „naqaḍa al-binā' wa-'l-ḥabl wa-'l-'ahd ḍidd abrama“.

Herrschertum als Bau: (Qalā'id al-iqyān, S. 64) ,wa-lammā tamma fi 'l-mulk amaduhū (aiy amad al-Mu'tamid Ibn-'Abbād) wa-arāda Allāh an tahirr 'amaduhū wa-tanqarị̣ ayāmuhū wa-tataqauwaḍ 'an 'irāṣ al-mulk ḩiyāmuhū“،, (Raihānat al-kuttāb, Bd. 1, S. 266) „,tumma bi-barakat al-i'tidād bi-maqāmikum as-sāmī aṣ-ṣāi id wa-'l-aṣīl al-qawāeid“", (Raiḥānat al-kuttāb, Bd. 1, S. 418) „fa-in dِahabnā ilā taqrīr mā 'indanā min at-tanā' 'alā mulkikum al-aṣīl al-binā' wa-'l-i'timād 'alā maqāmikum ar-rafī‘ al-'imād“, (Ṣubḥ, Bd. 7, S. 97) „wa-'1-ḩidma al-lāzima li-'l-matāāba al-'alīya al-wātiqìya al-mu'taṣimīya a'lā Allāh makānahā wa-šaiyada bi-'aḍudihī arkānahā farḍ lā yasa' ta’hīruhū“‘, (Raiḥānat al-kuttāb, Bd. 1, S. 288 f.) ,innanā ta'arrafnā mā kāna min qudūmikum as-sacīd 'alā ạ̣wāz Almarīya [...] wa-innakum qad ahaḍtum fī taskīn al-autān wa-tamhīdihā wa-'sti'nāf al'azā'im wa-tağdīdihā wa-ițā' nār al-fitan wa-ihmmādihā wa-i'lā' arkān tilka al-iyāla wa-

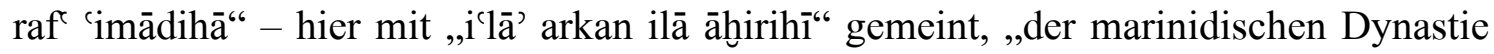
zum Obsieg verhelfen“, (al-Mann, S. 234) „kamā anna man ṣadaqa al-i'tilāq bi-ḥablihī (aiy ḥabl al-amr al-'azīz) wa-'t-tamassuk bi-ciṣamihī wa-rakana ilā dirāhū wa-āwā ilā ḥaramihī fa-qad ahadِa bi-'l-watīq min 'uhūd dimamihī“" - mit ,al-amr al-'azīz“" ist hier das Almohadentum gemeint. Auch ein aufrichtiger Gefolgschaftseid kann als ein Bau mit festem, lückenlos zusammengefügtem Fundament umschrieben werden: (Raihānat al-kuttāb, Bd. 1, S. 125) „fa-'aqadū lahū al-bai'a al-watīiqat al-asās“, (Mağmūc rasā’il muwaḥhịidiya, S. 61) „wa-tamma dalik (aiy amr al-bai'a) bi-'aun Allāh 'alā autaq mabānīhī wa-aṭlaq ma'ānīhī“،, (Mağmū' rasā’il muwaḥḥidīya, S. 62) ,wa-lamma 'stawā bi-fac̣l Allāh bunyānuhū (aiy bunyān al-bai'a) al-marṣūṣ wa-țabata 'alā aṣ-ṣidq wa-'ttalağ hạaītuhū al-manșūṣ̣“

\section{Vollendetheit und Vollkommenheit}


Die Vollendetheit eines beschriebenen Objekts ist häufig mit der Vorstellung verbunden, dessen Einzelteile seien in solch volkommener Weise zusammengefügt, dass es zwischen diesen Einzelteilen keine Zwischenräume oder „Windschiefheiten“ und dgl. gibt. Diese Vorstellung scheint bereits in Sure 67, Vers 3 vorzuliegen, wo es heißt: „mā tarā fī halq ar-Raḥmān min tafāut", d. h. „,du siehst in der Schöpfung Gottes keine Unvollkommenheiten“, sowie liegt auch den folgenden Passagen zugrunde: (Mağmū' rasā'il muwaḥhịīiya, S. 26) „(Qusanțīna) ra’s al-ğasad alladīi istatba'a ba'ḍuhū ba'ḍan wa-'statlā“", (Mağmū' rasā’il muwaḥhịidìya, S. 49) ,wa-naḥnu naḥmad Allāh 'alā dīnihī alladīi rafa'a 'alamahū [...] fa-lā halāl [...] yấrū mubramahū wa-lā naqụ ya'tawir muḥkamahū“, (Mağmū' rasā’il muwaḥhidīya, S. 68) „wa-in kānat mawaddātuhum (aiy mawaddāt al-muwaḥhidīn) al-wațīqa mauṣūlat al-ḥibāl [...] mağbūla 'alā al-iltihām wa'l-ittiṣāl“ - hier „von intakter Beschaffenheit“, (Mağmū‘ rasā’il muwaḥhịīìa, S. 62) „wa-lammā 'stawā bi-faḍl Allāh bunyānuhū (aiy bunyān al-bai'a) al-marṣūṣ wa-tabata 'alā aṣ-ṣidq wa-'t-țalağ ḥadītuhū al-manșūṣ“, (Mağmū' rasā’il muwaḥhịīya, S. 64) „wakānat ba'ḍa aiyām muḍākara min aš-šuyūh wa-'ț-ṭalaba wa-'1-'ummāl wa-man hạạara dalik al-Ġarb al-Wasaṭ fī tartībihī wa-tahdīibihī [...] fa-ra’au anna allad̄i ya'qid amrahū (aiy amr al-Ġarb al-Wasaț) bi-ma`āqid as-sadād wa-yabnī bunyānahū 'alā qawā'id alittiṣāl wa-'l-iț̣irād [...] an yakūn fī wasatịīi min al-ihwwa al-mad̄kūrīn man taskun ilaihī qulūbuhum“ - hier „das, was das Gebäude des Zentralen Maghreb auf die Grundlagen der lückenlosen Verkettung und des unausgesetzten Aufeinanderfolgens bzw. des Fließens setzt“, mit anderen Worten „das, was für die bestmögliche und vollkommene Verwaltung des Zentralen Maghreb erfoderlich ist", (Mağmū' rasā’il muwaḥhidīya, S. 69 f.) „wa-kullamā ữida 'alaihim hiṭāb [...] au ultumisa minhum 'alā faṣl min al-fuṣūl al-muqarrara (ya'nī fuṣūl min hiṭāb) ğawāb tạ̣āllat ašḩāṣuhum“ - hier bezieht sich „hum“ auf die versammelten Almohaden, an die im Zuge der Aufarbeitung eines antialmohadischen Aufruhrs eine Rede (hițāb) gehalten wird.

\section{Meutereien und kriegerische Auseinandersetzungen}

(Raiḥānat al-kuttāb, Bd. 2, S. 6) „fa-kaifa iḍā waqa'at al-fitna fī șuq inā wa-naẓarinā innamā hīya šu'la fī naqụ buyūtinā waqa'at“ - der Vergleich zwischen ,šu'la“, d. h. „glühendes Holzstück“, und „fitna“, hier „Meiterei, Aufstand“, ist insofern interessant, als das arab. Verb „fatana“ ursprünglich „,versuchen, erproben (z.B. das Gold im Feuer $)^{746 ،}$ bedeutete. „Fitna“ wird auch sonst häufig mit „Feuer“، assoziiert, dessen

\footnotetext{
${ }^{746}$ Handwörterbuch der neu-arabischen und deutschen Sprache, Bd. 2, S. 383.
} 
Löschung, Austretung die gewaltsame Beendigung des Aufstandes bedeute: (Mağmūc rasā'il muwaḥhidīya, S. 1) „ba'd kamāl al-ġazwa al-mubāraka wa-tamāmihā wa-iṭầ' alfitna bi-bard al-hudna wa-salāmihā“, (Qalā'id al-'iqyān, S. 77) ,wa-kānat tạ̄ifa min ahl Fās qad 'ātū fīhā wa-fasaqū wa-'ntaẓamū fĩ silk aṭ-ṭggyān wa-'ttasaqū [...] ilā an tadāraka amīr al-muslimīn [...] amrahum wa-aṭfa'a ğamrahum“ - „bis er ihrem Unwesen bzw. ihrem räuberischen Treiben Einhalt gebot“, (Mağmū' rasā’il muwaḥhidīya, S. 178) „waḥaṣala fĩ aidī al-muwaḥhịīn [...] aḍ-ḍāll al-g̉awīy al-musammā Rašīdan [...] mūqid nār fitnatihim wa-šarrihim“. Das Gesagte gilt auch allgemein für kriegerische Auseinandersetzungen: (Mušāhadāt, S. 102) ,,as-Sabta [...] dār an-nāšiba wa-hāamiya almuḍrima li-'1-ḥarb al-munāšiba“.

\section{Fahnen}

Erster bzw. anderen überlegen zu sein, kann dahingehend ausgedrückt werden, der Betreffende trage die - flatternde - Fahne des von ihm beherrschten Fachwissens, der ihm innewohnenden Eigenschaft oder auch der Oberhand allgemein: (Raihạnat alkuttāb, Bd. 2, S. 382) „(fulān) hāmil liwā’ al-ḩaț!̣“, (Raihānat al-kuttāb, Bd. 2, S. 307) „madīnat Aṣilāa [...] rāfía fi 'l-ḩiṣb al-liwā’ al-ḩāfiq“, (Raihānat al-kuttāb, Bd. 2, S. 309) „,madīna Ribāt Āsifĩ [...] rāfíat al-liwā’ bi-ṣiḥhat al-hawā'‘“; (Raihānat al-kuttāb, Bd. 1, S. 218) „wa-'arraftumūnā bimā kāna min aẓ-ẓuhūr allad̄ī ḩafaqat 'alaikum rāyatuhū“ synonym zu ,allad̄ī miniḥa lakum“, (Mağmū'a ğadīda, Bd. 1, S. 285) ,al-ḩilāfa as-sacīda adāma Allāh aiyāmahā wa-as'ada a'lāmahā“‘. Vor dem Hintergrund dieser Vorstellung wird das Zitat verständlich (Mağmū` rasā’il muwaḥhidīya, S. 233) „,wa-naqala ilaihā (aiy ilā Iblatātānsīya) min ahl aš-šimāl kull man talaqqā rāyat al-ḥarb bi-'l-yamīn“ - d. h. „diejenigen, die im Hinblick auf ihre Kriegserfahrung und Kriegstüchtigkeit unübertreffbar sind“.

\section{Schießscheiben und Geschossfänge}

Nicht selten ist die Vorstellung, man handle in einer bestimmten - häufig als löblich empfundenen und beschriebenen Weise - oder man besitze eine rühmliche Eigenschaft, indem man die Zielscheibe der betreffenden Handlungsweise oder des Attributs mit Pfeil(en) trifft. Folgende Beispiele mögen diese Beobachtung veranschaulichen: (Raiḥānat al-kuttāb, Bd. 1, S. 121) ,alladīi (aiy al-mulk an-naṣīi) yuṣīb šākilat al-ḥaqq

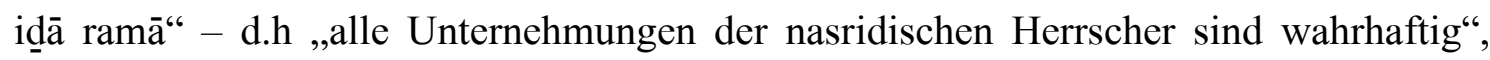
(Raiḥānat al-kuttāb, Bd. 1, S. 283) „kataba Allāh lakum [...] șun`an tuṣīb šākilat ar-rašād 
wa-'t-taufīq wa-'s-sadād nibāluhū“ - d. h. „Gott möge Euch ein solches Handeln bescheiden, durch welches Ihr rechtgeleitet, erfolgreich und recht handelnd seid“, (Raihānat al-kuttāb, Bd. 1, S. 446) „fa-innā katabnāhū ilaikum [...] lā zālat bi-'izzikum ḥauzat al-ḥaqq tuḥmā wa-šākilat an-naṣr turmā“،, (Mağmū'a ğadīda, Bd. 1, S. 516) „,hhtarnā al-ān li-ḩuț̣at al-qaḍā' bainakum fulānan adāma Allāh karāmatahū wataufīqahū wa-saddada ilā marāmī at-taḥīiq tafwīqahū“ - wobei hier mit ,hutṭat alqaụā̄““ das Amt des Richters (qāọī) gemeint ist und „tafwīq“ die Bedeutung hat „,nach entferntem Ziel hoch schießen“; (Raihānat al-kuttāb, Bd. 2, S. 252) ,ramat (aiy madīnat Basṭa) ilā garaḍ al-fahr bi-'s-sahm al-muṣīb wa-ahadodat min aqsām al-fạ̣l bi-aufā nașīb“. Eine interessante Mischung aus zwei unterschiedlichen Vorstellungen bildet der folgende Beleg: (Mağmū'a ğadīda, Bd. 1, S. 513) „waṣala Allāh ta‘āā taufĩqahū (aiy taufīq al-qāệi al-musta 'mal) wa-nahağa ilā marāmī al-iṣāba țarīqahū““ - denn hier vereint sich die eingangs erklärte Vorstellung mit einer anderen, die besagt, man handle in einer bestimmten Weise, indem man einen bestimmten Weg beschreitet bzw. geht“". Siehe hierzu die Belege im Kapitel „Wege und Pfade“.

Die eingangs genannte Vorstellung kann auch in der Bedeutung ,jemanden angreifen“ verwendet werden: (Raiḥānat al-kuttāb, Bd. 1, 132) „madīnat Istağğa [...] fa-ramā (aiy al-muslimūn) ġaraḍahā wa-'stabāḥa rabaḍahā“, (Raiḥānat al-kuttāb, Bd. 1, S. 144) ,,wa'hutilāf aš-šawānī allatī tasrī ilaihī (aiy Ğabal al-Fatḥ) surā aṭ-ṭaif wa-tuhliṣ sihāmahā ilā garaḍihī“ - hier „schmerzvolle Schläge versetzen, durch Angriffe schwächen“.

\section{Die Rennbahnen}

Verbreitet ist die Vorstellung, ein Gewerbe, Wissenschaftsgebiet oder ein Charakteristikum sei eine Rennbahn, in welcher dessen Vertreter gleich Rennpferden um die Wette od. besser um die höchste Kompetenz laufen ${ }^{747}$. Dies erklärt u. a., warum bei Ibn-al-Hațīb Literaten mit Rennpferden od. mit Reittieren verglichen werden. Hierzu einige Beispiele: (Raiḥ̄anat al-kuttāb, Bd. 2, S. 386),,(fulān) rafa'a bi-quṭihī rāyat had̄ā aš-ša'n 'alā wufūr ḥalbatihī wa-fara'a qunnat al-baiyān 'alā sumūw haḍbatihī' - der Betreffende stach hervor durch sein Können in dem beschriebenen Wissensbereich, obwohl viele andere sich damit auch befassten“, (Raihānat al-kuttāb, Bd. 2, S. 375) „(fulān) kātib šurūṭ lā yusāğal fī miḍmārihā“،, (Maqāmāt a-Ḥarīrī, S. 120) „nadautu biḍawāḥ̄ az-Zaurā’ maca mašyaḩa min aš-šu'arā' lā ya laq lahum mubārin bi-g̉ubār wa-lā yağrī ma'ahum mumārin fī miḍmār،, (Maqāmāt al-Ḥarīīi, S. 227) „fa-tarāsalā (aiy Abū- 
Zaid as-Sarūğī wa-fatāhū) fi 'n-naẓm wa-tabārayā wa-tağāwalā fị ḥalbat al-iğāza watağārayā““, (Maqāmāt al-Ḥarīrī, S.172f.) ,wa-kānat 'indī ğārīya lā yūğad lahā fi 'l-ğamāl muğārīya“, (Qalā’id al-'iqyān, S. 34) ,wa-țala'a fī samā’ihī (aiy fī samā’ al-Mu'tamid Ibn-'Abbād) kull nağm muttaqid wa-kull dī fahm muntaqid fa-aṣbahat haḍratuhū maydānan li-rihān al-ậhān wa-gāàtan li-ramy hadaf al-bayān wa-miḍmāran li-iḥrāz haṣl kull mánā wa-faṣl“" - im letzten Teil des Zitats liegt eine interessante Vermischung von zwei ursprünglich unterschiedlichen Vorstellungen vor, denn „haṣl“ ist ein Pfand im Schieß- und nicht in einem Rennwettbewerb.

Mit dieser Vorstellung kann auch die Vortrefflichkeit, die Unübertroffenheit und wie auch immer geartete Einzigartigkeit bzw. Beschaffenheit des beschriebenen Objekts ausgedrückt werden, wie es aus den folgenden Beispielen hervorgeht: (Raihānat alkuttāb, Bd. 1, S. 70) „rāği`an ilaihī (aiy li-šaih al-g̉uzāt) naẓar al-qawā̄id al-ġarbīya [...] ruğū'a al-istiqlāl wa-'l-istibdād wa-'l-'izz al-fasīh al-mağāl al-ba'īd al-āmād““ - wobei sowohl „al-mağāl““ als auch „al-āmād“ den Zusammenhang „Rennbahn; Wettrennen“ eindeutig nahelegen, (Ṣubḥ, Bd. 7, S. 69) ,wa-qad ittaṣala binā mā kāna min duhūl ḥaḍrat Biğāya ḥarasahā Allāh fī țā'atikum [...] wa-'aqdikum minhā wa-min uhtihā assābiqa ad -dimām [...] 'alā 'aqīlataiy al-aqtạ̄r allatī lā yağma' bainahumā illā malik humām [...] wa-man ğama'a Allāh lahū baina al-birr al-mutarākị̣ al-ḩuyūl wa-'1-ğaiš almutadāfíc as-suyūl““ - hier ,außergewöhnlich große Tugendhaftigkeit“, (Qalā’id al‘iqyān, S. 39) „fa-wāfāhū (aiy wāfā Ibnu-Muğāhid al-Mu'tamida Ibn-'Abbād) wa-alfā mağlisahū qad atla'at abārīquhū ağyādahā wa-aqāmat bihī hail as-surūr țirādahā“, (Raihānat al-kuttāb, Bd. 1, S. 269) ,fa-țiqū minnā bi-'l-ḩulūṣ alladī tasābaqat ilā al-ġāya al-quṣwā ğiyāduhū“, (Raiḥānat al-kuttāb, Bd. 1, S. 390) „wa-innanā warada 'alainā kitābukum [...] ḥā'izan fĩ maydān al-balāga mazīyat at-taqdīm“, (Raiḥānat al-kuttāb, Bd. 1, S. 421) ,fa-innanā warada 'alainā kitābukum [...] al-mustaulī min mayādīn al-faḍl ‘alā ab`ad al-āmād““, (Mağmū` rasā’il muwaḥhidīya, S. 80) „mubaiyinīn bi-annahā (aiy alfutūh) [...] muttaṣila fī ‘unfuwānihā ğārīya fĩ maidānihā mil’a 'inānihā“‘.

Und schließlich kann ganz allgemein ein bestimmtes Handeln, Vorgehen u. a. auf der obigen Vorstellung aufbauend umschrieben werden: (Raiḥānat al-kuttāb, Bd. 1, S. 370) „wa-lammā ra'ainā anna had̄ā at-ṭāgìya ahlakahū Allāh qad ğamaḥa fĩ maiydān almaṭāmic hawāhū (wa-fi 'l-aṣl al-mu'tamad 'alaihī haulan) wa-aẓhara min al-ğadr mā nawāhū“،, (Mağmū` rasā’il muwaḥhidīya, S. 150) „hattā yanqād fī zimāmihī (aiy fĩ zimām al-amr al-cazīz) muṣhiban ḍū aš-širād wa-'n-nifār wa-ya’wī ilā durāhū al-amīn

${ }^{747}$ Diese Vorstellung ist bereits in der folgenden Redewendung enthalten: „fulān lā yušaqq ġubāruhū“ 
wa-rabwatihī dāt al-qarār wa-'l-'ain aṣ-ṣacb al-ğāmic [wa-la'alla maqṣūd hunā l-ğāmiḥ] fī țalaq al-ibāya wa-'l-istikbār“" - mit ,al-amr al-'azīz“" ist hier das Almohadentum als religiös-politische Auffassung gemeint, (Șubḥ, Bd. 1, S. 263) „(bei der Ansprache von Hağğāğ Ibn-Yūsuf an die Bewohner Kufas) li-annakum țālamā auḍa'tum fi 'l-fitna wa'ḍtağa ‘um fī manām aḍ-ḍalāl“, (Mağmū'a ğadīda, Bd. 1, S. 151) ,wa-qad 'alimtum [...] mā kāna min al-muntazī fīhā (aiy fi 'l-Qafṣa) min al-ị̣̂ā' fi 'l-fitna wa-'l-murūq min ațțā'a“; (Raiḥānat al-kuttāb, Bd. 1, S. 267) „wa-'alimnā anna ad-daula [...] qad dālat [...] wa-'l-'ahd al-qadīm qad tağaddad [...] fa-ğarainā fi 'l-masarra mil'a al-a inna“, (Maqāmāt al-Ḥarīī, S. 106) „wa-lammā balag̉tuhā (aiy al-Ġūta) [...] alfaituhā kamā taṣifuhā alalsun [...] wa-ğarait țalaqan ma'a al-hawā““ - hier „frönte ich allerlei Genüssen“, (Raihānat al-kuttāb, Bd. 1, S. 261) „wa-'alā hadihī al-ḥāl al-mulimma [...] famaqāmukum šuġl bālinā wa-fī maidān musāhamatikum mağāl āmālinā“ - hier , wir hoffen, Euch beizustehen“, (Raihānat al-kuttāb, Bd. 1, S. 262) „wa-ẓahara annahū lam yahluṣ (aiy ilaikum) ġairuhū (aiy ġair al-kitāb al-mad̄kūr) min ğumlat mukātabāt 'adīda ba'atnāhā wa-rakā’ib muhāṭabāt ilaikum ḥațatnāhāa“. Die ,ğgiyād“" können dabei auch durch ,a inna“ ersetzt werden: (Mağmū' rasā’il muwaḥhidīya, S. 147) „wa-idāa arsaltum aršīyat afkārikum fī qulb aḍkārikum wa-aṭlaqtum acinnat i'tibārikum fī mayādīn mā marra 'alā abṣārikum“, (Mağmū'a ğadīda, Bd. 1, S. 131) ,yamīlūn (aiy ahl Ābila) ‘alā ğawānibihim (aiy ğawānib ahl al-Andalus) bi-'l-gāāāt fa-lā yağidūn man yaṣrif tațāwul i'tidā'ihim wa-lā man yarda` a innat istišrā'ihim“.

\section{Seiten und die geographische Verfasstheit von seelischen und emotionalen Zuständen}

Die Erwähnung der Seite bzw. der Seiten eines Objektes kann zum Ausdruck bringen, dass es sich um dieses Objekt selbst handelt. Folgende Belege mögen dies veranschaulichen: (Mağmū'a ğadīda, Bd. 1, S. 494) „wa-an ta lamū anna mașāliḥakum mu'tamada bi-'l-i'tinā' wa-anna ğawānibakum muta'ahhada bi-'r-ri'āya fī kull al-ānā̄‘،, (Mağmū'a ğadīda, Bd. 1, S. 455) „wa-bi-muqtaḍā mā lanā bikum min ğamīl al-cināya allatī nastaṣhibuhā fī ğawānibikum“, (Mağmū'a ğadīda, Bd. 1, S. 270) „(bei der Beschreibung des bekannten Ausgangs der Schlacht bei las Navas de Tolosa) wa-'1muslimūn 'azīzatun ğawānibuhum maḥrūsa bi-qudrat Allāh katā'ibuhum“ - hier „die Almohaden gingen siegreich aus der Schlacht hervor“, (Raiḥānat al-kuttāb, Bd. 1, S. 362) ,șāa ilā naẓarihim (aiy naẓar as-salaf al-marīnī) ğumla min bilādihā (aiy min albilād al-andalusīya) miț Ğabal al-Fatḥ wa-Runda [...] fa-qarra [wa-yurwā aiḍan fa- 
‘azza] ğanābuhā wa-qawīyat asbābuhā“‘, (Mağmū'a ğadīda, Bd. 1, S. 511) ,wa-nasta'mil fī ašğālikum man yatawallāhā bi-'l-kifāya wa-'ḍ-ḍabṭ iẓhāran li-ātār al-macdala fìkum wa-ịtāran li-'l-iḥtiyāṭ 'alā ğawānibikum wa-nawāḥikum“, (Raiḥānat al-kuttāb, Bd. 1, S. 69) „waṣala Allāh lahū (aiy li-šaih kad̄ā) asbāb sacādatihī wa-ḥarasa aknāf mağādatihī. Vor dem Hintergrund dieser Überlegungen ist es denkbar, dass z.B. im Zitat (Mağmū rasā’il muwaḥhidīya, S. 161) „wa-rağa'a al-muwaḥhidūn [...] min ġazwatihim almabrūra allatī [...] ballagiahum (Allāh) min nikāyat a'dā'ihim wa-tadwīh aknāfihim waarğā’ihim mā tağāwaza amānīhim“ mit ,aknāf" und „arğăa’“ nicht die Randbezirke, sondern die Gesamtheit der Feinde, denen der geschilderet Plünderungszug gegolten hat, und somit die Gesamtheit der bewohnten feindlichen Gebiete gemeint ist.

Es kommt nicht selten vor, dass abstrakte Objekte als im Raum konkret gegeben und aufgefasst und umschrieben werden. Sie werden gemäß dieser Vorstellung häufig als konkret fassbare - obgleich häufig nicht näher definierte - geographische Gegebenheiten begriffen und demgemäß beschrieben. Folgende Beispiele sollen dies veranschaulichen: (Mağmū' rasā’il muwaḥhịīya, S. 145) „fa-hūwa (aiy al-amr al-'azīz) [...] maḥfūẓ al-ğanā’ib maklū’ an-nawāḥī ma'ṣūm al-arğāa‘، - mit „al-amr al-'azīz“ ist hier das Almohadentum als religiös-politisches Gedankengebäude gemeint. (al-Mann, S. 235) „fa-innā katabnāhū [...] min manzil al-muwaḥhidīn [...] bi-dāhil ğabal alKawākib [...] wa-qad kunnā bimā li-'llāh 'alainā min 'ahd al-qiyām bi-ḥuqūq had̄ā alamr al-'azīz wa-'1-ḥiyāța li-arğâ'ihī wa-'d-dabb 'an ğawānibihī wa-tağdīd al-'ināya litaṣfīyat mašāri ihī min al-aqdāè wa-taḥlīyat al-muḥuuwimīn 'alaihā min ahl al-ahwā' [..] tawağğahnā lahā bi-'l-ḥaraka al-mubāraka“.

Ferner ist die Vorstellung häufig, Abstrakta wie seelische, emotionale und körperliche Zustände bzw. Empfindungen usw. seien konkret im geographischen Raum lokalisierbar, sodass das Verweilen oder auch Vorbeigehen an dem festen geographischen Ort dieser Abstrakta ihrer sinnlichen Wahrnehmung gleichkomme: (Mağmū' rasā'il muwaḥḥidīya, S. 75) „wa-'stamarrū (aiy al-muwaḥḥidūn) 'alā ḥaṣr alqașaba al-maḍūra wa-'1-kāfirūn yarauna iḩwānahum fĩ qabḍat al-usra [sic] wa-ḥālat al'usra fa-yahtariqūn finā' al-ḥasra“‘, (Qalā'id al-'iqyān, S. 74) ,fa-'tuqila al-Mu'tamid huilāl tilka al-ḥāl (aiy atnā' taurat ibnihī) wa-atnā'ahā wa-uḥilla sāḥat al-ḩuṭūb wa-finā’ahā“، d. h. „,man hat ihn allerlei Widerwärtigkeiten kosten lassen“, (Mağmū'a ğadīda, Bd. 1, S. 479) „wa-hūwa subḥānahū yaṣil istiqrārakum fī kanaf al-cāfìya“, (Mağmū'a ğadīda, Bd. 1, S. 454) „wa-innā katabnāhū (aiy katabnā had̄ā al-kitāb ilaikum) kataba Allāh lakum 'āfīya tatabauwa'ūn aknāfahā“‘, (Mağmū'a ğadīda, Bd. 1, S. 513) „wa-naqșid an 
tastamirr umūrukum 'alā mā yuḥ̣̄ikum bi-'l-amal al-anğạ̣ wa-yu’wīkum fī ta'arruf alamana wa-takaiyuf ad-da'a ilā al-ğanāb al-arḥab al-afsaḥ“, (Mağmū'a ğadīda, Bd. 1, S. 454) ,,annā nataḩauwalukum min ğamīl an-naẓar mā [...] yuğrī maṣāliḥakum kullahā 'alā mā yūğib bi-faḍl Allāh ta‘ālā fĩ kanaf ad-da'a wa-'1-amān iḥtilālakum“, (Mağmū'a ğadīda, Bd. 1, S. 456) ,wa-ladainā min istiṣhāb an-naẓar al-asadd fī umūrikum [...] mā narğū an [...] yu’wīkum kanaf al-amān““, (Kitāb a'māl al-a'lām, S. 69) ,wa-lam yubāšir al-Manșūr (aiy Muḥammad Ibn-Abī-'Āmir al-Manṣūr) ḥarban ašadd 'alaihī wa-lā aṣ'ab maqāman wa-ag̉laẓ karīhatan min hạarbihī fī gazātihī kad̄ā“, (Mağmūc rasāìl muwaḥhidīya, S. 69) ,wa-'l-ayām tamurr yaum ba'd yaum wa-'l-aqwāl tatawağğah fī 'atb wa-laum wa-'l-kull ya'rị̣ fī mawāqif at-tauba nās ba'd nās wa-qaum ba'd qaum“, (al-Mann, S. 233 f.) „wa-inna lahū (aiy li-'l-amr al-'azīz) ma'a kull muta'arriḍ bi-'lmuhạādda wa-'š-šiqāq [...] min wašîk ahֵdihī wa- āăgil naqmihī [...] mā [...] yaqif bihī mimmā ğanā min tamrat garsihī wa-ğanā bi-'amalihī adِ-damīm 'alā nafsihī mawāqif ḥairatihī wa-nadamihī“, (21 almor. Briefe, S. 174) „wa-Allāh yuṭbit aqdāmakum fī mawāṭin ar-riḍā“،, (Raiḥānat al-kuttāb, Bd. 2, S. 251) „wa-ğuznā fī kanaf al-yumn wa-'1qabūl bi-ḥiṣn al-Babūl“, (Raiḥānat al-kuttāb, Bd. 1, S. 502) ,wa-lā bariḥa (aiy fulān) fī ğawānib iḥsāninā rāiḥ̣an wa-ḡādiyan“, (Raiḥānat al-kuttāb, Bd. 1, S. 503) „(bei der Beschreibung des Umsturzes in Granada und der Flucht des nasridischen Sultans nach Wādī Āš) wa-ḩalaṣnā giilāban bi-ḥāl infirād illā min [...] șidq al-lağa’ ilā rạ̣matihī (aiy raḥmat Allāh) allatī sāḥatuhā 'an miținā lā taḍīq“, (Raiḥānat al-kuttāb, Bd. 2, S. 84) „amara bihī (aiy bi-ẓahīr karīm) al-amīr fulān waṣala Allāh sacādatahū wa-ḥarasa mağādatahū [...] wa-aqtạahū ğānib al-in‘ām al-ğasīm“, (Mağmū' rasā’il muwaḥhịidīya, S. 9) „fa-'ttas'at lahum wa-li-siwāhum min a'yān al-qabāill al-mad̄kūrīn kāffatan aknāfuhū (aiy aknāf al-amr al-'azīz) wa-'staqarra bihim ilā manāzil al-birr wa-'t-tarfī' istidnā'uhū wa-'sti' țāfuhū“،.

Ferner ist in den nachfolgenden Beispielen die Vorstellung belegt, der Aufenthalt am geographischen Standort einer bestimmten Handlung, Handlungsweise bringe zum Ausdruck, jemand handle in der dadurch definierten Art und Weise: (Mağmū' rasā’il muwaḥhidīya, S. 216) ,wa-hadaū (aiy qabā’il 'Auf wa-'š-Šarīd) mustaršidīn bi-hadyihā (aiy bi-hady as-sa‘āda) al-munğī min madāḥị̣ al-fitan wa-ahwā’ihā““ - hier synonym zu „,min at-tamādī al-muhlik fí 'l-fitan wa-'l-ahwā̄‘،, (Mağmū' rasā'il muwaḥhịīiya, S. 18) „wa-ra'ainā an nuhāṭibakum [...] bimā auğaba subḥānahū min [...] at-taḥ̂̄īr min attawaqquf fī mawāqif ig̀nā̄ aš-šaitān wa-taḍlīlihī““ - hier „,die Warnung, sich vom Widerpart Gottes in die Irre führen zu lassen“, (Mağmū` rasā’il muwaḥhidīya, S. 41) 
„fa-'stamarra taḩabbuṭuhum (aiy ahūwaiy al-mahdī) fī masālik al-'aṭab watawarruṭuhum fĩ țalab wa'dihim al-murtaqab“ - hier sinngemäß „die beiden meuternden Brüder des Mahdi ließen sich nicht von ihrem letztlich für sie verhängnisvollen Treiben abbringen“; (Raihānat al-kuttāb, Bd. 1, S. 218) „ğa`alanā Allāh mimman istamarra fī maqām aš-šukr qiyāmuhū wa-qu'ūduhū“،, (Mağmū` rasā’il muwaḥhịidìya, S. 47) „waiyākum min 'ibādihī (aiy min 'ibād Allāh) al-'ārifīn bi-mawāqi` an-ni`am [...] al-wāqifīn bi-țācatihī (aiy bi-țậat Allāh) mawāqif amrihī al-multazam“. Auf die gleiche Vorstellung scheint auch das folgende Zitat Bezug zu nehmen: (al-Mann, S. 305) „wainna aš-šaih [...] Ibn-Hamušk waffaqahū Allāh kušifa lahū 'an wağh hudāhū wa-ḥuli’a 'an mawārid radāhū wa-tabaiyana lahū anna had̄ā al-amr al-'azīz hūwa al-markab almunği““ - hier „das sichere Untergehen der betreffenden Person wurde abgewendet, indem man ihn von den Tränken des Untergangs vertrieben hat"،

\section{Die Gänzlichkeit eines Sachverhaltes}

Die Benennung von zwei Gegensätzen in Bezug auf ein Objekt kann die Ganzheit dieses Objektes zum Ausdruck bringen. Das häufigste Beispiel dafür in den almohadischen Briefen ist „Īrād wa-iṣdār“" mit den vielen möglichen Abänderungen. Die Verwendung dieses Stilmittels ist auch in vielen anderen Gegensatzpaaren belegt: (21 almor. Briefe, S. 128) „baina yadaiy harakatinā [...] yammana Allāh fātiḥatahā wa'uqbāhā“، - in den almoh. Briefen würde an dieser Stelle ,yammana Allāh īrādahā waiṣdārahā“‘ stehen; (Mağmū' rasā’il muwaḥhidīya, S. 255) ,ilā an ği’nāhā (aiy ği’nā alMahdīya) wa-nūr bayāḍihā qad gaašāhū aẓ-ẓulm ẓalāman wa-ạ̣kām ahl at-tağsīm qad atqqalat kāhilahā wa-ḥammalat ma‘ālimahā wa-mağāhilahā huuṭūban ğisāman“ - hier „die Bestimmungen der genannten Feinde der Almohaden erlegten der Stadt in ihrer gesamten räumlichen Ausdehnung gewaltige Unheile auf'; (Raihānat al-kuttāb, Bd. 1, S. 414) „wa- 'indanā li-uhūwatikum al-karīma [...] widād karīm šāhiduhū wa-ġà’ibuhū“; (Raihānat al-kuttāb, Bd. 1, S. 278) ,(fulān) šakara Allāh mad̄āhibahū wa-ḥarasa šāhid wuddihī wa-ḡā’ibahū“, (Raihānat al-kuttāb, Bd. 1, S. 288) ,fa-qad 'alima al-ḡà'ib wa-'ššāhid wa-'ṣ-ṣādir wa-'l-wārid mā 'indanā lakum min al-ḥubb“; (Raiḥānat al-kuttāb, Bd. 1, S. 283) „wa-aṣḥabahū (aiy aṣḥaba Allāh had̄ā al-maqāma) al-i'āna wa-'t-taufĩq fī ẓa'nihī wa-ḥallihī‘; (Raihānat al-kuttāb, Bd. 1, S. 285) „fa-bādarnā bi-hanā’ikum mubādarat al-ḩulūṣ alladī lā yašūbuhū ar-raib wa-'t-tašaiyư allad̄ī yatasāwā minhū almaḥḍar wa-'1-ġaib“; (Mağmū'a ğadīda, Bd. 1, S. 505) „wa-qalladanā (aiy Allāh) min amānat al-qiyām bimā ya'ūd naf'uhū 'alā dānīhā (aiy dānī ar-ra'īya) wa-nāziḥihā'،; 
(Raiḥānat al-kuttāb, Bd. 2, S. 254) ,ḥallalnāhā (aiy madīnat Buršāna) fi 't-tabrīz al-ḥafîl wa-'1-mašhad al-ğāmic baina aḍ-ḍarra wa-'l-fîl wa-ḥušira ahluhā baina dān wa-nāziḥ wamatala hạāmīyatuhā min nābil wa-rāmị̣“ - hier kommen gleich drei bekannte Gegensatzpaare vor: ,aḍ-darra wa-'1-fîl“, ,ad-dānī wa-'n-nāziḥ“ und „nābil wa-rāmị̣“; (Raiḥānat al-kuttāb, Bd. 1, S. 67) „tarği` al-qabā’il wa-'l-ašyāh̆ ilā naẓarihī (aiy naẓar šaih al-g̉uzāt) fi 's-sakanāt wa-'l-ḥarakāt“، - d. h. „fī kull umūrihā'،; (Raiḥānat al-kuttāb, Bd. 1, S. 69) „limā kāna lahū al-qadr al-ğalīl [...] wa-'l-fạ̣ā’il allatī karuma minhā aliğmāl wa-'t-tafṣ̂̄1“ - hier „,vollkommen edle Tugenden“, und ausschlaggebend bei diesem Zitat m.E. ist, dass ,iğmāl““ und „tafșīl“ als ein Gegensatzpaar aufgefasst und gebraucht werden; (Maqāmāt al-Ḥarīīi, S. 270 f.) „wa-ğa'altu aḍrib fi 'l-arḍ gauran wanağdan ilā an iqtanaitu hağmatan min ar-rāḡìya“, (Maqāmāt al-Ḥarīrī, S. 425) „ḥaddata al-Ḥarit Ibn-Hammām qāl lahiğtu [...] bi-an ağūb al-barārī ‘alā ẓuhūr al-mahārī unğidu țauran wa-asluku tāratan ġauran ḥattā falaitu al-macālim wa-'1-mağāhil“, (Qalāid al(iqyān, S. 61) „(bei der Beschreibung der Belagerung Cordobas durch die Almoraviden) ilā an șabbahūhā (aiy al-murābiṭun Qurṭuba) li- ida kānat bainahum wa-baina ahlihā fī tasannum aswārihā wa-taqaḥhum anğādihā wa-aġwārihā“ - hier , die gesamte räumliche Ausdehnung der Stadt“, (Raihānat al-kuttāb, ohne Beleg) „kaifa lā targ̉ab an-nufūs fī ğiwārihā (aiy fī ğiwār madīnat kad̄ā) wa-tuhaiyim al-ḩawāṭir baina anğādihā ag̉wārihā"; (Maqāmāt al-Ḥarīrī, S. 410) „fa-asra'tu ilaihī (aiy ilā Abī-Zaid as-Sarūğī) li-uṣāfiḥahū wa-asta'rif sāniḥahū wa-bāriḥahū“ - hier ,über alles ausfragen“; (Raiḥanat al-kuttāb, Bd. 1, S. 464) „bādarnā ta'rīf maqāmikum allad̄ī na'lam musāhamatahū fīmā sā'a wasarra wa-ạ̣lā wa-amarra“, (Raihạnat al-kuttāb, Bd. 1, S. 429) ,wa-'r-riḍā 'an ālihī [...] alladīna tamassakū bi-'ahdihī (aiy bi-'ahd Muḥammad) 'alā iḥlā' al-ḥawādit waimrārihā'“; (Raiḥānat al-kuttāb, Bd. 1, S. 475) ,ammā ba'd ḥamd Allāh 'alā kull ḥāl cạtịl au hāal“; (Mağmū'a ğadīda, Bd. 1, S. 322) ,wa-lā yasa'ahū al-katm bal yağib al-bid' bi-'tta' rīf bihī wa-'1-hatm“ - ,einen Sachverhalt in seiner Gänze darlegen“.

\section{Wege und Pfade}

Die interessante Vorstellung, jemand handle in einer bestimmten Weise, indem er den Weg einer bestimmten Handlungsweise, Eigenschaft beschreite, gehe usf. ist im mittelalterlichen Schrifttum sehr verbreitet gewesen. Folgende Belege mögen dies veranschaulichen: (Raihānat al-kuttāb, Bd. 1, S. 414) „waṣalanā kitābukum ṣuḥbat alhail allad̄ī tafaḍ̣altum bi-ihdā’ihī wa-salaktum bihā subul al-mulūk ma`a awiddā’ihā"“ d. h. „mit welchen ihr uns die Behandlung habt zuteil werden lassen, welche die Könige 
ihren Freunden gegenüber zuteil werden lassen“, (Raihạnat al-kuttāb, Bd. 1, S. 414) „alladī (aiy Muḥammad) hadānā ilā sulūk al-ḥaqq wa-'ttibā' subulihī“, (Mağmū'a ğadīda, Bd. 1, S. 516) „wa-hūwa (aiy al-qāḍi al-musta'mal) bi-ḥaul Allāh tacālā yasluk fī aḥkāmikum sanan aš-šarī‘a al-abyan“ - hier „nach Maßgabe des islamischen Gesetzes“, (Mağmū'a ğadīda, Bd. 1, S. 515) „(die kalifale Anordnung an die almohadischen Untertanen) sīrū fī kull umūrikum 'alā as-sanan al-abyan al-auḍạ̣ tafūzū fī dalikum bi't-tağr al-arbaḥ“, (Mağmū'a ğadīda, Bd. 1, S. 505) ,wa-alzamanā (aiy Allāh) min assulūk fi 'n-naẓar lahā (aiy li-ra'īya) 'alā qadīm (wa-'1-arğah hunā qawīm) as-subul wawādihịihā“ - hier „Gott hat uns die Pflicht auferlegt, die Herrschaft über die Untertanen in einer gerechten und billigen (wörtl. transparenten) Weise auszuüben“, (Mağmū'a ğadīda, Bd. 1, S. 502) ,wa-tabaiyana sulūkuhū (aiy sulūk al-qāḍi al-musta`mal) 'alā taraddud isti'mālihī fĩ hadihī al-ḩuṭ̣a li-'ț-ṭuruq al-wāḍiḥa wa-'s-subul al-qawīma““ - hier „,in seiner Eigenschaft als Richter in unbescholtener und einwandfreier Weise gehandelt haben“", (Mağmūa ğadīda, Bd. 1, S. 501) „wa-amarnāhū (aiy al-qāḍ̄ī al-musta'mal) an [...] lā ya'dil mā lam ta'tariḍ šidda šar'īya 'an sanan ar-rifq“, (Mağmū'a ğadīda, Bd. 1, S. 499) „wa-waṣaināhū (aiy al-qāọ̄i al-musta'mal) bi [...] al-ḥukm bi-'l-ḥaqq al-wāḍị yasluk sananahū wa-yaqfū atarahū“،. Vor dem Hintergrund dieser angeführten Belege lassen sich andere mit dem Motiv „Pfade“ im Zusammenhang stehende Wörter besser erklären und verstehen, wie z.B. „sīra“ oder ,ātārr“: (Mağmūca ğadīda, Bd. 1, S. 504) „wa-hūwa (aiy al-qāḍī al-musta'mal) bi-ma'ūnat Allāh tacālā yuğrīkum 'alā mā 'ahidtum min ḍabṭ al-ạ̣kām [...] wa-yasīr fìkum as-sīra allatī aliftumūhā“, (daselbst) „wa-hūwa (aiy al-qāḍ̂̄ al-musta'mal) alladī [...] ḥasunat fī tamšīyatihā (aiy fī tamšñyat huuṭ̣at alqaụā’) 'alā aqwam țuruqihā țūla iqāmatihī cindakum [...] ātāruhū““ - hier haben jeweils „tamšīyat" die Bedeutung „die Ausübung des Richteramtes“ und „ātār" - wobei sich natürlich damit nicht die gesamte Bedeutungsfülle dieses Wortes erschöpft „Amtshandlungen“, sodass die gesamte Passage mit „,es waren bei der Ausübung des Richteramtes in der bestmöglichen Weise während des Aufenthaltes des Betreffenden unter euch trefflich seine Amtshandlungen“ zu übersetzen wäre. Eine interessante m.E. Weiterentwicklung der eingangs erwähnten Vorstellung und deren Ausschmückung bildet das folgende Zitat: (Qalā'id al-'iqyān, S. 61) „,mā 'štag̉ala (aiy al-Ma’mūn Ibn-alMu'tamid Ibn-'Abbād) bi-mucātāât al-mudāma wa-lā tawag̉gala li-'l-'iṣyān šíc annadāma“ - d. h. „der Betreffende hat nicht dem Weingenuss gefrönt und hat sich kein Aufbegehren zuschulden kommen lassen, welches letztlich ihn nur gereut hätte“. 
Auch die Aussage, etwas sei in einem bestimmten Zustand z.B. der Augenscheinlichkeit, Wohlgeordnetheit usw. oder weise eine bestimmte Beschaffenheit auf, kann mittels der gleichen Vorstellung ausgedrückt werden: (Mağmū'a ğadīda, Bd. 1, S. 511) „wa-bi-ḍalikum (aiy bi-inhāẹ al-qāḍī al-ğadīd) tastamirr al-ahwāl 'alā mahya' aṣ-ṣalāḥ wa-minhāğihī“،, (Mušāhadāt, S. 102) „wa-takallufuhum (aiy takalluf ahl madīnat Sabta) zāhir mahmā 'uriḍat walīma au 'aqīqa wa-'qtiṣāduhum lā taltabis minhū țarīqa“ - hier ,ihre Sparsamkeit springt in die Augen“, (Raihānat al-kuttāb, Bd. 2, S. 28) „wa-'d-du'ā' li-sulțānikum al-asmā bi-'s-sa'd allad̄ī yug̉nā bi-watāqat sababihī wa-wuḍụ̄ madhabihī 'an zağr al-bāriḥ wa-'s-sāniḥ“, (Ṣubḥ, Bd. 7, S. 69) „auza'akum Allāh šukrahā (aiy šukr li-taysīr Biğāya) min nicma ğallat mawāhibuhā wa-waḍaḥat mad̄āhibuhā““ - falls dies richtig überliefert ist, denn in „Raihānat al-kuttāb“ (Bd. 2, S. 30) findet sich eine abweichende Version.

Ferner kann die Wendung „sich auf dem Pfad einer Sache befinden“ die Bedeutung haben ,in Übereinstimmung mit etwas sein bzw. handeln“, wie es aus den folgenden Belegen hervorgeht: (Mağmū'a ğadīda, Bd. 1, S. 511) „fa-innahū (aiy al-qāḍ̄i almusta'mal) [...] ma'mūr an yağcal al-kitāb wa-'s-sunna wa-'l-iğmāe ḍawābiṭ îrādihī waiṣdārihī wa-rawābiṭ inhā'ihī wa-'timārihī fa-lā yašuḍd fị hukm 'an ğawāmi'ihā wa-lā yanfự lahū faṣl illā 'alā ğawāddihā al-wāḍiha“ - hier „,in Übereinstimmung mit dem Koran, der Sunna und der einmütigen Meinung der anerkannten islamischen Autoritäten“, (Mağmū`a ğadīda, Bd. 1, S. 504) „wa-ḥaddadnā lahū (aiy li-'l-qāḍī almusta'mal) al-wașāyā bi-'ttiqā' Allāh [...] wa-'l-i'timād 'alā mā ğā'a bihī rasūl Allāh [...] wa-'alā iğmā̄ al-umma allad̄ī lā yaḍill man iqtafā wāḍị̣ sananihī‘‘.

„Der breite und klare Weg“ kann auch gleichbedeutend mit der islamischen Botschaft sein, denn (Raiḥānat al-kuttāb, Bd. 1, S. 436 f.) ,wa-'ṣ-ṣalāt 'alā saiyidinā wa-maulānā Muḥammad rasūlihī al-hādī ilā as-sabīl al-wāḍị̣ wa-'n-nahğ al-lāḥib“. Weitere zahlreiche Belege hierfür lassen sich im einleitenden Teil der almohadischen Briefe finden.

\section{Wirtschaftlichkeit und Kommerziellität des mittelalterlichen Sprachgebrauchs}

(Raihānat al-kuttāb, Bd. 1, S. 368) „fa-lam yatni 'azmahū [šaiy’un mā] 'an iqāmat sūq at-ṭa'n wa-'ḍ-ḍarb“ - „sūq at-ṭa'n wa-'ḍ-ḍarb“, wörtl. „Markt des Stechens und des Hauens bzw. Markt der Lanzenstiche und der Schwerthiebe“, bedeutet hier „Kampf, Schlacht“, (Raihānat al-kuttāb, Bd. 2, S. 19) „fa-barazat ḥāmīyatuhā (aiy ḥāmīyat madinat kad̄ā) 'alā muta'addidāt al-abwāb muqīmatan aswāq at-ṭicān wa-'ḍ-ḍirāb fa-ābat 
bi-ṣafqat al-husrān wa-'t-tabāb“ - ,șafqa“" bedeutet hier und in anderen ähnlichen Zusammenhängen „Ausgang, Ergebnis“, (Raihānat al-kuttāb, Bd. 1, S. 284) „wa-anna Allāh ta‘ālā ağrā lakum ‘ādat aẓ-ẓafar lammā šabbat nār al-ḥarb wa-'aqada lakum ṣafqat aẓ-ẓuhūr fī sūq aṭ-ṭa'n wa-'ḍ-ḍarb“, (Raihānat al-kuttāb, Bd. 1, S. 367) „wa-lā kasadat baḍā'i al-ḥamīya al-ilāhīya fī aswāqihā (aiy fī aswāq al-bilād al-andalusīya) an-nāfiqa““ - d. h. „der Eifer der merinidischen Sultane bei der Bekriegung von andersgläubigen Feinden der Nasriden in al-Andalus war nicht erlahmt"; (Raihānat al-kuttāb, Bd. 1, S. 355) ,țumma talāḥaqa arsālukum al-ǧilla fa-wağabat ḥinna'id aš-šafă'a wa-'uriḍat 'alā sūq al-faḍl wa-'l-ḥilm min al-istiltāf wa-'l-isti'tāf al-biḍā'a“, (Raihānat al-kuttāb, Bd. 1, S. 544) „wa-zawāyāhā (aiy zawāyā ḥaḍrat Ġarnāṭa) mubāraka maqșūda yanfur ilaihā alğumhūr fi 'l-layālī allatī yaqūm bihā li-'l-birr sūq“. Kommerziell geht es auch in den folgenden Beispielen zu: (Mağmū' rasā’il muwaḥḥidīya, S. 253) ,wa-aqamnā bihā (aiy bi-Qābis) muddatan nuṣlị̣ min aḥwāl ahlihā mā fasada wa-nunfiq min āmāl qaumihā mā kasad“ - hier „Hoffnungen erfüllen“, (Raihạānat al-kuttāb, Bd. 1, S. 364) „wa-hadihī al-bilād al-andalusīya [...] hīya [...] 'uddat li-aslāfikum al-kirām ilā macādihim wamatğar ḥasanātihim“, (Raiḥānat al-kuttāb, Bd. 1, S. 177) „wa-qafalnā wa-'l-alwīya (wafi 'l-aṣl al-mu'tamad 'alaihī al-aulawīya) bi-'n-naṣr ḩāfiqa wa-aswāq az-ẓuhūr nāfiqa“", (Mağmū'a ğadīda, Bd. 1, S. 270) „mauqif [...] ištadda fîhī al-kifāḥ wa-urhiṣat fīhī alarwāḥ“ - „Kriegsschauplatz, an dem die Seelen zu billigen Preisen gehandelt wurden, d. h. viele der Kämpfenden gefallen sind“. Vielleicht muss vor diesem kommerziellen Hintergrund die folgende Passage neu verstanden werden: (Riḥlat Ibn-Ğubair, S. 200) „(bei der Beschreibung einer Predigt, welcher der Verfasser in Baghdad beigewohnt hat) wa-tamādā (aiy tamādā al-ḩațîb) fĩ wa'zịīi ilā an ațāra an-nufūs hišyatan wariqqatan wa-tahāfata 'alaihī al-a'āğim mu'linīn bi-'t-tauba [...] fa-yulqūn nawāṣīhim baina yadaihī fa-yastad'î ğalamain wa-yağuzzuhā nāṣiyatan nāṣīyatan wa-yaksū 'imāmatahū al-mağzūza an-nāṣīyati fa-yūụa' 'alaihī (aiy 'ala al-ḩaṭīb) li-'l-ḥ̄in 'imāma uhrā min aḥad qurrā'ihī wa-ğulasā'ihī mimman qad 'arafa manza'ahū al-karīm fī dalik fa-bādara bi-'imāmatihī li-'stiğlāb al-'arḍ an-nafīs li-makārimihī aš-šahīra“ - mit anderen Worten „li-kaiy lā tazāl sūq makārimihū qā’imatan“, d. h. „,damit diese seine edle Wesensart nicht aufhört, sich zugunsten der Reumütigen zu manifestieren, aus Mangel am Turban auf seinem Kopf“. Gaudefroy-Demombynes übersetzt es mit „Celuici s'empresse de donner son turban pour gagner le précieux honneur dû aux mérites que tous reconnaissent à ce cheikh“. (Raihānat al-kuttāb, Bd. 1, S. 369 f.) ,wa-lā 'hutāla (aiy al-quṭr al-andalusī) illā fî ḥulal șanā'icikum (aiy șanā'ic as-sulṭān al-marīnī) al-fāhira wa- 
lā taqallada illā durar makārimikum an-nāfiqa fī matāğir ad-dunyā wa-'l-āḩira“, (Raihānat al-kuttāb, Bd. 2, S. 396) „wa-lammā anifa al-kasāda sūquhū (aiy sūq adīb fulān) ahadoda bi-'1-'azm wa-adḩala 'alā ta'illātihī 'āmil al-ğazm“ - hier ist „kasād as-sūq““ synonym zu ,humūl ad- $\underline{d i k r “ . ~}$

Im gleichen wirtschaftlichen Zusammenhang bleiben auch folgende Zitate, wobei mit dem profitablen Geschäftsabschluss entweder Erfolg oder Nutzen bzw. Vorteile konnotiert werden: (Riḥlat Ibn-Ğubair, S. 222) „fa-lau lam narkab tabağ al-baḥr [...] illā li-mušāhadat mağlis min maǧālis had̄ā ar-rağul la-kānat aṣ-ṣafqa rābiḥatan“, (Ṣubḥ, Bd. 7, S. 45) „(nach der Schilderung des Todes des christlichen Herrschers bei der Belagerung Gibraltars und beim Dank dem merinidischen Herrscher für die während dieser Belagerung gewährte materielle Unterstützung) wa-lau-lā at-tacalluq biasbābikum fī anwā’ tilka al-g̉ayāhib wa-mā ḩalaṣa ilā hadihī al-bilād min mawāhibikum [...] la-mā rağaca al-kufr bi-ṣafqat al-ḩāìb“, (Raihānat al-kuttāb, Bd. 1, S. 362) „fağāhada (aiy wālidukum) 'adūwa Allāh fīhā (aiy fī bilād al-Andalus) ḥaqqa ğihādihī [...] wa-'āmala Allāh 'alā aṣ-ṣafqa ar-rābiḥa allatī yağiduhā fī macādihī“, (Raiḥānat al-kuttāb, Bd. 1, S. 486) ,ammā ba`d ḥamd Allāh [...] murbiḥ tiğārat man qaṣada wağhahū bi'amalihī‘. (Raiḥānat al-kuttāb, Bd. 2, S. 28) ,ṣalāt 'alā maulānā Muḥammad [...] muẓfirihim (aiy muẓfir an-nās) min as-sacāda ad-dā'ima bi-arbạ al-baḍā'ic“c, (Raiḥānat al-kuttāb, Bd. 2, S. 29) ,wa-lā zāla taufīq Allāh 'ā’idan 'alā tadbīrikum as-sa'̄ìd bi-'s-sa'y an-nāğiḥ wa-'t-tağr ar-rābiḥ“, (Mağmū' rasā'il muwaḥhidīya, S. 2) „fa-'t-tauba aṣl li-'la'māl ar-rāğiḥa wa-'l-matāğir ar-rābiḥa“", (Mağmū' rasā’il muwaḥhidīya, S. 223) „lā yaqța'ūn (aiy al-muwaḥḥidūn) wādīyan illā 'azuma bihī ağruhum wa-rabiḥa inda Allāh tacālā tağruhum wa-zakā ladaihī subḥānahū 'amaluhum wa-karuma dِuhruhum“, (Mağmū'a ğadīda, Bd. 1, S. 515) ,sīrū fī kull umūrikum ‘alā as-sanan al-abyan al-auḍạ̣ tafūzū fĩ dِalikum bi-'t-tağr al-arbaḥ“; (Maqāmāt al-Ḥarīrī, S. 207), „wa-baraza al-wā̄iz yatahādā baina rufqatihī wa-yatabāhā bi-fauz șafqatihī“ - hier ist damit der Erfolg gemeint, den der „Prediger“ erzielt hat, denn er hat einem Kläger, der vom Herrscher zunänchst zurückgewiesen wurde, durch seine wortgewaltige Predigt zu seinem (des Klägers) Recht verholfen und zwar dergestalt, dass der Herrscher, durch die Predigt beeindruckt, seine anfängliche Zurückweisung des Klägers revidierte und der Klage des Letzteren stattgab sowie den Übeltäter bestrafte.

Geldliche Schuldverpflichtungen: Eng mit diesem wirtschaftlichen Kontext sind auch die folgenden Beispiele verknüpft: (Șubh, Bd. 7, S. 40) (bei der Beschreibung der Belagerung einer Festung) ,țumma annahum (aiy al-muhāṣarīn) hāmarahum tạariq al- 
wağal fa-'ağğalū adā’ dainihī (aiy dain al-ḥiṣn al-muhạạar) qabl ḥulūl al-ağal“ - die Festung wird hier mit einer ausstehenden Geldschuld verglichen, derer die Belagernden habhaft werden wollen bzw. sie zurückhaben wollen, und die Belagerten tilgen diese Schuld vor dem Eintreten des Fälligkeitstermins, d. h. ergeben sich vor der bevorstehenden sicheren Bezwingung“; (Raiḥānat al-kuttāb, Bd. 1, S. 162) „(am Anfang der Schilderung der Erstürmung und Verwüstung Jaens) innā nağlū 'alaikum ḩabar alfath [...] al-mu'rib 'ammā ba'dahū in šā' Allāh 'an duyūn fi 'l-kufr tuqtaḍā"، - d. h. „Bezwingung (von Jaen), welche weitere Bezwingungen von in der Gewalt der Ungläubigen befindlichen Städten ankündigt“, (Mağmū`a ğadīda, Bd. 1, S. 371) „,kataba Allāh li-'l-maqām al-imāmī [...] su'ūdan taqtạ̣i dain al-fath mu'ağğalan „Glückhaftigkeit, welche die imamitische Hoheit ihre Siege rasch erlangen lässt“", (Raiḥānat al-kuttāb, Bd. 2, S. 299) „qultu fa-Lauša qāl mar’ā bahīğ [...] wa-nahr saiyāl wa-ğgụn maiyād maiyāl wa-ğannāt wa-'uyūn wa-liḍ̂̄āt lā tumṭal bihā duyūn“ - hier „Genüsse, derer man sich ohne Aufschub erfreut“. Die Vermutung liegt nahe, dass mit der Geldschuld (ad-dain) das „erstrebte Objekt“ konnotiert wird, sodass mit deren Begleichung das Habhaft-Werden dieses Objektes gemeint ist. Stimmte es, so müsste die Passage (Raihānat al-kuttāb, Bd. 2, S. 402) ,wa-naša'a ibnuhū had̄ā mufaddā bi-'lanfus wa-'l-'uyūn maqụīy ad-duyūn ḥāllan min aḍ-ḍamā'ir maḥall az-ẓunūn“ die Bedeutung haben, dass diesem Sohne jeder seiner Wünsche erfüllt wurde, keiner seiner Wünsche ihm verwehrt wurde, (Șubh, Bd. 7, S. 107),,(bei der Beglückwünschung von Abū-Inān Fāris zur Wiedereinnahme Tilimsans, die ihm Ibn-al-Hatị̄b aus Chella zukommen ließ, wo er sich an das Grab von Abu-'l-Hasan al-Marīnī, der sich um die Eroberung dieser Stadt zu seinen Lebzeiten ohne Erfolg bemüht hatte, wendet und die folgenden Worte sagt) yahnīk yā maulaiy radd ḍāllatik al-manšūda [...] fa-qad istaḥaqqahā wārituk al-arḍā wa-saifuk al-amḍā wa-qāḍī dainika wa-qurrat 'ainika“. Weiteres Bsp. (Mağmū' rasā’il muwaḥḥidīya, S. 247), „(nach der Einnahme Mallorcas) fa-ra'ā an-nās min amrin [...] u'milat fīhī li-'l-hulafā' ḍurūb min at-tadbīr [...] wa-Allāh subḥānahū qad qaḍa bi-an yakūn wārita su'ūdihim wa-'1-fā'iza bi-inğāz wu'ūdihim wa-'1mutaqāḍīya duyūn āmālihim“ - d. h. das Eintreffen der Hoffnungen der verstorbenen rechtgeleiteten Kalifen kommt Gott zugute? (Raihānat al-kuttāb, Bd. 1, S. 284) „waannakum šara'tum fĩ faṣl al-bilād al-marrākušīya allatī manāṣiluhā māḍìya wa-ag̉rāụuhā li-duyūn al-āmāl mutaqāọīya“ - wörtl. „die Absichten, die diese Stadt fasst, lassen alle Hoffnungen wahr werden“, d. h. sie besitzt ein solches Maß an Macht, Reichtum usw., dass es die Erfüllung all ihrer Wünsche bewirkt bzw. erzwingt. Weiteres Bsp. (Raihāanat 
al-kuttāb, Bd. 1, S. 300 ff.) ,(bei der Beschreibung der Vertreibung von Christen, die sich Alexandriens für kurze Zeit bemächtigt hatten) fa-ḩarağa al-'adūw al-ḩāsir 'ammā ḥāzahū wa-'s-suyūf turhiquhū ḥait tulfīhī wa-'s-sihām tutbituhū wa-tanfīhī wa-guramā' karrat al-islām taqtaḍi minhū (aiy min al-'adūw) dainahā wa-tastaufīhī“ - hier schlage ich eingedenk der bekannten Kampftechnik „farr wa-karr“ vor, „karrat al-islām“ mit „der Vergeltungsschlag, der vom Islam dem Christentum versetzt wird“ zu übersetzen, sodass der abschließende Teil des Zitats wahrsch. lauten müsste ,und die (muslimischen) Gläubiger des Vergeltungsschlages des Islam nahmen die ihnen gegenüber zu entrichtende Geldschuld dieses Vergeltungsschlages in vollem Maße entgegen“, mit anderen Worten „die Muslime trugen dabei, dem Christentum den Vergeltungsschlag des Islam beizubringen, den gewaltigen Sieg davon“; (Raihānat alkuttāb, Bd. 1, S. 135 f.) ,wa-innahū taqaddamat muṭāla'at maqāmikum bimā sannāhū Allāh li-ğaiš al-muslimīn [...] wa-annahum ta'āhadū mā bainahum min diyār al-kuffār mu'āhadat al-ġarīm“ - d. h. „die Muslime sind in die Gegenden der Christen eingefallen und haben einige davon den Letzteren entrissen“.

(Raihānat al-kuttāb, Bd. 2, S. 413) ,ilā an fasada mā baina mudabbirihā (aiy mudabbir ad-daula an-naṣrīya) Ibn-Mạ̣rūq wa-bainahū (aiy al-adīb al-mauṣūf) wa-nuḥhịyat lahū 'anhū hanāt augiarat șadrahū wa-aqdat 'ainahū fa-gaarrabahū ba'd mā qarrabahū wağafāhū ba'd mā 'ṣtafāhū fa-ğamma [wa-la'allahū fa-ḥumma] fi 'l-iğtirāb ḥainuhū wa'qtaḍā fĩ ba'ḍ bilād Ifrīqīya dainahū“ - hier ist höchstwahrscheinlich das Subjekt zu „iqtaḍā““, „der Tod“ (ḥain), und gemeint ist dann, dass der Tod ihn in irgendeiner Stadt Ifrīqīyas ereilt hat. (Mağmū' rasā’il muwaḥhịidīya, S. 78), „fa-qaiyadathū (aiy qaiyadat as-sulaiținn) al-manīyatu bi-qaidihā [...] wa-'qtaḍat nafsahū al-ḩabīta iqtiḍā' al-'azm [wala'alla al-maqșūd hunā al-ġarīm] 'ağğala 'alā an-nasī’a naqdahā'،. Meines Erachtens tritt in den letzten zwei Zitaten der Tod in Gestalt eines Gläubigers auf, der den von ihm an den Schuldner geliehenen Geldbetrag, d. h. das Leben, von diesem Schuldner, also vom Menschen, ein- bzw. zurückfordert. (Raihānat al-kuttāb, Bd. 1, S. 471) ,wa-'d-du‘ā’ limaqāmikum al-a'lā bi-'l-'ināya allatī lā maṭla li-ġarīmihā““ - auch hier wird ,garīm“ in der Bed. „Gläubiger“ gebraucht, und der Satz bedeutet soviel wie ,göttliche Obsorge, die euch sofort und ohne Aufschub zuteil wird“. (Raihāanat al-kuttāb, Bd. 2, S. 255 f.) „wa-kānat al-bilād aš-šarqīya qad ahlafathā al-g̉uyūt [...] wa-šakat ilā sacāat maqdaminā ma`arrat al-qaḥat [...] fa-adina Allāh fĩ inğāz al-wa`d wa-qarrabat garāma algamām fi 'l-maqām a'wānu ar-ra'd fa-'tarafa wa-samaḥa wa-'nqāda li-ḥukm al-qạ̣ā' 
ba'd an ğamaḥa [...] wa-qaḍāhā ad-dain fī dufa` šattā““ - wohlgemerkt hat hier ,g̉arīm““ die Bed. „Schuldner“.

(Qalā'id al-'iqyān, S. 65) ,wa-hūwa (aiy al-Mu'tamid Ibn-'Abbād) mustamsik bi-'urā

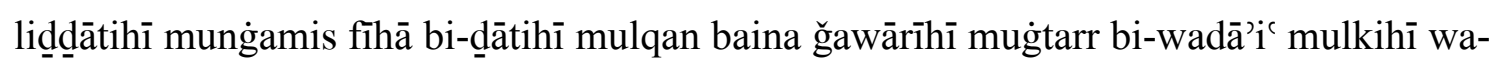
'awārīhī" - hier vielleicht ,verblendet durch seine vergängliche Herrschaft, d. h. Herrschaft, die ihm nur geliehen wurde“, (Qalā'id al-'iqyān, S. 140) ,anta [...] 'ālim bi'z-zamān wa-'nqilābihī 'ārif bi-i'āratihī wa-'stilābihī‘, (Raqm al-ḥulal, S. 98) „lā tuhda'anna bi-zīnatihī (aiy bi-zīnat az-zaman) min zuhruf 'ammā qalīl yastaridd mu'ārahū““

\section{Umkreisen und Umfliegen des Erstrebten}

Das Streben nach einer Sache kann auf folgende Weise ausgedrückt werden: (Raiḥānat al-kuttāb, Bd. 1, S. 270) ,al-ḥamd li-'llāh [...] alladīi acādakum ilā mulkikum [...] wayassara 'alaikum marāmahū 'alā ṭ̂l al-ḥaum 'alā al-wurūd“', (Raiḥānat al-kuttāb Bd. 1, S. 363) „anna malik Qaštāla qad țama'a fị hadihī al-bilād al-mad̄kūra wa-kaliba 'alaihā [...] wa-anna āmalahū bihā ḥā'ima wa-'l-ḥaraka ilaihā qā’ima“, (Raihānat al-kuttāb, Bd. 1, S. 378) „lau-lā anna Allāh šag̉ala al-'adūwa 'anhū (aiy 'an bāb al-Andalus) bi-fitnat qaumihī lam yaṣrif wağhahū illā ilaihī wa-lā ḥauwama țairahū illā 'alaihī“, (Raiḥānat alkuttāb, Bd. 1, S. 367 f.) ,,wa-lammā ra'ā aṭ-ṭàgīya [...] anna daulat al-islām qad ista'nafat šabābahā wa-anna Allāh fataḥa li-hadihī al-ğazīra bāban [...] šariha ilā iṭ̂ā’ nūr Allāh alladīi wa'ada bi-itmāmihī wa-'htabala al-girra allatī hāma ‘alaihā ṭam‘uhū‘‘.

\section{Bücher, Schriften und Register}

(Raiḥānat al-kuttāb, Bd. 1, S. 285), ,wa-lā taslū 'ammā 'indanā lakum min al-ḥubb allad̄ī [...] tawaffarat wa-al-ḥamd li-'llāh asbābuhū fa-qad taqarrara fī mudauwanat aṣ-ṣidq bābuhū“،, (Ṣubḥ, Bd. 7, S. 100) ,,al-ḥaḍra al-'alīya [...] lā zālat aḥādīt naṣrihā sālimat almutūn ș̣ạ̣ịhat al-isnād wa-ṣahāàif futūḥihā tağma` șalāḥ al-'ibād“،, (Raiḥānat al-kuttāb, Bd. 1, S. 394) ,al-wudd allad̄ī [...] tabata fĩ șuḥuf al-hulūṣ mastūunuhū“, (Raihānat alkuttāb, Bd. 1, S. 362) „fa-kāna min 'azm as-sulțān al-muğāhid al-arḍā [...] mā hūwa ma'lūm wa-fĩ șuḥuf al-faḩr marsūm“, (Raihānat al-kuttāb, Bd. 1, S. 366) ,wa-'d-du'ā' limaqām uhūwatikum al-'uẓmā aṭla'a Allāh 'alaihā min as-sacāda wağhan ğamīlan warasama āyāt naṣrihā fĩ aurāq fahrihā"“.

(Raihānat al-kuttāb, Bd. 1, S. 342) „kataba Allāh lakum [...] naṣran tusṭar fī ṣuhuuf alaiyām 'ağā'ibuhū“, (Raiḥānat al-kuttāb, Bd. 1, S. 443 f.) ,kataba Allāh lakum futūḥan 
manẓūmatan [...] wa-ṣanā'i fī șuhuf al-aiyām marsūma“, (Raihānat al-kuttāb, Bd. 1, S. 398) „kataba Allāh lakum sa`dan tusțar fĩ naṣr al-islām ğumaluhū“‘.

(Mağmū' rasā’il muwaḥhịidīya, S. 183) „kataba Allāh lakum min bašā’ir had̄ā al-amr al'azīz asarra masmū' [...] wa-auza'akum min šukr muwallīhā wa-ḥamd musabbibihā subḥānahū wa-musannīhā mā yuṭbit lakum fĩ șuhue al-qubūl ar'ā 'amal ṣāliḥ wa-du'ầ' marfüَ“،, (Mağmū'a ğadīda, Bd. 1, S. 492) „wa-'l-yadِkur (aiy al-qāḍī) mattā hạạara alhiṣmān ladaihī [...] yauman yaḥ̣ur fịhī 'inda rabbihī wa-tưraḍ 'alaihī mūda'āt șahạāifíhī wa-kutubihī (aiy șaḥāîf rabbihī)“.

(Raihānat al-kuttāb, Bd. 1, S. 364) „wa-haḍihī al-bilād al-andalusīa [...] hīya 'uddat liaslāfikum al-kirām ilā ma‘̄âdihim [...] wa-ṣaḥifat a'mālihim az-zakīya“.

\section{Das Motiv des Schattens}

Die häufige Vorstellung, das beschriebene Objekt befinde sich unter dem Schatten eines bestimmten Zustandes, bringt zum Ausdruck, es sei in diesem Zustand. Dabei konnotiert die Länge dieses Schattens entweder die zeitliche Ausdehnung dieses Zustandes oder auch dessen Intensitätsgrad: (Raihāanat al-kuttāb, Bd. 1, S. 261) „had̄ā wa-'l-'adūw allad̄ī sālama al-islām bi-sabab ğihādikum wa-taqallaṣat aṭmācuhū bi'mtidād ẓilāl imdādikum“, (Mağmūca ğadīda, Bd. 1, S. 489) „waṣala Allāh asbāb anni`am ladaikum wa-aḍfā ẓilāl al- iṣam ladaikum“, (Mağmū'a ğadīda, Bd. 1, S. 454) ,wahūwa subḥānahū yuḍfī zịāl al-aman 'alā arğā'ikum“, (al-Bayān al-mugirib, S. 175) ,waharağa al-madِkūr Rašìd bi-qațāihim ilā Biğāya [...] wa-ẓill al-hudna fī tilka al-bilād mamdūd wa-mā̄ al-‘āfìya bihā maskūb wa-maurūd“, (Mağmū'a ğadīda, Bd. 1, S. 455) „wa-bi-muqtaḍā mā lanā bikum min ğamīl al- ināya allatī nastaṣhibuhā fĩ ğawānibikum wa-'r-ri'āya allatī nuḍfī ẓilālahā ‘alā šāhidikum wa-ğā’ibikum“, (Mağmū'a ğadīda, Bd. 1, S. 453),,(bei der Ernennung eines Statthalters) wa-ukkida 'alaihī fī an yạ̣sim adwā' aššarr wa-'l-fasād wa-yu'mil fī qam` ūlī al-i'tidā’ wa-'1-bag̉y kull al-ištidād ḥattā yansaḥib li-'l-amān 'alā tilkum al-arğā' zill wārif“", (Mağmū'a ğadīda, Bd. 1, S. 504) „wa-innā katabnāhū kataba Allāh lakum insiḥāb zilāl al-āfīya 'alaikum wa-'nsidālahā“، bezeichnenderweise legen hier „insiḥāb“ und ,insidāl“ die Bed. „lange schleppende Gewänder bzw. Schleier“ und somit die damit konnotierte Bedeutung „reichlich vorhanden sein“ nahe, siehe hierzu die Einträge im Kap. „Kleider und Gewänder“; (Mağmū'a ğadīda, Bd. 1, S. 459) ,wa-Allāh [...] yasluk bi-kum fī kull ḍalikum 'alā subul as-sabīl wa-yu’wīkum min tasauwug an-na'mā wa-'r-raḥmā ilā az-ẓill aẓ-ẓalīl“, (Ṣubḥ, Bd. 7, S. 72) „(nach dem Tod des kastilischen Königs bei der Belagerung 
Gibraltars) fa-rahịma Allāh inqiṭā'anā ilā karamihī [...] fa-ğalā bi-fac̣lihī subḥānahū ẓalām aš-šidda wa-madda 'alā al-ḥarīm wa-'l-aṭâal ẓilāl rạ̣matihī al-mumtadda“, (Mağmū'a ğadīda, Bd. 1, S. 475) „wa-'lamū anna wara'a had̄ā min ḥusn tafaqqud liaḥwālikum mā nuwālīhī lakum ma'a al-aḥyān wa-namidd bihī ‘alaikum ẓill ar-rifq wa-'1ḥanān“", (Mağmū'a ğadīda, Bd. 1, S. 456) „,wa-ladainā min istiṣhāb an-naẓar al-asadd fī umūrikum [...] mā narğū an [...] yufị̣ 'alaikum zill al-'adl wa-'l-iḥsān“ - in diesem Zitat liegt in ,yufị̣ 'alaikum zill al-'adl wa-'l-iḥsān“ eine interessante Mischung aus zwei unterschiedlichen Vorstellungen, nämlich der eingangs beschriebenen mit derjenigen, welche besagt, Gnadenerweise ergössen sich gleich einem Wasserstrom über die Begnadeten. Siehe hierzu das Kapitel „Gnadenbezeigungen und Gunsterweise“.

Bei den nachfolgenden Belegen handelt es sich um keine Zustände. Sie scheinen m. E. aufs engste mit der Vorstellung verknüpft zu sein, abstrakte Begriffe wie z.B. Herrschaft seien u. a. Bauwerken gleich - siehe hierzu das obige Kapitel „Bauten“ - , sodass die Länge bzw. die Kürze des Schattens des beschriebenen Objekts die Höhe bzw. die Niedrigkeit seines Baus ausdrückt. Die Vorstellung, der Schatten eines Zustandes sei dieser Zustand selbst, hängt insofern damit zusammen, als dieser Schatten auf den ihn werfenden Bau zurückgeht und von ihm also bewirkt wird. So drückt der Satz (Ṣubḥ, Bd. 7, S. 100) ,al-ḥaḍra al-'alīya abqā Allāh ẓill mulkihā ‘alā al-'ibād“ den zweifachen Wunsch aus, Gott möge die almohadische Herrschaft sowie den dadurch bedingten Zustand - des allgemeinen Wohlergehens, Wohlstandes, Sicherheit usw. - für die Unertanen weiterhin bestehen lassen. (Qalāid al-iqyān, S. 45) „wa-qad maḥat alḥawāditu dịyā'ahā (aiy ḍiyā' az-Zahrā') wa-qallaṣat ẓilālahā wa-afyā'ahā“‘, (Qalā'id al'iqyān, S. 64) ,wa-hūwa (aiy al-Mu'tamid Ibn-'Abbād) sāhin bi-rauḍ wa-nasīm [...] watilka al-ğuyūš tağūs hilālahū wa-tuqalliṣ ẓilālahū“ - hier „,während al-Mu'tamid Ibn'Abbād weltlichen Genüssen frönte, verringerten die almoravidischen Heere seine Herrschaft, d. h. entrissen ihm seine Besitzungen eine nach der anderen“".

\section{Körperhaftigkeit bzw. Konkretheit des Abstrakten}

Die nachstehenden Belege wurden zusammengetragen in dem Bestreben, die innere Logik der arabischen Sprache besser verstehen zu können. Diese manifestiert sich unter anderem auch darin, welche Wörter mit einer konkreten Bedeutung herangezogen werden, um einen abstrakten Sachverhalt zu beschreiben bzw. in einer übertragenen Bedeutung gebraucht zu werden. 
Abstrakta als Körper: (Raiḥānat al-kuttāb, Bd. 1, S. 301) „fa-inna al-islām ka-'l-ğasad yatadācā kulluhū li-ta'allum ba'đ̣ihī wa-yatasāham ihwwanuhū fì basṭihī wa-qabḍihī", (Qalā’id al-'iqyān, S. 49) ,wa-hūwa (aiy yaum az-Zallāqa) yaum šafā al-islām ba'd mā ašfā“ - siehe ferner zum Vergleich des Islam mit einem Bau die Einträge im Kapitel „Bauten“.

Pechsträhnen, Unheile und Heimsuchungen usw. als Lebewesen oder Tiere: (Raiḥānat al-kuttāb, Bd. 1, S. 463) ,wa-lā istauḥašat nafs wa-lā nabaḍa li-'l-fitna 'irq“; (Maqāmāt a-Ḥarīīi, S. 123) „yā qaum innī min unās ganaū dahran wa-ğafn ad-dahr 'anhum gadịị̣“", (Ṣubh, Bd. 7, S. 98 f.) „wa-lau anna makānan 'aḍ̣̣ahū ad-dahr min anyāb ḥawāditihī alğūn bimā bihī 'aḍ̣ahā (aiy Labla)“, (Maqāmāt al-Ḥarīrī, S. 289) „wa-'lmaḥū ad-dahr wa-lu'm karrihī wa-sū' miḥālihī wa-makrihī kam țamasa ma'laman wa-amarra maṭ̂aman wa-țahṭạ̣a 'aramraman wa-dammara malikan mukarraman hammuhū [!] sakk almasāmi` wa-saḥh al-madāmic“، (Raqm al-ḥulal, S. 110) „wa-'ntabaha ad-dahr lahū (aiy li-'l-amīr an-naṣrī) min naumihī 'alā yadaiy tạ̄’ifa min qaumihī“, (Maqāmāt al-Ḥarīrī, S. 131) „wa-ğārukum fĩ ḥaram wa-wafrukum fī ḥarab mā lāḍa murtāc bikum fa-ḩāfa nāb an-nūwab“, (Maqāmāt al-Ḥarīrī, S. 202) „fa-ğud fī marāọī Allāh bi-'l-māl rāọīyan [...] wa-bādir bihī șarf az-zamān fa-innahū bi-mihllabihī al-ašğā yaġūl wa-nābihī“، (al-Mann, S. 76) „la'alla 'iyānan minkum li-'abīdikum (yā amīr al-mu'minīn) wa-qurban lakum minhum yudāl bihī al-bu'd fa-qad 'aḍḍahum nābun min al-kufr mu'ḍil wa-kānū bikum dahran wa-anyābuhū durd“،, (Maqāmāt al-Ḥarīrī, S. 271) ,tumma awaitu ilā 'arab ardāf aqyāl wa-abnā' aqwāl fa-auṭanūnī amna' ğanāb wa-fallū 'annī ḥadd kull nāb“, (Maqāmāt al-Ḥarīīī, S. 298 f.) ,țumma qāl (aiy Abū-Zaid) mā allad̄ī nābak ḥattā zāyalta ğanābak fa-qult dahr hāọa wa-ğaur făḍa“, (Maqāmāt a-Ḥarīī, S. 231 f.) „fa-ammā al-ān fa-'1waqt 'abūs“, (Raihānat al-kuttāb, Bd. 1, S. 219) ,wa-māğat 'alā al-arḍ buhūr al-katāìb wa-ḍaḥikat an-nuṣūl fi 'l-yaum al-'abūs wa-dārat baina ar-riğāl li-'l-āğāl al-ku'ūs“, (Kitāb acmāl al-a lām, S. 7) „lammā [...] inqaraḍat daulat Banī-Umaiya wa-ṣāḥat bihim al-aiyām wa-waqa'a aṭ-ṭalab 'amman aflata minhum“, (Maqāmāt a-Ḥarīrī, S. 262) „faqāl ílam anna ad-dahr al-`abūs alqānī ilā Ṭūs“; (Maqāmāt a-Ḥarīrī, S. 249) „fa-balautu min šitā'ihā (aiy min šitā’ al-Karağ) al-kāliḥ“; (al-Iktifā’, S. 124) ,wa-anāhna al-ğaur bikalkalihī wa-ḍaraba al-bāṭil bi-ğirānihī“, (Qalā’id al-'iqyān, S. 112) „wa-'1-fitna qad anšabat aẓfārahā wa-a'malat asinnatahā wa-šifārahā wa-ag̣tašat lailahā"،; (Raiḥānat alkuttāb, Bd. 1, S. 218) „'arraftumūnā bimā kāna min az-ẓuhūr [...] wa-anna ‘adūwakum lammā ḍāqat 'alaihī al-masālik wa-fagaarat afwāhahā ilaihī al-mahālik“, (Maqāmāt a- 
Ḥarīīî, S. 185) „ilā an 'arāhū (aiy Abā-Zaid as-Sarūḡī) maraḍ imtadda madāhū wa'araqathū mudāhū'“.

Die Schlingen des Todes: (Raihānat al-kuttāb, Bd. 1, S. 462) „(bei der Beschreibung der Ermordung des nasridischen Sultans) fa-lammā ța'anahū (al-qātil) wa-atbatahū waa'laqa bihī šarak al-ḥain wa-mā aflatahū“, (Mağmū' rasā’il muwaḥḥidīya, S. 226) „walau aṣhạara al-kāfir la [...] 'ulliqat bihī ḥabā’il al-halaka wa-ašrākuhā“‘.

Affekte: (Maqāmāt a-Ḥarīrī, S. 186) ,asālū al-g̉urūb wa-'atṭū al-ğuyūb wa-ṣakkū alhudūd wa-šağğū ar-ru'ūs“" - hier Ausdruck der tiefsten Trauer bzw. der größten Besorgnis um den Zustand des kranken Abū-Zaid as-Sarūğī.

Zeitangaben: (Maqāmāt a-Ḥarīrī, S. 189) „fa-ma 'staiqaẓnā illā wa-'l-ḥarr qad bāḩ wa-'1yaum qad šāh““, (Raihānat al-kuttāb, Bd. 2, S. 258) „ḥalalnāhā wa-'l-yaum gadụ̣ aššabība“, (Raiḥānat al-kuttāb, Bd. 2, S.253) „wa-nazalnā bi-ẓāhir hịnn Ṣ̌īūn wa-qad tara'ra'a šabāb al-yaum“.

Schießbögen und Pfeile: (Maqāmāt al-Ḥarīrī, S. 200) „yā ibna ādam mā ag̉rāk bimā ag̉arrak [...] tuhmil mā ya'nīk wa-tanzi` fī qaus ta'addīk“, (Maqāmāt al-Ḥarīrī, S. 414) „,tumma lafata (aiy al-qāẹī) wağhahū ilā al-g̉ulām wa-qad naṣala lahū ashum al-malām wa-qāla lahū a ra'aita buṭl za'mik wa-ḩaṭa’ wahmik“, (Maqāmāt al-Ḥarīrī, S. 286) „wakunt yauma'id qawīm aš-šaṭāt ğamūm an-našāt armī 'an qaus al-mirāḥ ilā garaḍ alafrāḥ“, (Maqāmāt al-Ḥarīrī, S. 178) ,țumma sa’alnāhū 'ammā ạ̣dața ğāruhū al-qattāt [...] ba'd an rāša lahū nabl as-si'āya wa-ğadiama ḥabl ar-ri'āya“, (Raiḥānat al-kuttāb, Bd. 2, S. 397) „tanāwala (aiy qā̄id fulān) hutṭ̂t al-madīna fa-ağrāhā wa-rāša nabl al-aḥkām wa-barāhāa“ - die Verben ,rāša“ und „,barā““ legen hierbei „naffad̄a“ bzw. ,anfaḍa“ nahe; (Maqāmāt al-Ḥarīrī, S. 298) „fa-'ağibtu min fatānat al-mursil wa-'1-mursal wa-'alimtu annahā as-sarūğīya [...] wa-mā kadِdabtu an bādartu ilā al-hāan [...] li-anẓur kunh fahmī wa-hal qarṭasa fi 't-takahhun sahmī wa-id̄ā anā fi 'l-firāsa fāris wa-Abū-Zaid bi-waṣīd alhā̄n ğālis“ - hier „ob ich mit meiner Annahme recht hatte“.

Holzstücke als Sinnbild der Körperkraft und Stärke sowie der löblichen Beschaffenheit allgemein: (Maqāmāt al-Ḥarīīī, S. 208) „mā gaiyaratnī ba'daka al-ḥawādit wa-lā 'ltahāā 'ūdī hatṭb kārit wa-lā farā hạadī nāb fāriț“ - obwohl der arabische Kommentator „fāriț“" mit „mufsid“ übersetzt, hat es doch eine ganz konkrete Bedeutung, nämlich „(die Eingeweide) ausschüttend, (den Bauch) aufschlitzend“, (Maqāmāt al-Ḥarīīī, S. 364 f.) „wa-ḥāditātin qara'at marwatī [...] wa-'htaṣarat 'ūdī wa-yā waila man tahtaṣir al-aḥdātu ag̣ṣānahū“, (Ṣubḥ, Bd. 7, S. 103) „,fa-cāda (aiy al-islām) ilā al-waṭan wa-wağada ḥāla assuhd tạ'm al-wasan wa-auraqa 'ūduhū (aiy 'ūd al-islām) wa-'ttasaqat su'ūduhū wa-'āda 
ilā șị̣hatihī bi-'n-naẓar al-imāmī allad̄ī ğầa ya ūuduhū“،, (Raiḥānat al-kuttāb, Bd. 1, S. 217 f.) ,wa-lā zā'ida bi-faḍl Allāh [...] illā [...] aṣ-ṣun` alladị ta’allaqat fī ufuq ad-dīn alḥanīf su'ūduhū wa-'l-fath allad̄i tafattaḥa bihī zahruhū (aiy zahr ad-dīn) wa-auraqa 'ūduhū“, (Mušāhadāt, S. 82) „wa-'l-ḥiraf bihā (aiy bi-madīnat Barğa) dِāwīyat al-'ūd“ hier „das Handwerk dort ist in einem bemitleidenswerten Zustand“, (Qalā’id al-'iqyān, S. 35) „tumma 'nḥarafat al-ayām fa-alwat bi-išrāqihī (aiy bi-išrāq al-Mu'tamid Ibn'Abbād) wa-aḍwat yāni'a īrāqihī'; (Maqāmāt al-Ḥarīrī, S. 384) „id iḥtaffa binā dū țimrain qad kāna yunāhiz al-'umrain [...] fa-'zdarāhū al-qaum li-ṭimraihī [...] wa-ahadūū yatadā'aun faṣl al-hitạ̄b wa-ya'taddūn 'ūdahū (aiy 'ūd dị tịmrain) min al-ḥatạa“, (Mağmū' rasā’il muwaḥhidīya, S. 188), „wa-lāqat rịhuhum (aiy rīḥ a'dā’ al-muwaḥhịīin) i'ṣāran wa-șāra nab'uhum bi-za`mihim marhan wa-'afāran wa-mā zādathum ğumū'uhum al-muḍallala illā tabāran“.

Wohlgesittetheit als Süße des Wassers: (Maqāmāt al-Ḥarīrī, S. 210) „fa-laqīt bihā (aiy bi-siqy al-Furāt) kuttāban [...] a d dab ahlāqan min mā' al-furāt"

Gegenwart einer Person als Schatten: (Maqāmāt al-Harīrī, S. 211 f.) „alfainā bihā šaiḩan 'alaihī saḥq sirbāl [...] fa-'āfat al-ğamāca maḥ̣arahū [...] fa-lammā lamahạa minnā istițāl zillihī wa-'stibrād tallihī“ - hier ,jemandem lästig, unangenehm sein“, (Maqāmāt alHarīrī, S. 428) „fa-qāla (aiy Abū-Zaid as-Sarūḡī) a tastaṣhibūn ibn sabīl zāduhū fĩ zabīl ẓilluhū gair taqīil wa-mā yabgì̄ siwā maqīi““, (Maqāmāt a-Ḥarīrī, S. 185) „wa-lam azal atba' zillahū (aiy ẓill Abī-Zaid as-Sarūḡī) aynamā 'nba't wa-altaqit lafẓahū kullamā nafat".

Zückung des Schwertes als Schaden bringendes Vorgehen: (Maqāmāt a-Harīrī, S. 250 f.) „fa-ğarrada ad-dahr suyūf al-ġadr wa-šanna gāāāt ar-razāyā al-ġubr“, (Maqāmāt alḤarīrī, S. 222) ,innī kafaltu had̄ā al-ġulām faṭīman [...] wa-lammā mahara wa-bahara ğarrada saif al-'udwān wa-šahar“, (Maqāmāt al-Ḥarīīi, S. 216) „wa-lau lā qalam alḥussāb [...] la-kāna niẓām al-mucāmalāt maḥlūlan wa-ğurḥ az-ẓulumāt maṭlūlan wa-ğīd at-tanāṣuf mag̉lūlan wa-saif at-tazālum maslūlan“".

Vorzügliche literarische Erzeugnisse als Wohlgerüche: (Maqāmāt a-Harīīī, S. 238) „wag̉ala 'alainā dimr 'alaihī țimr [...] wa-ğalasa yafự̣̣ laṭā'im an-natr wa-'n-naẓm“. Auch der für sich allein heute befremdlich anmutende Ausdruck „Nawāfiğ al-adab“, wörtl. „die Moschusbehälter der Literaturwerke“, d. h. die schönsten Literaturwerke, ist exakt in der gleichen Vorstellung verankert.

Worte - mündlich oder schriftlich - sowie erfreuliche Nachrichten als Perlen, Schmuck und dgl.: (Maqāmāt al-Ḥarīrī, S. 129) „fa-sallama aš-šaih taslīma adīb arīb wa-ḥāwara 
muhāwarat qarīb lā gaarīb fa-u ǧibnā bimā natara min simṭihī“", (Maqāmāt a-Ḥarīrī, S. 184) „wa-hūwa (aiy Abū-Zaid as-Sarūḡī) yantur min fīhī ad-durar“, (Maqāmāt al-Ḥarīrī, S. 322) ,wa-ẓalaltu muddat muqāmī bi-Mișr a šū ilā šuwāẓihī (aiy šuwāẓ Abī-Zaid) waaḥsūu șadafatī bi-durar alfāẓihī“, (Raihānat al-kuttāb, Bd. 2, S. 41) „(bei der Ankunft der Nachricht vom Tod des kastilischen Königs bei der Belagerung Gibraltars) wa-amarnā li-'l-ḥin fa-qullidat labbāt al-manābir bi-had̄ā al-ḩabar“, (Șubḥ, Bd. 7, S. 75) ,wa-qad waṣala kitābukum allad̄i [...] ağmala muqtaḍā al-bušrā wa-faṣṣalahū wa-naẓạama habar al-fatḥ wa-wașșalahū“, (Șubḥ, Bd. 7, S. 100) „wa-inna al-ḩițāb al-`alīy al-karīm warada rāṣifan ağalla ad-durar wa-wāṣifan ağmal al-futūḥ al-g̉urar", (Raihānat al-kuttāb, Bd. 2, S. 41) „fa-qarriṭū bihī (aiy bi-ḩabar maut al-malik al-qaštālī wa-hūwa muhāṣir li-Ğabal al-Fatḥ) al-ādān wa-bašširū bihī al-iqāma wa-'1-ad̄ān“.

Wiesen als Ort der Erfahrung des Erquicklichen und Erbetenen: (Maqāmāt al-Ḥarīīī, S. 269) „fa-labițtu bị̣̣a sinīn an`amu fì dịyāfatihī wa-arta'u fī rīf ra’fatihī ḥattā gamaratnī mawāhibuhū" - hier „sich des Gedeihlichen erfreuen“, (Maqāmāt al-Ḥarīīi, S. 123) „yā qaum innī min unās ganaū dahran wa-ğafn ad-dahr 'anhum gaḍ̣̣̂ [...] kānū iḍā mā nuğ`atun a'wazat fi 's-sana aš-šahbā' rauḍan arị̣̣“, (Maqāmāt al-Ḥarīrī, S. 408) „qāla (aiy al-fatā) innahū (aiy aš-šaih) mud șafira min al-māl wa-munīya bi-'l-imhāāl yasūmunī an atalammaz bi-'s-su'āl““ - hier „seit er verarmt ist“, (Maqāmāt al-Harīīī, S. 405 f.) „sa'altu naḥārīr ar-ruwāt 'amman tạ̣wīhī (aiy madīnatu Șa'da) min as-sarāt wa-ma'ādin

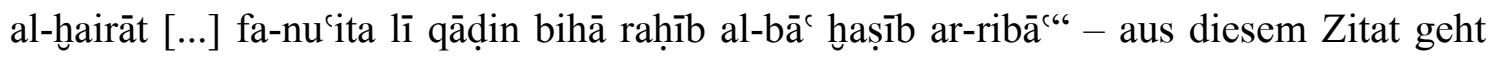
hervor, dass die Vorstellung, jemands Wiese sei reich an Futter, d. h. jemand sei wohlhabend, eng mit der Vorstellung verknüpft ist, jemand sei freigebig und willig, andere an diesem Reichtum teilhaben zu lassen, (Maqāmāt al-Harīrī, S. 131) „fa-zafratī fī șưud wa-'abratī fĩ șabab wa-antum muntağa` ar-rāğī wa-marmā at-ṭalab luhākum munhalla“, (Maqāmāt al-Ḥarīrī, S. 411) „wa-'rḥal rikābak 'an rab'in ẓami’ta bihī ilā alğanāb allad̄ī yahmī bihī al-mațar“، (Qalā’id al-ciqyān, S. 34) „wa-kānat ḥaḍratuhū (aiy haḍrat al-Mu'tamid Ibn-'Abbād) mațaḥan li-'l-himam wa-masraḥan li-āmāl al-umam“ - d. h. sehr viele erhofften sich die Erfüllung ihrer Hoffnungen in seiner Residenzstadt. Die Handhaben des Urteils: (Maqāmāt al-Harīrī, S. 484) „wa-'staqdaḥtu ra’yahū (aiy ra’y al-yāfi') fi 't-tazwīğ fa-qāl a wa-tabḡinā 'awānan am bikran tu'ānā fa-qultu ihtar lī mā tarā fa-qad alqaitu ilaik al-`urā“‘ - der arab. Kommentar „kināyatun 'an tafwīḍ al-amr ilaihī“.

Webstühle: (Raihānat al-kuttāb, Bd. 1, S. 198) „wa-kāna baina al-farīqain [...] ḥarb lam yunsağ ‘alā minwālihā“، - „lam yunsağ 'alā minwālihā“، heißt eigentl. ,einzigartig“ - 
siehe hierzu z.B. „innahū nasīğ wahdihī ${ }^{748 ، ~-~, ~ h i e r ~ a b e r ~ b e d e u t e t ~ e s ~ „, v o n ~ n i c h t ~}$ gekannter Heftigkeit“. Ein interesanter Gebrauch von „Webstuhl“, nämlich in der Bedeutung ,gemäß dem Urteil des almoravidischen Herrschers handeln“, liegt im folgenden Zitat vor: (21. almor. Briefe, S. 175) „wa-hūwa (aiy al-wālī) bi-lisāninā mutakallim wa-'ammā fī ḍamīinā mutarğim wa-fī qālib ra’yinā mufrìg wa-'alā minwālihī musdin (min asdā yusdī isdā'an) wa-mulhịim“.

Edle Pferde: (Raiḥānat al-kuttāb, Bd. 1, S. 363), ,fa-mitllukum man yağrī 'alā a arāqihī alkarīma ğarya al-ǧiyād al-citāq“, (Raihānat al-kuttāb, Bd. 1, S. 534) ,wa-natnī bimā hauwalakum Allāh tacālā min al-mağd allad̄ī aḥraztumūhū bi-'l-istiḥqāq wa-ğaraitum fîhī ğarya al-ğiyād 'alā al-a'rāq“ - d. h. ,euer ganzes Handeln und Tun zeugen davon, dass das Ruhmreichtum euch angeboren ist, in die Wiege gelegt wurde“, mit anderen Worten ,al-mağd allad̄ī hūwa šīma min šīyamikum“. Weiteres Bsp. (Raiḥānat al-kuttāb, Bd. 1, S. 418) „maqām maḥall abīnā al-ğārī fi 'l-fạ̣l ğarya al-ğawād 'alā a'rāqihī“. Dieses gleiche Bild liegt auch dem folgenden Zitat zugrunde (Raihānat al-kuttāb, Bd. 1, S. 421) „fa-innanā warada 'alainā kitābukum [...] al-mustaulī min mayādīn al-faḍl 'alā ab`ad al-āmād al-muğrī šīyam al-mağd 'alā mu'tādihā‘،.

(Raiḥānat al-kuttāb, Bd. 1, S. 516) „wa-bimā yatazaiyad 'indanā min al-umūr fa-rakā'ib at-ta'rīf bihā ilaikum maḥtūta“", (Raiḥ̄nat al-kuttāb, Bd. 2, S. 10) „fa-ya'lam Allāh annanā [...] lā ğuliba ilainā habar illā ahdaināhū inda ḥalb darrihī wa-rakkaḍnā tịrfahū ba`d taqlībihī wa-farrihī“‘ - d. h. nach der Zurkenntnisnahme von Nachrichten haben wir sie umgehend euch zukommen lassen.

Aufnahme von Lasten als Kriegsbeginn: (Raihānat al-kuttāb, Bd. 1, S. 366) „ammā matābatakum al-karīma fa-wazar al-islām kullamā aḩaḍat al-ḥarb auzārahā"“ - synonym $\mathrm{zu}$ „kullamā indala'at al-ḥarb“. In der gleichen Vorstellung ist auch das folgende Zitat verankert: (Raihānat al-kuttāb, Bd. 2, S. 381) „fa-lammā waḍa'at al-ḥarb auzārahā“c, d. h. „lamā ḩabat nīrān al-ḥarb“.

Trinkbecher als Symbol des Todes und der Schlacht: (Raihānat al-kuttāb, Bd. 2, S. 87) „,(bei der Rede, die Ibn-al-Hațīb an Abu-'l-Ḥasan al-Marīn̄i am Mausoleum des Letzteren hielt) fa-tawassadta at-tarā wa-ațalta al-karā wa-šaribta al-ka's allatī šaribahā al-warā“, (Raqm al-ḥulal, S. 111), ,wa-dāma (aiy al-malik al-mauṣūf) fi 'l-mulk qarīr al'ain ḥattā saqāhū ad-dahr ka’s al-ḥain“; (Raiḥānat al-kuttāb, Bd. 1, S. 137) ,wa-dahuala al-muslimūn ğafnahū (aiy ğafn ḥiṣn Qanīṭ) 'anwtan ba'd ḥarb adārū ka'sahā““ - hier „,nach einem verlustreichen Gefecht“, (Raihānat al-kuttāb, Bd. 1, S. 131) „wa-nālat (aiy

\footnotetext{
748 al-Munğid fi 'l-lug̉a wa-'l-a'lām, S. 1010.
} 
sarāyā al-muslimīn) min ḥumātihā (aiy min ḥumāt ğihāt an-naṣārā) a'ẓam an-nail waadārat 'alā mutadabbirīhā akwās al-manāyā“‘, (Raihānat al-kuttāb, Bd. 1, S. 175) „(beim Angriff auf eine Festung) wa-'alat bi-'š-šahāda al-aṣwātu [...] wa-dārat li-'1-āğāl alku’ūs“, (Raihānat al-kuttāb, Bd. 1, S. 219) „wa-ḍahikat an-nuṣūl fí 'l-yaum al-'abūs wadārat baina ar-riğāl li-'l-āğāal al-ku’ūs“،, (Șubḥ, Bd. 7, S. 75) ,wa-qad waṣala kitābukum [...] tu'arrifūn mā atāḥa lakum al-laṭîf al-ḩabīr [...] wa-annakum min ba'd al-kā’ina [...] ğahhaztum al-ğuyūšs al-muhtāara [...] wa-lam yakun illā an ḥamīya waṭis an-nizāl warağafat al-arḍ li-haul az-zalzāl wa-tu'ūṭiyat ku'ūs al-āğāl [...] fa-kāna li-ḥizbikum azzuhūr“; (Mağmūc rasā’il muwaḥhịīya, S. 173) „wa-yuğarri ūnahū (aiy yuğarric ahlu Qusantīna muhāṣirahum min Mayūrqa) min al-mad̄alla wa-'l-ihāna ka'san zu’āman“.

Drall von Stricken als Intensitätsgrad: (Raihānat al-kuttāb, Bd. 1, S. 165) „wa-'staulaū (aiy al-muslimūn) 'alā aqtār al-madīna istīlā’an a'ğala al-mağānīqa 'an ar-rukūc wașawā'iqa aṣ-ṣaḩr 'an al-wuqū' wa-ḥabla al-ḥarb 'an al-iḥkām“" - d. h. die Muslime haben die Stadt ohne größeren Kampf eingenommen.

\section{Licht und Finsternis}

Den almohadischen Briefen ist bei der Schilderung der Bezwingung einer Stadt durch die Almohaden das folgende Schilderungsmuster eigen: Eine Stadt wird von den Almohaden (wieder)eingenommen und die Finsternis dieser Stadt weicht vor dem Licht (des Almohadentums). So z.B. (Mağmūc rasā’il muwaḥhidīya, S. 23) „wa-qad taqaddama i'lāmukum bimā kāna min șun` Allāh tacālā fĩ fatḥ hadihī al-bilād allatī yassara marāmahā [...] wa-nauwara ẓalāmahā bi-ạ̣wā' had̄ā al-amr as-sāĩd waanwārihī“, (Mağmū' rasā'il muwaḥhidīya, S. 176) ,wa-aṭallat (aiy al-asāṭil) [...] 'alaihā (aiy 'alā al-Ğazā’ir) fa-tayassara lahum marāmuhā wa-'nfarağa li-'l-ḥīn ibhāmuhā watağallā bi-anwār hadihī ad-da'wa al-`alīya gaaihabuhā ad-dāğī wa-ẓalāmuhā“‘.

Das Motiv des Lichtes und der Finsternis ist auch sonst im mittelalterlichen Schrifttum ganz häufig. „Licht“ ist dabei immer positiv belegt und hat religiöses Moment inne: (Mağmū' rasā’il muwaḥḥidīya, S. 4) ,wa-'ṣ-ṣalāt 'alā Muḥammad nabīyihī allad̄ī ’nğābat bi-nūrihī ḥanādis al-kufr wa-ẓulamuhū“، (Maqāmāt al-Ḥarīrī, S. 317) „wa-ašhadu anna Muḥammadan 'abduhū ar-rahīm [...] ibta'atahū li-yansah az-ẓulma (aiy zulmat alğāhilīya) bi-'ḍ-ḍiyā’‘،, (Raiḥānat al-kuttāb, Bd. 1, S. 361) „wa-aṭla'a (aiy Allāh) fī āfāqihā (aiy fî āfāq al-ğazīra al-andalusīya) al-qașīya li-hadihī al-umma almuḥammadīya nūr șabāḥihā“،, (Raihānat al-kuttāb, Bd. 1, S. 367 f.) ,wa-lammā ra’ā aṭțāgīya [...] anna daulat al-islām qad ista’nafat šabābahā wa-anna Allāh fataḥa li-hadihī 
al-ğazīra bāban [...] šariha ilā iṭ̂ā’ nūr Allāh allaḍī wa'ada bi-itmāmihī', (Maqāmāt alHarīīī, S. 110) ,allahumma yā muḥyī ar-rufāt [...] kuffa 'annī akuff aḍ-ḍāimīn waahriğnī min zuulumāt aẓ-zạalimīn“.

Einige Konnotationen des Lichten: (Raihānat al-kuttāb, Bd. 1, S. 239) ,ammā ba'd ḥamd Allāh [...] muṭli` anwār az-ẓafar bi-'l-auṭār fī ẓulmat al-aḥṭār“, (Ṣubḥ, Bd. 7, S. 60) „wa-ilā had̄ā ağzala Allāh masarratakum bi-ẓuhūr ad-dīn wa-'tilā' șubhịīi al-mubīn hier, „Sieghaftigkeit“.

\section{Farbenpracht}

(al-Fitan wa-'l-ḥurūb, Bd. 1, S. 185) „bintum wa-binnā fa-mā 'btallat ğawāniḥunā šauqan ilaikum wa-lā ğaffat maāqīnā - hāālat la-faqdikum aiyāmunā fa-gadat sūdan wakānat bikum bīạan layālīnā““ - mit „Weiß“ wird hier „Freude“ konnotiert und mit „Schwarz“ hingegen „Trauer“, (Qalā’id al-ciqyān, S. 37) „wa-ahbbaranī (aiy fulān) annahū dahala 'alaihī (aiy 'alā al-Mu'tamid Ibn-'Abbād) fị lailatin qad tanā as-surūr manāmahā wa-'mtaṭā al-ḥubūr gāaribahā wa-sanāmahā [...] wa-satara bayāọ al-amān̄̄ sawādahā“, (Maqāmāt a-Ḥarīrī, S. 121) „fa-lammā ardā ad-dahr al-a'ḍād [...] wa-lam yabqa lanā tanīya wa-lā nāb fa-mud ig̉barra al-'aiš al-aḥ̣ar wa-'zwarra al-maḥbūb alaṣfar wa-'swadda yaumī al-abyạ̣ [...] ḥattā ratā lī al-'adūw al-azraq“ - beachte den Unterschied zwischen „ahḍar““ und „ag̉bar“. Siehe ferner zu „al-`adūw al-azraq“ den Eintrag bei at-Táālabī (Fiqh al-lug̉a, S. 88). (Qalā'id al-iqyān, S. 114) „wa-ahbaranī (aiy fulān) anna al-ğadb tawālā bi-ḥaḍratihī (aiy bi-ḥaḍrat ạ̣ad mulūk aṭ-ṭawā'if) ḥattā ğaffat mad̄ānibuhā wa-'g̉barrat ğawānibuhā“‘, (Maqāmāt a-Ḥarīrī, S. 250 f.) „fa-ğarrada ad-dahr suyūf al-ġadr wa-šanna gāāāt ar-razāyā al-ġubr“, (Maqāmāt al-Ḥarīrī, S. 123) „yā qaum innī min unās ganaū dahran wa-ğafn ad-dahr 'anhum gaḍ̣ị̣ [...] kānū iḍā mā nuğcatun a'wazat fi 's-sana aš-šahbā' rauḍan arị̣̄“; (Maqāmāt al-Ḥarīrī, S. 453) „fa-lam azal zīran li-'l-ġīd wa-udunan li-'1-ag̉ārīd ilā an wāfā an-nadīir wa-wallā al-'aiš an-naḍìr“, (Mağmū' rasā’il muwaḥhidīya, S. 225),,(bei der Schilderung des Verwüstungszuges der Almohaden durch das christliche Gebiet) wa-wağada al-muwaḥhidūn hadihī al-madīna al-mad̄kūra qad aḩadat zaḩārifahā wa-labisat min an-nuḍra ḥulalahā"“

(Rasā’il wa-maqāmāt andalusīya, S. 79), „wa-inna wafāt al-qāḍ̄i abīka [...] waradatnī falaqītu ma'ahā wağh ad-dahr arbad“‘

(Mağmūc rasā’il muwaḥhidīya, S. 206) „wa-anna ahֵdat Allāh ar-rābīya [...] țaraqathum (aiy al-muhạạarīn bi-Gafṣa) bi-'l-ḥawādit an-nukr wa-'1-manāyā al-ḥumr țawāriquhā“، 
(Mağmū' rasā'il muwaḥhidīya, S. 245), ,wa-ḥakama (aiy Allāh) fỉhim (aiy fi 'l-a'dā') bi'l-'adāāb al-hūn wa-ramāhum bi-sihām al-ḩuṭūb al-ğūn“, (Ṣubḥ, Bd. 7, S. 98 f.) ,wa-lau anna makānan ‘aḍḍahū ad-dahr min anyāb ḥawāditihī al-ğūn bimā bihī 'aḍ̣ahā (aiy Labla)“،

\section{Vorislamisches Brauchtum}

(Raihānat al-kuttāb, Bd. 1, S. 127) „maqām maḥall abīnā [...] abqāhū Allāh [...] yaụrib qidāḥ an-naṣr fī ma’ziq kull țán wa-ḍarb“ - Anspielung auf das vorislamische Spiel „maisir“, bei welchem die Anteile des geschlachteten Tieres unter den Teilnehmern anhand von Pfeilen (qidḥ Pl. qidāḥ) ausgelost wurden. Der Pfeil mit dem meisten Anteil hieß dabei „al-Mu'allā“،. Eine ausführliche Beschreibung dieses Spiels mit der Angabe der dazugehörenden Terminologie findet sich in „Nihāyat al-arab fî funūn al-adab“ (Bd. 3, S. 118). In eben diesem Kontext muss man das folgende Zitat verstehen: (Raihāanat al-kuttāb, Bd. 1, S. 162) „wa-maqāmukum 'uddat al-islām allad̄ī yakšif ğalāhū wanusāhimuhū fī [...] al-mubaššarāt allatī tafūz bi-qidhịhā yadāhū““ - wohlgemerkt entstammen sowohl „qidh"“ als auch „fãza“ dem spezifischen Sprachgebrauch des erwähnten Spiels. (Maqāmāt al-Ḥarīīi, S. 127) „(yaqūl Abū-Zaid as-Sarūğīi) wa-lau salaktu sabīlan ma'lūfatan țūla 'umrī la-ḩāba qidḥ̄ wa-qadhị̄“.

Weitere Beispiele (Raiḥānat al-kuttāb, Bd. 2, S. 374) ,wa-qa'ada bi-baladihī yadrus al'ilm wa-yuğīl qidāḥahū“،, (Raihānat al-kuttāb, Bd. 2, S. 366) „wa-ağāla fĩ kull fann qidāḥan fa-ğallā fī maidān al-iğāda wa-barraza“ - hier „sich mit etwas

auseinandersetzen, sich mit etwas beschäftigen bzw. befassen“; (Mağmūc rasā’il muwaḥhidīya, S. 191) „(im abschließenden Teil des Briefes) wa-ağìī fĩ nawādīkum wa-maḥāḍirikum wa-baina bawādīkum wa-ḥawāḍirikum qidāḥ at-taḥaddut bihā (aiy bi'n-ni`am) wa-dikrihā“ - hier „sprechet über diese (geschilderten) Gnadenbezeigungen und erwähnet sie“. (Raiḥānat al-kuttāb, Bd. 2, S. 370) „wa-tawallā al-ạ̣kām aš-šar'̄iya fa-ağāla qidāḥahā“ - hier ,,in seiner Eigenschaft als Richter Urteile fällen“. (Riḥlat IbnĞubair, S. 183) „wa-uğīlat fī sabab inșirāf hadihī al-malika al-mutrafa qidāḥ aẓ-ẓunūn wa-sullat al-ḩawāṭir 'alā istiḩrāğ sirrihā al-maknūn“.

(Riḥlat Ibn-Batṭūṭa, S. 384) „wa-fĩ kull 'ilm lahū (aiy li-maulānā) al-qidḥ al-mu'allā““ synonym zu „šufüf“, d. h. ,,in jedem Wissensbereich ist er allen anderen überlegen“. Interessanterweise entstammen „haẓ: und „nașīb“ ebenfalls der Beschreibung des erwähnten Auslosungsverfahrens des geschlachtenen Tieres, denn in „Nihāyat al-arab“ (Bd. 1, S. 118) heißt es: „wa-yu'tā bi-'l-qidāḥ wa-hūwa aḥad 'ašar qidhạ sab'a minhā 
lahā ḥaẓ in fāzat wa-'alā ahlihā gurm in hāat bi-qadr mā lahā min al-ḥaẓ in fāzat [...]

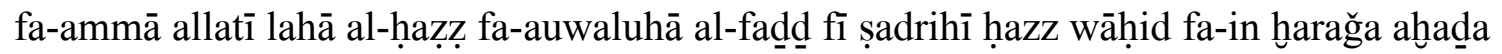
naṣīban wa-in hāāba garima șāḥibuhū taman naṣīb tumma at-tau’am lahū naṣībān in fāza [...] țumma ạ̣-ḍarīb wa-lahū țalātat anșibā̄‘، - es gab demnach wohl einen Unterschied zwischen „ḥaẓ" und „naṣīb“, der im späteren Sprachgebrauch verschwindet. Vor diesem Hintergrund drängt sich der Schluss auf, dass in den folgenden Beispielen auf den beschriebenen vorislamischen Brauch ebenfalls Bezug genommen wird: (Mağmū'a ğadīda, Bd. 1, S. 516) ,wa-yūfîkum (aiy Allāh) min an-naẓar al-ğamīl mā yuhẓịkum biaufar ḥuẓūz an-ni`am al-mustaḥsana“, (Mağmū'a ğadīda, Bd. 1, S. 509) „adāma Allāh karāmatahum bi-taqwāhū wa-ağzala ḥuẓūẓahum min na'māhū wa-raḥmāhū“.

\section{Literaturverzeichnis}

Quellen

Abu-'l-Fidā', Ismā'īl: Géographie d'Aboulféda, traduite de l'arabe en français par Reinaud, 2 Bde, Paris, 1848 und 1883

Alarcón y Santón, Maximiliano Agustin u. Ramón García de Linares [Hrsg.]: Los documentos árabes diplomaticos del archivo de la corona de Aragon, Madrid [u. a.] 1940. Abk. „Documentos arabes“

al-Anbārī, Abū-Bakr Muhammad Ibn-al-Qāsim: Šarḥ al-qașāìid as-sab` at-ṭiwāl alğāhilīyāt, ed. von 'Abd-as-Salām Muḥammad Hārūn, Kairo 1963

al-'Askarī, Abū-Hilāl: Kitāb ğamharat al-amțāl, ed. von Muhammad Abu-'l-Faḍl Ibrāhīm [u. a.], 2 Bde, Kairo 1964

'Azzāwī, Aḥmad: Rasā'il muwaḥhịīiya : mağmū'a ğadīda, 2 Bde, Kenitra 1995-2001, 1. Aufl. Abk. „Mağmū'a ğadīda““

al-Baidaq, Abū-Bakr aṣ-Ṣanhāğīi: Kitāb ahbār al-mahdī Ibn-Tūmart wa-'btidā' daulat almuwaḥhidīn, in: Documents inédits d’histoire almohade, ed. von E. Lévi-Provençal, Paris 1928. Abk. „Kitāb ahbār al-mahdī Ibn-Tūmart““

al-Bakrī, Abū-'Ubaid: Kitāb al-mugirib fī dikr bilād Ifrīqīya wa-'l-Mag̉rib. Description de 1'Afrique septentrionale par Abou-Obeid-el-Bekri traduite par Mac Guckin de Slane, Paris 1965. Abk. „Kitāb al-mug̉rib fī dikr bilād Ifrīqīya wa-'1-Mag̉rib“ ad-Damīrī, Kamāl-ad-Dīn: Ḥayāt al-ḥayawān al-kubrā, 2 Bde, Kairo 1954 ad-Dāya, Muḥammad Rị̣wān [Hrsg.]: Nubḍat al-'aṣr fi 'nqiẹā' daulat Banī-Naṣr, Damaskus 1984. Abk. „Nubd̄at al-'așr““ 
García de Linares, Ramón siehe Alarcón y Santón, Maximiliano Agustin

Goldziher, Ignatz [Hrsg.]: Le livre de Mohammed Ibn Toumert, Mahdi des Almohades, Algier 1903

al-Ḥimyarī, Muḥammad Ibn-'Abd-al-Mun'im: Kitāb ar-rauḍ al-mi'ṭār fī habar al-aqțār : (mu'ğam ğug̉rāfī ma'a masrad 'āmm), ed. von Iḥsān 'Abbās, Beirut 1975. Abk. „Kitāb ar-rauḍ al-mi'ṭār"

al-Ḥarīrī: Maqāmāt al-Ḥarīī̄, [Kairo] 1969

Ibn-al-Abbār, Abū-'Abdallāh Muḥammad Ibn-'Abdallāh Ibn-Abī-Bakr al-Quḍāīi: I'tāb al-kuttāb, ed. von Șāliḥ al-Aštar, Damaskus 1961

Ibn-al-Abbār, Abū-'Abdallāh Muhammad Ibn-'Abdallāh Ibn-Abī-Bakr al-Quḍāc̄ī: Kitāb al-ḥulla as-siyarā', ed. von Ḥusain Mu’nis, 2 Bde, 1. Aufl., Kairo 1963

Ibn-Abī-Dīnār: al-Mu'nis fī ahbār Ifrīqīya wa-Tūnis, Tūnis 1387 H.

Ibn-Abī-Zar: al-Anīs al-muțib bi-raự al-qirțās fī ahbār mulūk al-Mag̉rib wa-ta'rīh madinat Fa's, ed. von 'Abd-al-Wahhāb Binmanșūr, Rabat 1999. Abk. „al-Anīs almuṭib“"

Ibn-al-Ațīr, Abu-'1-Ḥasan 'Alī Ibn-Abi-'1-Karam Muḥammad Ibn-Muḥammad Ibn-'Abdal-Karīm Ibn-'Abd-al-Wāḥid aš-Šaibānī: al-Kāmil fī 't-tā'rīhn, 9 Bde, Kairo [o.J.]. Abk. „al-Kāmil““

Ibn-Bassām aš-Šantarīnī, Abu-'l-Ḥasan 'Alī: aḍ-Dַahīra fī maḥāsin ahl al-Ǧazīra, ed. von Iḥsān 'Abbās, 8 Bde, Beirut 1979

Ibn-al-Faqīh: Muhtașar kitāb al-buldān, hrsg. von M.J. de Goeje, Leiden 1885

Ibn-Ğubair: The travels of Ibn Jubayr, ed. by William Wright, second edition revised by M.J. de Goeje, Leiden 1907. Abk. „Riḥlat Ibn-Ğubair“

Ibn-Hुaldūn: Kitāb al-'ibar wa-diwān al-mubtada' wa-'l-ḩabar fī aiyām al-'arab wa-'1'ağam wa-'l-barbar wa-man 'āṣarahum min dِawī as-sulțān al-akbar, 7 Bde, Beirut 1959. Abk. „Kitāb al-'ibar“

Ibn-Ȟāqān, Abū-Naṣr al-Fatḥ Ibn-Muḥammad Ibn-'Ubaid-Allāh al-Qaisī: Qalā'id al'iqyān, ed. Muhammad aṭ̂̄āhir Ibn- 'Āšūr, Tunis 1990

Ibn-al-Ḩaṭîb, Lisān-ad-Dīn: Kunāsat ad-dukkān bacd intiqāl as-sukkān: ḥaula al-calāqāt as-siyāsīya baina mamlakatai Ġarnāța wa-'l-Mag̉rib fi 'l-qarn at-tāmin al-hiğrī, ed. Muḥammad Kamāl Šabbāna [u. a.], [Kairo] [1966]. Abk. „Kunāsat ad-dukkān““ Ibn-al-Ḩaṭỉb, Lisān-ad-Dīn: al-Iḥāṭa fī aḩbār Garnāṭa, ed. Muhammad 'Abdallāh 'Inān, 4 Bde, 4. Aufl., Kairo 2001. Abk. ,al-Iḥāta“a 
Ibn-al-Hुaṭ̣ib, Lisān-ad-Dīn: Nufạḍat al-ğirāb fī 'ulālat al-ig̣tirāb, ed. von Aḥmad Muhtār al-'Abbādī, Kairo [o.J.]. Abk. „Nufāḍat““

Ibn-al-Ḩațīb, Lisān-ad-Dīn: Raihānat al-kuttāb wa-nuğcat al-muntāb, ed. von Muḥammad 'Abdallāh 'Inān, 2 Bde, Kairo 1980-1981, 1. Aufl.

Ibn-al-Ḩaṭỉb, Lisān-ad-Dīn: Ta'rīḩ Isbāniya al-islāmīya au kitāb a'māl al-a'lām fî man būyi‘a qabl al-iḥtilām min mulūk al-islām, ed. E. Lévi- Provençal, Beirut 1956. Abk. „A'māl al-a' lām“

Mušāhadāt Lisān-ad-Dīn Ibn-al-Hูaṭīb fị bilād al-Mag̉rib wa-'1-Andalus : mağmūca min rasā'ilihī, ed. von Aḥmad Muhtār al-'Abbādī, [S. 1.] 1983

Ibn-'Id̄ārī al-Marrākušī: al-Bayān al-muġrib fĩ aḩbār al-Andalus wa-'1-Mag̉rib : qism almuwaḥhidīn, ed. von Muḥammad Ibrāhīm al-Kattānī [u. a.], Beirut [u. a.] 1985, 1. Aufl. Abk. ,al-Bayān al-mugirib“

Ibn-Isḥāq Ibn-Yasār, Muḥammad: Sīrat Ibn-Isḥāq al-musammāt bi-kitāb al-mubtada' wa-'1-mab`at wa-'1-maġāzī, ed. Muhammad Hamīd Allāh, Konya 1981. Abk. „Sīrat IbnIshāqu“

Ibn-al-Kardabūs: Kitāb al-iktifā' fī ahbār al-ḩulafā', ed. von Aḥmad Muhtāar al-'Abbādī, Revista del Instituto Egipcio de Madrid, 1965-66

Ibn-al-Mahdī, Aḥmad: Natīğat al-iğtihād fi 'l-muhādana wa-'l-ğihād, ed. von Ismā'īl al'Arabī, Beirut 1980. Abk. „Natīğat al-iğtihād“

Ibn-Marzūq, Šams ad-Dīn Abū-'Abdallāh Muhammad Ibn-Aḥmad: El Musnad : hechos memorables de Abū 1-Ḥasan sultan de los Benimerines, estudio, traducción, anotación, indices anotados por María J. Viguera, Madrid 1977

Ibn-al-Qaț̣ān: Naẓm al-ğumān, Bd. 6, ed. von Maḥmūd 'Alī Makkī, Ribat [um 1968] Ibn-Ṣāhịib-aṣ-Ṣalāt: al-Mann bi-'l-imāma : ta'rīh bilād al-Mag̉rib wa-'l-Andalus fī 'ahd al-muwaḥhidīn, ed. von 'Abd-al-Hādī at-Tāzī, Beirut 1987, 3. Aufl. Abk. ,al-Mann bi-'1imāma“"

al-Idrīsī, Abū-'Abdallāh Muḥammad Ibn-Muhammad 'Abdallāh Ibn-Idrīs al-Ḥammūdī al-Ḥasanī: Kitāb nuzhat al-muštāq fi 'hntirāq al-āfāq, 9 Teile, Neapel [u. a.] 1970-1984 Ibn-al-Kardabūs: Kitāb al-iktifā' fī ahbār al-ḩulafā', ed. von Aḥmad Muhtār al-'Abbādī, Revista del Instituto Egipcio de Madrid, 1974-75

al-Kattānī aṭ-Ṭabīb, Abū-'Abdallāh Muhammad: Kitāb at-tašbīhāt min ašcār ahl alAndalus, ed. von Iḥsān 'Abbās, Beirut [o.J.]. Abk. „Kitāb at-tašbīhāt'“ 
Lafuente y Alcántara, Emilio [Hrsg.] : Ahbār mağmū'a fī fatḥ al-Andalus wa-dikr umarā'ihā rahịmahum Allāh wa-'1-ḥurūb al-wāqi`a bihā bainahum, anonym, Madrid 1867. Abk. „Ahbār mağmū'a“

Lévi-Provençal, Evariste [Hrsg.]: Mağmūe rasā̄il muwaḥhiidīya min inšăa kuttāb addaula al-mu’minīya, Rabat 1941. Abk. „Mağmū' rasā’il muwaḥhidīya“

Lévi-Provençal, Evariste [Hrsg.]: Muḍakkarāt al-amīr 'Abdallāh āhiir mulūk banī Zīrī biĠarnāṭa, Kairo 1955, Abk. „Mudakkarāt““

Lévi-Provençal, Evariste: Un recueil de lettres officielles almohades: une étude diplomatique et historique. In: Hespéris. Archives berbères et bulletin de l'institut des hautes études marocaines, 1941, Tome XXVIII, S. 1-80.

al-Maidānī, Abu-'l-Faḍl Aḥmad Ibn-Muḥammad Ibn-Aḥmad Ibrāhīm: Mağma` al-amtāl, ed. von Muḥammad Muḥyi-'d-Dīn 'Abd-al-Ḥamīd, 2 Bde, Damaskus [u. a.] [o.J.]

al-Malaṭị, 'Abd-al-Bāsiṭ: ar-Rauḍ al-bāsim fī ḥawādit al-'umr wa-'t-tarāğim, Teilw. hrsg. von Robert Brunschvig in Islamic Geography, Vol. 187, Frankfurt am Main 1994, Reprint of the Edition of Paris 1936. Abk. ,ar-Rauḍ al-bāsim“

al-Maqarrī at-Tilimsānī, Aḥmad Ibn-Muhammad: Nafḥ at-țīb min ġuṣn al-Andalus arrațīb wa-dikr wazīrihā Lisān-ad-Dīn Ibn-al-Ḩațỉb, ed. von Yūsuf aš-Šaih Muḥammad alBuqā̄ī, 9 Bde, Beirut 1998, 1. Aufl. Abk. „Nafh at-ṭịb“

al-Marrākušī, 'Abd-al-Wāḥid: al-Mưğib fī talhīị ahbbār al-Mag̉rib : min ladun fatḥ alAndalus ilā āḩir ‘aṣr al-muwaḥhịīn ma'a mā yattaṣil bi-tā’rīh hadihi al-fatra min ahbār aš-šu'arā’ wa-a'yān al-kuttāb, hrsg. von Muhammad Sa'̄ì al-'Aryān [u. a.], Kairo 1949, 1. Aufl. Abk. ,al-Mu'ğib“

al-Marrākušī, 'Abd-al-Wāḥid siehe Dozy, Reinhart: The history of the Almohades, preceded by a sketch of the history of Spain, from the time of the conquest till the reign of Yúsof Ibn-Téshúfin and of the history of the Almoravides by Abdo-'1-Wáhid alMarrékoshí

al-Mufaḍdal Ibn-Salama Ibn-'Așim al-Kūfī, Abū-Ṭālib: Kitāb al-fāhuir, ed. von C. A. Storey, Kairo 1982, 2. Aufl.

an-Nāṣirī, Abu-'l-'Abbās Aḥmad Ibn-Hālid: Kitāb al-istiqșā’ li-ahbār dūwal al-Mag̉rib al-Aqșā, ed. Ğa`far an-Nāṣirī [u. a.], 4 Bde, Casablanca 1954-1955, Abk. „Kitāb alistiqșā̄"،

an-Nuwairī, Aḥmad Ibn-'Abd-al-Wahhāb: Nihāyat al-arab fī funūn al-adab, 20 Bde, Kairo [o.J.] 
al-Qalqašandī, Aḥmad Ibn-'Alī: Șubḥ al-a šāà fī șinā'at al-inšā'), ed. Muḥammad Ḥusain Šams-ad-Dīn, 15 Bde, Beirut [o.J.]. Abk. „Șubḥ“

Sa'd 'Īsā, Fauzī [Hrsg.]: Rasā'il wa-maqāmāt andalusīya, Alexandria [o.J.]

at-Tiğānī: Rihlat at-Tiğān̄i : qāma bihā fi 'l-bilād at-tūnisīya wa-'l-quṭr at-ṭarābulusī Abū-Muḥammad 'Abdallāh Ibn-Muḥammad Ibn-Aḥmad at-Tiğānī min sanat 706 ilā 708 hiğrīya, ed. von Ḥasan Ḥusnī 'Abd-al-Wahhāb, Tunis 1958. Abk. „Riḥlat at-Tiğānī“‘ al-'Uḍī, Aḥmad Ibn-'Umar Ibn-Anas: Nuṣuṣ̣ 'an al-Andalus min kitāb Tarṣī' al-ahbār wa-tanwī‘ al-ātār wa-'l-bustān fị garā'ib al-buldān wa-'l-masālik ilā ğamī‘ al-mamālik, ed. von 'Abd-al-'Azīz al-Ahwānī, Madrid 1965. Abk. „Nuṣūṣ 'an al-Andalus““

Viguera, Maria J. siehe Ibn-Marzūq, Šams-ad-Dīn Abū-'Abdallāh Muhammad IbnAhmad

al-Wāqidī, Muḥammad Ibn-'Umar Ibn-Wāqid: Kitāb al-magaāzī, ed. by Marsden Jones, 3 Bde, London 1966

al-Ya'qūbī, Aḥmad Ibn-Abī-Ya`qūb Ibn-Ğa`far Ibn-Wahb Ibn-Wāḍiḥ: Tar'īh al-Ya'qūbī, 2 Bde, Beirut [o.J.]

Yāqūt Ibn-'Abdallāh al-Ḥamawī ar-Rūmī al-Bag̉dādī, Šihāb-ad-Dīn Abū-'Abdallāh: Kitāb mu'ğam al-buldān, hrsg. von Ferdinand Wüstenfeld, Leipzig 1924

Zağlūl 'Abd-al-Ḥamīd, Sacd [Hrsg.]: Kitāb al-istibṣār fī 'ağā’ib al-amṣār : waṣf Makka wa-'l-Madīna wa-Miṣr wa-bilād al-Mag̣rib li-kātib marrākušī min kuttāb al-qarn as-sādis al-hiğrī (12 mīlādī), Alexandria 1958. Abk. „Kitāb al-istibșār fî̀ 'ağā'ib al-amșār“ Zakkār, Suhail [Hrsg.]: Kitāb al-ḥulal al-maušīya fī dikr al-aḩbār al-marrākušīya : limu'allif andalusī min ahl al-qarn at-tāmin al-hiğrī, Casablanca 1979, 1. Aufl. Abk. „Kitāb al-ḥulal al-maušīya“ az-Zarkašī : Ta'rīh ad-daulatain al-muwaḥhidīya wa-'l-ḥafṣīya, Tunis 1966

\section{Sekundärliteratur}

Abun-Nasr, Jamil M.: A history of the Maghrib in the Islamic period, Cambridge 1987 Aguilar Sebastián, Victoria: Aportación de los árabes nómadas a la organización militar del ejército almohade, in: Al-Qantara, Revista de Estudios Arabes (Consejo Superior de Investigaciones Científicas, Instituto de Filología), Band XIV, Fasc. 1, Madrid 1993, S. 393-415

Attahiri, Mohamed: Kriegsgedichte zur Zeit der Almohaden, Frankfurt am Main [u. a.] 1992 
Bel, Alfred: Les Benou Ghânya. Derniers représentants de l'empire almoravide et leur lutte contre 1'empire almohade, Paris 1903. Abk. „Les Benou Ghânya“

Bel-Haj Mahmoud, Nefti: La psychologie des animaux chez les arabes notamment à travers le Kitâb al-Hayawân de DJĀḤIZ, Paris 1977

Bosworth, Clifford Edmund: The new Islamic dynasties : a chronological genealogical manual, Edinburgh 1996

Bourouiba, Rachid: La doctrine almohade, in: Revue de 1'Occident musulman et de la Méditerranée, Aix-en-Provence 1973, S. 141-158

Cressier, Patrice (Hrsg.): Los almohades : problemas y perspectivas, 2 Bde, Madrid 2005

Daif, Šauqī: al-Fann wa-mad̄āhibuhū fi 'n-natra al-'arabī, Kairo 1980, 9. Aufl.

Dozy, Reinhart: The history of the Almohades, preceded by a sketch of the history of Spain, from the time of the conquest till the reign of Yúsof Ibn-Téshúfin and of the history of the Almoravides by Abdo-'1-Wáhid al-Marrékoshí, Amsterdam 1968. Abk. „The history of the Almohades“

Fil'štinskij, Isaak Moiseevič: Arabskaja literatura v srednie veka, 2 Bde, Moskau $1977 / 78$

Fletcher, Richard: Moorish Spain, London 1994

Camps, Gabriel: Comment la Berbérie est devenue le Maghreb arabe, in: Revue de l'Occident musulman et de la Méditerranée, Aix-en-Provence 1983, S. 7-24

Fricaud, Emile: Les Talaba dans la société almohade (le temps d'Averroès), in: AlQantara, Revista de Estudios Ārabes (Consejo Superior de Investigaciones Científicas, Instituto de Filología), Band XVIII, Fasc. 1, Madrid 1997, S. 331-413

Hinz, Walther: Islamische Maße und Gewichte : umgerechnet ins metrische System, in: Handbuch der Orientalistik, Ergänzungsband 1, Heft 1, Leiden 1955

Houben, Hubert: Roger II. von Sizilien, Herrscher zwischen Orient und Okzident, in: Peter Herde (Hrsg.), Gestalten des Mittelalters und der Rennaissance, Darmstadt 1997 Huici Miranda, Ambrosio: Historia política del imperio almohade, Band I, II, Tetuán 1956/57, Nachdruck Granada 2000

Huici Miranda, Ambrosio: Las grandes batallas de la Reconquista durante las invasiones africanas (Almoravides, Almohades y Benimerines), Madrid 1956

Huuri, Kalervo: Zur Geschichte des mittelalterlichen Geschützwesens aus orientalischen Quellen, In: Studia Orientalia, edidit societas orientalis fennica, IX 3, Helsinki 1941 Julien, Ch.-André: Histoire de 1'Afrique du Nord, Paris 1956 
Kračkowskij, Ignatij J.: Izbrannye sočinenija, 6 Bde, Moskau [u. a.] 1955 - 1960

Lagardère, Vincent: Les Almoravides jusqu'au règne de Yūsuf b. Tāšfīn (1039-1106), Paris 1989

Lagardère, Vincent: Les almoravides : le djihad andalou (1106-1143), Paris 1998

Lohlker, Rüdiger: Islam. Eine Ideengeschichte, Wien 2008

Molina, Luis: Nota sobre murūs, in: Al-Qantara, Revista de Estudios Arabes (Consejo Superior de Investigaciones Científicas, Instituto Miguel Asín), Band IV, Fasc. 1 у 2, Madrid 1983, S. 283-300

Nagel, Tilman: Geschichte der islamischen Theologie, München 1994 an-Nağğāār, 'Abd-al-Wahhāb: Qiṣaṣ al-anbiyā') : laqad kāna fi qiṣașihim 'ibra li-ūlī alalbāb, Beirut 1995, 1 Aufl. Abk.: „Qị̣aṣ al-anbiyā'‘“

O'Callaghan, Joseph F.: A history of Medieval Spain, London 1975

Singer, Hans-Rudolf: Der Maghreb und die Pyrenäenhalbinsel bis zum Ausgang des Mittelalters, in: Ulrich Haarmann (Hrsg), Geschichte der arabischen Welt, München (1994), S. 264-321

Šaiḩa, Ğum`a: al-Fitan wa-'l-ḥurūb wa-ataruhā fi 'š-ši'r al-andalusī : (min suqūt al-ḩilāfa 5 h/11 m. ilā suqūṭ Garnāṭa 9 h./15 m.), 3 Bde, Tunis 1994-1997. Abk. ,al-Fitan wa-'1hurūb“

Terrasse, Henri: Histoire du Maroc des origines a l'établissement du Protectorat francais, 1. Band, New York 1975

Le Tourneu, Roger: Ibn Khaldun, laudateur et contemteur des Arabes, in: Revue de 1'Occident musulman et de la Méditerranée, Aix-en-Provence 1966, S. 155-168

'Umar Mūsā, 'Izz-ad-Dīn : al-Muwaḥḥidūn fi 'l-Ġarb al-Islāmī : tanẓimātuhum wanuẓumuhum, Bairūt 1991. Abk. ,al-Muwaḥhidūn fi 'l-Ġarb al-Islāmī“‘

Wasserstein, David: The rise and fall of the party-kings : politics and society in Islamic Spain 1002-1086, Princeton 1985

Hilfswerke

Baranov, Ch. K.: Arabsko-russkij slovar', 2 Bde, Moskau 1996, 8. Aufl.

Brockelmann, Carl: Geschichte der arabischen Litteratur, 2 Bde und 3 Supplementbände, Leiden 1937-1949, zweite den Supplementbänden angepasste Aufl. al-Ğauharī, Ismācīl Ibn-Ḥammād: aṣ-Ṣihāḥ : Tāğ al-lug̉a wa-ṣihāḥ al-‘arabīya, ed. von Aḥmad 'Abd-al-Ġafūr 'Atṭār, 6 Bde, [Kairo] [1956]. Abk. ,aṣ-Ṣihạạ̣“ 
Dozy, Reinhart: Supplément aux dictionnaires arabes, 2 Bde, Beirut 1991, Reproduction de l'édition originale de 1881

Freytag, Georg Wilhelm: Lexicon arabico-latinum praesertim ex Djeuharii Firuzbadiique et aliorum arabum operibus adhibitis golii quoque et aliorum libris confectum : accedit vocum latinarum locupletissimus, 4 Bde, Halis Saxonum 18301837. Abk. „Lexicon arabico-latinum“

Ibn-Manẓūr al-Ifrīqī al-Miṣrī, Abu-'l-Fạ̣l Ğamāl-ad-Dīn Muḥammad Ibn-Mukarram: Lisān al-`arab, 7 Bde, Beirut 1997-1998, 1. Aufl.

Ibn-aš-Šağarī, Hibat-Allāh Ibn-'Alī Abu-'s-Sacādāt al-'Alawī al-Ḥasanī: Ma 'ttafaqa lafụuhū wa-'ȟtalafa ma'nāhū, ed. von 'Ațìya Rizq, Beirut 1992 at- Ta āālabī, Abū-Manșūr: Kitāb fiqh al-lugia wa-sirr al-'arabīya, Beirut 1996 al-Munğid fi 'l-lugga wa-'1-a lām, Beirut 2002, 39. Aufl.

Lewis, B. [u.a.]: The encyclopaedia of Islam, Leiden [u. a.] 1960 - 2004

Wehr, Hans: Arabisches Wörterbuch für die Schriftsprache der Gegenwart : arabisch deutsch, 5. Auflage, neu bearbeitet und erweitert von Lorenz Kropfitsch, $2003-2004$ Lexikon des Mittelalters, München [u. a.], 10 Bde, 1980-1999 


\section{Lebenslauf}

\section{Persönliche Daten}

Name:

Anschrift:

E-Mail:

Geburtsdatum:

Geburtsort:

Staatsangehörigkeit:

\section{Schulbildung}

10.1981-07.1991

01.1993-12.1994
Andreas Herdt

Christophorusweg 4, 37075 Göttingen

aherdt@gwdg.de

09. Oktober 1973

Kustanaj, Kasachstan

deutsch

Mittelschule in Kustanaj

Realschulabschluss

Lehrgang am Göttinger Institut -

Sonderlehrgänge für Spätaussiedler e.V.-

Hochschulreife

\section{Studium}

04.1995

Aufnahme des Studiums der Slawistik und der Romanischen Philologie an der Philosophischen Fakultät der GeorgAugust-Universität Göttingen

10.1995 Studienfachwechsel von Slawistik zu Arabistik 05.2003 Abschluss des Studiums Magister Artium (Note 1) 